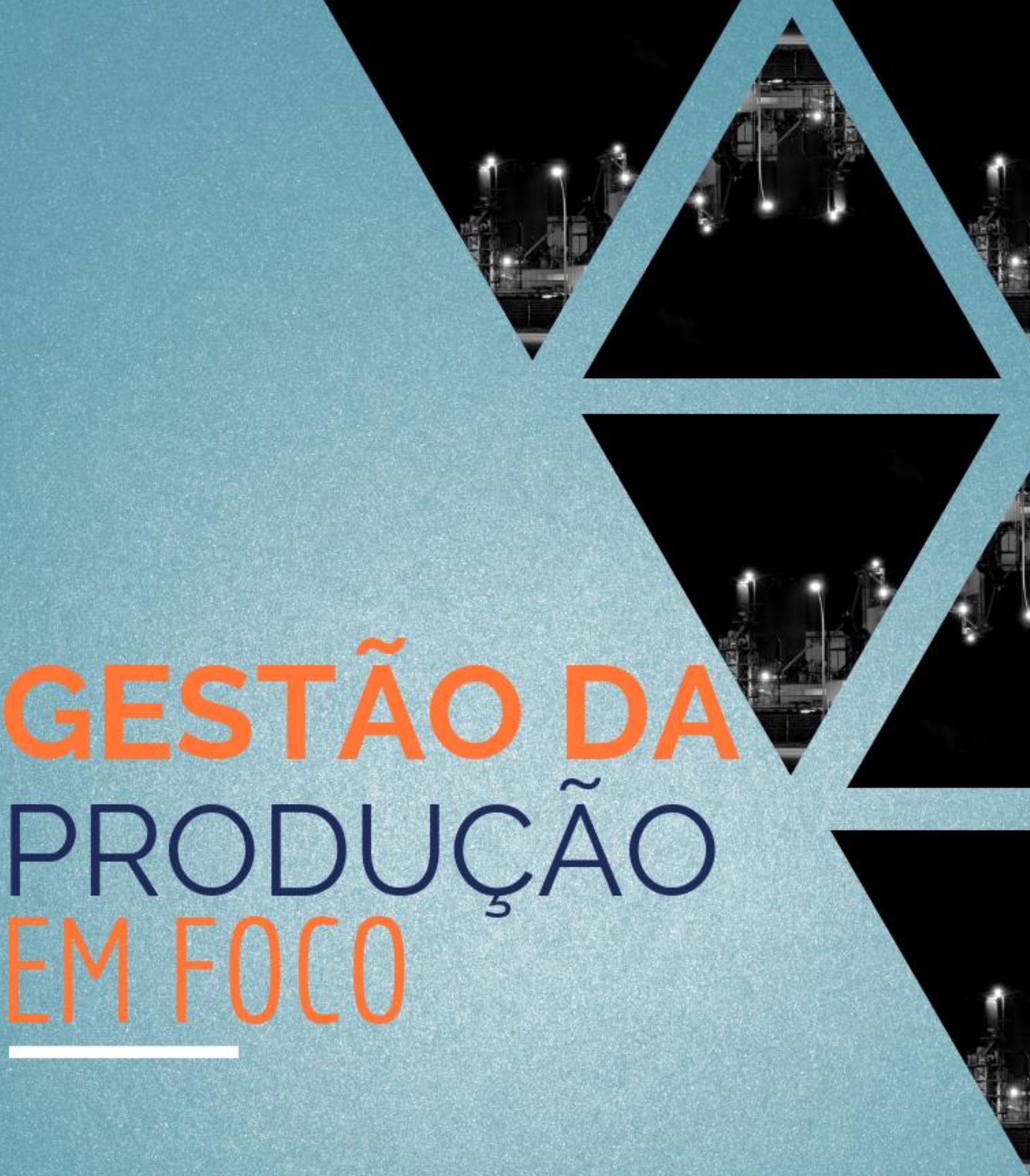

$>$ Editora Poisson A. 
Editora Poisson

\title{
Gestão da Produção em Foco Volume 27
}

\author{
1a Edição
}

Belo Horizonte

Poisson

2019 
Editor Chefe: Dr. Darly Fernando Andrade

\section{Conselho Editorial}

Dr. Antônio Artur de Souza - Universidade Federal de Minas Gerais

Ms. Davilson Eduardo Andrade

Dr. José Eduardo Ferreira Lopes - Universidade Federal de Uberlândia

Dr. Otaviano Francisco Neves - Pontifícia Universidade Católica de Minas Gerais

Dr. Luiz Cláudio de Lima - Universidade FUMEC

Dr. Nelson Ferreira Filho - Faculdades Kennedy

Ms. Valdiney Alves de Oliveira - Universidade Federal de Uberlândia

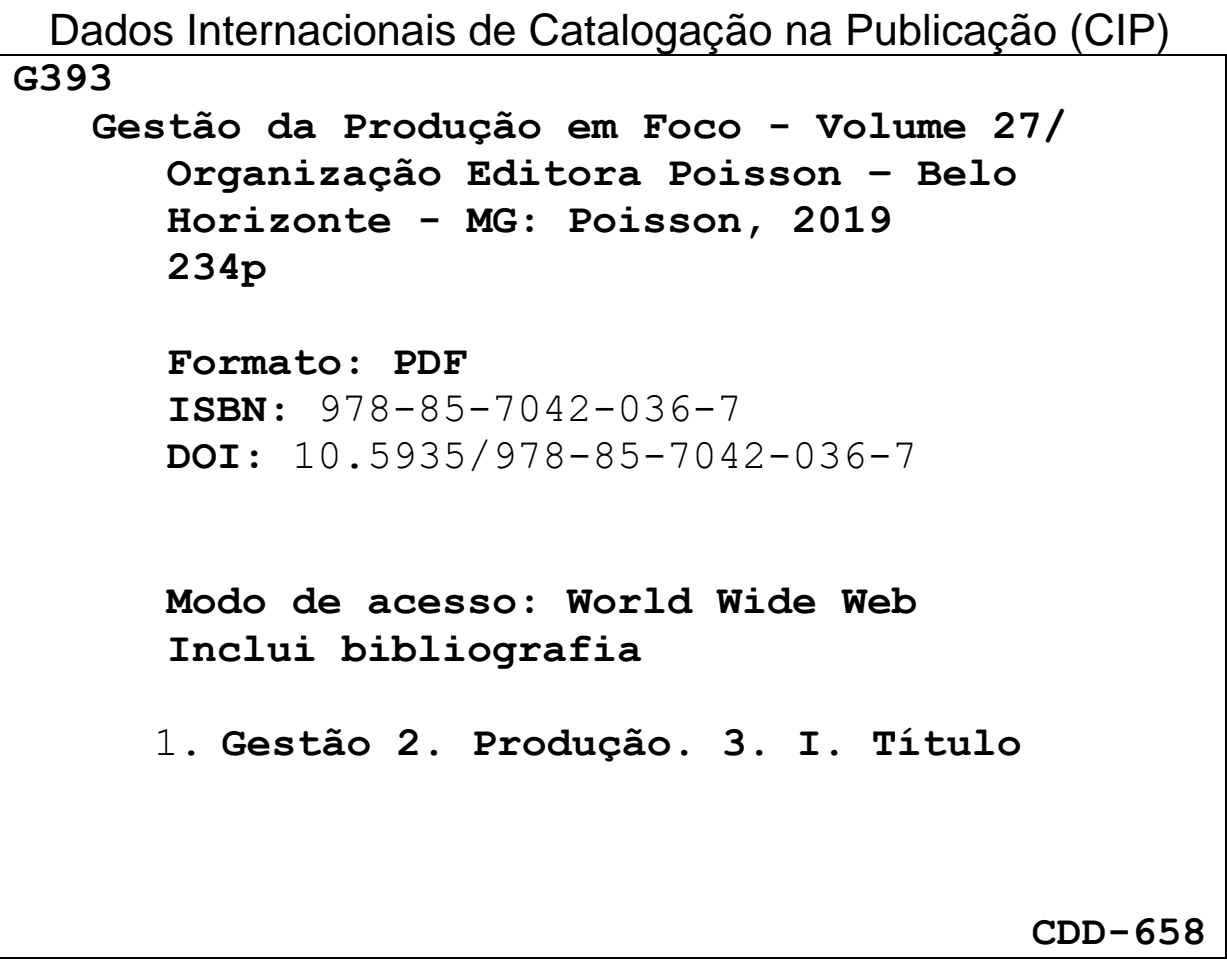

O conteúdo dos artigos e seus dados em sua forma, correção e confiabilidade são de responsabilidade exclusiva dos seus respectivos autores.

Baixe outros títulos gratuitamente em www.poisson.com.br

contato@poisson.com.br 


\section{Sumárīo}

Capítulo 1: Aplicação de ferramenta de gestão para melhoria no controle de estoque em uma indústria de bebidas.

Rafael Duarte Araújo, João Marcelo Carneiro, Thuanny Cunha dos Reis, Raíssa Costa Martins

Capítulo 2: Aplicação das ferramentas QFD e FMEA em uma empresa fornecedora de tubos CRA

Camilla Campos Martins da Silva, Taís Barros da Silva Soares, Fredjoger Barbosa Mendes, Jarbas Dellazeri Pixiolini, Rodolfo Cardoso

Capítulo 3: Aplicação do Lean Seis Sigma para aumento da capacidade de expedição de minério de ferro em um terminal ferroviário

Thiago Henrique Freitas Policarpo, Sílvia Maria Santana Mapa

Capítulo 4: Aplicação do método de análise e solução de problemas (MASP) no setor de corte em uma empresa de beneficiamento de pedras

Rener Antônio Melo Nascimento, Larissa Havenna Matos Santos, Rodrigo Lustosa Soares, Marcos Antônio Oliveira Ferreira, José Lucas Viana Morais

Capítulo 5: SMED e Ferramentas da Qualidade para controle e redução dos tempos de paradas das máquinas injetoras.

Kayque Bezerra de Oliveira, Francisca Jeanne Sidrim de Figueiredo, Mariane Leite de Souza, Antonio Luis Araujo Silva, Amanda Duarte Feitosa, Dalila Rayanne do Nascimento Andrade

Capítulo 6: A Maturidade do Sistema Lean: Um estudo de caso em uma Pequena e Média Empresa (PME) do segmento da saúde

Karina Bataglia, Paulo Sérgio de Arruda Ignácio, Alessandro Lucas da Silva, Antonio Carlos Pacagnella Júnior

Capítulo 7: Padronização do processo de abastecimento de locomotivas, um estudo de caso na gestão de combustível da ferrovia da Vale S.A. em São Luís - MA.

Ana Carolina Silva Mouzinho, Raissa Vieira Guimarães Ribeiro, Jonatas Barreto de Andrade Costa, Thiago Ferreira Silva

Capítulo 8: Aplicação de ferramentas de qualidade para a minimização do desperdício em uma empresa de beneficiamento de pedras 


\section{Sumárīio}

Capítulo 9: Aplicação da metodologia cliente oculto no levantamento de oportunidades da qualidade em uma lanchonete em Teresina-PI

Rener Antônio Melo Nascimento, José Lucas Viana Morais, Larissa Havenna Matos Santos, Eduardo de Oliveira Souza Neto, Natan Melo Nascimento

Capítulo 10: Avaliação multicritério de uma concessionária automotiva.. Aldery Silveira Júnior., Ana Carolina Alves, Jorge Alfredo Cerqueira Streit, Lorrane Alves Ribeiro

Capítulo 11: Mineração de dados educacionais: Análise de trabalhos correlatos. 123 Elpidio Oscar Benitez Nara, Gustavo Choaire, Jones Luís Schaefer, Ismael Cristofer Baierle

Capítulo 12: O impacto do layout no fluxo de produção e na segurança do trabalho ........ Thayza de Souza de Almeida, Cristiane Aparecida Bolino Santos, Daniel Guimarães Tedesco, Jackson Milano

Capítulo 13: Critérios para seleção de fornecedores verdes: Uma revisão de literatura .... 142 Daiane Ferreira França

Capítulo 14: Impactos ambientais causados pelo descarte do lodo de estações de tratamento de água em corpos hídricos.

Uedja Tatyane Guimarães Medeiros Lima, Amanda Tenório da Costa, Janaína Accordi Junkes

Capítulo 15: A gestão de ativos 4.0: Contribuição para a sustentabilidade. 159 Natali da Costa Emerick , Édison Renato Pereira da Silva

Capítulo 16: Gestão de resíduos sólidos: Estudo de caso em uma indústria madeireira no Amazonas.

Amanda Almeida de Souza, Beatriz Ferreira da Cruz, Emilly Felipe de Lima e Lima, Rute Holanda Lopes, Adilson Tavares Cruz, Nilce Lene Torres de Lima

Capítulo 17: Reutilização de reciclados no processo de injeção

Fabiano Santos Ribeiro, Deivid Henrique Borges, João Vicente Lucio Batista, Acácio Ponciano Rodrigues 


\section{Sumárīio}

Capítulo 18: Avaliação de riscos ambientais no processo produtivo de uma mineradora no estado de Sergipe

Celio Lemos Santos Junior, Gláucia Regina de Oliveira Almeida, Nathalia Stephane Santos Nascimento, Ádria Maria de Castro Vasconcelos, Aline Santos Passos

Capítulo 19: Aproveitamento da água condensada dos aparelhos de ar condicionados do laboratório de materiais da Universidade CEUMA - São Luís-MA

Fernanda Gomes Dias, Alicia Silva Carvalho, Danielle Alves Costa Silva, Ruan Rodrigues da Silva, Ailton Celio Alves de Araújo Júnior, Osman José de Aguiar Gerude Neto 


\section{Gapítulo 1}

\section{APLICAÇ̃̃O DE FERRAMENTA DE GESTÃO PARA MELHORIA NO CONTROLE DE ESTOQUE EM UMA INDÚSTRIA DE BEBIDAS}

\section{Rafael Duarte Araújo}

João Marcelo Carneiro

\section{Thuanny Cunha dos Reis}

\section{Raíssa Costa Martins}

Resumo: As empresas necessitam de melhorias continuas para serem competitivas no mercado atual, por isso ocorre uma exigência maior da melhora no nível de serviço. No artigo em questão é apresentado um estudo de pesquisa aplicada, por meio da utilização de planilha eletrônica como ferramenta de análise de dados e estudo de pesquisa aplicada, com dados primários e secundários. Para tal, foram utilizados modelos de gestão de estoque, compras e modelos úteis e práticos de previsão de demanda e integração do planejamento de vendas aos setores operacionais da empresa, no sentido de mitigar os problemas de falta de produto acabado à disposição para vendas. Com isso, a aplicação de métodos quantitativos nas causas de falta de produtos, realização de planos de vendas, classificação de estoques e alinhamento dos setores envolvidos, viabilizando a redução nos níveis de rupturas em 0,8\%, representado por 385.920 caixas, consequentemente, melhora do nível de serviço da empresa e mitigação do risco de redução do volume de compra pelo cliente ou até mesmo a paralisação do fornecimento para o mesmo, trazendo resultados que atendam aos índices de faturamento desejado e mantendo a empresa competitiva no mercado.

Palavras-chave: ferramentas de gestão, Cadeia de Suprimentos, gestão de estoques. 


\section{INTRODUÇÃO}

A gestão de estoques é uma preocupação de quase todas as empresas que atuam no mercado de produção e distribuição de produtos, visando a diminuição de custos para aumento dos lucros, as organizações da atualidade buscam trabalhar com estoques cada vez menores.

Segundo Dennis (2008) a diferença entre o preço do mercado e o custo de fabricação é o que define o lucro sobre cada produto que a empresa vende, portanto, a melhor maneira de aumentar os lucros é diminuindo os custos.

A diminuição dos estoques é uma maneira eficiente de diminuir os custos dentro da organização e assim elevar a margem de lucro, porém, é importante saber que a minimização dos estoques não deve impactar o nível de serviço oferecido pela empresa, ou seja, a gestão de estoques, quando bem feita, possibilita à organização obter melhorias significativas na sua administração, visto que repercute em uma melhoria na produção planejada, traz maior segurança nas tomadas de decisões, além de prevenir possíveis atrasos nas entregas para os clientes (MONTANHEIRO; FERNANDES, 2008).

\section{REVISÃO BIBLIOGRÁFICA}

A cadeia de suprimentos envolve todos os estágios envolvidos no atendimento de um pedido, desde o fornecedor primário até a chegada do produto acabado ao cliente final, passando por áreas que se relacionam com o produto dentro da empresa, como por exemplo, o desenvolvimento de novos produtos, o marketing, as operações, a produção e até mesmo as finanças de uma empresa, todos esses estágios garantem a satisfação do cliente final, portanto, estão inseridas, de forma direta ou indireta, na cadeia de suprimentos (CHOPRA E MEINDL 2003).

\subsection{GESTÃO DE ESTOQUES}

Segundo Bertaglia (2011), os estoques podem ser classificados em categorias que estão vinculadas ao fluxo de material e à forma em que pode ser encontrado nas diferentes etapas do processo. Portanto, temse materiais estocados como:

Matéria Prima: que pode ser obtida por compra ou extração natural e que passará por uma transformação ao entrar no processo produtivo;

Produto em Processo: que é justamente o estado que a matéria-prima fica durante transformações no processo de fabricação;

Produto Semiacabado: são materiais que foram processados e estão gerando estoques intermediários, pois estão aguardando operações adicionais para serem finalizados;

Produto Acabado: que é o material após todas as transformações realizadas e completadas, incluindo operações de controle de qualidade;

Estoque de Distribuição: equivale aquele material que foi inspecionado e testado, e encontra-se em no centro de distribuição.

Estoque em Consignação: são materiais que estão estocados no cliente e podem ser tanto produtos acabados, como peças de manutenção, porém, pertencem ao fornecedor até que seja consumindo pelo cliente.

Para Chiavenato (2005), as finalidades para se manter os estoques estão pautadas em dois motivos: garantir o funcionamento da empresa, neutralizando os efeitos da demora ou atraso no fornecimento e proporcionar economias de escala por meio da compra ou produção de lotes econômicos, além da flexibilidade nos processos produtivos.

Para se obter uma boa gestão nos estoques, é necessário o conhecimento dos custos que envolvem o seu controle, para Lélis (2015) os custos de estoques podem ser desmembrados em quatro partes principais:

Custo de aquisição: É o valor pago pelo produto comprado e está relacionado ao poder de negociação da área de compras em relação ao fornecedor. Quanto maior o preço pago no produto, maior será o custo de estoque, conforme equação 1:

Custo de aquisição = Preço unitário $\mathrm{x}$ Quantidade comprada 


$$
C=P * Q
$$

Em que:

$\mathrm{C}=$ Custo de aquisição;

$\mathrm{P}=$ Preço unitário;

$\mathrm{Q}=$ Quantidade comprada.

Custo de armazenagem: No custo de armazenagem, o administrador é responsável por mantê-lo, já que é um dos itens que mais

onera o custo total da empresa. O cálculo do custo de armazenagem pode ser feito por meio da equação 2 :

$$
C A m_{i}=E M * P M_{u} * T * C A m_{u}
$$

Em que:

$\mathrm{CAm}_{i}=$ custo de armazenagem do item i;

$\mathrm{EM}=$ estoque médio no tempo $\mathrm{T}$;

$P M_{u}=$ preço médio unitário;

$\mathrm{T}=$ tempo de estocagem;

$C A m_{u}=$ custo de armazenagem unitário.

Custo de pedido: Representa o valor desembolsado pela empresa para efetuar o pedido de determinado lote de compra e refere-se diretamente aos custos

administrativos e operacionais da área de compras. Segue equação 3 para base de cálculo de custo de pedido:

$$
\mathrm{CP}=\mathrm{n}\left(\mathrm{CPA}_{\mathrm{u}}+\mathrm{CPV}_{\mathrm{u}}\right) C P=n\left(C P A_{u}+C P V_{u}\right)
$$

Em que:

$\mathrm{CP}=$ custo de pedido;

$\mathrm{n}=$ número de pedidos;

$C P A_{u} \mathrm{CPA}_{\mathrm{u}}=$ custo de pedidos administrativos unitário;

$C P V_{u}=$ custo de pedidos variável unitário.

Custo de falta: Um item que pode causar muitos e profundos prejuízos à empresa compradora. Ainda mais complexo é o fato de que esse é um custo difícil de calcular com exatidão porque envolve um número muito alto de fatores, conforme visualização da figura 1. 
Figura 1 - Custo de falta de estoque

\begin{tabular}{|l|l|c|}
\hline \multicolumn{3}{|c|}{ Custo de falta de estoque } \\
\hline \multicolumn{1}{|c|}{ Custo } & \multicolumn{1}{|c|}{ Descrição } & Fator \\
\hline Mão de obra & $\begin{array}{l}\text { Salários, encargos e benefícios adicionais referentes ao tempo em que a linha } \\
\text { de produção ficou parada. }\end{array}$ & $M O$ \\
\hline Equipamentos & $\begin{array}{l}\text { Custo do equipamento referente ao tempo em que a produção ficou parada } \\
\text { por falta do item ou pela reprogramação da produção. }\end{array}$ & $E$ \\
\hline Material & Custo adicional do material comprado em outros fornecedores. & $M P$ \\
\hline Multas & $\begin{array}{l}\text { Multas contratuais pagas pelo atraso de fornecimento do produto final da } \\
\text { empresa compradora causado pela falta do material. }\end{array}$ & $U M$ \\
\hline Prejuízos & $\begin{array}{l}\text { Lucro referente às vendas não realizadas por cancelamento de pedidos ou } \\
\text { vendas futuras não realizadas causadas pela falta do material, e consequente } \\
\text { impossibilidade de fornecimento dentro dos prazos acordados. }\end{array}$ & $P R$ \\
\hline
\end{tabular}

Fonte: FRANCISCHINI, Paulino G. Gurgel, AMARAL, Floriano do (2002, p. 170).

O objetivo fundamental do processo de gestão de estoque passa a ser, portanto, a obtenção de uma quantidade de reabastecimento que minimiza este custo total
$\left(Q^{*}\right)$. Este é o ponto em que os custos de manter estoque e de ressuprimento são iguais, conforme visualização da figura 2.

Figura 2 - Custo de manter estoque

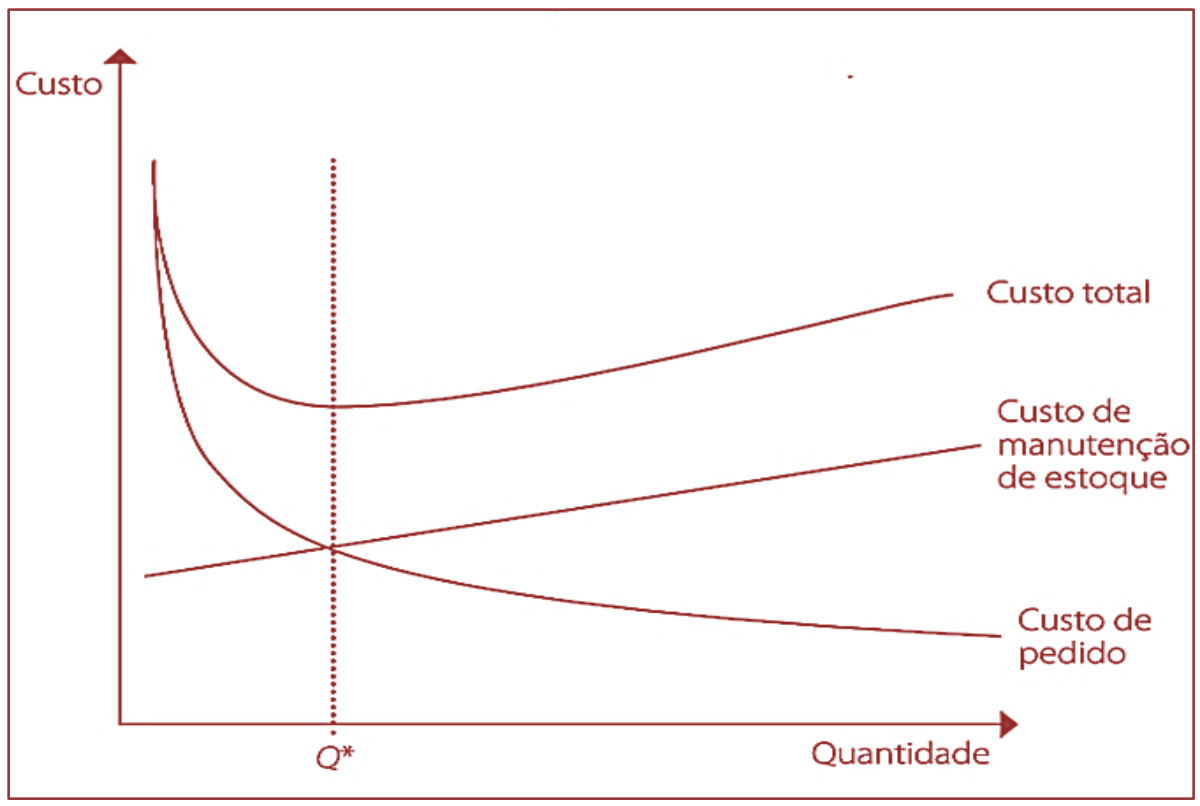

Fonte: FRANCISCHINI, Paulino G. Gurgel, AMARAL, Floriano do (2002, p. 178).

Contudo, manter baixos níveis de estoques, não significa que a empresa terá ganhos, pois é necessário ter um forte gerenciamento logístico em toda cadeia, para se manter o nível de serviço aos clientes.

\subsection{CLASSIFICAÇÃO ABC}

Segundo Bertaglia (2011) a classificação ABC, ou administração por excessos, equivale a separar itens em três classes conforme o valor consumido. De acordo com a regra de Pareto, pode-se dizer que os itens de classificação A são equivalentes a $20 \%$ da quantidade de estoque e equivalem a $80 \%$ do valor, os itens classificados como $\mathrm{B}$, equivalem a $30 \%$ da quantidade de estoque e $15 \%$ do valor, já os itens classificados como C, equivalem a $50 \%$ da quantidade de estoque e $5 \%$ do valor. 
Para Bertaglia (2011), os itens de classe A são considerados mais importante e devem ter uma mais atenção e gerenciamento haja que vista que possuem mais importância, pois possuem representam maior valor do capital. Os itens de classe B são mais rotineiros, porém não possuem um valor de capital tão elevado como os itens $A$. Já os C devem receber um esforço pequeno devido ao seu baixo valor de capital, porém mantendo um certo cuidado para garantir a disponibilidade do item.

Graficamente, a curva da classificação ABC é representada conforme figura 3 :

Figura 3 - Classificação ABC

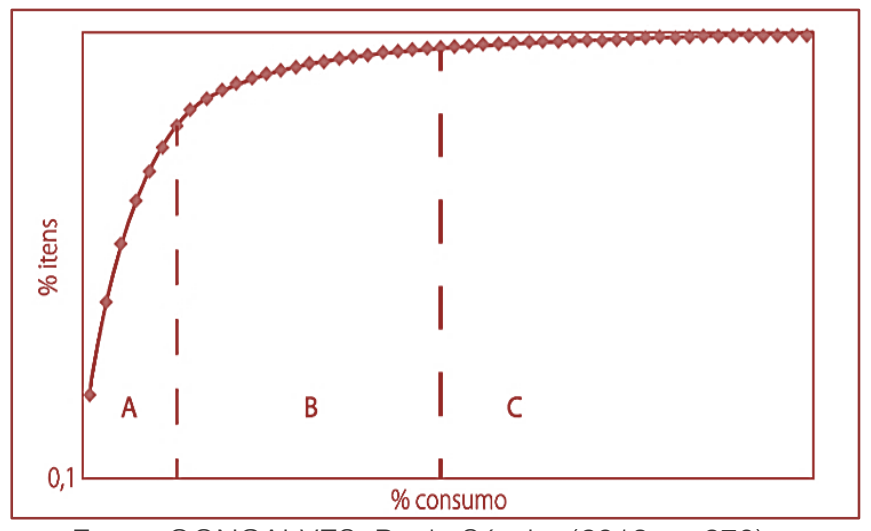

Fonte: GONÇALVES, Paulo Sérgio. (2013, p. 276).

\section{METODOLOGIA}

$\mathrm{Na}$ presente pesquisa, foram utilizados dois tipos de dados: Primários e Secundários. Os dados primários da empresa foram obtidos através de relatórios do planejamento da empresa em estudo, baseado em dados realizados no período de 12 meses (julho de 2015 - junho de 2016). Em relação aos dados secundários, foram obtidos por meio de pesquisa em livros e artigos relacionados ao tema do trabalho.

Para as coletas de dados, foram utilizadas as seguintes ferramentas: informações gerais da empresa e dados da demanda histórica da empresa. A coleta de dados de demanda histórica da empresa foi realizada através do acesso de documentos e arquivos dos computadores, consultando relatórios do sistema de informação da empresa, como: portfólio de produtos, históricos de demanda, lista técnica para cada produto, lista de fornecedores, histórico de compras, capacidade produtiva, capacidade de armazenagem.

Os procedimentos metodológicos realizados no estudo de caso do presente trabalho estão demonstrados na figura 4:

Figura 4 - Fluxo Metodológico

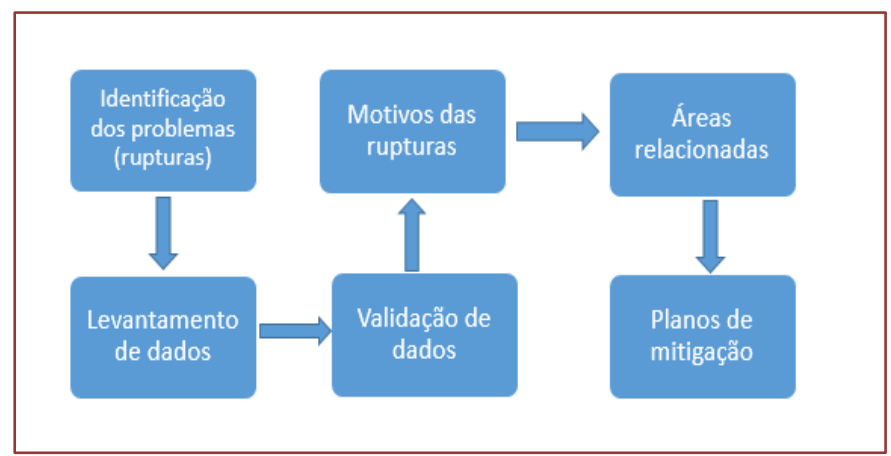

Fonte: Elaboração do autor (2017). 


\section{APRESENTAÇÃO E ANÁLISE DE} RESULTADOS

O estudo é realizado em uma empresa de grande porte do ramo de bebidas e detém mais de $90 \%$ das vendas da categoria que está inserida com seu portfólio de 88 produtos no Estado do Ceará. Possui uma média mensal de produtividade de 10.800.000 litros de bebidas que ocorre em uma planta fabril própria no Estado do Ceará e em três indústrias parceiras de subcontratação no Estado de São Paulo. A empresa possui 7 Centros de Distribuição (CD) espalhados por todo o país.

\subsection{APURAÇÃO E ANÁLISE DAS RUPTURAS}

Foram apurados os dados de rupturas, ou seja, pedidos que não tinham sido faturados ou atendidos, durante 12 meses, através de relatórios diários enviados pelo setor de atendimento ao cliente e validados pelo setor de planejamento de operações nos quais são indicados o motivo da ruptura e qual o setor responsável. Durante este período pode-se observar, conforme figura 5 , que as rupturas ocorrem de forma sazonal.

Figura 5 - Rupturas por período em caixas

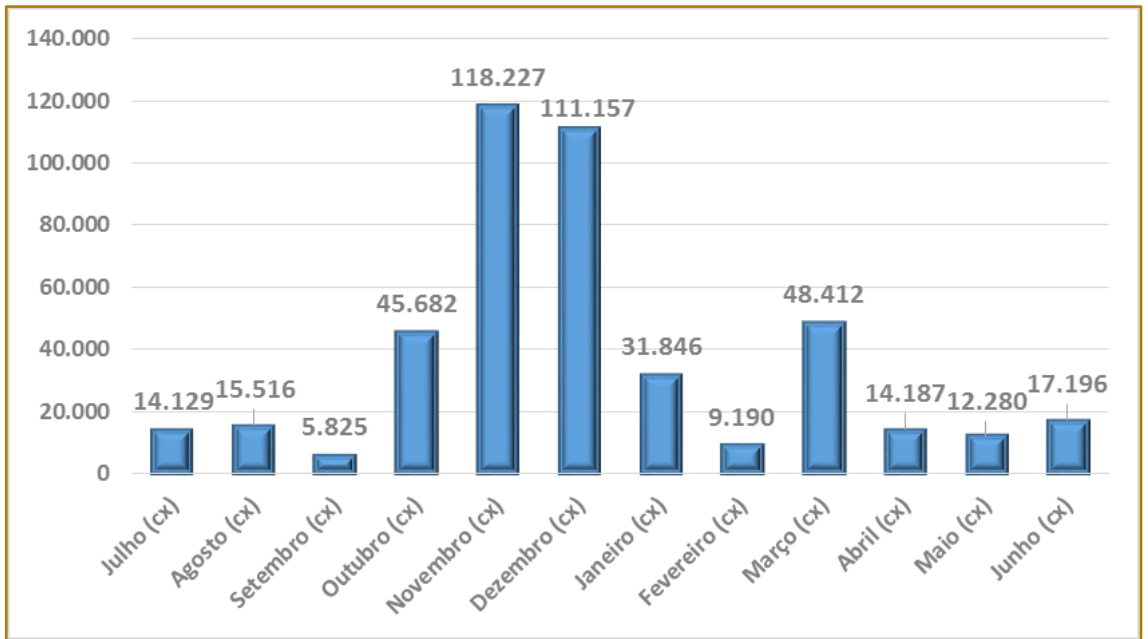

Fonte: Elaboração do autor (2017).

Essas rupturas foram classificadas em 14 principais motivos e elencados os setores responsáveis por cada um deles. Se houver um pedido gerado pelo vendedor em que a área responsável não conseguir alocar estoque para faturamento, toda a quantidade do pedido será classificada como ruptura (tabela 1).

Tabela 1 - Motivos e Áreas responsáveis pela ruptura em caixas

\begin{tabular}{|c|c|c|}
\hline Motivo da Ruptura & Quantidade da Ruptura & Área Responsável \\
\hline Variação de Demanda & $145.144 \mathrm{cx}$ & Planejamento de Demanda \\
\hline Capacidade Produtiva & $113.937 \mathrm{cx}$ & Manufatura \\
\hline Indisponibilidade de Insumos & $43.619 \mathrm{cx}$ & Compras e Planejamento de OP \\
\hline Incapacidade de recebimentos CD & $37.314 \mathrm{cx}$ & Logística \\
\hline Atraso no abastecimento & $28.672 \mathrm{cx}$ & Logística \\
\hline Incremento de S\&OP & $27.994 \mathrm{cx}$ & Planejamento de OP \\
\hline Problemas técnicos & $20.150 \mathrm{cx}$ & Compras \\
\hline Phasing in/out & $9.556 \mathrm{cx}$ & Logística \\
\hline Limitação de fornecimento de Insumos & $8.721 \mathrm{cx}$ & Jurídico \\
\hline Sinistro Veículos & $3.207 \mathrm{cx}$ & Logística \\
\hline Legal Technical & $2.072 \mathrm{cx}$ & Jurídico \\
\hline Problema na formulação & $1.832 \mathrm{cx}$ & Manufatura \\
\hline Problema de Qualidade & $840 \mathrm{cx}$ & Qualidade \\
\hline Problema de pedido & $609 \mathrm{cx}$ & Planejamento de Operações \\
\hline Total & $443.647 \mathrm{cx}$ & \\
\hline
\end{tabular}


Com esses dados é possível classificar, em percentual, os motivos de rupturas e as áreas responsáveis, conforme figura 6 e 7 .

Figura 6 - Percentual dos motivos das rupturas

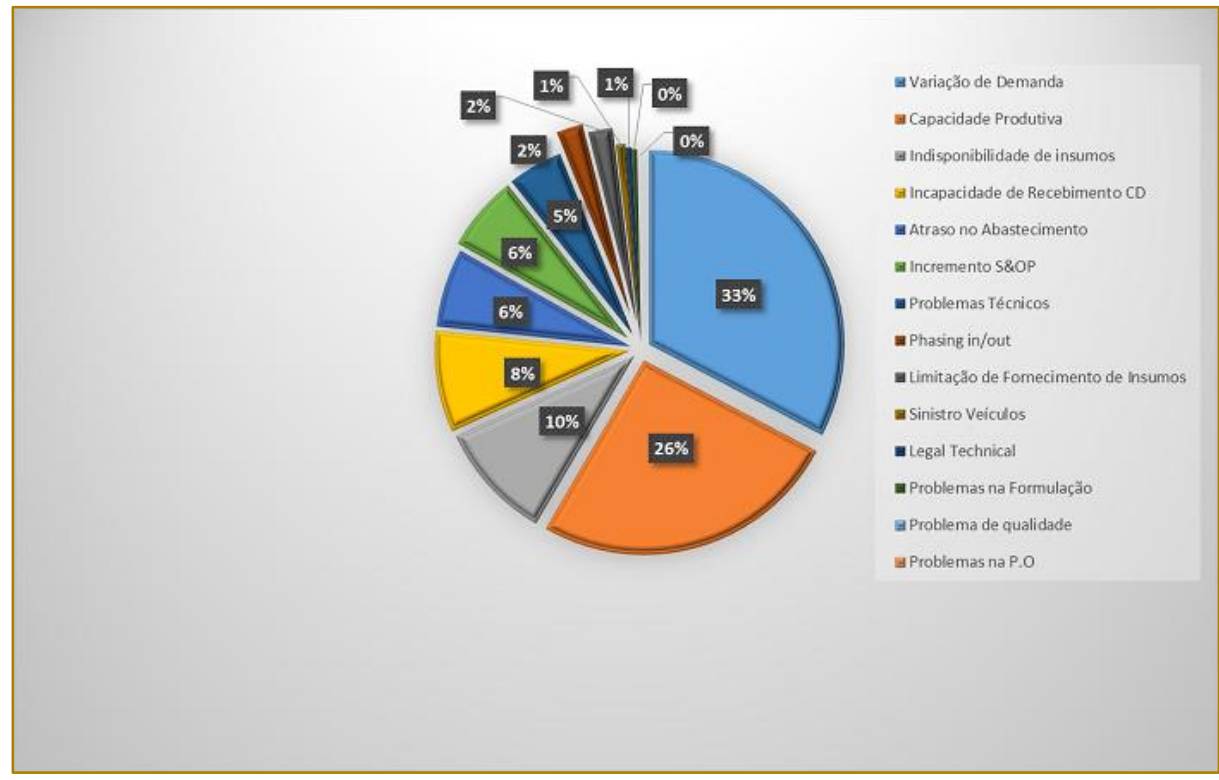

Fonte: Elaboração do autor (2017).

Figura 7 - Percentual das áreas responsáveis pela ruptura

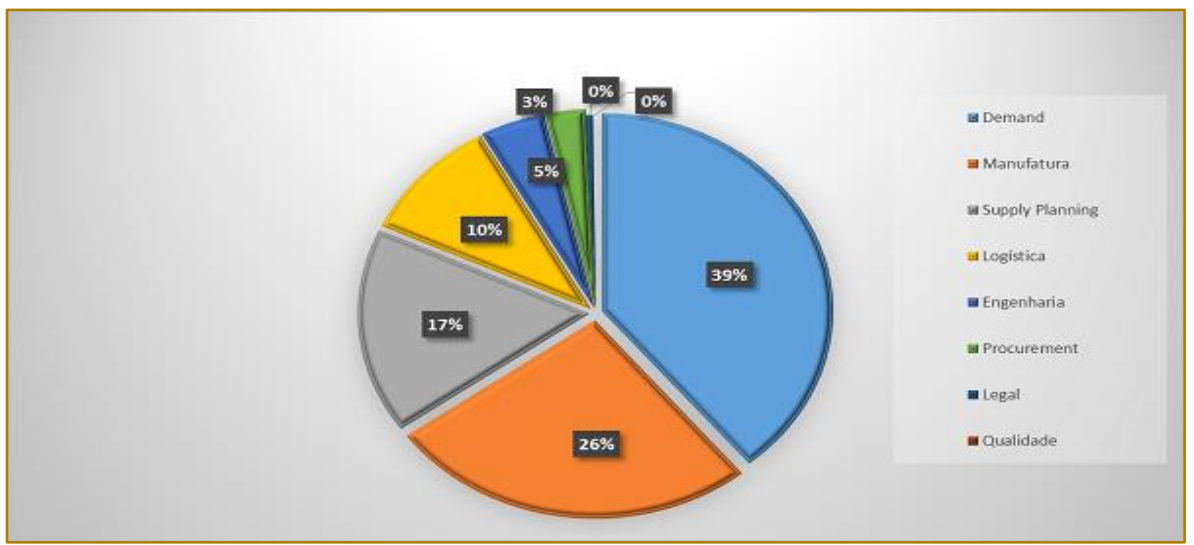

Fonte: Elaboração do autor (2017).

Os 14 principais motivos de forma detalhada:

a) Variação de Demanda: São erros relacionados a previsões de demanda com variação superior a $40 \%$ por centro de distribuição e 30\% para Brasil.

b) Capacidade Produtiva: Falta de produto acabado, quando se tem uma demanda para determinado produto superior à capacidade de produção.

c) Indisponibilidade de Insumos: Falta de insumo para produção do produto acabado.

d) Incapacidade de recebimento no CD: Problemas logísticos em geral tais como falta de local para armazenar o produto e falta de capacidade de atendimento ao plano de descarregamento.

e) Atraso no abastecimento: Problemas logísticos de transporte tais como erro na roteirização do pedido, falta de veículos para envio das mercadorias e atraso na entrega para o pedido.

f) Incremento de S\&OP: São volumes incrementados no plano de vendas após o fechamento do plano de vendas no mês que não tiveram tempo suficiente para atendimento da demanda. 
g) Problemas técnicos: São erros de projetos de engenharia que impossibilitam a produção do produto tais como restrições e concorrências em tubulações e restrições e concorrências em tanques, problema de produtividade em linha em decorrência ao layout das linhas, intervenções estruturais que ultrapassam os prazos acordados e problemas com manutenções preventivas.

h) Phasing In/Out. Problemas de não sincronização entre o esgotamento de um produto antigo e o ponto de ressuprimento de um material novo que irá substitui-lo o antigo.

i) Limitação de fornecimento de insumos: Ruptura ocasionada pela falta de insumo para entrega por parte do fornecedor que são ocorrem por problemas tais como não recebimento do insumo, má qualidade de matéria prima para produção e atraso no abastecimento pela modalidade CIF (Cost, Insurance and Freight).

j) Sinistro de veículos: Avaria de veículos que transportam as mercadorias, ocorrendo perda total da carga que podem ser caudas por falta de manutenção dos veículos ou das via, descumprimento da carga horária de trabalho (motoristas) ou do limite de velocidade. k) Legal Techical: Rupturas ocorridas pela não suprimento devido a adaptação dos produtos as novas legislações.

I) Problema de formulação: Rupturas ocasionadas pela falta de líquido formulado (bebida realizada com ingredientes e proporções de acordo com a receita da bebida) para o envase.

m) Problema de qualidade: Esse tipo de ruptura ocorre quando há um desabastecimento dos estoques, impossibilitando faturamento, por conta de um recall do lote para análise de causa-raiz pelo setor de qualidade devido ao grande número de reclamações de determinado produto.

n) Problema de pedido: problemas ocasionados por erros no processo de faturamento com emissão de notas fiscais (NF) e entrega dos produtos tais como erro no cadastro do produto, faturamento da quantidade errada de produto e entrega de produto errado.

Diante deste cenário, se faz necessário a realização da priorização das rupturas e mapeio de todo o processo para montar planos de ação eficientes para que os problemas sejam resolvidos, conforme figura 8 , de forma gráfica, utilizando o princípio de Pareto.

Figura 8 - Gráfico de Pareto

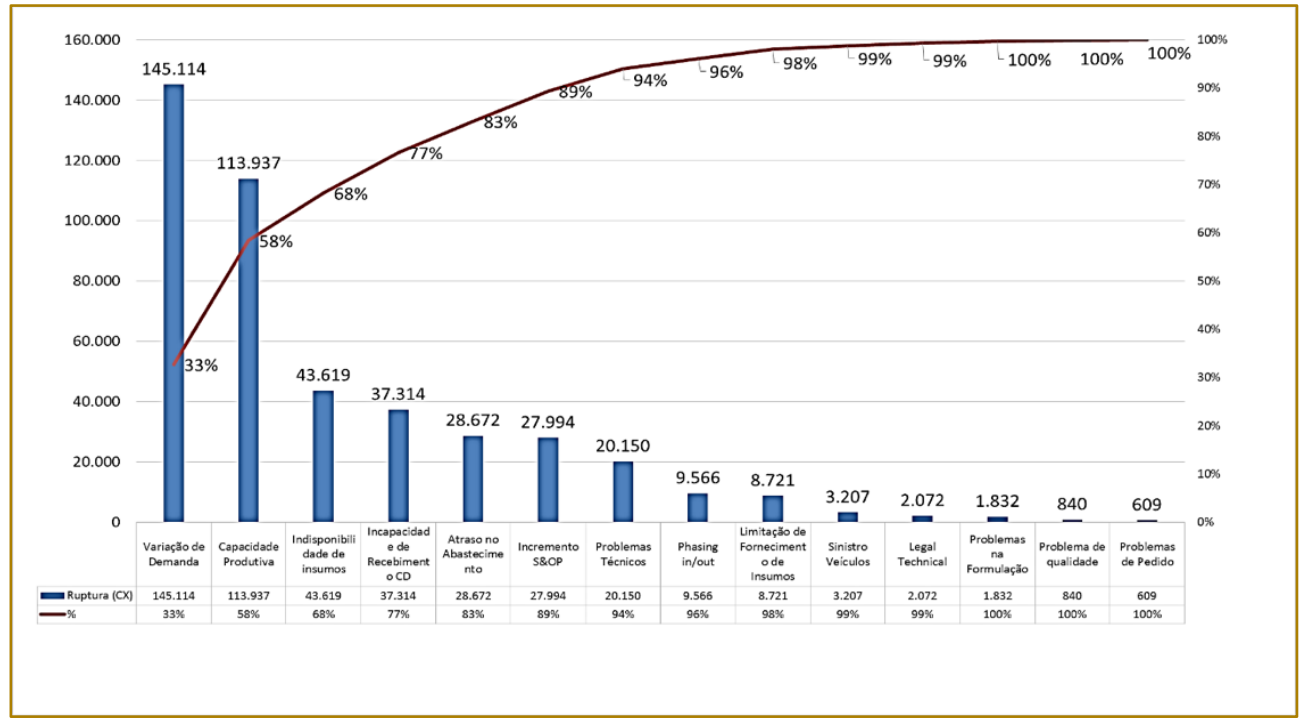

Fonte: Elaboração do autor (2017).

Conclui-se, então, que aproximadamente 80\% dos problemas estão relacionados com os seguintes motivos de rupturas, os quais devem ser priorizados:

a) Variação de Demanda 
b) Capacidade Produtiva

c) Indisponibilidade de insumo

d) Incapacidade de Recebimento no CD

\section{PROPOSTA DE MELHORIA}

Nesta seção será apresentada uma proposta de melhoria da situação apresentada anteriormente, tendo como finalidade diminuir as limitações e problemas apresentados.

\subsection{VARIAÇÃO DE DEMANDA}

Como causa principal de falta de produto acabado para faturamento da empresa, portanto para melhorar o processo de planejamento de vendas, foram implementadas reuniões de ciclo de S\&OP, em que, de forma mensal, as áreas de operações, vendas e finanças se reúnem para escolher o melhor plano de vendas para a empresa, nas quais cada setor leve suas informações para validar o plano. Esse plano visa obter informações como, por exemplo, a avaliação do setor de operações para atendimento de determinado produto em um certo período, podendo, em conjunto, realizarem a determinação de um novo mix de produtos para o período, mantendo as vendas e garantindo faturamento para a empresa. Logo, é mantido o nível de serviço.

É interessante também a utilização de uma média móvel ou uma suavização exponencial para se utilizar como base para as modelagens de previsão de demanda, sendo interessante apurar-se a tendência das previsões, a sazonalidade de vendas e os erros encontrados pelas últimas previsões. Alinhando a otimização das técnicas utilizadas para previsão de demanda aos ciclos de S\&OP, é possível melhorar a variação encontrada de demanda e, consequentemente, melhorar os níveis de ruptura em relação a essa problemática.

\subsection{CAPACIDADE PRODUTIVA}

Alinhamento da equipe de planejamento e controle da produção com o setor comercial para conhecimento das variações de vendas e também aos setores de engenharia com relação ao processo de otimização de linhas, além do setor de manutenção para manter a produtividade dos equipamentos, através das manutenções preventivas, dessa forma, realizar uma boa programação para se produzir a quantidade certa no tempo certo, evitando a falta do produto para faturamento.

\subsection{INDISPONIBILIDADE DE INSUMOS}

Baseando-se na seguinte metodologia, através da obtenção dos dados descritos na tabela 2, é possível mensurar a política para manter os estoques, realizando uma boa gestão, evitando falta de insumos e rupturas.

Tabela 2 - Dados para análise quantitativa de estoques

\begin{tabular}{|c|l|l|}
\hline$N^{\circ}$ & \multicolumn{2}{|c|}{ Dados } \\
\hline 1 & Curva ABC & $\begin{array}{l}\text { Classificação de estoque pela curva ABC definição do nível de } \\
\text { serviço }\end{array}$ \\
\hline 2 & Erro de Demandas & Considerar o erro absoluto entre previsão e vendas \\
\hline 3 & Bias ou Viés & Variaçães positivas e negativas em relação ao planejamento \\
\hline 4 & Tempo de Pedido & $\begin{array}{l}\text { Tempo necessário para que o pedido seja processado e } \\
\text { produzido }\end{array}$ \\
\hline 5 & Tempo de Transito & Tempo de viagem entre um fornecedor e a planta industrial \\
\hline 6 & Intervalo de Intervalo de Revisão & Tempo para a revisão no planejamento de pedido \\
\hline 7 & Frequência de Entrega & Tempo entre dois suprimentos \\
\hline 8 & Análise de Qualidade & $\begin{array}{l}\text { Tempo necessário para garantia de que o material está dentro do } \\
\text { pedido }\end{array}$ \\
\hline
\end{tabular}

Fonte: Elaboração do autor (2017). 
Foi escolhido o padrão, a seguir, de nível de serviço de acordo com a classificação $A B C$ e desenvolvida a ferramenta de gestão de estoques, obtendo-se os seguintes resultados (figura 9):

Produtos A: Classificados com necessidade de nível de serviço 98\%
Produtos B: Classificados com necessidade de nível de serviço 96\%

Produtos C: Classificados com necessidade de nível de serviço 95\%

Figura 9 - Classificação de política de estoque

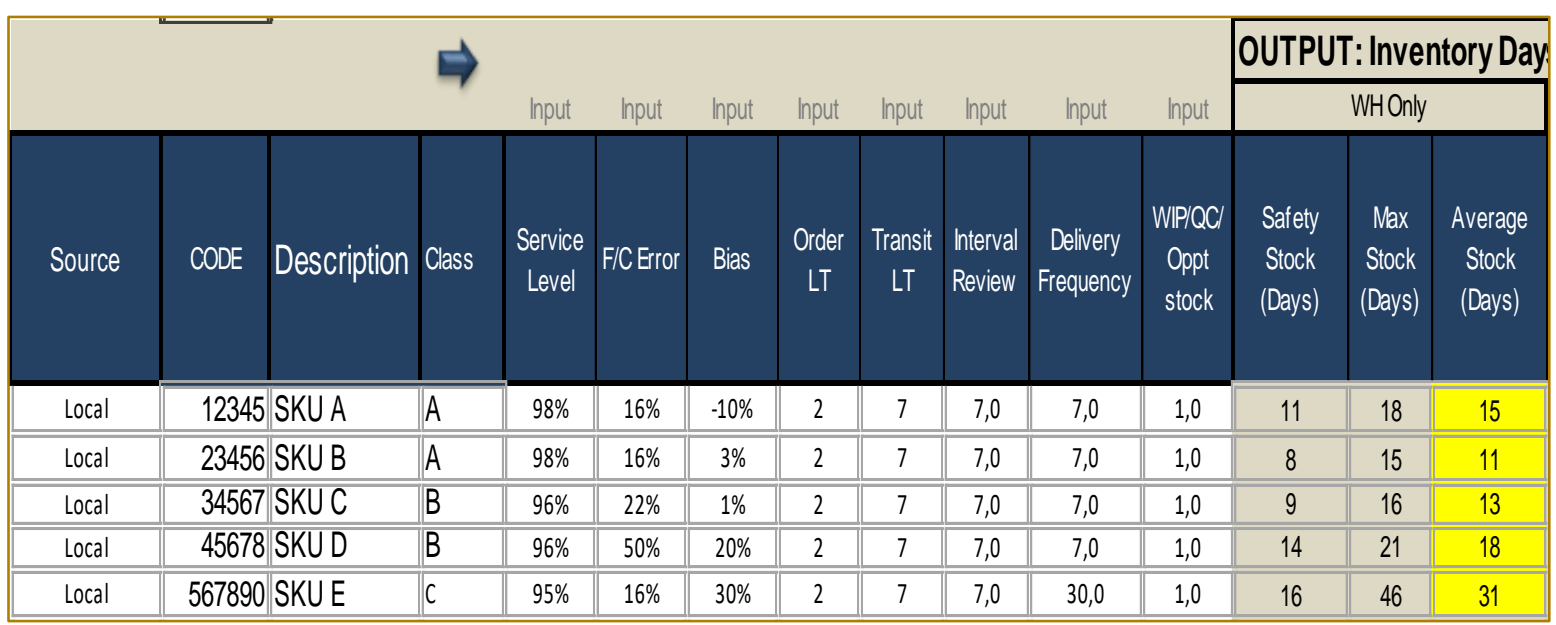

Fonte: Elaboração do autor (2017)

\subsection{INDISPONIBILIDADE NO CD}

Utilizando-se da mesma metodologia apresentada na figura 9, agora para armazenagem de estoque de produto acabado, priorizando os produtos que possuem planos de vendas. Dessa forma, obtém-se melhores níveis de estoques para cada centro de distribuição e com isso faz-se um melhor dimensionamento de armazenagem e movimentação do centro de distribuição, evitando problemas com rupturas.

Em paralelo, a realização de estudos de demanda diários de carretas para recebimento no $\mathrm{CD}$, possibilita um melhor dimensionamento de empilhadeiras e docas necessárias para atendimento do plano de distribuição.

\section{CONSIDERAÇÕES FINAIS}

Nesta seção serão apresentados os resultados obtidos, juntamente com as considerações finais sobre 0 estudo realizado.

\subsection{CONCLUSÕES}

Tendo em vista o objetivo deste trabalho, que é: analisar e propor melhorias para reduzir a indisponibilidade de produto acabado para venda por meio da adoção de métodos quantitativos aplicados nas causas da falta de produtos, pode-se concluir que, para se manter competitiva no mercado, a empresa necessita manter um bom nível de serviço, evitando as rupturas para evitar situações como redução do volume de compra pelo cliente ou até mesmo a paralisação do fornecimento para o mesmo. Pois cliente insatisfeitos tomam decisões, conforme relacionadas na figura 10 : 
Figura 10 - Penalidades impostas por clientes

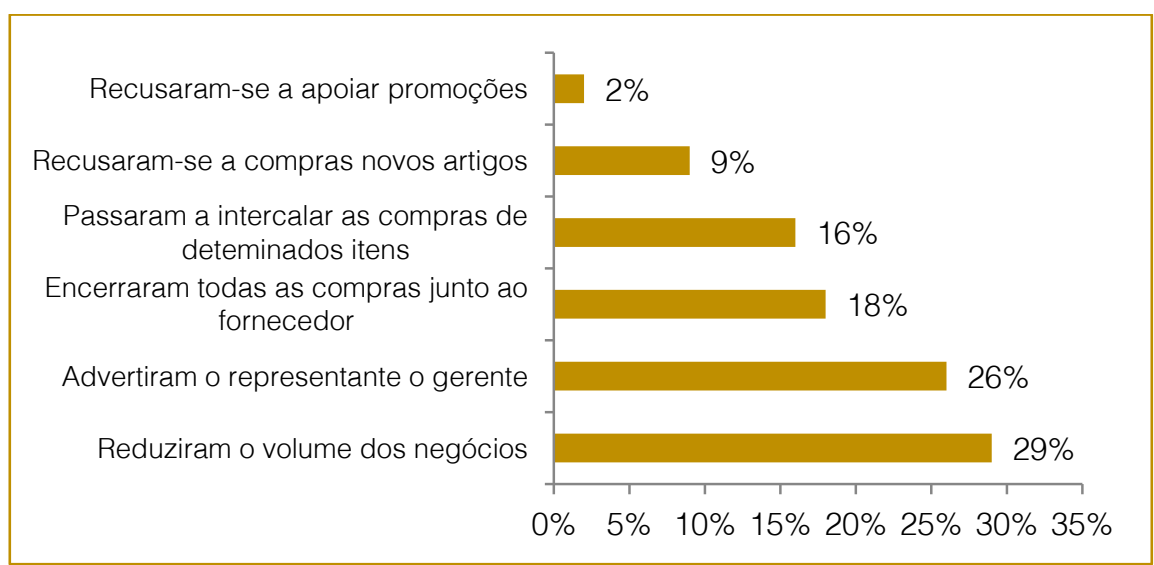

Fonte: STEVEN, G. Baritz.; Lorin Zissman (1983).

Os resultados das modificações apresentadas foram uma redução de 0,8\% dos níveis de ruptura da empresa em questão, representando redução no volume de ruptura de 385.920 caixas, aumentando o nível de serviço da empresa, consequentemente sua competitividade e crescimento no mercado. Com base nesses dados apresentados, é possível afirmar que objetivo principal foi alcançado.

\subsection{SUGESTÕES PARA TRABALHOS FUTUROS}

Sugere-se que seja realizado o mesmo trabalho para os demais motivos de rupturas

\section{REFERÊNCIAS}

[1]. BERTAGLIA, Paulo Roberto. Logística e Gerenciamento da Cadeia de Abastecimento. São Paulo: Saraiva, 2011.

[2]. CHIAVENATO, Idalberto. Planejamento e controle da produção. 2.ed. São Paulo: Manole, 2008.

[3]. CHOPRA, S.; MEINDL, P. Gerenciamento da cadeia de suprimentos. Estratégia, planejamento e operação. 1. ed. Rio de Janeiro: Prentice Hall Brasil, 2003.

[4]. DENNIS, Pascal. Produção Lean Simplificada. Tradução Rosalia A. N. Garcia. Porto Alegre: Bookman, 2008.

[5]. FRANCISCHINI, Paulino G. Gurgel, AMARAL, Floriano do. Administração de Materiais e do Patrimônio. São Paulo: Pioneira Thomson, 2002 supracitados, mitigando ao máximo possível os níveis de ruptura e aumentando ainda mais o nível de serviço da empresa. É interessante também aprofundar as causas das rupturas, podendo os motivos de rupturas serem classificados em nível 1, em seguida em nível 2, com o detalhamento do problema.

É interessante, também, capacitar a equipe de vendas com cursos de previsão de demandas e técnicas de planejamento e controle de produção. Dessa forma, tem-se uma equipe mais especializada, com percepção da complexidade de atendimento de pedidos fora do planejado e, consequentemente, uma melhora no nível de ruptura pelo motivo de variação de demanda.

[6]. GONÇALVES, Paulo Sérgio. Logística e cadeia de suprimentos: O essencial. 1.ed.São Paulo: Manole, 2013.

[7]. LÉLIS, Eliacy Cavalcanti. Administração de materiais. São Paulo: Pearson, 2015.

[8]. MONTANHEIRO, W. J.; FERNANDES, L. A. Gestão de estoques de materiais em uma confecção. In: SIMPÓSIO DE EXCELÊNCIA EM GESTÃO E TECNOLOGIA, 5, 2008, Resende. Anais: Resende, Associação Educacional Dom Bosco, 2008.

[9]. STEVEN, G. Baritz.; Lorin Zissman, "Researching customer service: The right way", Proceedings of the national council of physical distribution management. 2. ed. New Orleans: National council of physical distribution management, 1983): 611. 


\section{Capítulo 2}

\section{APLICAÇÃO DAS FERRAMENTAS QFD E FMEA EM UMA EMPRESA FORNECEDORA DE TUBOS CRA}

\section{Camilla Campos Martins da Silva}

Taís Barros da Silva Soares

Fredjoger Barbosa Mendes

Jarbas Dellazeri Pixiolini

Rodolfo Cardoso

Resumo: Um dos maiores desafios para uma organização é, além de entender perfeitamente as necessidades do cliente, ser capaz de traduzir corretamente essas necessidades, diferindo da maioria das empresas, que às vezes consideram suas próprias perspectivas como verdade absoluta. Além disso, ao projetar um produto ou serviço que atenda às expectativas do cliente, você precisa estar ciente dos requisitos básicos necessários, como a confiabilidade do produto que está sendo oferecido. Dentro deste contexto, o objetivo deste projeto é integrar o Quality Function Deployment (QFD) e as ferramentas de análise de efeitos e modo de falha (FMEA) para impulsionar os resultados de um fabricante e fornecedor de tubos de ligas resistentes à corrosão (CRA) e propor alternativas viáveis para resolver os problemas mais impactantes, com foco no cliente. 


\section{INTRODUÇÃO}

Diante de um cenário mundial onde a globalização e o contexto do ambiente de negócios são alimentados por uma elevada competitividade, estudos referentes aos recursos existentes na indústria de óleo e gás, têm demonstrado que a cadeia de fornecedores de bens e serviços apresenta características específicas que necessitam de tratativas efetivas para garantir o alcance de uma vantagem competitiva sustentável, e consequentemente, sua sobrevivência em um panorama tão dinâmico e instável, no qual tais empresas estão imersas. (ACCENTURE, 2016; KEUER et al., 2016).

A vantagem competitiva é obtida quando uma organização desenvolve ou adquire um conjunto de atributos que influenciam na escolha do cliente pelo produto ou serviço oferecido pela empresa, em detrimento dos fornecidos pelos seus concorrentes. É necessário ter em mente que o ponto de partida para alcançar a excelência é o cliente. Quer externo ou interno à organização, é necessário saber se suas expectativas estão sendo atendidas (PORTER, 2004).

Sendo assim, um dos maiores desafios para uma organização é, além de compreender perfeitamente as necessidades do cliente, conseguir traduzi-las corretamente, diferenciando-se da maioria das empresas que, por vezes, consideram suas próprias perspectivas como verdade absoluta. Foi com esse objetivo que a ferramenta QFD (desdobramento da função qualidade ou Quality Function Deployment) foi instituída, a fim de possibilitar a compreensão do que realmente o cliente espera e como essa expectativa pode ser traduzida e atendida (CHENG, 2007).

Complementarmente, ao projetar um produto ou serviço que atenda a expectativa do cliente, é preciso atentar-se aos seus requisitos básicos necessários, como por exemplo, a confiabilidade do que está sendo oferecido. Neste âmbito, foi desenvolvida a ferramenta FMEA (Análise dos modos de falha e seus efeitos ou Failure Mode and Effect Analysis), utilizada com o objetivo de identificar as possíveis falhas, analisá-las detalhadamente e atuar de forma a evitá-las ou mitigá-las, tornando possível a obtenção de resultados efetivos dentro da organização (FRANCESCHINI e GALETTO, 2001).

A indústria de petróleo e gás opera em ambientes extremamente complexos e agressivos, sendo imprescindível a utilização de materiais com características específicas, projetados exclusivamente para a mesma (THOMAS, 2004). Para a obtenção do petróleo, o processo de perfuração dos poços e elevação do óleo até a superfície deve ser feito através de estruturas instaladas com tubos em aços proprietários de acordo com cada local explorado, em todos os processos produtivos da cadeia de petróleo. Esses tubos são desenvolvidos e fabricados de acordo com a criticidade dos poços perfurados, com propriedades e metalurgias especiais que impedem a ruptura e retardam a corrosão (CENPES, 2008).

A empresa $V$ é uma produtora integrada de tubos sem costura para poços de petróleo com metalurgia a partir de Aço Carbono até Super 13\% Cromo. Para aços CRA, que são aços resistentes à corrosão, a empresa estabeleceu a sua parceria estratégica com o fornecedor Tubacex, um líder mundial integrado na fabricação de tubos de aço inoxidável sem costura, a fim de otimizar a produção para OCTG. Todos os graus CRA são produzidos de acordo com as especificações da empresa $V$ e podem ser rosqueados com as principais conexões Premium da mesma.

Dentro desse contexto, a empresa $\mathrm{V}$ possui uma elevada responsabilidade, pois a corrosão e ruptura da tubulação de um poço de petróleo pode causar diversos danos à organização, ao cliente e até mesmo ao meio ambiente (como um desastre ambiental), sendo este, um dano irreparável. Essas consequências podem ser originadas por tubos que não suportem as condições do local onde foram situados, como: presença de H2S, CO2, resistência insuficiente à corrosão, elevadas tensões, tração, compressão, pressões interna e externa ou colapso e outros tipos de esforços sofridos por esses materiais (ABRAHAM, 2005).

Neste âmbito, o intuito deste projeto é realizar uma pesquisa aplicada em uma empresa multinacional fornecedora de tubos sem costura atuante no setor de óleo e gás, através da aplicação das ferramentas QFD e FMEA de forma integrada, visando a fabricação de tubos em aços inoxidáveis (CRA), a fim de compreender de forma clara o que o cliente espera do produto, identificar falhas potenciais que esse produto possa apresentar e propor alternativas viáveis para tratativa e mitigação dessas falhas, garantindo a confiabilidade do produto fornecido. 


\section{REFERENCIAL TEÓRICO}

\subsection{MATERIAIS CRA}

Os aços inoxidáveis surgiram por volta de 1870, e foram nomeados de "rustless". O primeiro objetivo para a utilização desse tipo de aço foi para evitar a corrosão no armamento bélico. Com o tempo, foi observado que essas ligas gerariam benefícios para outros ramos industriais. Porém só nos anos 70, iniciou-se o desenvolvimento de pesquisas para a utilização desse aço na produção de gás em poços corrosivos, através de graus OCTG (Oil Country Tubular Goods) específicos (CARBÓ, 2008).

É considerado "aço inoxidável", se a liga contém, no mínimo $12 \%$ de cromo, que é o principal elemento responsável pela criação de uma camada apassivadora na superfície do produto, que o protege contra a corrosão. Alguns elementos como molibdênio, cobre e ferro, podem reforçar ainda mais essa resistência (SILVA, 2006).
Os aços inoxidáveis são classificados segundo a ISO 13680:2010 e API 5CRA em 4 classes relacionadas com a sua estrutura metalúrgica: martensíticos, ferríticos, austeníticos-ferríticos (ou duplex) e austeníticos. Martensítico (principalmente 13\% de $\mathrm{Cr}$ e super $13 \% \mathrm{Cr}$ ) é endurecido por um tratamento térmico apropriado, mas a sua utilização é limitada a ambientes com baixas pressões parciais de H2S.

Os tubos CRA são usados em projetos de poço que necessitam de vida longa de seus tubos e requisitos de alto rendimento, já que estes projetos envolvem ambientes extremamente corrosivos, com: Altas temperaturas (atingindo $220^{\circ} \mathrm{C}$ ), alta pressão de $\mathrm{CO} 2$ e H2S (hidrogênio superior a 35\%), alto teor de cloreto e baixo $\mathrm{pH}$ e presença de Sulfeto.

A figura 1 apresenta o guia de seleção do aço que deve ser utilizado dependendo da relação entre a pressão de CO2 E H2S que o ambiente, no qual o tubo será utilizado, apresenta.

Figura 1 - Guia de Seleção de material

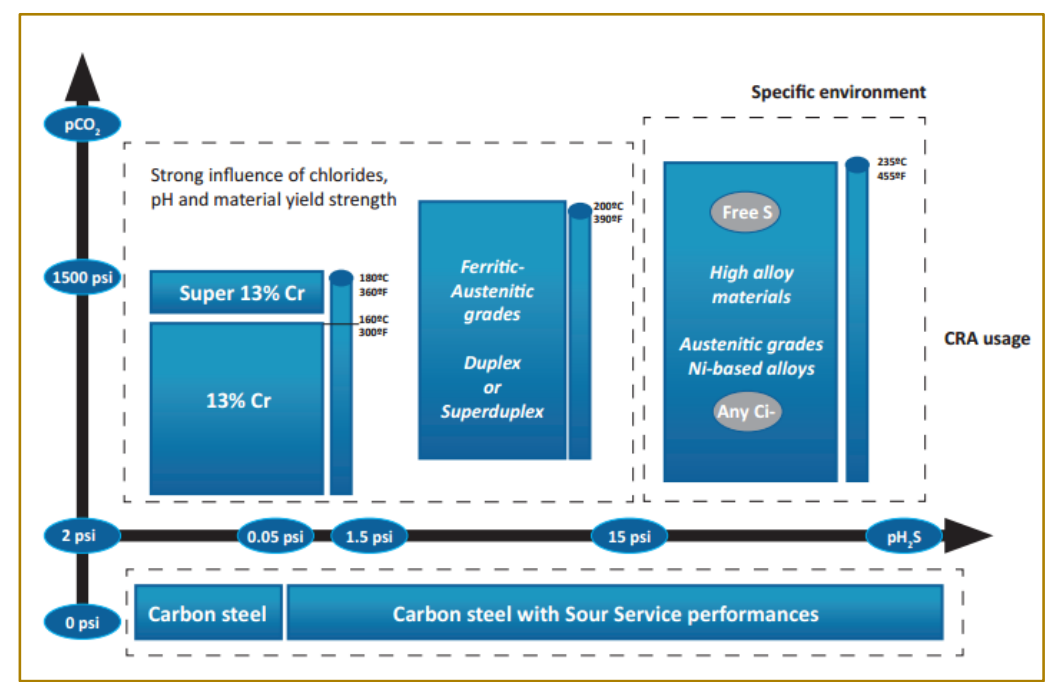

Fonte: Catálogo OCTG, 2015.

É possível observar que a principal variável que indica a necessidade da utilização de tubos com aço CRA é a alta pressão de H2S no ambiente.

\subsection{QFD}

O QFD, do inglês, Quality Function Deployment, é uma ferramenta de qualidade que surgiu no Japão por volta de 1960, a partir dos professores Akao e Mizuno, que almejavam obter, através de um método, quais os pontos críticos para a garantia da qualidade. Em 1986, o QFD foi difundido mundialmente, através da sua popularização nos Estados Unidos, porém algumas características das ideias originalmente propostas foram alteradas. (CARNEVALLI ET AL., 2004; CHENG, 2007; MELO, 2007).

O QFD é um método que facilita o processo de planejamento da qualidade através de uma série de relações de causa e efeito, que serão trabalhadas por meio de matrizes. Através dele, é possível relacionar as 
necessidades da qualidade ("o que se espera") com os requisitos existentes ("como se pretende fazer"), e identificar a intensidade do relacionamento entre eles.

De acordo com Cheng (2007) e Melo (2007), o principal objetivo dessa ferramenta é o de capturar os principais desejos e necessidades de um cliente sobre um produto ou serviço e tornar explicito os aspectos que influenciam a qualidade percebida, de forma a identificar quais os pontos críticos a serem tratados. Ou seja, o QFD possui um potencial forte de ouvir, traduzir e transmitir, de forma priorizada, a voz do cliente para dentro da empresa.

Os principais resultados obtidos por empresas que fizeram uso da metodologia confirmam os grandes benefícios de usar o QFD. Dentre estes, estão: Aumento da satisfação dos clientes, melhor comunicação interna, ganho de mercado, capacitação de recursos humanos, redução nas reclamações dos clientes e, não menos importante, melhoria da qualidade e confiabilidade do produto (CARNEVALLI ET AL., 2004; CHENG, 2007; MELO, 2007).

\subsection{FMEA}

De acordo com Zeithaml et al. (1990), entre as principais dimensões da qualidade de um serviço ou produto está a confiabilidade, apresentada como a certeza de que o produto fornecido cumpra exatamente o que foi proposto em seu projeto de fabricação e comercialização.

Segundo a norma brasileira NBR 5462-1994, item 2.2.6.4, a confiabilidade de um produto é a probabilidade de que este produto desempenhe a função requerida, por um intervalo de tempo pré-estabelecido, sob condições definidas de uso. Segundo Elsayed (1996), a confiabilidade é a probabilidade que um produto ou serviço opere adequadamente e sem falhas sob as condições de projeto, durante um tempo especificado, a vida de projeto.

O FMEA, do inglês, Failure Mode and Effect Analysis, surgiu em 1963, em estudos realizados pela agência americana NASA para a missão Apollo. Posteriormente, o FMEA foi aplicado na indústria automobilística, onde foi utilizado para quantificar e ordenar os defeitos potenciais ainda na fase de projeto, com o objetivo de impedir que essas falhas chegassem ao cliente final (PUENTE ET AL., 2002)

De acordo com Franceschini et al. (2001) o FMEA é uma ferramenta de confiabilidade que visa à identificação de falhas e problemas potenciais de um produto ou sistema antes de serem repassados ao consumidor final. Além disso, esse método permite priorização das tratativas das possíveis falhas, através da quantificação da criticidade de seus modos e de uma lista de ações preventivas para seu controle.

Desta forma, o principal objetivo dessa ferramenta é evitar que ocorram falhas durante a operação do produto ou do processo, por meio da análise das falhas potenciais e propostas de ações de melhoria. Sendo assim, sua utilização, diminui as chances de falha, buscando, consequentemente, aumentar a confiabilidade do mesmo.

Esta dimensão da qualidade, a confiabilidade, têm se tornado cada vez mais importante para os consumidores, pois, já que está diretamente relacionada com a satisfação do cliente no produto ou serviço adquirido. A falha de um produto, dependendo da sua gravidade, pode causar danos irreparáveis para a reputação de uma empresa (TOLEDO, 2016).

\section{PLANO DE PESQUISA}

A pesquisa baseou-se na integração das ferramentas QFD e FMEA, resultando na identificação dos requisitos do cliente e as formas como estes podem ser atendidos, os possíveis modos, efeitos e causas das falhas. Desta forma o método utilizado ao longo do desenvolvimento deste projeto pode ser dividido nas fases abaixo: 
Tabela 1 - Desdobramento das características da qualidade

\begin{tabular}{|c|c|}
\hline ETAPAS DA PESQUISA & DESCRIÇÃO \\
\hline $\begin{array}{l}\text { Fase 1: Estudo de Mercado com a } \\
\text { equipe de Vendas }\end{array}$ & $\begin{array}{l}\text { Nessa etapa os principais concorrentes foram levantados, as vantagens e } \\
\text { desvantagens frente a estes foram analisadas; }\end{array}$ \\
\hline $\begin{array}{l}\text { Fase 2: Realização de entrevistas } \\
\text { com os clientes: }\end{array}$ & $\begin{array}{l}\text { Foram levantadas as principais características que o produto e serviço } \\
\text { prestado pela empresa devem oferecer ao cliente, seguida de um } \\
\text { questionário quantitativo; }\end{array}$ \\
\hline Fase 3: Aplicação do QFD & $\begin{array}{l}\text { Através das fases } 3 \text { e } 4 \text {, os requisitos do cliente e do produto foram } \\
\text { definidos, e o desdobramento da matriz de qualidade foi realizado; }\end{array}$ \\
\hline Fase 4: Aplicação do FMEA & $\begin{array}{l}\text { Inicialmente foram realizadas reuniões com a equipe técnica, para a } \\
\text { identificação das possíveis falhas no produto. Cada causa foi avaliada e } \\
\text { pontuada através do NPR; }\end{array}$ \\
\hline $\begin{array}{l}\text { Fase 5: Priorização das causas e } \\
\text { ações propostas }\end{array}$ & $\begin{array}{l}\text { Priorização das causas e ações propostas: identificaram-se quais falhas } \\
\text { devem ser monitoradas de maneira a não comprometer a qualidade do } \\
\text { produto; }\end{array}$ \\
\hline Fase 6: Análise dos resultados & $\begin{array}{l}\text { Os resultados obtidos através do QFD e do FMEA foram analisados e } \\
\text { integrados, a fim de se obter uma conclusão única, em termos de } \\
\text { atendimentos às perspectivas do cliente e garantia de qualidade. }\end{array}$ \\
\hline
\end{tabular}

Fonte: Elaborado pelos autores, 2007.

\section{RESULTADOS E ANÁLISES}

\subsection{ESTUDO DE MERCADO COM A EQUIPE DE VENDAS}

Para a realização do estudo de mercado, foi solicitado o auxílio do setor de Vendas da empresa. Inicialmente, foi realizado um levantamento geral dos concorrentes existentes da empresa $\mathrm{V}$ e uma avaliação do nível de influência que cada uma dessas exerce no mercado em questão, possibilitando a elaboração de uma análise consistente do atual cenário que a empresa vivencia.

Dentre estes, foi selecionado um concorrente potencial para a realização da pesquisa, o qual atua no mesmo segmento da empresa $V$ com o fornecimento de produtos semelhantes para o setor de óleo e gás. O auxílio da equipe de vendas também foi essencial para a elaboração da análise da avaliação competitiva presente no QFD, permitindo a realização de uma comparação consistente das duas empresas em relação aos requisitos do cliente e a compreensão das vantagens e desvantagens da empresa $V$ frente a este concorrente.

\subsection{REALIZAÇÃO DE ENTREVISTAS COM O CLIENTE}

Para a realização das entrevistas, foi selecionado o principal cliente da empresa no Brasil. As entrevistas foram realizadas com engenheiros e técnicos de poços de petróleo da companhia. Foram levantados os principais requisitos do cliente em relação aos produtos e serviços realizados pela empresa $\mathrm{V}$, referente a comercialização de produtos CRA. Além disso, foi discutido a respeito das dificuldades enfrentadas pelo cliente em suas operações, a criticidade dos ambientes explorados e de que forma e/ou com que materiais e em quais condições estes atenderão às suas necessidades.

\subsection{APLICAÇÃO DO QFD}

As principais etapas da aplicação do QFD foram feitas com o apoio do cliente, o que permitiu a realização de um estudo mais preciso. Primeiramente, através das entrevistas, foi possível fazer o desdobramento das características da qualidade que são esperadas pelo cliente. Como a proposta de negócio da empresa $\mathrm{V}$, engloba, não só o fornecimento de produtos ao cliente, mas também uma solução integrada com serviços que complementam a utilização de tal produto, o QFD criado foi dividido em duas partes principais: serviço (Qualidade no atendimento ao cliente) e produto (Qualidade do produto), conforme a tabela 2. 
Tabela 2 - Desdobramento das características da qualidade

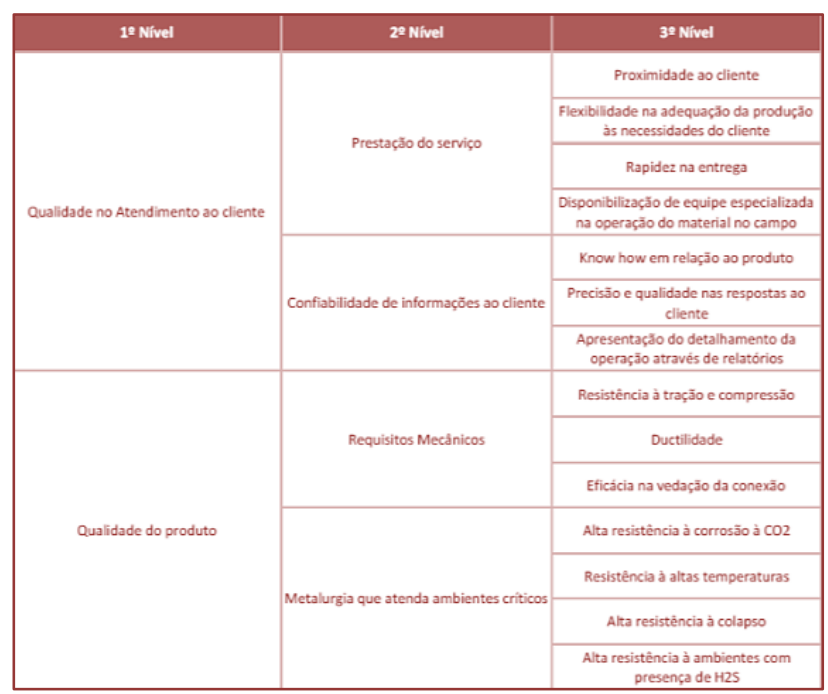

Fonte: Elaborado pelos autores, com base em CHENG,

2007.

Posteriormente, foi solicitado ao cliente que classificasse todos os itens do terceiro nível da tabela 2 com pesos, de forma a sequenciar as características que, para ele, são as mais críticas e deveriam ser priorizadas por um fornecedor. Os pesos foram dados de 1 a 10 , sendo 1 para a característica menos importante e 10 para a mais importante, conforme tabela 3.

Tabela 3 - 3o nível desdobramento das características da qualidade - Pesos

\begin{tabular}{|l|c|}
\hline \multicolumn{1}{|c|}{ 32 Nivel } & Peso \\
\hline nnow how em relação ao produto & 10 \\
\hline ficácia na vedação da conexão & 10 \\
\hline Alta resistência à corrosão à cO2 & 10 \\
\hline lexibilidade na adequação da produção às \\
pecessidades do cliente
\end{tabular}

Fonte: Elaborado pelos autores, com base em CHENG, 2007

De acordo com as informações levantadas junto ao cliente, iniciou-se o preenchimento da Casa da Qualidade, conforme figura 3.
Conforme explicitado, o QFD foi dividido em duas partes, serviço e produto, permitindo uma análise apropriada para cada tópico que foi sinalizado pelo cliente como relevante. As 
características de qualidade que serão abordadas no estudo foram transferidas para a coluna que representa o "o que" o cliente espera receber. Os pesos dados pelo mesmo também foram representados na coluna "Peso".

A próxima etapa foi levantar o "como/de que forma" o produto ou serviço atenderia tais requisitos, demonstrado na linha horizontal "Requisitos do produto", o qual foi realizado com o apoio da equipe técnica da empresa $\mathrm{V}$. O passo seguinte foi verificar a intensidade da relação entre tais requisitos do produto e os requisitos do cliente, avaliando-as nos quesitos forte, médio e fraco, com pesos 9, 3 e 1 respectivamente, conforme legenda explicativa da figura 3. Após, efetuou-se a multiplicação entre os pesos dados a cada nível de relação e o peso do requisito do cliente, avaliado pelo mesmo. O resultado da multiplicação foi evidenciado em cada célula. A soma dos resultados das multiplicações gerou o "peso absoluto" para cada item, que, dividido pela soma total dos pesos absolutos, gerou o "peso relativo", ou seja, a proporção de cada item em relação ao todo.

A etapa seguinte foi iniciar o preenchimento do telhado da casa da qualidade, o qual representa a intensidade da relação entre os requisitos do produto, ou, o nível da relação entre cada "como/de que forma" a organização atenderá o seu cliente, conforme legenda da figura 3. Esta etapa foi realizada através de uma análise crítica da equipe de trabalho juntamente com a equipe técnica da empresa $\vee$ com o objetivo de avaliar a influência de cada requisito do produto em relação aos demais.

Também foi realizada uma análise de caráter externo com o apoio da equipe de vendas, avaliando a relação competitiva entre a empresa e seu principal concorrente, com pontuações entre 1 e 5 , sendo 1 para a pior posição e 5 para a melhor. Por fim, foi avaliado novamente o desempenho da empresa e do mesmo concorrente, porém, na percepção dos técnicos da empresa, finalizando a Casa da Qualidade, ou QFD.

Através da análise da matriz QFD é possível verificar que o requisito do produto "funcionário especializado disponibilizado no cliente", possui uma importância relevante levando em consideração os requisitos do cliente referente à qualidade no atendimento, apresentando um peso relativo de $36,7 \%$. Isso indica que investimentos nessa característica de serviço, irão garantir que grande parte dos requisitos de qualidade no atendimento ao cliente sejam atendidas.

Entre os requisitos do produto, que interferem diretamente os requisitos do cliente relacionados à qualidade do produto, os que tiveram maior destaque foram: "índice de vedação", "\% de elementos extras" e "\% de cromo na liga", com respectivamente, 29,7\%, $26,4 \%$

e $24,7 \%$.

Figura 3 - Casa da Qualidade

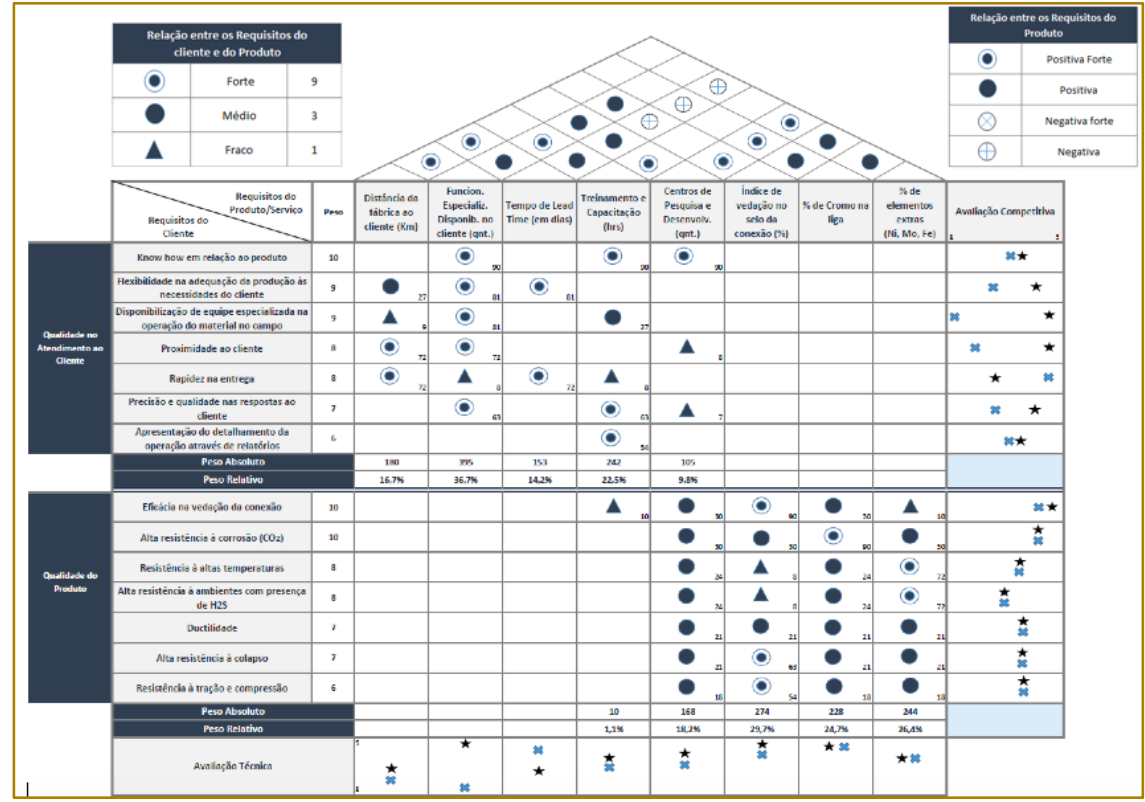

Fonte: Elaborado pelos autores, com base em CHENG, 2007. 


\subsection{APLICAÇÃO DO FMEA E TRATATIVA DAS CAUSAS DAS FALHAS}

Após a aplicação do QFD, o FMEA foi realizado com o objetivo principal de aumentar a confiabilidade dos tubos CRA comercializados pela empresa $\mathrm{V}$, através da identificação dos modos de falha potenciais, seus efeitos, causas, e taxas de ocorrência.
As análises e tratativas das possíveis falhas em relação a esse produto são de grande importância, considerando que os tubos CRA são utilizados em poços mais profundos, com maior severidade nas condições ambientais. Para isso, inicialmente foi elaborada a representação hierárquica do produto, que contém os principais componentes de um tubo CRA, como representado na figura 4:

Figura 4 - Representação hierárquica do produto

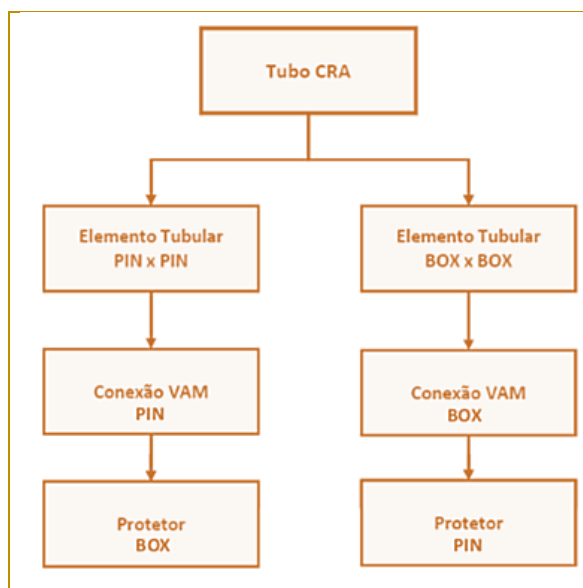

Fonte: Elaborado pelos autores, com base em Puente et al., 2002.

O tubo CRA é comercializado com os seguintes componentes:

Elemento tubular pino x pino: É o maior e principal componente do produto, pois além de possuir maior massa é o elemento que exerce a função primária para qual o tubo foi projetado. São nas extremidades desta parte que estão usinadas as conexões pino.

Elemento tubular caixa x caixa: É o elemento de ligação entre os tubos, também conhecida como luva, este elemento recebe o pino do outro tubo no momento do acoplamento durante a formação da coluna.

Conexão VAM: É a parte usinada do elemento tubular pino-pino e da luva. Possui projeto dedicado a suportar esforços combinados de tração, compressão, pressão interna e externa exercida inclusive por gás.
Protetor: É um elemento plástico no formato da conexão VAM que protege as extremidades usinadas contra danos mecânicos e contra elementos corrosivos.

Em sequência, foram selecionados os principais requisitos do produto, oriundos do QFD, que poderiam falhar, considerando o resultado do peso relativo, a criticidade de cada requisito e seu potencial de melhoria. Os requisitos selecionados foram "Índice de vedação no selo da conexão", "\% de cromo na liga" e "\% de elementos extras". Levando em consideração estes, os três principais modos de falhas foram levantados: fissura da coluna, corrosão avançada do tubo e perda da estanqueidade na conexão, como apresentado na tabela 4. 
Tabela 4 - Relação entre requisito do produto e seu principal modo de falha

\begin{tabular}{|l|c|}
\hline \multicolumn{1}{|c|}{ Requisito do Produto } & Modo de Falha Potencial \\
\hline índice de vedação no selo da conexão & Perda de estanqueidade na conexão \\
\hline$\%$ de cromo na liga & Corrosão avançada do tubo \\
\hline$\%$ de elementos extras (Ni, Mo, Fe) & Fissura de coluna \\
\hline
\end{tabular}

Fonte: Elaborado pelos autores, com base em Puente et al., 2002.

Foi feita uma árvore de falhas a partir destes, com o objetivo de identificar as causas raízes responsáveis por cada modo de falha levantado, conforme figura 4.

Através da análise da figura 4, é possível observar que a fissura da coluna e a corrosão avançada do tubo tiveram as mesmas causas raízes. Desta forma, se estas causas forem tratadas, irão influenciar em duas falhas distintas, simultaneamente. Em relação à perda de estanqueidade da conexão, novas causas raízes foram encontradas, todas elas relacionadas com a deterioração da região de vedação da conexão, conhecida como selo.

Após a elaboração da árvore de falhas, o que possibilitou o encontro das causas raízes referentes aos modos de falhas potenciais referentes aos requisitos do produto selecionados, a tabela representativa do FMEA foi elaborada, e o RPN foi calculado, permitindo a proposição de ações, de acordo com a priorização das causas, de acordo com a figura 5.

Figura 4 - Árvore de falhas

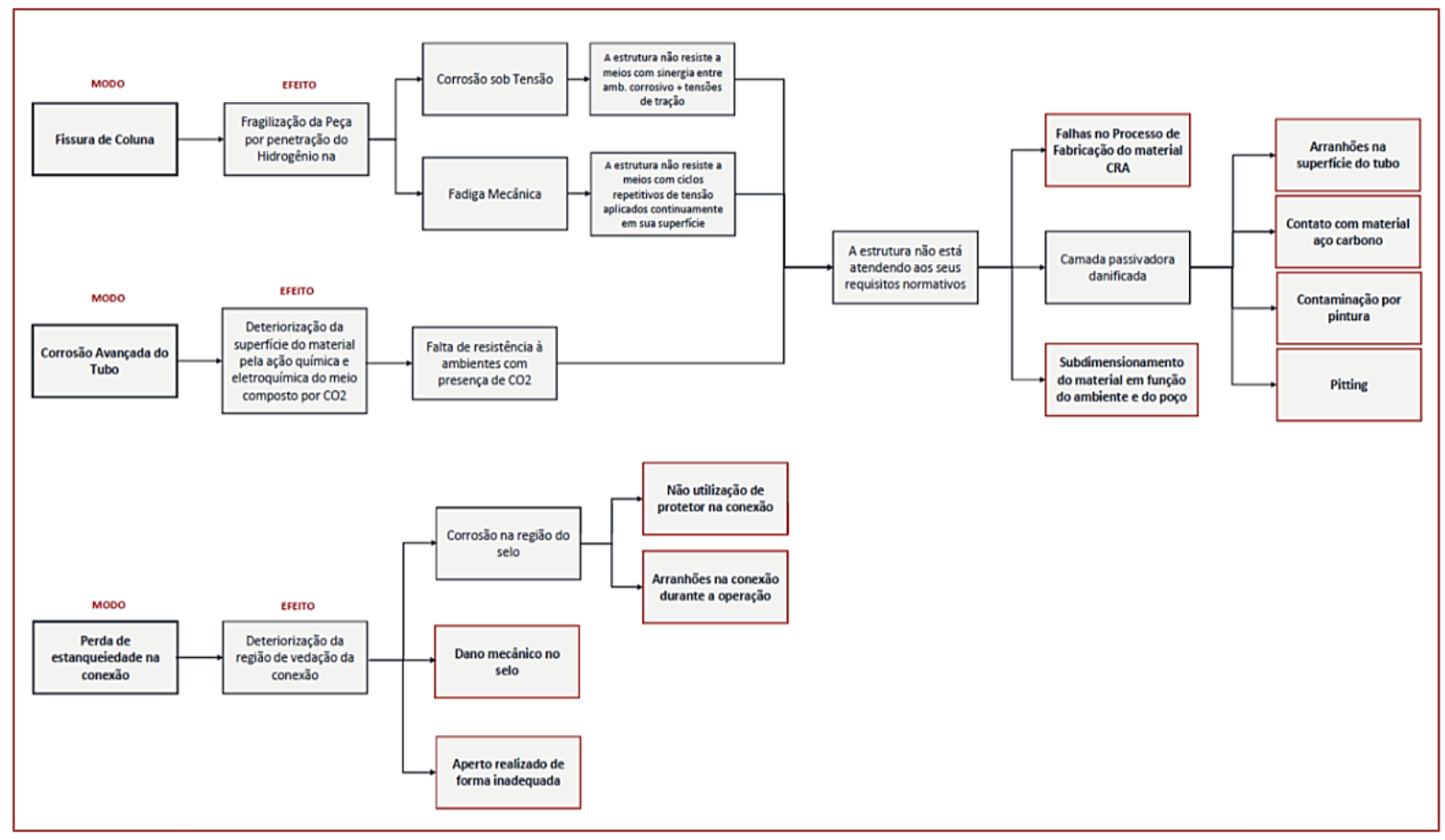

Fonte: Elaborado pelos autores, com base em Oakland, 1994. 
Figura 5 - FMEA

\begin{tabular}{|c|c|c|c|c|c|c|c|c|c|c|c|}
\hline \multicolumn{12}{|c|}{ F.M.E.A. - ANÁLUSE DE MODOS DE FALHAS E SEUS EFETTOS } \\
\hline \multicolumn{2}{|r|}{ 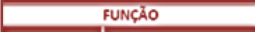 } & \multirow[b]{2}{*}{$\begin{array}{l}\text { REQUISTODO } \\
\text { PRODUTO } \\
\text { REUCIONADO }\end{array}$} & \multicolumn{3}{|c|}{ FALHAS POSSIVEIS } & \multirow[b]{2}{*}{ 总 } & \multirow[b]{2}{*}{ 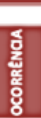 } & \multirow[b]{2}{*}{ 욣 } & \multirow[b]{2}{*}{ 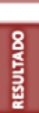 } & \multicolumn{2}{|c|}{ AÇĀO CORRETIVA } \\
\hline $\begin{array}{l}\text { NOME DO } \\
\text { COMPONENTE } \\
\text { I PROCESSO }\end{array}$ & $\begin{array}{l}\text { FUNCR̃ODO } \\
\text { COMPONENTE/ } \\
\text { PROCESSO }\end{array}$ & & $\begin{array}{l}\text { MODO DE FALHA } \\
\text { POTENCANL }\end{array}$ & $\begin{array}{l}\text { EFETO POTENCALL DA } \\
\text { FALHA }\end{array}$ & CAUSA PRINCPAL DA FALHA & & & & & RECOMENDAÇËS & ACGES SUGERIDAS \\
\hline \multirow{2}{*}{$\underset{\text { CIN }}{\text { Conex }}$} & \multirow{4}{*}{\begin{tabular}{|c|} 
Realizar a junção \\
estrutural entre tubos
\end{tabular}} & \multirow{4}{*}{\begin{tabular}{|c|} 
indice de vedaçăo no \\
selo da conexăo (\%)
\end{tabular}} & \multirow{4}{*}{$\begin{array}{l}\text { Perda de } \\
\text { estanqueidade na } \\
\text { conexão }\end{array}$} & \multirow{4}{*}{ 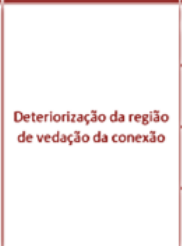 } & $\begin{array}{c}\text { 1- Não utilizaç̃o de protetor } \\
\text { na conex̃̃o }\end{array}$ & 9 & 2 & 1 & 18 & Manter o protetor na conexð̃o & $\begin{array}{l}\text { Disponibilizar protetores } \\
\text { adequados à cada tipe de } \\
\text { conexão }\end{array}$ \\
\hline & & & & & $\begin{array}{l}\text { 2- Arranhōes na conexão } \\
\text { durante a operaş̧วิo }\end{array}$ & 6 & 3 & 3 & 54 & $\begin{array}{l}\text { Manter a integridade } \\
\text { meç̇nica da conexảo }\end{array}$ & $\begin{array}{c}\text { Urtizar constantemente o } \\
\text { protetor } \\
\text { Evitar choques e quedas }\end{array}$ \\
\hline \multirow{2}{*}{$\begin{array}{c}\text { Conexåo BOX } \\
\times \text { XBOX }\end{array}$} & & & & & 3- Dano mecánico no selo & 8 & 4 & 4 & 128 & $\begin{array}{l}\text { Manter a integridade } \\
\text { meḉnica do selo }\end{array}$ & $\begin{array}{c}\text { Uilizar constantemente o } \\
\text { protetor } \\
\text { Evitar choques e quedas }\end{array}$ \\
\hline & & & & & $\begin{array}{l}\text { 4- Aperto realizado de } \\
\text { forma inadequada }\end{array}$ & 9 & 4 & 5 & 180 & Seguir o manual do fabricante & $\begin{array}{l}\text { Utilitar stabibing guide } \\
\text { Adotar valores de toquve e } \\
\text { velocidade de aperto }\end{array}$ \\
\hline \multirow{3}{*}{$\begin{array}{c}\text { Elemento } \\
\text { Tubular PIN x } \\
\text { PIN }\end{array}$} & \multirow{3}{*}{$\begin{array}{l}\text { Permitit o transporte } \\
\text { de fluidos ressistindo } \\
\text { aos esforços } \\
\text { combinados }\end{array}$} & \multirow{6}{*}{$\begin{array}{c}\text { \% de elementos extras } \\
(\mathrm{Ni}, \mathrm{Mo}, \mathrm{Fe})\end{array}$} & \multirow{6}{*}{ Fissura de Coluna } & \multirow{6}{*}{$\begin{array}{c}\text { Fraglitizaçăo da Peça por } \\
\text { penetraş̧o do Hidrogênio } \\
\text { na superficle }\end{array}$} & $\begin{array}{l}\text { 5- Falhas no processso de } \\
\text { fabricaşăo do material CRA }\end{array}$ & 9 & 2 & 6 & 108 & Seguir especificaçōes técnicas & $\begin{array}{l}\text { Estabelecer um rigido } \\
\text { controle de processoe } \\
\text { produto de acordo com }\end{array}$ \\
\hline & & & & & $\begin{array}{c}\text { 6- Arranhōes na superficie } \\
\text { do tubo }\end{array}$ & 7 & 7 & 2 & 98 & $\begin{array}{l}\text { Manter a integridade } \\
\text { superficial do tubo }\end{array}$ & $\begin{array}{l}\text { Preservar a camada } \\
\text { passivadora } \\
\text { Utilizar embalagens }\end{array}$ \\
\hline & & & & & $\begin{array}{c}7-\text { Contato com material aço } \\
\text { carbono }\end{array}$ & 7 & 7 & 2 & 98 & $\begin{array}{l}\text { Manter o material CRA } \\
\text { segregado }\end{array}$ & $\begin{array}{l}\text { Disponibilizar uma brea } \\
\text { especifica para estocagem } \\
\text { de material CRA }\end{array}$ \\
\hline \multirow{3}{*}{$\begin{array}{c}\text { Elemento } \\
\text { Tubular BOX X } \\
\text { BOX }\end{array}$} & \multirow{3}{*}{\begin{tabular}{|c} 
Acoplar dois elementos \\
tubulares Pin X Pin
\end{tabular}} & & & & $\begin{array}{l}\text { 8. Contaminaşão por } \\
\text { halogénios }\end{array}$ & 6 & 1 & 1 & 6 & $\begin{array}{l}\text { Utilizar somente tintas } \\
\text { autorizadas }\end{array}$ & $\begin{array}{l}\text { Nöo utilizar tintas que } \\
\text { contenham halogenios }\end{array}$ \\
\hline & & & & & 9. Pitting & 9 & 3 & 6 & 162 & $\begin{array}{l}\text { Garantir a proteşa da da } \\
\text { superficie do material }\end{array}$ & $\begin{array}{c}\text { Preservar a cammada } \\
\text { passivadora } \\
\text { Aplicar graxa de estocosem }\end{array}$ \\
\hline & & & & & $\begin{array}{l}10 \text { - Subdimensionamento } \\
\text { do material em funş̧o do } \\
\text { ambiente e do poco }\end{array}$ & 9 & 1 & 6 & 54 & $\begin{array}{l}\text { Utilizar tubos conforme } \\
\text { recomendaçoes do fabricante }\end{array}$ & 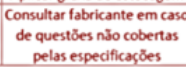 \\
\hline \begin{tabular}{|l|} 
Elemento \\
Tubular PIN x \\
PIN
\end{tabular} & $\begin{array}{c}\text { Permitit o transporte } \\
\text { de fluidos }\end{array}$ & \multirow{2}{*}{ \% de Cromo na liga } & \multirow{2}{*}{$\begin{array}{l}\text { Corrosšo Avanşada } \\
\text { do Tubo }\end{array}$} & \multirow{2}{*}{ 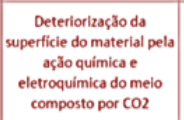 } & \multirow{2}{*}{ Causas 5, 6, 7, 8, 9e 10 . } & & & & & & \\
\hline \begin{tabular}{|c|} 
Elemento \\
Tubular BOX x \\
BOX
\end{tabular} & $\begin{array}{c}\text { Acoplar dois elementos } \\
\text { tubulares Pin X Pin }\end{array}$ & & & & & & & & & & \\
\hline
\end{tabular}

Fonte: Elaborado pelos autores, com base em Puente et al., 2002

Tabela 5 - Avaliação do Risco

\begin{tabular}{|c|c|}
\hline \multicolumn{2}{|c|}{ Risco (NPR) } \\
\hline Avaliação & Pontuação \\
\hline Muito Baixo & 1 a 49 \\
\hline Baixo & 50 a 79 \\
\hline Moderado & 80 a 100 \\
\hline Moderadamente Alto & 100 a 200 \\
\hline Alto & 200 a 350 \\
\hline Muito Alto & >350 \\
\hline
\end{tabular}

Fonte: Elaborado pelos autores.

Levando em consideração a figura 5 e a tabela 5, foi possível avaliar, de uma forma geral, a distribuição dos riscos existentes, como apresentada na figura 6.

Figura 6- Risco NPR representatividade

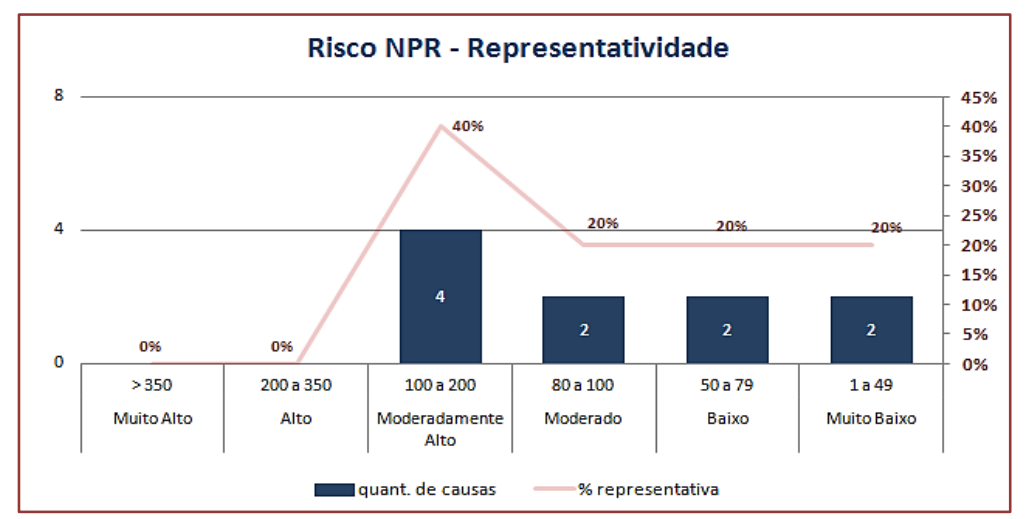

Fonte: Elaborado pelos autores. 
Através deste gráfico, é possível verificar que, levando em consideração as causas raízes encontradas, $40 \%$ apresenta um risco moderadamente alto, 20\% moderado, 20\% baixo e $20 \%$ muito baixo. Desta forma ao tratar os riscos moderadamente alto e moderado, estaríamos atacando 60\% das causas raízes existentes.

A figura 7 apresenta as causas raízes que deveriam ser priorizadas, de acordo com o nível de risco apresentado:

Figura 7- NPR das Causas raízes.

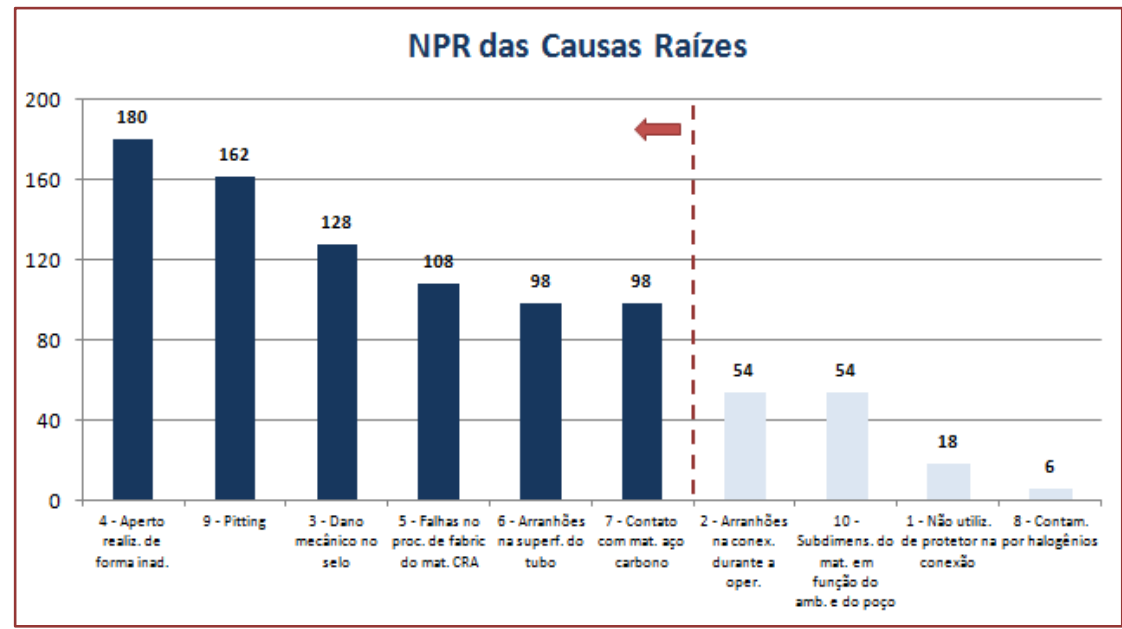

Fonte: Elaborado pelos autores.

$\mathrm{Na}$ figura 7, as causas que apresentaram um risco moderadamente alto ou moderado foram destacadas. É recomendável que as ações referentes às causas raízes que apresentaram um maior risco sejam priorizadas.

\section{CONCLUSÕES}

Através da aplicação das ferramentas QFD e FMEA, foi possível identificar, com a visão do cliente, as características essenciais de um produto que a empresa oferece ao mesmo (tubos CRA) e soluções em serviços, identificando pontos chaves de melhoria do

\section{REFERÊNCIAS}

[1] ABRACO. Tratamento de petróleo para remoção de H2S. INT, 2006. Disponível em: $<$ https://

www.nssmc.com/product/catalog_download/pdf/P0 03en.pdf >. Acesso em 30 de julho de 2016.

[2] ABRAHAM, Marcio. et. al. O impacto da gestão da qualidade na competitividade empresarial. 2005. Disponível em: $<$ http://www.marco.eng.br/qualidade/ROTEIROBASICO-PARA-EXERCICIO-QFD.pdf>. Acesso em 30 de julho de 2016. produto através da simulação de possíveis falhas, seus modos, efeitos e causas.

Foi elaborada uma proposta de recomendações e ações, baseada no FMEA, e apresentada à gerência da empresa. A iniciativa desse estudo proporcionou $\mathrm{O}$ interesse da organização em ampliá-lo aos pontos que não foram abordados no mesmo, como outros clientes, e, também, outras linhas de produtos que a empresa comercializa, a fim de garantir que todos os produtos e soluções oferecidos pela empresa estejam de acordo com as reais necessidades de todos os clientes, melhorando continuamente a posição competitiva da organização.

[3] ACCENTURE. Energy Perspectives ${ }^{\mathrm{TM}}$ Special edition - Issue 8 Rougher Seas Ahead, Accenture Strategy Energy, 2016.

[4] API 5CRA. API Specification 5LD CRA Clad or Lined Steel Pipe. Disponível em: < http://www.api.org/ /media/files/publications/whats \%20new/5ld_e4\%20pa.pdf> Acesso em 15 de agosto de 2016.

[5] ASSOCIAÇÃO BRASILEIRA DE NORMAS TÉCNICAS, NBR 5462: Confiabilidade e mantenabilidade. Rio de Janeiro: ABNT, 1994. 
[6] BAPTISTA, José Antonio. A importância da análise de causa raiz (Root cause analysis) na melhoria do desempenho da manutenção industrial. ABRAMAN, 2011. Disponível em: < http://www.abraman.org.br/arquivos/191/191.pdf >. Acesso em 01 de agosto de 2016.

[7] CARNEVALLI, José Antonio; SASSI, Andreza Celi; MIGUEL, Paulo A. Cauchick. Aplicação do QFD no desenvolvimento de produtos: levantamento sobre seu uso e perspectivas para pesquisas futuras. Gestão \& Produção, v. 11, n. 1, p. 33-49, 2004.

[8] CARneVAlLI, J. A.; Miguel, P. A. C. Revisão, análise e classificação da literatura sobre o QFD - tipos de pesquisa, dificuldades de uso e benefícios do método. Gestão e Produção, v.14, n. 3, p.557-579, 2007.

[9] CENPES. Desafios de materiais na área de E\&P. 2008. Disponível em: < http://www.nucleoinox.org.br/upfiles/arquivos/downl oads/apresent_petrobras_desafios_sele\%C3\%A7\% C3\%A3o_materiais_v2.pdf >. Acesso em 15 de julho de 2016.

[10] CHENG, Lin Chih. QFD: desdobramento da função qualidade na gestão de desenvolvimento de produtos. Blücher, 2007.

[11] ELSAYED, E. System reliability engineering. Reading, Massachusetts: Addison Wesley Longman, 1996.

[12] FRANCESCHINI, Fiorenzo; GALETTO, Maurizio. A new approach for evaluation of risk priorities of failure modes in FMEA. International Journal of Production Research, v. 39, n. 13, p. 2991-3002, 2001.

[13] ISO 13680:2010. Disponível em:http://www.iso.org/iso/catalogue_detail.htm?csn umber $=56098>$ Acesso em 15 de agosto de 2016 .

[14] KEUER, W.; MCCREERY, J.; NORTON, J. How Shale Companies Can Transform to Survive, Bain \& Company, 2016.

[15] MELO FILHO, Leonel Del Rey de; CHENG, Lin Chih. QFD na garantia da qualidade do produto durante seu desenvolvimento-caso em uma empresa de materiais. Production Journal, v. 17, n. 3, p. 604-624, 2007.

[16] OAKLAND, John. Gerenciamento da Qualidade Total. 1aㅡ ed. São Paulo: Nobel, 1994.

[17] PEARSON EDUCATION DO BRASIL; Gestão da Qualidade. São Paulo: Pearson Education do Brasil, 2011.

[18] PEREIRA, Marco Antonio. QFD: Quality Function Deployment. 2016. Disponível em: <http://www.marco.eng.br/qualidade/ROTEIROBASICO-PARA-EXERCICIO-QFD.pdf>. Acesso em 30 de julho de 2016.

[19] PUENTE, J.; PINO, R.; PRIORE, P.; FOUENTE, D de $L$. A decision support system for applying failure mode and effects analysis. International Journal of Quality \& Reliability Management, Bradford, v. 19, n. 2, p. 137-151, 2002.

[20] SILVA, André Luiz V. da Costa e; MEI, Paulo Roberto. Aços e Ligas Especiais, 2a edição revisada e ampliada. São Paulo: Edgard Blücher, 2006.

[21] SLACK, N.; CHAMBERS, S.; JOHNSTON, R.. Administração da Produção. 3ae ed. São Paulo: Atlas, 2009.

[22] THOMAS, José Eduardo. Fundamentos de engenharia de petróleo. $2^{\underline{a}}$ ed. Rio de Janeiro: Interciência, 2004.

[23] TOLEDO, José. FMEA - Análise do Tipo e Efeito de Falha. 2016. Disponível em: < www.gepeq.dep.ufscar.br/arquivos/FMEAAPOSTILA.pdf >. Acesso em 30 de julho de 2016.

[24] Vallourec Group. V\&M 13\% Cr \& Super $13 \% \mathrm{Cr}$ steel grades for Sweet CO2 corrosion service. Disponível em: <http://www.vallourec.com/OCTG/EN/E-

Library/gradesbrochures/Lists/Publications/13CR_4 v_1210.pdf $>$. Acesso em 30 de julho de 2016.

[25] ZEITHAML, Valarie A.; PARASURAMAN, Anathanarayanan; BERRY, Leonard L. Delivering quality service: Balancing customer perceptions and expectations. Simon and Schuster, 1990. 


\section{Capítulo 3}

\section{APLICAÇÃO DO LEAN SEIS SIGMA PARA AUMENTO DA CAPACIDADE DE EXPEDICÃO DE MINERIO DE FERRO EM UM TERMINAL FERROVIÁRIO}

\section{Thiago Henrique Freitas Policarpo}

\section{Sílvia Maria Santana Mapa}

Resumo: A metodologia Lean Seis Sigma é composta por um conjunto de práticas e ferramentas com foco em análise e solução de problemas complexos. Sua abordagem estruturada permite a obtenção de resultados consistentes e sustentáveis. Este trabalho visa aumentar a capacidade de expedição de um terminal ferroviário de carregamento de minério de ferro para atender a necessidade estratégica da empresa que o opera, por meio da aplicação da metodologia Lean Seis Sigma. Para isso, foi realizada uma pesquisa exploratória do conceito e aplicação da metodologia Seis Sigma e do Lean Manufacturing, seguido de um estudo de caso, onde o problema foi definido e tratado via aplicação do Lean Seis Sigma. O projeto possibilitou a quebra de paradigmas através de comprovações estatísticas, se mostrou eficaz na solução do problema, apresentando aumento no nível sigma do processo, alcance da meta geral, ganhos financeiros, além de estabilidade no período de verificação iniciado após a implementação de todas as ações propostas.

Palavras chave: Lean Manufacturing, Seis Sigma, Mineração, Ferrovias. 


\section{INTRODUÇÃO}

As organizações têm incorporado cada vez mais a cultura da melhoria contínua. O principal objetivo é tornar seus processos mais produtivos em termos de eficiência e qualidade. Esse cenário tem demandado o desenvolvimento de ferramentas que orientem as equipes de melhoria e, por isso, diversas técnicas têm surgido para auxiliar na identificação e solução de problemas. Nesse contexto, a metodologia Lean Seis Sigma surge como uma estratégia que integra diversos métodos para produzir resultados consistentes e sustentáveis.

O princípio fundamental da metodologia Seis Sigma é a redução da variabilidade para buscar ganhos financeiros através do aumento da produtividade e controle do processo. Assim, ela propõe um conjunto de práticas estruturadas e qualitativas para a melhoria sistemática de produtos e processos (WERKEMA, 2004). A metodologia Seis Sigma possui algumas ferramentas já utilizadas na maioria dos processos de qualidade e as completa com análises estatísticas para quantificar as etapas (RODRIGUES, 2014).

Naturalmente, a metodologia sofreu diversas alterações ao longo do tempo. Entre elas, as duas mais significativas são: a incorporação do DMAIC (sigla em inglês para as cinco etapas: Define, Measure, Analyse, Improve, Control) e dos conceitos do Lean Manufacturing, ou manufatura enxuta (DIRGO, 2005). O primeiro caso veio para direcionar o projeto de forma semelhante ao PDCA, proposto originalmente por Deming, porém com etapas mais bem definidas. No segundo, foi acrescentado o enfoque proposto pelo
Lean Manufacturing na velocidade dos processos e menor lead time a partir da redução dos desperdícios, sendo chamado de Lean Seis Sigma (OHNO, 1997; WERKEMA, 2006).

O objetivo deste trabalho é avaliar a execução da metodologia Lean Seis Sigma pelas etapas do DMAIC e os resultados alcançados após a implementação das ferramentas e ações levantadas durante o projeto. Sua aplicação foi realizada por meio de um estudo de caso em um terminal ferroviário de uma empresa de grande porte do setor minerário, localizada no município de Ouro Preto, Minas Gerais.

\section{REFERENCIAL TEÓRICO}

\subsection{SEIS SIGMA}

O Seis Sigma vem de um conceito de gestão com o objetivo de empregar ações que visam a melhoria contínua e resultados sustentáveis com foco no cliente. A metodologia integra ferramentas estatísticas a um enfoque gerencial estratégico, aplicados através de etapas estruturadas (PEREZ-WILSON, 1999).

Na metodologia, o nível de qualidade de um processo é medido pela quantidade de defeitos para cada milhão de ocorrências (partes por milhão de oportunidades - ppmo) (RISSI, 2007). Ela é referenciada pelo nível Sigma, que é inversamente proporcional à ocorrência de defeitos. Na Tabela 1 é possível observar os níveis Sigma e sua respectiva frequência de ocorrência de defeito e percentual de acertos.

Tabela 1: Nível Sigma, número de defeitos e percentual de acerto.

\begin{tabular}{|c|c|c|} 
Nivel Sigma & $\begin{array}{c}\text { Defeitos por milhão } \\
\text { de oportunidades } \\
\text { (ppmo) }\end{array}$ & $\begin{array}{c}\text { Percentual de } \\
\text { acertos }\end{array}$ \\
\hline 1 & 690000 & $31 \%$ \\
\hline 2 & 308733 & $69,2 \%$ \\
\hline 3 & 66803 & $93,32 \%$ \\
\hline 4 & 6210 & $99,379 \%$ \\
\hline 5 & 233 & $99,997 \%$ \\
\hline 6 & 3,4 & $99,99966 \%$ \\
\hline
\end{tabular}

Fonte: Dirgo, 2005. 
A aplicação do Seis Sigma pode ser sequenciada pelo modelo de melhoria contínua DMAIC, em que cada etapa utiliza desde ferramentas da qualidade e estatística básica até as mais complexas. Entender o objetivo, a importância de cada etapa e a aplicação de cada ferramenta é essencial para o sucesso do projeto (DIRGO, 2005; LYNCH et al., 2003).

Thomsett (2005) explica que a fase "Define" possui como foco definir o problema a ser tratado, o patrocinador e o cliente do projeto, ou seja, o escopo. O autor ainda enfatiza que é necessário explicitar de forma clara a meta geral estabelecida, os ganhos financeiros, as restrições e os limites do projeto. O cronograma do projeto também é definido nesta fase. Durante essa fase as ferramentas e estudos mais utilizados, segundo Rodrigues (2014), são: o fluxograma, mapa do processo, lista de verificação, indicadores de desempenho, fator crítico do processo, desdobramento da função qualidade (QFD) e análise de valor.

A próxima fase a ser desenvolvida é a "Measure". Seu principal objetivo, segundo Thomsett (2005), é coletar os dados do processo e avaliar como eles se comportam. A partir do entendimento do processo, são feitas priorizações para que sejam definidas quais variáveis serão monitoradas. Elas devem representar problemas a serem tratados e, para cada uma delas, deve ser definida uma meta específica, que será a base para 0 alcance da meta geral estabelecida (STAMATIS, 2004; RISSI, 2007; DANTAS JÚNIOR, 2015). Para essa etapa, as ferramentas mais comuns são: o histograma, série temporal, gráfico de Pareto, análise de capabilidade, teste de normalidade, cartas de controle e gráfico box-plot (STAMATIS, 2004; RODRIGUES, 2014).

Antes de avançar para a próxima fase, é necessário avaliar o "Problema" definido na fase "Define" em relação às informações levantadas nesta etapa. Este processo, conforme proposto por Thomsett (2005), visa refinar o escopo, objetivos e metas, obtendo um resultado mais assertivo. Na terceira etapa, "Analyze", Stamatis (2004) explica que o processo é analisado mais detalhadamente, e o principal objetivo desta fase é realizar estudos para identificar as oportunidades de melhoria e as causas raízes dos problemas. Júnior (2015) afirma que este estudo é essencial para estreitar o foco e agir somente nas causas mais impactantes do processo. $\mathrm{O}$ uso das ferramentas Diagrama de Causa e Efeito, Análise dos Modos e Efeitos de Falhas (FMEA), Análise de dispersão, Análise de variância (ANOVA) e planejamento do experimento são comuns nessa fase (RODRIGUES, 2014). Porém, Dirgo (2005) afirma que há uma infinidade de outras ferramentas estatísticas que podem ser utilizadas nesta etapa, e que o desafio é escolher a mais apropriada para cada situação.

Para iniciar a quarta fase, "Improve", é necessário revisar todas as fases anteriores, ajustando-as às novas informações (THOMSETT, 2005). Stamatis (2004) define como principal objetivo dessa etapa a geração e implementação de ideias. Isso só é possível devido aos resultados obtidos nas fases anteriores, pois subsidiarão a proposição de melhorias para o processo. Werkema (2004) propõe que as soluções a serem implementadas sejam organizadas em um plano de ação com os prazos, responsáveis e metas. Geralmente, esse plano de ação é baseado na ferramenta $5 \mathrm{~W} 2 \mathrm{H}$. Outras ferramentas utilizadas nessa etapa são: o Brainstorming, Diagrama de Causa e Efeito, Design of Experiments (DOE), Benchmarking, dentre outras ferramentas da qualidade e estatísticas (DIRGO, 2005; RODRIGUES, 2014; DANTAS JÚNIOR, 2015).

A quinta etapa, denominada "Control", tem o objetivo de manter os ganhos obtidos através da aplicação da ferramenta. Para efetivação desta fase é necessário medir e monitorar o andamento dos processos e antecipar ações corretivas e de prevenção de desvios. Todos os procedimentos, manuais, desenhos e demais descritivos devem ser revisados e atualizados, incluindo os novos parâmetros (STAMATIS, 2004; DANTAS JÚNIOR, 2015). O resultado da fase de controle é permitir aos responsáveis pelo processo visualizar e entender o desempenho, medir e acompanhar as metas específicas e geral e gerar ações para corrigir desvios, caso eles ocorram. Também devem ser levantados e validados os ganhos auferidos pela implementação da metodologia Seis Sigma (STAMATIS, 2004; RISSI, 2007).

\subsection{LEAN MANUFACTURING}

O Lean Manufacturing surgiu no Japão, a partir da necessidade de se produzir variedade de carros com baixa disponibilidade de recursos no período pós- 
guerra. Sua aplicação se deu na Toyota Motor Company, como um modelo gerencial denominado Sistema Toyota de Produção. Taiihi Ohno, executivo da Toyota e responsável pela criação e implantação do sistema, desenvolveu-o com foco na eliminação de desperdícios no processo, com o objetivo de reduzir custos, aumentar a qualidade e a velocidade de entrega do produto aos clientes finais (WERKEMA, 2006).

O Lean Manufacturing foca na redução dos sete desperdícios, identificados por Ohno (1997) como: Espera, caracterizado por tempo de espera de funcionários aguardando processamento ou atividade anterior, linha de produção esperando por peças e materiais, equipamentos parados para manutenção ou reparo; Defeito, que ocorre quando o produto está fora de especificação; Transporte, resultado do transporte excessivo de materiais ou serviços; Movimentação, caracterizado pelo excesso de movimentos gerados por uma operação ou processo; Excesso de estoque, devido ao excesso de inventário de matéria prima ou produto em processo; Excesso de produção, ou excesso de inventário de produto acabado; Super processamento, gerado por etapas do processo que não agregam valor ao produto.

Womack e Jones (2004) afirmam:

Existe um poderoso antídoto ao desperdício: o pensamento enxuto (Lean Thinking), que é uma forma de especificar valor, alinhar na melhor sequência as ações que criam valor, realizar essas atividades sem interrupção toda vez que alguém as solicita e realizá-las de modo cada vez mais eficaz.

Para isso, é necessário praticar os princípios do pensamento enxuto que, segundo Womack et al. (1992), são:

- Especificar o valor: esse valor é definido pelo cliente a partir de uma necessidade e a empresa é responsável por identificálo e traduzi-lo em um bem ou serviço que atenda essa necessidade específica do cliente;

- Identificar a cadeia de valor: o segundo princípio é identificar e caracterizar os processos da cadeia de valor em três tipos: que geram valor; que não geram valor, mas são necessários; e que não geram valor;

- Criar fluxos contínuos: equalização da produção, de modo a criar um fluxo contínuo para o processo. Organizar as etapas numa determinada sequência é importante para que o produto passe para a etapa seguinte sem a formação de estoques intermediários;

- Produção puxada: a melhor forma de reduzir desperdícios é fazer com que a produção seja puxada pela demanda dos clientes. Esse princípio também se aplica aos clientes internos, fazendo com que o processo posterior determine a produção do anterior;

- Buscar a perfeição: se refere à capacidade de manter uma rotina de melhoria contínua. Isso torna os processos cada vez mais enxutos e livres de desperdícios.

\section{METODOLOGIA}

Inicialmente essa pesquisa tratou de fazer um levantamento bibliográfico acerca dos principais temas em estudo. A fundamentação na literatura consiste na análise e síntese das informações, visando definir as linhas de ação para abordar o assunto e gerar ideias novas.

Com relação ao método utilizado, essa pesquisa pode ser classificada como um Estudo de Caso único, pois foi baseado em apenas um problema, o qual se buscou levantar os dados e analisar o problema. $\mathrm{O}$ estudo de caso é um método indutivo, em que a teoria é comprovada a partir de observações empíricas, com ênfase na interação entre os dados e sua análise. "O estudo de caso único tem a vantagem de permitir um maior aprofundamento e maior riqueza na coleta de dados" (CAUCHICK MIGUEL, 2012, p.136).

A pesquisa em questão pode ser classificada quanto ao objetivo como descritiva, pois, além de descrever cada particularidade dos processos adotados nos carregamentos, busca interligar informações coletadas em banco de dados às coletadas fisicamente. Para Gil (2008, p. 42) a pesquisa descritiva busca "descrever as características de determinada população ou fenômeno ou, então, o estabelecimento de relações entre variáveis. Utiliza de técnicas padronizadas de coleta de dados, tais como o questionário e a observação sistemática".

Classifica-se como uma pesquisa de natureza aplicada, típica de investigação que utiliza como procedimento técnico o Estudo de 
Caso. Quanto à abordagem, o estudo pode ser classificado como qualitativo, ao avaliar a execução da metodologia Lean Seis Sigma pelas etapas do DMAIC, e quantitativo, ao analisar os resultados alcançados após a implementação das ferramentas e ações levantadas durante o projeto.

\subsection{ESTUDO DE CASO}

O projeto foi elaborado pela Equipe de Operação de um terminal ferroviário de uma empresa mineradora de grande porte. O terminal possui o formato do tipo "pêra" (Figura 1), e o minério de ferro é descarregado através de transporte terrestre via carretas, sendo estocados na parte interna e externa da "pêra". Para realizar o carregamento do lote, é necessária a utilização de máquinas do tipo pá carregadeira e a operação de carregamento dos vagões é de responsabilidade da Equipe de Operação. A circulação dos trens é responsabilidade da Equipe de Gestão Ferroviária.

Figura 1 - Terminal ferroviário tipo "pêra"

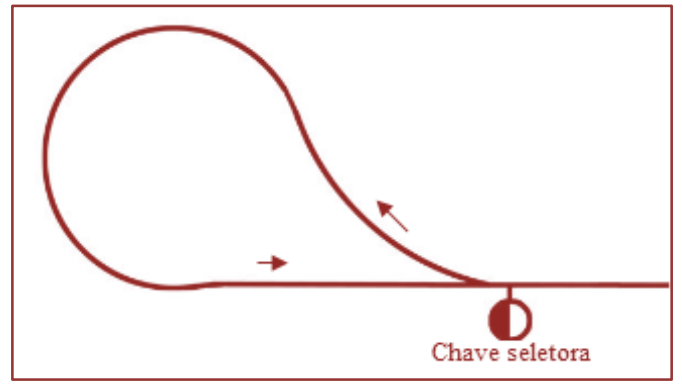

Fonte: Elaborado pelos autores

A empresa responsável pela operação do terminal projetou um aumento na expedição de minério de ferro para os anos de 2015 a 2018 (Figura 2) que superava a sua capacidade já no primeiro ano em quase 500 mil toneladas. Esse cenário trouxe a necessidade de realizar um estudo para aumentar a capacidade do terminal para atender à demanda prevista.

Figura 2 - Massa expedida no terminal ferroviário

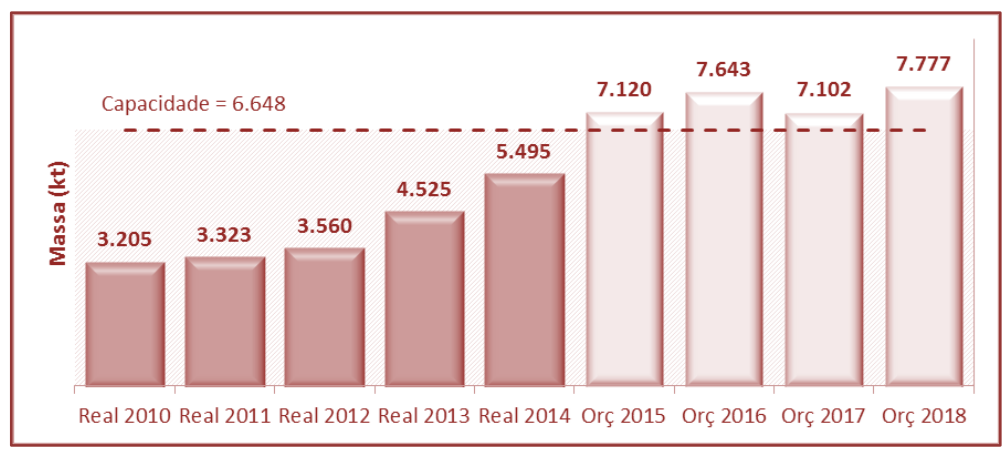

Fonte: Elaborado pelos autores

Baseado na complexidade do problema, no alinhamento com os objetivos estratégicos da empresa, e na ausência de informações sobre as causas e soluções ótimas, foi escolhido o método Lean Seis Sigma para tratá-lo. O foco do projeto foi direcionado ao aumento da capacidade do terminal. Os próximos tópicos irão apresentar a metodologia DMAIC aplicada à análise e solução do problema em questão.

\subsection{DEFINE}

O problema caracterizado foi a "baixa capacidade de expedição de minério de ferro do terminal ferroviário". Para construir uma 
solução, foram estudados os parâmetros que afetam a capacidade do terminal. São eles:

- Intervalo entre a chegada de trens: que é o tempo mínimo necessário para retirar um trem carregado do terminal e levá-lo ao pátio de manobra mais próximo, livrando o trecho da ferrovia de via singela para que o trem vazio se locomova até o terminal;

- Peso líquido de minério de ferro por vagão: é o peso médio de minério de ferro por vagão, descontado a tara, e mede o aproveitamento do espaço físico da caixa do vagão;

- Tempo de permanência de trens no terminal: É a soma de tempo de todos os eventos realizados desde a chegada do trem no terminal até sua saída, descontado o tempo de inspeção e manobras de segurança, realizadas pela Gestão Ferroviária.
Os dois primeiros parâmetros não foram priorizados pela ausência de autonomia para interferir no processo, no primeiro caso, e o desempenho do indicador no período de janeiro de 2014 a janeiro de 2015 não apresentar média mensal fora da meta estabelecida pela empresa, no segundo. O "tempo de permanência de trens no terminal" foi selecionado por ser um parâmetro controlado pela Equipe de Operação, e seu desempenho apresentar somente as médias dos meses de setembro, novembro e dezembro de 2014 dentro da meta estabelecida para a empresa e, visualmente, estabilidade somente no período de setembro de 2014 à janeiro de 2015 (Figura 3). Portanto, o objetivo do projeto foi atuar no parâmetro "tempo médio de permanência de trens" para reduzir sua média, e utilizou como período de referência, chamado neste trabalho de baseline, os dados de setembro de 2014 à janeiro de 2015.

Figura 3 - Tempo médio de permanência de trens

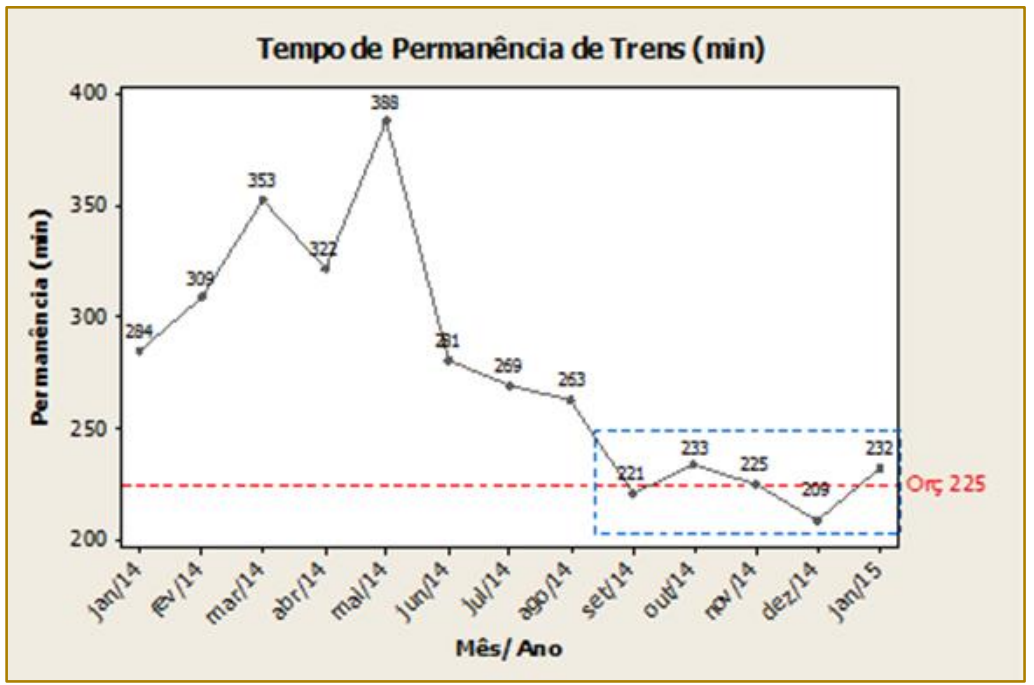

O valor da meta geral foi estabelecido através da redução de $50 \%$ da lacuna existente entre a média e o menor valor do intervalo especificado na Tabela 2. A meta geral foi descrita como "reduzir o tempo médio de permanência de trens do terminal ferroviário em 8 minutos, saindo de 224 minutos para 216 minutos, até julho de 2015".

Tabela 2 - Medidas descritivas do Tempo médio de permanência de trens em minutos.

\begin{tabular}{|c|c|c|c|c|c|c|}
\hline \multicolumn{5}{|c|}{ Desvio } & \multicolumn{3}{c|}{ Média Quartil } & Mediana & 20 Quartil & Máximo \\
\hline 223,94 & 9,87 & 208,93 & 214,86 & 224,6 & 232,7 & 233,27 \\
\hline
\end{tabular}


O nível sigma do processo foi calculado através do software Minitab ${ }^{\circledR}$, utilizando 0 tempo de permanência dos 416 trens carregados no período baseline, como limite superior de especificação a meta da empresa de 225 minutos e como alvo a meta do projeto. O resultado foi de 1,52 sigmas, ou seja, 492.021,65 defeitos por milhão de oportunidades.

O ganho de capacidade foi calculado através de uma simulação no software Arena ${ }^{\circledR}$, inserindo os três parâmetros citados, alterando apenas o valor do "tempo médio de permanência de trens" para 216 minutos. O resultado foi um aumento de capacidade de expedição dos atuais 6,648 milhões de toneladas por ano para 6,766 milhões de toneladas por ano. A capacidade final estimada não alcançou a demanda prevista para o ano de 2015, porém a meta foi mantida, por ter sido definida de forma quantitativa. A capacidade financeira, considerando o preço do minério de ferro de $\$ 69,07$ dólares por tonelada, aumentaria em \$8.150.260 dólares no ano.

\subsection{MEASURE}

$\mathrm{Na}$ segunda fase do projeto, foi montado o mapa do processo simplificado com base nas informações fornecidas pela Equipe de Operação e procedimentos operacionais da área. As principais atividades identificadas dentro do processo estão ilustradas na Figura 4:

Figura 4 - Mapa do processo simplificado

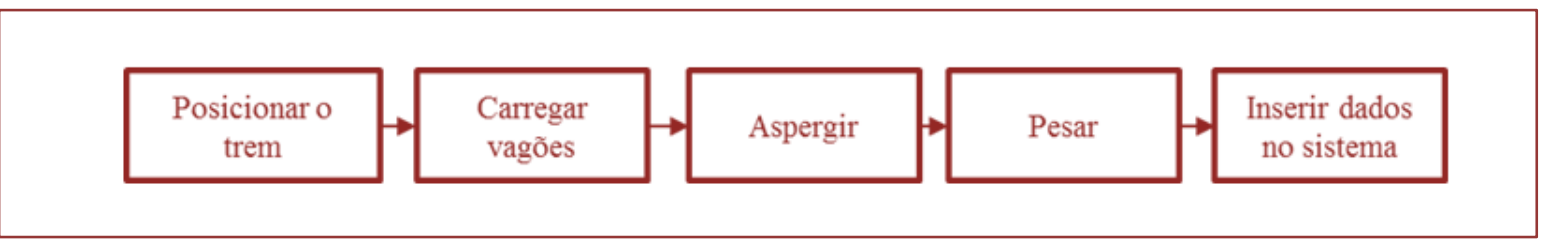

Baseado nos princípios do Lean Manufacturing, os eventos das etapas do processo foram agrupados em duas categorias: "processos", que são as atividades que agregam valor, e "desvios", que são as atividades que não agregam valor ao produto final, e correspondem a $18 \%$ do tempo médio de permanência de trens.

Continuando o processo de estratificação, foram priorizados dois focos de atuação da categoria "processos", e três da categoria "desvios". No primeiro caso foram "em carregamento", que representa o tempo dispendido durante a atividade de carregar os vagões, e "em aspersão", que representa o tempo dispendido para realizar a aspersão do polímero sobre a carga. Juntas, representam $87,4 \%$ do tempo total da categoria. No segundo caso foram priorizados "aguardando pesagem", tempo em que o trem, após carregado, aguardava a configuração da Balança Ferroviária Dinâmica para realização da pesagem bruta, "aguardando aspersão", tempo em que o trem aguardava o aspersor estar posicionado e carregado com o polímero para iniciar a aspersão, e "limpeza de linha", tempo em que o trem aguardava a limpeza de material que foi derramado sobre os trilhos para iniciar a circulação. Juntos, totalizaram $52 \%$ do tempo total da categoria.

As metas dos focos priorizados foram definidas por mais de um método. Como o tempo da atividade "em carregamento" está diretamente relacionado com 0 porte e quantidade de máquinas carregadeiras e, devido aos custos envolvidos na contratação de novos equipamentos, optou-se por manter a média já praticada.

Para o tempo da atividade "em aspersão", foi proposta uma redução até o primeiro quartil, e as atividades da categoria "Desvio", por não agregarem valor ao processo, foi proposta uma redução para uma média de 3 minutos para cada uma. Todas elas tiveram o prazo definido para julho de 2015. Os valores são apresentados na Tabela 3 e totalizaram uma redução de 20,05 minutos, mostrando a possibilidade de superar a meta estabelecida para o tempo médio de permanência de trens. 
Tabela 3 - Metas dos focos priorizados.

\begin{tabular}{|cccccc|}
\hline Indicador & $\begin{array}{c}\text { Média atual } \\
(\mathbf{m i n})\end{array}$ & $\begin{array}{c}\mathbf{1}^{\circ} \text { Quartil } \\
(\mathrm{min})\end{array}$ & $\begin{array}{c}\text { Meta proposta } \\
(\mathrm{min})\end{array}$ & $\begin{array}{c}\text { Redução } \\
(\mathbf{m i n})\end{array}$ & $\begin{array}{c}\text { Percentual de } \\
\text { redução }\end{array}$ \\
\hline Em carregamento & 122,43 & 102,96 & 122,43 & 8,12 & - \\
Em aspersão & 38,1 & 29,98 & 29,98 & 8,12 & $21 \%$ \\
Aguardando pesagem & 7,08 & - & 3 & 4,08 & $58 \%$ \\
Aguardando aspersão & 7,04 & - & 3 & 4,04 & $57 \%$ \\
Limpeza de linha & 6,81 & - & 3 & 3,81 & $56 \%$ \\
\hline
\end{tabular}

\subsection{ANALYZE}

Foram utilizados dois métodos para o levantamento das possíveis causas geradoras dos problemas priorizados. O primeiro foi o Mapa de Processo, onde foram definidos todos os parâmetros controlados e não controlados do processo, além de identificados quais deles eram críticos. O segundo foi o Diagrama de Ishikawa, agrupando as causas sob as categorias: máquina, medida, meio ambiente, mão-deobra, método e matéria prima. Ele foi construído a partir de Brainstormings com a Equipe de Operação. Esses processos geraram 31 possíveis causas geradoras para os cinco focos das quais, a partir de uma matriz de priorização, análises estatísticas e estudos de campo, foram comprovadas 14 causas fundamentais.

\subsection{IMPROVE}

Após a revisão dos dados gerados pelas fases anteriores, iniciou-se um processo de geração de ideias, através de Brainstormings realizados com a Equipe de Operação e a Gestão Ferroviária. Esse processo resultou em dezesseis ações a serem implementadas com o objetivo de mitigar as causas geradoras dos problemas.

Foram quatro ações focadas na revisão e otimização dos processos já existentes, duas de investimentos em infraestrutura, uma para desenvolver nova ferramenta de trabalho, duas para treinamento e capacitação da Equipe de Operação, duas focadas na manutenção de equipamentos do processo e cinco ações com o objetivo de criar novos processos de comunicação entre a Equipe de Operação e Equipe de Gestão Ferroviária. Todas elas foram organizadas em um plano de ação baseado na ferramenta $5 \mathrm{~W} 2 \mathrm{H}$, e seus responsáveis e prazos definidos de acordo com a autonomia e conhecimento de cada membro da equipe desenvolvedora do projeto.

Foram implementadas quatorze ações com pleno sucesso. Uma das ações focadas na otimização dos processos já existentes teve resultado parcial devido a limitações não identificadas inicialmente, mas proporcionou um aumento de produtividade satisfatório. Outra ação não pôde ser implementada, pois foi limitada por estratégias da empresa mineradora adotadas para suportar mudanças não previstas no mercado.

\subsection{CONTROL}

Após a implantação de cada ação, foram iniciadas as ações de monitoramento e controle, prevista na quinta fase do projeto. Os controles foram direcionados para os indicadores, visando avaliar o resultado das ações implantadas e possíveis efeitos colaterais não previstos.

Os principais controles estabelecidos foram: a criação de novos processos de comunicação entre as equipes, treinamento periódico da Equipe de Operação e a análise diária dos tempos dos focos priorizados, que proporcionou visibilidade dos desvios gerados no dia anterior $e$, com isso, o direcionamento da Equipe de Operação para realizar ações pontuais efetivas.

A meta geral do projeto foi superada, conforme observado na Figura 5, com a média do período de verificação, de junho a dezembro de 2015, em 185 minutos, totalizando uma redução de 39 minutos, ou seja, $17,4 \%$. 
Figura 5 - Tempo médio de permanência de trens por fase do projeto

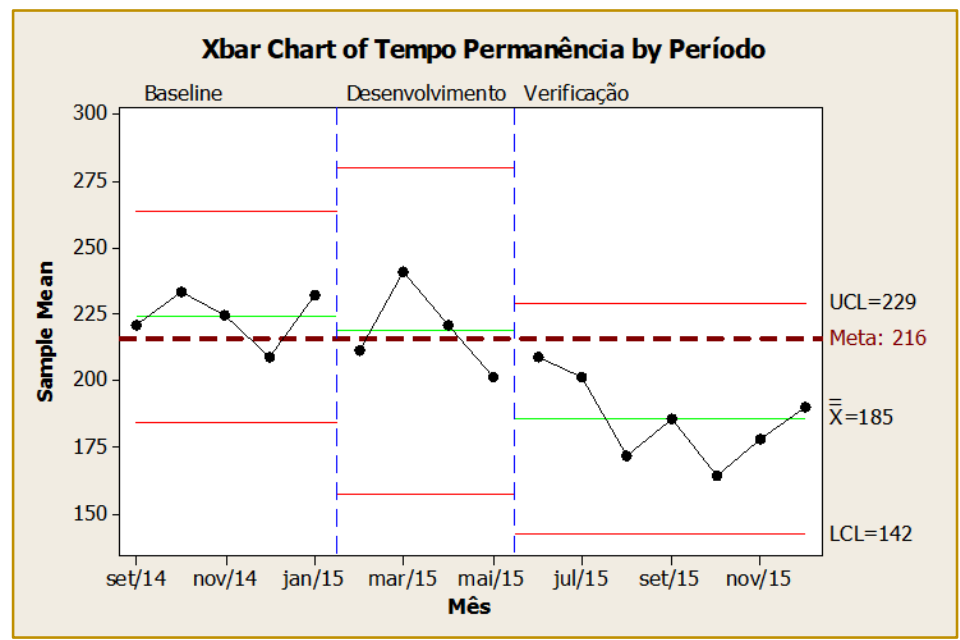

O foco "em carregamento" não alcançou a meta prevista, tendo sua média aumentada em 7 minutos, saindo de 122 minutos para 129 minutos. O aumento ocorreu devido às fortes chuvas na região no mês de dezembro, reduzindo a produtividade do processo, e a substituição no mês de junho de uma das pás carregadeiras por outra de menor porte, como estratégia de redução de custos, que gerou a necessidade de outra revisão no processo de carregamento para adequação ao novo cenário. Os demais focos tiveram sua média reduzida e alcançaram a meta proposta, conforme Tabela 4.

Tabela 4 - Resultados dos focos priorizados

\begin{tabular}{|lccccc|}
\hline Indicador & $\begin{array}{c}\text { Média anterior } \\
(\mathbf{m i n})\end{array}$ & $\begin{array}{c}\text { Meta proposta } \\
(\mathbf{m i n})\end{array}$ & $\begin{array}{c}\text { Média } \\
\text { atual }\end{array}$ & $\begin{array}{c}\text { Variação } \\
(\mathbf{m i n})\end{array}$ & $\begin{array}{c}\text { Variação } \\
\text { percentual }\end{array}$ \\
\hline Em carregamento & 122,43 & 122,43 & 129 & $+6,57$ & $+5,37 \%$ \\
Em aspersão & 38,1 & 29,98 & 10 & $-28,1$ & $-73,75 \%$ \\
Aguardando pesagem & 7,08 & 3 & 2 & $-4,08$ & $-71,75 \%$ \\
Aguardando aspersão & 7,04 & 3 & 1,4 & $-4,04$ & $-80,11 \%$ \\
Limpeza de linha & 6,81 & 3 & 1,9 & $-3,81$ & $-72,1 \%$ \\
\hline
\end{tabular}

As ações de treinamento e capacitação da Equipe de Operação e de otimização dos processos já existentes, também geraram um maior aproveitamento da caixa do vagão, pois as cargas ficaram mais uniformes e distribuídas, fazendo com que o peso médio de minério de ferro por vagão saísse de 79,192 toneladas para 82,042 toneladas, representando um aumento de aproximadamente 3,59\%. O nível sigma do processo sofreu alteração, saindo de 1,52 para 2,18 (248.252,16 defeitos por milhão de oportunidades), o que corresponde a um ganho de 0,66 sigmas.

A simulação da capacidade do terminal foi realizada alterando os parâmetros "peso líquido de minério de ferro por vagão" e "tempo médio de permanência de trens no terminal" para a média realizada após o projeto, e resultou em um ganho de capacidade de 1,626 milhões de toneladas de minério de ferro expedido no ano, superando a expectativa inicial de 118 mil toneladas. Isso significa que o terminal possui uma capacidade de 8,274 milhões de toneladas expedida por ano, atendendo a necessidade de expedição para os próximos anos, conforme observado na Figura 6. A capacidade financeira, utilizando o valor inicial do preço do minério de ferro de $\$ 69,07$ dólares/tonelada, aumentou em \$112.307.820 dólares no ano. 
Figura 6 - Capacidade do terminal ferroviário

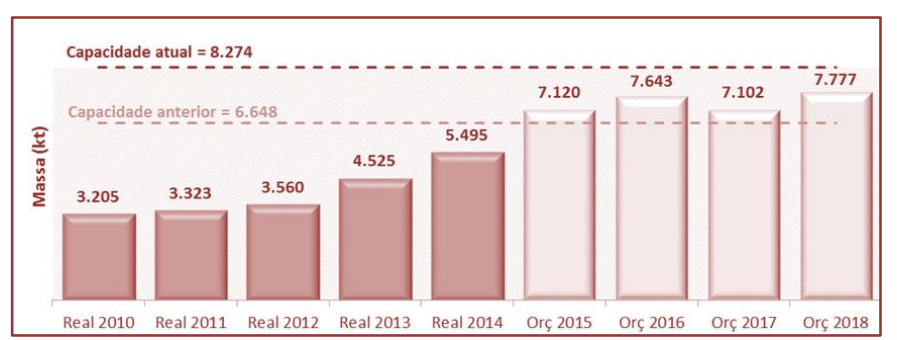

\section{CONSIDERAÇÕES FINAIS}

Foi identificado ao longo do trabalho que o Lean Seis Sigma possui uma estrutura de análise e solução de problemas robusta, que permite aos envolvidos esmiuçar os detalhes do processo e agirem diretamente na sua causa raiz. As ferramentas estatísticas e de qualidade utilizadas dão ao usuário a capacidade de entender melhor o comportamento das variáveis do processo e o levam a um caminho estruturado e focado na melhoria do processo.

No processo estudado, o Lean Seis Sigma foi utilizado com o intuito de eliminar as perdas do processo e otimizar as tarefas para aumentar a capacidade de expedição do terminal ferroviário. Os maiores ganhos observados vieram de ações simples, como a reformulação dos processos e melhoria na comunicação entre as partes envolvidas, que não requeriam grandes investimentos financeiros.

Outro ponto observado foi a quebra de paradigmas comuns que geram a alta

\section{REFERÊNCIAS}

[1]. CAUCHICK MIGUEL, P.A. (org). Metodologia de Pesquisa em Engenharia de Produção e Gestão de Operações. Rio de Janeiro: Elsevier, 2012.

[2]. DANTAS JÚNIOR, C. P. A metodologia Six Sigma e suas áreas de aplicação. Ampliando Revista Científica da Faculdade Cenecista de Rio Bonito. Rio de Janeiro: v. 2, n.2 FACERB, 2015.

[3]. DIRGO, R. Look Forward Beyond Lean and Six Sigma: a Self-Perpetuating Enterprise Improvement Method. Fort-Lauderdale: J. Ross Publishing, 2005.

[4]. GIL, A. C. Como elaborar projetos de pesquisa. 4. ed. São Paulo: Atlas, 2008.

[5]. OHNO, T. O sistema Toyota de produção: além da produção em larga escala. Porto Alegre: Bookman, 1997. resistência à mudança e é uma das grandes dificuldades enfrentadas pela empresa em melhorar continuamente. A quebra desses paradigmas veio da quantificação das perdas que os processos estavam gerando e a comprovação, através de análise estatística, da possibilidade de mudança e permitiu reconstruir processos antigos de maneira eficiente, eliminando os desperdícios.

Após a execução do projeto Lean Seis Sigma, o ganho de capacidade de expedição do terminal aumentou em 24,45\%, resultado muito superior ao previsto inicialmente de $1,77 \%$. Esse resultado veio principalmente das ações de treinamento e revisão dos processos que proporcionaram 0 comprometimento da equipe com a mudança e a eliminação de desperdícios durante a execução das atividades. Portanto, os resultados alcançados constataram a eficiência da aplicação da metodologia Lean Seis Sigma sequenciada pelas etapas do DMAIC como solução para o aumento da capacidade de expedição de minério de ferro em um terminal ferroviário.

[6]. PEREZ-WILSON, M. Seis Sigma: compreendendo o conceito, as implicações e os desafios. Rio de Janeiro: Qualitymark, 1999.

[7]. RISSI, L. A. Aplicação da metodologia Seis Sigma para resolução do problema da falta de acurácia no estoque de uma empresa. 53 p. Monografia (Bacharel em Engenharia de Produção) Escola de Engenharia de São Carlos, Universidade de São Paulo - USP, 2007.

[8]. RODRIGUES, M. V. Entendendo, aprendendo e desenvolvendo sistemas de produção lean manufacturing. Rio de Janeiro: Elsevier Editora Ltda., 2014.

[9]. STAMATIS, H. D. Six Sigma Fundamentals: A complete guide to the system, methods and tools. New York: Productivity Press, 2004

[10]. THOMSETT, M. C. Getting started in Six Sigma. John Wiley \& Sons Inc.: New Jersey, 2005 
[11]. WERKEMA, M. C. C. Criando a Cultura Seis Sigma. Nova Lima: Werkema Editora Ltda, 2004. 253 p.

[12]. WERKEMA, M. C. C. Lean Seis Sigma: Introdução às ferramentas do Lean Manufacturing. Belo Horizonte: Werkema Editora Ltda, 2006. 120 p. v. 4.
[13]. WOMACK, J.; JONES, D. A mentalidade enxuta nas empresas: elimine o desperdício e crie riqueza. 11르 reimpr. Rio de Janeiro: Elsevier, 2004.

[14]. WOMACK, J; JONES, D.; ROOS, D. A Máquina que Mudou o Mundo. 5 ed. Rio de Janeiro: Campus, 1992. 


\section{Capítulo 4}

\section{APLICAÇÃO DO MÉTODO DE ANÁLISE E SOLUÇÃO DE PROBLEMAS (MASP) NO SETOR DE CORTE EM UMA EMPRESA DE BENEFICIAMENTO DE PEDRAS}

\section{Rener Antônio Melo Nascimento}

Larissa Havenna Matos Santos

\section{Rodrigo Lustosa Soares}

\section{Marcos Antônio Oliveira Ferreira}

José Lucas Viana Morais

Resumo: O aumento das exigências dos clientes e a crescente demanda por produtos customizados faz com que as empresas que trabalham com sistema de produção por encomenda necessitem de processos com maior controle de qualidade e com menor desperdício possível. O presente trabalho procurou explicar, por meio do Método de Análise e Solução de Problemas (MASP), as causas ligadas ao grande excesso de refugo gerado pelo setor de corte em uma empresa de beneficiamento de pedras, na cidade de Teresina-PI. Após a aplicação do MASP, constatou-se por meio do diagrama de causa e efeito que a maior parte das perdas eram geradas por negligência dos próprios colaboradores. De forma a sanar esse problema, foi proposto um plano de ação baseado na ferramenta $5 \mathrm{~W} 2 \mathrm{H}$ para os gestores da empresa com intuito de aplicação e verificação posterior dos resultados obtidos.

Palavras-chave: Marmoraria, MASP, 5W2H 


\section{INTRODUÇÃO}

$\mathrm{Na}$ situação atual da indústria, as organizações procuram aumentar sua capacidade de concorrer no setor que atuam a fim de garantir sua permanência, além de aspirar uma possível liderança de mercado. Para isso, muitos esforços devem ser tomados, tanto por parte do empregador como do empregado. A redução de desperdícios, diminuição de custos, melhoria dos processos, dentre outros, podem ser facilitadas por meio de ferramentas que auxiliem na análise e gerenciamento dos problemas da empresa.

Nesse contexto, uma ferramenta muito útil e prática que pode ser aplicada é o Método de Análise e Solução de Problemas (MASP), que segundo Piechnicki et al (2011) é uma ferramenta que deve ser utilizada sistematicamente em detrimento a uma situação insatisfatória, ou para alcançar uma melhoria objetivada. Conforme Yamane e Souza (2007), o MASP utiliza ferramentas da qualidade (diagrama de Pareto, histograma, diagrama de Ishikawa, e outros) de maneira seriada e padronizada, com um ciclo envolvendo: descrição, análise, providências, decisão, implementação, padronização e feedback.

A metodologia MASP tem uma ótima reputação entre empresas de manufatura (CAMPAGNARO et al, 2008), podendo ser uma grande aliada na melhoria dos processos de fabricação, agindo sobre todo o fluxo em busca de pontos que devam ser analisados e aperfeiçoados, de forma que a produção seja otimizada. Dessa forma, empresas de beneficiamento de mármore podem ter inúmeros pontos a serem explorados por essa técnica, partindo do fato de que trabalham com processos de beneficiamento de materiais de preços geralmente elevados e processos que normalmente geram desperdícios significativos de material e tempo, o que pode ser lançado como a problemática desta pesquisa.

Esse estudo tem como principal objetivo a análise e a solução de problemas relacionados à perda e desperdício de material, encontrados na etapa inicial do beneficiamento de rochas ornamentais, isto é, no processo de corte ou serragem das pedras, buscando maneiras de reduzi-los e propor melhorias. E como justificativa, apoia-se no fato de o Brasil situar-se entre os 5 (cinco) maiores produtores de rochas ornamentais no mundo (BRASIL, 2007), com a atividade de beneficiamento final de pedras ornamentais presente em quase todo o país, tendo cerca de 12.000 empresas empregando em média 100.000 pessoas, movimentando em torno de U\$ 2,1 bilhões por ano (SEBRAE, 2014), necessitando assim de pesquisas que possam contribuir com o avanço e otimização das atividades do setor.

\section{REFERENCIAL TEÓRICO}

Esse tópico aborda inicialmente a definição de marmoraria e o funcionamento do seu processo produtivo. Após isso, busca conceituar e caracterizar os processos de produção enxuta e gestão da qualidade, de forma a embasar o Método de Análise e Solução de Problemas.

\subsection{MARMORARIAS}

Marmoraria é uma definição que se conecta às antiquadas estruturas designadas ao processamento de mármore, embora atualmente trabalhem com todo tipo de rocha ornamental (SANTOS, 2005). Segundo Chirzóstomo (2014), as marmorarias realizam serviços com alto grau de envolvimento do cliente em que, partindo de um desenho inicial, escolhe-se o material que será utilizado e segue-se à etapa de produção propriamente dita.

\subsubsection{PROCESSO DE PRODUÇÃO}

Pelos constructos teóricos de Santos et al. (2007), o processo de produção em marmorarias embasa-se no recebimento das chapas de pedra parcialmente polidas, serragem das peças nas medidas repassadas pelo cliente, retirada dos excessos e polimento de bordas e superfícies, e por fim, a montagem e acabamento da peça seguindo fielmente o projeto.

O processo de beneficiamento de pedras ornamentais foi descrito por Cunha (2006), consiste nas seguintes etapas, conforme apresentado na Figura 1: 
Figura 1 - Etapas do beneficiamento de pedras

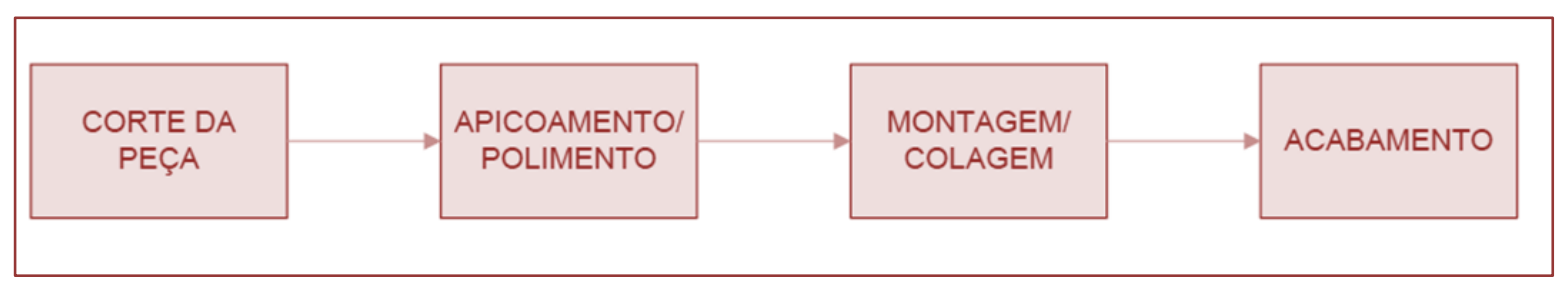

Fonte: Próprio Autor

a) Etapa de corte: as placas são serradas nas medidas e formas desejadas, por intermédio de serras manuais ou semiautomáticas, que usam discos específicos para cada tipo de pedra;

b) Etapa de apicoamento: consiste no aprimoramento final das partes cortadas, com a utilização de lixadeiras ou politrizes manuais;

c) Etapa de montagem: Com as peças cortadas, afeiçoadas e polidas conforme as necessidades do projeto, inicia-se o processo de colagem das partes, onde são feitos talhos nas superfícies de contato para permitir uma melhor adesão das peças, e acelera- se o processo de secagem dessa cola mediante o uso de catalisadores;

d) Etapa de acabamento: retira-se o excesso de cola e rebarbas por meio de lixamento, e aplica-se polimento e lustro, e quando necessário, ao final de todo o processo, realiza- se a aplicação de materiais à base de resinas e ceras para corrigir pequenas rachaduras e ranhuras.

\subsection{PRODUÇÃO ENXUTA}

Womack et al. (1992), no livro "A Máquina que Mudou o Mundo", explica como se deu o fato do surgimento da produção enxuta, no qual tal filosofia nascera dentro da fábrica da Toyota Motor Company, no Japão. O autor supracitado comenta que o pensamento lean surgiu em meados do final da década de 40, em um momento que a economia japonesa vivia um caos generalizado, fortes pressões sindicalistas dificultavam as relações trabalhistas entre patrão e empregado. Além disso, seu mercado doméstico não era propicio a fabricação de carros devida a forte concorrência das companhias americanas fortalecidas pelo sistema de produção em massa e recuperação japonesa no pósguerra.
Queiroz e Rentes (2010), descrevem que a produção enxuta tem ocasionado revoluções significativas nas empresas, mesmo em momentos de crise e de economia adversa, na qual essas alterações estruturais estão relacionadas pelos modernos e dinâmicos sistemas de gestão financeira dessas organizações. Neste aspecto, se vê o pensamento de zero desperdício e eficiência máxima contrastando os pressupostos da produção em massa, que defendem que as otimizações locais isoladas resultam na otimização global da empresa.

Lander e Linkar (2007), citam que nos últimos anos a adesão das ideias e técnicas de produção enxuta vem ganhado mais usuários. A maioria das organizações que usam essas técnicas conseguem alavancar suas operações mesmo em um universo produtivo com uma limitada oferta de produtos, operando em situações de baixo volume e mesmo assim atendendo os conceitos de produtividade e excelência operacional.

Nos constructos de Rother e Shook (1999), a produção enxuta é o conjunto das melhores práticas de produção, que quando ultrapassam as barreiras departamentais dos empreendimentos com um único e exclusivo objetivo: eliminar o desperdício e criar valor dentro da cadeia produtiva. Desde a sua criação, o Lean Thinking vem sendo aplicado em diversos setores, com êxito no sentido de reduzir custos, proporcionar qualidade superior aos produtos, gerar lead times mais curtos, reduzir os desperdícios, entre outros (RODRIGUES; PICCHI, 2010).

Para Ohno (1988), o ato de se desperdiçar algo dentro de um ambiente produtivo está correlacionado a todos os elementos de produção que só aumentam os custos do produto final, sem agregar valor algum ao mesmo, ou seja, são processos da produção que não agregam valor ao produto, do ponto de vista que não atendem ou superem as expectativas do cliente, 
porém são incorporadas dentro do fluxo produtivo, mesmo sendo obvio para as pessoas que convivem o cenário de perda.

\subsection{GESTÃO DA QUALIDADE}

A gestão da qualidade não se restringe apenas ao controle da produção, a qualidade intrínseca aos produtos e serviços ou ao uso de ferramentas isoladas. Numa visão mais abrangente, a gestão da qualidade busca um modelo de gerenciamento que possibilite eficiência e eficácia nas organizações (MARSHALL JUNIOR et al., 2012).

Para Carpinetti (2010), a gestão da qualidade vista de forma estratégica, parte do princípio que o ciclo de vida do produto, incluindo a pesquisa de mercado com foco no cliente, condiciona a uma contínua identificação de novos requisitos e necessidades. A partir disso, surge o princípio da melhoria contínua de produtos e processos, com o intuito de oferecer maior valor ao mercado.

A eliminação e simplificação de processos que não agregam valor aos produtos são um dos princípios da gestão da qualidade. Existem muitas atividades nas empresas que são mal dimensionadas que podem, na maioria das vezes, ser completamente eliminadas por meio de mudança nos seus processos. Garantir a qualidade se dá por meio de emprego de um processo controlado, um quadro de pessoal treinado e consciente dos objetivos da empresa e da busca incessante pela melhoria de todos os processos (OLIVEIRA, 2003). A Figura 2 mostra o relacionamento entre os princípios de gestão da qualidade.

Figura 2 - Relacionamento dos princípios de gestão da qualidade

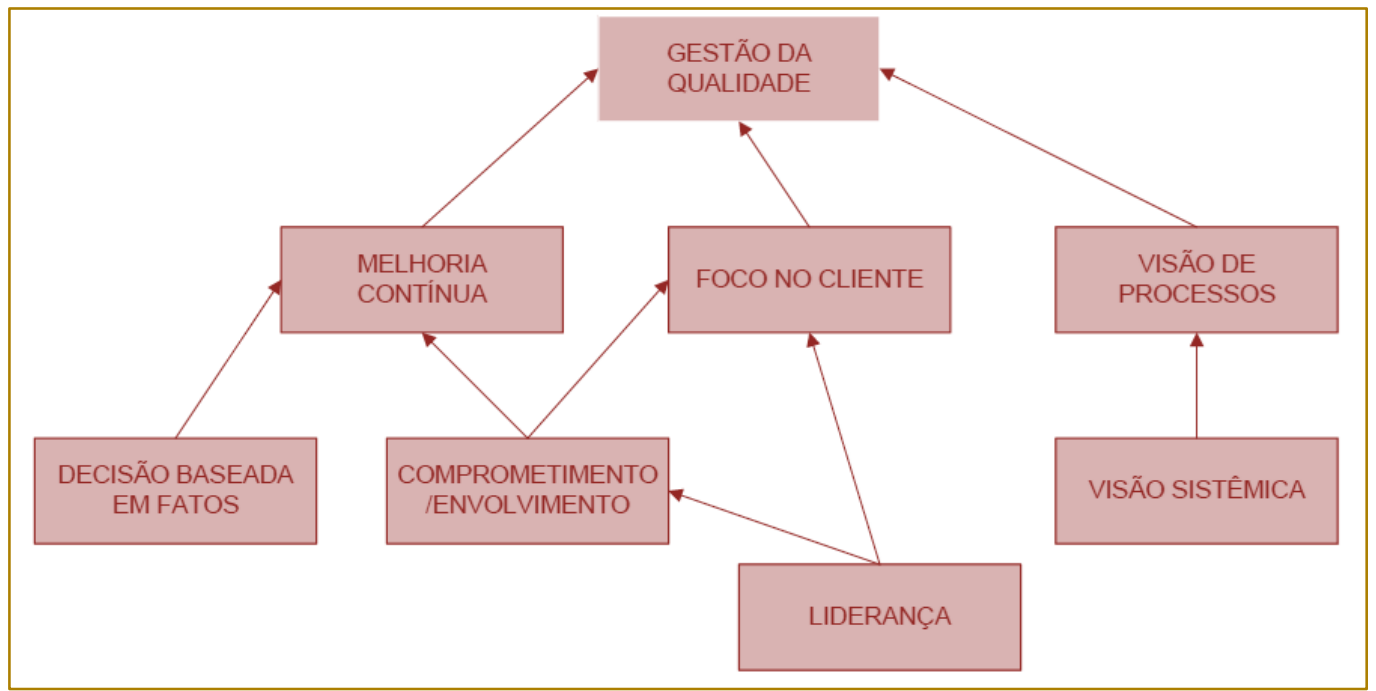

Fonte: Adaptado Carpinetti (2010).

Pela observação da Figura 2 pode-se notar a relação intrínseca entre os 7 (sete) princípios da gestão da qualidade, que devem estar sempre interligados, e comunicando-se eficientemente, de maneira que as informações fluam corretamente dentro do sistema, propiciando maior coordenação no gerenciamento da qualidade, tanto de produtos, quanto de serviços.

\subsection{MÉTODO DE ANÁLISE E SOLUÇÃO DE PROBLEMAS}

De acordo com Sampara, Mattioda e Cardoso (2009), a necessidade de implementar uma sistemática de soluções de problemas afim de aumentar a eficiência do processo produtivo está cada vez mais evidente, uma vez que as empresas buscam manter-se competitivas no mercado, gerando retorno a todo capital investido. Os autores afirmam ainda que grandes benefícios podem ser obtidos mediante a utilização do método de análise e solução de problemas, tais como: aumento da 
produtividade e redução de custos produtivos.

Motta e Marins (2012) inferem que o MASP se utiliza de algumas ferramentas ou técnicas da qualidade, como por exemplo: brainstorming, diagrama de Ishikawa, gráfico de Pareto, 5W2H, estratificação, entre outros.

Campagnaro et al (2008), definem o MASP como uma ferramenta gerencial de forma sistemática em etapas lógicas, que visam a identificação de uma não conformidade e de suas possíveis causas, e partindo de uma análise acerca destas, elaborar planos de ação de cunho corretivo e preventivo, ou seja, pode ser compreendido como um "guia" de ações a serem executadas em uma ordem metodológica com o intuito de solucionar uma não conformidade encontrada, e garantir que este problema não reincida. Para estes autores, de uma forma geral, o método contém 4 etapas:

- Identificação do problema: Nesta etapa o problema é apontado, os impactos provenientes deste, a frequência que o mesmo ocorre, e o levantamento de qualquer característica que auxilie a descrição precisa do erro.

- Identificação das causas raiz: Levantar possíveis causas potenciais associadas ao problema apontado, para este processo podem ser usadas algumas técnicas como: brainstorming, técnica dos 5 por quês, entre outras.

- $\quad$ Elaboração de estratégias de ação: Mediante a(s) causa(s) identificadas, esta etapa consiste em propor ações que reduzam ou eliminem o acontecimento de não conformidades e os prejuízos decorrentes.

- Verificação das ações: Por meio das ações propostas é necessário verificar a eficiência das mesmas.

A relação entre o MASP e o ciclo PDCA é evidente, uma vez que de forma geral ambos almejam a melhoria continua dos processos organizacionais, deste modo, pode-se ainda afirmar que o MASP foi desenvolvido de forma derivada ao ciclo PDCA (SILVA, 2014).

\section{METODOLOGIA}

\subsection{PROCEDIMENTOS METODOLOGICOS}

A presente pesquisa consiste na aplicação dos Métodos de Análise e Solução de Problemas (MASP) no processo de corte de uma empresa que trabalha com beneficiamento de pedras, situada na cidade de Teresina-PI. Procurou-se evidenciar possiveis falhas deste setor, causas relacionadas, e por fim, elaboração de estratégias de melhorias a serem executadas.

Em um primeiro momento foi realizada uma pesquisa bibliográfica de conteúdo acadêmico, em livros e artigos científicos, mediante busca feita em plataformas de pesquisa, como: Scielo, Scorpus, Web of Knowledge ,Emerald Periódicos da Capes e Google acadêmico; para que houvesse uma fundamentação de apoio ao tema e objetivos da pesquisa. Na Figura 3 abaixo, pode ser visto o arraigar da elaboração do presente construto teórico na qual foi dividido em 5 etapas do roteiro metodológico de desenvolvimento do mesmo.

Figura 3 - Roteiro Metodológico da Pesquisa

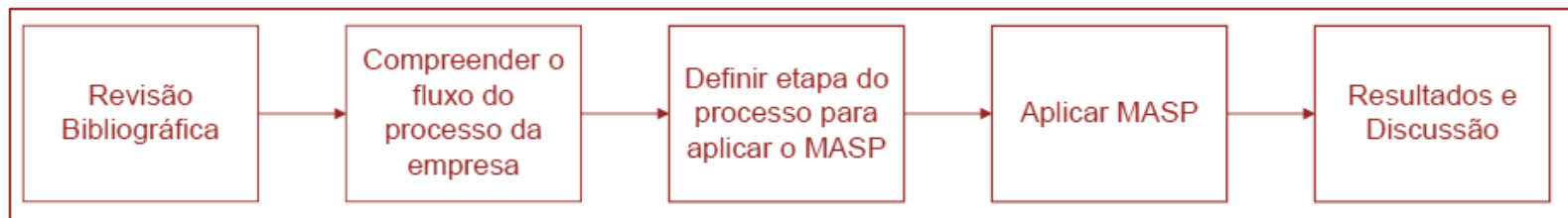

Fonte: Próprio Autor

\subsection{COLETA DE DADOS}

Dentro dos horários e limites disponibilizados pela empresa foi realizado, pela equipe de estudo, um acompanhamento do processo de corte de chapas de granito, tendo as mesmas medidas padrões de $195 \mathrm{~cm} \times 215 \mathrm{~cm} \times$ $2 \mathrm{~cm}$ (largura $x$ comprimento $x$ espessura), embora todas elas apresentem algum defeito nas bordas como pequenas trincas ou pedaços quebrados, originados geralmente 
dos processos de movimentação e acondicionamento nos caminhões de entrega dos fornecedores.

A coleta foi realizada em um período de quatro dias, durante o mês de julho de 2016, seguindo uma sequência padrão de três atividades, sendo as três primeiras realizadas por simples observação e a última por participação, que foram:

a) Supervisão dos funcionários durante a movimentação das chapas no trajeto do estoque à máquina utilizada no setor de corte, com a finalidade de identificar possíveis avarias à matéria-prima durante sua movimentação;

b) Acompanhamento da medição e demarcação da linha de corte na superfície da pedra, a fim de identificar se estão demarcando corretamente sem ocasionar perdas desnecessárias de material;

c) Observação do posicionamento da pedra sob a mesa da máquina de corte, no intuito de verificar se a serra realizou o corte precisamente sob a linha de demarcação.
4 ANÁLISE E DISCUSSÃO DOS RESULTADOS

\subsection{CARACTERIZAÇÃO DA EMPRESA}

O seguinte trabalho foi desenvolvido na empresa Polipedras, localizada em um ponto estratégico, de grande fluxo de pessoas, na cidade de Teresina-PI, situada na Av. Universitária, 60 - Bairro de Fátima, próximo à Universidade Federal do Piauí e dos três shoppings da cidade. A empresa atua no setor de beneficiamento de pedras, mármores, granitos e superfícies em silestone. Suas atividades tiveram início na cidade de Parnaíba-PI, de maneira simples em 1953, com extração e beneficiamento da ardósia retirada em Piracuruca-PI. Além do beneficiamento, a Polipedras trabalha com projeto de móveis de pedras, como armários, mesas, bancadas e instalação in loco de pisos e revestimentos atendendo um mercado consumidor das classes alta e média de Teresina. Possui um total de 23 funcionários, operando nos turnos matutino e vespertino.

\subsection{PROCESSOS INTERNOS DA EMPRESA}

Inicialmente, na visita a empresa, analisouse os macroprocessos internos e externos que correspondem a todo fluxo de funcionamento do estabelecimento, descrito na Figura 4.

Figura 4 - Macroprocessos da empresa

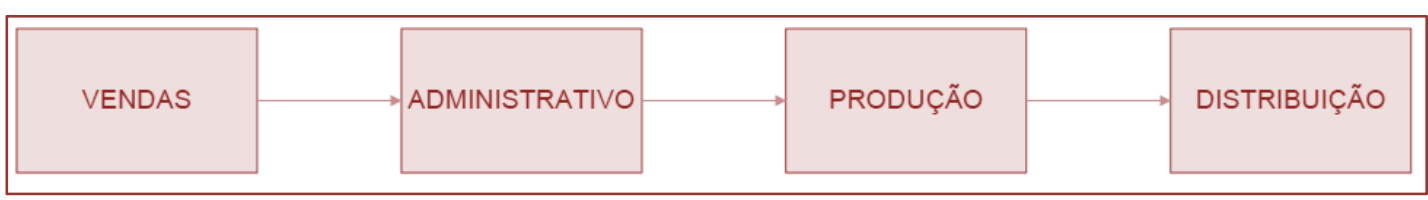

Fonte : Próprio Autor

A Figura 4 demostra o macroprocesso delineando suas subdivisões internas, no qual demostram o fluxo produtivo nos setores da empresa desde o processo de vendas, passando pelo administrativo, pela produção (manufatura) onde são transformados os insumos e a área de distribuição onde faz parte do processo de entrega dos produtos aos cliente, fechando assim a cadeia interna da empresa.

\subsection{DIAGRAMA DO FLUXO DO PROCESSO}

Foi levantado um estudo do fluxo produtivo de toda a empresa com o intuito de realizar uma análise de todo o processo de manufatura e seus possíveis problemas, pelo fato de a etapa de corte ser o início do processo de beneficiamento, podendo influenciar nos procedimentos ao longo da cadeia de produção. 
Figura 5 - Fluxograma da empresa

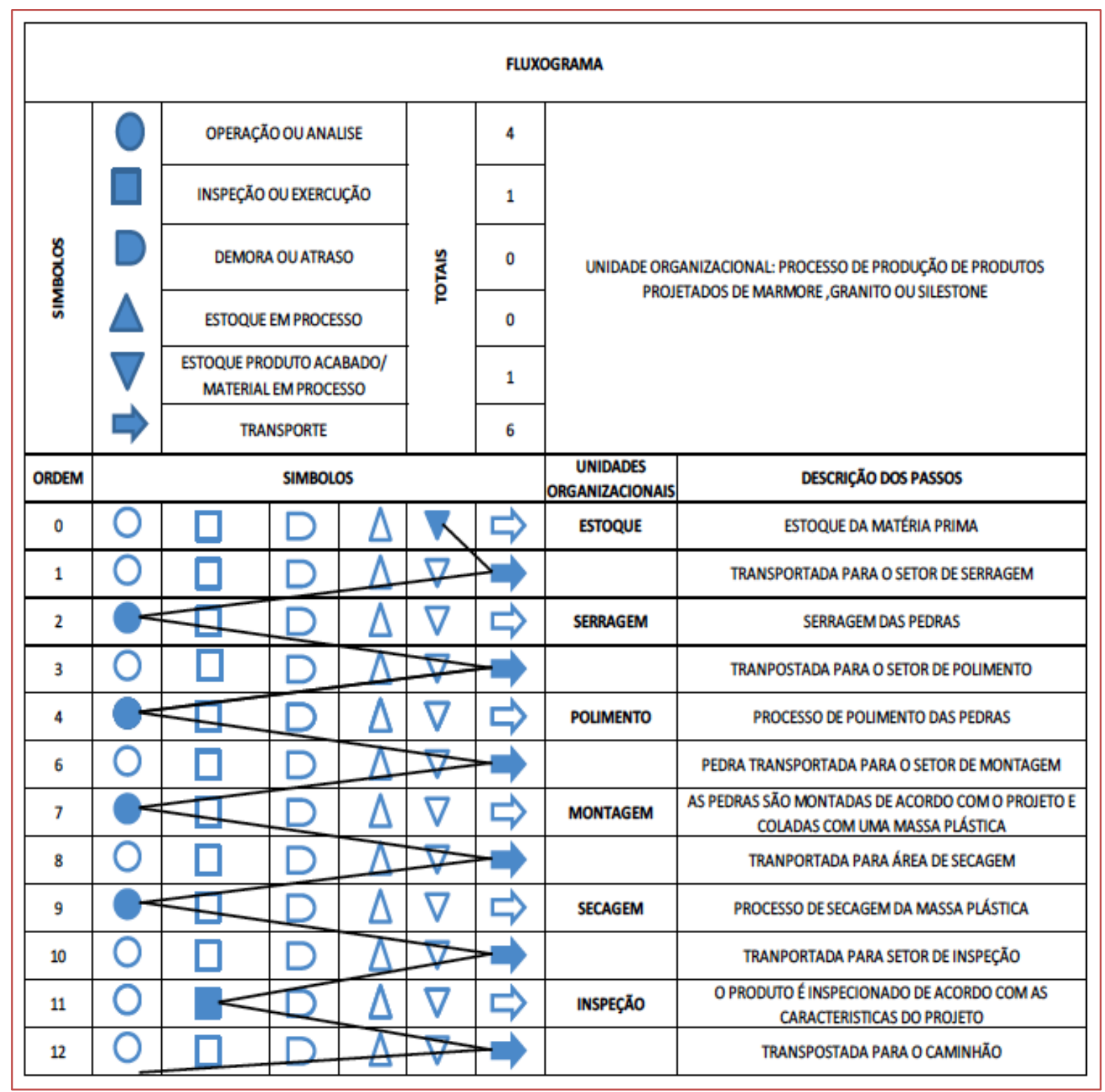

Fonte: Próprio autor.

Para a elaboração do fluxograma fez de início uma revisão na literatura sobre suas principais características e, em seguida, mapeou-se com auxílio do supervisor de produção todos os procedimentos utilizados na elaboração dos produtos, desde a retirada de material no estoque até o transporte do produto acabado ao caminhão, mantendo a atenção, para que não houvesse confusão quanto a processos de operação e espera.

\subsection{APLICAÇÃO DO MASP}

Após analisar e compreender o fluxo do processo descrito anteriormente seguiu-se o seguinte passo a passo para aplicação da técnica, onde pode ser visto na figura 6 : 
Figura 6- Etapas de Aplicação

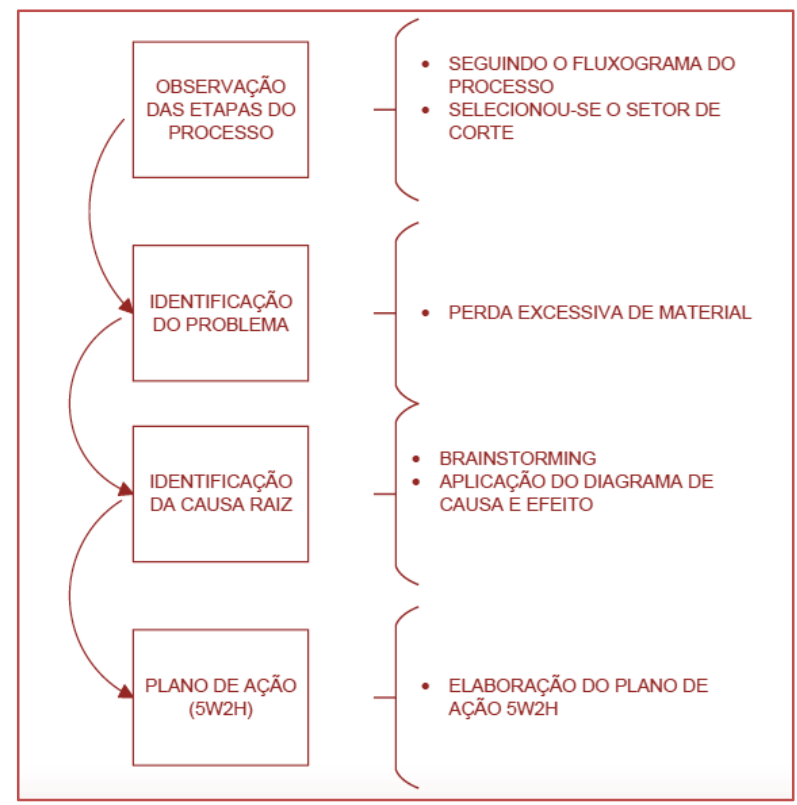

Fonte: Próprio Autor

Observou-se que na etapa de corte a perda excessiva de material era significativa. De forma a tentar identificar a(s) causa(s) mais prováveis, utilizou-se o diagrama de causa e efeito ou digrama espinha de peixe. $\mathrm{Na}$ figura 7 estar exposto as principais causas dos problemas.

Figura 7- Diagrama de Ishikawa

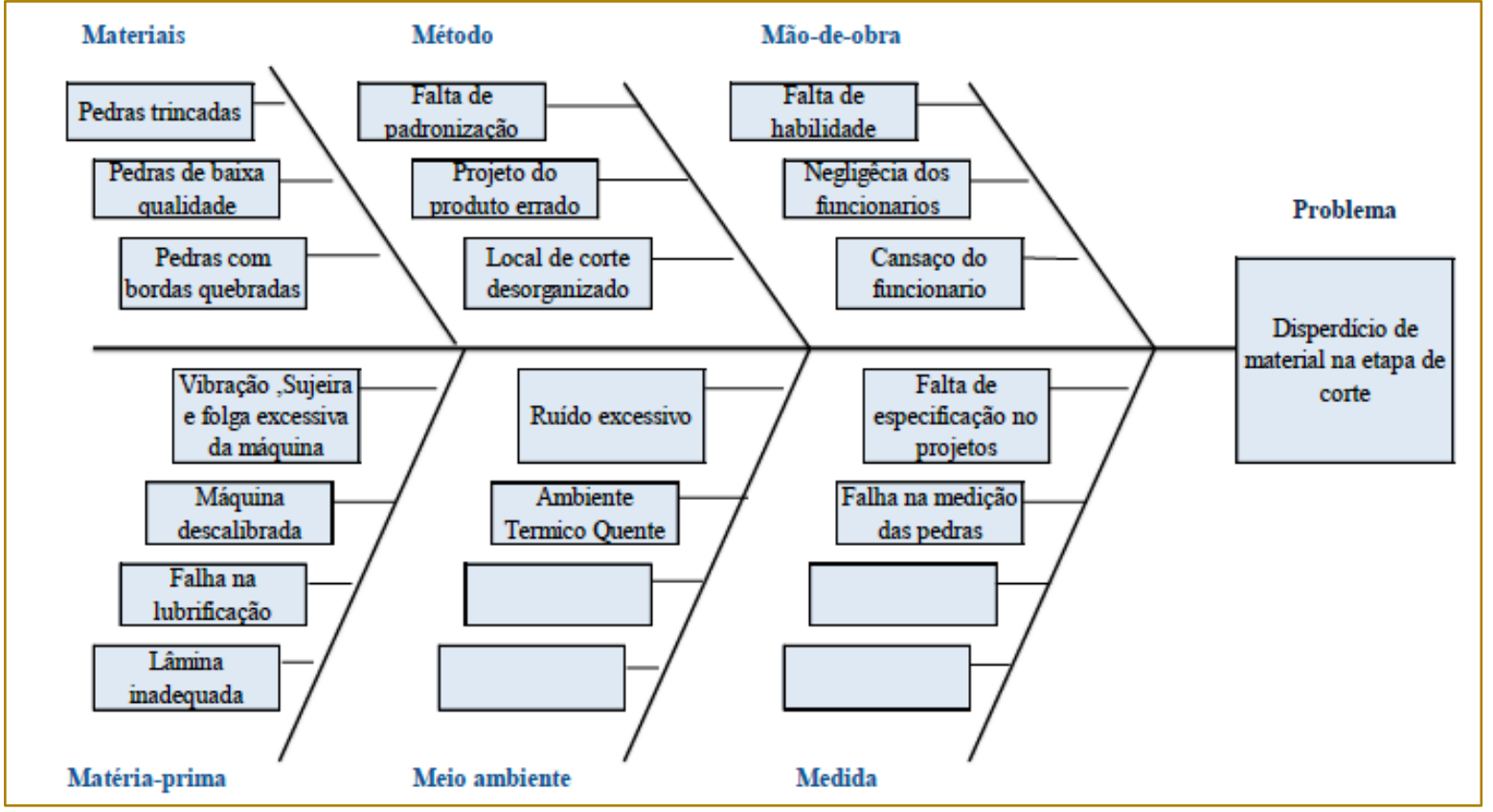

Fonte: Próprio Autor.

A partir do diagrama apresentado acima e das constatações realizadas durante a observação feita durante a pesquisa, notouse que a causa mais recorrente para o desperdício situava-se nos próprios funcionários, que por negligência ou imperícia, não se preocupavam em reduzir o tamanho do refugo gerado na etapa de corte. 
Além da falta de preocupação em diminuir o tamanho da peça descartada os funcionários não possuíam uma documentação adequada no que tange as especificações dos projetos. Todas as medidas e especificações estavam desenhadas manualmente uma folha de papel. A falta de um padrão ou clareza nas informações, podem contribuir para intensificação das perdas encontradas.

De forma a reduzir essa incidência, foi proposto um plano de ação baseado na técnica 5W2H apresentado no Quadro 1.

Quadro 1 - Plano de ação

\begin{tabular}{|c|c|c|c|c|c|c|}
\hline $\begin{array}{c}\text { What } \\
\text { O que faremos? }\end{array}$ & $\begin{array}{c}\text { Why } \\
\text { Por que faremos? }\end{array}$ & $\begin{array}{l}\text { Where } \\
\text { Onde } \\
\text { faremos? }\end{array}$ & $\begin{array}{c}\text { Who } \\
\text { Quem fará? }\end{array}$ & $\begin{array}{l}\text { When } \\
\text { Quando } \\
\text { faremos? }\end{array}$ & $\begin{array}{c}\text { How } \\
\text { Como faremos? }\end{array}$ & $\begin{array}{l}\text { How much } \\
\text { Quanto } \\
\text { custa? }\end{array}$ \\
\hline $\begin{array}{l}\text { Elaborar } \\
\text { procedimento } \\
\text { operacional para } \\
\text { as máquinas de } \\
\text { corte }\end{array}$ & $\begin{array}{l}\text { Padronizar processo } \\
\text { de corte e sua } \\
\text { operacionalização }\end{array}$ & $\begin{array}{l}\text { Chão de } \\
\text { fábrica da } \\
\text { empresa }\end{array}$ & $\begin{array}{c}\text { Gerente e } \\
\text { Supervisor de } \\
\text { produção }\end{array}$ & 1 Semana & $\begin{array}{l}\text { Elaborando } \\
\text { procedimentos } \\
\text { padrões de } \\
\text { medição da peça } \\
\text { útil e refugo, afim } \\
\text { de ter um registro } \\
\text { documentado. }\end{array}$ & $\begin{array}{c}\text { Sem custos } \\
\text { adicionais }\end{array}$ \\
\hline $\begin{array}{l}\text { Criar matriz de } \\
\text { habilidades para } \\
\text { operadores do } \\
\text { processo de corte }\end{array}$ & $\begin{array}{l}\text { Afim de criar níveis } \\
\text { mínimos de } \\
\text { habilidades nos no } \\
\text { processo de corte } \\
\text { que os operadores } \\
\text { devem possuir para } \\
\text { seguir na operação }\end{array}$ & $\begin{array}{l}\text { Chão de } \\
\text { fábrica da } \\
\text { empresa }\end{array}$ & $\begin{array}{c}\text { Gerente e } \\
\text { Supervisor de } \\
\text { produção }\end{array}$ & 1 Semana & $\begin{array}{l}\text { Levantando } \\
\text { habilidades } \\
\text { unitárias de } \\
\text { operação e } \\
\text { classificando em } \\
\text { níveis de } \\
\text { execução: } \\
\text { treinando, operar } \\
\text { com auxilio, operar } \\
\text { sozinho e treina. }\end{array}$ & $\begin{array}{c}\text { Sem custos } \\
\text { adicionais }\end{array}$ \\
\hline $\begin{array}{l}\text { Criar check list de } \\
\text { limpeza e reaperto } \\
\text { dos } \\
\text { subcomponentes } \\
\text { das máquinas de } \\
\text { serra. }\end{array}$ & $\begin{array}{l}\text { Evitar falhas de } \\
\text { maquinário e } \\
\text { processo de corte } \\
\text { por falta de } \\
\text { confiabilidade por } \\
\text { excesso de sujeira. }\end{array}$ & $\begin{array}{l}\text { Chão de } \\
\text { fábrica da } \\
\text { empresa }\end{array}$ & $\begin{array}{l}\text { Gerente e } \\
\text { Supervisor de } \\
\text { produção }\end{array}$ & 1 Semana & $\begin{array}{l}\text { Levantar todos os } \\
\text { pontos que } \\
\text { precisam ser } \\
\text { reapertados } \\
\text { definindo } \\
\text { metodologia, } \\
\text { tempo de intervalo } \\
\text { e ferramenta para } \\
\text { reaperto. Criando } \\
\text { cronograma de } \\
\text { limpeza da } \\
\text { máquina. }\end{array}$ & $\begin{array}{c}\text { Sem custos } \\
\text { adicionais }\end{array}$ \\
\hline $\begin{array}{l}\text { Criar } \\
\text { procedimento e } \\
\text { check list de } \\
\text { lubrificação dos } \\
\text { subcomponentes } \\
\text { mecânicos que } \\
\text { necessitam de } \\
\text { lubrificação }\end{array}$ & $\begin{array}{l}\text { Evitar falhas por } \\
\text { quebra, } \\
\text { desalinhamento ou } \\
\text { desgaste excessivo } \\
\text { de maquinário por } \\
\text { falha na lubrificação } \\
\text { que porventura } \\
\text { possa comprometer } \\
\text { o processo de corte } \\
\text { e aumento de } \\
\text { refugo. }\end{array}$ & $\begin{array}{l}\text { Chão de } \\
\text { fábrica da } \\
\text { empresa }\end{array}$ & $\begin{array}{l}\text { Gerente e } \\
\text { Supervisor de } \\
\text { produção }\end{array}$ & $\begin{array}{c}2 \\
\text { Semanas }\end{array}$ & $\begin{array}{l}\text { Criar mapa de } \\
\text { lubrificação com } \\
\text { todos os } \\
\text { subcomponentes } \\
\text { mecânicos } \\
\text { expandidos, } \\
\text { padronizando a cor } \\
\text { do lubrificante por } \\
\text { grau de } \\
\text { viscosidade e por } \\
\text { ponto unitário, } \\
\text { delimitando o } \\
\text { tempo de troca e } \\
\text { criando } \\
\text { procedimento com } \\
\text { metodologia de } \\
\text { lubrificação do } \\
\text { subcomponente. }\end{array}$ & $\begin{array}{c}\text { Sem custos } \\
\text { adicionais }\end{array}$ \\
\hline $\begin{array}{l}\text { Criar } \\
\text { gerenciamento } \\
\text { por ordem de } \\
\text { produção de } \\
\text { consumo de } \\
\text { pedra. }\end{array}$ & $\begin{array}{l}\text { Criar controle do } \\
\text { quanto se consumiu } \\
\text { de pedra para se } \\
\text { elaborar um produto } \\
\text { final e gerenciar o } \\
\text { percentual exato de } \\
\text { perda por refugo. }\end{array}$ & $\begin{array}{l}\text { Chão de } \\
\text { fábrica da } \\
\text { empresa }\end{array}$ & $\begin{array}{l}\text { Gerente e } \\
\text { Supervisor de } \\
\text { produção }\end{array}$ & $\begin{array}{c}2 \\
\text { Semanas }\end{array}$ & $\begin{array}{l}\text { Criando uma } \\
\text { planilha com ordem } \\
\text { de produção que } \\
\text { se possa gerar a } \\
\text { unidade consumida } \\
\text { de pedra e unidade } \\
\text { utilizada para } \\
\text { elaborar o produto } \\
\text { final }\end{array}$ & $\begin{array}{c}\text { Sem custos } \\
\text { adicionais }\end{array}$ \\
\hline
\end{tabular}


Desde já o plano de ação tem envolvimento com as principais causas identificadas no diagrama de Ishikawa focalizando em ações preventivas onde foram identificadas oportunidades no local do estudo, sendo que as mesmas tiveram cunho de sugestão de implementação na empresa a baixo custo, mostrando assim que a ferramenta $5 \mathrm{~W} 2 \mathrm{H}$ pode ser útil para desenvolvimento de um plano de ação condizente com a realidade financeira da empresa e no qual sendo construído correlacionado com as causas do problema pode trazer benefícios a empresa a um horizonte de curto prazo

\section{CONSIDERAÇÕES FINAIS}

No tocante da utilização da ferramenta MASP, a mesma demostrou ser um instrumento simples, de fácil aplicação e de grande utilidade para as etapas de identificação e tratamento do problema dentro do contexto aplicado. O racional metodológico das etapas do MASP auxiliou na identificação, observação, levantamento das causas e no auxílio da determinação ações tratativas dos problemas na empresa estudada, podendo assim se constatar de fato que a corroboração do conjunto das diversificadas ferramentas da qualidade, as quais tiveram grande impacto no desenvolver da pesquisa.

\section{REFERÊNCIAS}

[1]. BRASIL. Ministério da Saúde. Secretaria de Educação Profissional e Tecnológica. Rochas Ornamentais. Brasília, 2007. Disponível em: <http://portal.mec.gov.br/setec/arquivos/pdf3/publi ca_setec_rochas.pdf.>. Acesso em: 08/05/2016.

[2]. CAMPAGNARO, Carlos Alberto et al. Um estudo sobre Métodos de Análise e Solução de Problemas (MASP) na cadeia de fornecimento das montadoras automotivas nacionais. XXVIII Encontro Nacional de Engenharia de Produção, Rio de Janeiro, 2008.

[3]. CARPINETTI, L.C.R. Gestão da Qualidade: conceitos e técnicas. São Paulo: Atlas, 2010.

[4]. CHIRZÓSTOMO, DANILO. Avaliação e controle do ambiente de trabalho em atividades de uma marmoraria. 2014. Pós Graduação. Centro Universitário de Lins.

[5]. DA CUNHA, IRLON DE ÂNGELO. Exposição ocupacional à vibração em mãos e braços em marmorarias no município de São Paulo: proposição de procedimento alternativo de
A relevância da metodologia MASP permitiu uma maior conscientização dos diversificados problemas existentes dentro de uma organização e como sistematicamente pode se priorizar uma anomalia na qual trará resultado mais rápidos a empresa, e como um gestor pode se antever os mesmos com seu auxilio. Antemão, mesmo com as dificuldades encontradas pela falta de um histórico de dados e de uma gestão organizacional de uso de indicadores para tomada de decisões gerenciais pela empresa, a convivência da realidade dos problemas na organização foi de fundamental importância para aplicação da metodologia MASP.

Em relação às dificuldades encontradas durante a aplicação do método, deveu-se principalmente a falta de padronização das ordens de serviços e fluxo desordenado devido principalmente ao layout encontrado atualmente. Como forma de trabalhos futuros, sugere-se a possibilidade de realizar um rearranjo físico do chão de fábrica atual, com intuito de melhorar o fluxo e permitir mais liberdade de movimentação, segurança e conforto para os colaboradores. Ademais, com relação a falta de padronização dos projetos recebidos, sugere-se o uso de softwares de edição gráfica, como Auto Cad e Corel Draw, que possibilitem melhor visualização e padronização das ordens de serviço.

medição. 2006. Tese de Doutorado. Universidade de São Paulo.

[6]. LANDER, E. LIKER, J.K. The Toyota Production System and art: making highly customized and creative products the Toyota way. International Journal of Production Research, v. 45, n.16, p. 3681-3698, 2007.

[7]. MARSHALL JUNIOR, I. et al. Gestão da qualidade e processos. Rio de Janeiro: Editora FGV, 2012.

[8]. MOTTA, SINUÊ COELHO SANTOS; MARINS, CRISTIANO SOUZA. Análise da Aplicação da Ferramenta MASP no Controle de Estoque de uma Usina Siderúrgica. IX SIMPÓSIO DE EXCELÊNCIA EM GESTÃO E TECNOLOGIA, 2012.

[9]. PIECHNICKI, Ademir Stefano et al. Utilização da Metodologia de Análise e Solução de Problemas na redução das perdas de água: um estudo de caso na SANEPAR. Revista de Engenharia e Tecnologia, v. 3, n. 2, p. Páginas 9099, 2011. 
[10]. OHNO, T. Sistema Toyota de Produção. Além da Produção em Larga Escala. Bookman. Porto Alegre. ed. 1a. 1997.

[11]. OLIVEIRA, O. J. Gestão da qualidade: introdução à história e fundamentos. In: OLIVEIRA, O. J. (Org.) Gestão da Qualidade: tópicos avançados. Cengage Learning Editores, 2003.

[12]. QUEIROZ, J.A., RENTES, A.F. Contabilidade de custos vs. contabilidade de ganhos: respostas às exigências da produção enxuta. Gestão \& Produção, v.17, n.2 São Carlos 2010.

[13]. RODRIGUES, M.R., PICCHI, F.A. Análise de Experiências de Aplicação do Lean Thinking na Construção de Edificações No Brasil. XXI Encontro Nacional de Tecnologia do Ambiente ConstruídoENTAC. Canela-RS, 2010.

[14]. ROTHER, M.; SHOOK, J. Aprendendo a enxergar: mapeando o fluxo de valor para agregar valor e eliminar o desperdício. São Paulo: Lean Institute, 1999.

[15]. SAMPARA, EJM; ADAMI, R. Análise de insumos e aplicação de sistemática de solução de problemas para geração de melhorias. Anais do ENEGEP XXIX-Encontro Nacional de Engenharia de Produção, 2009.

[16]. SANTOS, Alcinéa Meigikos dos Anjos et al . Características da exposição ocupacional a poeiras em marmorarias da cidade de São Paulo. Rev. bras. saúde ocup., São Paulo , v. 32, n. 116, p. 11-23, Dec. 2007

[17]. SANTOS, Alcinéa Meigikos dos Anjos. Exposição Ocupacional a Poeiras em Marmorarias: Tamanhos de Partículas Característicos. 2005. Tese de Doutorado. Universidade Federal De Minas Gerais.

[18]. SEBRAE (Espírito Santo). Boletim: Marmorarias. 2014. Disponível em: <http://www.sebraemercados.com.br/wpcontent/uploa ds/2015/10/2014_08_06_BO_Agosto_ConstrucaoCivil_ $m$ armores_pdf.pdf>. Acesso em: 15 jun. 2016.

[19]. SILVA, William Felipe. Utilização do masp (método de análise e solução de problemas) na melhoria do fluxo de informações: um estudo de caso. 2014. 56 f. TCC (Graduação) - Curso de Engenharia de Produção, Univem, Marília, 2014.

[20]. WOMACK, J. P., JONES, D. T., ROOS, D. A Máquina que mudou o mundo. Rio de Janeiro: Campus, 1992.

[21]. YAMANE, A. K.; SOUZA, LGM. Aplicação do mapeamento de árvore de falha (FTA) para melhoria contínua em uma empresa do setor automobilístico. In: Encontro Nacional de Engenharia de Produção, 17., 2007, Foz do Iguaçu. Anais... Foz do Iguaçu. ENEGEP: 2007. 


\section{Capítulo 5}

\section{SMED E FERRAMENTAS DA QUALIDADE PARA CONTROLE E REDUÇÃO DOS TEMPOS DE PARADAS DAS MÁQUINAS INJETORAS}

Kayque Bezerra de Oliveira

Francisca Jeanne Sidrim de Figueiredo

Mariane Leite de Souza

Antonio Luis Araujo Silva

Amanda Duarte Feitosa

Dalila Rayanne do Nascimento Andrade

Resumo: O ambiente atual de mercado exige das empresas a busca continua por melhorias e consequentemente a necessidade de usar ferramentas que possibilitem ganhos no processo produtivo. Este trabalho tem como objetivo reduzir o tempo de paradas das injetoras, com foco na utilização do SMED, seu resultado foi de uma pesquisa exploratória com abordagem qualitativa. O estudo foi aplicado no setor de GRC (injetoras) que produzem as bases da máquina de costura na empresa localizada em Juazeiro do Norte. Devido ao setor ser composto por máquinas antigas, não existe troca de moldes, os setups só acontecem com algum problema encontrado. Durante o período de seis meses foram observadas as paradas e por meio de ferramentas da qualidade foram identificadas as com maior desperdício de tempo, e se observou a oportunidade de aplicação da ferramenta SMED. No trabalho foram aplicados os quatro estágios da ferramenta, definidos por Shingo. Como previsto obteve-se redução de 160 minutos no total geral dos setups estudados, o que equivale a 17\% da produção diária. Com a redução do tempo, a previsão é que os setups passem a ter maior tempo de folga eliminando atrasos no setor GRC e consequentemente na linha de produção que depende do mesmo. Além disso, a presente pesquisa possibilitou uma maior conhecimentos e aprendizagem para a atuação do Engenheiro de Produção, mostrando a importância dos estudos de tempos que são relacionados às paradas no setor de máquinas injetoras. 


\section{INTRODUÇÃO}

As condições atuais de mercado fazem com que as empresas tenham de buscar melhorias em suas atividades para poder sobreviver à concorrência. Sempre há possibilidade de ganhos, pois nenhum processo produtivo é perfeito, mas para que se obtenham reduções nos custos com estes processos, é preciso que as organizações utilizem ferramentas capazes de mostrar onde investir e atuar (COSTA; DE SANTANA; TRIGO, 2015).

Para aumentar a disponibilidade de um equipamento é preciso aumentar a confiabilidade ou reduzir o tempo médio de reparo, ou os dois, simultaneamente. Neste trabalho, o ponto focado foi à redução do tempo de paradas e reparos.

O SMED (Simple Minute Exchange Die) reduzir o tempo de troca de ferramentas em um setup a um digito de minuto, tempo possível de ser atingido a partir da racionalização das atividades realizadas pelo operador da máquina. Para o português foi traduzido como troca rápida de ferramentas (THARISHENEPREM, 2008). O Lean Manufacturing ou Manufatura Enxuta tem como ponto principal o combate às perdas ou desperdícios existentes em uma estrutura industrial a qual objetiva conseguir excelência na competitividade pela melhoria contínua no processo, pois a cada dia cresce a exigência em termos de qualidade por parte dos consumidores, o que faz com que adotem práticas que permitam a produção de produtos cada vez mais satisfatórios e com qualidade superior (MUTHUKUMARAN; VENKATACHALAPATHY; PAJANIRADJA, 2013).

O presente trabalho foi desenvolvido em uma empresa de máquinas de costura localizada em Juazeiro do Norte no Estado do Ceará, com foco no setor de GRC. A pesquisa objetiva mostrar como diminuir o tempo de paradas das injetoras, com foco na utilização do SMED, ferramenta desenvolvida pelo Sistema Toyota de Produção (STP), que possibilita identificar com segurança quais os motivos das paradas e auxiliar na tomada de decisões com 0 intuito de melhorar a produtividade.

\subsection{METODOLOGIA}

O estudo foi de caráter exploratório, descritivo e qualitativo. De acordo com Prodanov e Freitas (2013) a pesquisa de natureza aplicada procura produzir conhecimentos para uma situação prática e são dirigidos a solucionar problemas específicos de um processo e que possam ser de fácil aplicação. A pesquisa exploratória tem como objetivo estudar problemas em situações sobre a qual existe pouco conhecimento acumulado para que possa descobrir novas práticas e desenvolver novos modelos (BERTO; NAKANO, 2014).

De acordo com Jung (2004), o procedimento de pesquisa de estudo de caso único estuda, explica ou descreve um sistema de produção particular, e a abordagem qualitativa possui como características a subjetividade, síntese, raciocínio dialético e indutivo, busca de particularidades e preocupa-se com a qualidade.

O tempo de setup é o tempo efetuado para deixar as máquinas e ferramentas habilitadas para o início de produção. O setup engloba a preparação ou paradas de máquinas, e também envolve atividades de longa duração (CAS et al., 2015).

Como instrumento de pesquisa, foi utilizado um diário de bordo contendo espaços para descrição dos procedimentos, objetivando obtenção de informações e dados relevantes que irão colaborar com objetivo central do estudo. Todos os dados foram coletados obedecendo aos critérios de análise e autorização por parte da empresa. Os mesmos serão formatados em tabelas e gráficos e analisados dentro de uma estatística descritiva.

O projeto seguiu as etapas do método SMED. Os dados coletados foram analisados e sugeridos técnicas e ferramentas para possíveis melhorias. Depois de serem feitas as alterações foi realizado um acompanhamento na célula a fim de perceber as melhorias alcançadas.

\section{REFERENCIAL TEÓRICO}

\subsection{GESTÃO DA QUALIDADE}

Melhorar a qualidade dos produtos é essencial para o sucesso da competitividade de uma empresa. Com o intuito de melhorar a qualidade, as empresas utilizam sistemas de Gestão da Qualidade que visam o sucesso em longo prazo através da melhoria contínua (ULUSKAN; GODFREY; JOINE, 2016).

A gestão da qualidade torna-se essencial para as empresas, surge da necessidade de 
deixar o processo eficiente e produtivo, reduzindo as falhas e consequentemente os custos. Ela faz isso de forma estratégica satisfazendo as necessidades do consumidor, gerando valor e melhorando a imagem da organização (FERREIRA; GASPARINI, 2016).

\subsubsection{FERRAMENTAS DA QUALIDADE}

Fazem parte do sistema geral do TQM as "Sete Ferramentas básicas da Qualidade" que podem ajudar a desenvolver e resolver com eficiência problemas operacionais. As ferramentas da qualidade podem ser usadas em todas as fases do processo de produção, desde o início do desenvolvimento do produto até o marketing do produto e suporte do cliente. As sete ferramentas da qualidade são: Estratificação, Folha de verificação, gráfico de Pareto, Diagrama de Ishikawa, Diagrama de correlação, Histograma e Carta de controle (PUNYISA, 2017).

\subsubsection{BRAINSTORMING}

Brainstorming é uma metodologia aplicada ao longo de um processo, na qual as pessoas apresentam suas próprias ideias. Após várias rodadas de discursões o líder do grupo seleciona as melhores opiniões sobre o assunto para se chegar a uma solução (SHEN et al., 2016).

\subsubsection{GRÁFICO DE PARETO}

O Gráfico de Pareto é uma ferramenta com modelo gráfico de coluna que ajuda a organizar os problemas de acordo com sua prioridade ou frequência, representando os elementos de maneira decrescente (CESARIO; RODRIGUES, 2017). Através do Pareto é possível ver fatores mais significativos (PUNYISA, 2017).

\subsection{LEAN MANUFACTURING}

Desde o início da concepção da linha de montagem e o desenvolvimento Toyota Production System (TPS), a eficiência vem sendo o objetivo central da manufatura. O Lean Manufacturing foca na eliminação sistemática de resíduos das operações de uma organização usando um conjunto de práticas de trabalho para produzir produtos de acordo com a taxa de demanda (YANG; HONGN; MODI, 2011).
Além disso, existe o que chamamos de Lean Thinking que é aplicado com o intuito de mudar a cultura da empresa a pensar de modo enxuto. Pode-se estabelecer sete passos do lean thinking: Estabelecer visão estratégica, identificar e estabelecer equipes, identificar produtos, identificar processos, revisar layout, selecionar a estratégia de extração apropriada e melhorar continuamente (MRUGALSKA; WYRICKA, 2016).

\subsubsection{SMED}

A ferramenta de redução do SETUP, popularmente conhecida como SMED (Single Minute Exchange of Dies) e traduzida como troca rápida de ferramenta, tem como base o estudo de tempo e pode ser separado em tempo de troca e tempo de ajuste interno e externo. As atividades que são necessárias parar a máquina são chamadas de tempo de configuração interna e a atividade executada sem parar a máquina são chamadas de tempo de configuração externa (SUNDARA; BALAJIB; SATHEESHKUMAR, 2014).

A Troca Rápida de Ferramentas (TRF) mudou o pensamento sobre os sistemas produtivos, e ainda hoje é destaque na procura por competitividade entre as organizações. Com o TRF é possível obter uma redução de setup, tornando viável a produção de pequenos lotes, além de diminuir os custos, reduzir retrabalhos, reduzir defeitos nas peças e aumentar a capacidade de produção (CAS et al., 2015). Shigeo Shingo introduziu o sistema SMED com o intuito de simplificar as atividades operacionais em menos de 10 minutos da sua duração total (BENJAMIN; MURUGAIAH; MARATHAMUTHU, 2013).

Shingo (2000) apresentou quatro estágios conceituais da aplicação da metodologia SMED, a seguir:

Estágio inicial: Setup interno e externo não se distinguem.

O estágio inicial é marcado pelos tempos reais vigentes, é necessário nessa etapa que se identifiquem, através de cronometragens, os tempos gastos em cada tipo de setup. Caso o processo seja muito complexo ou demorado, deve se usar filmadoras, não só os cronômetros. É importante que seja dada atenção ao operador que realiza a tarefa, pois somente ele poderá identificar o que faz e os problemas externos que afetam a operação e preparação da máquina, pois nem sempre os 
atrasos podem ser atribuídos à forma de executar suas atividades.

\section{Estágio 1: Separando os setups}

Nesta etapa se organizam as atividades, classificando e separando-as em tempos internos que são realizadas com a máquina parada, e tempos externos, que podem ser realizadas com a máquina em operação.

Estágio 2: Convertendo setups internos em externos

Nesta etapa busca-se converter estágios considerados internos em externos. O operador deverá buscar padronizações nas ferramentas para realizar o máximo de tarefas possíveis, estabelecendo fixadores ou suportes permanentes das ferramentas, caso haja a parada da máquina substitua-se somente tal fixador ou suporte e não tudo o que neles ficam contidos.

Estágio 3: Melhoria permanente nas operações da máquina

Nesta etapa ocorre a busca pela melhoria que não se resume somente às máquinas, mas a tudo que está relacionado a ela, como a melhoria na estocagem e transporte de matrizes, navalhas, guias, batentes e etc., eliminação de ajustes, implementação de operações em paralelo e outras. O terceiro estágio opera no sentido de que muitos tempos de setup não são reduzidos logo num primeiro trabalho, sendo necessários que se repitam os estágios conceituais até que se alcancem os menores números possíveis.

\section{ESTUDO DE CASO}

\subsection{DESCRIÇÃO DO PROCESSO PRODUTIVO NO SETOR DE GRC}

O processo produtivo começa com a injeção do termofixo chamado GRC. O processo de injeção de termofixo inicia na entrada da matéria prima, e devem estar sempre armazenados em uma sala fria com temperatura que varia de $15^{\circ} \mathrm{C}$ a $25^{\circ} \mathrm{C}$. Logo após, a matéria-prima é retirada do estoque por uma empilhadeira e transportado para as injetoras onde são abastecidas e injetadas a uma temperatura de aproximadamente $180^{\circ} \mathrm{C}$.

Após serem processadas, as peças são carimbadas pelo operador que faz uma inspeção visual nas mesmas com o objetivo de localizar falhas de injeção e remover as rebarbas existentes por meio de lixamento manual. Em seguida as peças são levadas para 0 estoque intermediário onde permanecem até a aprovação do inspetor de qualidade.

No passo seguinte, o inspetor seleciona a amostragem nos lotes e analisa as peças visualmente, confere as dimensões e realiza um teste de impacto nas amostras, caso a produção seja aprovada, segue para a operação seguinte: preparação das partes para a pintura. Se a amostra for recusada, todas as peças do lote são analisadas e se define se o lote será retrabalhado ou selecionado. As peças que forem selecionadas e classificadas como refugos são quebradas e armazenadas em um saco de ráfia para serem transportadas a uma área especifica até a data da coleta e transporte até $\mathrm{o}$ aterro sanitário, pois esse material é classificado como perigoso, por não se decompor a exposição ao meio ambiente, gerando bônus financeiro que não agregam valor ao produto final. 
Figura 1: Fluxograma do processo no setor de GRC

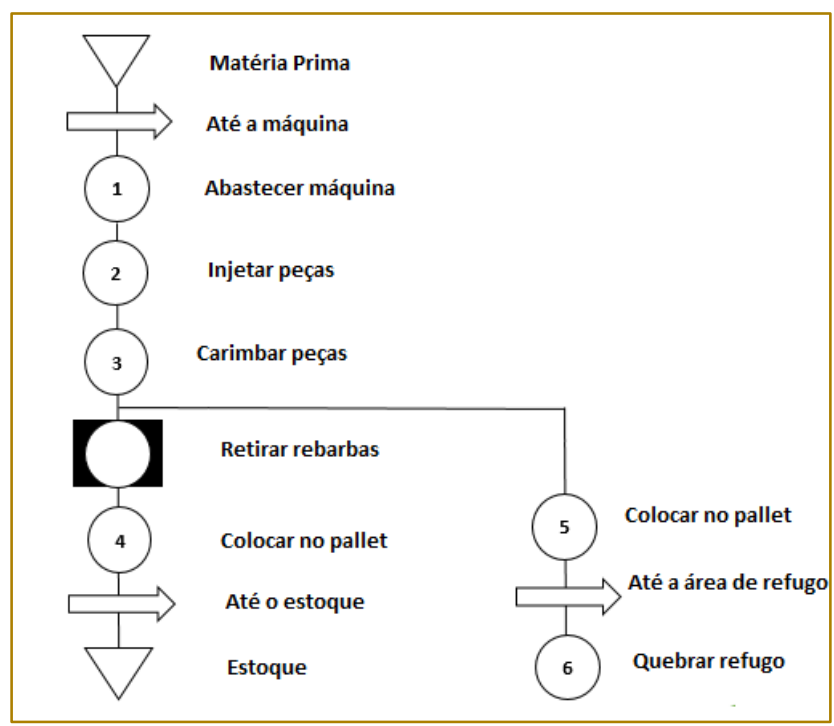

Fonte: Elaborado pelo autor (2018)

\subsection{DIAGNÓSTICO DO SETOR}

O setor de GRC possui três máquinas injetoras, antigas, com cerca de 20 anos, e seus moldes são fixos, por não haver a necessidade de troca dos mesmos na empresa. Devido a esse fator, é feito uma programação levando em conta alguns atrasos como, por exemplo, o aquecimento do molde que antecede o processo. Mesmo descontando esse tempo, alguns setups não programados interferem na produtividade do setor.
Ao longo de seis meses foi feita uma pesquisa de quais paradas não programadas geravam maior perca de tempo na produção das peças. Essa pesquisa foi feita através de um diário de bordo, entregue a cada operador diariamente, para que fossem descritas todas as paradas e seus respectivos tempos.

Diante dos dados foi utilizado o gráfico de Pareto para que fossem verificadas as paradas que geravam muita perca de tempo (Figura 1).

Figura 2 - Gráfico de Pareto com representação dos tempos totais das paradas

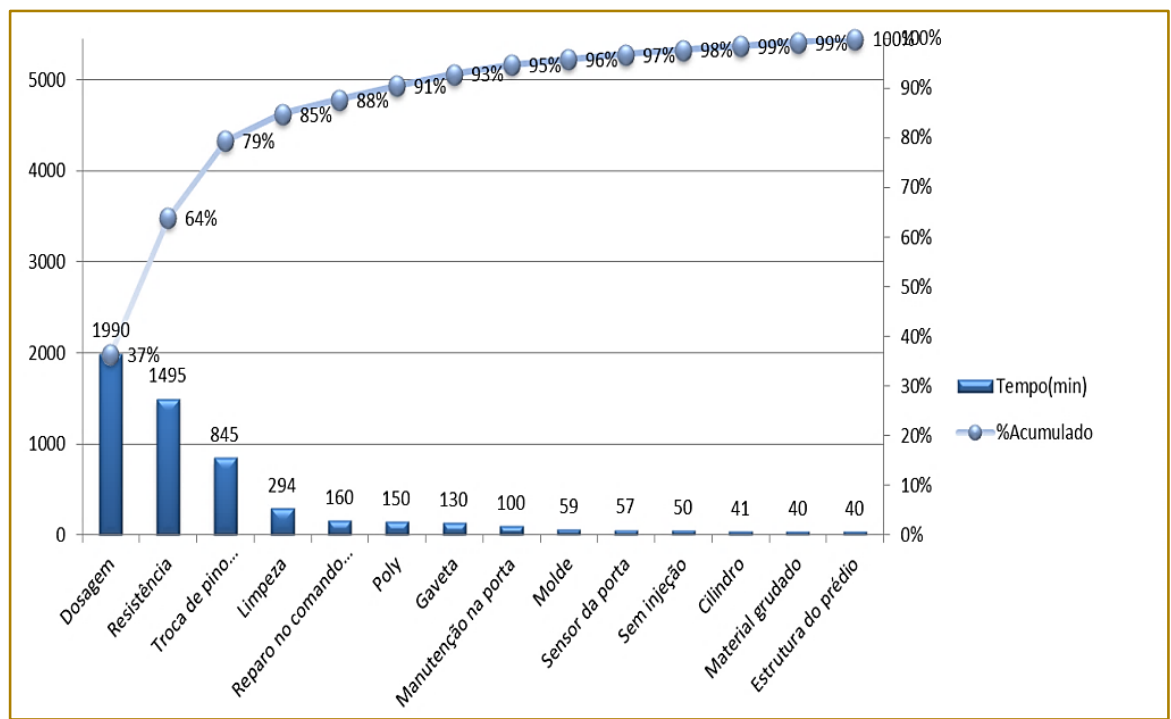

Fonte: Elaborado pelo autor (2018) 
Observando o gráfico percebe-se que as paradas de dosagem, resistência e troca de pino quebrado representam cerca de quase $80 \%$ do tempo perdido.

\section{APLICAÇÃO DO SMED NOS SETUPS QUE REPRESENTAM MAIOR TEMPO DESPERDIÇADO}

O índice de tempo desperdiçado no setor GRC provoca atrasos na produção, deste setor que é central no processo produtivo. Este fator motivou a aplicação da metodologia SMED, procurando minimizar o tempo das principais paradas, com o intuito de reduzir esse índice.

O processo SMED foi aplicado a uma máquina de injeção, e o mesmo processo foi replicado em outras máquinas. A escolha desta máquina piloto ocorreu devido as informações detalhadas existentes sobre a mesma e que permitiriam fazer todos os passos do SMED.

\subsection{TEMPOS}

Para definição do equipamento de aplicação do estudo de caso, foi realizada a verificação dos tempos de setup junto ao gráfico de Pareto. Como definido anteriormente as paradas que geraram mais tempo desperdiçados foram estudadas. Durante esse procedimento verificou-se os horários em que foram produzidas as últimas peças do produto e o horário de produção da primeira peça em velocidade nominal. A partir desses dados, foi possível verificar o tempo de setup de cada parada e os respectivos tempos de folga, conforme descrito na Tabela 1.

Tabela 1 - Cronometragem dos tempos de setup

\begin{tabular}{|l|c|c|}
\hline \multicolumn{1}{|c|}{ Tipo de Setup } & $\begin{array}{c}\text { Tempo de Setup } \\
93 \text { minutos e } 30 \\
\text { segundos }\end{array}$ & 90 minutos \\
\hline Troca de resistência & $\begin{array}{c}148 \text { minutos e } 30 \\
\text { segundos }\end{array}$ & 90 minutos \\
\hline Dosagem & $\begin{array}{c}144 \text { minutos e } 30 \\
\text { segundos }\end{array}$ & 90 minutos \\
\hline Troca de pino & Fonte: Elaborado pelo autor (2018)
\end{tabular}

Como pode ser visto na Tabela 1, a parada com problema de dosagem foi a parada com maior tempo de setup, com um total de 148 minutos e 30 segundos entre a última peça do produto e a primeira, trabalhando com 90 minutos de folga durante o setup da linha, seguido da troca de pinos com 144 minutos e 30 segundos e a troca de resistência com 93 minutos e 30 segundos. O setup da linha acarreta atrasos na produção devido ao tempo de setup hipotético utilizado para a programação de produção ser de 90 minutos. Conforme verificado na cronometragem, a injetora trabalha com folga zero, influenciando diretamente no excedente do tempo de setup e na capacidade da linha.

\subsection{APLICAÇÃO DO SMED}

\subsubsection{ESTÁGIO INICIAL}

Nesse estágio da implementação da ferramenta SMED foi realizado o mapeamento de todas as atividades do operador durante a execução dos setups e os tempos de cada atividade foram cronometrados. O tempo total de operação foi de 148 minutos e 30 segundos em 11 atividades para dosagem, 93 minutos e 30 segundos em 14 atividades para troca de resistência e 144 minutos e 30 segundos em 14 atividades para troca de pino. As atividades executadas estão representadas nos apêndices $A, B$ e $C$ e o tempo de cada atividade foi representado em gráficos (Figura 3). 
Figura 3: Gráfico com tempo de cada atividade para dosagem antes da aplicação do SMED

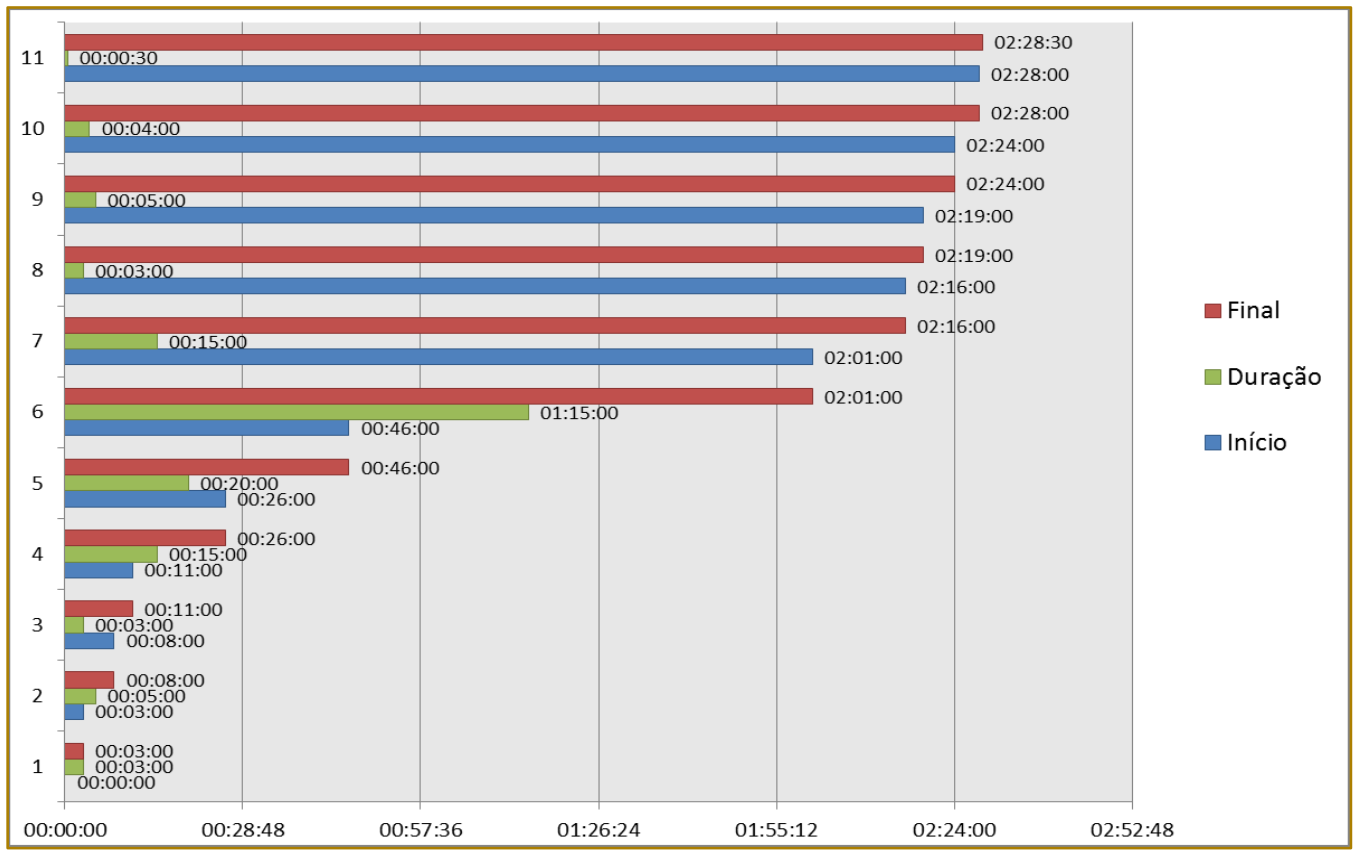

Fonte: Elaborado pelo autor (2018)

Diante do gráfico observa-se os tempos de cada atividade no setup de dosagem, tendo a linha azul como início de cada atividade, a linha verde como período de duração da mesma e a linha vermelha com o tempo final da sequência de atividades. Foi observado que as atividades 5 e 6 tinham um maior tempo de duração. No gráfico a seguir temos os tempos das atividades para troca de resistência (Figura 4).

Figura 4: Gráfico com os Tempos de cada atividade para troca de resistência antes da aplicação do SMED

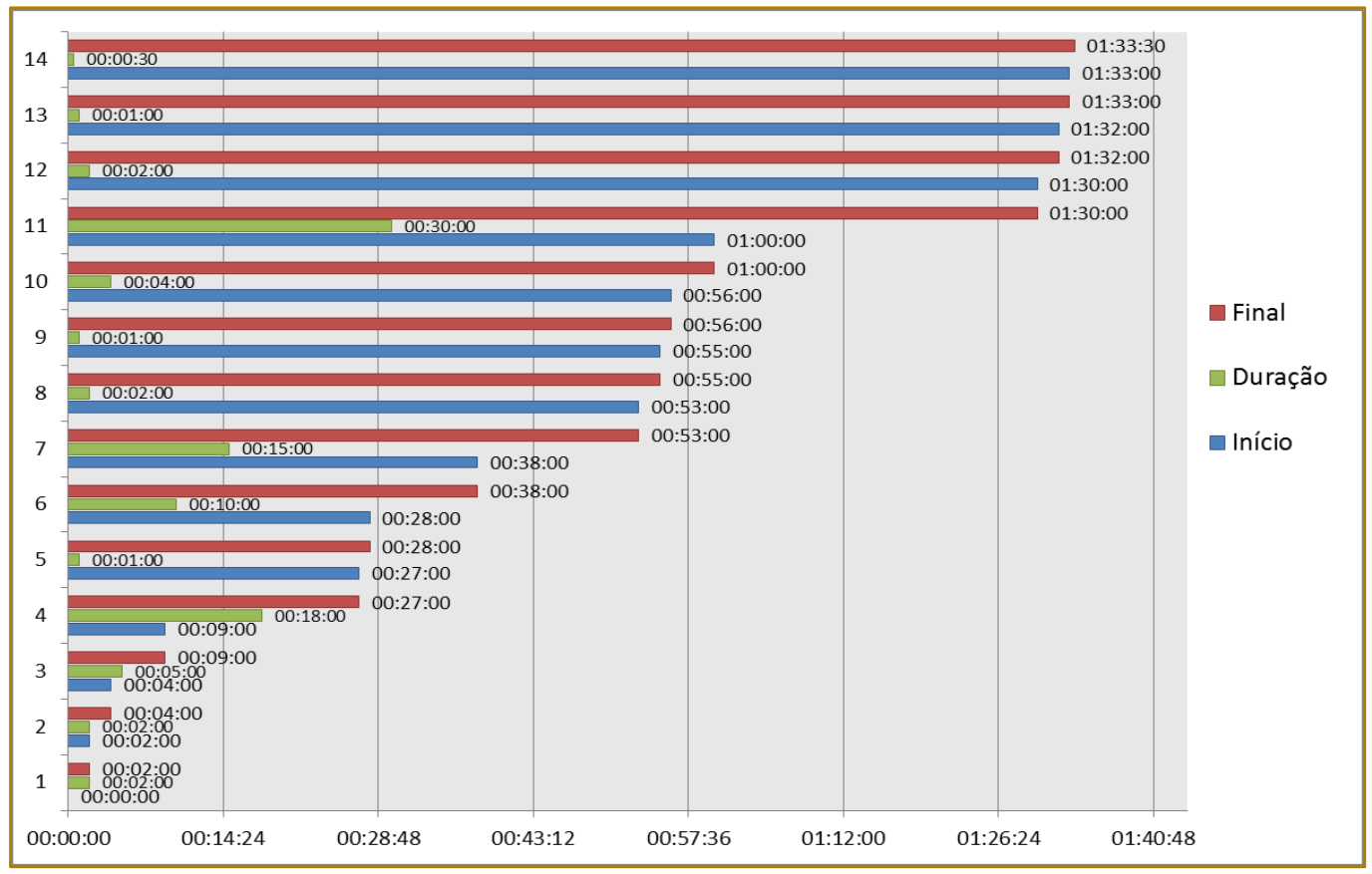

Fonte: Elaborado pelo autor (2018) 
No gráfico observamos que na troca de resistência as atividades que levavam mais tempo são a 4,7 e 11. A troca de resistência é o setup que tem o tempo total mais próximo do tempo de folga. No gráfico a seguir temos os tempos das atividades para troca de pino (Figura 5).

Figura 5: Gráfico com o tempo de cada atividade para troca de pino antes da aplicação do SMED

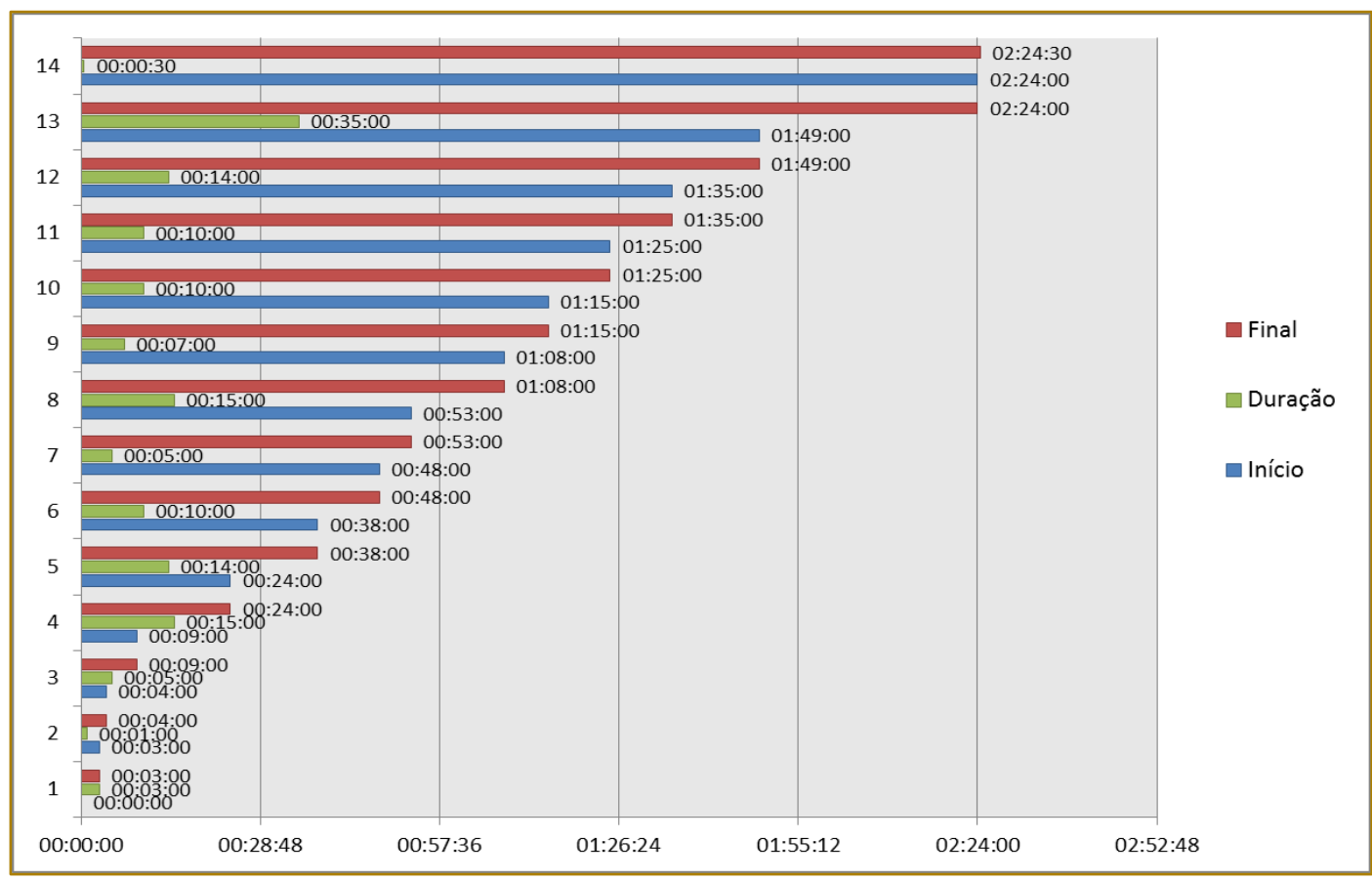

Fonte: Elaborado pelo autor (2018)

No gráfico observamos que a atividade 13 possui o maior tempo, por ser um setup de muitas atividades, que requer maior atenção.

\subsubsection{ESTÁGIO 2}

Neste estágio torna-se necessário analisar todas as atividades de setup e identificar quais podem ser executadas com a máquina em movimento (externa), reduzindo o tempo de equipamento parado. Essa análise foi realizada em conjunto com a equipe operacional e como resultado foi possível transferir seis atividades internas para externas, obtendo-se uma redução de 43 minutos no tempo de equipamento parado, nos três setups abordados, conforme pode ser visto na Tabela 2,3 e 4.

Tabela 2 - Atividade transformada em externa (Dosagem)

\begin{tabular}{|c|c|c|}
\multicolumn{1}{|c|}{ № Atividade } & Duração \\
\hline 10 & Organizar insumos da produção anterior & $00: 04: 00$ \\
\hline TOTAL & & $0: 04: 00$ \\
\hline
\end{tabular}

Fonte: Elaborado pelo autor (2018).

$\mathrm{Na}$ tabela 2 temos a atividade 10 no setup de dosagem, onde transformando a atividade 10 em externa, foi possível reduzir 4 minutos. 
Tabela 3 - Atividades transformadas em externas (Troca de resistência)

\begin{tabular}{|c|l|c|}
\hline \multicolumn{1}{|c|}{ № } & \multicolumn{1}{|c|}{ Atividade } & Duração \\
\hline 2 & Responsável vai buscar amperímetro & $00: 00$ \\
\hline 3 & $\begin{array}{l}\text { Separar chaves necessárias para retirar a } \\
\text { resistência }\end{array}$ & $00: 05: 00$ \\
\hline 7 & $\begin{array}{l}\text { Vai até a loja buscar outra do mesmo } \\
\text { Modelo }\end{array}$ & $00: 02: 00$ \\
\hline 12 & Organizar chaves utilizadas & $0: 24: 00$ \\
\hline TOTAL & & \\
\hline
\end{tabular}

Fonte: Elaborado pelo autor (2018)

Na tabela 3 mostras as atividades 2,3,7 e 12 que foram transformadas em externas, sendo a parada para troca de resistência a que conseguimos um maior tempo externo, com 24 minutos.

Tabela 4 - Atividade transformada em externa (Troca de pino)

\begin{tabular}{|c|l|c|}
\hline \multicolumn{1}{|c|}{ № } & \multicolumn{1}{|c|}{ Atividade } & Duração \\
\hline 8 & $\begin{array}{l}\text { Vai até a loja buscar pino referente ao } \\
\text { quebrado }\end{array}$ & $00: 15: 00$ \\
\hline TOTAL & \multicolumn{2}{|c|}{ Fonte: Elaborado pelo autor (2018) } \\
\hline
\end{tabular}

Na tabela 4 temos a atividade 8 da troca de pino que foi possível transforma-la em externa, reduzindo 15 minutos das atividades internas.

\subsubsection{ESTÁGIO 3}

Neste último estágio de implementação do método SMED, todas as atividades foram analisadas com o objetivo de identificar oportunidades de melhorias no setup. No caso estudado, essa análise foi realizada no formato de brainstorming junto com a equipe de operação e manutenção, quando foram levantadas ideias para eliminar atividades, combinar tarefas paralelas e simplificar execuções de algumas atividades.

\subsection{TEMPOS DE SETUP}

As ações de melhorias definidas no estágio três foram planejadas e serão executadas com mão de obra interna da empresa e materiais de baixo custo no início desse ano, já que a empresa estava prestes a ficar de férias. Após a conclusão de todas as ações, foi previsto uma nova cronometragem das atividades de setup (Figura 6). 
Figura 6: Gráfico com a previsão dos tempos após melhoria na atividade de setup (Dosagem)

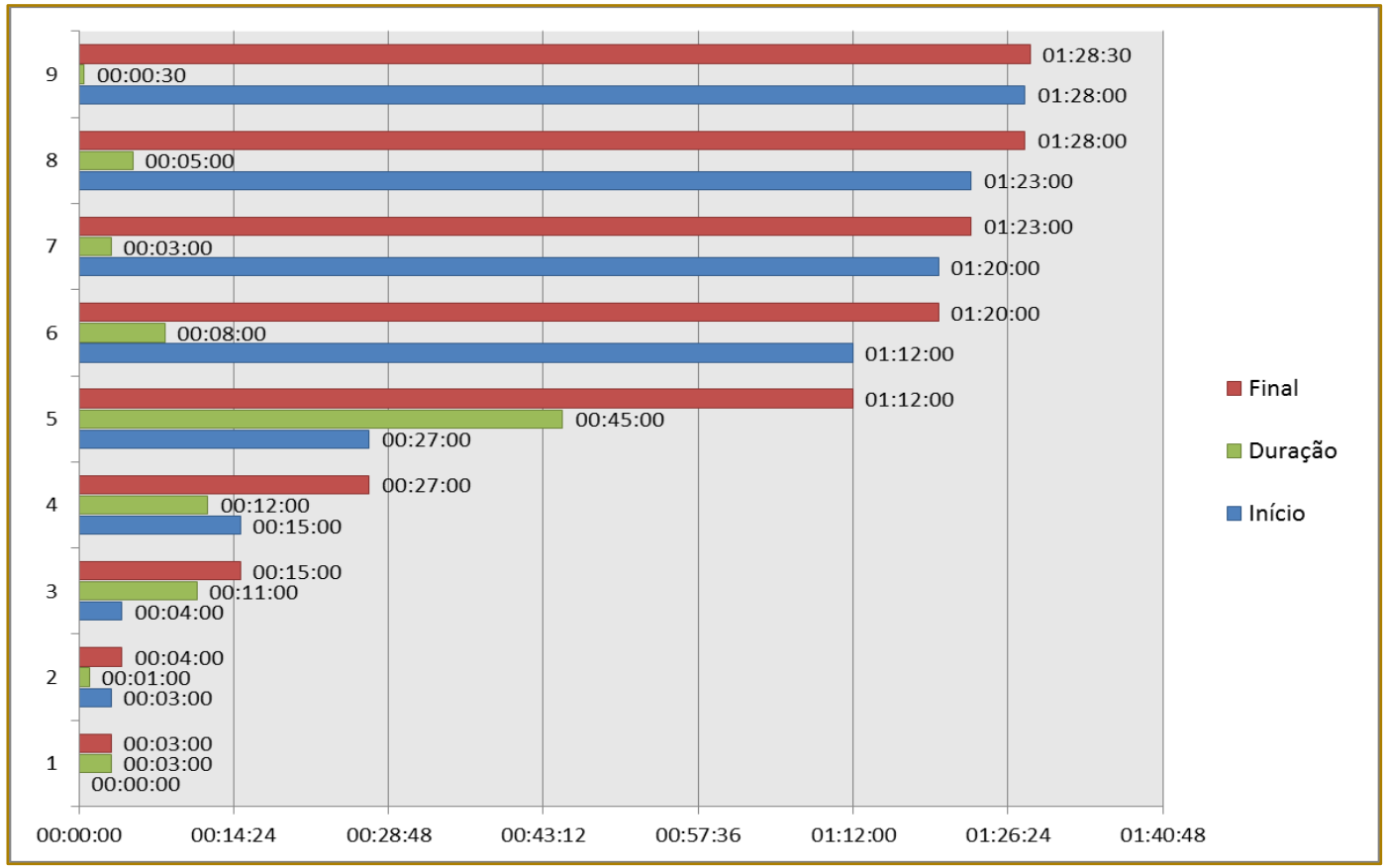

Fonte: Elaborado pelo autor (2018)

Diante do gráfico podemos observar os tempos previstos após as melhorias e a redução das duas atividades propostas, assim tornando o procedimento de dosagem com tempo dentro do prazo de folga e acabando com a possibilidade de atrasos na produção.

Figura 7: Gráfico com a previsão dos tempos após melhoria na atividade de setup (Troca de resistência)

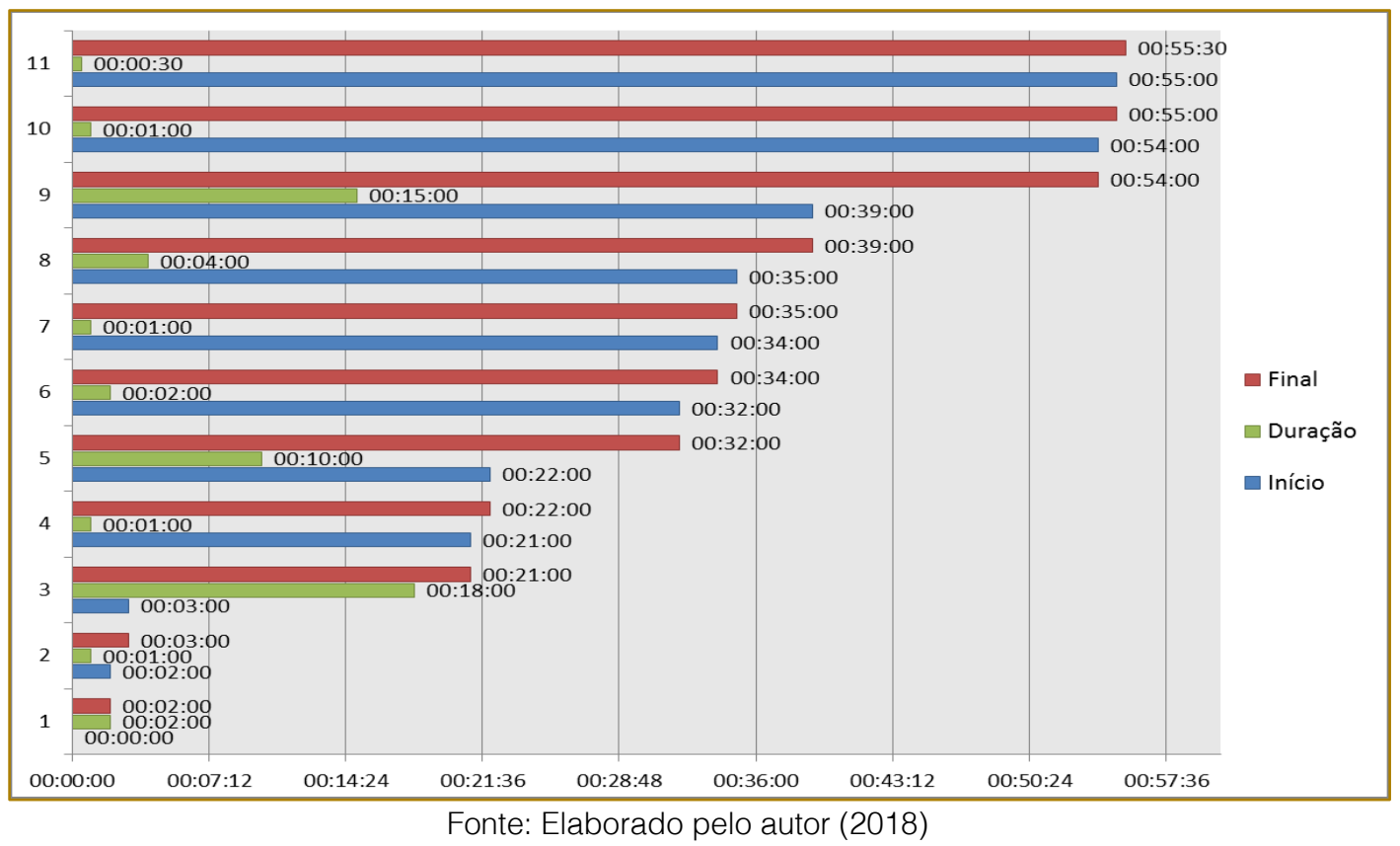


O gráfico da Figura 7 mostra o tempo previsto de setup para troca de resistência, que permitiu eliminar três atividades e reduziu o tempo total do procedimento que ficou dentro do tempo de folga.

Figura 8: Gráfico com a previsão dos tempos após melhoria na atividade de setup (Troca de pino)

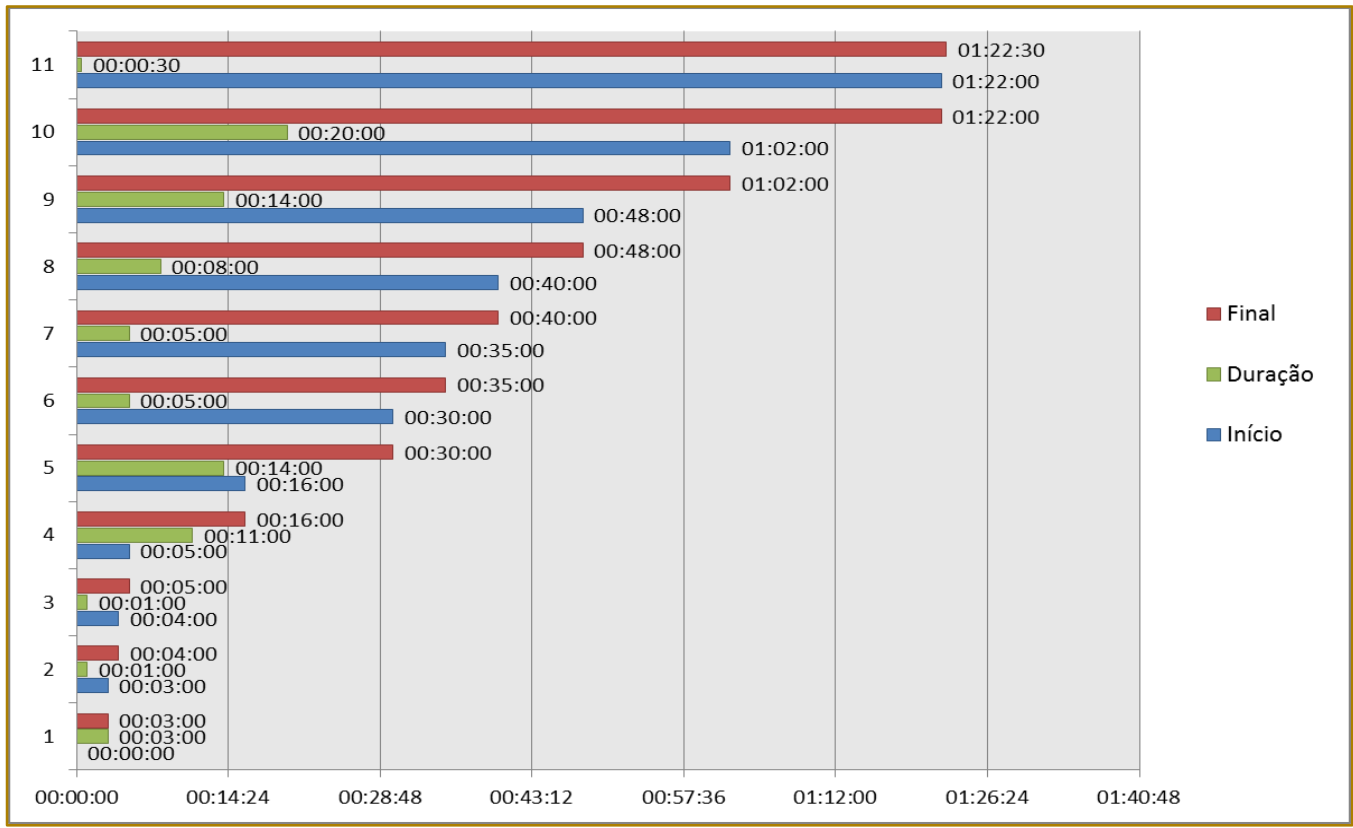

Fonte: Elaborado pelo autor (2018)

Diante do gráfico (Figura 8), podemos observar os tempos previstos para troca de pino após as melhorias e eliminação de três atividades, que como os outros setups estudados passou a ter o tempo total dentro do tempo previsto para folga.

\section{CONCLUSÃO}

Este trabalho apresentou os resultados de uma pesquisa exploratória que teve o objetivo de aplicar a ferramenta SMED para redução do tempo de setup e analisar as lacunas encontradas no método. O método utilizado para a realização deste trabalho foi qualitativo com aplicação do SMED em um setor de máquinas da empresa estudada, por meio de observações realizadas e previsão de resultados alcançados.

O previsto resultado atingido no estudo de caso, quanto ao tempo de setup e consequente aumento de produtividade, são satisfatórios, já que, a partir do desenvolvimento do método, obteve-se uma redução no geral de 160 minutos no tempo de setup dos equipamentos, que pode dependendo da máquina gerar mais 73 peças o que equivale a $17 \%$ da produção diária.

Apesar disso, a aplicação do método não possibilitou o atingimento do tempo em um único dígito de minuto, considerado o objetivo da ferramenta proposta por Shingo. Além disso, outros setores foram impactados com a redução do tempo de setup, um exemplo disto é o setor de pré-montagem que depende do setor de GRC, que, com a melhoria dos tempos, aumentou a produtividade.

O presente trabalho possibilitou uma maior expansão de conhecimentos e aprendizagens para a atuação no ramo de Engenharia de Produção, fazendo relevância no estudo dos tempos relacionados às paradas no setor de máquinas injetoras. 


\section{REFERÊNCIAS}

[1]. BENJAMIN, Samuel Jebaraj; MURUGAIAH Uthiyakumar; MARATHAMUTHU, M. SRIKAMALADEVI. The use of SMED to eliminate small stops in a manufacturing firm. Journal of Manufacturing Technology Management, 24(5), 792-807.

https://doi.org/10.1108/17410381311328016, 2013.

[2]. BERTO, Rosa Maria Villares de Souza; NAKANO Davi. Revisitando a produção científica nos anais do Encontro Nacional de Engenharia de Produção. Produção, 24(1), 225-232. https://doi.org/10.1590/S010365132013005000007, 2014.

[3]. CAS, Franciele da; DA SILA, Macáliston Gonçalves; DA LUZ, Daniel Fonseca; PACHECO, Diego Augusto de Jesus. Implicações da redução de setup na produtividade da indústria farmacêutica. Revista GEINTEC, 5(1), 1764-1779. https://doi.org/10.7198/S2237-0722201500010014, 2015.

[4]. CESARIO, Laís de Melo; RODRIGUES, Adriano. A melhoria da qualidade em uma indústria do sul de Minas Gerais: Implementação do controle estatístico do processo. Revista Eletrônica FEOL REFEOL, 1, 1-15, 2017.

[5]. COSTA, Ariana de Sousa Carvalho; DE SANTANA, Lídia Chagas; TRIGO, Antônio Carrera. Qualidade do atendimento ao cliente: um grande diferencial competitivo para as organizações. Revista de Iniciação Científica - RIC Cairu, 2(2), 155-172, 2015

[6]. FERREIRA, Jonathan Dias; GASPARINIB, Vicente Afonso. Análise da Gestão de Qualidade da Produção de Macarrão : um Estudo de Caso na Empresa "Beta " Analysis of Quality Management in Pasta Production: a Case Study in "Beta " Company. Rev. Cienc. Gerenc, 20, 70-76, 2016.

[7]. JUNG, C. F. Metodologia Para Pesquisa \& Desenvolvimento: Aplicada a Novas Tecnologias, Produtos e Processos. Rio de Janeiro: Axcel Books, 2004.

[8]. MRUGALSKA, Beata; MAGDALENA, K. Wyrwicka. Towards Lean Production in Industry 4. 0. Procedia Engineering, 12(1), 2016. https://doi.org/10.1016/j. proeng.2017.03.135,2016.

[9]. MUTHUKUMARAN,

G., VENKATACHALAPATHY, V.S., PAJANIRADJA, K. Impact on integration of Lean Manufacturing and Six Sigma in various applications - a review. IOSR Journal of Mechanical and Civil Engineering (IOSRJMCE) E-ISSN: 2278-1684 Volume 6, Issue 1 (Mar.
- Apr. 2013), PP 98-101 Www.iosrjournals.org, 6(1), 98-101. Retrieved from www.iosrjournals.org, 2013.

[10]. PRODANOV, C. C.; FREITAS, E. C. Metodologia do Trabalho Científico: Métodos e Técnicas da Pesquisa e do Trabalho Acadêmico. 2. ed. Novo Hamburgo: Feevale, 2013.

[11]. PUNYISA, Kuendee. Application of 7 Quality Control ( 7 QC ) Tools for Quality Management: A Case Study of a Liquid Chemical Warehousing. 4th International Conference on Industrial Engineering and Applications, 6-10, 2017.

[12]. SHEN, Xianjun; ZHOUL, Jin; XINGPENG, JIANGL; XIAOHUA, Hul; HEL, Tingting; YANGL, Jincai; XIE, Dan. A novel identified temporal protein complexes strategy inspired by density-distance and brainstorming process. IEEE International Conference on Bioinformatics and Biomedicine (BIBM), 1269-1274, 2016.

[13]. SHINGO, Shigeo. Sistema de troca rápida de ferramenta: uma revolução nos sistemas produtivos. Tradução de Eduardo Schaan e Cristina Schumacher. Porto Alegre, Bookman, 2000 .

[14]. SUNDARA, R; BALAJIB, A. N; SATHEESHKUMAR. R.M. A review on lean manufacturing implementation techniques. Procedia Engineering, 97, 1875-1885. https://doi.org/10.1016/j.proeng.2014.12.341, 2014.

[15]. THARISHENEPREM, Supramaniam. Achieving Full Fungibility and Quick Changeover By Turning Knobs In Tape and Reel Machine By Applying SMED Theory. 33rd International Electronics Manufacturing Technology Conference 2008, (M), 2008.

[16]. ULUSKAN, Meryem; GODFREY, Blanton. A; JOINES, Jeffrey. A. Integration of Six Sigma to traditional quality management theory: an empirical study on organisational performance. Total Quality Management \& Business Excellence, 3363(March), $1-18$.

https://doi.org/10.1080/14783363.2016.1150173, 2016.

[17]. YANG, Ma Ga ; HONGN, Paul ; MODI, Sachin.B. Impact of lean manufacturing and environmental management on business performance: An empirical study of manufacturing firms. International Journal of Production Economics, 129(2), 251-261. https://doi.org/10.1016/j.ijpe.2010.10.017, 2011. 


\section{Papítulo 6}

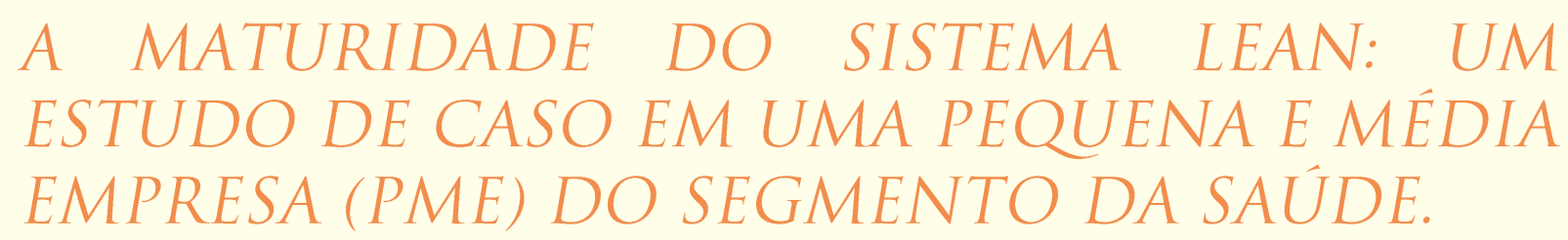

Karina Bataglia

Paulo Sérgio de Arruda Ignácio

Alessandro Lucas da Silva

Antonio Carlos Pacagnella Júnior

Resumo: A globalização e as tecnologias emergentes impactam de forma direta as indústrias mundialmente fazendo cada vez mais necessário a utilização de métodos para a melhoria do processo produtivo. Após a Segunda Guerra, foi desenvolvido o método japonês Toyota de Produção, introduzindo o conceito Lean Manufacturing, - qual busca a otimização de recursos básicos, a satisfação do cliente e, principalmente, a redução dos desperdícios em qualquer processo da empresa, visto que estes são etapas de não agregação de valor. Depois de implementado, é de grande importância à mensuração do nível de maturidade Lean da empresa para atingir os resultados com uma melhor eficiência, principalmente em PME, onde a implementação pode exigir o uso dos melhores recursos da empresa. Este projeto de Iniciação Científica tem como principal objetivo avaliar a maturidade do sistema Lean Manufacturing de uma PME do segmento da saúde. Para isso, será estudado seu desempenho no desenvolvimento de processos Lean, por meio de um estudo de caso, aplicando também os métodos exploratório-descritivo, através de observações e entrevistas. Os conhecimentos adquiridos servirão de subsídio para outros trabalhos, sobre o uso do presente modelo para a medição da maturidade Lean, no desempenho obtido após sua implementação e em qual direção devem seguir as ações estratégicas a serem tomadas.

Palavras-chave: Lean Healthcare. Maturidade Lean. Hospital. Lean Thinking. 


\section{INTRODUÇÃO}

O método Lean Manufacturing surgiu do sistema japonês Toyota de Produção, denominado TPS (Toyota Production System), desenvolvido pela Toyota Motor Corporation, após a $2^{a}$ Guerra Mundial e tem como propósito minimizar $o$ desperdício $e$ as operações que não agregam valor ao processo produtivo, através de uma série de atividades de melhoria (CALADO et al., 2014).

A filosofia Lean busca reduzir desperdícios em qualquer processo da empresa, realizar a otimização de recursos básicos e estabelecer uma cultura voltada à busca contínua pela satisfação do cliente, se baseando nos cinco princípios apontados por Womack e Jones (2004a): Identificar o valor definido pelo cliente; priorizar a cadeia de valor de um produto ou serviço; controlar e eliminar desperdícios na entrega ao cliente; ativar a produção puxada a demanda e eliminar as atividades que não agregam valor.

O objetivo geral deste trabalho é avaliar a maturidade do sistema Lean Manufacturing de uma PME do segmento da saúde, avaliando seu desempenho no desenvolvimento de processos Lean.

O problema de pesquisa atualmente identificado é o quanto o Lean Manufacturing está implementado e consolidado na área da saúde em PME. É evidente a dificuldade de implementar e mensurar o Lean Healthcare uma vez que Lean foi desenvolvido para a indústria automotiva e seus conceitos de padronização, nivelamento e otimização do fluxo não necessariamente conseguem ser aplicados na área da saúde necessitando de adaptações.

Logo, fica também evidente que é necessário um tempo suficiente para criar a experiência necessária em Lean Healthcare e desenvolver um conhecimento aplicável e consistente atingindo altos níveis de maturidade.

Atualmente a demanda na área da saúde cresce rapidamente e esta demanda relaciona-se com aumento de expectativas na qualidade do atendimento, número de pacientes que necessitam de atendimento, diminuição nos tempos de espera e a aplicação de novos tratamentos que necessitam de um grande investimento financeiro. Ao mesmo tempo, devido as diversas crises econômicas que o país vem sofrendo, o sistema de Healthcare precisa enfrentar essa situação com orçamentos restritos o que leva à necessidade de utilização de recursos escassos de forma mais eficaz e eficiente (HASLE, NIELSEN e EDWARDS, 2016).

As PME na área da saúde estão sempre em busca por soluções para o aumento da produtividade de seus serviços com a finalidade de assegurar um bom atendimento à população. Para isso muitos conceitos de gestão operacional são implementados como uma tentativa para melhoria dos serviços, tais como círculos de qualidade, gestão da qualidade total, Lean Manufacturing, entre outros (HASLE, NIELSEN e EDWARDS, 2016).

Sendo assim, foi identificado uma oportunidade de ampliar a pesquisa no Lean Healthcare, a principal justificativa desse trabalho é ampliar o conhecimento da maturidade das PME na área da saúde, permitindo que essas empresas possam utilizar esse conhecimento para melhorar a eficiência de seus atendimentos e operações internas.

\section{REVISÃO DA LITERATURA}

O Lean Thinking pode ser descrito como uma filosofia de produção e um sistema de qualidade desenvolvida pela corporação Toyota através do conjunto de elementos da produção em massa e artesanal. Essa filosofia tem como seu principal foco a padronização para que estoques sejam eliminados e processos melhorados (JOOSTEN $\mathrm{e}$ BONGERS e JANSSEN, 2009).

Com o tempo, várias ferramentas e métodos foram desenvolvidos para serem aplicados na indústria começando pela automotiva, ramo de atuação da Toyota, e passando mais tarde a ser adaptada para a indústria manufatureira e de serviços. Hines, Holweg e Rich (2004) demonstram essa evolução do Lean Thinking através dos estágios de aprendizado organizacional, como ilustrado no Quadro 1. 
Quadro 1- Evolução do Lean Thinking

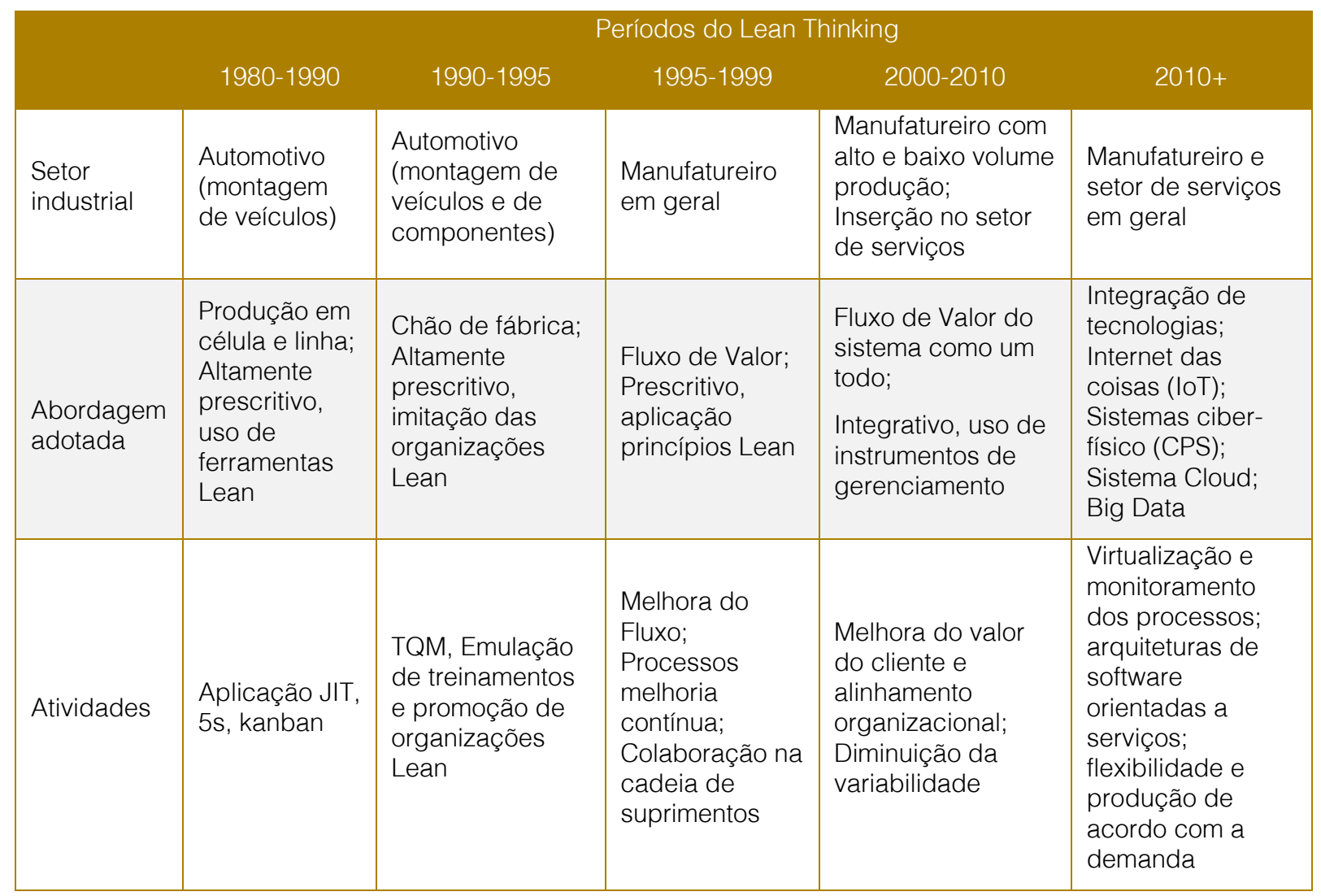

A evolução do pensamento Lean Thinking permitiu, a partir do ano 2000, adaptar algumas técnicas inserindo o Lean no setor de serviços através da aplicação dos métodos nas atividades operacionais $e$ estratégias mais focadas no gerenciamento. Abdi, Shavarini e Hoseini (2006) argumentam que o uso do Lean Thinking em serviços requer uma customização comportamental demandada pelo consumidor final ao determinar a proposta de valor fazendo com que a entrega do serviço esteja alinhada com a demanda e se atinja altos níveis de eficiência.

A aplicação Lean visa eliminar todas as fontes de desperdício visto que são etapas de não agregação de valor e despendem o uso desnecessário de recursos humanos e materiais, criando custos diretos e indiretos além de custos administrativos. O processo de eliminação destes desperdícios, segundo Monden (2012), está retratado na Figura 1.
Quando se trata de PME, uma implementação eficiente das práticas Lean passa a ser um desafio, pois pode exigir altos investimentos, dedicação dos melhores recursos e treinamento de muitos empregados da empresa (DORA,2014; ACHANGA et al., 2006; SANCHEZ e PEREZ, 2001).

Kumar and Antony (2008) fizeram uma pesquisa em 64 PME localizadas no Reino Unido a fim de realizar uma comparação entre as diferentes práticas de gerenciamento da qualidade. Em seus estudos, $26,5 \%$ das empresas adotaram o Lean Manufacturing e nelas foram identificadas diversas barreiras que as impediam de atingir o sucesso tais como falta de conhecimento; de treinamento; disponibilidade de recursos; resistência interna; e baixa participação dos funcionários. 
Figura 1 - Fluxograma do processo de eliminação de desperdício para redução de custo

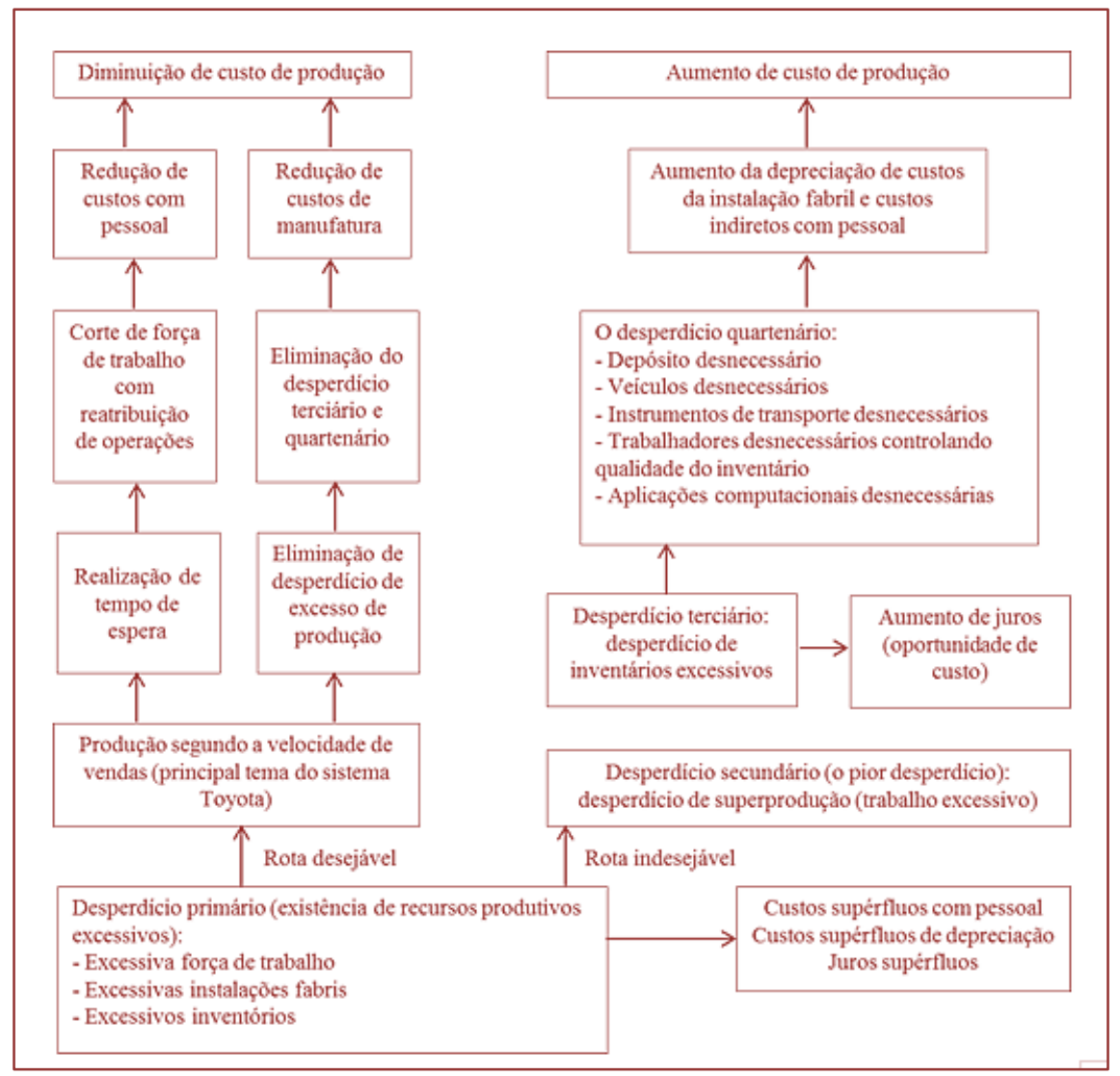

Fonte: Adaptado de SCHEEL et. al, 2016.

\subsection{LEAN HEALTHCARE}

O sistema de saúde vem enfrentando diversos desafios relacionados ao aumento de demanda pelos seus serviços, as práticas de instituições dessa área estão cada vez mais orientadas pelas necessidades dos pacientes, aumento do número de clientes que necessitam de atendimento e das expectativas em relação a qualidade dos serviços.

Hastle et al. (2016) afirma que o lean pode contribuir para o desenvolvimento dos hospitais, mas ainda precisa ser reconstruído de uma maneira a se integrar com os principais tratamentos e processos deste setor focando, principalmente, no paciente e considerando a integração do valor operacional do lean com o valor clínico e experimental além de incluir as interações profissionais e sociais nestes ambientes para que tenha sucesso ao ser implementado.

Com melhor entendimento e maior facilidade de adaptação nota-se um crescente número de estudos publicados sobre Lean Healthcare em cadeias de laboratórios, hospitais, departamentos ambulatoriais, centros e salas de operações, departamento de enfermagem e em procedimentos cirúrgicos (FILLINGHAM, 2007; RADNOR, 2010). Esses estudos mostram que Lean Healthcare reduz tempos de esperas, melhora a qualidade do atendimento, aumenta a produtividade e eficiência, permite uma capacidade de expansão sem a necessidade de espaço adicional e aumenta a utilização das salas cirúrgicas.

A maioria das implementações lean no sistema healthcare começa com o uso dos instrumentos lean customizados para os aspectos operacionais do sistema de entrega de cuidados a saúde. A princípio, faz-se a diferenciação entre atividades que agregam valor das que não que agregam sendo a análise do paciente em processamento uma técnica usada para facilitar a identificação, segundo Kujala et al. (2006). Nessa análise a jornada do paciente no sistema de saúde é analisado baseado em categorias apresentadas no Quadro 2 facilitando identificar atividades que não agregam valor para eliminação de desperdício. 
Quadro 2 - Separação de tempos de agregação e não agregação de valor

\begin{tabular}{|c|c|}
\hline Lean Thi & Siste \\
\hline $\begin{array}{l}\text { Tempos que } \\
\text { agregam valor }\end{array}$ & $\begin{array}{l}\text { Diagnóstico e tempo de tratamento } \\
\text { Tempo de diagnóstico: coletar e analisar informação clínica } \\
\text { Tempo de cuidados ativos: intervenções clínicas } \\
\text { Tempo de cuidados passivos: tempo em observação, sem intervenções clínicas } \\
\text { Tempo de Espera } \\
\text { Positivo: condição do paciente pode melhorar sem intervenções }\end{array}$ \\
\hline $\begin{array}{c}\text { Tempos que } \\
\text { não agregam } \\
\text { valor } \\
\text { (desperdícios) }\end{array}$ & $\begin{array}{l}\text { Diagnóstico e tempo de tratamento } \\
\text { Tempo supérfluo: diagnósticos ou tempo em observação ou intervenções } \\
\text { desnecessárias } \\
\text { Administrativo } \\
\text { Tempo de Espera } \\
\text { Passivo: sem expectativas de mudanças na condição do paciente } \\
\text { Negativo: condição do paciente provavelmente irá piorar }\end{array}$ \\
\hline
\end{tabular}

Entretanto, quando se trata do sistema healthcare faz-se necessário incluir também análises de aspectos sócio técnicos para que as melhorias não sejam apenas pontuais e sim alcançadas no sistema como um todo. Segundo Joosten et al. (2009) e Berwick (2003), um exemplo de um avanço sócio técnico está relacionado à percepção dos gerentes em relação aos seus trabalhos, ou seja, identificarem que suas atividades não são diretamente relacionadas a estruturar melhorias para o sistema healthcare.

Joosten et al. (2009) e Berwick (2003) afirmam que as dificuldades relacionadas ao alcance da melhoria no sistema como um todo através do Lean Thinking aparecem em sua implementação. Pesquisas voltadas a dinâmica sócio técnica em organizações lean são carentes, principalmente quando se trata da área da saúde, pois há muitas pesquisas abordando aspectos operacionais e sua relação com a performance que é possível atingir com lean mas estudos que mostram a sua aplicação em healthcare são limitados.

Muito dessa escassez de estudos voltados a aplicação lean healthcare e sua imaturidade neste setor deve-se ao tempo relativamente pequeno da presença do lean em hospitais quando comparado a indústria automobilística. Entretanto, a imaturidade do lean não se trata apenas do tempo presente nos setores da saúde e do acúmulo de experiência prática, mas também da escassez de desenvolvimento de ferramentas e métodos adequados ás necessidades especiais destes setores (HASTLE et al., 2016).

\section{MÉTODO}

O presente projeto trata-se de um estudo de caso único. Segundo Yin (2015, pg 02) "estudo de caso é a investigação de um fenômeno contemporâneo em seu contexto no mundo real, especialmente quando as fronteiras entre o fenômeno e o contexto puderem não estar claramente evidentes". A configuração do estudo, apesar de não seguir uma sequência rígida, é definida por uma ordem que consiste em: formulação do problema ou das questões de pesquisa, definição das unidades-caso, seleção dos casos, elaboração do protocolo, coleta de dados, análise e interpretação dos dados e elaboração do relatório (Figura 2) (GIL, 2010).

O estudo de caso de acordo com Marconi e Lakatos (2011, pg 276) é um "levantamento com mais profundidade de determinado caso ou grupo humano sob todos os seus aspectos. Entretanto, é limitado, pois se restringe ao caso que estuda, ou seja, um único caso, não podendo ser generalizado". Nesse método obtêm-se tanto dados quantitativos quanto qualitativos, cabendo ao 
pesquisador classificar as relações entre as propriedades do ambiente, relatando assim, o desenvolvimento de um caráter interpretativo no que se refere aos dados obtidos (GIL, 2010).

Figura 2 - Metodologia do estudo de caso

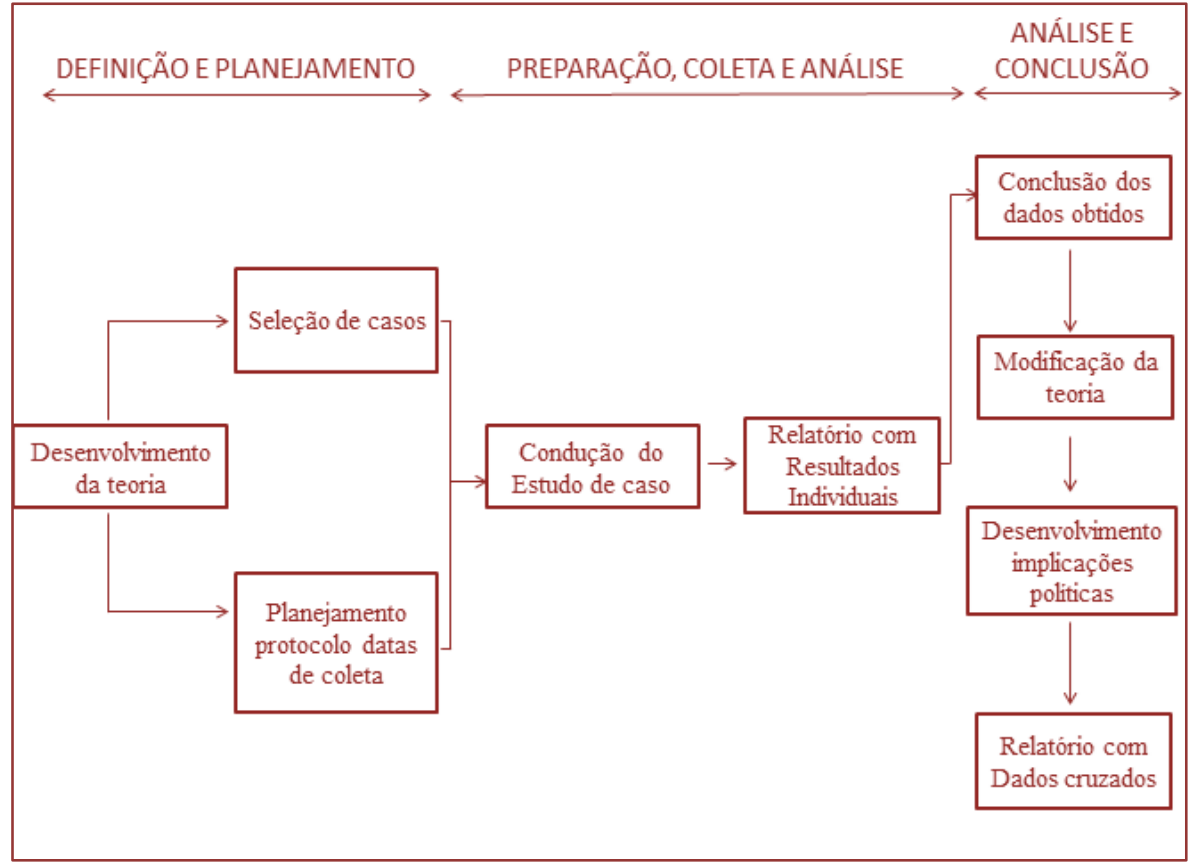

Fonte: Adaptado de YIN, 2013 pg 49

A aplicação da pesquisa será pela combinação dos estudos exploratóriodescritivos, nos quais envolverão a contextualização do objeto e fonte de informação variada, advinda de observação e entrevistas, além da descrição do comportamento do sistema ou problema modelado. Para Markoni e Lakatos (2011) e Gil (2010), é importante definir uma série de aspectos para que a inter-relação entre pesquisador e entrevistado atinja maior eficácia, como o interesse, a utilidade, o objetivo, as condições da entrevista e o compromisso do anonimato.

Em conjunto com a revisão da literatura, para a definição e planejamento do estudo de caso, com a auxilio do softwre VOSviewer foi possível mapear os artigos contidos na base de dados para entender como os estudos se relacionam e quais relações são relevantes nos artigos publicados. O Vos Viewer é uma ferramenta usada para criação de mapas baseados em dados na rede ou de uma base de dados construídos por quem está usando. As relações podem ser construídas com base em publicações científicas, pesquisadores, organizações de pesquisas, países, palavraschave ou algum termo específico.

Para o presente estudo foi construído o mapa a seguir baseado nas Palavras chave dos artigos que compõe o banco de dados. Notase que a maior concentração se dá no healthcare relacionando-se diretamente com os focos dessa pesquisa. 
Figura 4 - Mapa de conexões VOSviewer

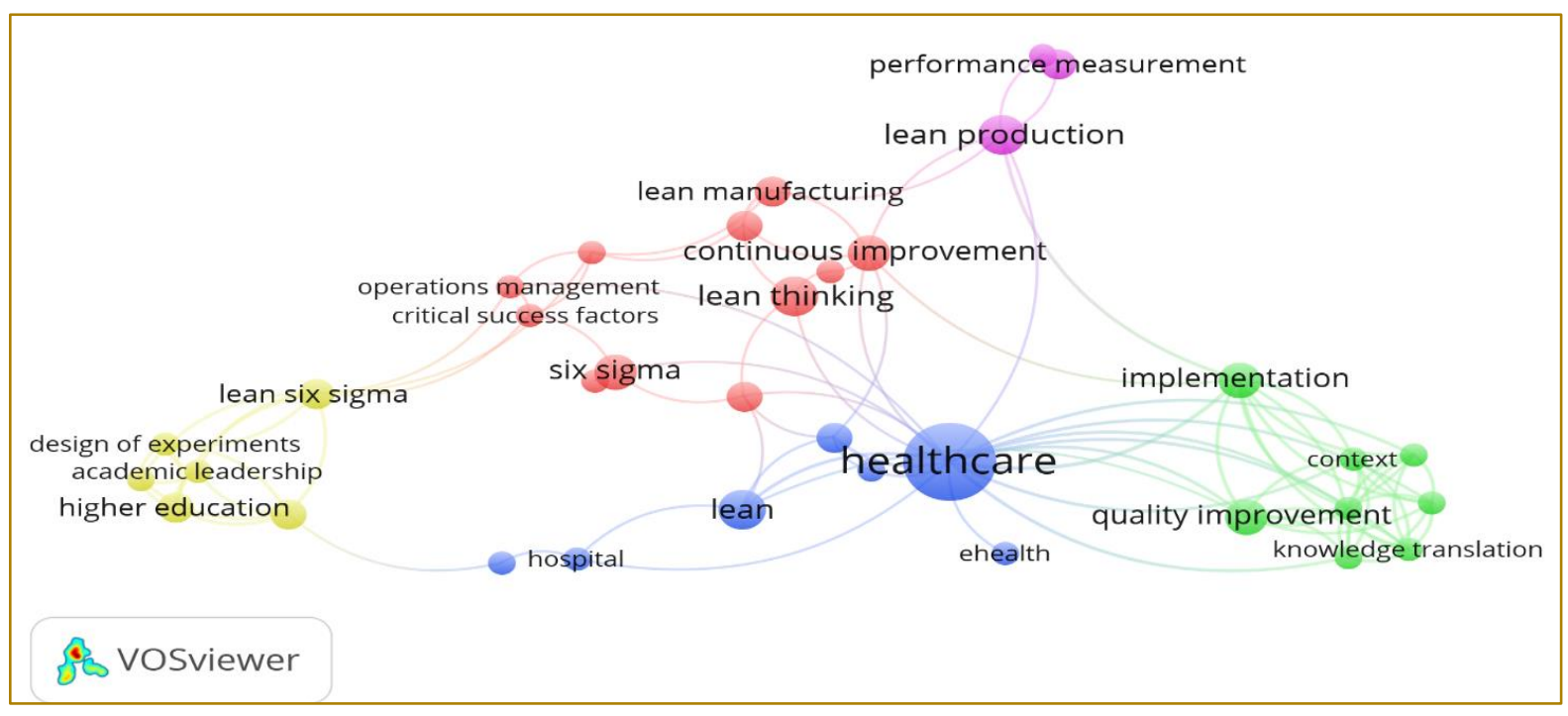

Após o desenvolvimento da teoria, iniciou-se a seleção do caso e planejamento da coleta determinando o foco da pesquisa na realização de coleta de dados, com o apoio de um roteiro de entrevista seguindo um modelo adaptado de Scheel et al. (2016), baseado na norma SAE J4001 (1999) e
Lucato et al. (2005), e adaptado para a área da saúde baseado em Kaltenbrunner et al. (2017) para que seja possível medir a maturidade Lean na empresa. A entrevista é composta por 59 questões contempladas dentro dos seguintes elementos, descritos na Tabela 3.

\section{Tabela 3- Elementos para composição do roteiro de entrevistas para o estudo de caso}

\begin{tabular}{|ll|}
\hline Ética e organização & $\begin{array}{l}\text { Depreende-se que um dos principais requisitos é o envolvimento da } \\
\text { gerência e disseminação dos conceitos Lean pela organização, de modo } \\
\text { a incentivar e até premiar ações voltadas à sua aplicação. }\end{array}$ \\
\hline Pessoas e RH & $\begin{array}{l}\text { Faz-se necessário a democratização da tomada de decisões, treinamento } \\
\text { dos funcionários e formação de equipes interdisciplinares. }\end{array}$ \\
\hline Sistema de Informação & $\begin{array}{l}\text { Permite facilitar o acompanhamento do desempenho das iniciativas das } \\
\text { equipes. }\end{array}$ \\
\hline Relação Cliente/ Fornecedor e & Uma das chaves de sucesso é a parceria \\
\hline Serviço e Gestão do Serviço & $\begin{array}{l}\text { Maneiras como os serviços são geridos, se há o uso de ferramentas } \\
\text { relacionadas à gestão do ciclo de vida do produto/serviço, a fim de } \\
\text { reduzir tempo e custo dos serviços e de lançamento de novos produtos e } \\
\text { serviços. }\end{array}$ \\
\hline $\begin{array}{l}\text { Engloba a maior parte das ferramentas voltadas ao Lean: cadeia de valor, } \\
\text { produção puxada, redução do setup (preparação de máquina ou } \\
\text { procedimentos), controle visual da produção, manutenção preditiva, } \\
\text { controle estatístico de processo e padronização das operações. }\end{array}$
\end{tabular}

Fonte: Adaptado de SCHEEL et. al, 2016.

As respostas contemplam 4 níveis das melhores práticas, portanto, devem ser dadas de 0 a 3. 
Tabela 4 - Níveis para avaliação dos componentes

\begin{tabular}{|c|c|}
\hline Nível & Significado \\
\hline 0 & $\begin{array}{l}\text { O componente não está completamente implementado ou existem grandes inconsistências na sua } \\
\text { implantação }\end{array}$ \\
\hline 1 & O componente está implementado, mas existem pequenas inconsistências na sua implantação \\
\hline 2 & O componente está implementado e com resultados efetivos \\
\hline 3 & $\begin{array}{l}\text { O componente está completamente implementado e apresentou melhorias de resultados durante o } \\
\text { último ano }\end{array}$ \\
\hline
\end{tabular}

Concluído a etapa de definição e planejamento, iniciou-se a preparação, coleta e análise dos dados conduzindo o estudo de caso na empresa escolhida, e o desenvolvimento de um relatório com os resultados seguindo a técnica de Lucato, Maestrelli e Vieira Jr. (2006) a seguir.

A medição do nível de maturidade Lean é baseada na adaptação da técnica de Lucato, Maestrelli e Vieira Jr. (2006) que desenvolveram o Grau de Aderência à Norma para cada elemento da norma SAE J4000, assim como o Grau de Enxugamento da organização, definidos pelas Equações 1 e 2 , respectivamente, devido ao fato de existir limitação das normas SAE pois elas não permitem definir o grau de enxugamento de cada um dos elementos de implementação do Lean, assim como da empresa como um todo, uma vez que cada componente invariavelmente será classificado em níveis diferentes.

$$
\begin{gathered}
\text { Grau de aderência a Norma }=g=\frac{\sum g_{e}}{p} \\
\text { Grau de enxugamento }=g_{e}=\frac{\sum \text { avaliação dos componentes de cada elemento }}{\sum \text { pontos possiveis para os componentes do elemento }}
\end{gathered}
$$

Sendo "e" um elemento qualquer e "p" o número de elementos considerados na comparação.

Além disso, para analisar o grau de relacionamento entre os itens do roteiro de entrevista foram dimensionados os coeficientes de correlação, podendo estar entre -1 e +1 inclusive. Tem-se um relacionamento forte entre duas variáveis quando valores altos de uma variável estão relacionados com os valores altos ou baixos da outra variável, entretanto, quando temos valores altos de uma variável relacionados com os valores altos e baixos da outra variável, temos um relacionamento fraco entre as variáveis (LIRA, 2004). Sendo assim, realizou-se uma análise de correlação com o auxílio do software Excel considerando uma correlação forte coeficientes acima de 0,7.

\section{DESENVOLVIMENTO}

O hospital em questão começou a adotar medidas relacionadas a cultura Lean em 2017 buscando uma melhoria em seus processos. Desde então foram realizadas várias ações visando uma maior produtividade e controle antes, durante e após as cirurgias, e um melhor preparo de seus funcionários.

Pode-se citar como exemplo destas ações a compra de relógios de parede para melhor controle do tempo de cirurgia e outros tempos relevantes; a revisão dos kits da farmácia; equipe exclusiva para higienização do Centro Cirúrgico (CC) ; troca dos computadores com softwares mais recentes; reuniões com equipe do CC; reunião com enfermeiros; implantação de sessões de orientações individuais; 807 horas de treinamentos; substituição e adequação dos instrumentais cirúrgicos; adequação da sala de recebimento dos instrumentais; implantação do controle de inventário; uso do 5S para organização do inventário. 
Além dessas medidas implementadas com foco na melhoria contínua, foram mapeadas diversas outras demandas para que os processos do Centro Cirúrgico atinjam níveis maiores de maturidade. Após a aplicação das ações no CC do hospital, tornou-se evidente os benefícios conquistados com adoção da cultura Lean, trazendo um controle melhor dos tempos e processos operacionais, além de melhor capacitação de seus funcionários e uso do espaço disponível.

\subsection{RESULTADOS}

Conforme a tabela 4 e os níveis de cada elemento obtidos na entrevista, calculou-se a mediana do nível de cada pergunta e somaram-se as respectivas pontuações dentro dos elementos como demonstrado a seguir.

Tabela 5 - Resultados das entrevistas

\begin{tabular}{|c|c|c|c|c|c|c|c|c|c|c|c|c|c|c|c|c|c|c|c|c|c|c|}
\hline & & \multicolumn{18}{|c|}{ Componentes } & \multirow{2}{*}{ Mediana } & \multirow{2}{*}{$\begin{array}{c}\text { Coeficient } \\
\text { de } \\
\text { Variaçâo }\end{array}$} & \multirow{2}{*}{ Total } \\
\hline & & 1 & 2 & 3 & 4 & 5 & 6 & 7 & 8 & 9 & 10 & 11 & 12 & 13 & 14 & 15 & 16 & 17 & 18 & & & \\
\hline \multirow{6}{*}{ 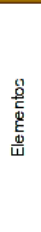 } & 1.Ética & 2 & 2 & 3 & 2 & 3 & 3 & 2 & 2 & 3 & 2 & 2 & 3 & 2 & & & & & & 2 & 0,2 & 31 \\
\hline & 2.Pessoase RH & 3 & 3 & 3 & 3 & 2 & 2 & 2 & 3 & 2 & 2 & 2 & 2 & 3 & & & & & & 2 & 0,2 & 32 \\
\hline & 3.Sistema de Informaçâo & 3 & 3 & 3 & 2 & & & & & & & & & & & & & & & 3 & 0,4 & 11 \\
\hline & 4. Relaçâo como cliente & 2 & 2 & 2 & 2 & & & & & & & & & & & & & & & 2 & 0 & 8 \\
\hline & $\begin{array}{l}\text { 5.Seniço e gestào do } \\
\text { serviço }\end{array}$ & 2 & 2 & 2 & 2 & 2 & 2 & 2 & & & & & & & & & & & & 2 & 0 & 14 \\
\hline & $\begin{array}{l}\text { 6. Produto fluxo de } \\
\text { processos }\end{array}$ & 3 & 3 & 3 & 3 & 3 & 2 & 2 & 2 & 2 & 2 & 3 & 2 & 3 & 2 & 2 & 2 & 2 & 2 & 2 & 0,5 & 43 \\
\hline
\end{tabular}

Para calcular o grau de enxugamento ("g"), baseados nas equações 1 e 2 e nas informações fornecidas na Tabela 6, obtevese os seguintes graus de enxugamento.

Tabela 6 - Grau de enxugamento e de aderência dos elementos

\begin{tabular}{|l|c|c|}
\hline \multicolumn{2}{|c|}{ Grau de enxugamento } & $79,5 \%$ \\
\hline 1. Ética & $g_{1}=\frac{\sum L_{1}}{3 x 13}=\frac{31}{39}=0,795$ & $82,1 \%$ \\
\hline 2. Pessoas e RH & $g_{2}=\frac{\sum L_{2}}{3 x 13}=\frac{32}{39}=0,821$ & $91,7 \%$ \\
\hline $\begin{array}{l}\text { 4. Relação com o Cliente, } \\
\text { Fornecedor e Organização }\end{array}$ & $g_{3}=\frac{\sum L_{3}}{3 x 4}=\frac{11}{12}=0,917$ & $66,7 \%$ \\
\hline 5. Serviço e Gestão do Serviço & $g_{4}=\frac{\sum L_{4}}{3 x 4}=\frac{8}{12}=0,667$ & $66,7 \%$ \\
\hline 6. Produto e Fluxo de processos & $g_{5}=\frac{\sum L_{5}}{3 x 7}=\frac{14}{21}=0,667$ & $79,6 \%$ \\
\hline Grau de aderência & $g_{6}=\frac{\sum L_{6}}{3 x 18}=\frac{43}{54}=0,796$ & $77,7 \%$ \\
\hline \multicolumn{1}{|c|}{ Total } & $g=\frac{g_{1}+g_{2}+g_{3}+g_{4}+g_{5}+g_{6}}{6}=0,777$ & \\
\hline
\end{tabular}

Por fim, na tabela 7 encontram-se os resultados da análise referentes aos 1.711 coeficientes de correlação encontrados para entender melhor como os elementos e seus componentes estão relacionados entre si. 
Tabela 7 - Correlação entre os elementos

\begin{tabular}{|c|c|c|c|c|c|c|c|c|}
\hline \multirow[t]{2}{*}{$\begin{array}{l}\text { Elementos } \\
\text { Relacionados }\end{array}$} & \multicolumn{4}{|c|}{ Quantidade de coeficientes } & \multicolumn{4}{|c|}{$\begin{array}{l}\text { Percentual de coeficientes em relação a } \\
\text { quantidade total }\end{array}$} \\
\hline & Total & $\begin{array}{l}\text { Entre } 0,7 \\
\quad \text { e } 0,8\end{array}$ & $\begin{array}{l}\text { Entre } 0,8 \\
\quad \text { e } 0,9\end{array}$ & $\begin{array}{l}\text { Entre } 0,9 \\
\quad \text { e } 1\end{array}$ & $\begin{array}{l}\text { Entre } 0,7 \\
\quad \text { e } 0,8\end{array}$ & $\begin{array}{l}\text { Entre } 0,8 \\
\quad \text { e } 0,9\end{array}$ & $\begin{array}{l}\text { Entre } 0,9 \\
\quad \text { e } 1\end{array}$ & $\begin{array}{l}\text { Entre } 0,7 \\
\quad \text { e } 1\end{array}$ \\
\hline E1 E1 & 78 & 6 & 0 & 0 & $7,7 \%$ & $0,0 \%$ & $0,0 \%$ & $7,7 \%$ \\
\hline E1 E2 & 169 & 6 & 1 & 0 & $3,6 \%$ & $0,6 \%$ & $0,0 \%$ & $4,1 \%$ \\
\hline E1 E3 & 52 & 1 & 0 & 0 & $1,9 \%$ & $0,0 \%$ & $0,0 \%$ & $1,9 \%$ \\
\hline E1 E4 & 52 & 3 & 0 & 0 & $5,8 \%$ & $0,0 \%$ & $0,0 \%$ & $5,8 \%$ \\
\hline E1 E5 & 91 & 6 & 1 & 0 & $6,6 \%$ & $1,1 \%$ & $0,0 \%$ & $7,7 \%$ \\
\hline E1 E6 & 234 & 4 & 1 & 0 & $1,7 \%$ & $0,4 \%$ & $0,0 \%$ & $2,1 \%$ \\
\hline E2 E2 & 78 & 7 & 0 & 0 & $9,0 \%$ & $0,0 \%$ & $0,0 \%$ & $9,0 \%$ \\
\hline E2 E3 & 52 & 3 & 1 & 0 & $5,8 \%$ & $1,9 \%$ & $0,0 \%$ & $7,7 \%$ \\
\hline E2 E4 & 52 & 5 & 1 & 0 & $9,6 \%$ & $1,9 \%$ & $0,0 \%$ & $11,5 \%$ \\
\hline E2 E5 & 91 & 2 & 2 & 0 & $2,2 \%$ & $2,2 \%$ & $0,0 \%$ & $4,4 \%$ \\
\hline E2 E6 & 234 & 4 & 1 & 0 & $1,7 \%$ & $0,4 \%$ & $0,0 \%$ & $2,1 \%$ \\
\hline E3 E3 & 6 & 0 & 0 & 0 & $0,0 \%$ & $0,0 \%$ & $0,0 \%$ & $0,0 \%$ \\
\hline E3 E4 & 16 & 2 & 0 & 0 & $12,5 \%$ & $0,0 \%$ & $0,0 \%$ & $12,5 \%$ \\
\hline E3 E5 & 28 & 0 & 1 & 0 & $0,0 \%$ & $3,6 \%$ & $0,0 \%$ & $3,6 \%$ \\
\hline E3 E6 & 72 & 7 & 1 & 0 & $9,7 \%$ & $1,4 \%$ & $0,0 \%$ & $11,1 \%$ \\
\hline E4 E4 & 6 & 3 & 0 & 0 & $50,0 \%$ & $0,0 \%$ & $0,0 \%$ & $50,0 \%$ \\
\hline E4 E5 & 28 & 4 & 1 & 0 & $14,3 \%$ & $3,6 \%$ & $0,0 \%$ & $17,9 \%$ \\
\hline E4 E6 & 72 & 4 & 2 & 0 & $5,6 \%$ & $2,8 \%$ & $0,0 \%$ & $8,3 \%$ \\
\hline E5 E5 & 21 & 0 & 0 & 0 & $0,0 \%$ & $0,0 \%$ & $0,0 \%$ & $0,0 \%$ \\
\hline E5 E6 & 126 & 3 & 1 & 0 & $2,4 \%$ & $0,8 \%$ & $0,0 \%$ & $3,2 \%$ \\
\hline E6 E6 & 153 & 16 & 9 & 2 & $10,5 \%$ & $5,9 \%$ & $1,3 \%$ & $17,6 \%$ \\
\hline
\end{tabular}

\subsection{DISCUSSÃO}

O cenário ideal, onde uma empresa pode ser considerada totalmente madura no Lean, teríamos a maior pontuação possível em cada elemento, ou seja, todos os componentes teriam um nível de pontuação 3 e o grau de enxugamento total de $100 \%$ indicando uma aderência completa das melhores práticas do Lean.

A empresa analisada em questão obteve um grau de aderência $77,7 \%$ estando $22 \%$ abaixo do cenário ideal. Não é possível afirmar se este é um nível de maturidade aceitável para a área da saúde pois não há uma base de dados para realizar comparações. Sendo assim, segue o parecer geral dos elementos considerando os resultados obtidos e as informações coletadas sobre as práticas Lean foram implementadas na empresa.
Apesar de não haver uma base para comparação, os graus de enxugamento encontrados em cada elemento se apresentam com valores elevados indicando um bom nível de maturidade Lean na organização. Estes altos índices de maturidade podem se dar pelo fato dos indivíduos que responderam às perguntas não terem conhecimento do que é ser maduro em Lean, visto que as implantações de práticas relacionadas a manufatura enxuta são recentes na organização.

Analisando os coeficientes de correlação, nota-se uma maior concentração de quantidade de índices acima de 0,7 entre os componentes do sexto elemento. Estes são um dos mais relacionados entre si indicando que se um dos componentes tende a aumentar outros componentes também 
tendem a aumentar. Entre eles estão presentes os maiores índices de correlação (+ $0,91)$ entre os componentes 45 e 52 e, 53 e 58. Entretanto, quando se avalia percentualmente nota-se que o quarto elemento tem 50\% dos seus coeficientes acima de 0,7 seguido de $17,6 \%$ do sexto elemento.

O terceiro e quinto elemento são os elementos cujos componentes menos se correlacionam entre os componentes do elemento que pertencem pois não possuem nenhum índice de correlação acima de 0,7. Apesar do quinto elemento ter uma baixa correlação entre seus componentes, $17,9 \%$ dos coeficientes de correlação entre seus componentes e os componentes do quarto elemento estão acima de 0,7 indicando uma relação entre eles.

\section{CONCLUSÃO}

O presente estudo de caso permite classificar uma empresa da área da saúde em relação a maturidade do Lean Manufacturing, sendo possível medir qual o nível de aderência das melhores práticas da cultura Lean em 6 diferentes âmbitos. Através dele identifica-se os pontos fortes e as deficiências da empresa escolhida, sendo possivel apontar quais

\section{REFERÊNCIAS}

[1] ABDI, F., SHAVARINI, S.K. AND HOSEINI, S.M.S., Glean lean: how to use lean approach in service industries?, Journal of Services Research, Vol. 6, pp. 191-206, 2006.

[2] ACHANGA, P.; SHEHAB, E.; ROY, R.; NELDER, G. Critical success factors for lean implementation within SMEs. Journal of Manufacturing Technology Management, Bradford, v. 17, n. 4 , p. $460-471,2006$.

[3] BALLÉ, M.; RÉGNIER, A. Lean as a learning system in a hospital ward. Leadersh Health Serv ;20:33-41, 2007.

[4] BERGMILLER, G.G.; MCCRIGHT, P.R. Achieving Total Sustainability by Cleaning Up the Dirty Dozen. IIE Annual Conference.Proceedings, Norcross, p. 1-8, 2011.

[5] BERWICK D. Improvement, trust, and the healthcare workforce. Qual Saf Health Care;12:i2i6, 2003.

[6] CALADO, R.D.; BATOCCHIO, A.; CALARGE, F.A.; SILVA, M.B. Método de diagnóstico de empresa: melhoria de desempenho componentes devem ser melhorados dentro da organização para uma melhoria contínua até o atingimento da situação ideal onde a aderência é de 100\%.

O hospital analisado obteve um nível de maturidade abaixo de $70 \%$ apenas nos elementos 4 e 5, indicando ser as áreas mais deficientes dentro da organização, e uma aderência total de $77,7 \%$.

Analisando a correlação entre todos os elementos tem-se: (1) os componentes do quarto elemento são os que tem uma maior relação positiva; (2) a segunda maior relação de é entre componentes do quarto com o quinto elemento de 17,9\%; (3) a terceira maior relação é de 17,6\% entre componentes do sexto elemento; (4) todas as outras relações estão abaixo de 12,5\%.

Apesar do bom resultado de nível de maturidade, ressalta-se que o método aplicado neste estudo não foi aplicado em outras organizações do mesmo setor e não foram encontrados resultados de níveis de maturidade de Lean Manufacturing na área da saúde para realizar uma comparação. Além disso, os altos índices de maturidade podem estar relacionados ao pouco conhecimento dos entrevistados do que é ser maduro em Lean.

da organização. 1a edição. Estados Unidos: Globalsouth Press Inc, 2014.

[7] CARLAGE, F.A.; SATOLO, E.G. Determinação do grau de aderência ao sistema lean production para empresas da indústria automobilística: um estudo tipo. XXVII Encontro Nacional de Engenharia de produção. A energia que move produção: um diálogo sobre integração, projeto e sustentabilidade. Foz do Iguaçu: 2007.

[8] DORA, M.; GOUBERGEN, D.V.; KUMAR, M.; MOLNAR, A.; GELLYNCK, X. Application of lean practices in small and medium-sized food enterprises. British Food Journal, Bradford, v. 116, n. 1, p. 125-141, 2014.

[9] FILLIGHAM, D. (2007), "Can lean save lives?", Leadership in Health Services, Vol. 20 No. 4, pp. 231-241

[10] FULLERTON, R.R.; WEMPE, W.F. Lean manufacturing, non-financial performance measures, and financial performance. International Journal of Operations \& Production Management, Bradford, v. 29, n. 3, p. 214-240, 2009. 
[11] GIL, A. C.; Como Elaborar Projetos de Pesquisa. 5a edição. São Paulo: Atlas, 2010.

[12] HASLE P, NIELSEN A P, EDWARDS K. Application of Lean Manufacturing in Hospitals the need to consider maturiry, complexity, and the value concept. Human Factors and Ergonomics in Manufacturing \& Service Industries, v. 26, p. 430442, 2016

[13] HINES P, HOLWEG M, RICH N. Learning to evolve: a review of contemporary lean thinking. International Journal of Operations \& Production Management;24: 994-1011, 2004.

[14] JOOSTEN, Tom; BONGERS, Inge and JANSSEN, Richard. Application of lean thinking to health care: Issues and observations. International Journal for Quality in Health Care, vol. 21, no. 5, p. 341-347, 2009.

[15] KALTENBRUNNER, M., BENGTSSON, L., MATHIASSEN, S.E. AND ENGSTRÖM, M., "A questionnaire measuring staff perceptions of lean adoption in healthcare: development and psychometric testing", BMC Health Services Research, Vol. 17 No. 235, pp. 1-11, 2017.

[16] KAPANOWSKI, G. LEAN MATURITY ASSESSMENT: FROM THEORY TO PRACTICAL USE. Cost Management, Boston, v. 30, n. 3, p. 2835, May 2016.

[17] KARIM, A.; ARIF-UZ-ZAMAN, K. A methodology for effective implementation of lean strategies and its performance evaluation in manufacturing organizations. Business Process Management Journal, Bradford, v. 19, n. 1, p. 169196, 2013.

[18] KUJALA J, LILLRANK P, KRONSTRÖM V et al. Time-based management of patient processes. Journal of Health Organization Management;20:512-24, 2006.

[19] KUMAR, M.; ANTONY, J. Comparing the quality management practices in UK SMEs. Industrial Management \& Data Systems, Wembley, v. 108, n. 9, p. 1153-1166, 2008.

[20] LANGLOIS, T.D. Examining the Association Between Leadership Styles and an Organization's Lean Manufacturing Maturity Level. 154. (Order No. 3719111) - Northcentral University, Ann Arbor, 2015.

[21] LIRA, S.A.; Análise de Correlação: Abordagem Teórica e de Construção dos Coeficientes com Aplicações.

[22] LUCATO, W.C.; MAESTRELLI, N.C.; VIEIRA JÚNIOR, M. Determinação do Grau de Enxugamento de uma Empresa: uma proposta conceitual. Revista de Ciência \& Tecnologia, vol. 12, n. 24, pp.25-38, 2005.

[23] MALMBRANDT, M.; ÅHLSTRÖM, P. An instrument for assessing lean service adoption. International Journal of Operations \& Production Management, Bradford, v. 33, n. 9, p. 1131-1165, 2013.

[24] MARKONI, M. A.; LAKATOS, E. M. Metodologia Científica. 6를 Edição. São Paulo: Atlas, 2011.

[25] MAZZOCATO, P., SAVAGE, C., BROMMELS, M., ARONSSON, H. and THOR, J. (2010), "Lean thinking in healthcare: a realist review of the literature", Quality \& Safety in Health Care, Vol. 19 No. 5, pp. 376-382.

[26] MONDEN, Y. Toyota Production System. An Integrated Approach to Just-In-Time. 4a edição. Boca Raton: CRC Press, 2012.

[27] RADNOR, Z. J., \& HOLWEG,M.. From tools to systems: A critical appraisal of lean healthcare implementations. In Managing Operations in Service Environments, 17th EurOMA Conference, Porto, Portugal, June 3-7, 2010

[28] SAE. International J4000: Identification and Measurement of Best Practice in Implementation of Lean Operation. 1999.

[29] SANCHEZ, A.M.; PEREZ, M.P. Lean indicators and manufacturing strategies. International Journal of Operations \& Production Management, Bradford, v. 21, n. 11, p. 1433-1451, 2001.

[30] SCHEEL, V.P.; IGNÁCIO, P.S.A.; JÚNIOR, A.C.P.; SILVA, A.L. Análise comparativa entre o Sistema Toyota de Produção e as normas internacionais SAE J4000/1: um estudo de caso em uma indústria lean. XXXVI Encontro Nacional de Engenharia de Produção. Jõao Pessoa: 2016. Universidade Federal do Paraná, Curtiba, 2004.

[31] WOMACK, J.P.; JONES, D.T; ROOS, D. A Máquina Que Mudou O Mundo. Baseado no Estudo do Massachusetts Institute of Technology sobre o futuro do automóvel. Rio de Janeiro: Elsevier, 2004b.

[32] WOMACK, J.P.; JONES, D.T. A Mentalidade Enxuta nas Empresas. Lean Thinking. Elimine o desperdício e crie riqueza. Revista e Atualizada. Rio de Janeiro: Elsevier, 2004a.

[33] WONG, W.P.; CHEAH, C.H. Linking organizational culture to lean implementation in the Malaysian electrical and electronics industry: A conceptual framework. Advances in Management, 4(4), 50-57, 2011.

[34] YIN, R.K. Case Study Reasearch Design and Methods. $2^{\circ}$ Edition. London: SAGE Publications, 2013.

[35] YIN, R.K. Estudo de caso Planejamento e Métodos. 5a Edição. Porto Alegre: Bookman Editora Ltda.,

2015. 


\section{Capítulo 7}

\section{PADRONIZACEÃO DO PROCESSO DE ABASTECIMENTO DE LOCOMOTIVAS, UM ESTUDO DE CASO NA GESTÃO DE COMBUSTIVVEL DA FERROVIA DA VALE S.A. EM SÃO LUIS - MA.}

\section{Ana Carolina Silva Mouzinho}

Raissa Vieira Guimarães Ribeiro

Jonatas Barreto de Andrade Costa

Thiago Ferreira Silva

Resumo: Este artigo apresenta o desenvolvimento e aplicação do projeto de padronização na área de abastecimento de em locomotivas em uma empresa multinacional. Para a realização deste estudo de caso, foram utilizados os seguintes instrumentos de coleta de dados: entrevistas, levantamento, mapeamento e visitas in loco. Este modelo de simplificação permite a visualização do encadeamento e das interfaces entre os conjuntos de processos, assim como a forma que estão organizadas as atividades e como podem ser otimizadas através do desenho de fluxos e definição de tarefas críticas. Este desenho permite facilmente identificar gargalos, reprocessamentos de atividades e sinalizar as funções importantes para o gerenciamento das tarefas do dia a dia. Diante disto, este estudo buscou implantar um projeto de padronização de processos para as atividades críticas dentro do macroprocesso de gerir combustíveis, visando respeitar o princípio de empregar rotinas facilmente comunicáveis e entendidas por todos na organização, a implantação concentrou-se nas atividades relacionadas ao processo de abastecimento de locomotivas. O relatório de resultados e a percepção inicial demonstra que o método aplicado pode funcionar como uma cadeia de melhorias rumo a excelência.

Palavras-chave: Padronização, Abastecimento de Locomotivas, Melhoria contínua, Excelência 


\section{INTRODUÇÃO}

Paim (2009), define que o paradigma da melhoria dos processos está em voga atualmente, em grande parte pelo fato de que se instaurou na economia um ciclo de implantação de tecnologia da informação que requer investimentos sistemáticos e significativos para, essencialmente, melhorar o fluxo de informações ao longo dos processos. Ainda segundo o autor afirma, os quadros conceituais baseados em processos difundidos na Engenharia de Produção encontram na administração científica, no Sistema Toyota de Produção (TPS), nos Sistema de Controle da Qualidade Total (TQC), na Reengenharia de Processos (BPR) e na Teoria das Restrições (TOC) suas principais fontes.

Segundo Paim (2009) um processo é uma sequência de atividades realizadas sobre um objeto de interesse qualquer, interno ou externo. O autor destaca que é importante haver a noção de cliente interno, sendo esse quem compra e utiliza os produtos gerados pelos processos e, tendo liberdade de escolha, participa do julgamento de valor sobre o que a empresa oferece e decide se comprará novamente, ou não, o produto.

Os clientes e fornecedores internos, conforme princípio do Just In Time, devem produzir/processar em um mesmo ritmo (takttime) minimizando os estoques intermediários de produtos inacabados entre áreas de processos interligadas. Pelo conceito do sistema de produção "puxado", o que define o ritmo de processamento de uma área é o ritmo da necessidade de seu cliente interno. Por conseguinte, o takt-time do sistema de produção total é definido pela última área de processamento, ou seja, aquela cujo cliente é o externo (mercado externo demandante).

Para Liker (2007), o verdadeiro sucesso vem de um processo de melhoria focado na identificação das perdas, a partir da compreensão da raiz do problema.

Todos os processos devem ser controlados através de Indicadores Chave de Processos (KPl's), definidos objetivamente com valores e padrões de normalidade/anormalidade. Os desvios da normalidade do processo ensejam métodos de Controle Estatístico de Processos (CEP) e observação prática da atividade para buscar as causas dos desvios. As ações de solução devem ser focadas nas causas e não nos efeitos do problema. Isso garante que não se repitam.
O primeiro estágio da implantação de um sistema de gestão de processos é a padronização de processos e implantação de KPI's. A partir daí é possível controlar desvios, promover melhorias e aplicar tecnologias que prescindem de estabilidade e previsibilidade na produção.

O trabalho foi desenvolvido na VALE S.A. que desponta como a terceira maior mineradora em valor de mercado e maior produtora de minério de ferro do mundo, operando em cerca de 30 países. A operação de produção de minério de ferro nos estados de MaranhãoPará compõe-se essencialmente das minas de ferro na região de Carajás no Sul e Sudeste do Pará, transporte ferroviário pela Estrada de Ferro Carajás (EFC) que liga as minas ao Porto no Terminal Portuário de Ponta da Madeira (TPPM) em São Luís/MA. No Porto - minério é carregado em navios para transporte aos clientes finais.

A maior fonte energética da ferrovia é o óleo diesel que abastece as locomotivas. O óleo diesel nessa operação representa $46 \%$ dos custos operacionais da ferrovia e cerca de $1 \%$ do óleo diesel consumido no Brasil.

O processo de padronização visa implantar um sistema de gestão no processo de abastecimento, criando um lastro para o ciclo de evolução contínua e sustentável. Pela própria metodologia do VPS a padronização é implantada paulatinamente em um subprocesso de cada vez. Após a estabilização, parte-se para outro subprocesso.

\section{FUNDAMENTAÇÃO TEÓRICA}

\subsection{PADRONIZAÇÃO DE PROCESSOS}

Segundo Liker (2007), é imprescindível para que melhorias sejam implantadas, a definição clara de padrões em uma operação. Se um processo não estiver padronizado e for submetido à alguma melhoria, não é possível a mensuração real do que realmente foi aperfeiçoado.

Ainda segundo afirma o autor:

- estabelecimento de processos e procedimentos padronizados é a maior chave para a criação de desempenho consistente. É somente quando o processo é estável que se pode iniciar a progressão criativa da melhoria contínua. (...) A criação de processos padronizados baseia-se na definição, clareza (visualização) e utilização sistemática dos 
métodos que garantirão os melhores resultados possíveis. Como tal, a padronização não é aplicada como um elemento isolado a intervalos específicos. Ao contrário, é parte da atividade contínua de identificação de problemas, do estabelecimento de métodos eficazes e da definição do modo como esses métodos devem ser conduzidos (LIKER, 2007, p. 118).
A Toyota foca no desenvolvimento de padronização como uma base para a melhoria contínua, logo, os resultados que se esperam devem ser superiores aos padrões estabelecidos, que servem como parâmetros. No modelo enxuto para a redução de perdas, devemos trabalhar reduzindo até a eliminação (se possível) das variações entre os processos.

Figura 1 - Redução enxuta de perdas resulta em menor custo total, melhor prazo e qualidade

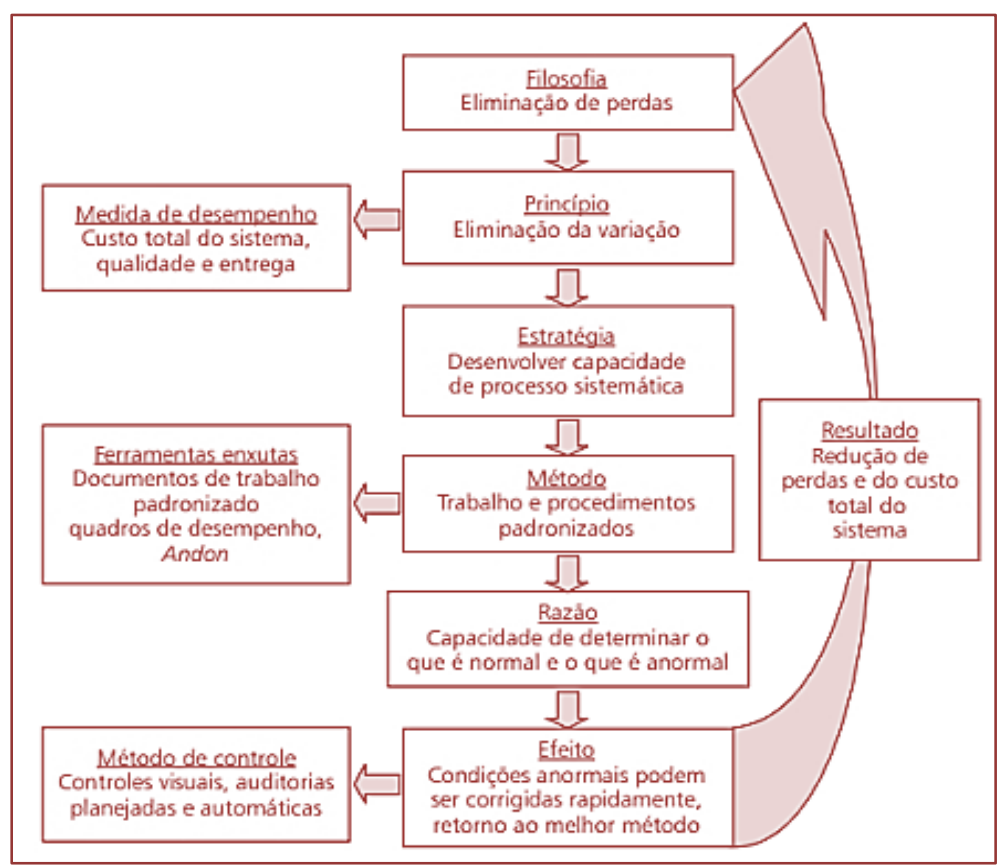

Fonte: Liker, 2007.

\subsection{SISTEMA TOYOTA DE PRODUÇÃO (TPS)}

O Sistema Toyota de Produção foi idealizado e desenvolvido no Japão em um cenário pósguerra, onde o objetivo principal do TPS consiste na identificação e na eliminação das perdas, e na redução dos custos. Os estoques são eliminados a partir do tratamento e da superação das condições ocultas que causam essas perdas (SHINGO, 2007).

O TPS enfatiza a resolução de desperdícios e problemas focando no chão de fábrica. Segundo essa filosofia, resolver os desperdícios pequenos é menos dispendioso, exige menor esforço e previne o surgimento de grandes desperdícios. A resolução de problemas deve ser feita diariamente e por todos os níveis hierárquicos, de forma que os níveis superiores devem apoiar os níveis inferiores fornecendo capacitação e recursos.

\subsection{SISTEMA VALE DE PRODUÇÃO (VPS)}

A VALE S.A. com base no TPS idealizou o Sistema Vale se Produção, onde o objetivo é relacionar o desempenho diário em cada grupo de trabalho às métricas desdobradas pela alta gestão até o nível de chão de fábrica.

O VPS é um modelo de gerenciamento da Vale com foco em melhoria contínua e sustentabilidade, fundamentado no pensamento enxuto, o modelo busca garantir sempre o aperfeiçoamento dos processos rumo à excelência. $O$ projeto de padronização do subprocesso de fornecimento de combustível descrito nesse artigo, tem como essência o Sistema Vale de Produção, que direciona as sistemáticas e etapas dos processos aos quais a Supervisão de Combustível é o agente funcional responsável. 


\section{MÉTODOS}

Segundo GIL (2002), pode-se definir pesquisa como o procedimento racional e sistemático que tem como objetivo proporcionar respostas aos problemas que são propostos. Desta forma, o trabalho foi realizado por meio de pesquisa intervencionista, documental e de campo, a fim obter as informações necessárias para o desenvolvimento da pesquisa, por meio de uma abordagem quantitativa. Sendo assim, é próprio de uma pesquisa intervencionista, um estudo que não se satisfaz apenas na explicação do que se está sendo estudado, mas que pretende interferir de alguma forma na realidade, no dia-a-dia do seu objeto de pesquisa (VERGARA, 2000).

Uma vez que, a pesquisa de campo foi realizada na Gestão de Combustíveis EFC da Vale S.A., observa-se que este método se apoia nos dados obtidos por meio de pesquisa documental e de dados adquiridos na execução das atividades, coletados por meio de materiais cedidos pela organização em estudo com autorização da empresa.

Para aplicação efetiva do projeto $e$ as metodologias que foram abordadas durante os marcos do projeto, foi realizado primeiramente um diagnóstico inicial, onde ocorreram visitas constantes à área em questão. Em paralelo, foram realizadas reuniões com a equipe.
Foi realizado um acompanhamento intenso da operação em todos os três turnos de trabalho para aquisição dos tempos de execução de atividades, mapeamento de problemas e possíveis melhorias. Após adquirir todos os dados quantitativos necessários, foram aplicadas ferramentas e programas de qualidade, alinhados ao pensamento enxuto do projeto de padronização para solucionar problemas e manter as melhorias.

\subsection{CICLO DE ABASTECIMENTO DE LOCOMOTIVAS}

A Gestão de Combustíveis da EFC possui quatro postos de abastecimento de locomotivas, sendo um em São Luís e um em Açailândia, no Maranhão, e dois em Marabá, Pará. O posto de São Luís abastece todas as locomotivas que passam pelo TFPM, antes da formação do trem. Após a formação do trem, a composição segue para a mina onde os vagões são carregados de minério e, na volta ao TFPM, o trem formado e carregado se posiciona nos dois postos de Marabá para abastecer o volume necessário para retornar ao TFPM sem pane-seca. $O$ posto de Açailândia abastece locomotivas auxiliares (denominadas helper) que circulam somente nesta região de aclive e se acoplam temporariamente ao trem de minério para auxiliar na subida de rampa deste trecho.

Figura 2 - Postos de abastecimento ao longo da EFC

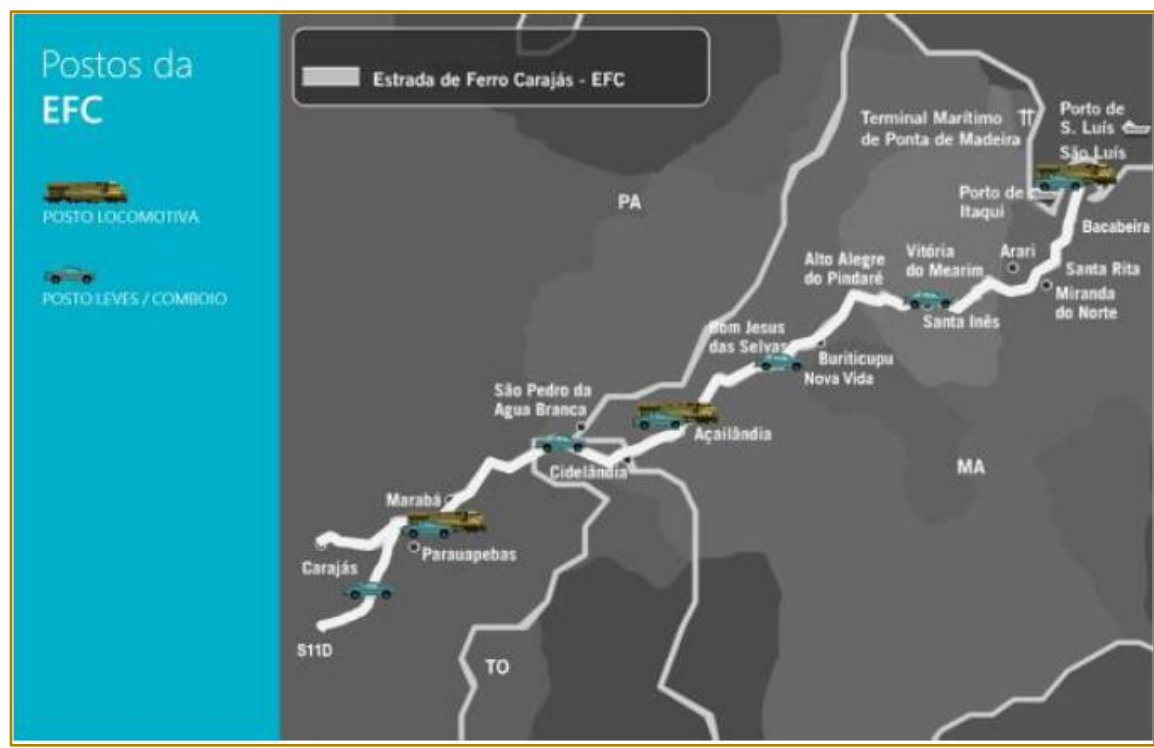

Fonte: Projeto de simplificação do subprocesso de fornecimento de Combustível em São Luís - MA

Quando o trem de minério retorna ao TFPM desmembradas dos lotes de vagões e em São Luís, as locomotivas são seguem para 0 abastecimento de 
combustível. Os vagões continuam em um ciclo paralelo, onde vão para a descarga nos viradores de vagões e, em seguida, para manutenção na oficina de vagões. Após as manutenções necessárias realizadas, o trem de minério é novamente formado para outro ciclo de viagem.

\subsection{DIAGNÓSTICO INICIAL}

O projeto de simplificação de processos na Gestão de Combustível, pertencente à gerência de $\mathrm{CCO}$ e Combustível, iniciou-se em 2012, com a clara definição de que na supervisão a principal entrega seria o abastecimento de locomotivas na quantidade certa, no tempo certo, com correta contabilização financeira do produto, e sem danos ambientais e pessoais. Nesse artigo são apresentadas as etapas referentes ao subprocesso fornecimento de combustível, considerado pelo levantamento como o subprocesso mais relevante.

A Gestão de Combustível tem responsabilidade fundamental no cumprimento da estratégia da VALE S.A. pois é quem movimenta e gerencia o óleo diesel, que é a maior fonte de energia da Ferrovia e representa $46 \%$ do custo operacional. O consumo do óleo diesel cresce proporcionalmente ao peso $\mathrm{x}$ distância transportado (tonelada $x$ quilômetro). Cerca de $98 \%$ do consumo de óleo diesel da Ferrovia é referente a locomotivas que transportam minério de ferro, estreitando a relação entre o negócio da Gestão de Combustível e o principal produto da VALE S.A.

O posto de locomotivas de São Luís foi selecionado como estudo de caso e ponto de partida do projeto por se tratar de um processo responsável pelo volume de abastecimento mais significativo da EFC, sendo de 80\% (Marabá - PA com 12\% e Açailândia - MA com 8\%). Além disso, o posto está incluso no ciclo de locomotivas do Terminal Ferroviário Ponta da Madeira (TFPM), considerado trecho crítico para o desmembramento, nova formação e partida de trens de transporte de minério.

O processo do posto de combustível da ferrovia foi dividido em três subprocessos. O subprocesso "receber" compreende a manobra de posicionamento do vagão-tanque com combustível, retirada de amostra de qualidade do diesel até o resultado da análise de amostra do laboratório; o subprocesso "armazenar" compreende a descarga do vagão-tanque nos tanques de armazenamento. O subprocesso "fornecer" trata da adução do diesel dos tanques de armazenamento até os tanques das locomotivas no PIAL, conforme esquematizado nas figuras 3 e 4 .

Figura 3 - Macro Processo da Gestão de Combustível

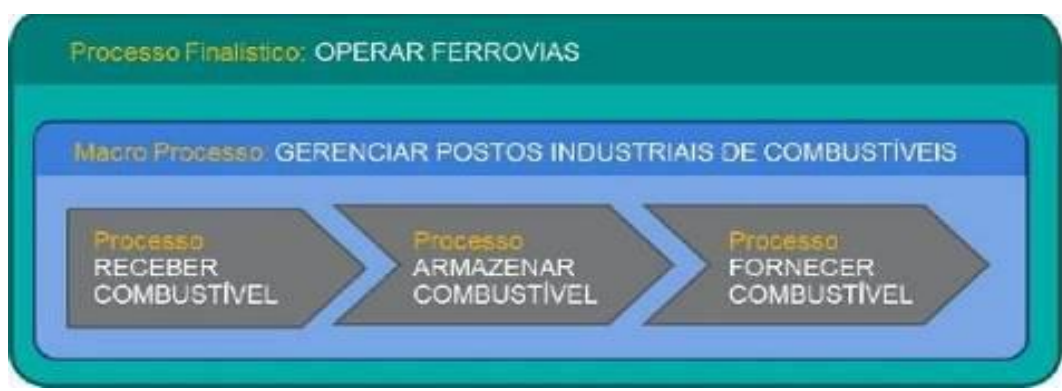

Fonte: Projeto de simplificação do subprocesso de fornecimento de Combustível em São Luís - MA 
Figura 4 - Esquemático dos Subprocessos da Gestão de Combustível

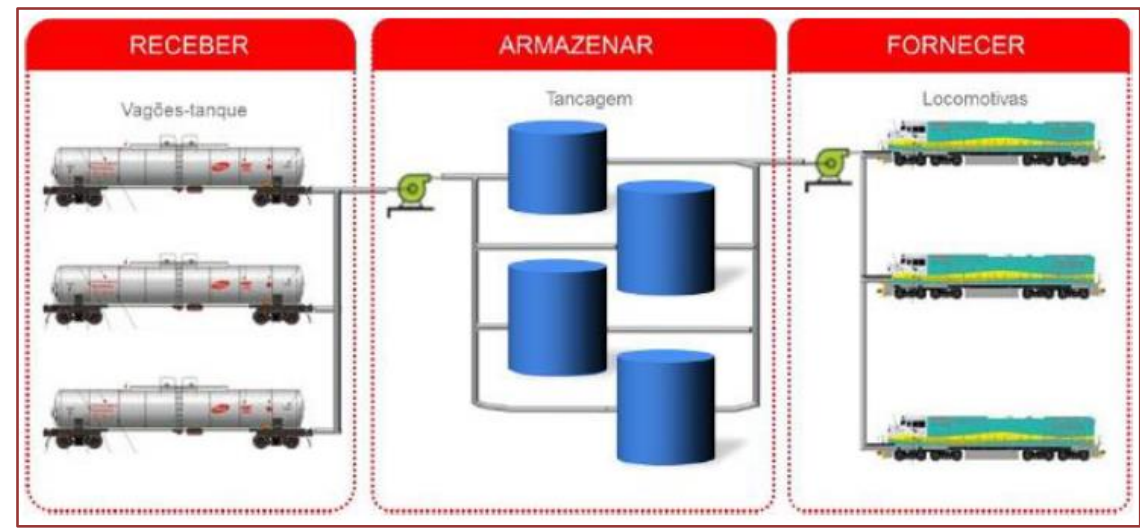

Fonte: Projeto de simplificação do subprocesso de fornecimento de Combustível em São Luís - MA

Dentro do subprocesso priorizado partiu-se pelo levantamento de todos os padrões operacionais escritos e regulamentos como padrão inicial de referência. A área possuía 31 documentos, atualizados e utilizados. Sob essa óptica, foram diagnosticadas as atividades em campo, permitindo a verificação das divergências nos fluxos de execução da atividade "fornecer combustível", entre diferentes turnos de trabalho e operadores acompanhados.

\subsection{SIMPLIFICAÇÃO E PADRONIZAÇÃO DOS FLUXOS DE ATIVIDADES E INFORMAÇÕES}

Foram realizados encontros diários durante três semanas do mês de julho 2014 com todos os 3 turnos de operação. Os operadores eram escolhidos de maneira aleatória e conforme disponibilidade. Vale ressaltar que não existia um fluxograma padrão para a atividade, sendo ele após finalização, um importante insumo para o desenho do PRO. As primeiras etapas do projeto podem ser demonstradas na figura 5 .

No posto de abastecimento, foram obtidos de forma amostral os tempos de cada passo da operação, deslocamento e espera. Isso possibilitou mensurar os desperdícios e atividades que agregam ou não valor.

Para a realização de um Fluxograma do processo fornecer, contou-se com a participação dos operadores, os controladores do posto, o sistema Unilog e o Centro de Controle de Pátio.

Figura 5 - Resumo primeiras etapas projeto padronização

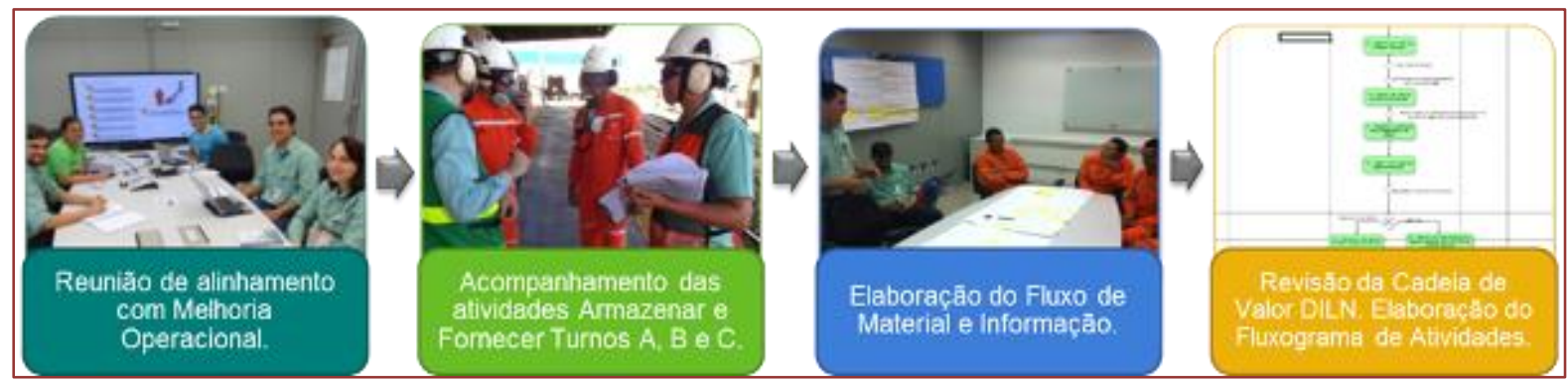

Fonte: Projeto de simplificação do subprocesso de fornecimento de Combustível em São Luís - MA

O mapa de Fluxo de Materiais e Informações foi um dos trabalhos realizados durante o projeto que garantiu a visualização global do processo, correlacionando as atividades de atuação dos frentistas ao abastecer as locomotivas, realizado as atividades constatadas no procedimento operacional com o controle e monitoramento executado 
pelos controladores do posto, garantido as liberações e mudanças de status das locomotivas. A ferramenta foi crucial na definição do passo a passo do processo, o que mais tarde foi de extrema importância para construção do PRO padronizado. Com a atividade padronizada foi possível identificar os principais desperdícios e tratá-los utilizando o método kaizen.

Figura 6 - Desenvolvimento de Mapa de Fluxo de Materiais e Informações com equipe operacional

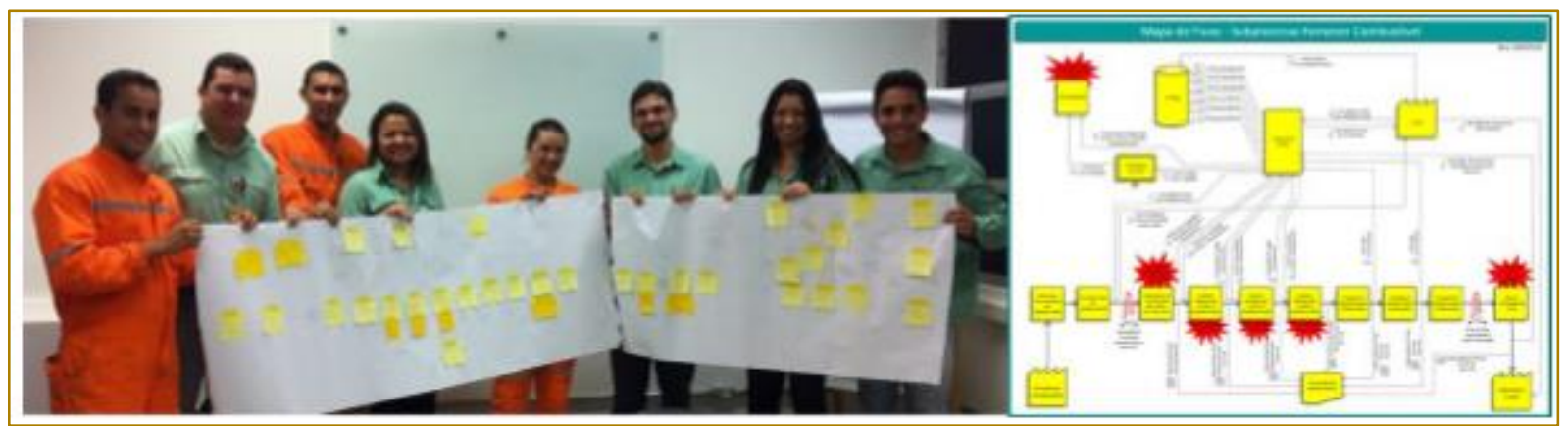

Fonte: Projeto de simplificação do subprocesso de fornecimento de Combustível em São Luís - MA

\subsection{MELHORIAS IMPLANTADAS}

Ao longo do ano de 2014 foram mapeadas em conjunto com a equipe da Gestão de Combustível, algumas oportunidades de melhorias (76 itens), para serem implantadas na área. Destes itens, foram realizados 61 kaizen's, que equivale a $80 \%$ de toda amostra, 9 itens ficaram pendentes, pois precisavam de um investimento maior de tempo e projeto, 6 itens ficaram sem possibilidade de acontecer, pois havia conflito de projeto, como pode ser analisado na figura 7.

Figura 7 - Oportunidades de melhoria

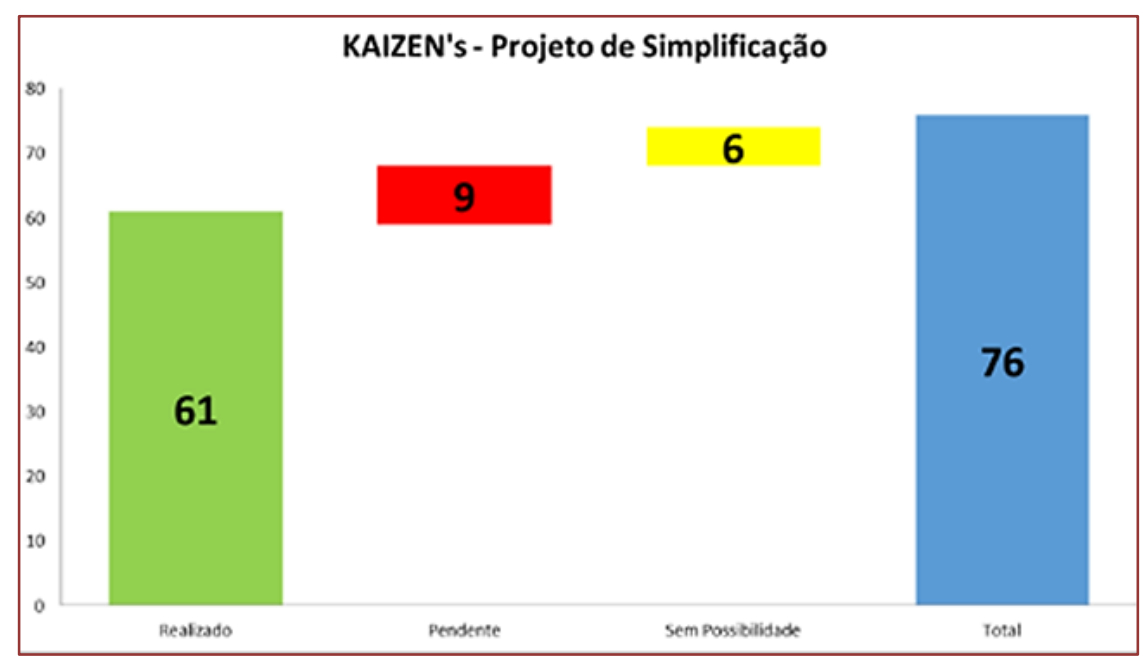

Fonte: Projeto de simplificação do subprocesso de fornecimento de Combustível em São Luís - MA

\section{Padrão Visual do PRO - Abastecimento}

Elaboração do Padrão Visual, simplificação do PRO original, feita de maneira mais enxuta e de fácil compreensão. O PRO simplificado fica localizado no posto de locomotivas com o intuito de tornar comum a visualização do procedimento para firmar o passo a passo das atividades. 
Figura 8 - Padrão Visual do PRO 9369 Abastecimento

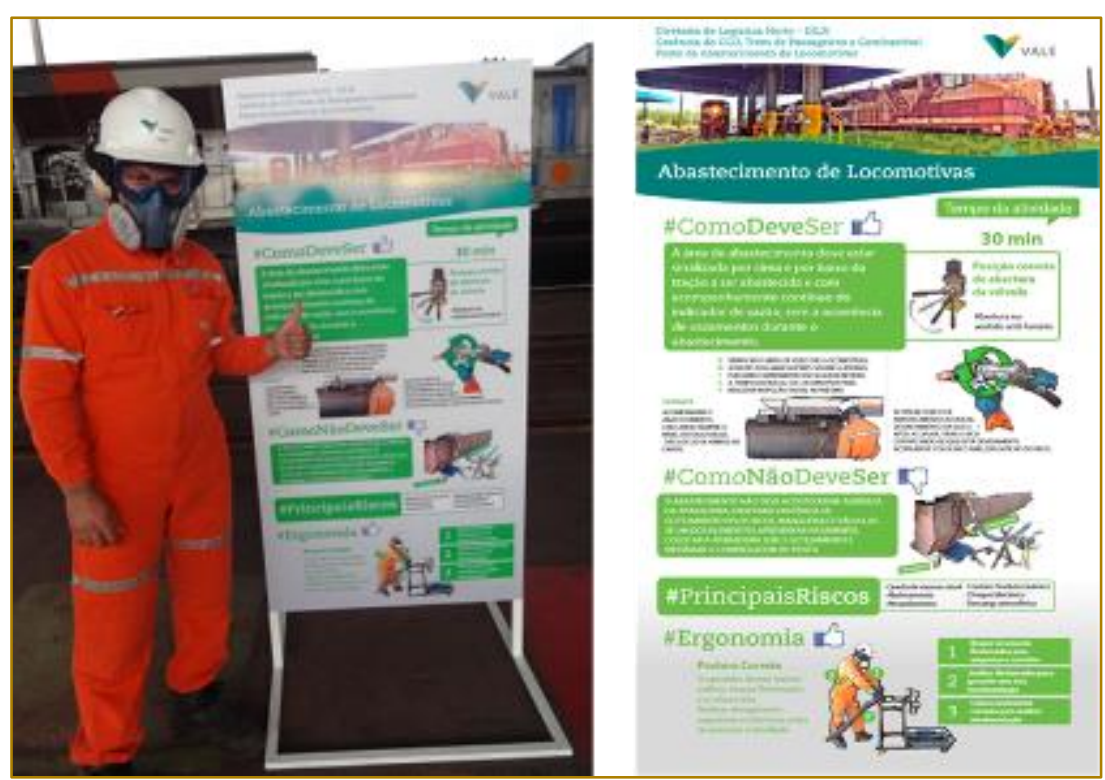

Fonte: Projeto de simplificação do subprocesso de fornecimento de Combustível em São Luís - MA

\section{PRO interativo}

Elaborou-se um procedimento interativo 3D, onde o operador é desafiado a demonstrar o conhecimento do procedimento através de jogo em quiz, resultando em uma pontuação ao final. O objetivo principal é despertar o interesse dos operadores de forma lúdica. Antes, havia desinteresse dos frentistas em reler o procedimento para se reciclarem e tirarem dúvidas referentes à atividade.

Figura 9 - PRO interativo sendo operado pelo frentista

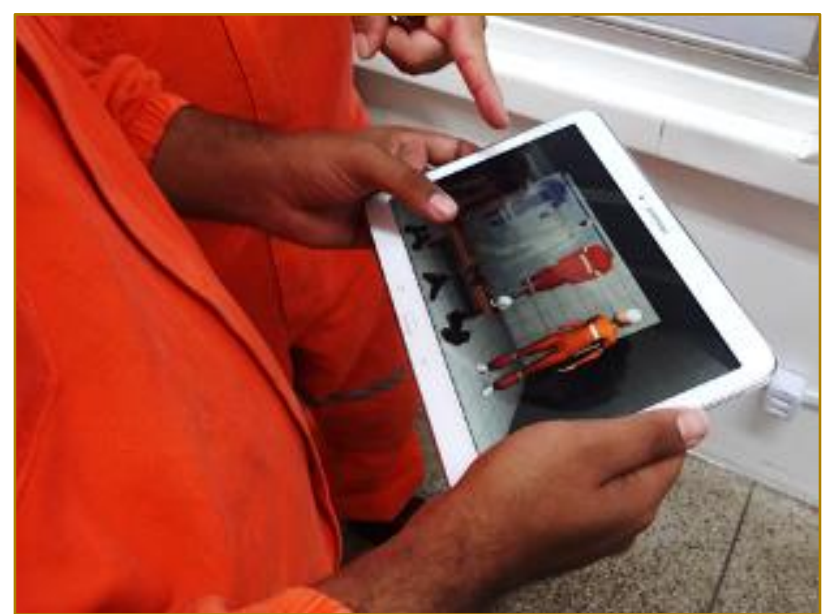

Fonte: Projeto de simplificação do subprocesso de fornecimento de Combustível em São Luís - MA 


\section{Realidade Aumentada}

Com um novo conceito de ambientação, criou-se a ambientação da área em perspectiva de realidade aumentada com o objetivo principal facilitar e deixar mais claro a visão dos operadores e visitantes sobre a área visitada, além de enfatizar os riscos existentes.

Figura 10 - Realidade aumentada do Posto de Locomotivas

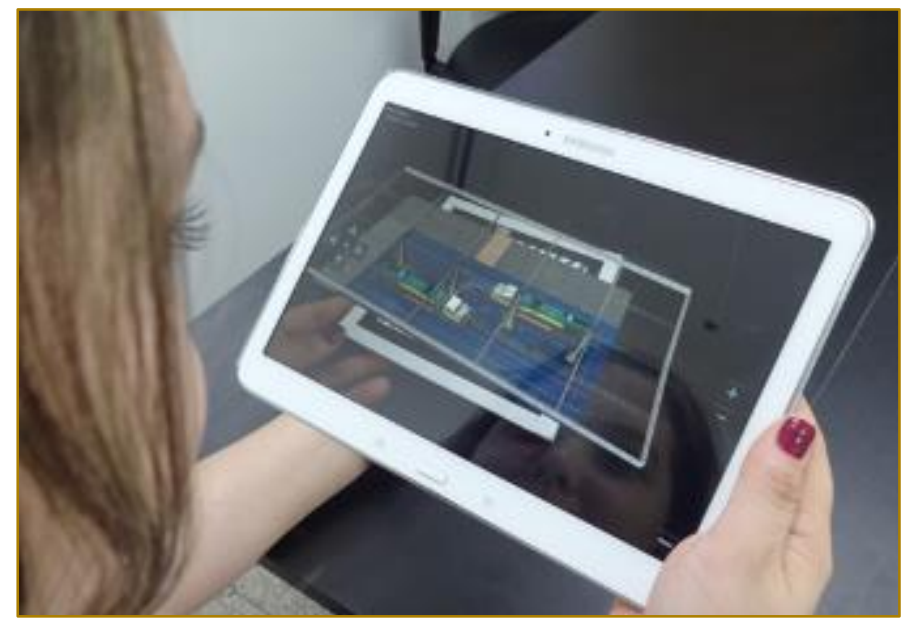

Fonte: Projeto de simplificação do subprocesso de fornecimento de Combustível em São Luís - MA

\section{Pintura do Posto de Locomotivas}

Outra iniciativa importante realizada pela própria equipe do combustível foi a pintura do piso do posto de abastecimento, utilizando a ferramenta 5S. Foram melhoradas as pinturas do posto onde sinaliza as demarcações de segurança e estabelecidas situações de condições Normal X Anormal. Dessa forma ficou mais fácil o operador identificar o caminho seguro da área.

Figura 11 - Pintura do Posto de Locomotivas

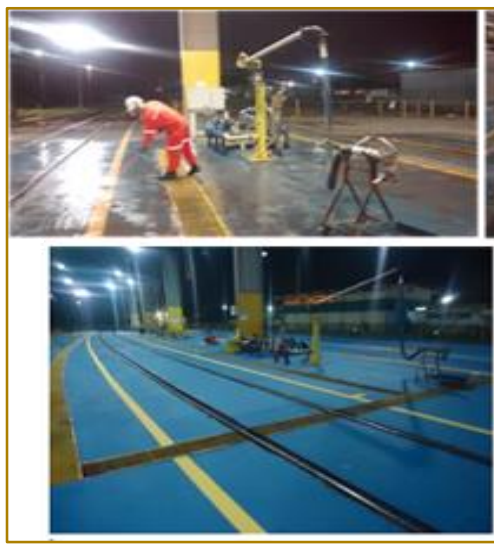

Fonte: Projeto de simplificação do subprocesso de fornecimento de Combustível em São Luís - MA

Conforme citado anteriormente, foi realizado um levantamento das oportunidades de melhorias no diagnóstico inicial, além dos Kaizens mostrados, foram propostas melhorias para a maioria dos problemas. A figura 12 apresenta alguns exemplos das melhorias implantadas, com seus respectivos status: 
Figura 12 - Amostra Kaizen's e Boas Práticas realizadas durante o projeto

\begin{tabular}{|c|lc|}
\hline № & \multicolumn{1}{|c}{ Kaizen } & Status \\
\hline 1 & Não temos rota de atividade definida - fluxo (Fluxo já está no PRO) & Ok \\
\hline 2 & $\begin{array}{l}\text { Coloca no posto armário para os frentistas - posto (Está sendo } \\
\text { providenciado por Barbosa) }\end{array}$ & Ok \\
\hline 3 & Não tem fluxo definido de abastecimento (Fluxo já está no PRO) \\
\hline 4 & Verifiar teste do diesel na própria Gestão de Combustível (JONATAS) & Ok \\
\hline 5 & $\begin{array}{l}\text { Cronograma de lubrificação de válvulas - tancagem (Já está contemplado } \\
\text { no plano mensal de manutenção) }\end{array}$ & Ok \\
\hline 6 & $\begin{array}{l}\text { Ver eficiência do plano de manutenção para lubrificação de válvulas (Já } \\
\text { está contemplando no plnao mensal de MANUTENÇÂO) }\end{array}$ & Ok \\
\hline 7 & Revisar o check list de descarga - armazenar (Projeto de Padronização) \\
\hline 8 & Fazer um sinalização nos vagões - Cheio e vazio (Kaizen) \\
\hline 9 & Cadeira para os frentistas no posto (Providenciado) & Ok \\
\hline 10 & $\begin{array}{l}\text { KAIZEN - "andom" para oficina, o frentista sinaliza os problemas } \\
\text { encontrados na própria locomotiva (inspeção) (KAIZEN) }\end{array}$ & Ok \\
\hline
\end{tabular}

Fonte: Projeto de simplificação do subprocesso de fornecimento de Combustível em São Luís - MA

Seguem exemplos na figura 13, da maneira em que são documentados alguns Kaizens para disseminação com a equipe (até nível gerencial) e padronização:

Figura 13 - Exemplos de Kaizen's realizados na área

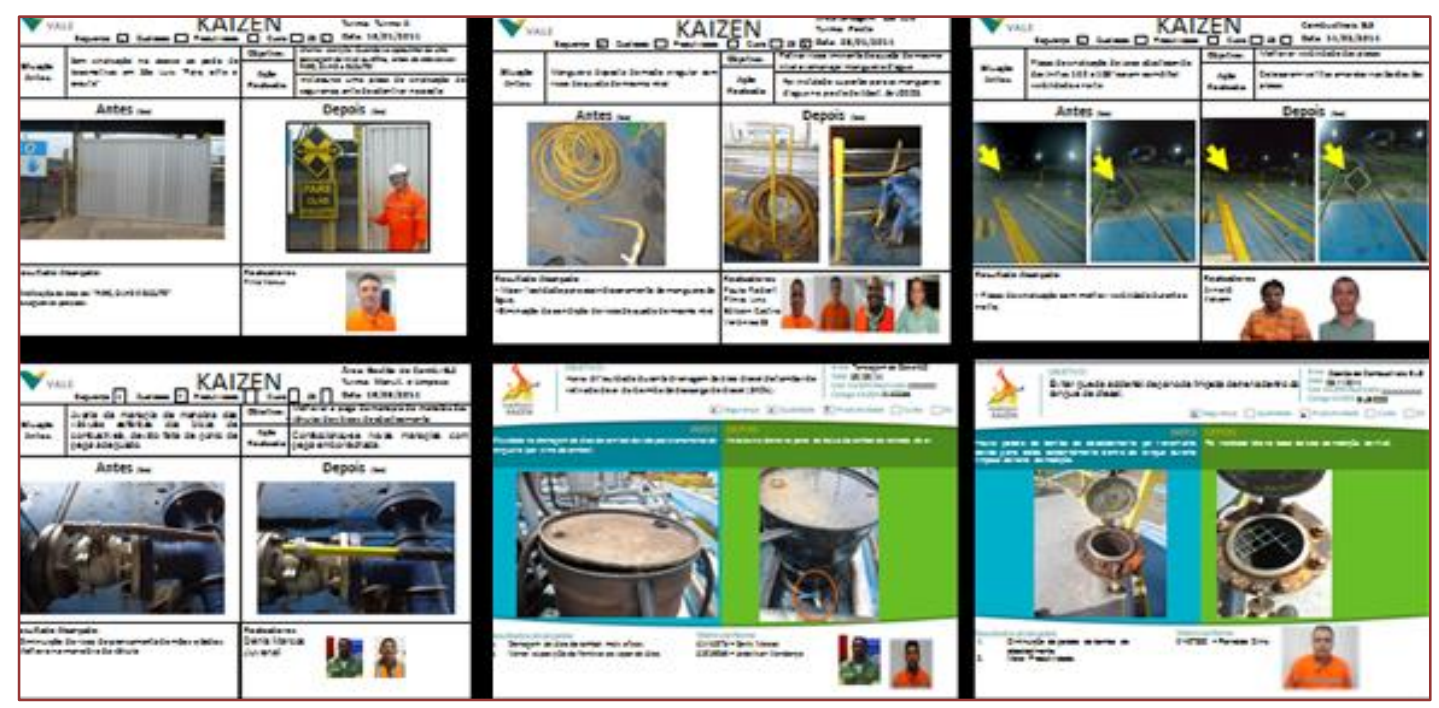

Fonte: Projeto de simplificação do subprocesso de fornecimento de Combustível em São Luís - MA

\section{Instrução de Trabalho (PRO Simplificado)}

Um dos grandes ganhos do projeto foi a simplificação do procedimento de abastecimento de locomotivas através da elaboração da Instrução de Trabalho que tornou a linguagem mais clara e simples através do uso de ilustração a cada passo da atividade.
Com a nova estrutura, mais enxuta e clara para o operador, a reciclagem e consulta se tornou muito mais proveitosa. O procedimento anterior possuía em torno de 30 páginas e linguagem técnica rebuscada, e foi reduzido para duas folhas $A 4$, mantendo a instrução padrão da atividade e um alto nível de qualidade, com linguagem mais clara ao operador. 
Figura 14 - Instrução de Trabalho de Abastecimento de Locomotiva

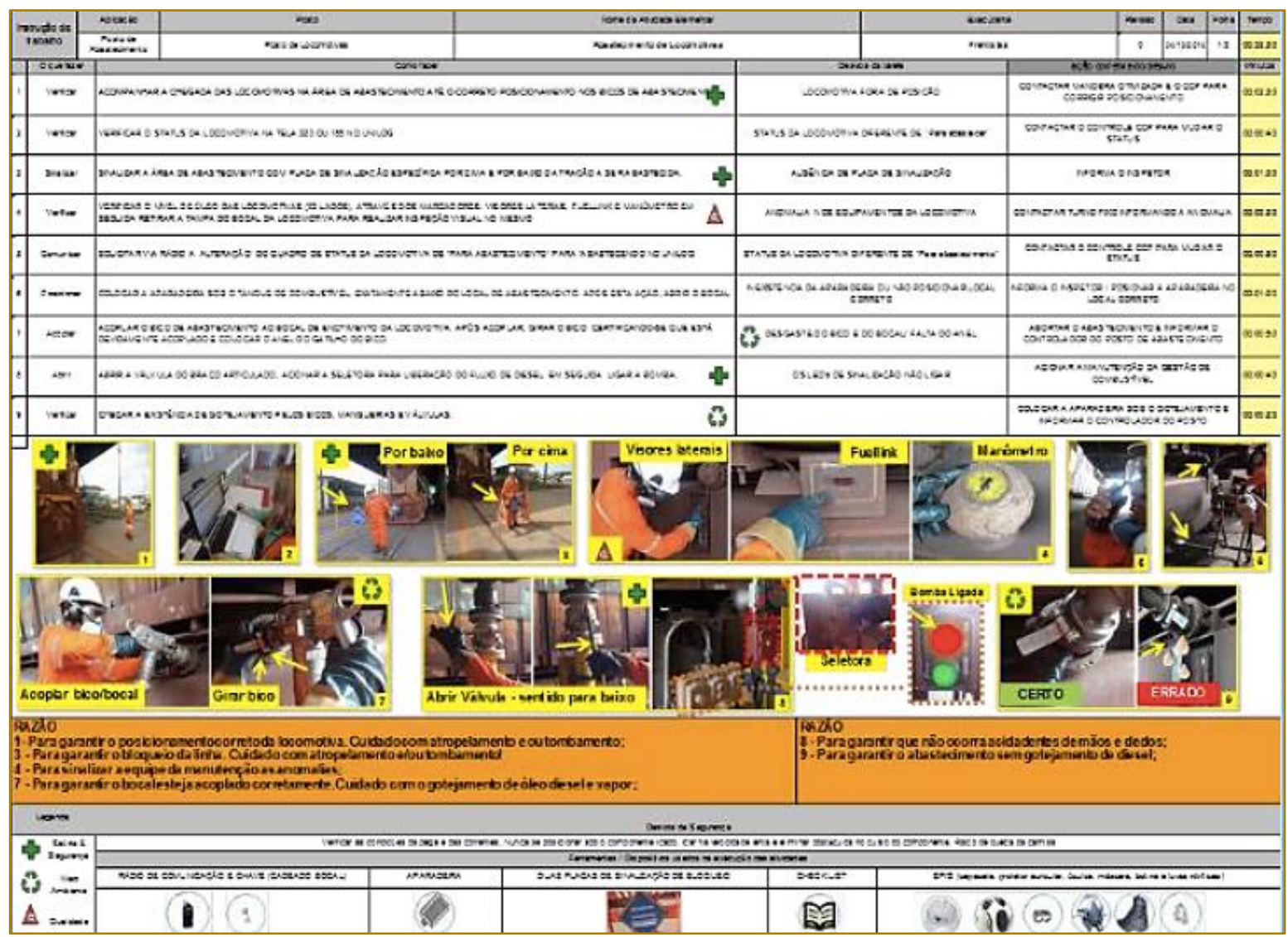

Fonte: Projeto de simplificação do subprocesso de fornecimento de Combustível em São Luís - MA

\section{Aplicação do FMDS como sistema de gestão visual}

O FMDS (Floor Management Development System) é um programa de gerenciamento de chão de fábrica criado em 2006 pela Toyota e implementado no Brasil pela primeira vez em 2008. Tem como princípio expor problemas para todos os níveis hierárquicos pensarem em soluções, estimulando o trabalho em equipe e cooperação por um ambiente de comunicação direta entre líder e liderado. O principal foco do FMDS é a resolução diárias de problemas do chão de fábrica permitindo a produção enxuta e ininterrupta.

Os Indicadores Chave de Processo (KPI's) foram disponibilizados em painéis digitais acessíveis na sala de operadores e de forma compreensíveis para os operadores do chão de fábrica. Isso tornou possível todos identificarem anormalidades no processo (pontos de causa de desvios) e trabalharem em sua solução.

A aplicação do painel de KPl's gera engajamento, uma vez que, com o resultado da sua aplicação surgem os kaizens (melhorias) realizados por todos, direcionados para a solução de problemas apontados e retorno do KPI aos padrões de normalidade.

O uso de controles visuais é o passo mais importante no processo de desenvolvimento da padronização. A razão primária para o controle visual é a definição do estado "normal" desejado (padrão) e, a seguir, o reconhecimento rápido de qualquer desvio do padrão (LIKER, 2007). 
Figura 15 - Painel de indicadores FMDS

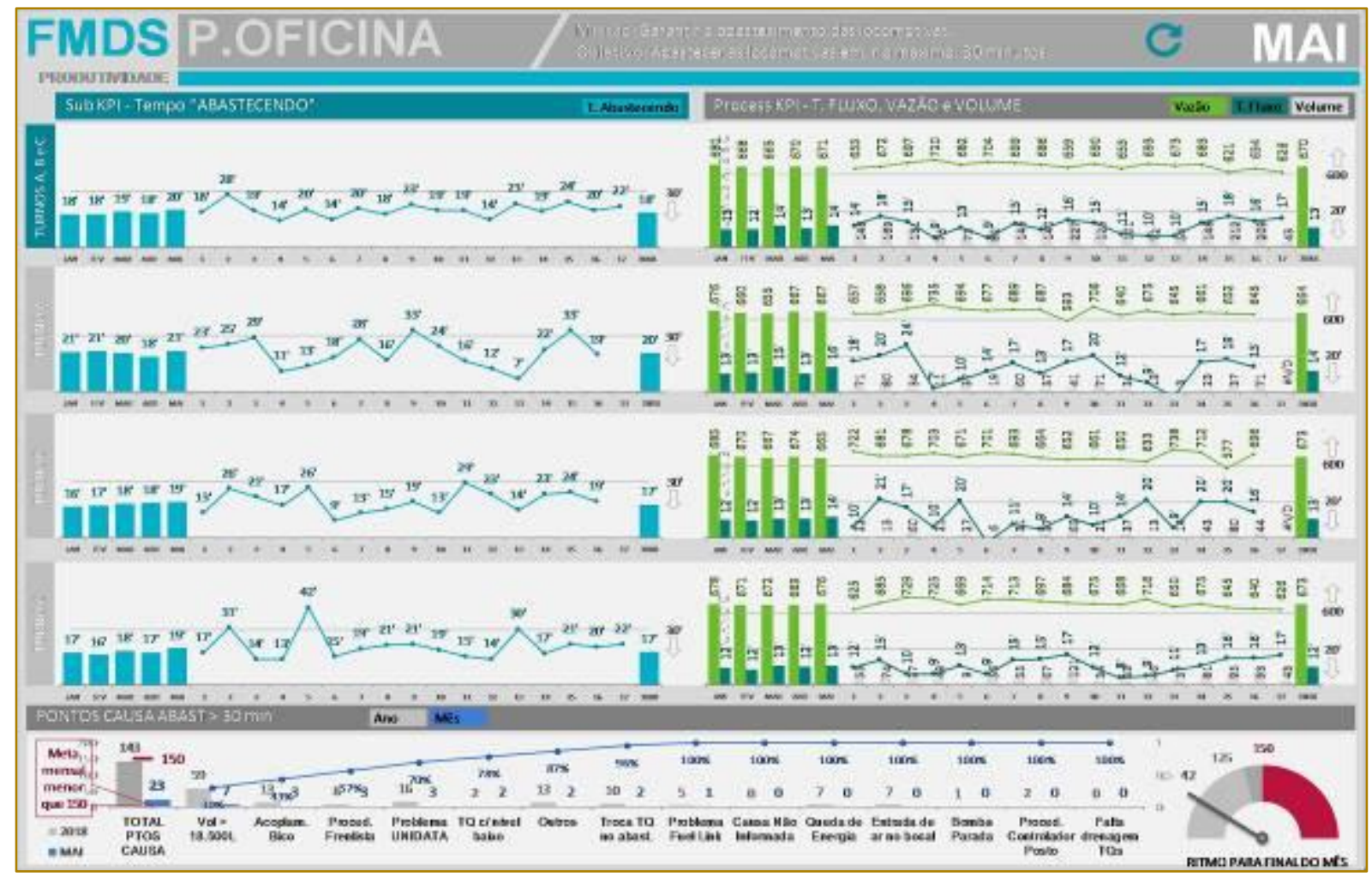

Fonte: Gestão de Combustível São Luís - MA

\section{RESULTADOS OBTIDOS}

A aplicação do gerenciamento visual possibilitou uma percepção de falhas diárias e controle muito mais eficaz, possibilitando ao operador perceber problemas além de prevêlos antes mesmo de acontecer. Verificou-se também uma maior integração por parte dos funcionários com os processos, um entendimento mais profundo e objetivo da relação direta entre os desvios diários e os impactos nos indicadores de resultado da área. O sentimento de "dono" foi um grande ganho, a cultura de manter o que foi implantado. O projeto "padronização do subprocesso fornecimento de combustível", objeto deste estudo, reduziu desperdícios em toda a cadeia do subprocesso, como o desperdício de movimento, espera e defeito.

O volume de consumo e número de abastecimentos representam o crescimento da demanda do cliente interno, fruto do crescimento da produção da empresa, com estabilidade até o ano de 2014 e crescimento acentuado a partir de 2015 devido à duplicação de trechos da ferrovia. A queda de demanda neste posto deve-se à transferência de demanda de abastecimento para um novo posto de abastecimento em São Luís a partir de abril de 2016. 
Figura 16 - Volume de consumo $\left(\mathrm{m}^{3}\right)$

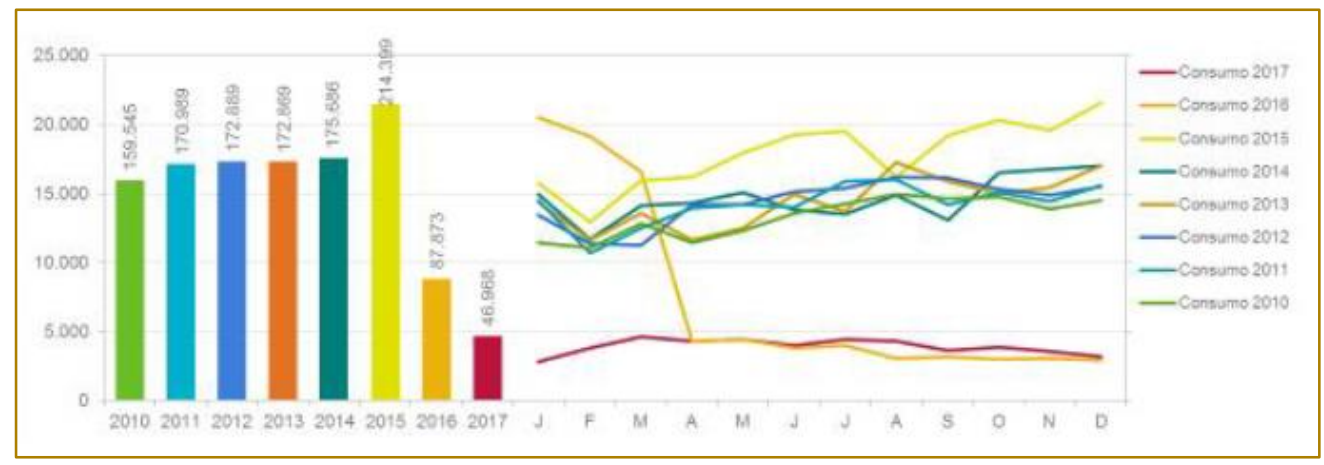

Fonte: Gestão de Combustível São Luís - MA

Figura 17 - Quantidade de Abastecimentos (unidade)

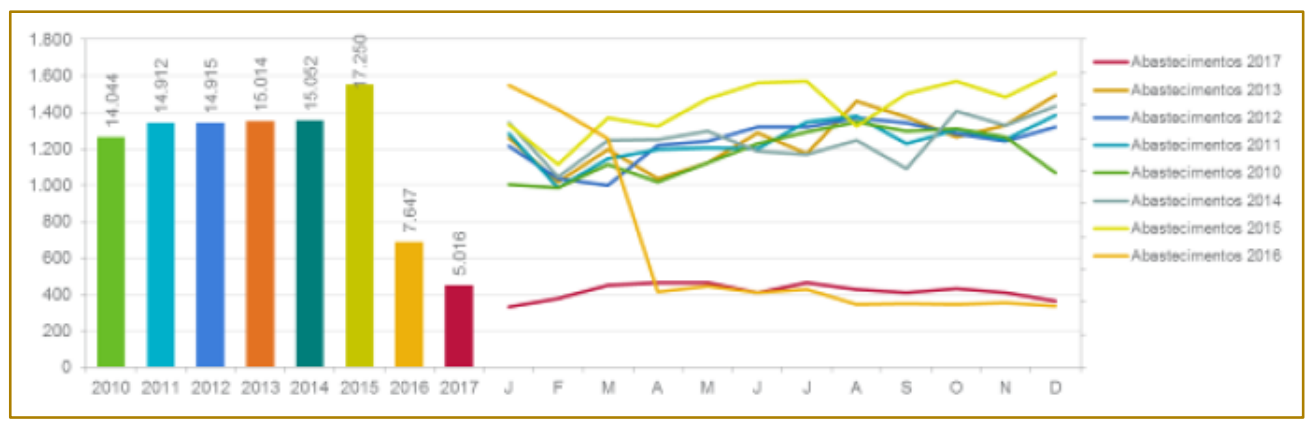

Fonte: Gestão de Combustível São Luís - MA

Mesmo com o crescimento da demanda de produção, houve evolução no indicador de vazão (litros/minuto) que representa a eficiência ou rapidez de abastecimento proporcionalmente ao volume. Mesmo sem aquisição de novos ativos a área demonstrou uma melhoria sustentável neste indicador em 30\% de 2012 a 2017.

Figura 18 - Vazão de abastecimento (litros/min)

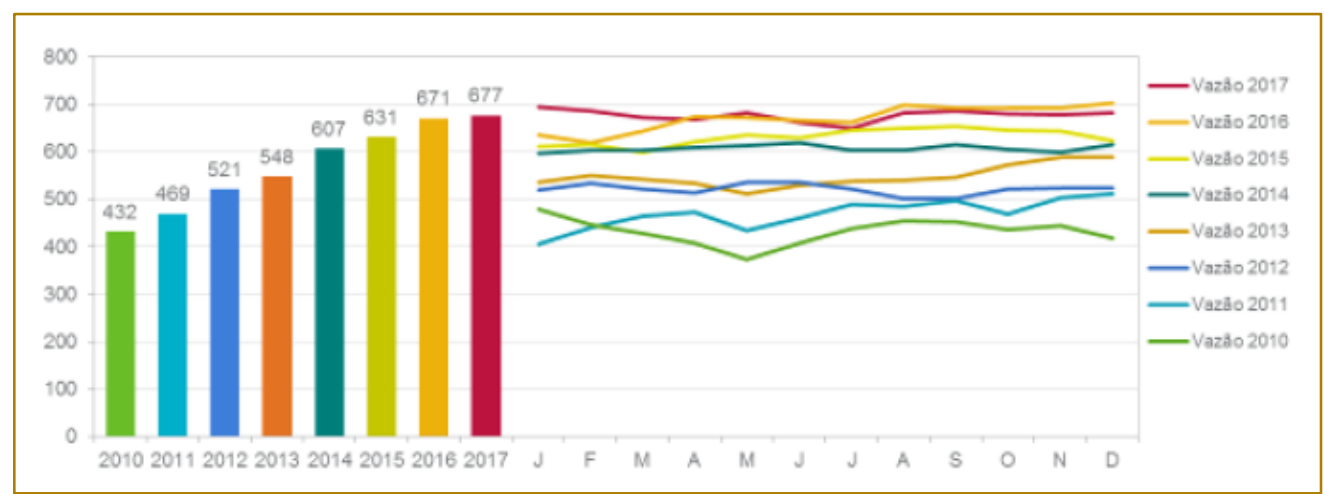

Fonte: Gestão de Combustível São Luís - MA

Analogamente ao KPI de vazão, o tempo de abastecimento de locomotivas caiu de forma sustentável em 16\% de 2012 a 2017 em uma tendência estável de evolução. 
Figura 19 - Tempo de Abastecimento (min)

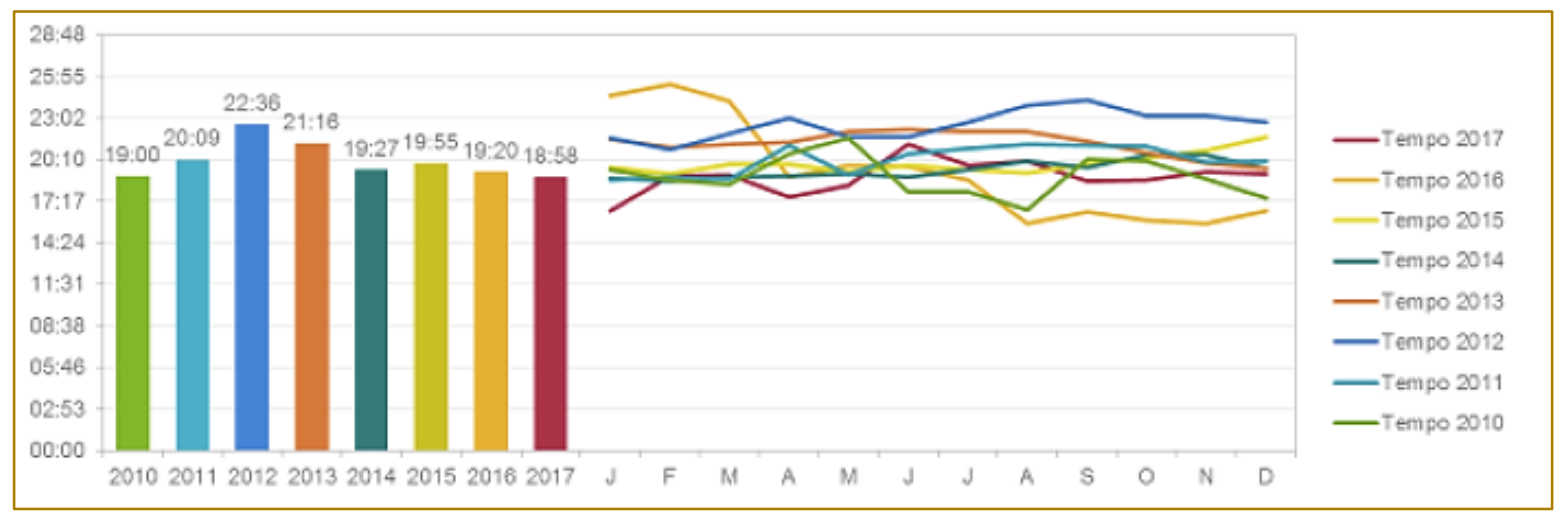

Fonte: Gestão de Combustível São Luís - MA

Como resultados intangíveis: motivação da equipe; fortalecimento da gestão participativa; profissionalização na análise e solução de problemas. Durante a implantação do projeto foi proporcionado uma aproximação entre a equipe, possibilitaram um maior conhecimento dos problemas operacionais do ambiente de trabalho e uma maior integração entre operadores e líderes; o FMDS foi um grande precursor neste item, transmitindo as diretrizes desenvolvidas em metas da diretoria, de maneira fácil e objetiva, de uma forma que operador passou a se enxergar como parte do processo, estando ele, treinado e ambientado com os indicadores da área.

\section{CONCLUSÃO}

A melhoria contínua de processos associada a novas tecnologias é condição necessária para a perpetuação e desenvolvimento da companhia no mercado. Entretanto, só é possível iniciar um ciclo de melhoria sustentável após o processo de padronização de indicadores e procedimentos produtivos.

A contextualização da área de processo dentro de negócio através do Diagrama de

\section{REFERÊNCIAS}

[1]. Intranet VALE. Disponível em: $<w w w . i n t r a n e t . v a l e . c o m>$. Acesso em: 03 mai 2018.

[2]. GIL, Antonio Carlos. Como elaborar projetos de pesquisa. 4. ed. - São Paulo: Atlas, 2002.

[3]. Guia de implementação da padronização VALE. Versão 2011.
Alocação de Funções (FAD) permitiu definir as metas dos KPl's da área para atender a demanda do cliente externo.

O desenho em conjunto com os operadores do FMl inicial com definição de entraves e oportunidades de melhoria permitiu enxergar ações de melhoria e consensuar a forma mais eficiente de operar - FMl ideal. Foram realizados 61 kaizens das 76 oportunidades levantadas, aplicados ao chão de fábrica. 0 desenvolvimento de painel de indicadores acessivel aos operadores proporcionou direcionamento de ações e engajamento dos operadores, refletindo-se nos KPI's.

Mesmo com o aumento de consumo do posto, que é a demanda do cliente interno, a vazão aumentou em 30\% de 2012 a 2017 com tendência contínua de evolução, revelando a sustentabilidade da padronização. O tempo de abastecimento teve uma redução de 16\% em um ano.

O sistema de padronização, FMDS e melhoria permanece em constante evolução e, atualmente, já funciona em todos os subprocessos de todos os postos da EFC.

[4]. LIKER, Jeffrey K. O Modelo Toyota [recurso eletrónico] : manual de aplicacão / Jeffrey K. Liker, David Meier ; traduc,ão Lene Belon Ribeiro. - Dados eletrónicos - Porto Alegre : Bookman, 2007.

[5]. PAIM, R. Gestão de processos [recurso eletrónico] : pensar, agir e aprender / Rafael Paim 
... [et al.]. - Dados eletrónicos. - Porto Alegre : Bookman, 2009.

[6]. SHINGO, Shigeo O sistema Toyota de produc,ão [recurso eletrónico] : o ponto de vista da Engenharia de Producão / Shigeo Shingo ; traduc,ão Eduardo Schaan. - Dados eletrónicos. Porto Alegre : Bookman, 2007.

[7]. SOARES, F. S. A., implantação do projeto padronização no processo de abastecimento de locomotivas, um estudo de caso na gestão de combustíveis, VALE S.A. 2015. 89 f. Monografia (Graduação em Engenharia da Produção). Universidade Estadual do Maranhão, São Luís, 2015.

[8]. VALE. Manual do Projeto de simplificação subprocesso fornecer. Supervisão gestão de Combustível São Luís. Versão 2014.1

[9]. VERGARA, S. C. Projetos e relatórios de pesquisa em administração. 3. ed. São Paulo; Atlas, 2000. 
CCO - Centro de Controle Operacional

EFC - Estrada de Ferro Carajás

FMDS - Floor Management Development System

Helper - Locomotivas de apoio em trecho de grande aclive

Just In Time - Disponibilização de recursos no tempo certo

Kaizen - Melhoria contínua

Kick off - Reunião com a equipe para início do projeto

$\mathrm{KPI}$ - Key Process Indicator

PRO - Procedimento operacional

Status - Estado em que algo se encontra

Takt-time - Ritmo de produção

TFPM - Terminal Ferroviário de Ponta da Madeira

TPPM - Terminal Portuário de Ponta da Madeira

TPS - Toyota Production System

Unilog - Sistema de controle da Ferrovia

VPS - Vale Production System 


\section{Capítulo 8}

\section{APLICAÇÃO DE FERRAMENTAS DE QUALIDADE PARA A MINIMIZAÇÃO DO DESPERDICIO EM UMA EMPRESA DE BENEFICIAMENTO DE PEDRAS}

\section{Rener Antônio Melo Nascimento}

\section{José Lucas Viana Morais}

\section{Larissa Havenna Matos Santos}

Natan Melo Nascimento

\section{Eduardo de Oliveira Souza Neto}

Resumo: O beneficiamento de pedras ornamentais é uma atividade bastante difundida e atrativa no Brasil, sendo responsável por um faturamento anual de U\$2,1 bilhões por ano. No momento da compra, o cliente leva em consideração alguns fatores para decidir qual empresa e tipo de pedra escolher como, por exemplo: estética, atendimento ao cliente, prazo de entrega e flexibilidade. Para alcançar uma melhoria no processo produtivo, este estudo buscou reduzir os desperdícios gerados pela empresa e, consequentemente, ganhar vantagens competitivas. Para tanto, foram aplicadas as ferramentas da qualidade Ishikawa, árvore e afinidades, a fim de identificar as causas dos desperdícios. Com as causas definidas, foram propostas diversas melhorias, buscando atacar a causa raiz dos problemas. Espera-se que este trabalho ajude a empresa a sanar os desperdícios e ganhar vantagens competitivas no mercado.

Palavras-chave: Pedras ornamentais, Desperdícios, Ferramentas da Qualidade, Vantagens competitivas 


\section{INTRODUÇÃO}

O setor industrial de beneficiamento de rochas ornamentais, como o granito e o mármore, é responsável pela fabricação de produtos, de várias formas e com várias utilidades, compreendendo desde a fabricação de peças comuns para residências e decoração de ambientes públicos à decoração de ambientes requintados. Esses materiais são usados em larga escala na construção civil, com preços que variam de acordo com sua singularidade e raridade.

Conforme publicação da Associação Brasileira da indústria de Rochas Ornamentais (2009), no ano de 2008, o Brasil foi eleito o sexto maior produtor de pedras ornamentais no mundo. O Boletim Marmorarias elaborado pelo Sebrae/ES (2014) afirma que o ofício de beneficiamento final de pedras ornamentais está presente em quase todo o país, com cerca de 12.000 empresas empregando em média 100.000 pessoas, com uma movimentação em torno de $U \$ 2,1$ bilhões por ano. Conforme o mesmo Boletim, o país ocupou, em 2014, a $8^{\circ}$ posição no ranking de países exportadores de blocos e de 5o maior exportador de rochas ornamentais acabadas.

Para que uma rocha seja considerada ornamental é necessário que alguns requisitos sejam admitidos. Para Mattos (2002), ela deve apresentar beleza estética, ou seja, tem de ser homogênea (sem irregularidades) e possuir características tecnológicas dentro de padrões aceitáveis pelas normas técnicas do setor. A questão da estética influencia diretamente na decisão do cliente a respeito do tipo de rocha que irá comprar, por esse motivo há sempre uma preocupação da empresa quanto à inspeção da matéria-prima que recebem.

Além da questão estética, fatores como atendimento ao cliente, prazo de entrega e flexibilidade exercem influência no momento de optar por uma empresa, sendo estes indicadores de qualidade para se competir no mercado. A empresa precisa garantir requisitos mínimos de qualidade em suas operações, além de sempre ter que apresentar preços competitivos.

O presente estudo, realizado em uma empresa na cidade de Teresina-PI, propõe apresentar propostas de melhoria relacionadas com a qualidade, com foco na redução dos desperdícios gerados pelo sistema produtivo e por falhas administrativas da empresa, atacando as causas raízes dos problemas. Como forma de atingir esse objetivo, aplicou-se as seguintes ferramentas da qualidade: diagrama de Ishikawa (ferramenta básica da qualidade) e diagrama em árvore e de afinidades (ferramentas gerenciais).

O uso dessas ferramentas é justificado pelo fato de promoverem uma abordagem geral das causas dos problemas, possibilitando o desmembramento dos mesmos em 6 naturezas diferentes (Método, Meio Ambiente, Máquinas, Mão-de-Obra, Material e Medição), além de possibilitarem uma análise geral de todos os processos da empresa e propostas de soluções baseadas em opiniões de todo o corpo de colaboradores, alinhando todas as informações com o embasamento teórico necessário

\section{REFERENCIAL TEÓRICO}

\subsection{GESTÃO DA QUALIDADE}

Os primórdios de preocupação com a qualidade de produtos e serviços teve início com a Revolução Industrial, onde surgiram os métodos de produção em série. Contudo, o maior crescimento foi com o advento da Segunda Guerra Mundial, onde produzir com a menor quantidade de erros possíveis e com uniformidade, transformou-se na meta de alguns países.

A implantação de um Sistema de Gestão da Qualidade (SGQ) é uma tarefa complexa, exigindo grande esforço de todos que fazem parte da empresa. Segundo Correia, Melo e Medeiros (2006), uma das principais causas das dificuldades de implementação de um $S G Q$, por parte das pequenas e médias empresas, é a falta de conhecimento sobre a estrutura e metodologia do SGQ. Para Rabelo, Filho e Oliveira (1995, p.14) "uma hipótese básica é que a organização sistemática do treinamento é um fator importante para o sucesso de um programa de melhoria da qualidade".

Para isso, de acordo com Santi et al (2012), diminuir os custos de produção e aumentar a qualidade dos produtos tornaram-se medidas eficazes para fixar-se no mercado e enfrentar a concorrência, partindo do princípio de que a qualidade deve ser planejada e parte de um processo contínuo de revisão e melhorias. Atualmente, praticar a melhoria nas organizações é o ponto de partida para manter-se competitivo no mercado (GONZALEZ; MARTINS, 2007). 
Além disso, conforme Rabelo, Filho e Oliveira (1995), a instalação de um programa de Gestão da Qualidade Total irá, imprescindivelmente, enaltecer questões de caráter social para a organização como, por exemplo, na capacidade de planejamento e esforços corporativos de funcionários e colaboradores. Neste sentido, as ferramentas de qualidade se dividem em básicas e gerenciais. Segundo Toledo et al (2013), as ferramentas gerenciais são totalmente aplicáveis quando surgem alguns problemas que não podem ser resolvidos pelas sete ferramentas básicas.

\subsection{DIAGRAMA DE ISHIKAWA}

As ferramentas da qualidade também precisam de dados exatos e mais mecânicos, nesse contexto, as ferramentas básicas da qualidade se encaixam melhor nessa tarefa. Neste cenário, o diagrama de Ishikawa ajuda a entender os principais problemas e suas prováveis causas. Ele também faz com que seja possível indicar as relações entre causa e efeito e serve para exprimir as relações da causa de um problema (ENARSSON,1998). Outro nome comumente usado para se referir a essa ferramenta é diagrama de peixe.

O diagrama de causa e efeito é construído, mostrando o efeito no lado direito do diagrama e as principais causas e subcausas listadas no lado esquerdo (GARG,2014). Daniels (1997) reforça essas causas que são muitas vezes as seguintes: mão de obra, máquinas, métodos e materiais. Para Barker (1990), é necessário um estudo prévio e planejado para garantir um processo livre de erros, sendo o diagrama de Ishikawa essencial neste cenário.

\subsection{DIAGRAMA EM ÁRVORE}

Uma das ferramentas gerenciais é o diagrama em árvore. Sua aplicação está ligada entre variáveis sociais e econômicas para assim proporcionar a melhor decisão exploratóriaconfirmatória (PITOMBO; COSTA, 2015), sendo desenvolvida no estudo de decisões em sequências e ampliada no valor quantitativo da informação (NEVES, 1992). Para Carnevalli e Miguel (2007), esta ferramenta é de suma importância para a análise e organização das informações envolvidas de forma hierárquica, facilitando seu melhor uso que o digrama de afinidades em aplicações de caráter menos teórico.

\subsection{DIAGRAMA DE AFINIDADES}

O diagrama de afinidades também tem um caráter organizador, entretanto, segundo Dellaretti (1996), esta ferramenta tem uso limitado, apenas permitindo o agrupamento de diversas variáveis e ordená-las de forma para facilitar 0 entendimento geral do problema e sua solução, sem levar em conta dados quantitativos, organizando-os em grupos ou famílias baseados na afinidade entre cada um deles. Ainda de acordo com Karsak et al (2003) e Bezerra (2007), o diagrama de afinidades é uma técnica de reunir fatos e ideias de áreas relacionadas que estão desorganizadas.

Esta ferramenta exige várias etapas para sua preparação (FINLAY,1994), através de coleta de dados verbais. Estes dados são agrupados e simplificados em frases que são escritas em cartões diferentes, onde cada grupo de cartões são agrupados e rotulados. Os cartões e os rótulos por grupos devem estar subordinados um ao outro, isso ocorre repetidas vezes até que o número de grupos construídos seja satisfatório. Por fim, explica o autor supracitado, que o diagrama é desenvolvido com os rótulos, sub-rótulos e dados coletados verbalmente do início do processo.

\section{METODOLOGIA}

Nesta sessão são mostrados os métodos que foram utilizados no desenvolvimento deste artigo, além das técnicas de caracterização do objeto de estudo e os procedimentos.

\subsection{CLASSIFICAÇÃO DA PESQUISA}

Seguindo os conceitos metodológicos (GIL, 2006; TURRIONI; MELLO, 2012; COLLINS; HUSSEY, 2005), a pesquisa pode ser classificada por sua natureza, objetivos, abordagem do problema e procedimentos técnicos, sendo que esse é um trabalho de natureza aplicada, tendo em vista o intento de propor possíveis melhorias, que possam ser atribuídas à estrutura e procedimentos adotados pela empresa, tendo como base o gerenciamento de operações atrelado a técnicas de gestão da qualidade.

O objetivo do estudo tem caráter explicativo, pois se pretendeu atribuir razões para possíveis aspectos que viessem a ser relevantes no gerenciamento e desenvolvimento das operações e serviços. 
Quanto a sua abordagem, o trabalho proposto trata-se de um problema de natureza qualitativa, pois se alude à situação de uma empresa que não possui um setor especializado em gestão da qualidade. Buscou-se estabelecer um procedimento adequado para análise desse estudo, como elaboração de um referencial teórico para embasamento do trabalho. Após os dados foram coletados de forma organizada, sendo, posteriormente, analisados.

O trabalho proposto trata-se de um estudo de caso, pois se alude à situação de uma empresa que não possui setor especializado em gestão da qualidade. Para tanto, buscouse estabelecer um procedimento adequado, coletou-se os dados de forma organizada, analisou-se os dados obtidos, elaborando as três ferramentas da qualidade e, por fim, sugeriu-se melhorias a serem aplicadas.

\subsection{PROCEDIMENTOS METODOLÓGICOS}

\subsubsection{COLETA E ANÁLISE DE DADOS}

O estudo in loco foi realizado conforme descrito no Quadro 1:

Quadro 1-Descrição das atividades

\begin{tabular}{|c|l|}
\hline Data & \multicolumn{1}{c|}{ Atividades realizadas } \\
\hline $20 / 05 / 2015$ & Primeira visita à empresa. \\
\hline $21 / 05 / 2015$ & Identificação de problemas no chão de fábrica. \\
\hline $22 / 05 / 2015$ & Identificação dos problemas na administração da empresa e aplicação das ferramentas. \\
\hline $23 / 05 / 2015$ & Reunião do grupo a fim de organizar os dados obtidos. \\
\hline $25 / 05 / 2015$ & Início da construção das ferramentas da qualidade. \\
\hline
\end{tabular}

Fonte: Pesquisa direta

A descrição segue, respectivamente, nos tópicos abaixo:

- Conhecimentos gerais sobre a empresa e seus processos;

- Aplicação de brainstorming entre 0 grupo e supervisor de produção e conversas informais com os operadores;

- Reunião com o gerente da loja, onde foi explanada a relação da empresa com os fornecedores e clientes e o desempenho do setor de vendas;

- Todas as informações colhidas foram anotadas em fichas para facilitar a organização das ideias;

- Utilizando as fichas, os dados foram agrupados a fim de iniciar a construção das ferramentas.

\subsubsection{FERRAMENTAS DE ANÁLISE}

Como ferramentas para análise utilizou-se o diagrama de Ishikawa, diagrama em árvore e diagrama de afinidades.

\section{ANÁLISE DOS RESULTADOS \\ 4.1 A EMPRESA}

A empresa alvo do estudo atua na manufatura de pedras ornamentais. A missão da empresa consiste em atender a demanda dos seus clientes com o máximo de flexibilidade, praticando preços competitivos no mercado, além de buscar sempre pela sua expansão. $A$ estrutura da empresa pode ser melhor visualizada pela Figura 1: 
Figura 1: Organograma da empresa

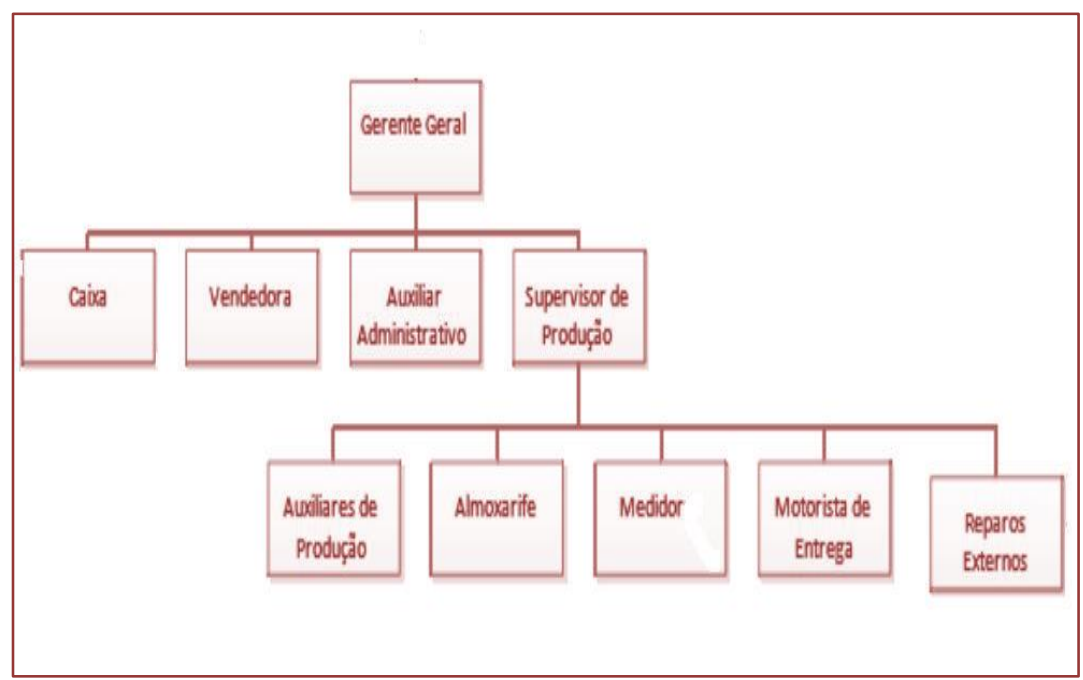

Fonte: Autores (2015)

Um levantamento foi feito sobre o processo produtivo de modo que este pudesse ser organizado para facilitar sua compreensão. $O$ mesmo segue uma sequência, que será descrita em sua respectiva ordem, como mostrado a seguir:

- Estocagem da matéria-prima: As chapas de pedra são estocadas no pátio da fábrica, sendo separadas por tipo (Granito Verde Ubatuba, Mármore 002, Granito Cinza Andorinha etc.);

- Transporte e serragem: Após o recebimento da nota pelo supervisor de produção, ele mobiliza os funcionários da serragem, que levam a chapa de pedra até a máquina de serragem para cortar as peças nas medidas especificadas;

- Encaminhamento das peças para o polimento: Ao sair da serragem as peças cortadas passarão para 0 setor de polimento, onde o(s) funcionário(s) realiza todo o processo de acabamento das partes da peça;

- Montagem: Todas as partes acabadas serão unidas no processo de montagem, por meio de massas plásticas ou resinas, formando o produto final;

- Secagem: Espera necessária para a secagem da massa plástica ou resina;

- Inspeção: Nessa etapa, as peças serão inspecionadas, a fim de verificar possíveis falhas internas no processo de fabricação;

- Transporte para o caminhão: Os funcionários levam a peça até o caminhão de entrega. Para melhor entendimento da sequência das operações, o fluxograma do processo produtivo pode ser visualizado mediante a Figura 2: 
Figura 2: Fluxograma do Processo

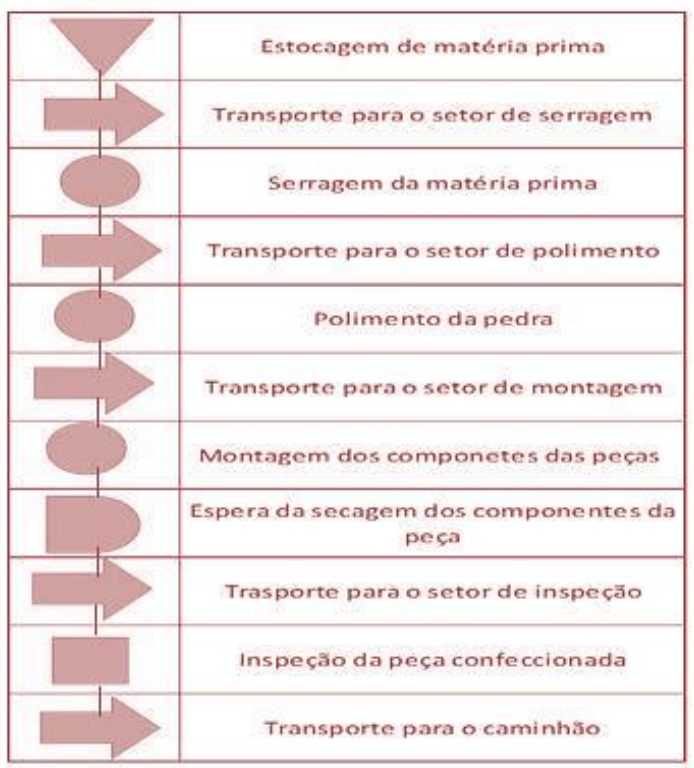

Fonte: Autores (2015)

O fluxograma ASME (American Society of Mechanical Engineers) contribui valorosamente com o objetivo do estudo, pois demonstra de forma clara as operações que não agregam valor ao processo como, por exemplo, transporte e espera, além de identificar que o processo de inspeção é realizado apenas com o produto finalizado, fato que pode ser bastante dispendioso para a empresa, já que um erro encontrado nesta inspeção pode já ter percorrido todas as etapas de produção, gerando, assim, um grande desperdício de força de trabalho e matéria- prima e, caso a peça não esteja perdida, irá necessitar de um retrabalho.

\subsection{DIAGRAMA DE ISHIKAWA}

Após o brainstorming realizado na empresa, as conversas informais com os operadores e a reunião com o gerente da loja, foi identificado que o causador da perca de mercado que a empresa vem passando é o excesso de desperdícios nos seus processos. Buscando entender as causas e efeitos disso, foi elaborado o diagrama de Ishikawa. A Figura 3 demonstra as causas e efeitos encontrados na empresa.

Figura 3: Diagrama de Ishikawa

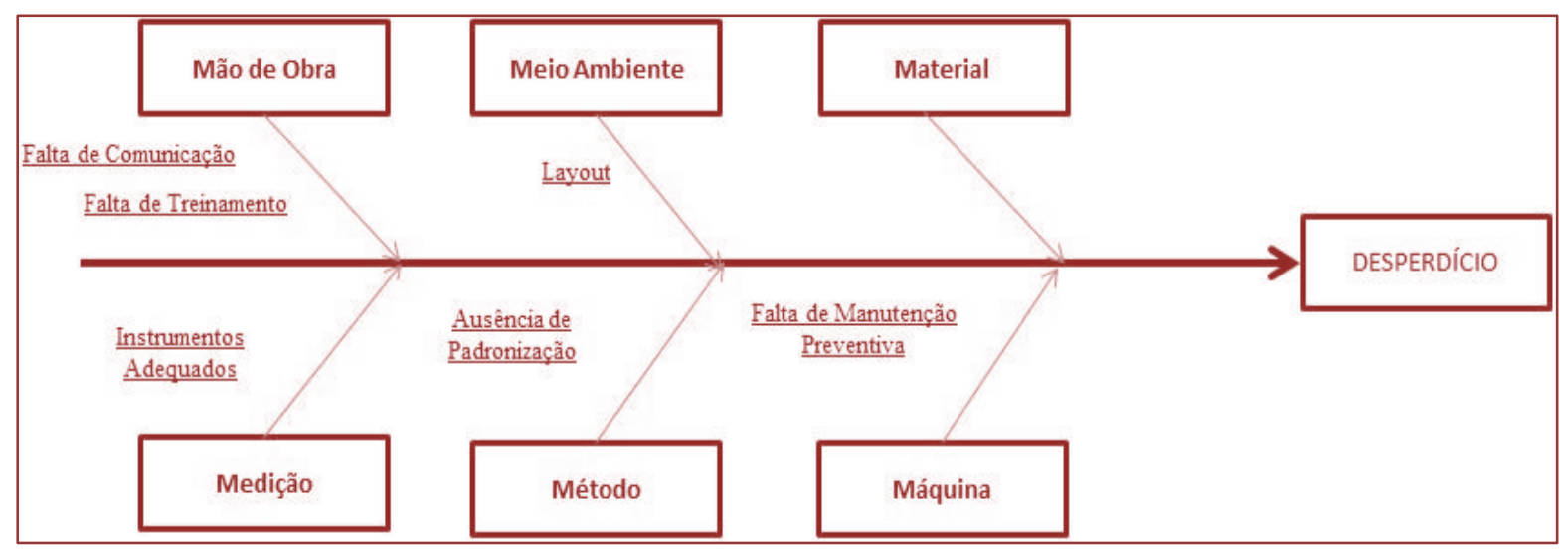

Fonte: Autores (2015) 
Assim como demonstrado pelo diagrama da figura 3, a falta de manutenção preventiva, a ausência de treinamento e comunicação dos funcionários, a inexistência de instrumentação adequada, layout do ambiente e a falta de padronização nas operações são as prováveis causas para 0 desperdício identificado no processo.

\subsection{DIAGRAMA EM ÁRVORE}

Foi elaborado um diagrama em árvore para detalhar os desdobramentos em níveis hierárquicos com o objetivo da redução do desperdício.

Figura 4: Diagrama em árvore Fonte: Autores (2015)

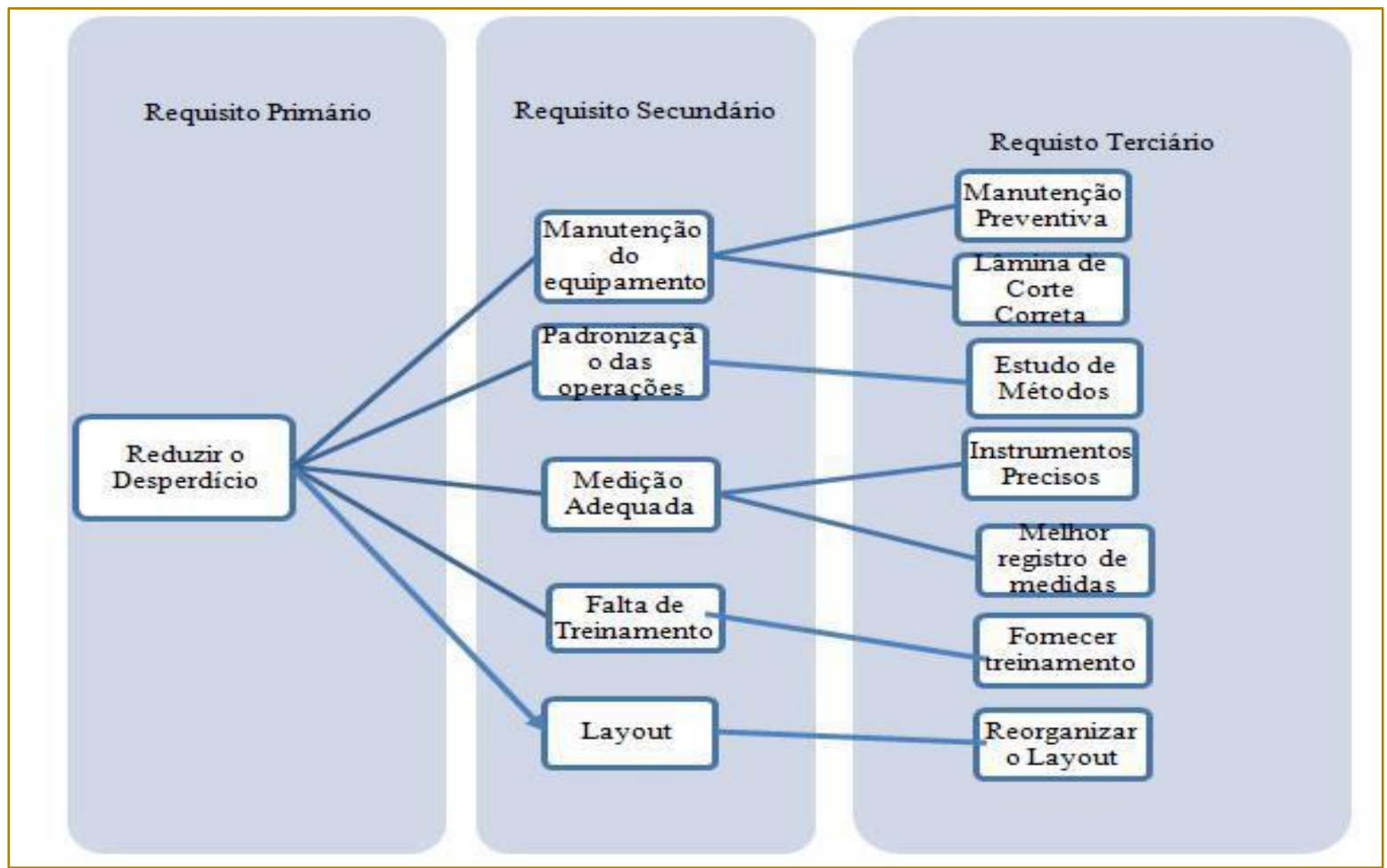

Fonte: Autores (2015)

O requisito primário (foco), como já mencionado, é reduzir o desperdício, para isto foi analisado quatro outros requisitos que estão diretamente ligados a esta causa: manutenção do equipamento, padronização das operações, medição adequada e falta de treinamento.

O requisito secundário, manutenção do equipamento, se refere a uma necessidade de manutenções preventivas juntamente com lâminas de corte apropriadas e calibradas para que se evitem paradas na produção, principalmente, no ato do corte, o que gera a inutilização de uma peça para aquele pedido.

Observa-se que não há padronização dos processos, no que tange a maneira de manejo da matéria-prima, muitas vezes transportada de maneira não cuidadosa, o que pode ocasionar fratura da peça, antes mesmo de chegar ao setor de produção. Neste sentido, - estudo de métodos proporcionaria a determinação de um roteiro de operações a ser seguido pelos funcionários do setor.

Neste mesmo contexto, a medição adequada realizada na etapa de projeto é primordial para a redução do desperdício, uma vez que medidas erradas provocam rebarbas ou falta de material na execução do projeto, causadas pela ineficiência dos instrumentos utilizados. Dessa mesma forma, no ato do corte realizado pelos serradores, é necessário que os mesmos estejam atentos às informações passadas via nota de pedido. Entretanto, é conhecido que os registros de pedidos nem sempre estão corretos, pois os mesmos não são feitos com bastante atenção, logo é necessário a quebra deste ciclo vicioso de erros, com a utilização de registros mais confiáveis e instrumentos mais precisos. 
A falta de treinamento pode ser relacionada como uma das principais causas de tanto rebotalho na produção. Uma vez que, funcionários com pouca experiência e sem treinamento fornecido pela empresa, não apresentam técnicas adequadas para a execução de operações no processo produtivo, influenciando diretamente no desperdício. Logo, é necessário por parte do empregador, um programa de treinamento visando qualificar o colaborador, buscando a redução de erros.

Por fim, no layout da fábrica foi constatado que os colaboradores transportam grandes placas de pedras entre o arranjo físico, provocando movimentação desnecessária, o que resulta em fadiga dos empregados. $\mathrm{Na}$ fábrica não há um espaço definido apenas para a circulação de materiais, havendo transporte de matéria-prima entre os maquinários e diversos setores, o que, muitas vezes, ocasiona a fratura da placa, que é explicada por acidentes de transporte por falta de um layout apropriado. A solução é a reorganização de tal arranjo, com o intuito da criação de um corredor apenas para a circulação da matéria-prima do estoque até o setor de corte.

\subsection{DIAGRAMA DE AFINIDADES}

Para a confecção do diagrama de afinidades, os dados anotados foram separados $e$ agrupados de acordo com suas relações e afinidades, sendo este procedimento repetido, por diversas vezes, até encontrar 0 agrupamento ótimo. A Figura 5 mostra a afinidade entre as causas dos desperdícios gerados na empresa.

Figura 5 - Diagrama de afinidades

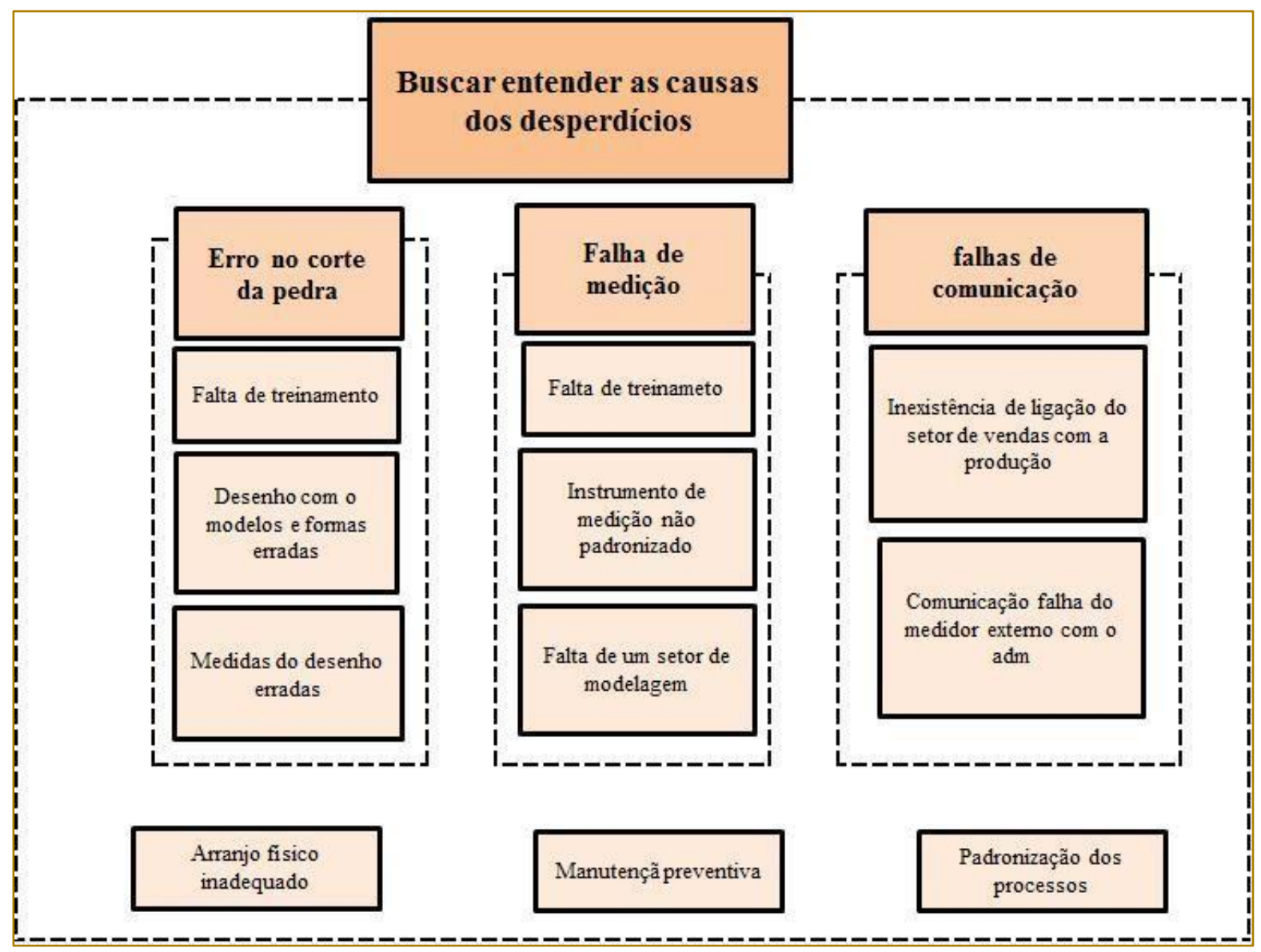

Fonte: Autores (2015)

Com aplicação das ferramentas do diagrama de Ishikawa, árvore e afinidade, foi possível desvendar as causas e efeitos que envolvem os desperdícios de matéria-prima na fábrica em estudo, possibilitando aos autores identificar as melhorias necessárias ao 
sistema, como também dar suporte as futuras tomadas de decisão na empresa.

\section{CONSIDERAÇÕES FINAIS}

Como já explicitado, a fábrica possui diversos viés de desperdícios e, para a eliminação destes e auxílio às tomadas de decisões, os autores sugeriram as seguintes melhorias:

- Treinamento integral do quadro de funcionários da produção, a fim evitar erros e violações nas operações;

- Desenvolvimento de um setor de modelagem, onde sejam utilizados ferramentas e padrões de medidas;

- Padronização das operações, a fim de facilitar a operação e o treinamento de funcionários;

- Utilização de uma única "linguagem" entre o responsável pelas medidas e o setor administrativo, utilizando folhas de desenho padronizadas;

- Rearranjo físico do chão de fábrica, destinando vias de transporte seguras e ergonômicas;

- Elaboração de um plano de manutenção para as máquinas e equipamentos;

- Implantação da inspeção no início do processo, evitando que erros passem despercebidos.

\subsection{CONCLUSÃO}

A busca por reduções de custos e desperdícios é de grande importância para o crescimento das empresas, pois mudanças que tragam benefícios nestas áreas dão um ganho de competitividade à elas. A realização do presente trabalho se mostrou bastante satisfatória para a empresa, possibilitando a identificação das causas e efeitos dos desperdícios gerados no seu sistema, além da implantação das melhorias propostas neste trabalho.

O objetivo do estudo foi a aplicação das ferramentas da qualidade, diagramas de Ishikawa, árvore e afinidade, a fim de identificar as perdas e desperdícios gerados pelos processos da empresa e, com base no conhecimento aqui adquirido, foram propostas melhorias para a solução das raízes dos problemas encontrados.

Este trabalho se limitou a estas "causas raiz" do problema, por terem sido as identificadas nas visitas técnicas, brainstorming e conversas informais na fábrica, entendendo assim a possibilidade de existirem outras. $O$ estudo tem caráter prático por ter sido realizado com dados reais, podendo assim ser utilizado para futuras melhorias que queiram ser adotadas pela empresa, como também utilizado por outras empresas do ramo para servir como parâmetro. Portanto, conclui-se o artigo deixando a possibilidade de sua utilização por trabalhos futuros na empresa, sendo este o ponto inicial do processo de melhoria da empresa em estudo.

sistema de gestão da qualidade: estudo de um caso. Produção, v. 16, n. 1, p. 111-125, Jan./Abr. 2006.

[6]. DANIELS, S. Back to basics with productivity techniques, Work Study, Vol. 46 Iss: 2, pp.52 - 57. 1997. DELLARETTI, O. F. As sete ferramentas do planejamento da qualidade (7FPQ). Belo Horizonte: Universidade Federal de Minas Gerais. Escola de Engenharia. Fundação Christiano Ottoni, 1996.

[7]. ENARSSON, L. Evaluation of suppliers: how to consider the environment, International Journal of Physical Distribution \& Logistics Management. Vol. 28 Iss: 1, pp.5-17, 1998.

[8]. FINLAY, J. S. The strategic visioning process. Public Administration Quarterly, vol. 18, n. 1, pp. 64-74. 1994.

[9]. GARG,A;Garg,P; Factors influencing ERP implementation in retail sector: an empirical study 
from India", Journal of Enterprise Information Management, Vol. 27 Iss: 4, pp.424 - 448,2014.

[10]. GIL, A. C. Como classificar as pesquisas. Como elaborar projetos de pesquisa, v. 4, p. 41-56, 2002. GIL, A. C. Métodos e técnicas de pesquisa social. Atlas. São Paulo, 2006.

[11]. GONZALEZ, R. V. D; MARTINS, M. F. Melhoria Contínua no ambiente ISSO 9001:2000: estudo de caso em duas empresas do setor automobilístico. Produção, v. 17, n. 3, p. 592-603, Set./Dez. 2007.

[12]. KARSAK, E. E.; SOZER, S.; ALPTEKIN, E. Product planning in quality function deployment using a combined analytic network process and goal programming approach. Computers \& Industrial Engineering. vol. 44, n. 1, p. 171-190.

[13]. MATTOS, I.C. 2002. Uso/adequação e aplicação de rochas ornamentais na construção civil - parte 1. In: III Simpósio sobre Rochas Ornamentais do Nordeste, Anais, Recife, PE.

[14]. NEVES, C das. Avaliação de um investimento em pesquisa adicional num novo processo de produção: considerações metodológicas e uma aplicação. Prod., São Paulo, v. 2, n. 2, Dec. 1992.
[15]. PITOMBO, C. S; COSTA, A. S. G. da. Aplicação conjunta de modelos não paramétricos e paramétricos para previsão de escolha modal. J. Transp. Lit., Manaus, v. 9, n. 1, Jan. 2015.

[16]. RABELO, F.V; FILHO, E.T; OLIVEIRA, C. A. B. Treinamento e gestão da qualidade. Revista de Administração de Empresas. São Paulo, v. 35, n. 3, p. 13-19, Mai./Jun. 1995.

[17]. SANTI, S.N; Godoy, L.P; Jose, D.C; Pappa, M.F. Os tipos de perdas em uma indústria de confecção do noroeste do Paraná. XXXII encontro nacional de engenharia de produção. Desenvolvimento Sustentável e Responsabilidade Social.

[18]. SEBRAE/ES. Dísponivel em: <www.sebrae2014.com.br/Sebrae/Sebrae/202014/ Boletins/2014/08/06BOAgostoConstrucaoCivilmarm orespdf.p df.> Acesso em 31/05/2015.

[19]. TOLEDO, J.C; BORRÁS, M.A.A; MERGULHÃO; MENDES, G.H.S. Qualidade : gestão e métodos. Rio de Janeiro : LTC, 2013.

[20]. TURRIONI, J.B.; MELLO, C. H. P.; Metodologia de pesquisa em engenharia de produção: estratégias, métodos e técnicas para condução de pesquisas quantitativas e qualitativas. Itajubá: UNIFEI, 2012. 


\section{Capítulo 9}

\section{APLICAÇÃO DA METODOLOGIA CLIENTE OCULTO NO LEVANTAMENTO DE OPORTUNIDADES DA QUALIDADE EM UMA LANCHONETE EM TERESINA-PI}

\section{Rener Antônio Melo Nascimento}

José Lucas Viana Morais

\section{Larissa Havenna Matos Santos}

\section{Eduardo de Oliveira Souza Neto}

Natan Melo Nascimento

Resumo: A competitividade do mercado, atrelada à exigência do consumidor, é um fator que impulsiona inovação, busca pela diferenciação e melhoria da qualidade, envolvendo produtos ou serviços. Neste contexto, faz-se importante a utilização do gerenciamento da qualidade e suas ferramentas. O método utilizado neste artigo foi o do cliente oculto, que se dá quando o investigador age como cliente sem transparecer que uma pesquisa está sendo realizada, mostrando imparcialidade. Foram utilizados checklists para a execução da tarefa associados à capacidade de memorização dos pesquisadores. Após a coleta dos dados, observou-se que a lanchonete possui elevada insatisfação dos clientes gerada por fatores como: falta de higiene no manuseio da comida, falta de cordialidade e interesse do atendente para com o cliente, falta de material que facilitasse o cliente escolher o que consumir, além de conservação inadequada dos alimentos. Com base nos resultados obtidos, foram elencadas algumas sugestões de melhoria, como treinamentos e conscientização do colaborador quanto à higiene e atendimento a fim de tornar a lanchonete um ambiente de agradável convivência, obter mais clientes e fidelizá-los e preparar o estabelecimento para um mercado competitivo.

Palavras-chave: cliente, oculto, QUALIDADE, Higiene, Satisfação 


\section{INTRODUÇÃO}

Na rotina, é fácil observar cada vez mais a necessidade das pessoas em alimentarem-se fora de casa. Nos construtos de Freitas (2004) comenta que as pessoas atualmente acabam optando por fast foods, lanchonetes e restaurantes para fazerem refeições devido à rotina corrida dos grandes centros. Atrelada à globalização, cresce a necessidade dessas organizações oferecerem produtos e serviços de qualidade que atendam os anseios dos clientes.

Concomitante a isso, a qualidade é um termo amplamente difundido que pode ter conceitos variados, tais como: máxima utilidade para o consumidor (DEMING,1950); adequação ao uso (JURAN, 1991); conformidade com requisitos (CROSBY, 1994), entre outros. Dessa forma, é visível e cada vez mais imprescindível a preocupação e a necessidade da qualidade nos processos de produção e serviços aos clientes, diante desta ideia, Zeithaml (1988) afirma que o valor percebido pelo cliente é obtido mediante a diferença entre o que ele espera do serviço e o que de fato é recebido.

De acordo com Marchetti e Prado (2001), para se avaliar o desempenho global das organizações deve-se levar em conta a mensuração de índices de satisfação do cliente, a avaliação constante do nível de satisfação e seus benefícios. Já Wicks et al., (1998) demonstra que o uso de pesquisas e modelos de satisfação de clientes não serve somente para medir o nível de desempenho empresarial, mais também em nortear as melhorias em itens insatisfatórios indicados pelos clientes.

Uma das formas para analisar a qualidade da prestação de serviços em uma empresa, é através do método cliente oculto. A principal vantagem de se utilizar essa técnica reside na imparcialidade, pois quem avalia não convive no ambiente que irá intervir, estando o consultor desapegado de manias, tornando suas percepções sobre o atendimento mais certeiras. (FABIANOWICZ, 2012)

Mediante os benefícios obtidos com aplicação da técnica supracitada, e considerando que a qualidade é um fator diferencial que contribui para a competição e sobrevivência das organizações no cenário atual, este estudo tem como principal objetivo analisar a satisfação dos clientes por intermédio da avaliação dos serviços prestados em uma lanchonete localizada na cidade de Teresina-
PI através da técnica do cliente oculto, com o intuito de propor estratégias de melhorias.

\section{REFERENCIAL TEÓRICO}

\subsection{GESTÃO DA QUALIDADE}

A relevância da gestão da qualidade no atual cenário empresarial vem se evidenciando cada vez mais, uma vez que devido à intensa competição existente entre as organizações, estas buscam, de forma incessante, diferenciais que possibilitem o seu destaque no mercado frente aos concorrentes, é desta forma que a gestão da qualidade atua, estabelecendo diretrizes estratégicas e operacionais para o alcance do sucesso (PALADINI, 2012).

Um importante princípio da gestão da qualidade é o foco no cliente, todos os esforços da organização devem estar voltados para proporcionar satisfação ao cliente, pois desta forma um bom relacionamento com o mesmo pode ser estabelecido, fazendo com que a empresa possa conseguir sua fidelidade e que ele tenha uma relação de parceria com a empresa, auxiliando-a em alguns aspectos como: recomendar a empresa para um amigo ou familiar, estabelecer comunicação com a empresa em casos de falhas na qualidade, assim como se tornar um avaliador confiável dos serviços da empresa. (SANTOS et al, 2010)

Carpinetti (2010) em seus construtos textuais afirma que não se deve compreender a qualidade mediante apenas um aspecto, pois existem alguns atributos que devem ser evidenciados e que são essenciais na gestão da mesma, destes pode-se citar: desempenho, durabilidade, facilidade de uso, conformidade, confiabilidade, entre outros. Desta forma, a empresa deve ter ciência de tais aspectos no intuito de satisfazer seus clientes.

\subsection{GESTÃO DA QUALIDADE EM SERVIÇOS}

O setor de serviços vem em constante crescente em sua participação na economia brasileira, pois como aponta o Instituto Brasileiro de Geografia e Estatística (IBGE, 2013) este setor é responsável por cerca de $69,4 \%$ do PIB nacional, e de forma complementar o Ministério do Trabalho e Emprego (MTE, 2012) mostra que os serviços geraram mais de 17 milhões de empregos em 
todo país, reforçando a relevância do mesmo para o Brasil.

Diante da importância do setor para a economia anteriormente citada, Lucinda (2010) afirma que a gestão da qualidade no setor de serviços deve ser encarada como um aspecto que possibilitará a organização a atingir os almejados diferenciais competitivos, ressalta-se ainda que existem algumas diferenças entre a gestão da qualidade de produtos e à de serviços.

De acordo com Fitzsimmons e Fitzsimmons (2014) para o entendimento da gestão da qualidade em serviços, é necessário compreender as características dos mesmos, dentre as quais se destacam:

- Intangibilidade: O cliente não pode cheirar, tocar, provar e ouvir serviços, ou seja, não é possível tanger um serviço;

- Heterogeneidade: A variabilidade dos serviços geralmente é alta, uma vez que o relacionamento e busca pelo atendimento das necessidades de cada cliente dificultam algum tipo de padronização;

- Perecibilidade: Refere-se ao grau de estocagem dos serviços, onde pode ser considerado zero, já que não é possível estocar serviços;

- Simultaneidade: O consumo dos serviços por parte do cliente ocorre de maneira simultânea a produção do mesmo;

- Interação com o cliente: Os serviços são caracterizados por demandarem um elevado contato com o consumidor, fator este que destoa quando se aborda a interação do cliente na produção de produtos.

Segundo Santos et al., (2010), os serviços que uma organização oferta devem ser planejados de forma minuciosa e sempre com qualidade, a prática de uma boa prestação de serviços possibilita que os clientes se sintam satisfeitos, e estes podem tornar-se potenciais parceiros, indicando a empresa para amigos e parentes, contribuindo com sugestões, e também com sua fidelização.

\subsection{SERVIÇOS DE ALIMENTAÇÃO}

Desde as últimas décadas, nas cidades, os alimentos prontos estão amplamente disponíveis nos supermercados, lanchonetes e restaurantes, a facilidade para obter comida passou a ser uma coisa corriqueira (REBELATO,1997). O setor de bares, restaurantes e lanchonetes vem passando por um momento de muitas oportunidades no Brasil (GHOBRIL et al ,2014).

Onde Teles (2011) caracteriza que o setor do ramo alimentício está passando por um momento de transição situacional, por motivo no qual os clientes buscam por mais reconhecimentos de suas necessidades e satisfação pessoal, principalmente em lanchonetes e bares, onde se é necessário atender todos os atributos necessários dos mesmos para atingir um maior grau de competitividade no mercado atual.

Neste contexto, a Associação de Brasileira de Bares e Restaurantes (ABRASEL,2009) comenta que são necessários esforços ainda mais sinérgicos para se atingir níveis de qualidade no atendimento, e assim, transcender as expectativas dos clientes, sendo que qualidade em serviços alimentícios são experiências intangíveis, tornando assim uma reação pessoal, intrínseca e especifica de cada cliente, estando correlacionada diretamente na experiência de atendimento do estabelecimento. Onde segundo a Revista Bares e Restaurantes (2009) o cliente quando faz uso desse tipo de organização, avalia atributos como o ambiente, infraestrutura, atendimento, higiene alimentar, variedade de produtos e as propriedades organolépticas da alimentação, atuando como um tipo de fiscal, podendo fazer propaganda negativa para amigos e familiares e em casos mais graves denunciar aos órgãos responsáveis que venham a intervir nesses tipos de prestadores de serviço.

\subsection{CLIENTE OCULTO}

A técnica de cliente oculto é uma forma de observação participante, utilizando-se de pesquisadores que atuam como clientes ou potenciais clientes, no intuito de acompanhar a qualidade dos processos e procedimentos em prestações de serviço (WILSON, 1998). O cliente oculto age como um consumidor misterioso, tendo o intuito de avaliar o ambiente, atendimento, serviço, produto, estrutura, além de outros fatores que considera relevantes para a imagem e reputação da empresa (ROBAZZA et al, 2016)

Conforme Wiele (2005), a técnica de cliente oculto tem como grande vantagem a qualidade nas medições, pois os indivíduos 
que realizam essa técnica devem ser bem treinados e grandes conhecedores dos processos em questão sendo, portanto, capazes de medir os pontos de falha cruciais.
Vilímová (2014), destaca 3 etapas que podem ser seguidas na intenção de colocar essa técnica em prática, que podem ser visualizadas pelo Quadro 1

Quadro 1- Etapas da técnica de cliente oculto

\begin{tabular}{|c|l|l|}
\hline 1 & Definir metas & $\begin{array}{l}\text { As metas definidas devem ser transparentes, e devem ser usadas } \\
\text { como entrada para a lista de verificação. }\end{array}$ \\
\hline 2 & Coleta de Dados & $\begin{array}{l}\text { Devem englobar as dimensões gerais de qualidade aplicável à } \\
\text { serviços, além de explicitar os principais indicadores de desempeno } \\
\text { definidos pela organização }\end{array}$ \\
\hline 3 & $\begin{array}{l}\text { Relatório de } \\
\text { Resultados }\end{array}$ & $\begin{array}{l}\text { Contém informaçães subjetivas e questões abertas, além de medidas } \\
\text { objetivas baseadas na lista de verificação. }\end{array}$ \\
\hline
\end{tabular}

Fonte: Adaptado de Vilímiová (2014)

Tarantola et al. (2012), afirmam que os resultados fornecidos por tais pesquisas podem ser utilizados como ferramenta de avaliação e comparação do desempenho de diferentes empresas, ou filiais de uma mesma empresa, até mesmo para avaliar e comparar individualmente cada colaborador. Contudo, Jankal e Jankalová (2010), declaram que a intenção da técnica de cliente oculto não é mostrar aos colaboradores que eles realizam o seu trabalho de maneira errada, e sim melhorar permanentemente a sua atitude para com os clientes, além de crescimento profissional.

\section{METODOLOGIA}

\subsection{PROCEDIMENTOS METODOLÓGICOS}

Para este trabalho foram utilizados dados primários, não havendo necessidade de colher informações documentais da empresa, pois estas não possuem qualquer relação com a qualidade do serviço (ROESCH, 1996).

O instrumento de coleta utilizado foi uma lista de verificação adaptada para as necessidades da pesquisa, considerando os equipamentos - micro-ondas, geladeiras - e produtos vendidos no empreendimento, como salgados e sanduiches, além de condições higiênicas. Nessa lista estão presentes os fatores considerados importantes e que foram avaliados, divididos em: cordialidade aos clientes, cliente fazer pedido, conservação e preparação do alimento, entrega do pedido ao cliente, cobrança e recebimento do pagamento, agradecimento e convite para retorno

\subsubsection{ETAPAS DOS PROCEDIMENTOS METODOLÓGICOS}

Etapas Metodológicas utilizadas nesta pesquisa são: definição do empreendimento; elaboração do checklist; definir os aplicadores; execução do checklist; análise dos dados; apontar soluções, cada um dos itens será melhor detalhados nos tópicos subsequentes.

\subsubsection{CARACTERIZAÇÃO EMPREENDIMENTO}

A caracterização do empreendimento foi realizada através de observações realizadas por todos os integrantes do grupo. O objetivo de envolver todos os integrantes nesta etapa aconteceu com a finalidade de obtenção do conhecimento das características do recinto que seria estudado, portanto facilitaria futuramente a execução de etapas como elaborar a lista de verificação, analisar dados e sugerir melhorias.

\subsubsection{ELABORAÇÃO DO CHECKLIST}

A partir da caracterização do empreendimento, os pesquisadores fizeram reuniões para elaborarem a lista de verificação (quadro 2) com base em objetivos e parâmetros pré- determinados. Esta lista tem o objetivo de documentar o que é observado pelo cliente oculto, facilitando o arquivamento e análise de dados. 
Quadro 2- Lista de Verificação de itens relativos à qualidade.

1. O empregado é simpático?

2. O cumprimento é sincero?

Cliente fazer pedido

1.Existe cardápio?

2. Cliente consegue visualizar o que pode consumir?

3. O cliente só precisa fazer o pedido uma vez?

4.Atendente sugere outros produtos?

Conservação e preparação do alimento

1. O alimento é mantido na temperatura correta?

2. O alimento é mantido fora do alcance de animais?

3. É possível ver a preparação do alimento?

4. Os equipamentos de cozinha são limpos?

5. Os recipientes (copos e pratos) são limpos?

6. Enche os copos até o nível adequado?

7. Os equipamentos de fazer o alimento estão devidamente higienizados? Entrega do pedido ao cliente

1. O pedido é embrulhado?

2. As bordas do saco são dobradas duas vezes?

3. Usa bandejas de plástico para consumo dentro da lanchonete?

4. Usa toalha ou papel guardanapo de bandeja?

5. O alimento é manuseado de maneira adequada? Cobrança e recebimento do pagamento

1. O valor da conta é dito claramente e em voz suficientemente clara?

2. O valor recebido é dito claramente?

3. O troco é contado em voz alta?

4. O atendente não pega no alimento depois de manusear dinheiro?

1. O funcionário agradeceu?

2. O agradecimento é sincero?

3. Convida o cliente a voltar?

Fonte: Adaptado de Morgan (2002). 


\subsubsection{DEFINIÇÃO DO CLIENTE OCULTO}

Nessa etapa houve a determinação, dentre os integrantes do grupo de pesquisa, de quais seriam os mais aptos à aplicação da técnica, levando em consideração, para tal, a capacidade individual de memorização de cada um, além da perícia em se manter psicologicamente equilibrado no momento da realização do atendimento. Para isso, realizou-se dinâmicas de grupo baseadas na memorização de informações, e na habilidade de manter-se sério e focado mesmo frente a situações perturbadoras, visando assim, realizar a avaliação de forma coerente e coesa.

\subsubsection{APLICAR A LISTA DE VERIFICAÇÃO}

O processo de aplicação do questionário se deu por meio do consumo dos serviços oferecidos pela empresa em um total de 4 (quatro) visitas, sendo que todas foram realizadas por dois integrantes distinto em quatro dias diferentes, no intuito de comparar o desempenho de forma individual dos mesmos.

Essa atividade foi realizada utilizando um padrão:

- Direcionar-se diretamente ao colaborador, cumprimentando-o;

- Pedir cardápio;

- Identificar os produtos que estão no campo de visão de consumidor;

- Observar o acondicionamento dos alimentos e equipamentos de trabalho;

- Analisar a maneira como os alimentos são entregues pelo atendente;

- Verificar a conduta do atendente no momento da prestação de contas, e após o seu acerto.

Todas as informações coletadas pela percepção do avaliador foram devidamente memorizadas, e imediatamente após a finalização do serviço, o cliente oculto fez o preenchimento da lista de verificação, sem a influência de tendências de qualquer natureza, para que então seja feita a análise e diagnóstico.

\subsubsection{ANÁLISE DIAGNÓSTICO}

$\mathrm{Na}$ etapa de análise diagnóstico, foram realizadas reuniões com os pesquisadores para avaliar detalhadamente os resultados obtidos pelo cliente oculto, revelando quais os pontos merecem ser mais trabalhados.

\subsubsection{LEVANTAR SOLUÇÕES}

A partir do levantamento das áreas que merecem maior atenção, os avaliadores passaram a levantar soluções através de ferramentas como brainstorm e pesquisas bibliográficas para sugerir ações objetivas e rápidas que atendam às normas vigentes com o objetivo de aperfeiçoar o empreendimento.

\section{ANÁLISE DOS RESULTADOS}

De modo inicial, tabulou-se os checklists, para que desta forma fosse possível agrupar os macros aspectos contemplados na pesquisa: cordialidade aos clientes, cliente fazer o pedido, conservação e preservação dos alimentos, entrega do pedido ao cliente, cobrança e recebimento do pagamento, agradecimento e convite para retorno.

Para uma investigação mais detalhada, explorou-se cada aspecto individualmente com o intuito de relatar os resultados obtidos referentes às quatro avaliações realizadas durante a coleta de dados.

\subsection{CORDIALIDADE AOS CLIENTES}

Este aspecto contemplou características referentes ao atendimento do colaborador ao cliente, tais como: empatia, cordialidade, entre outros. Neste, observou-se que $75 \%$ das avaliações foram negativas, ou seja, demonstrou-se um nível de satisfação de apenas $25 \%$, porcentagem esta considerada muito baixa, possibilitando desta forma que a equipe de pesquisa inferisse que a empresa não satisfaz seus clientes no tocante à cordialidade de seus colaboradores para com o consumidor. A Figura 1 ilustra os resultados deste macro item: 
Figura 1 - Resultados referentes ao item "Cordialidade ao cliente"

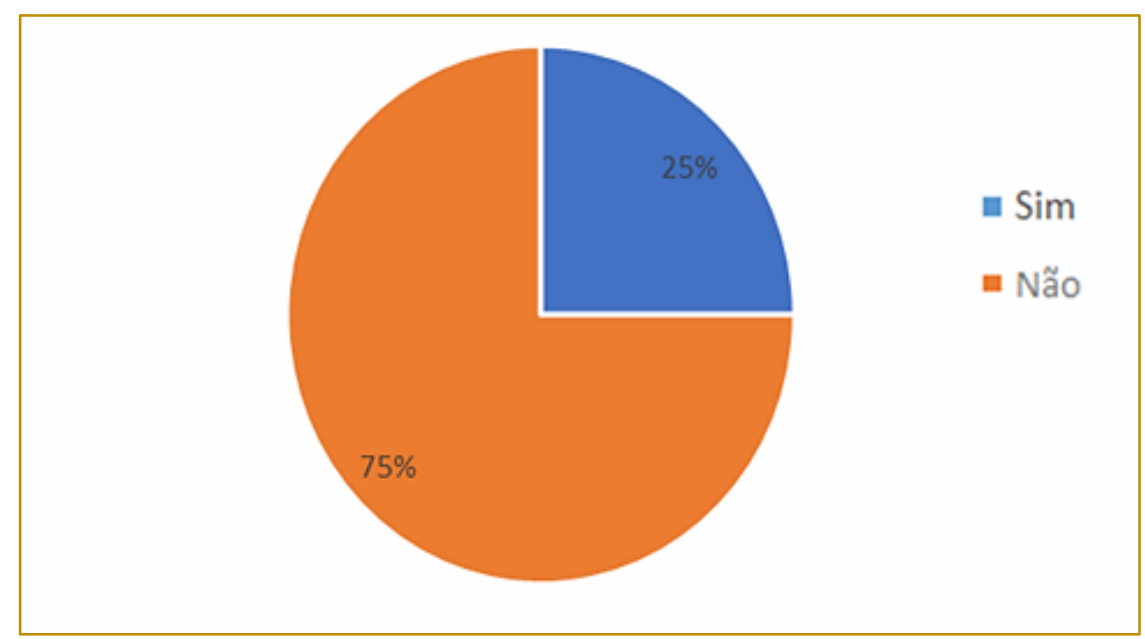

Fonte: Próprio Autor.

\subsection{CLIENTE FAZER PEDIDO}

Contemplou-se questões associadas à conveniência que o cliente possui na hora de realizar seu pedido, onde características como o cardápio e se o atendente auxilia o consumidor na escolha de seu pedido foram verificadas. Constatou-se que este aspecto foi avaliado com porcentagens iguais, ou seja, de um modo geral, este item não pode ser considerado com um nível de satisfação aceitável, pois existem resultados negativos consideráveis. Os resultados podem ser vislumbrados por intermédio da Figura 2.

Figura 2 - Resultados referentes ao item "Cliente fazer pedido".

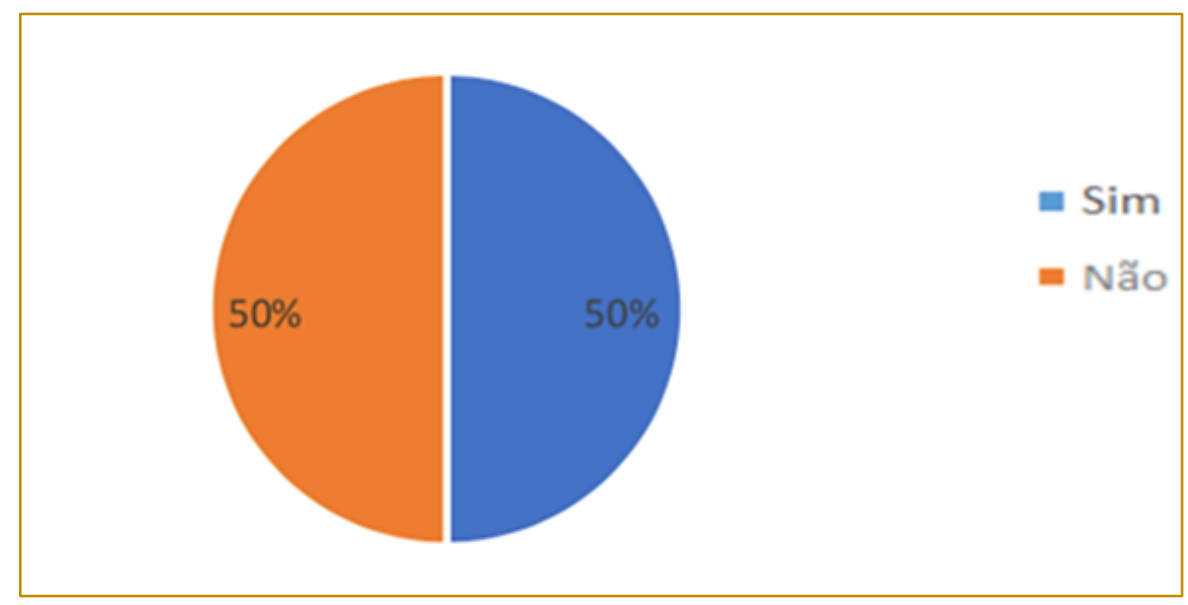

Fonte: Próprio Autor.

\subsection{CONSERVAÇÃO E PRESERVAÇÃO DO ALIMENTO}

Agregam-se neste aspecto atributos que se referem à preparação dos alimentos e como estes são conservados. Deste modo, características como higiene dos materiais de consumo (pratos, copos, talheres), e também a maneira como os produtos de consumo são preparados e preservados foram contempladas. Os resultados ilustrados pela Figura 3, apontam que o nível de satisfação é de $54 \%$, que pode ser considerado satisfatório. 
Figura 3 - Resultados referentes ao item "Conservação e preparação do alimento"

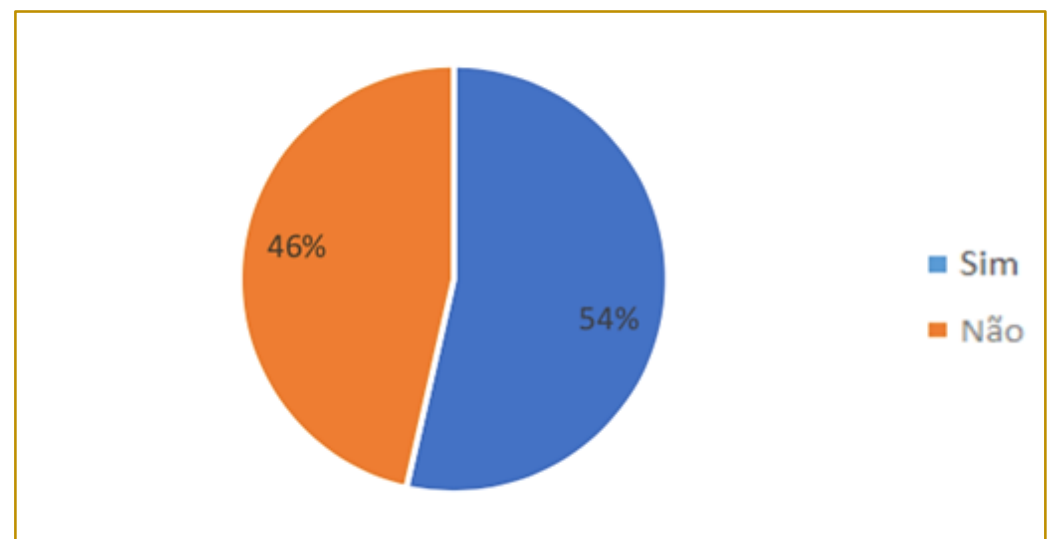

Fonte: Próprio Autor.

\subsection{ENTREGA DO PEDIDO AO CLIENTE}

Neste item, características associadas à forma como o pedido é entregue ao cliente (embalagem, acessórios que auxiliem ao consumo), e também o modo que 0 colaborador manuseia o produto. Verificou-se que neste aspecto, as avalições apresentaram resultados negativos, em virtude da porcentagem de $65 \%$ referentes à insatisfação do mesmo, com mostra a Figura 4.

Figura 4 - Resultados referentes ao item "Entrega do pedido ao cliente"

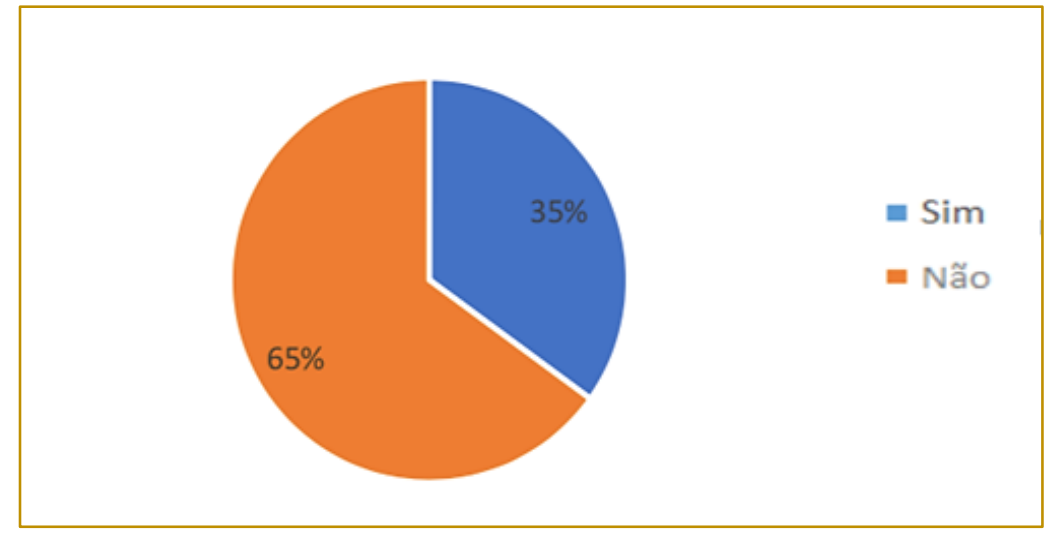

Fonte: Próprio Autor

\subsection{COBRANÇA E RECEBIMENTO DO PAGAMENTO}

Características que se referem aos procedimentos que envolvem o pagamento do cliente para a empresa, em virtude dos serviços realizados, tais como: clareza nos valores oferecidos e recebidos, trocos, e higiene após o contato com o dinheiro. Os pesquisadores verificaram que este item possuiu os piores índices da avaliação, pois suas características foram consideradas insatisfatórias gerando um nível de satisfação de apenas $13 \%$, ou seja, aproximadamente $87 \%$ dos atributos avaliados foram considerados deficientes, assim como ilustra a Figura 5. 
Figura 5 - Resultados referentes ao item "Cobrança e recebimento do pagamento"

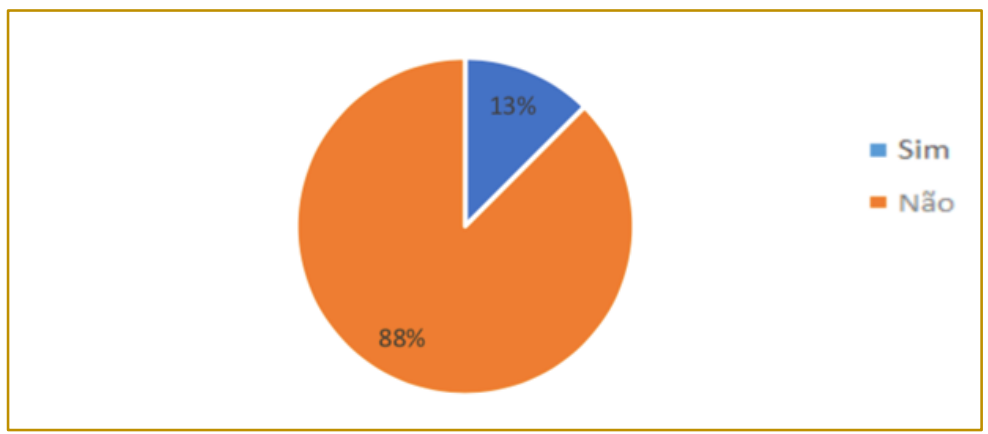

Fonte: Próprio Autor.

\subsection{AGRADECIMENTO E CONVITE PARA RETORNO}

Neste item, os aspectos se assemelham ao primeiro, pois referem-se à cordialidade e empatia do funcionário para com o cliente ao término do serviço, por exemplo: se o agradecimento é feito, e se o colaborador demonstra interesse que 0 consumidor retorne posteriormente ao empreendimento, construindo assim um princípio da fidelização do cliente. O nível de satisfação obtido foi $50 \%$, não podendo ser considerado satisfatório em virtude das falhas relevantes que foram identificadas. Os resultados associados a este item são mostrados na Figura 6.

Figura 6 - Resultados referentes ao item "Agradecimento e convite para retorno"

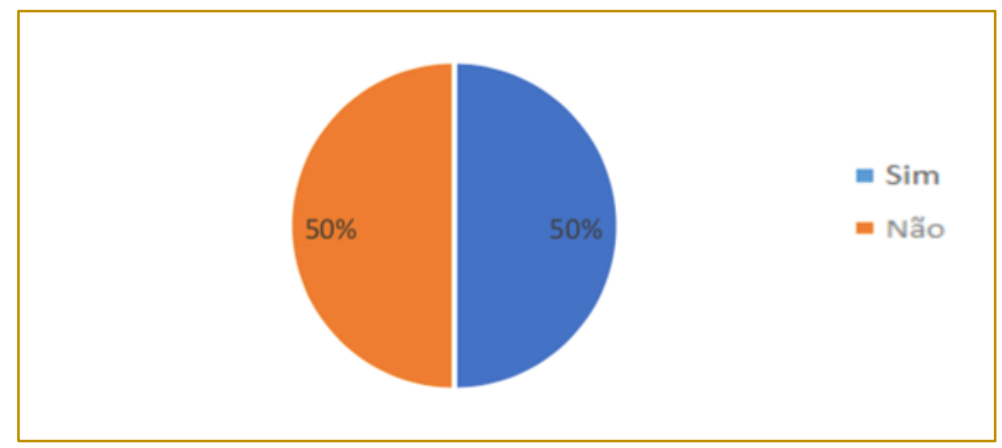

Fonte: Próprio Autor.

As falhas apontadas neste item foram referentes ao agradecimento, visto que este não era efetuado de maneira frequente, e a cordialidade e empatia após os serviços não eram verificadas, uma vez que o convite para o retorno muitas vezes não era feito, constatando a falta de interesse da empresa quanto à fidelização de seus consumidores.

\section{CONSIDERAÇÕES FINAIS}

O objetivo deste trabalho foi analisar o serviço prestado por uma lanchonete situada em Teresina, através do uso da técnica cliente oculto que tem como principal vantagem a imparcialidade do analista, já que este não possui qualquer vínculo com o ambiente estudado.

Através da precisa execução da atividade seguida da análise dos dados, observou-se que o estabelecimento possui predominantemente resultados negativos, acusando baixa satisfação dos clientes quanto à higiene, cordialidade, interesse dos colaboradores em realizar um bom atendimento, conservação dos alimentos, entrega de pedido. Uma das possíveis causas para tantos resultados negativos pode ser $\mathrm{o}$ fato de que este é o único local de alimentação na área. 


\subsection{SUGESTÕES DE MELHORIA}

Com a intenção de melhorar os índices de uma próxima pesquisa e a satisfação do cliente, o grupo elencou algumas atividades a serem realizadas:

- Treinamento de qualidade com os funcionários;

- Conscientização quanto à higiene, evitando manusear $\mathrm{O}$ alimento $e$ dinheiro ao mesmo tempo, e deixando o local limpo e agradável;

- Novas formas de armazenagem do produto e controle da temperatura;

- Treinamento de atendimento ao cliente;

\section{REFERÊNCIAS}

[1] ABRASEL, Associação Brasileira de Bares e Restaurantes. Programa Qualidade na Mesa: Melhoria na Qualidade do Atendimento para Bares e Restaurantes. 2009.

[2] CARPINETTI, L.C.R. Gestão da Qualidade: Conceitos e Técnicas. 2. ed. São Paulo: Atlas, 2010. CROSBY, P. Qualidade é investimento. Rio de Janeiro: José Olympio, 1994.

[3] DE FREITAS, Stella SteadGomideCarneiro. Gestão de qualidade em alimentos e bebidas através da higiene ambiental em unidades de alimentação coletiva. 2004. 122f. Dissertação (Projeto de Pesquisa) - Centro de Excelência em Turismo, Universidade de Brasilia, Brasilia, 2004.

[4] DEMING,W.E. Qualidade: A revolução da administração.Rio de Janeiro: MarquesSaraiva, 1990.

[5] DOS SANTOS, R. L. , et al. Uma análise sobre a qualidade dos serviços em uma academia de ginástica através do método SERVQUAL. Anais do XXXII Encontro Nacional de Engenharia de Produção, São Carlos (SP), Brasil, 2010.

[6] ENGLERT, Natália Fontoura. Cliente oculto: análise do processo de coleta, entrega e utilização das informações obtidas na melhoria do atendimento no varejo. 2011. 96p. Monografia (Trabalho de conclusão de curso) - Departamento de Ciências Administrativas, Universidade Federal do Rio Grande do Sul, Rio Grande do Sul, 2011.

[7] FABIANOWICZ, Francelize. O CLIENTE OCULTO COMO FERRAMENTA DE AVALIAÇÃO DE

[8] DESEMPENHO. 2012. 20 f. TCC (Graduação) - Curso de Gestão Estratégica de Pessoas, Universidade Tuiuti do Paraná, Curitiba, 2012.
- Local para lavar materiais de consumo (copos, pratos, talheres, depósitos, etc) com procedimentos adequados;

- Melhoria na exposição do cardápio.

- Através da execução das sugestões citadas, a lanchonete poderá ter mais clientes satisfeitos, devido uma melhor higienização e conforto, transferindo ao usuário maior segurança no consumo do produto, através de um marketing positivo, sendo assim com sobrevivência em caso de novos competidores, trazendo uma maior confiabilidade no seu gerenciamento da qualidade.

[9] FITZSIMMONS, J. A.; FITZSIMMONS, M. J. Administração de Serviços: Operações, Estratégia e Tecnologia da Informação.7 ed. Porto Alegre: AMGH Editora, 2014

[10] GERHARDT, T. E.; SILVEIRA, D.T. Métodos de pesquisa. Porto Alegre: UFRGS, 2009. 120p. vi

[11] GHOBRIL, A. N.; BENEDETTI, M. H.; FRAGOSO, N.D. Práticas Inovadoras no Setor de Bares, Restaurante e Lanchonetes. VIII Encontro de Estudos e Empreendorismo e Gestão de Pequenas Empresas, EGEPE, Goiânia, março de 2014.

[12] Instituto Brasileiro de Geografia e Estatística. Contas Nacionais Trimestrais: Indicadores de Volume e Valores Correntes. 2013. Disponível em: <ftp://ftp.ibge.gov.br/Contas_Nacionais/Contas_Na cionais_Trimestrais/Fasciculo_Indicadores_IBGE/20 13/>. Acessoem 24 de junho de 2016.

[13] JANKAL, Radoslav; JANKALOVÁ, Miriam.Mystery shopping - the tool of employee communication skills evaluation. Business: Theory and Practice/Verslas: TeorijairPraktika, v. 12, n. 1, p. 45-49, 2011

[14] JURAN, J.M.; GRYNA, F.M. Controle da qualidade - handbook. São Paulo: Makron Books,v.10, 1991. LUCINDA, M. A. Qualidade:Fundamentos e Práticas. Rio de Janeiro:Brasport, 2010.

[15] MARCHETTI, R.; PRADO, P. H. M. Um tour pelas medidas de satisfação do consumidor. Revista de Administração de Empresas, v. 41, n. 4, p. 56-67, 2001.

[16] MINISTÉRIO DO TRABALHO E EMPREGO. ANUÁRIO RAIS: Empregos em 31/12 por Setor. $2012 . \quad$ Disponivel em: 
<http://bi.mte.gov.br/scripts10/dardoweb.cgi>. Acesso em 16 de maio de 2016.

[17] MORGAN, Garteth. Imagens da Organização: edição executiva; tradução Geni G. Goldschmidt. 2. ed. São Paulo: Atlas, 2002.

[18] PALADINI, E. P. Gestão da Qualidade: Teoria e Prática. 3. ed. São Paulo: Atlas, 2012.

[19] PRODANOV, C.C; FREITAS, E.C; Metodologia do trabalho científico: métodos e técnicas da pesquisa e do trabalho acadêmico. Novo Hamburgo: Feevale, 2013. 274p.

[20] REBELATO, M. G. Uma Análise Sobre a Estratégia Competitiva e Operacional dos Restaurantes Self- Service.Gestão \& Produção v.4, n.3, p. 321-322, 1997.

[21] REVISTA Bares e Restaurantes. Conheça as boas e novas ideias para bares e restaurantes. Pulo do Gato. n. 70. Agosto/setembro. Belo Horizonte, 2009,

[22] ROESCH, Sylvia Maria Azevedo. Projeto de estágio do curso de Administração.2.ed., São Paulo. Atlas, 1996. ROBAZZA, E. et al A Comunicação Integrada a favor da construção da reputação do Dobrucki Pub. In: Congresso de Ciências da Comunicação na Região Sul, 17., 2016, Curitiba. Anais... Curitiba: INTERCOM, 2016. p. 1-13.

[23] TARANTOLA, C.; VICARD, P.; NTZOUFRAS, I. Monitoring and improving Greek banking services using Bayesian Networks: An analysis of mystery shopping data. Expert systems withapplications, v. 39, n. 11, p. 10103-10111, 2012.
[24] TELES, P. O Empreendedorismo em Bares e Lanchonetes e a Exigência do Mundo Contemporâneo.Daena:

InternationalJournalofGoodConscience, v. 6, n 1, p. 72-88, 2011.

[25] TURRIONI, J.B.; MELLO, C.H.P. Metodologia de pesquisa em Engenharia de produção. Minas Gerais: UNIFEI, 2012. 199p.

[26] VENTURA, Magda Maria. O estudo de caso como modalidade de pesquisa.RevSocerj, v. 20, n. 5, p. 383-386, 2007.

[27] VILÍMOVÁ, Andrea. Analysis of the Customers' Satisfaction in the Restaurant Planet Sushi. 2014. 68f. Tese de Doutorado. Vysokáškolahotelová v Praze.

[28] WICKS, A. M.; ROETHLEIN, C. J. A satisfaction-based Definition of Quality. Journal of Business \& Economics Studies, v. 15, n. 1, 2009.

[29] WIELE, T. V. der; HESSELINK, M.; IWAARDEN, J. V. Mystery shopping: A tool to develop insight into customer service provision. Total Quality Management, v. 16, n. 4, p. 529-541, 2005.

[30] WILSON, Alan M. The role of mystery shopping in the measurement of service performance. Managing Service Quality: An International Journal, v. 8, n. 6, p. 414-420, 1998.

[31] ZEITHAML, Valarie A. Consumer Perceptions of Price, Quality and Value: A MeansEnd Model and Synthesis of Evidence, 1988 


\title{
Gapítulo 10
}

\section{AVALIACÃO MULTICRITÉRIO DE UMA CONCESSIONÁRIA AUTOMOTIVA}

\author{
Aldery Silveira Júnior \\ Ana Carolina Alves \\ Jorge Alfredo Cerqueira Streit \\ Lorrane Alves Ribeiro
}

Resumo: A atual tendência de os serviços serem desenvolvidos com foco nas necessidades do cliente e não somente no produto, também é uma realidade nas concessionárias automotivas. Deste modo, cria-se um ambiente propício para conhecer as demandas do cliente e assim, aumentar a qualidade do atendimento. O objetivo da pesquisa objeto do presente trabalho foi avaliar uma concessionária automotiva localizada no Distrito Federal, a partir da ótica dos clientes. Para o atingimento de tal propósito, foram utilizados os pressupostos da metodologia Multicritério de Apoio à Decisão (MCDA) para estruturar um modelo de avaliação e combinar as análises geradas, uma vez que a tomada de decisão se baseia em escolhas múltiplas. A pesquisa classifica-se como exploratória, com revisão de literatura precedente à análise dos resultados. Quanto aos procedimentos técnicos, caracteriza-se como um estudo de caso, pois se construiu um modelo para avaliar a percepção dos clientes (stakeholders) sobre a qualidade dos serviços ofertados por uma concessionária. Os critérios básicos de avaliação considerados foram: Recepção dos clientes, Infraestrutura da concessionária e Serviços técnicos (mecânica e funilaria, por exemplo), esses critérios, pela abrangência dos mesmos, foram desmembrados em subcritérios. A avaliação global da concessionária resultou na nota 7,45, numa escala de zero a dez. Os resultados do estudo se mostraram relevantes para os gestores da concessionária, por auxiliá-los na reflexão sobre as necessidades de melhoria da qualidade do atendimento às necessidades e anseios dos clientes.

Palavras-chave: Qualidade de serviços; Atendimento ao cliente; Metodologia multicritério de apoio à decisão. 


\section{INTRODUÇÃO}

No atual cenário econômico caracterizado por uma intensa competição, a prestação de serviços constitui uma das principais fontes de lucros e vantagens competitivas para as concessionárias. Sendo assim, torna-se necessário que os agentes envolvidos no processo desenvolvam estratégias para avaliarem a percepção do cliente final sobre a qualidade dos serviços executados. Parte desta estratégia consiste em implementar programas de qualidade com o intuito de atuar preventivamente quanto às possíveis falhas e situações adversas relacionadas aos serviços prestados.

Nas concessionárias automotivas, os serviços passaram a ser desenvolvidos com foco nas necessidades do cliente e não somente no produto, criando-se um ambiente favorável para o diálogo com o cliente e investindo-se na qualidade do atendimento. Consequentemente, o cliente alvo cria vínculo emocional com a marca, o que tende em aumentar a fidelidade. Dessa forma, as concessionárias que estiverem atentas às reclamações e a as tratem com a devida agilidade, estarão propensas a continuarem no mercado de bens e consumo, e promoverão a fidelização da clientela.

A pesquisa, objeto do presente trabalho, destinou-se a avaliar uma concessionária automotiva situada no Distrito Federal, sob a ótica dos clientes. Ou seja, a partir da percepção dos clientes sobre os serviços que Ihe são oferecidos. Para o atingimento de tal objetivo, utilizou-se dos pressupostos da metodologia Multicritério de Apoio à Decisão (MCDA).

Mesmo diante da existência de diversas metodologias que se apresentam para avaliar a qualidade dos serviços, pode-se concluir que existe uma carência no tratamento dos problemas relacionados à satisfação da clientela. Principalmente aqueles relacionados à qualidade dos serviços prestados pelas concessionárias, principalmente no que se refere à subjetividade e imprecisões inerentes ao processo de julgamento individual. Em função disso e com o intuito de avaliar de forma coerente as alternativas apresentadas na pesquisa, entendeu-se que a metodologia MCDA se adequa aos propósitos do estudo realizado.

A pesquisa buscou avaliar a percepção dos clientes não só sobre a qualidade dos serviços técnicos prestados, mas também sobre a qualidade do atendimento e sobre infraestrutura instalada da concessionária foco. Afinal, sabe-se que somente a qualidade dos produtos vendidos e serviços prestados não constitui uma variável suficiente para se determinar a satisfação do cliente final. O atendimento inicial, a forma como se processa a recepção aos clientes e o tempo gasto para a prestação doa serviços técnicos, entre outros fatores, também constituem variáveis importantes para a fidelização e retenção de clientes. Daí a necessidade de se verificar como os clientes avaliam a concessionária como um todo.

\section{REFERENCIAL TEÓRICO}

Abordar-se-á, de forma an passant, sobre os seguintes tópicos: metodologia Multicritério de Apoio à Decisão (MCDA); o mercado automobilístico nacional; qualidade dos serviços e satisfação dos clientes.

\subsection{METODOLOGIA MULTICRITÉRIO DE APOIO À DECISÃO}

Os métodos multicritérios de apoio à decisão fazem parte do escopo da Pesquisa Operacional (PO). Destaca-se que não se refere, aqui, à Pesquisa Operacional tradicional que ganhou força e destaque após a Segunda Guerra Mundial para solucionar problemas decisórios complexos; mas, referese, sim, à nova abordagem que surgiu a partir dos estudos desenvolvidos na França por Roy, em 1968 e nos Estados Unidos por Keeney e Raiffa (1976) e Saaty (1977), autores considerados os pioneiros da metodologia multicritério de apoio à decisão.

MCDA é uma metodologia voltada para analisar situações complexas, a partir de um conjunto de indicadores quantitativos e qualitativos distintos, incluindo indicadores financeiros, físicos, de insumos, de processos, de produtos e de resultados; que pode ser utilizada tanto para apoio à decisão quanto como um conjunto de técnicas analíticas.

Conforme Moura (2007, p. 292), a metodologia Multicritério de Apoio à Decisão baseia-se:

(...) no mapeamento de variáveis por plano de informação e na definição do grau de pertinência de cada plano de informação e de cada um dos seus componentes de legenda para a construção do resultado final. A 
matemática empregada é a simples média ponderada.

Em geral os resultados são norteados por decisões de natureza operacional ou recomendações para novas atividades. A avaliação multicritério pode ser sintetizada para produzir uma conclusão final da avaliação dos critérios, ou irá produzir decisões adaptadas às preferências e prioridades dos envolvidos. Cada nível da metodologia estabelece as prioridades e preferências entre os critérios.

O objetivo da avaliação multicritério é estruturar e combinar as análises geradas para que se possa chegar em uma decisão, uma vez que a tomada de decisão se baseia em escolhas múltiplas, que em grande medida condiciona a decisão final. É possível sintetizar opiniões expressadas, para determinar prioridades, analisar situações de conflito, formular e proporcionar orientações de natureza operacional.

Ressalta-se que um dos aspectos mais marcantes dos métodos multicritérios diz respeito ao fato de poderem ser utilizados, tanto na análise do processo que antecede a tomada de decisão, quanto também para avaliar uma decisão já tomada, ou seja, para avaliar se os objetivos de uma determinada decisão foram ou não atingidos. Mais precisamente, podem ser utilizados tanto para análises ex ante, quanto para análises ex post (Gomes, 2007).

\subsection{O MERCADO AUTOMOBILÍSTICO NACIONAL}

Nas últimas décadas intensificou-se a chegada de novas marcas automotivas no Brasil. Este fator contribuiu à retomada de operações da indústria automobilística nacional e consequentemente impacta positivamente o cenário econômico brasileiro. Mercado este que absorve os lucros e estabilidade econômica advindos dos investimentos nesse setor, onde encontram-se um sólido parque industrial e uma grande variedade de rede de concessionárias.

No Brasil, pode-se observar que esse mercado evoluiu de um sistema que direcionava suas operações somente à produção, para um sistema orientado para executar estratégias com o intuito de obter a satisfação do cliente final. Cabe mencionar que de acordo com Casotti e Goldenstein (2008), o setor automotivo é reconhecido como um oligopólio global. Neste modelo há um constante processo de consolidação, desenvolvimento de novas tecnologias e modelos de gestão, dispondo de altos índices de parcerias comerciais, incorporações e fusões.

No atual cenário econômico, as montadoras direcionam seus resultados e definições de atividades não somente para a produção, distribuição e venda, mas com esforços que visam ao prolongamento do ciclo de vida dos veículos. As redes de concessionárias alinhadas as montadoras, executam serviços relacionados à venda do veículo novo, revenda dos veículos usados, reparo e manutenção de frotas, disponibilização de peças e acessórios, reciclando e permitindo a extensão da vida útil do veículo.

De acordo com Kotler e Keller (2006), a venda de bens de consumo duráveis, como os automóveis, requer venda pessoal e serviços. Sendo assim, segundo Lovelock e Wright (2001, p. 5), "serviços são um ato ou desempenho oferecido por uma parte à outra". Mediante essa afirmação, pode-se definir concessionárias como sendo uma prestadora de serviços que atua mediante contrato de concessão com redes de distribuição automobilísticas.

Dessa forma, as concessionárias se responsabilizam pela comercialização de veículos, peças e produtos vinculados ao setor automobilístico, bem como a prestação de assistência técnicas e demais serviços vinculados, estabelecendo-se por fim, um vínculo entre a montadora e a concessionária. Sendo assim, a forma de comunicação entre o cliente e a montadora em casos extremos de insatisfação, constituindo-se também como força de negociação afim de conquistar a satisfação do cliente.

\subsection{QUALIDADE DOS SERVIÇOS}

A existência da qualidade gera uma satisfação imediata para o cliente quando suas necessidades e expectativas são atendidas, proporcionando vantagens competitivas para as empresas. Todavia, compreender o conceito de qualidade depende da definição que cada indivíduo apresenta. Sendo assim, de acordo com Tófoli \& Tófoli (2006, p. 77): "O conceito de qualidade tem um sentido amplo, abrange situações completamente distintas, sendo identificado nos sistemas de produção, nas organizações, na otimização de processos, 
produtividade, custos e aprimoramento do sistema".

Cabe salientar que de acordo com Paladini (1994, p. 16), a definição de qualidade "deve ser refinada, para orientar-se para seu alvo específico: o consumidor". Dessa forma, a qualidade deve ser avaliada mediante a adequação ao uso, ao nível de excelência, conformidade com as especificações e diretrizes estabelecidas. A qualidade dos serviços ofertados torna-se satisfação para o cliente, quando o intangível se torna tangível, onde os resultados tornam-se visíveis e palpáveis.

No presente trabalho, constatou-se níveis diferenciados de insatisfação dos clientes quanto as alternativas expostas. Para Albrecht (1998), algumas das queixas comuns dos clientes estão relacionadas aos prazos de entregas que são descumpridos, preços que vão contra suas disponibilidades com gastos, apatia, demora e inflexibilidade no decorrer da recepção e atendimento, bem como o recebei a inabilidade com as tecnologias que as empresas the impõem. Frente a um mercado cada vez mais concorrido, torna-se imprescindível a utilização de um gerenciamento direcionado para proporcionar a qualidade dos serviços.

\subsection{SATISFAÇÃO DO CLIENTE}

De acordo com Sant'anna (2003, p.17), "é o consumidor que se encontra no ponto central absoluto do universo comercial. São as companhias que giram em torno do consumidor, e não o inverso". Diante do exposto e principalmente mediante um mercado de ampla concorrência como o automobilístico, conclui-se a importância das estratégias para satisfazer as expectativas dos clientes, propiciando assim a retenção, captação e fidelização dos clientes. Desse modo, Kotler \& Keller (2006, p. 142) fazem as seguintes explanações sobre satisfação:

\begin{abstract}
A sensação de prazer ou desapontamento resultante da comparação entre o desempenho (ou resultado) percebido de um produto em relação a suas expectativas. Se o desempenho não alcançar as expectativas o cliente ficará insatisfeito. Se alcançá-las, ele ficará satisfeito. Se o desempenho for além das expectativas o cliente ficará altamente satisfeito ou encantado.
\end{abstract}

No tocante às concessionárias, a percepção e expectativa do cliente quanto aos serviços e produtos disponibilizados influenciam 0 posicionamento das concessionárias nos rankings de lideranças e preferências no mercado automobilístico. Dentre os desafios desse setor, insta salientar a barreira que existe no primeiro contato com o cliente, onde se deve convence-lo a adquirir o produto e estabelecer assim, uma relação de confiança. Outro desafio está na comercialização dos serviços de pós venda, onde se deve reter o cliente ao demonstrar o melhor custo benefício mesmo após o término dos prazos de garantia.

De acordo com Kotler (2000, p. 58), "um cliente altamente satisfeito ou um cliente encantado vale, seguramente, muito mais para a empresa do que um cliente apenas satisfeito". Conclui-se assim que o reconhecimento e resolução das reais necessidades e demandas dos clientes, manutenção dos procedimentos de atendimento, redução de dispersões no decorrer da execução das vendas e realização qualificada de serviços, resultam em formas de reter a clientela e prospectar novos indicadores de compras futuras.

\section{METODOLOGIA DE PESQUISA}

O instrumento de intervenção utilizado foi a metodologia Multicritério de Apoio à Decisão, e seguiu as premissas, ditames e fundamentos epistemológicos propostos por Ensslin et al. (2001). Inicialmente, definiu-se o rótulo da pesquisa, como sendo a percepção dos clientes da concessionária sobre a qualidade dos serviços. Em seguida, ocorreu a identificação dos atores envolvidos nos processos de avaliação, a saber: agidos, decisores e facilitadores.

$\mathrm{Na}$ sequência, procedeu-se a identificação dos elementos de avaliação, denominados como critérios ou Pontos de Vistas Fundamentais (PVF), os quais foram validados pelos decisores, constituindo-se, assim na família de PVFs do modelo. Estes, devido a complexidade dos mesmos, foram decompostos em Pontos de Vistas Elementares (PVE), constituindo-se, assim, a estrutura básica do modelo multicritério de decisão, apresentada a seguir:

a) PVF 1 - Recepção dos clientes

- PVE 1.1 - Hospitalidade dos recepcionistas; 
- PVE 1.2 - Benesses disponibilizadas para os clientes (café, água, jornais, revistas, TV, música ambiente);

- PVE 1.3 - Agilidade do atendimento por parte dos recepcionistas;

b) PVF 2 - Infraestrutura da concessionária

- PVE 2.1 - Instalações físicas;

- PVE 2.2 - Limpeza e higienização das dependências;

- PVE 2.3 - Estacionamento para clientes;

- PVE 2.4 - Acessibilidade à Concessionária (localização / vias de acesso);

c) PVF 3 - Serviços técnicos (mecânica, funilaria, pintura, etc.)
- PVE 3.1 - Qualidade dos serviços prestados pela Concessionária

- PVE 3.2 - Tempo despendido pela Concessionária para execução dos serviços

- PVE 3.3 - Preço dos serviços prestados pela Concessionária

O passo seguinte constou da definiu-se os descritores dos critérios de avaliação. cada descritor corresponde a um conjunto de níveis de impacto (NI) destinados a descrever as performances plausíveis das ações potenciais, estas entendidas como as alternativas que estão sendo avaliadas. Os descritores utilizados foram comuns para todos os critérios de avaliação, os quais estão detalhados no Quadro 1.

Quadro 1 - Descritores dos critérios de avaliação

\begin{tabular}{|c|c|}
\hline Nivel de Impacto & Descritor \\
\hline N5 & Excelente \\
\hline N4 & Muito bom \\
\hline N3 & Bom \\
\hline N2 & Regular \\
\hline N1 & Ruim \\
\hline \multicolumn{2}{|c|}{ Fonte: Autores } \\
\hline
\end{tabular}

Com o intuito de quantificar a performance das ações potenciais, definiu-se, com o apoio do aplicativo Hivew3, as funções de valor. Para tanto, foram construídas uma série de matrizes de julgamento semântico, uma para cada PVE, a partir das escalas definidas pelo Hiview3. Apresenta-se na Figura 1, a título de exemplo, a matriz de julgamento semântico do PVE $1.1 \quad-$ Hospitalidade dos recepcionistas.

Figura 1 - Matriz de julgamento semântico do PVE 1.1 - Hospitalidade dos recepcionistas

\begin{tabular}{|c|c|c|c|c|c|c|c|}
\hline \multicolumn{6}{|c|}{ 의 Macbeth : Hospitalidade } & - & $\times$ \\
\hline & N5 & N4 & N3 & N2 & N1 & $\begin{array}{l}\text { Current } \\
\text { scale }\end{array}$ & extreme \\
\hline N5 & no & very weak & weak & strong & ২. strong & 100 & Y. strong \\
\hline N4 & & no & very weak & moderate & strong & 80 & strong \\
\hline N3 & & & no & weak & moderate & 60 & moderate \\
\hline N2 & & & & no & weak & 30 & weak \\
\hline N1 & & & & & no & o & $\begin{array}{c}\text { very weak } \\
\text { no }\end{array}$ \\
\hline \multicolumn{7}{|c|}{ Consistent judgements } & \\
\hline
\end{tabular}

Fonte: Hievew3 
A construção do modelo foi concluída com a definição das taxas de substituição (pesos) dos PVFs e PVEs. A Figura 2 demonstra a estrutura do modelo construído com a indicação dos pesos dos critérios e subcritérios.

Figura 2 - Árvore de valor

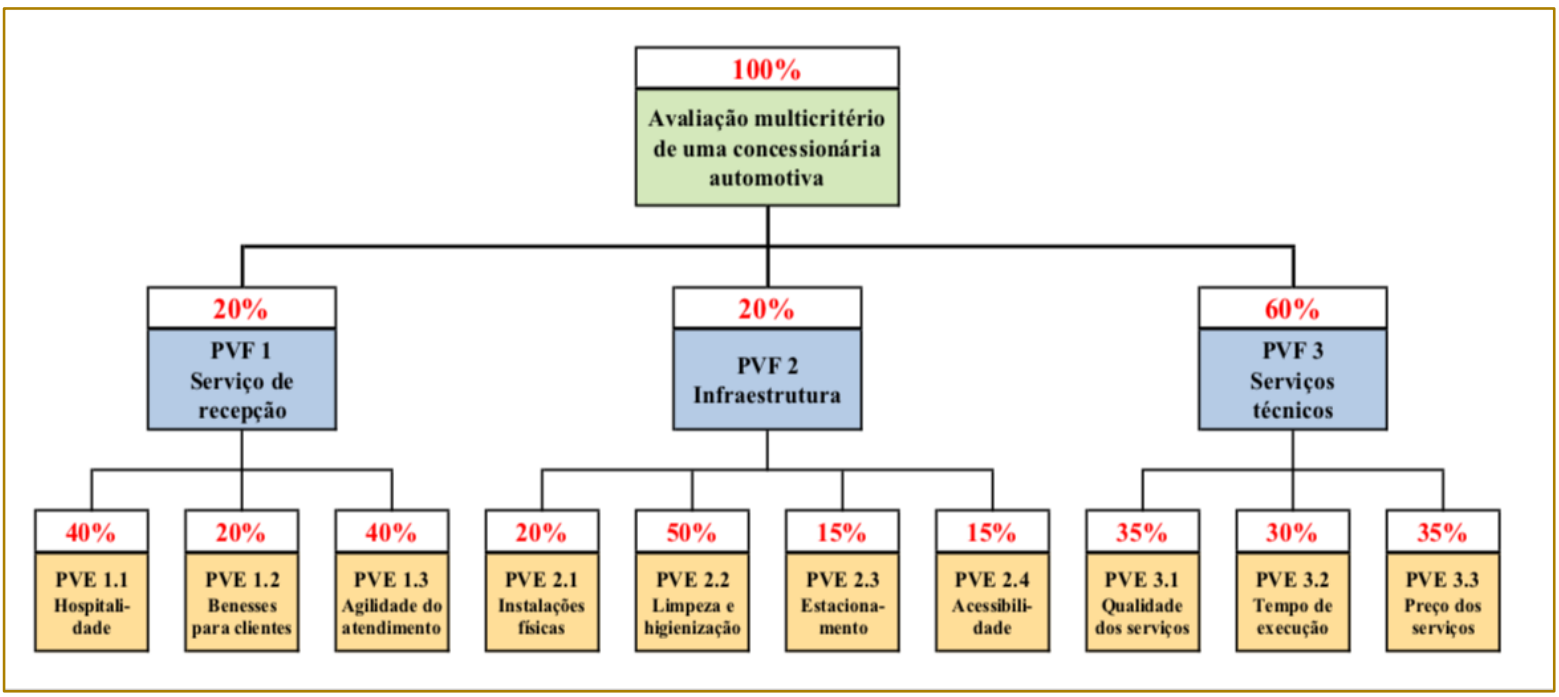

Fonte: Autores

A pesquisa classifica-se como exploratória, pois buscou-se aprofundar o nível de conhecimento sobre o objetivo da pesquisa, tendo a revisão literária proporcionado o embasamento teórico necessário para se proceder à análise dos resultados. A natureza do artigo define-se como estudo prático por se basear na realização de um caso real. Quanto aos procedimentos técnicos, a presente pesquisa caracteriza-se como um estudo de caso, pois construiu-se um modelo para avaliar uma concessionária, a partir da percepção dos seus clientes sobre a qualidade dos serviços que thes são ofertados, caracterizando-se em uma investigação empírica de um fenômeno contemporâneo em um contexto real (YIN, 2005).
O questionário aplicado aos clientes da concessionária foi construído a partir do modelo desenvolvido: cada PVE deu origem a uma pergunta específica, cujas alternativas de respostas foram definidas a partir dos descritores.

\section{APRESENTAÇÃO E ANÁLISE DOS RESULTADOS}

A pesquisa de campo foi realizada no período de 30 de outubro a 18 de novembro de 20117 e constou da aplicação de questionários a 34 clientes da concessionária. Os resultados foram tratados pelo aplicativo Hievew3, a partir dos parâmetros (pesos e funções de valores) definidos no modelo de avaliação. Apresenta-se na Figura 3 o resumo do resultado das avaliações.

Figura 3 - Resultado das avaliações

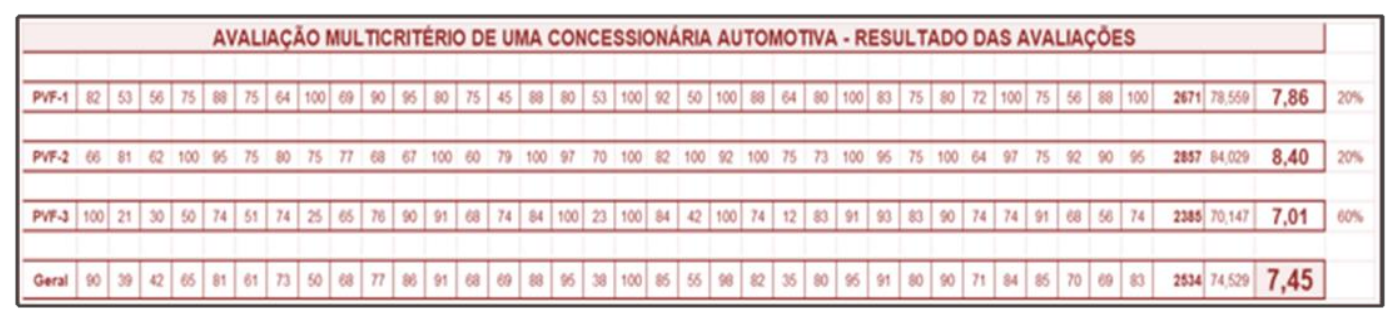

Fonte: Hievew3 
A avaliação global, conforme evidenciado, resultou na nota 7,45 , numa escala de zero a dez. Essa nota apesar de ser considerada boa, poderia ter sido bem melhor. As justificativas para essa avaliação são apresentadas nas análises a seguir.

No PVF 1 - Recepção dos clientes, que possui peso de $20 \%$, analisou-se três pontos de vistas elementares: Hospitalidade dos recepcionistas, Benesses disponibilizadas para os clientes (café, água, jornais, revistas, TV, etc.) e Agilidade do atendimento por parte dos recepcionistas. A avaliação final desse PVF ficou em 7,86, conforme demonstrados nos Quadros da Figura 4 (o primeiro Quadro apresenta os valores brutos, enquanto que o segundo Quadro apresenta os dados ponderados, com base dos pesos definidos no modelo de avaliação).

Figura 4 - Resultado da avaliação do PVF Recepção dos clientes

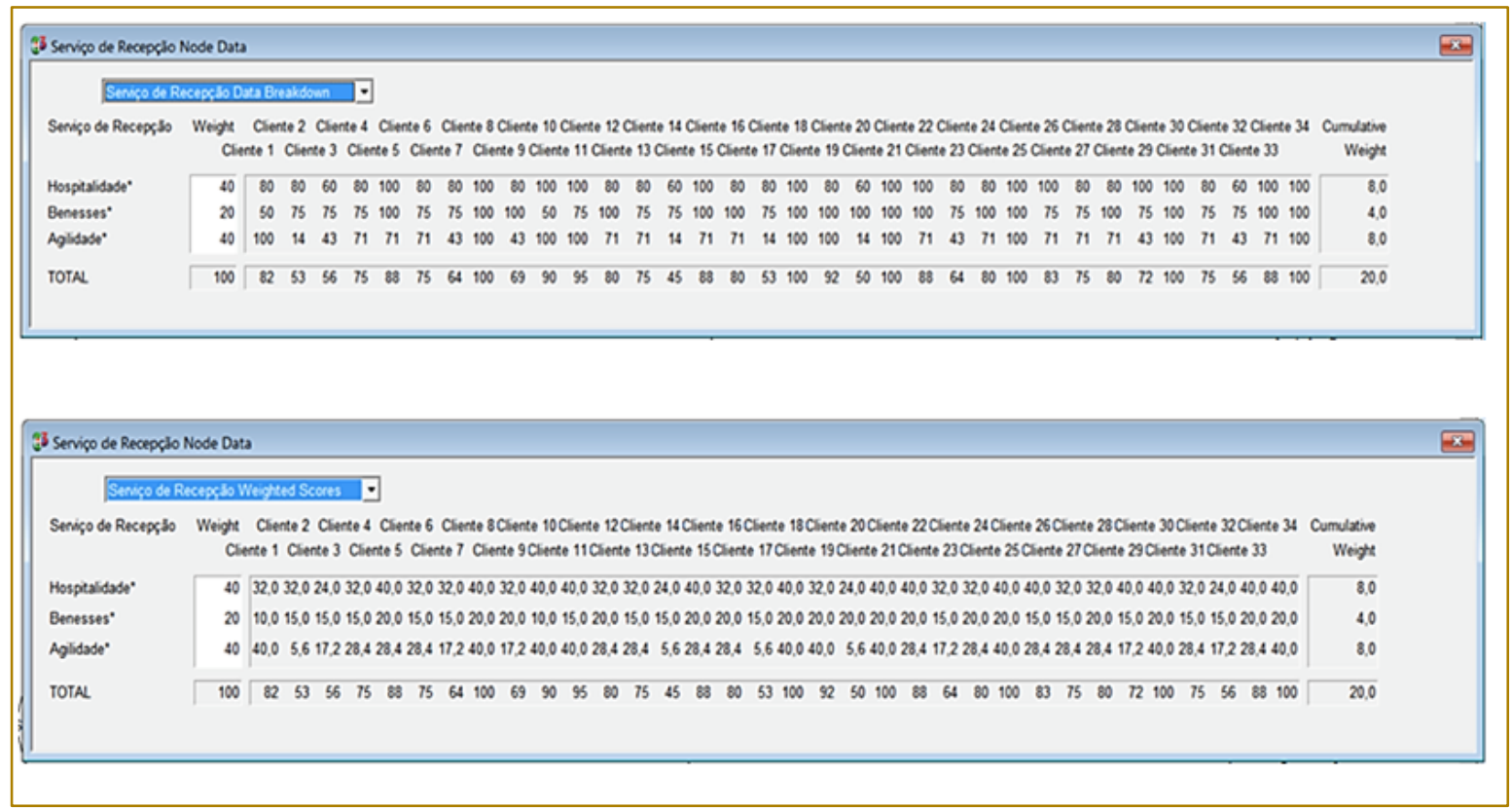

Fonte: Hievew3

Um possível motivo para a nota obtida consiste no fato de que a concessionária está constantemente desenvolvendo melhorias no ambiente destinado para a recepção dos clientes, no entanto, os colaboradores responsáveis pelo atendimento não passam por treinamentos e desenvolvimento de habilidades constantemente, contando ainda com a existência de novos contratados que não se adequam às diretrizes da concessionária quanto à recepção.
Quanto ao PVF 2 - Infraestrutura da concessionária, com peso de $20 \%$, analisouse quatro pontos de vista elementares: Instalações físicas, Limpeza e higienização das dependências, Estacionamento para clientes e Acessibilidade à concessionária, ou seja, localização e vias de acesso. A avaliação obtida por esse PVF foi 8,40 , a maior média entre os pontos de vista fundamentais analisados, conforme demonstrado nos Quadros da Figura 5. 
Figura 5 - Resultado da avaliação do PVF Infraestrutura

\begin{tabular}{|c|c|c|c|}
\hline \multicolumn{3}{|c|}{ Ji intrentrutura Node Dota } & $x$ \\
\hline \multicolumn{4}{|c|}{ 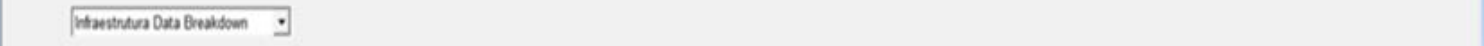 } \\
\hline Intrethena & 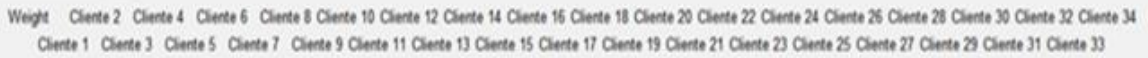 & Wenien & \\
\hline Acensibledos" & 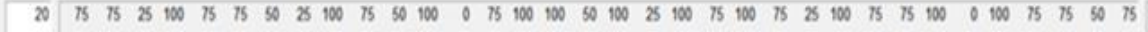 & 40 & \\
\hline Intaks bes: & 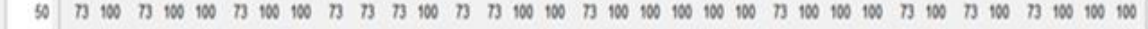 & 100 & \\
\hline Limperationizack bo" & 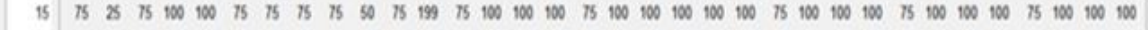 & 30 & \\
\hline Estrcionamento" & 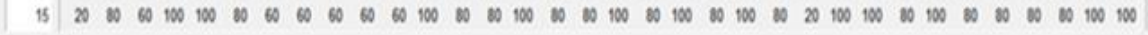 & 30 & \\
\hline TOTN & 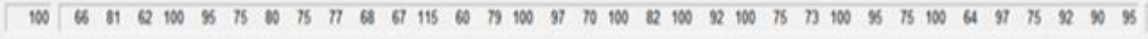 & 200 & \\
\hline \multicolumn{3}{|c|}{ 2 } & 묘 \\
\hline \multicolumn{4}{|c|}{ Hhrastrutua Wequed Scoes } \\
\hline Uhastreven & 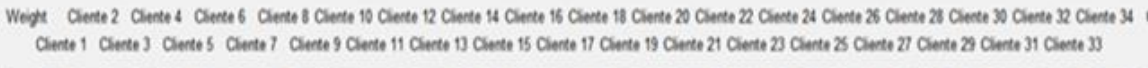 & Converen & \\
\hline Acensibliade" & 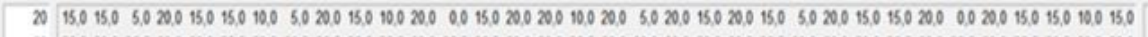 & 40 & \\
\hline metexples: & 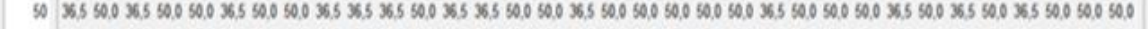 & 10,0 & \\
\hline Limperahigenaxsb" & 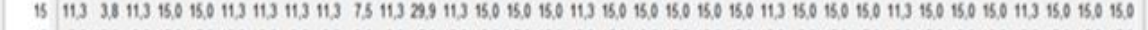 & 30 & \\
\hline Estccionumento" & 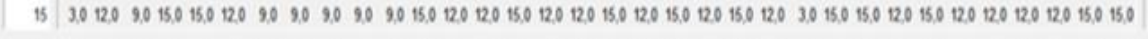 & 30 & \\
\hline TOTN & 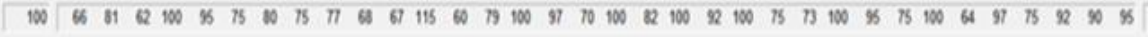 & 200 & \\
\hline
\end{tabular}

Fonte: Hievew3

A avaliação positiva demonstrada por parte dos clientes pode ser justificada mediante o fato de que as instalações da concessionária são regularmente vistoriadas pela marca automotiva da qual estabeleceu contrato, mantendo-se assim um elevado padrão de qualidade quanto ao espaço físico e manutenção do estacionamento. No tocante a acessibilidade à concessionária, a mesma está localizada em um setor geograficamente estratégico.

No que diz respeito, ao PVF 3 - Serviços técnicos, que engloba a mecânica, funilaria e pintura, analisou-se três PVE: Qualidade dos serviços prestados pela concessionária, Tempo despendido pela concessionária para execução dos serviços e Preço dos serviços prestados pela concessionária. Obteve-se nesse PVF a menor nota entre os três avaliados, 7,01, conforme demonstrado nos Quadros da Figura 6.

A respeito da nota obtida nesse PVF, pode-se expor uma série de variáveis que induziram aos clientes a essa avaliação final. Dentre essas variáveis está o fato de que atualmente, a marca automotiva da qual a concessionária possui um contrato, está enfrentando problemas de logística e faturamento quanto a produção de peças e acessórios, o que impacta diretamente no tempo que os automóveis ficam na oficina da concessionária.

Outra variável impactante quanto a avaliação dos clientes consiste na ineficiência da marca automotiva em produzir segunda via de etiquetas e plaquetas para os automóveis que saíram da garantia, essa ocorrência ocasionou problemas da parte dos clientes com relação ao Departamento de Trânsito do Distrito Federal (Detran-DF). Com relação aos preços cobrados pela concessionária, os clientes alegam que existem diferenças entre as peças genuínas preferencialmente escolhidas que não correspondem ao custo benefício. Essa variável também não se torna interessante para os clientes tendo em vista que os valores cobrados na oficina da concessionária são mais altos do que em estabelecimentos paralelos. 
Figura 6 - Resultado da avaliação do PVF Serviços técnicos

\begin{tabular}{|c|c|c|c|}
\hline \multicolumn{4}{|c|}{ 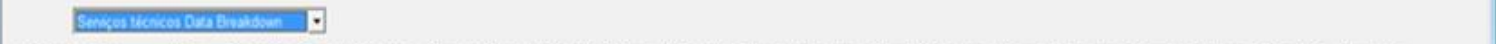 } \\
\hline Seniçes tiknicos & 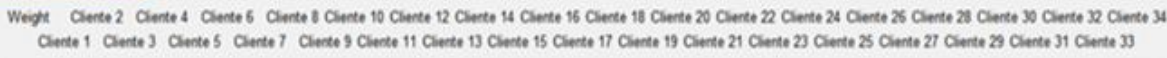 & \multicolumn{2}{|c|}{ Wuster } \\
\hline Cualdeses do renico" & 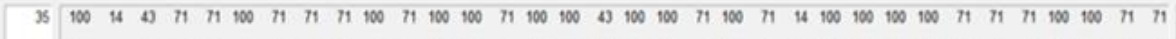 & 210 & \\
\hline Tempo de execusto". & 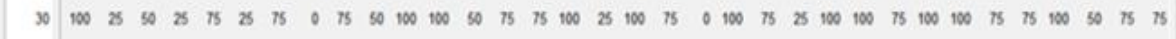 & 180 & \\
\hline TOTN & 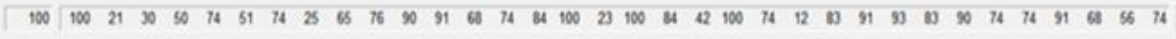 & 600 & \\
\hline \multicolumn{2}{|c|}{3 Senvipos therices Node Data } & & 这 \\
\hline \multicolumn{4}{|c|}{ 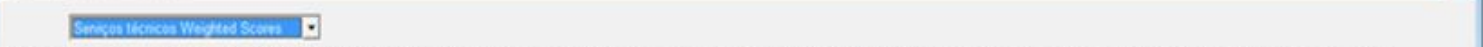 } \\
\hline Qualdade do rençso" & 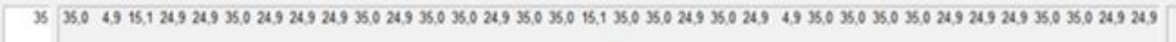 & 21.0 & \\
\hline Tempo de enecustot & 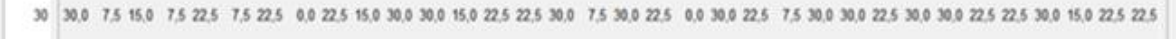 & 130 & \\
\hline Presso' & 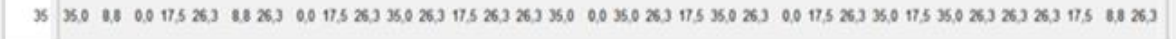 & 210 & \\
\hline TOTA & 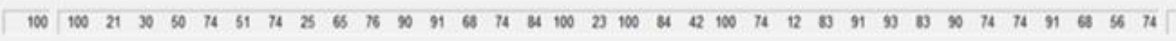 & 600 & \\
\hline
\end{tabular}

Fonte: Hievew3

Por fim, apresenta-se, para fins de demonstração, o Gráfico da Figura $7 \mathrm{com}$ a participação de cada PVE na avaliação global, de acordo com os pesos de cada um deles e as respectivas respostas impactadas pelos participantes da pesquisa.

Figura 7 - Participação de cada PVE no resultado global

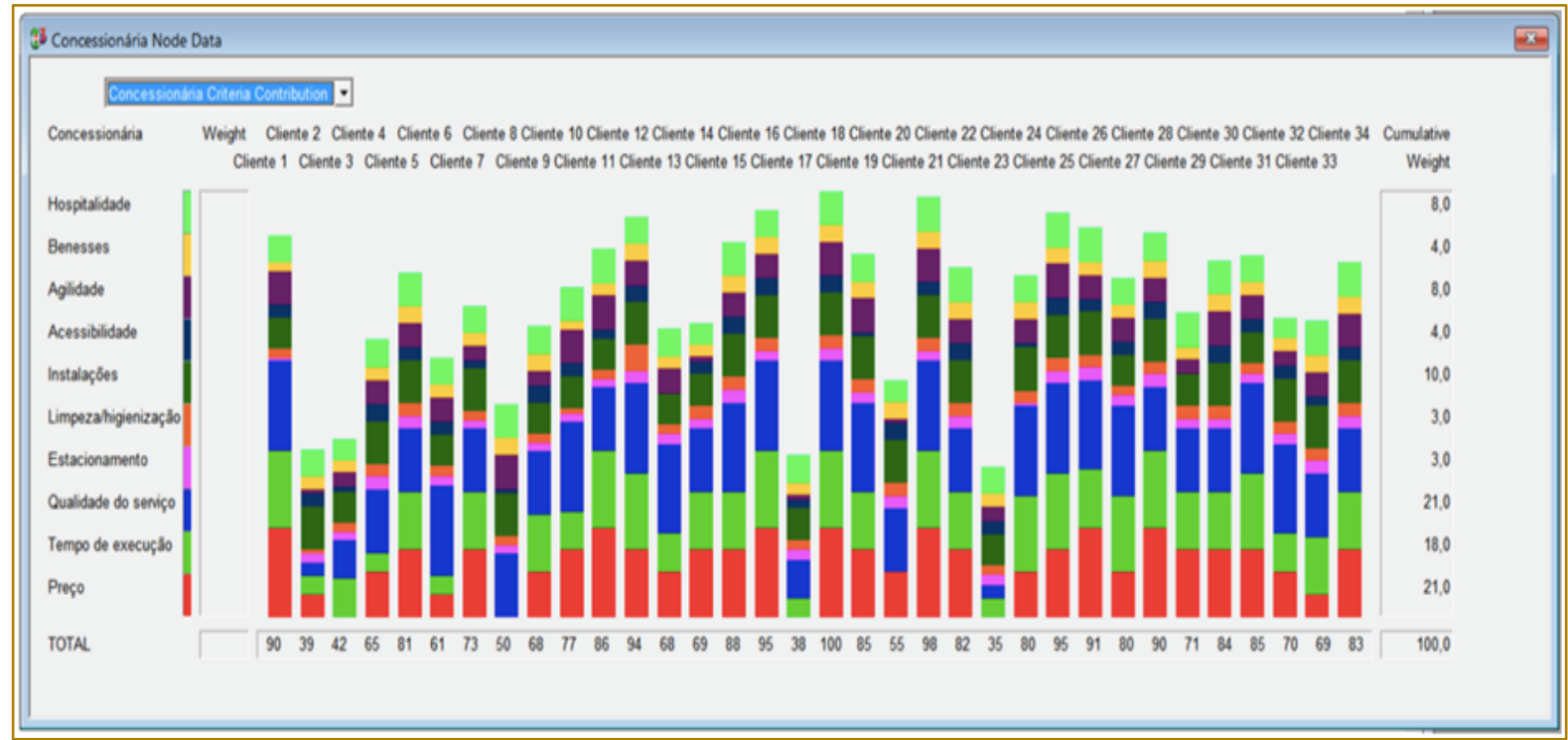

Fonte: Hievew3 


\section{CONCLUSÃO}

A fim de mensurar a qualidade dos serviços prestados pela concessionária " $X$ ", foi utilizado no artigo em questão o Método de Avaliação Multicritério que é capaz de analisar quantitativamente os resultados obtidos por meio de questionários de análise dos serviços prestados. O método foi essencial para chegar as médias de cada serviço oferecido, direta ou indiretamente, pois transformar dados qualitativos em quantitativos nos trouxe notas exatas para cada serviço prestado pela concessionária.

Para salientar, os resultados obtidos através da metodologia são interessantes para auxiliar o gestor do negócio a entender quais são as necessidades de melhora dentro do estabelecimento e pode aplicar seus esforços em pontos estratégicos o que pode posteriormente trazer um aumento da média obtida. É importante que o prestador de serviço esteja sempre atento aos problemas existentes em sua empresa, para que dessa forma seus clientes possam sempre usufruir de serviços com qualidade.

O fato dos serviços técnicos terem obtido a média mais baixa dentre os PVFs faz com que o gestor procure melhorar seus serviços

\section{REFERÊNCIAS}

[1]. CASOTTI, B. P. \& GOLDENSTEIN, Marcelo. Panorama do setor automotivo: as mudanças estruturais da indústria e as perspectivas para o Brasil. BNDES Setorial, Rio de Janeiro, n. 28, p.148-151, set. 2008.

[2]. COBRA, Marcos. Marketing de Serviço Financeiro. São Paulo: Cobra, 2000.

[3]. ENSSLIN, L.; MONTIBELLER NETO, G.; \& NORONHA, S. M. Apoio à Decisão: Metodologias para Estruturação de Problemas e Avaliação Multicritério de Alternativas. Florianópolis: Insular, 2001.

[4]. GOMES, L. F. A. M. Teoria da decisão. (Coleção debates em Administração). São Paulo: Thomson Learning, 2007.

[5]. KOTLER, Philip. Administração de Marketing: Análise, planejamento, implementação e controle. 5aㅡ ed. São Paulo: Atlas, 2000.

[6]. KOTLER, P. \& KELLER, K. L. Administração de marketing: a bíblia do marketing. 12. ed. São Paulo: Pearson, 2006. prestados nesse quesito, tendo em vista que os clientes não irão procurar uma oficina com serviços caros e com longos prazos de entrega, por isso esse Ponto de Vista Fundamental recebeu peso maior, uma vez que o carro é uma necessidade do cliente o mesmo não optará por infraestrutura ou boa recepção primeiramente, mas sim por qualidade dos serviços técnicos existentes.

Tendo em vista que o fornecedor da concessionária em análise é uma marca forte, traz para a empresa maior credibilidade, atraindo muitos clientes que apostam na marca mesmo não conhecendo a qualidade dos serviços prestados, dessa forma a avaliação multicritério pode ser interessante para auxiliar os novos clientes a tomarem decisão em escolher a concessionária. A transparência da empresa em mostrar esses resultados para o cliente pode acarretar em uma relação verdadeira entre eles, o que é fundamental para estabelecer os novos adeptos a marca e fidelizar a parcela que já conhece o estabelecimento. Esse fator também irá auxiliar a constantemente em investimentos no setor, trazendo para o consumidor final serviço de excelência no mercado do Distrito Federal.

[7]. LOVELOCK, C. \& WRIGHT, L. Serviços: Marketing e Gestão. São Paulo, Saraiva, 2001.

[8]. MOURA, A. C. Reflexões metodológicas como subsídio para estudos ambientais baseados em Análise de Multicritérios. Anais - XIII Simpósio Brasileiro de Sensoriamento Remoto, Florianópolis, 2007.

[9]. PALADINI, E. P. Qualidade Total na Prática: implantação e avaliação de sistemas de qualidade total. São Paulo: Atlas, 1994.

[10]. SANT'ANNA, Armando, Propaganda: teoria, técnica e prática. São Paulo: Pioneira Thomsom Learning, 2002.

[11]. TÓFOLI E. T. \& TÓFOLI I. A Busca da Qualidade no Atendimento em empresas do Setor Supermercadista da Região Noroeste do Estado de São Paulo. Facef Pesquisa, v. 9 n.1 São Paulo janabr 2006.

[12]. YIN, R.K. Estudo de caso: planejamento e métodos. 3. ed. Porto Alegre: Bookman, 2005. 


\section{Capítulo 11}

\section{MINERAÇÃO DE DADOS EDUCACIONAIS: ANÁLISE DE TRABALHOS CORRELATOS}

\section{Elpidio Oscar Benitez Nara}

Gustavo Choaire

Jones Luís Schaefer

Ismael Cristofer Baierle

Resumo: A evasão do ensino superior é caracterizada como sendo o desligamento da instituição de ensino superior e a não obtenção do seu diploma. Este é um problema que vem ocorrendo com frequência e varia de acordo com a instituição e o país. As Instituições de Ensino Superior públicas têm menor evasão que as privadas, ocasionando a preocupação de educadores e empresários. O presente artigo tem como objetivo principal pesquisar e analisar autores com trabalhos correlatos a Mineração de Dados Educacionais e identificar quais são principais riscos e motivos causadores do problema da evasão escolar no ensino superior. Para isso, foi realizada uma pesquisa bibliométrica e bibliográfica nas principais bases de dados: Scopus, Web of Science, Science Direct e Scielo.

Palavras-chave: Evasão Escolar; Mineração de dados Educacionais; Ensino Superior. 


\section{INTRODUÇÃO}

Conforme Tontini e Walter (2014), desde o final da década de 90, o governo federal, em parceria com as instituições de ensino superior (IES), busca ampliar o acesso ao ensino superior. A partir de 1994, as IES privadas foram incentivadas a ampliar as vagas ofertadas, enquanto que nas IES públicas as vagas passaram a ser ampliadas após 2002. Neste contexto, segundo Da Silva (2013), se a política de expansão do ensino superior se baseia na ampliação de vagas ofertadas, conhecer os fatores que impactam na permanência e evasão nestes cursos é fundamental para a concretização desta política.

Para Rigo, Cambruzzi e Barbosa (2014) a evasão que pode estar associada a situações de desistência definitiva após determinado contato com o curso ou a ocorrência da simples interrupção no ciclo de estudos, independentemente do nível do estudante dentro do curso ou da duração da interrupção. As perdas ocasionadas pelo abandono do aluno são desperdícios sociais, acadêmicos e econômicos. Enquanto que no setor público recursos são investidos sem o devido retorno, no setor privado as taxas de evasão representam uma importante perda de receita (BAGGI; LOPES, 2011; SILVA FILHO et al., 2007).

Embora existam estudos que abordem os fatores que levam o aluno a evadir, não são encontrados na literatura nacional estudos que tenham como objetivo identificar métodos que auxiliem as IES no diagnóstico do real risco de evasão (TONTINI; WALTER, 2014). Segundo Silva (2013), as metodologias encontradas na maior parte dos trabalhos nacionais tratam da evasão em casos específicos, impedindo que os resultados sejam generalizados ou replicados em outras IES. Como exemplo, citam-se trabalhos baseados na coleta de dados através da aplicação de questionários ou entrevistas aos alunos evadidos.

Alguns trabalhos vêm abordando o tema com a aplicação de técnicas de Mineração de Dados, a fim de gerar subsídios para a tomada de decisão gerencial no que tange a mitigação do problema da evasão (RIGO; CAZELLA; CAMBRUZZI, 2012; MANHÃES et al., 2012; RIGO; CAMBRUZZI; BARBOSA, 2014), outros as utilizam para buscar desenvolver métodos para a predição de desempenho acadêmico (GOTTARDO;
KAESTNER; NORONHA, 2012 e 2014), ou ainda buscar agrupar os estudantes através da descoberta de padrões comportamentais (MACHADO; BECKER, 2012; PENEDO; CAPRA, 2012). No entanto, a maioria dos trabalhos correlatos tem como foco os Ambientes Virtuais de Aprendizagem (AVAs), sobretudo na Educação a Distância (EAD).

O uso de técnicas de Mineração de Dados no campo da educação é conhecido como Mineração de Dados Educacionais (MDE). Segundo Dekker et al. (2009), a metodologia não é transparente e não estão claros quais algoritmos devem ser preferencialmente adotados neste contexto. Esta lacuna se deve à natureza dos dados obtidos nos diversos sistemas educacionais, uma vez que esta é mais diversa do que a observada nos dados tradicionalmente utilizados, demandando adaptações e o desenvolvimento de novas técnicas. Sendo assim, a exploração de algoritmos, técnicas e mecanismos é crucial para que sejam alcançados resultados que contribuam para a mitigação de contextos de evasão escolar (DEKKER et al., 2009; RIGO; CAZELLA; CAMBRUZZI, 2012).

O objetivo deste artigo é conhecer a evolução dos trabalhos relacionados à Mineração de Dados Educacionais no mundo cientifico, incorporando suas correlações de forma a agregar o conhecimento da mineração de dados na evasão escolar no ensino superior e apresentar as técnicas utilizadas nos artigos encontrados, indicando possíveis lacunas do conhecimento neste âmbito, possibilitando assim conhecimento sobre $\mathrm{o}$ assunto $\mathrm{e}$ direcionando possíveis trabalhos futuros.

\section{METODOLOGIA}

A bibliometria é utilizada como apoio na comparação em avaliações de indivíduos e instituições, tendo vantagem medidas objetivas de comparação (ABRAMO; COSTA; D'ANGELO, 2015). Com isso, foi realizada uma pesquisa bibliométrica para verificar trabalhos correlatos, tomando como fonte de dados os artigos publicados nas bases Scopus, Web Of Science, ScienceDirect e Scielo. Foram utilizadas as Palavras chave "Data Mining" e "Educational Data Mining" e algumas palavras associadas à evasão escolar.

Visando analisar os resultados obtidos, a pesquisa foi estruturada de modo que a busca pudesse ser replicada nas quatro 
bases de dados. Para tanto, as palavras foram pesquisadas dentro dos campos "Título do Artigo" (Article Title), "Resumo" (Abstract) e "Palavras-chave" (Keywords). Em todas as etapas da pesquisa, foram consultados apenas artigos científicos publicados nos últimos 10 anos até março do ano de 2015. Para analisar quantitativamente as técnicas de Mineração de Dados utilizadas foram elaboradas duas tabelas de forma a quantificar a utilização das técnicas em artigos científicos.

\section{RESULTADOS}

Segundo Sangodiah et al. (2015), na Malásia a evasão escolar é um problema predominantemente observado em Instituições de Ensino Superior (IES). Embora os índices de evasão variem de uma instituição para outra, em geral o problema é visto com preocupação pelas IES devido ao consequente desperdício de recursos acadêmicos e administrativos bem como pelos efeitos sociais adversos. Conforme o autor, embora haja inúmeras abordagens que visam minimizar o problema da evasão escolar, estas não são eficazes em prever quais os alunos com maior probabilidade de evadir. Nos últimos anos, abordagens que utilizam de técnicas de mineração de dados vêm sendo adotadas com o objetivo de prever os alunos com potencial risco de evasão, entretanto nem todas as técnicas e dados relevantes foram completamente exploradas. Assim sendo, o estudo se concentra na utilização de máquinas de vetores de suporte (Support Vector Machines - SVMs) visando predizer a probabilidade dos alunos ficarem em exame (probation status), fato que, segundo os autores, na maioria dos casos leva o aluno a se desligar do curso. O estudo também aborda outros fatores relevantes que contribuem para a evasão escolar na Malásia. Os resultados são tidos como satisfatórios, visto que atingem bons índices de acurácia mesmo com pequenos conjuntos de dados.

Lara et al. (2014) propõem o uso de descoberta de conhecimento em bases de dados (KDD) para extrair informações úteis a partir da análise dos dados gerados pela interação de alunos em ambientes e-learning, como o Moodle, por exemplo. Para isso, os autores desenvolveram modelos baseados em dados históricos, tanto de alunos que evadiram quanto de alunos que concluíram o curso. Os modelos gerados foram usados para classificar os estudantes dentro desses grupos.

Garcia-Saiz et al. (2014) abordam a análise de redes sociais (social network analysis - SNA) afirmando haver uma rede social inerente a qualquer contexto de aprendizagem, onde professores, alunos e recursos de aprendizagem se comportam como atores e diferentes relacionamentos podem ser definidos. A partir da análise destes relacionamentos, é possível obter informações sobre coesão de grupo e conexões entre indivíduos. O trabalho ressalta a importância de ferramentas que auxiliem os profissionais envolvidos no processo de ensinoaprendizagem, citando a descoberta de perfis comportamentais de alunos, a descoberta de padrões relacionados ao desempenho de alunos e/ou abandono de curso e possíveis aplicações. Por fim, os autores apresentam e descrevem uma ferramenta e-learning baseada em Mineração de Dados Web (Web Mining) e suas novas funcionalidades apoiadas em técnicas de SNA e classificação.

Tekin (2014) destaca o recente interesse pela extração de informações ocultas em bancos de dados educacionais visando ajudar alunos com baixo rendimento a melhorar seu desempenho acadêmico. Através de técnicas de mineração de dados, como agrupamento (clustering), classificação métodos de regressão e redes neurais (Neural Networks $\mathrm{NN}$ ), máquina de aprendizagem extrema (Extreme Learning Machine - ELM) e máquinas de vetores de suporte (Support Vector Machines - SVM) é possível extrair informações valiosas a partir dos dados educacionais. O estudo implementa diversas técnicas de predição em mineração de dados com o objetivo de prever a média final do aluno (Grade Point Average - GPA), e assim permitir que sejam realizadas ações proativas com foco nos alunos com maior probabilidade de obter médias baixas.

Seguindo essa linha de pesquisa, Strecht, Mendes-Moreira e Soares (2014) afirmam que prever o fracasso de alunos universitários pode ser de interesse para os gestores de cursos e programas, bem como para explicar o fenômeno da evasão escolar. Embora seja importante ter modelos a nível de curso, o desafio maior consiste em obter modelos que possam ser usados para extrair conhecimento útil a nível de IES. Portanto, para apoiar a tomada de decisão neste nível é preciso generalizar o conhecimento contido nos modelos individuais. Neste contexto, o 
trabalho propõe uma abordagem que permita agrupar e mesclar modelos interpretáveis a fim de substituí-los por modelos genéricos, sem comprometer a qualidade do desempenho preditivo. Embora os resultados obtidos sejam promissores, eles sugerem abordagens alternativas para o problema.

O trabalho desenvolvido por Yasmin (2013) demonstra a aplicação de análise da aprendizagem (Learning Analytics) visando determinar preditores de abandono escolar na Índia, no contexto do ensino aberto e à distância. O estudo, de caráter quantitativo, utilizou árvores de classificação para examinar a relação preditiva entre as variáveis demográficas dos alunos com $\mathrm{O}$ seu comportamento de abandono. As variáveis demográficas e acadêmicas dos alunos, como sexo, estado civil, situação empregatícia, tema escolhido, condição social, idade e nível de rendimentos foram tomados como variáveis independentes ou explicativas para prever as variáveis de resposta. A análise dos dados mostrou que alunos casados e empregados, bem como alunos pertencentes a uma faixa etária mais elevada, constituem um grupo relativamente desfavorecido e fortemente inclinado à evasão. A pesquisa, por sua vez, indicou que os homens empregados $e$ as mulheres casadas são mais propensos a evadir devido a fatores como gestação ou realocação, e que residir em locais remotos contribui para a alta taxa de evasão.

Para Delen (2011), o número de alunos mantidos na universidade tornou-se uma das medidas mais importantes de sucesso para as IES, uma vez que este índice impacta diretamente na reputação, bem estar financeiro e classificação da universidade. Do ponto de vista institucional, para reter os alunos é preciso uma profunda compreensão das causas por trás da evasão escolar. Esta compreensão é a base para predizer com precisão alunos em risco e, assim, intervir de forma adequada. Neste estudo, foram utilizados 8 anos de dados institucionais e três técnicas de mineração de dados: redes neurais artificiais, árvores de decisão e regressão logística. As técnicas permitiram desenvolver modelos analíticos para prever a evasão de calouros universitários. O modelo que utilizou redes neurais artificiais obteve o melhor resultado, com acurácia de $81 \%$. A análise de importância das variáveis revelou que as variáveis educacionais e financeiras são as mais importantes entre as preditoras.
Após uma revisão da literatura, Nandeshwar, Menzies e Nelson (2011) afirmam que identificar os atributos preditores, no contexto do problema da evasão e/ou retenção de alunos, é uma tarefa difícil. Os autores concluíram que há uma enorme lacuna de conhecimento que abre espaço para melhorias no estado atual da arte. Segundo os autores, as melhorias são possíveis se o estudo (a) explorar uma ampla gama de métodos de aprendizagem; (b) tomar cuidado ao selecionar os atributos; (c) avaliar a eficácia do modelo não apenas pelo seu desempenho mediano, mas também pela variância de desempenho; (d) estudar o delta dos fatores entre aqueles estudantes que permanecem e os que são mantidos. Usando essas técnicas, visando prever se os alunos permaneceriam durante os três primeiros anos de um curso de graduação, os seguintes fatores foram encontrados: antecedentes familiares e situação socioeconômica da família, média de notas (GPA, do termo inglês grade point average) e as notas das provas.

O estudo conduzido por Jadrić, Garača e Ćukušić (2010) parte do pressuposto de que um dos indicadores de potenciais problemas no sistema de ensino superior pode estar relacionado ao grande número de desistências dos alunos nos anos iniciais. Uma análise dos dados existentes forneceu informações sobre os alunos. Para entender melhor o problema da evasão escolar, os dados foram processados através da aplicação dos seguintes métodos de mineração de dados: regressão logística, árvores de decisão e redes neurais. Os modelos foram construídos de acordo com a metodologia SEMMA (acrônimo para Sample, Explore, Modify, Model and Assess) e comparados a fim de selecionar aquele que melhor predizia o abandono dos alunos. Por fim, o trabalho sugere um modelo útil para o planejamento estratégico de mecanismos adicionais visando a melhoria dos processos de ensino-aprendizagem.

Ayesha et al. (2010) aplicou o algoritmo de clusterização denominado K-means para analisar o comportamento de aprendizagem dos alunos. Foram estudados os resultados obtidos nas avaliações dos alunos. O estudo concluiu que todas as informações correlacionadas devam ser encaminhadas ao professor responsável pela turma antes da realização do exame final, visando ajudar os professores a reduzir os índices de evasão a 
um nível significativo, bem como melhorar o desempenho dos alunos.

Cocea e Weibelzahl (2009) partem da afirmação de que, em ambientes e-learning, o fator motivacional é fundamental para a qualidade no processo de aprendizagem, tendo consequências diretas nos índices de evasão. Um dos aspectos da motivação é o envolvimento, uma condição necessária para uma aprendizagem eficaz. A maioria dos sistemas de e-learning armazenam as ações do aluno em arquivos de log, que nos dão informações detalhadas sobre o comportamento do aluno. Técnicas de mineração de dados e de aprendizado de máquina podem dar significado a esses dados fornecendo informações úteis para possibilitar melhorias no processo de ensinoaprendizagem. Usando técnicas de mineração de dados para análise de arquivo de log a pesquisa investiga a possibilidade de prever o nível de envolvimento dos alunos. Assim sendo, a evasão pode ser prevista através do monitoramento das ações dos alunos. Neste trabalho, os autores apresentam os resultados compilados de três estudos desenvolvidos a partir desta abordagem com - objetivo de identificar padrões comportamentais que possam melhorar a acurácia das previsões.

A capacidade de prever a duração dos estudos é vista como uma ferramenta valiosa para as instituições de ensino superior, a fim de se antecipar aqueles alunos que podem vir a abandonar os estudos e, assim, tomar ações preventivas. Neste contexto, o estudo de Meinanda et al. (2009) teve como objetivo descobrir fatores que impactam na duração dos estudos por parte dos alunos e desenvolver um modelo capaz de representálos usando técnicas de mineração de dados. Como critério para a escolha do melhor modelo, foi adotada a Soma dos Erros ao Quadrado (do inglês Sum Square Error - SSE). O modelo construído para prever a duração dos estudos foi baseado em uma rede neural artificial utilizando uma arquitetura Perceptron Multicamadas (MLP). Verificou-se que os principais fatores que afetam a duração dos estudos são o Índice de Desempenho Cumulativo, o número de disciplinas cursadas, o número de disciplinas repetidas e o número de estudantes matriculados em determinadas disciplinas.

Os conceitos de causalidade e previsão são diferentes possuindo possuem diferentes implicações e são aplicados nos estudos sobre evasão escolar nos cursos de enfermagem, conduzidos por Moseley e Mead (2008). Segundo os autores, estudos sobre evasão escolar tendem a se concentrar no conceito de causalidade, tentando, sem muito sucesso, identificar as causas da evasão. No entanto, os autores argumentam que é possível obter melhores resultados quando o problema é trabalhado utilizando-se o conceito de previsão buscando prever quais os alunos com maior probabilidade de evadir. Um dos métodos utilizados para este fim é denominado Indução de Regras. Neste trabalho, os autores adotaram o software IBM SPSS e utilizaram Árvores de Respostas (Answer Trees) para realizar as previsões. O principal conjunto de dados consistiu de 3.978 registros, abrangendo 528 estudantes de enfermagem, divididos em um conjunto de treinamento e um conjunto de teste. O método obteve $84 \%$ de sensibilidade, $70 \%$ de especificidade e acurácia de $94 \%$ em casos inéditos. Os autores afirmam que o método requer grandes quantidades de dados de alta qualidade e concluem que, com esses dados, a indução de regras oferece uma forma de reduzir as taxas de evasão.

Shyamala e Rajagopalan (2007) utilizam árvores de decisão visando encontrar o melhor modelo preditivo capaz de prever o abandono do aluno de forma individual. A lista de alunos propensos a abandonar os estudos é então entregue a professores e gestores a fim de promover intervenções diretas ou indiretas. Em um outro estudo, Shyamala e Rajagopalan (2006) justificam a aplicação de técnicas de mineração de dados no contexto do ensino superior, oferecendo um modelo de mineração de dados para o sistema de ensino superior dentro das universidades. O trabalho apresenta uma abordagem baseada na classificação de alunos, visando prever a nota final do aluno com base em certas características extraídas a partir de bases de dados educacionais. Desta forma, é possível identificar precocemente os estudantes abaixo da média e propensos a evadir, permitindo ao professor auxiliar no momento apropriado, aqueles alunos que apresentam maior dificuldade.

Já o estudo de Rigou e Sirmakessis (2005) visa personalizar a experiência do aluno dentro de um Ambiente Virtual de Aprendizagem (AVA), adaptando a interface do usuário, conteúdos e cenários de aprendizagem com base nas preferências do usuário, buscando motivar a participação do 
aluno e, desta forma, mantê-lo dentro do ambiente.

Muitas técnicas de mineração de dados vêm sendo recentemente aplicadas no contexto da educação: classificação, predição, regras de associação, clustering (agrupamento), visualização, entre outras. Além destas, outras abordagens e algoritmos têm sido aplicados na resolução de problemas na área da educação: redes neurais, redes bayesianas, k-means, lógica fuzzy, agentes inteligentes, entre outras (LARA. et al., 2014). Com base nos artigos encontrados foi possível identificar os principais métodos utilizados pelos trabalhos que exploram o problema da evasão escolar. A Tabela 1 lista os métodos utilizados nos trabalhos encontrados.

Tabela 1 - Listagem dos métodos de mineração de dados encontrados

\begin{tabular}{|l|c|}
\hline \multicolumn{1}{|c|}{ Método } & Abreviação \\
\hline Decision Trees (Árvores de Decisão) & DT \\
\hline Neural Network (Redes Neurais) & LR \\
\hline Logistic Regression (Regressão Logística) & $\mathrm{C}$ \\
\hline Clustering (Clusterização) & $\mathrm{RI}$ \\
\hline Rule Induction (Indução de Regras) & $\mathrm{BN}$ \\
\hline Bayesian Networks (Redes Bayesianas) & SVM \\
\hline Support Vector Machine (Máquina de vetores de suporte) & $\mathrm{AR}$ \\
\hline Association Rules (Regras de Associação) & $\mathrm{NB}$ \\
\hline Naive Bayes & Outros \\
\hline Social Network Analysis (SNA); Extreme Learning Machine (ELM); Simple Logistic & \\
Classification (SL); Instance based classification with IBk algorithm (IBk); Attribute & \\
Selected Classification using J48 classifier and Best First search (ASC); Bagging using & \\
REP (reduced pruning tree classifier) (B); Classification via Regression (CvR); Answer & \\
Trees (AT) & \\
\hline
\end{tabular}

Fonte: Elaborado pelos autores (2015)

A Tabela 2 relaciona os métodos encontrados e os trabalhos nos quais estes foram utilizados. A primeira coluna faz referência ao trabalho no qual o método foi adotado. Cada uma das demais colunas representa um método descrito na Tabela 1. Cabe destacar que muitos dos trabalhos adotam dois ou mais métodos, visando complementar a análise ou comparar os resultados obtidos. A última linha da tabela apresenta o total de trabalhos encontrados que utilizam o respectivo método. É possível visualizar que os principais métodos utilizados no que tange o problema da evasão escolar são: árvores de decisão (Decision Trees - DT), redes neurais (Neural Network - NN), regressão logística (Logistic Regression - LR) e clusterização ou agrupamento (Clustering - $\mathrm{C}$ ).

Tabela 2 - Relação dos métodos utilizados nos trabalhos encontrados

\begin{tabular}{|c|c|c|c|c|c|c|c|c|c|c|}
\hline AUTORES & DT & NN & LR & C & $\mathrm{Rl}$ & $\mathrm{BN}$ & SVM & AR & NB & Outros \\
\hline (SANGODIAH, A., et al. 2015) & & & & & & & X & & & \\
\hline (GARCIA-SAIZ, D., et al. 2014) & & & & & & & & & & $x$ \\
\hline (TEKIN, A., 2014) & & $X$ & & & & & $x$ & & & $X$ \\
\hline (STRECHT, T. et al. 2014) & $\mathrm{X}$ & & & & & & & & & \\
\hline (LARA, J. S., et al. 2014) & & & & $X$ & & & & & & \\
\hline (YASMIN, D., 2013) & $\mathrm{X}$ & & & & & & & & & \\
\hline (MARQUEZ, C., et al. 2013b) & $X$ & & & & $\mathrm{X}$ & & & & & \\
\hline (MARQUEZ, C., et al. 2013a) & $\mathrm{X}$ & & & & $\mathrm{X}$ & & & & & \\
\hline (DELEN, D., 2011) & $\mathrm{X}$ & $\mathrm{x}$ & $x$ & & & & & & & \\
\hline (NANDESHWAR, A., et al. 2011) & $\mathrm{X}$ & $X$ & & & & $\mathrm{X}$ & & & $X$ & \\
\hline (JADRIC, M., et al. 2010) & $\mathrm{X}$ & $\mathrm{X}$ & $x$ & & & & & & & \\
\hline (DELEN, D., 2010) & $X$ & $X$ & $x$ & & & & & & & \\
\hline (AYESHA, S., et al. 2010) & & & & $X$ & & & & & & \\
\hline (COCEA, M., et al. 2009) & $\mathrm{X}$ & & $x$ & & & $X$ & & & & $X$ \\
\hline (MEINANDA, M. H., et al. 2009) & & $\mathrm{X}$ & & & & & & & & \\
\hline (MOSELEY, L. G., et al. 2008) & & & & & & & & & & $x$ \\
\hline (SHYAMALA, K., et al. 2007) & $\mathrm{X}$ & & & $X$ & & & & & & \\
\hline (SHYAMALA, K., et al. 2006) & $\mathrm{X}$ & & & & & & & & & \\
\hline (RIGOU, M., et al. 2005) & & & & & & & & $x$ & & \\
\hline TOTAL & 11 & 6 & 4 & 3 & 2 & 2 & 2 & 1 & 1 & 4 \\
\hline
\end{tabular}

Fonte: Elaborado pelos autores (2015) 


\section{CONSIDERAÇÕES FINAIS}

Com base nos trabalhos correlatos, pode-se dizer que os principais métodos utilizados no que tange o problema da evasão escolar são: árvores de decisão (Decision Trees - DT), redes neurais (Neural Network - NN), regressão logística (Logistic Regression - LR) e clusterização ou agrupamento (Clustering -

\section{REFERENCIAS}

[1]. AYESHA, S.; MUSTAFA, T.; RAZA SATTAR, A.; KHAN, M. I. Data mining model for higher education system. European Journal of Scientific Research, v. 43, n. 1, p. 24-29, 2010.

[2]. BAGGI, C. A. d. S.; LOPES, D. A. Evasão e avaliação institucional no ensino superior: uma discussão bibliográfica. Avaliação (Campinas; Sorocaba), v. 16, n. 2, p. 355-374, 2011.

[3]. COCEA, M.; WEIBELZAHL, S. Log file analysis for disengagement detection in e-Learning environments. User Modeling and User-Adapted Interaction, v. 19, n. 4, p. 341-385, 2009.

[4]. DA SILVA, G. P. Análise de evasão no ensino superior: uma proposta de diagnóstico de seus determinantes. Revista da Avaliação da Educação Superior, v. 18, n. 2, 2013.

[5]. DEKKER, G. W.; PECHENIZKIY, M.; VLEESHOUWERS, J. M. Predicting Students Drop Out: A Case Study. In: Proceedings of the International Conference on Educational Data Mining, Cordoba, Spain, T. BARNES, $M$. DESMARAIS, C. ROMERO and S. VENTURA Eds., p. 41-50, 2009.

[6]. DELEN, D. Predicting student attrition with data mining methods. Journal of College Student Retention: Research, Theory and Practice, v. 13, n. 1, p. 17-35, 2011.

[7]. GARCIA-SAIZ, D.; PALAZUELOS, C.; ZORRILLA, M. Data mining and social network analysis in the educational field: An application for non-expert users. Studies in Computational Intelligence, v. 524, p. 411-439, 2014.

[8]. GOTTARDO, E.; KAESTNER, C. A. A.; NORONHA, R. V. Previsão de desempenho de estudantes em cursos EAD utilizando mineração de dados: uma estratégia baseada em séries

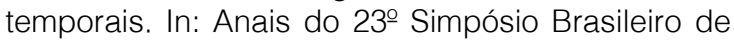
Informática na Educação (SBIE 2012), Rio de Janeiro, 2012

[9]. GOTTARDO, E.; KAESTNER, C. A. A.; NORONHA, R. V. Estimativa de desempenho acadêmico de estudantes: análise da aplicação de técnicas de mineração de dados em cursos a distância. Revista Brasileira de Informática na Educação, v. 22, n. 1, 2014.
C). Pode-se concluir também, dada a importância do problema da evasão frente ao crescente interesse pelo tema, há certa carência por trabalhos correlatos, tanto nacionais quanto internacionais. Porém, a Mineração de Dados Educacionais tem emergido nos últimos anos devido aos avanços computacionais e disponibilidade de grandes repositórios de dados educacionais.

[10]. JADRIĆ, M.; GARAČA, Z.; ĆUKUŠIĆ, M. Student dropout analysis with application of data mining methods. Management, v. 15, n. 1, p. 31-46, 2010.

[11]. LARA, J. A.; LIZCANO, D.; MARTÍNEZ, M. A.; PAZOS, J.; RIERA, T. A system for knowledge discovery in e-learning environments within the European Higher Education Area - Application to student data from Open University of Madrid, UDIMA. Computers \& Education, v. 72, p. 23-36, 2014.

[12]. MACHADO, L. S.; BECKER, K. O Uso da Mineração de Dados na Web aplicado a um Ambiente de Educação a Distância. In: Simpósio Brasileiro de Banco de Dados (SBBD 2012) / Simpósio Brasileiro de Engenharia Software (SBES 2002), 2002, Gramado. Anais do I Workshop de Teses e Dissertações em Banco de Dados, 2002.

[13]. MANHÃES, L. M. B.; CRUZ, S. M. S. da; COSTA, R. J. M.; ZAVALETA, J.; ZIMBRÃO, G. Identificação dos Fatores que Influenciam a Evasão em Cursos de Graduação Através de Sistemas Baseados em Mineração de Dados: Uma Abordagem Quantitativa. In: Anais do VIII Simpósio Brasileiro de Sistemas de Informação (SBSI 2012), São Paulo, 2012

[14]. MEINANDA, M. H.; ANNISA, M.; MUHANDRI, N.; SURYADI, K. Prediksi masa studi sarjana dengan artificial neural network. Internetworking Indonesia Journal, v. 1, n. 2, p. 3135, 2009.

[15]. MOSELEY, L. G.; MEAD, D. M. Predicting who will drop out of nursing courses: A machine learning exercise. Nurse Education Today, v. 28, n. 4, p. 469-475, 2008.

[16]. NANDESHWAR, A.; MENZIES, T.; NELSON, A. Learning patterns of university student retention. Expert Systems with Applications, v. 38, n. 12, p. 14984-14996, 2011.

[17]. PENEDO, J. R.; CAPRA, E. P. Mineração de Dados na Descoberta do Padrão de Usuários de um Sistema de Educação à Distância. In: Anais do VIII Simpósio Brasileiro de Sistemas da Informação (SBSI 2012), São Paulo,2012.

[18]. RIGO, S. J.; CAZELLA, S. C.; CAMBRUZZI, W. Minerando Dados Educacionais com foco na evasão escolar: oportunidades, desafios e 
necessidades. In: Congresso da Sociedade Brasileira de Computação, 2012, Curitiba. Workshop Desafios da Computação aplicada à Educação, 2012.

[19]. RIGO, S. J.; CAMBRUZZI, W.; BARBOSA, J. L. V.; CAZELLA, S. C. Aplicações de Mineração de Dados Educacionais e Learning Analytics com foco na evasão escolar: oportunidades e desafios. Revista Brasileira de Informática na Educação, v. 22, n. 1, 2014.

[20]. RIGOU, M.; SIRMAKESSIS, S. Bringing personalization to online learning communities. WSEAS Transactions on Information Science and Applications, v. 2, n. 12, p. 2160-2167, 2005.

[21]. SANGODIAH, A.; BELEYA, P.; MUNIANDY, M.; HENG, L. E.; RAMENDRAN SPR, C. Minimizing student attrition in higher learning institutions in Malaysia using support vector machine. Journal of Theoretical and Applied Information Technology, v. 71, n. 3, p. 377-385, 2015.

[22]. SHYAMALA, K.; RAJAGOPALAN, S. P. Mining student data to characterize drop out feature using clustering and decision tree techniques. International Journal of Soft Computing, v. 2, n. 1, p. 150-156, 2007.
[23]. SHYAMALA, K.; RAJAGOPALAN, S. P. Data mining model for a better higher educational system. Information Technology Journal, v. 5, n. 3, p. 560-564, 2006.

[24]. STRECHT, P.; MENDES-MOREIRA, J.; SOARES, C. Merging decision trees: A case study in predicting student performance. Lecture Notes in Computer Science (including subseries Lecture Notes in Artificial Intelligence and Lecture Notes in Bioinformatics), v. 8933, p. 535-548, 2014.

[25]. TEKIN, A. Early prediction of students' grade point averages at graduation: A data mining approach. Egitim Arastirmalari - Eurasian Journal of Educational Research, n. 54, p. 207-226, 2014.

[26]. TONTINI, G.; WALTER, S. A. Can students' propensity to desertion be identified and reduced?: strategic actions and tactical results for high education institutions. Avaliação: Revista da Avaliação da Educação Superior (Campinas), v. 19, n. 1, p. 89-110, 2014.

[27]. YASMIN, D. Application of the classification tree model in predicting learner dropout behaviour in open and distance learning. Distance Education, v. 34, n. 2, p. 218-231, 2013. 


\section{Gapítulo 12}

\section{O IMPACTO DO LAYOUT NO FLUXO DE PRODUÇÃO E NA SEGURANÇA DO TRABALHO}

\section{Thayza de Souza de Almeida}

\section{Cristiane Aparecida Bolino Santos}

\section{Daniel Guimarães Tedesco}

\section{Jackson Milano}

Resumo: O layout possui um papel importantíssimo para o desenvolvimento das atividades fabris de uma empresa, sendo responsável por ditar o fluxo do processo, consequentemente, alterando os níveis de produtividade, que são indicadores de eficiência de suma importância para as instituições. Para que a problemática fosse definida, foram utilizadas ferramentas da qualidade, como: brainstorming, diagrama Spaghetti, matriz GUT e Diagrama de Ishikawa, que possibilitaram, primeiramente, uma visão mais ampla dos processos e de suas falhas. A partir disto foi possível desenvolver um plano de ação que abrangesse tanto a disposição dos recursos materiais, como a priorização da qualidade, da segurança do trabalho e do descarte dos resíduos advindos do processo produtivo. Levando em consideração os tópicos mencionados, este estudo de caso, que foi realizado em uma empresa de manufatura de vidros reciclados, irá avaliar as condições de trabalho dos colaboradores, os níveis de movimentação e, por conseguinte auxiliar no aumento da produtividade. 


\section{INTRODUÇÃO}

Segundo Niegel (2009, p. 181) o layout está diretamente vinculado com o posicionamento dos recursos produtivos dentro de uma empresa e, como estes irão relacionar-se com as mais variadas tarefas da operação. Atualmente é fácil ter a percepção que a adoção de um layout deve considerar as restrições do ambiente, seu tipo de material, o maquinário e o fluxo da linha de produção, e, quando aliado a técnicas de segurança no trabalho, o arranjo físico proporciona um aumento significativo nos índices de produtividade da empresa.

Em pesquisa realizada pelo Serviço Social da Indústria (SESI), entre outubro de 2015 e fevereiro de 2016, com cerca de 500 empresas de médio e grande porte, foi constatado que $48 \%$ dessas organizações na adoção de medidas preventivas para a segurança no ambiente laboral, poder-se-ia diminuir o absenteísmo. E para $43,6 \%$ dessas instituições a utilização desse tipo de programa aumenta a produtividade de forma significativa. Além de 34,8\%, acreditam que essas ações reduzem custos. Visto isso, a adoção dessa prática reduz drasticamente as possíveis ações trabalhistas e gastos com encargos decorrentes dos acidentes de trabalho.

Tendo isto em vista, observa-se uma grande oportunidade de atuação na área, o que gera benefícios para a instituição que utilizar esta filosofia de priorização da segurança no trabalho. Contudo houve a necessidade de padronizar o tráfego dos colaboradores para que o fluxo de produção se torna mais contínua. Para tal fim, foram utilizadas inúmeras ferramentas da qualidade que proporcionaram um suporte para a visualização do problema que mais impactava o processo produtivo, no caso, o layout.

\section{FUNDAMENTAÇÃO TEÓRICA}

\subsection{ARRANJO FÍSICO OU LAYOUT}

Segundo Niegel (2009, p. 181-182), o arranjo físico dita o ritmo do fluxo dos recursos transformadores, por isso é de extrema importância analisar bem o tipo de layout que será implantado, posto isso, uma escolha equivocada acarretaria em fluxos muito longos, custos altos e operações inflexíveis, por exemplo. Além disso, um bom arranjo físico deve prezar os seguintes itens: segurança inerente, extensão do fluxo, clareza de fluxo, conforto para os funcionários, coordenação gerencial, acessibilidade, uso do espaço e flexibilidade de longo prazo.

Ainda, de acordo com Niegel (2009, p. 182), um fator importante para determinar o layout mais apropriado é analisar o tipo de processo realizado pela empresa, pois esse assume suma importância saber o volume e a variedade de produtos que são produzidos pela companhia. Os arranjos físicos são divididos em tipos básicos e complexo e flexível, esses contendo quatro formas e este um, sendo eles:

- Arranjo físico posicional: também conhecido como layout por posição fixa, é usado principalmente para a fabricação de produtos únicos e de grande extensão;

- $\quad$ Arranjo físico funcional: o arranjo físico funcional é a manufatura por departamento, com isso o produto deve-se deslocar para realizar seus processos;

- Arranjo físico celular: nesse tipo de layout os recursos produtivos são organizados de forma a suprir as necessidades de produção de um único tipo de produto. O produto movimenta-se dentro da célula buscando os processos necessários para a sua produção;

- Arranjo físico por produto: Também chamado de layout linear, esse arranjo físico é utilizado para produzir artigos com pouca ou nenhuma diversificação. As máquinas são alocadas de forma que se siga uma sequência de operação já pré-estabelecida, o fluxo é de fácil controle.

- Arranjo físico misto: esse tipo de layout é composto pela utilização de dois ou mais layouts básicos.

\subsection{TIPOS DE PROCESSOS}

Para as empresas atingirem suas metas, ou até mesmo estabelecê-las, faz-se necessário o conhecimento sobre o tipo de processo que esta utiliza, para isto, Slack e Johnston (2009, p.92) dividem os processos nos seguintes tipos:

- Processo por projeto: é um processo indicado para baixos volumes e alta variedade de produtos, apresentando um início e um término de cada produto bem definido; 
- Processo por jobbing: é indicado para a s produções de baixo volume e alta variedade, os seus recursos são compartilhados com os demais produtos a serem manufaturados;

- Processos em lotes: apresenta uma gama maior de níveis de volume;

- Processo de produção em massa: indicado para produções de altas quantidades, mas de menor variedade;

- Processo contínuo: apresenta um fluxo em linha e em quase sua totalidade é feito de apenas fabricado um produto, por ser de alto volume a sua variabilidade torna-se baixa.

\subsection{CICLO PDCA}

O ciclo PDCA, segundo Slack, Chambers e Johnston (2009, p.578), é uma ferramenta desenvolvida com o intuito de realizar uma melhoria contínua (kaizen). Possui quatro as seguintes etapas:

- Planejamento $(\mathrm{P})$ : estabelecimento de metas e objetivos;

- $\quad$ Execução (D): realização do trabalho planejado, subdividida em três etapas: educação e treinamento sobre o método; realização do trabalho e coletas de dados para o trabalho seguinte;

- Checagem (C): análise do que foi feito, identificação entre o que foi planejado e o que foi realizado;

- Ação (A): é a etapa em que se aplicam ações corretivas para um desenvolvimento contínuo do projeto.

\section{$2.45 S$}

Responsável pela organização do ambiente de trabalho, proporciona uma facilidade na realização dos processos da empresa, também aumenta o rendimento de seus colaboradores. Segundo P. Martins e P. Laugeni (2015, p.464), esse programa não necessita de altas tecnologias para ser implementado, sendo composto pelos seguintes passos:

- Seiri: trata-se de desfazer de tudo que não for necessário e que não agrega valor ao processo;
- Seiton: leva em consideração o nível de importância dos processos, viabilizando o acesso aos itens de maior relevância;

- Seiso: considera a alocação dos materiais e a eliminação de resíduos advindos do processo produtivo;

- Seiketsu: aumenta o nível de segurança no trabalho, pois a alocação correta dos materiais diminui o índice de acidentes;

- Shitsuke: treinamento dos colaboradores para a implementação corretas das outras etapas do programa.

\subsection{LEAD TIME}

Lead Time de acordo com Ericksen, Stoflet e Suri (2007), é o prazo para execução e entrega de um produto. A determinação do tempo gasto desde o pedido do cliente até a entrega do produto acabado, levando em consideração o número de processos empregados e o tempo para execução. A classificação do tempo se subdivide em: preparação, operação, espera e transporte.

\subsection{KAIZEN}

O kaizen segundo P. Martins e P. Laugeni (2015, p. 464), é uma filosofia que preza a melhoria contínua dos processos, tendo seu foco voltado, principalmente, para a eliminação de perdas.

\subsection{DIAGRAMA SPAGHETT|}

O diagrama Spaghetti é citado por Slack, Chamers, Johnston (2009, p. 586), como uma ferramenta muito simples e útil que auxilia na escolha do layout ideal, tanto industrial quanto administrativo. Os gráficos têm como objetivos fazer a análise de distâncias percorridas pelos operadores na execução das suas respectivas funções. Sua aplicação auxilia na identificação dos problemas ocasionados por perda de tempo, realizando movimentos desnecessários, provocando a desarticulação do fluxo de trabalho, e isso faz com que haja uma maior espera para a finalização dos pedidos, já que certas etapas realizadas não agregam valores. Aplicado de forma correta pode--se ter uma melhora na fluidez na realização das tarefas, aumentando assim a eficiência do processo. 


\subsection{BRAINSTORMING}

É definido por Ferreira, Miguel, Naveiro e Romeiro (2011, pág. 86) como uma reunião de um grupo de pessoas com diferentes pontos de vistas e perspectivas do trabalho, em que o intuito é de ocorrer uma "tempestade" de ideias, fazendo que todos participem, gerando uma grande gama de ideias em prol de um objetivo, solucionar um problema.

\subsection{DIAGRAMA DE ISHIKAWA}

Segundo Kaoro Ishikawa (1993, p.19), é uma ferramenta utilizada para obter um maior controle da qualidade a partir de um gráfico subdividido em seis categoria, sendo elas: método, matéria-prima, mão de obra, máquinas, medida e meio ambiente. É uma ferramenta muito utilizada, pois proporciona fácil visualização das possíveis causas de determinado problema.

\subsection{MATRIZ GUT}

Sua proposta de acordo com criadores Kepner e Tregoe (1981, pág. 58), é auxiliar na definição da priorização de fatores que obtém maior influência sobre a causa de um problema. Ela está ligada ao ciclo PDCA, pois a mesma ajuda na hora de planejar (P).

$\mathrm{Na}$ sua construção, precisamos considerar as seguintes características e seus níveis de gravidade que variam de 1 até 5 , sendo 1 o de menor importância e o 5 o de maior importância. Essa matriz leva em consideração os seguintes tópicos:

Gravidade: qual o tamanho do impacto da não solução do problema na sua produção;

Urgência: tempo demandado para a sua resolução;

Tendência: caso não corrigido, qual o nível de crescimento do problema.

\subsection{SEGURANÇA DO TRABALHO}

Para Saliba (2015, p.23), a segurança do trabalho caracteriza-se por ser uma ciência encarregada de prevenir acidentes de trabalho, os quais possam ser desencadeados por alguns fatores de risco proveniente do processo produtivo. Tais fatores precisam ser analisados em todos os âmbitos para que medidas preventivas sejam adotadas. Tendo tal problema em vista, a NR12 foi criada com a intenção de padronizar os métodos de prevenção de acidentes, dentre eles está a padronização do arranjo físico, por exemplo.

\section{METODOLOGIA}

Este estudo pode ser classificado, segundo Lakatos (2003, p. 186), como um estudo de caso com dados qualitativos, pois as soluções apresentadas no decorrer deste artigo não devem ser generalizadas, uma vez que, o objeto de estudo se trata de uma organização específica, que possui suas particularidades e permite que a problemática seja levada mais a fundo e, que conceitos sejam implementados a partir da análise dos dados obtidos por constatação.

O estudo inicialmente foi direcionado com a utilização de ferramentas básicas da qualidade, como o brainstorming, matriz GUT e diagrama de Ishikawa, que possibilitaram a identificação do problema que deveria ser abordado. Posteriormente, foram empregadas ferramentas como o diagrama Spaghetti, 5S, kaizen e ciclo PDCA, que auxiliariam na análise e resolução do problema.

\section{DESENVOLVIMENTO}

\subsection{ESTADO ATUAL}

Para identificar o problema a ser solucionado, foram analisados diversos setores da empresa, como o estoque e o setor de produção, para, assim, aplicar os conhecimentos necessários para a resolução das ocorrências.

Diante disto, houve a necessidade da realização de uma pequena reunião com os membros da equipe para listar todos os possíveis problemas existentes na empresa. Realizou-se então, um agrupamento de tais problemas nas seguintes categorias: método, matéria-prima, mão de obra, máquinas, medidas e meio ambiente, os chamados 6 m's. Segue na tabela 1 os problemas visualizados durante a visita à fábrica. 
Tabela 1: Brainstorming

\begin{tabular}{|c|c|c|c|c|c|}
\hline Método & Matéria-Prima & $\begin{array}{c}\text { Mão de } \\
\text { Obra }\end{array}$ & Máquinas & Medida & $\begin{array}{c}\text { Meio } \\
\text { Ambiente }\end{array}$ \\
\hline \multirow[t]{3}{*}{ Desorganização } & Distância & Artesanal & Distância & Lead Time & Calor/Frio \\
\hline & & Segurança & Forno & Sazonalidade & \\
\hline & & & Temperagem & & \\
\hline
\end{tabular}

Fonte: Do autor

Depois de elencar os itens nessa tabela, deve-se escolher qual dos problemas será priorizado. Para isto é interessante utilizar alguma ferramenta que direcione qual item será abordado.
Para escolher o problema que será resolvido primeiro, utiliza-se a matriz de gravidade $X$ urgência $X$ tendência. Veja a tabela 2 a seguir.

Tabela 2: Matriz de Gravidade, Urgência e Tendência

\begin{tabular}{|l|c|c|c|c|}
\hline & G & U & \multicolumn{2}{c|}{ G } \\
\hline Desorganização & 5 & 5 & 5 & 125 \\
\hline Distância & 5 & 5 & 4 & 100 \\
\hline Artesanal & 1 & 1 & 1 & 1 \\
\hline Segurança & 5 & 5 & 4 & 100 \\
\hline Forno & 1 & 2 & 1 & 2 \\
\hline Temperagem & 2 & 2 & 1 & 4 \\
\hline Lead time & 5 & 5 & 4 & 100 \\
\hline Sazonalidade & 3 & 3 & 2 & 18 \\
\hline Calor/frio & 4 & 3 & 2 & 24 \\
\hline
\end{tabular}

Fonte: Do autor

Como é visto na tabela 2, os problemas que necessitam de maior atenção são: a desorganização, distância, segurança e lead time. Para tanto, necessita-se agir primeiramente no problema que possui maior pontuação na matriz GUT, no caso, a desorganização. Para entender melhor o que pode estar acarretando o problema de organização deve-se analisar todos os fatores que estão relacionados a provável causa do problema, para isto, utiliza-se o Diagrama de Ishikawa.

Para tornar as raízes do problema mais visíveis, é interessante agrupá-las em categorias semelhantes para que sejam mais bem visualizadas, sendo assim, uma ferramenta que se adequa a tal necessidade é o Diagrama de Ishikawa (Figura1). Observe na figura 1 abaixo a aplicação do Diagrama de causa efeito para a desorganização existente na fábrica. 
Figura 1: Diagrama de Causa e efeito

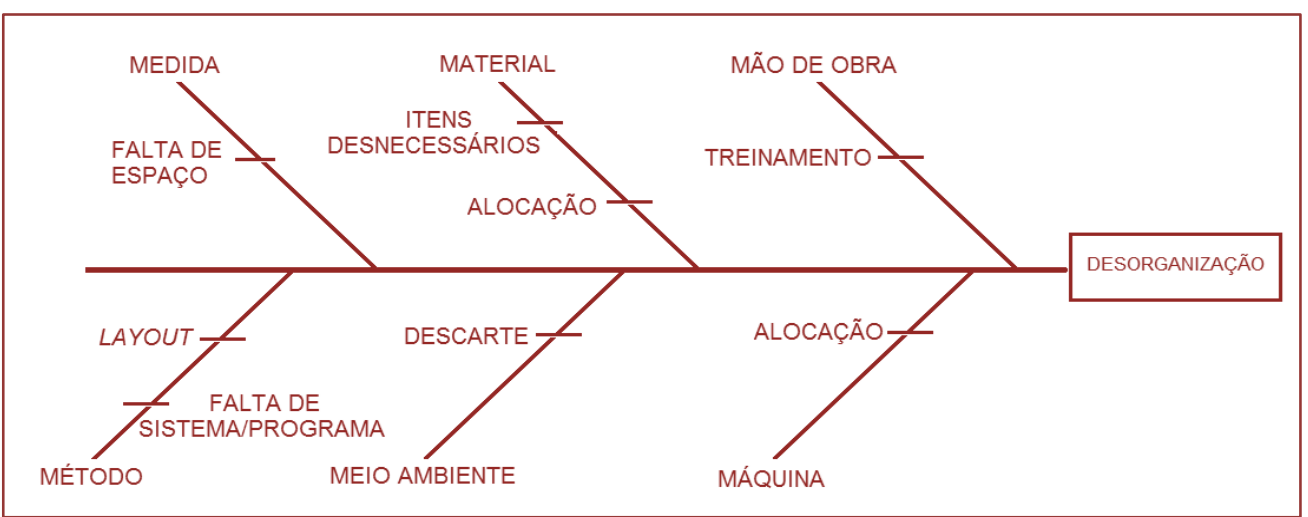

Fonte: Do autor

A partir das possíveis causas é possível aplicar novamente uma Matriz GUT para priorizar qual item precisa ser trabalhado primeiro.

Depois de analisar o Diagrama de causa e efeito da desorganização, ocorre na instituição, consegue utilizar-se da matriz GUT para ver qual dessas causas devem ser priorizadas e receberão atenção primeiro. Atenta-se na tabela 3 a matriz GUT para a desorganização.

Tabela 3: Matriz Gravidade, Urgência e Tendência da desorganização

\begin{tabular}{|c|c|c|c|c|}
\hline & G & U & $\mathrm{T}$ & GxUxT \\
\hline Falta de espaço & 5 & 3 & 3 & 45 \\
\hline Itens desnecessários & 4 & 4 & 5 & 80 \\
\hline Alocação & 5 & 5 & 4 & 100 \\
\hline Treinamento & 4 & 4 & 3 & 48 \\
\hline Layout & 5 & 5 & 5 & 125 \\
\hline Falta de sistema/prog. & 4 & 5 & 4 & 80 \\
\hline Descarte & 4 & 4 & 4 & 64 \\
\hline
\end{tabular}

Fonte: Do autor

A partir desta nova análise da matriz GUT, com enfoque na desorganização da empresa, é visto que a principal causa de tal problema é o layout adotado pela instituição em sua linha de produção. Portanto, necessita-se direcionar os esforços da empresa para a concepção de um novo arranjo físico.

Compreende-se, primeiramente, que o tipo de processo que a empresa utiliza é o Processo por Lotes, já definido na introdução teórica. Como é analisado no layout atual (Figura 2), a parte da produção está muito desorganizada, processos estão mal alocados, o que influência tanto na segurança do trabalho como também no fluxo dos funcionários durante a operação. 
Figura 2: Layout atual

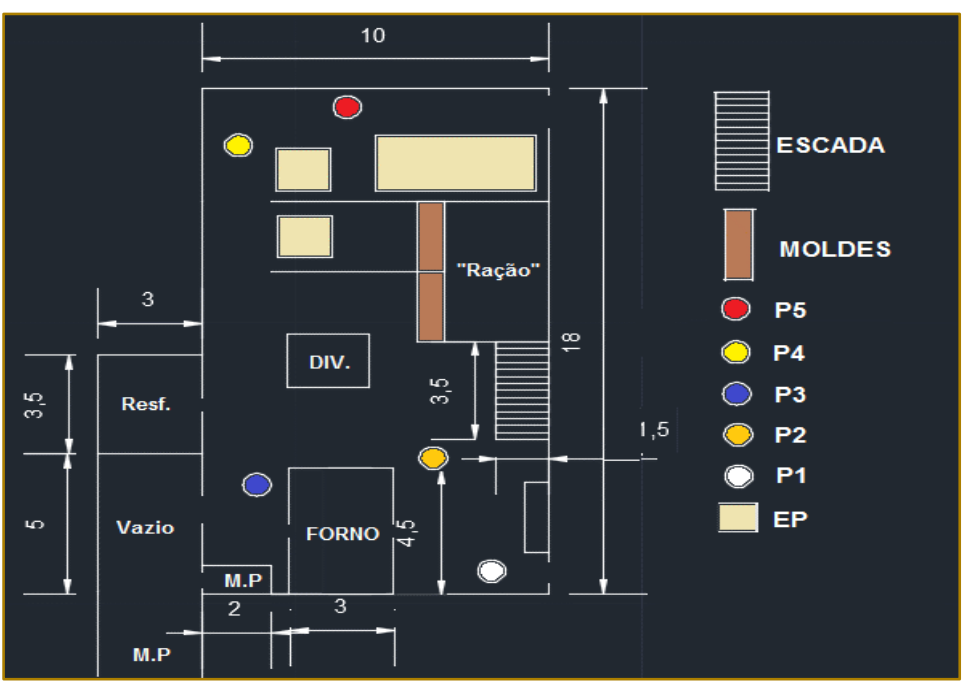

Fonte: Do autor

Na figura 2, observamos que há vários pontos em que se formam estoques entre os processos ("EP"), o que dificulta a movimentação dos funcionários, logo o fluxo do processo. Além disso, os processos P1 e P3 são realizados com o auxílio de moldes (para os copos, potes, etc.), enquanto o P2 é o processo em que o vaso de vidro é fabricado a partir do sopro.

Um grande problema que que foi percebido é quanto à movimentação no processo $\mathrm{P} 2$, uma vez que, para a realização de tal processo é necessário a utilização de uma haste/tubo longo, para a fabricação do produto, e apesar disto, o processo está longe do local de resfriamento do vidro, o que acarreta uma maior probabilidade de acidentes no percurso.

Por fim, os processos, P4 e P5 são os processos de acabamento, onde há $\mathrm{O}$ polimento e a lavagem do vidro, respectivamente.

Com o auxílio do Diagrama Spaghetti consegue-se obter uma imagem da movimentação dos funcionários entre os processos. Com isto, considera-se que em muitos momentos os processos se cruzavam. Observe a figura 3:

Figura 3: Diagrama de Spaghetti no layout atual

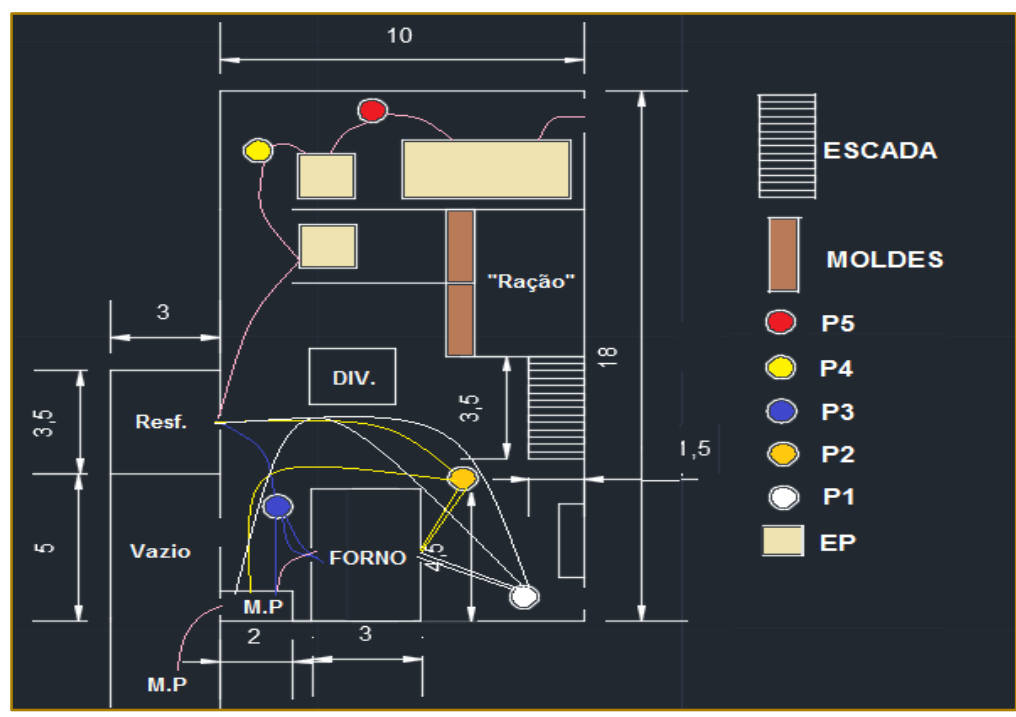

Fonte: Do autor. 
A partir do fluxo de funcionários, demonstrado pelo Diagrama, visualiza-se mais facilmente o problema em que se agirá. Vendo o layout da empresa pode-se perceber que se faz necessário a utilização de algum programa de qualidade para obtenção de melhores resultados. Para isso, recomenda-se a utilização do programa 5S, pois os seguintes problemas foram listados:

- Apenas um local para o descarte de resíduos advindos do processo produtivo;

- $\quad$ Fluxo de processos que se cruzam;

- Estantes com moldes alocados de forma inadequada;

- Produtos mal alocados entre os processos.

Como os processos possuem grandes problemas relacionados ao seu fluxo, o Lead time consequentemente fica elevado, uma vez que, os movimentos são demasiadamente grandes, como por exemplo, a utilização de um único local para descarte de rejeitos, gerando um enorme deslocamento para alguns processos.

\subsection{ESTADO FUTURO}

Aplicado os conceitos pesquisados e analisados, tornou-se possível a concepção de um novo layout que é observado na figura 4:

Figura 4: Layout futuro.

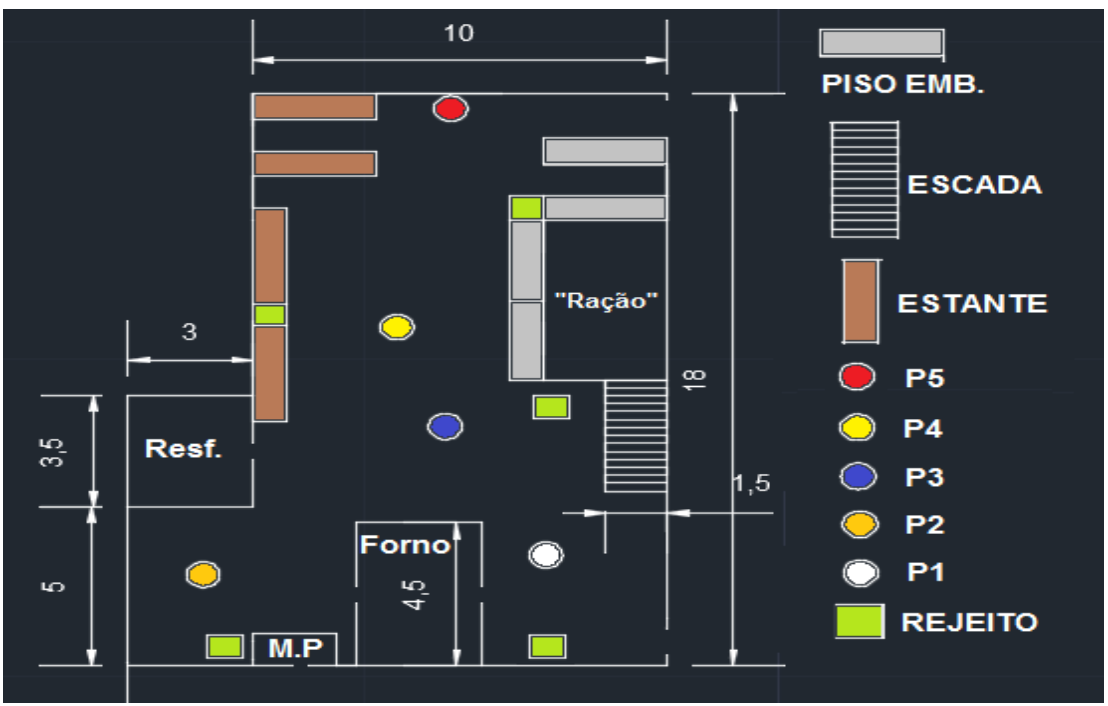

Fonte: Do autor.

Verifica-se que no layout futuro o espaço que antes era vazio, e, assim, tornar o local onde o produto P2 será produzido, tal escolha se deve ao fato de este processo ser o procedimento conhecido como sopro, e como citado anteriormente, demanda um espaço maior para uma melhor movimentação.

Além disso, recomenda-se a implementação, em todos os processos, de tambores para que sejam descartados todos os rejeitos da produção, diminuindo a movimentação que atualmente ocorre para tal descarte. O funcionário que trabalha no período noturno conseguirá ser o responsável por esvaziar os tambores dos processos assim como retirar os produtos da área de resfriamento realocando-os na estante posicionado ao lado desta área, além de realizar a limpeza da fábrica.

As estantes que comportam os moldes, nesse novo modelo, foram realocadas para que não fiquem posicionadas entre os processos, para não acarretar assim, em uma quebra do fluxo. Os locais que atualmente comportam os estoques entre processos passarão a ser demarcados pela a utilização de pisos emborrachados, que além de definir um local fixo para esse produto também poderão auxiliar em uma redução nos níveis de perda, pois o material não escorregará ou estará sujeito a grandes choques diretamente com o chão. 


\section{Diagrama de Spaghetti futuro}

Como a principal mudança para o fluxo, vale ressaltar novamente a adoção de tambores perto de todos os postos de trabalhos, evitando que o funcionário tenha que cruzar as linhas de fluxo de outros processos para devolver a matéria prima ao início da produção.

Abaixo teremos, na figura 5, as mudanças da movimentação que possibilitarão ser obtidas por meio das medidas sugeridas anteriormente.

Figura 5: Diagrama Spaghetti futuro

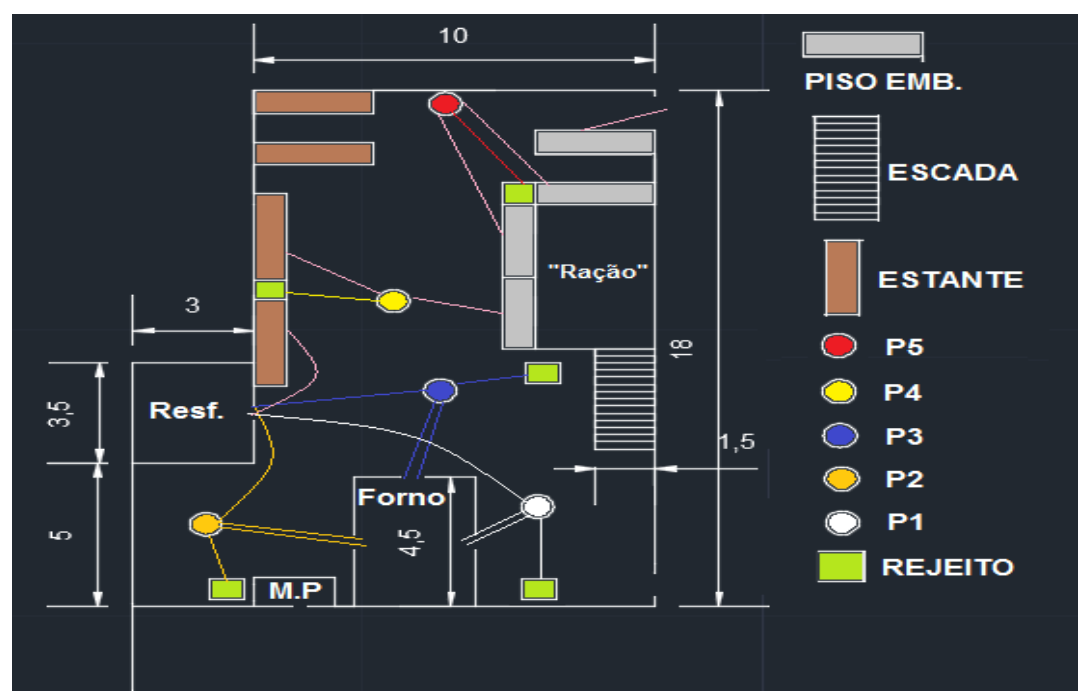

Fonte: Do autor.

Observa-se acima, que nesse novo modelo de arranjo físico, as linhas de fluxo só se cruzarão uma única vez, além disso, a movimentação dos funcionários reduzir-se-á bastante com a adoção do novo posicionamento dos processos e a adoção de novos pontos de descarte.

\section{Aplicação do Kaizen}

Para que a melhoria seja sempre continua, a aplicação do Kaizen será necessária, para que a empresa faça constantes mudanças. Indicamos que sejam feitos acompanhamentos diários ou semanais, que sejam verificadas as quantidades de itens a serem produzidos, sendo sempre anotado para fazer comparações, utilizando-se de diversas ferramentas de acompanhamento para definir até quando a medida sugerida será eficiente para o processo produtivo.

\section{Aplicando o Programa 5s}

A partir dos conceitos do programa 5S sugerimos a adoção de práticas, para que a organização e a limpeza da fábrica sejam as mais adequadas possíveis, uma vez que, além de melhorar a produtividade a aplicação de tal programa pode proporcionar um ambiente de trabalho mais agradável e adequado para se trabalhar. Visto isso, as medidas que deverão ser adotadas são:

- $\quad$ Adoção de um novo espaço, que não era utilizado, para a realocação do processo P2;

- Estantes para moldes realocados com melhor acesso para os funcionários;

- Estantes para os vidros temperados:

- Chão ao redor emborrachado para dificultar a quebra;

- Assim proporcionando ao processo um melhor aproveitamento dos recursos disponíveis.

\section{Aplicando o Lead Time}

Com a diminuição dos movimentos, os tempos dos processos também sofrerão uma queda, o que, consequentemente, acarretará uma diminuição do lead time, logo, um aumento na produtividade dos processos. 


\section{Aplicando o Ciclo PDCA}

Uma forma de acompanhar a implementação deste projeto algumas falhas é utilizando o Ciclo PDCA, em que é possível observar e acompanhar:

- Planejamento: Identificar o layout que mais se adequa as necessidades do ambiente fabril;

- Execução: Aplicar ferramentas e métodos que possibilitem a aplicação de um novo modelo de arranjo físico;

- Checagem: Utilizar indicadores de qualidade para o acompanhamento dos resultados obtidos com a melhoria implementada;

- Ação: Se necessário, refazer o plano de ação, para que este adeque-se as necessidades que futuramente venham a surgir, promovendo assim, um melhoramento contínuo dos processos (kaizen).

\section{CONCLUSÃO}

Através da aplicação dos conhecimentos de diversas ferramentas da qualidade e de métodos de avaliação, relacionamos quais seriam os possíveis problemas e necessidades do ambiente produtivo, chegando assim, ao possível cerne do problema abordado, a desorganização. Tal problema está intimamente relacionado com a disposição de materiais, estoques e fluxo de produção, ou seja, com o layout adotado pela instituição.

Diante disso, recomendamos que as sugestões apresentadas no desenvolvimento do estudo de caso, sejam incorporadas pela empresa para que haja uma otimização dos recursos disponíveis na fábrica, um aumento na segurança do processo e uma redução nos tempos e movimentos, proporcionando uma maior flexibilidade para o atendimento de grandes demandas.

Contudo, os demais problemas listados no brainstroming devem ser analisados posteriormente para que ocorra um processo de melhoria contínua (kaizen) e evitando desperdício de recursos e aumentando a eficiência dos processos.

[4]. CUNHA, Marcilio. Ergonomia e segurança no trabalho - 5. Disponível em: < http://slideplayer.com.br/slide/51895/ >Acesso em: 28 de julho de 2016

[5]. ERICKSEN, P. D.; STOFLET, N. J.; SURI, R. Manufacturing Critical-path Time (MCT): Tge QRM Metric for lead time. Technical Report, Center for QRM, Wisconsin-Madison, 2007.

[6]. FERREIRA. C.V.; MIGUEL, P.A.C.; GOUVINHAS R.P.; NAVEIRO, R.M.; ROMEIRO FILHO, E. (Coordenação), Projeto do Produto, Elsevier, ABEBRO, 2011.

[7]. Importância do layout. Disponível em: <http://silassoares.com.br/importancia-do-layout/> Acesso em: 21 de junho de 2016.

[8]. ISHIKAWA. K. Controle de qualidade total à maneira japonesa. 1 ed. Campus - RJ, 1993.

[9]. JABBOUR, Ana Beatriz Lopes de Sousa. Engenharia de produção: minidicionário acadêmico / Ana Beatriz Lopes de Souza Jabbour, Dhárana Gassi Pereira, João Vitor Pedroso de Lima - RJ, Alta Books, 2015.

[10]. LAKATOS, Eva Maria. Fundamentos de metodologia científica. 1 Marina de Andrade 
Marconi, Eva Maria Lakatos. - 5. ed. - São Paulo: Atlas 2003.

[11]. LAUGENI, Fernando P. Administração da produção/Fernando P. Laugeni, Petrônio Garcia Martins. -3. ed.-São Paulo: Saraiva,2015.

[12]. LORENZATTO, Júlia Trindade; RIBEIRO, José Luis Duarte. Projeto de layout alinhado às práticas de produção enxuta em uma empresa siderúrgica de grande porte. Disponível em: < http://www.abepro.org.br/biblioteca/enegep2007_T R570429_9507.pdf> Acesso em: 21 de junho de 2016.

[13]. SALIBA, Tuffi Messias. Curso básico de segurança e higiene ocupacional / Tuffi Messias Saliba; colaboradora Maria Beatriz de Freitas Lanza. - 6.ed. - São Paulo: LTr, 2015.

[14]. SILVA, Maria Laura Viana. A importância do layout dentro das indústrias para o aumento da produtividade. Disponível em: < http://www.techoje.com.br/site/techoje/categoria/de talhe_artigo/1661> Acesso em: 21 de junho de 2016.
[15]. SILVA, Monica Gomes da; MOREIRA, Bruna Brandão. Aplicação da metodologia SLP na reformulação do layout de uma microempresa do setor moveleiro. Disponível em: < http://www.abepro.org.br/biblioteca/enegep2009_tn _stp_091_618_13943.pdf> Acesso em: 21 de junho de 2016.

[16]. SITE ANDREFONTENELLE. Estudo de Caso. Disponivel em: <http://www.andrefontenelle.com.br/tipos-depesquisa/\#Estudo_de_Caso> Acesso em: 25 de fevereiro de 2018.

[17]. SLACK, Nigel. Administração da produção/Nigel Slack, Stuart Chambers, Robert Johnston; tradução Mari a Teresa Corrêa de Oliveira. -3. ed. -São Paulo:Atlas,2009.

[18]. SOTILLE, Mauro Afonso. A ferramenta GUT - Gravidade, Urgência e Tendência. Disponível em: < http://www.pmtech.com.br/PMP/Dicas\%20PMP\%20 -\%20Matriz\%20GUT.pd $\mathrm{f}>$ Acesso em: 18 outubro 2017. 


\section{Gapítulo 13}

\section{CRITERIOS PARA SELEÇÃO DE FORNECEDORES VERDES: UMA REVISÃO DE LITERATURA}

\section{Daiane Ferreira França}

Resumo: Com as exigências ambientais do mercado cada vez mais rígidas, as organizações verdes desenvolveram análises mais criteriosas para seleção de fornecedores. O presente estudo tem como objetivo identificar os critérios mais discutidos na literatura recente para selecionar fornecedores ambientalmente sustentáveis. Foram investigadas publicações científicas feitas entre os anos de 2013 a 2018 e, posteriormente, os critérios encontrados foram categorizados para melhor apresentação dos dados. Assim, foram apontados como critérios verdes mais considerados na literatura recente: produção e controle de poluição, sistemas de gestão ambiental, eco-design ou design verde, consumo de recursos, emissões atmosféricas, tecnologia e inovação verdes, competências verdes e imagem verde.

Palavras-chave: gestão verde da cadeia de suprimentos; fornecedores verdes; seleção de fornecedores. 


\section{INTRODUÇÃO}

A preocupação ambiental e a gestão da cadeia de suprimentos tornaram-se uma questão estratégica para as organizações. A competitividade e a globalização criaram cadeias de suprimentos complexas que envolvem indústrias, clientes e fornecedores situados em diversos países, gerando a necessidade de uma gestão integrada com o intuito de otimizar o custo benefício das cadeias de suprimento (WISNER; TAN; LEONG, 2012). Enquanto isso, a degradação e a poluição ambientais fizeram surgir legislações rígidas e consumidores mais conscientes em relação à sustentabilidade ambiental, gerando uma pressão nas organizações para o desenvolvimento de ações proativas com o intuito de reduzir impactos ambientais (SEHNEM et al, 2015).

Dentro desse contexto, o meio ambiente converteu-se em um dos fatores essenciais para o sucesso da cadeia de suprimentos, o que ocasionou a necessidade de associar a sustentabilidade ambiental à gestão da cadeia de suprimentos, originando a Gestão Verde da Cadeia de Suprimentos. Assim, a escolha de fornecedores que compartilhem de objetivos sustentáveis com a empresa compradora tornou-se imprescindível para garantir a sustentabilidade da cadeia de suprimentos verde, e as organizações passaram a estabelecer critérios para assegurar que seus fornecedores são de fato ambientalmente sustentáveis, ou fornecedores verdes.

Em vista disso, nota-se a relevância da escolha de critérios para seleção de fornecedores verdes para as cadeias de suprimentos atuais. Esse fator justifica a escolha da problemática deste trabalho, que consiste em: "Quais os critérios mais considerados pelas organizações na escolha de fornecedores verdes? "Dessa forma, o objetivo deste artigo é investigar e descrever os critérios mais discutidos na literatura recente - 2013 a 2018 - para seleção desses fornecedores.

Com vistas a atingir esse objetivo foi realizado um levantamento bibliográfico a respeito dos temas Green Supply Chain Management e Seleção de fornecedores apresentados nas seções 2 e 3 deste artigo; posteriormente, foi realizada uma busca, através da plataforma de pesquisa Science Direct, de artigos científicos que tratam da seleção de fornecedores verdes (green suppliers) e fornecedores sustentáveis (sustainable suppliers). Após, os critérios mais citados nas publicações foram analisados e compilados em categorias, as quais foram descritas neste artigo na seção 4. Por fim, foram feitas considerações finais acerca da matéria, na seção 5 .

\section{GESTÃO VERDE DA CADEIA DE SUPRIMENTOS}

A Gestão Verde da Cadeia de Suprimentos surgiu em um contexto de crescentes exigências ambientais por conta de legislações, consumidores e indústrias mais sensíveis à questão da sustentabilidade, e foi resultante de uma combinação de esforços para otimizar cadeias de suprimentos e garantir a sua sustentabilidade ambiental. Segundo Srivastava (2007), Green Supply Chain Management (GSCM - Gestão Verde da Cadeia de Suprimentos) pode ser definida como:

"(...) a integração da preocupação ambiental à gestão da cadeia de suprimentos, a qual inclui as etapas de projeto do produto, obtenção e seleção de material, processos de produção, entrega do produto ao consumidor final e, ainda, a gestão do produto após o fim da sua vida útil" (SRIVASTAVA, 2007, p.54 e 55).

Já Min e Kim (2012, p.40) conceituam a GSCM como: "O uso de iniciativas ambientalmente responsáveis em todos os aspectos da cadeia de suprimentos, que se inicia na etapa de gestão de compras e vai até a gestão do fim da vida do produto". Desse modo, a implementação da gestão verde dá-se através da adoção de diversas práticas que transcendem os níveis das cadeias de suprimentos. Apesar de ainda haver discussão acerca da definição dessas práticas e dos seus resultados no desempenho das organizações, há otimismo em relação ao seu uso de forma geral e aos seus efeitos nas performances ambiental e econômica das empresas, sobretudo a longo prazo (ZHU; SARKIS; LAI, 2013).

Como mencionado, analisando a literatura existente acerca do tema, é notável que não há consenso quanto ao delineamento das práticas de GSCM. Esfahbodi, Zhang e Watson (2016) destacam como práticas de GSCM a Distribuição Sustentável, as Compras Sustentáveis, o Design Sustentável e a Recuperação do investimento. Já Zhu e Sarkis 
(2004) apontam como principais práticas a Gestão Ambiental Interna, a Gestão Verde da Cadeia de suprimentos Externa - a qual inclui Compras Verdes e Práticas de Cooperação com o Consumidor -, a Recuperação do investimento e o Eco-design.

Enquanto Srivastava (2007) caracteriza o Design verde e as Operações verdes - as quais abrangem Gestão de Resíduos, Manufatura Verde/Remanufatura e Logística Reversa - como atividades de GSCM. Hong, Zhang e Ding (2018) propõem uma classificação diferenciada das práticas de GSCM, dividindo-as em cinco categorias, sendo elas: Confiança e Coordenação, Aprendizado, Orientação estratégica, Gestão de riscos, e Continuidade da cadeia de suprimentos.

Considerando que o objetivo deste estudo é elencar os fatores usados como critérios para escolha de fornecedores verdes, dar-se-á foco às práticas que integram ou abrangem as compras sustentáveis e o relacionamento com fornecedores. Sendo assim, é pertinente destacar as práticas de GSCM descritas por Zhu e Sarkis (2014) e Esfahbodi, Zhang e Watson (2016).

Zhu e Sarkis (2004) evidenciam que as práticas externas de GSCM podem trazer resultados positivos nas performances econômica e ambiental das empresas. Para os autores, tais práticas constituem atividades que envolvem fornecedores e consumidores, como o compartilhamento de especificações de projeto com fornecedores, a cooperação com os objetivos ambientais dos fornecedores, a realização de auditorias ambientais para gestão interna de fornecedores, a busca por parceiros com certificação ISO 14001, a avaliação de práticas sustentáveis dos fornecedores de segundo nível da cadeia de suprimentos, entre outros.

Já Esfahbodi, Zhang e Watson (2016) afirmam que a prática de compras sustentáveis depende de um esforço colaborativo entre as empresas e os fornecedores detentores de recursos verdes, 0 que assegura às organizações os recursos e a expertise necessários para desenvolver produtos e serviços ambientalmente sustentáveis. Dessa forma, pode-se verificar que o papel dos fornecedores é essencial para proporcionar efetividade à Gestão Verde da Cadeia de Suprimentos.

\section{SELEÇÃO DE FORNECEDORES}

Segundo Wisner, Tan e Leong (2012), a Gestão de fornecedores é parte integrante das atividades de gestão de compras e consiste no encorajamento dado aos fornecedores para que estes apresentem o desempenho esperado. Ainda segundo os autores, esse processo envolve a verificação das capacidades dos fornecedores - tanto parceiros futuros como atuais - em atender os requisitos de desempenho desejáveis, além de envolver o desenvolvimento desses fornecedores, visando assegurar que futuramente a performance esperada seja alcançada. Tal avaliação constitui parâmetro para a seleção dos fornecedores de uma organização.

Buller (2012) evidencia que a seleção de fornecedores deve observar se há aderência do core business do fornecedor ao foco no mercado da cadeia de suprimentos. Sendo assim, um alto nível de cooperação, a comunicação clara, o compartilhamento de informação, e metas e objetivos semelhantes são fatores de sucesso dos relacionamentos entre membros de qualquer cadeia de suprimentos. (BOWERSOX; CLOSS, 2007). Desse modo, na seleção de fornecedores deve-se considerar, sobretudo o alinhamento estratégico das visões e valores das partes envolvidas.

De acordo com Ayres (2009), além do alinhamento estratégico entre as organizações, os seguintes fatores são considerados critérios na escolha de um fornecedor: capacidade de fabricação, confiabilidade, serviço pós-venda, localização geográfica, saúde financeira, condições comerciais e aspectos relacionados à preservação do meio ambiente e à responsabilidade social. Esse último é um fator que representa um critério cada vez mais importante nas cadeias de suprimentos atuais, sobretudo nas cadeias verdes, que buscam fornecedores sustentáveis.

Assim, ao escolher um fornecedor, o fabricante deve buscar parceiros que tenham culturas compatíveis, visão estratégica comum e filosofias operacionais complementares às suas (BOWERSOX; CLOSS, 2007). Quando a visão da parte compradora envolve a busca por sustentabilidade ambiental, esta deve fazer parte dos critérios de seleção dos fornecedores. 


\section{CRITÉRIOS PUBLICADOS PARA SELEÇÃO DE FORNECEDORES VERDES}

A Gestão Verde da Cadeia de Suprimentos fomentou a implementação de práticas ambientalmente sustentáveis em todos os níveis da cadeia. Isso tornou necessária uma seleção de parceiros mais criteriosa. A fim de garantir que os fornecedores também compartilhem da mesma visão em relação à sustentabilidade, a Gestão de Compras e de Fornecedores das organizações verdes incluíram diversos fatores a serem analisados durante a seleção de um fornecedor. Essas seleções a partir de critérios ambientalmente sustentáveis foram descritas em diversas publicações na literatura recente, e nesta seção serão apresentados os critérios mais discutidos.

Nas publicações consultadas - em sua maioria, estudos de caso -, os critérios foram escolhidos a partir de revisão de literatura e da opinião de especialistas nas áreas de gestão da cadeia de suprimentos e gestão ambiental. Os critérios mais utilizados estão elencados no Quadro 1.

Um dos fatores mais considerados durante a seleção de fornecedores ambientalmente sustentáveis é a Produção e o controle de poluição. Segundo Qin, Liu e Pedrycz (2016), a Produção de poluição pode ser definida como o volume médio de emissões de poluentes, águas residuais, resíduos sólidos e materiais perigosos liberados por uma empresa em um período determinado. Logo, seu controle dá-se através de iniciativas como gestão de resíduos sólidos e efluentes, e redução do uso de materiais perigosos (GHADIMI; TOOSI; HEAVEY, 2017).

Para tanto, empresas têm exigido de seus fornecedores checklists para verificar o uso de substâncias perigosas (GUREL et al, 2015); o uso de materiais que produzam o mínimo de resíduos poluentes durante a produção (LUTHRA et al, 2016); o uso de tecnologias do tipo end-of-pipe, visando reduzir a quantidade de poluentes ao fim do processo produtivo (HASHEMI; KARIMI; TAVANA, 2014); entre outras medidas de controle de poluição. Desse modo, o critério Produção e controle de poluição considera a emissão e o tratamento dado a todos os tipos de resíduos gerados na produção dos itens fornecidos.

QUADRO 1 - Critérios para seleção de fornecedores verdes mais citados na literatura recente.

\begin{tabular}{|c|c|}
\hline CRITÉRIO & PUBLICAÇÕES QUE O CITAM \\
\hline $\begin{array}{l}\text { Produção e } \\
\text { controle de } \\
\text { poluição }\end{array}$ & $\begin{array}{l}\text { (CHERAGHALIPOUR; FASARD, 2018); (GHADIMI; TOOSI; HEAVEY, 2017); (QIN; LIU; PEDRYCZ, 2016); } \\
\text { (LUTHRA et al, 2016); (HASHEMI; KARIMI; TAVANA, 2014); (GOVINDAM; KADZINISKI; SIVAKUMAR, } \\
\text { 2016); (GUREL et al, 2015); KANNAN; GOVINDAN; RAJENDRAN, 2014); (GHORABAEE et al, 2016); } \\
\text { (AWASTHI; GOVINDAN; GOLD, 2017); GALANKASHI et al, 2015); (KANNAN, 2017); (VAHIDI; TORABI; } \\
\text { RAMEZANKHANI, 2017); (GHADIMI; HEAVEY, 2014); (GHADIMI; DARGI; HEAVEY, 2017). }\end{array}$ \\
\hline $\begin{array}{c}\text { Sistemas de } \\
\text { gestão ambiental }\end{array}$ & $\begin{array}{l}\text { (CHERAGHALIPOUR; FASARD, 2018); (GOREN, 2018); FALLAPOUR et al, 2017); (QIN; LIU; PEDRYCZ, } \\
\text { 2016); (LUTHRA et al, 2016); (GOVINDAM; KADZIŃSKI; SIVAKUMAR, 2016); (GUREL et al, 2015); } \\
\text { (SONG; XU; LIU, 2017); (HAMDAN; CHEAITOU, 2017); (KANNAN; GOVINDAN; RAJENDRAN, 2014); } \\
\text { (BANAEIAN, 2016); (GHORABAEE et al, 2016); (VAHIDI; TORABI; RAMEZANKHANI, 2017). }\end{array}$ \\
\hline $\begin{array}{l}\text { Eco-design ou } \\
\text { design verde }\end{array}$ & $\begin{array}{l}\text { GOREN, 2018); (FALLAPOUR et al, 2017); (ORJI; WEI, 2015); (LUTHRA et al, 2016); (GHAYEBLOO et al, } \\
\text { 2015); (SONG; XU; LIU, 2017); YAZDANI et al, 2016); (GHORABAEE et al, 2016); GALANKASHI et al, } \\
\text { 2015); (KANNAN; JABOUR; JABOUR, 2013); (HAMDAN; CHEAITOU, 2016). }\end{array}$ \\
\hline $\begin{array}{l}\text { Consumo de } \\
\text { recursos }\end{array}$ & $\begin{array}{l}\text { (GOREN, 2018); (QIN; LIU; PEDRYCZ, 2016); (HASHEMI; KARIMI; TAVANA, 2014); (GOVINDAM; } \\
\text { KADZINSKI; SIVAKUMAR, 2016); (SONG; XU; LIU, 2017); (YAZDANI et al, 2016); GHORABAEE et al, } \\
\text { 2016); (AWASTHI; GOVINDAN; GOLD, 2017); (GALANKASHI et al, 2015); (VAHIDI; TORABI; } \\
\text { RAMEZANKHANI, 2017). }\end{array}$ \\
\hline $\begin{array}{l}\text { Emissões } \\
\text { atmosféricas }\end{array}$ & $\begin{array}{l}\text { (CHERAGHALIPOUR; FASARD, 2018); JAIN et al, 2016); GOVINDAM; KADZIŃSKI; SIVAKUMAR, 2016); } \\
\text { (YU; YANG; CHANG, 2017); (DOBOS; VÖRÖSMARTY, 2014); (JAUHAR; PANT, 2017); (AWASTHI; } \\
\text { GOVINDAN; GOLD, 2017); (GALANKASHI et al, 2015). }\end{array}$ \\
\hline $\begin{array}{c}\text { Tecnologia e } \\
\text { Inovação verdes }\end{array}$ & $\begin{array}{l}\text { (FALLAPOUR et al, 2017); (QIN; LIU; PEDRYCZ, 2016); (LUTHRA et al, 2016); (HAMDAN; CHEAITOU, } \\
\text { 2017); (KANNAN; GOVINDAN; RAJENDRAN, 2014); GHORABAEE et al, 2016); (KANNAN, 2017); } \\
\text { (VAHIDI; TORABI; RAMEZANKHANI, 2017). }\end{array}$ \\
\hline $\begin{array}{l}\text { Competências } \\
\text { verdes }\end{array}$ & $\begin{array}{l}\text { (GHADIMI; TOOSI; HEAVEY, 2017); (MOUSAKHANI; NAZARI-SHIRKOUHI; BOZORGI-AMIRI, 2017); } \\
\text { (QIN; LIU; PEDRYCZ, 2016); (ORJI; WEI,2015); (LUTHRA et al, 2016); (GHADIMI; HEAVEY, 2014); } \\
\text { (GHADIMI; DARGI; HEAVEY, 2017). }\end{array}$ \\
\hline Imagem verde & $\begin{array}{l}\text { (GHADIMI; TOOSI; HEAVEY, 2017); (MOUSAKHANI; NAZARI-SHIRKOUHI; BOZORGI-AMIRI, 2017); } \\
\text { (QIN; LIU; PEDRYCZ, 2016); (KANNAN; GOVINDAN; RAJENDRAN, 2014); (HAMDAN; CHEAITOU, 2016); } \\
\text { (GHADIMI; HEAVEY, 2014); (GHADIMI; DARGI; HEAVEY, 2017). }\end{array}$ \\
\hline
\end{tabular}
Fonte: Elaborado pela autora (2018). 
Outro critério considerado na seleção de fornecedores verdes é o Sistema de gestão ambiental dos candidatos a fornecedores. De acordo com Qin, Liu e Pedrycz (2016, p. 633), a gestão ambiental trata-se da "aplicação de técnicas de gestão a fim de buscar o equilíbrio econômico e fornecedores eficazes, considerando o meio ambiente como uma limitação". Assim, o critério Sistemas de gestão ambiental considera se o fornecedor possui a estrutura organizacional, o planejamento e os recursos para desenvolver, implementar e manter políticas de proteção ao ambiente (GHORABAEE et al, 2016). Isso inclui não só políticas internas da empresa, mas também certificações concedidas por organizações internacionais; sendo a ISO 14001, segundo Ghorabaee et al (2016), a mais requisitada pelas empresas.

Além da certificação ISO 14001, outros fatores são ponderados ao se analisar o preenchimento do critério Sistema de gestão ambiental, tais como: conformidade com a EUP (Energy Using Product), a qual consiste em uma diretriz internacional que regula as consequências ambientais da energia usada pelos produtos; a emissão de químicos redutores da camada de ozônio (ODC Ozone Depleting Chemicals); a adoção da Restrição de Substâncias Perigosas (RoHS Restriction of hazardous substance), que consiste em uma diretriz com intuito de reduzir o uso de materiais tóxicos e nocivos (GUREL et al, 2015), entre outros. Em suma, avalia-se se a empresa fornecedora adota ações gerenciais em benefício do meio ambiente.

Eco-design ou Design verde é outro dos critérios mais citados na literatura recente para seleção de fornecedores verdes. Para Orji e Wei (2015), Design verde envolve proporcionar facilidade de desmontagem e de reciclagem do produto ao fim do seu ciclo de vida. Segundo Ghorabaee et al (2016), ao analisar esse critério, as organizações verificam se o fornecedor realiza o design dos produtos com intuito de reduzir o consumo de materiais e energia, de viabilizar reuso e reciclagem de materiais e de diminuir o uso de materiais perigosos. Enquanto que Ghayebloo et al (2015) consideram a confiabilidade dos componentes usados e a facilidade de recuperação e desmontagem de produtos de extrema importância caso a empresa contratante deseje assegurar a logística reversa. Dessa forma, o critério Ecodesign inclui aspectos ambientais que vão desde o início - como projeto e fabricação até o final do ciclo de vida do produto - como reciclagem e reuso.

Outro critério verde utilizado é o Consumo de recursos. Esse critério avalia o consumo de matéria-prima, energia e água no processo de produção do fornecedor (GHORABAEE et al, 2016). Segundo Goren (2018), o aumento no preço da energia e a escassez de matériasprimas e de recursos naturais nos anos recentes geraram preocupação nas cadeias de suprimento que desejavam manter competitividade. Os autores Galankashi et al (2015) e Govindam, Kadzińskie e Sivakumar (2016) consideram a eficiência energética como um dos principais critérios na seleção de um fornecedor verde. Portanto, é preciso buscar fornecedores que tenham controle do seu consumo de recursos naturais - como energia, água e matérias-primas -, não só para garantir a sustentabilidade ambiental, mas também para assegurar vantagem competitiva.

Emissões atmosféricas também são um critério para seleção de fornecedores verdes bastante citado na literatura recente. Tal critério visa verificar se o potencial fornecedor emite gases estufa durante a produção do item fornecido (CHERAGHAPOUR; FASARD 2018). Govindan, Kadziński e Sivakumar (2016) referem-se também à realização de controle da quantidade, bem como o tratamento de emissões de gases perigosos, como SO2, $\mathrm{NH} 3, \mathrm{CO}$ e $\mathrm{HCl}$.

Além disso, Yu, Yang e Chang (2017) propõem que, ao escolher um fornecedor, devem-se considerar não só as emissões de gases durante o processo de produção, mas também as emissões durante o transporte do produto, do fornecedor até a empresa contratante. Para tanto, é necessário que se criem sistemas que auxiliem na determinação dos gases estufa emitidos por cada um dos componentes dos produtos fornecidos, sendo estes sistemas a estrutura tecnológica central para implantação de um sistema de gestão ambiental, segundo Jain et al (2016). Portanto, para atender a esse critério, o fornecedor verde deve ter controle das emissões de gases estufa e de gases perigosos durante todo o ciclo de vida do produto.

Outro critério contemplado para seleção de fornecedores verdes é a Tecnologia e Inovação verdes. Ao analisar esse critério, as empresas verificam se o candidato a fornecedor possui capacidade de 
desempenhar atividades de Pesquisa e Desenvolvimento (P\&D) para criar e implementar tecnologias, processos, práticas e métodos mais limpos (LUTHRA et al, 2016). Ghorabaee et al (2016) definem o uso de tecnologia verde como a aplicação de química verde, ciências ambientais, monitoramento ambiental e aparelhos eletrônicos para modelar, monitorar e conservar o meio ambiente e os recursos naturais, bem como para atenuar os efeitos negativos da ação humana.

Enquanto Kannan, Govindan e Rajendran (2014) avaliam esse critério a partir da infraestrutura para P\&D do fornecedor; do nível tecnológico - verificando se 0 desenvolvimento tecnológico do fornecedor é capaz de satisfazer às demandas atuais e futuras da empresa compradora -; e do nível de implementação de tecnologias limpas. Qin, Liu e Pedrycz (2016), por sua vez, apontam a necessidade de avaliar se o potencial fornecedor soluciona questões ambientais através de design do produto e inovação técnica. Portanto, é importante que os fornecedores demonstrem que adotam tecnologias para reduzir impactos ambientais, bem como invistam em pesquisas e inovações para o desenvolvimento de métodos de produção cada vez mais sustentáveis.

Competências verdes também são consideradas na seleção de fornecedores ambientalmente sustentáveis. Orji e Wei (2015) conceituam o critério Competências verdes como todo o conhecimento e as habilidades necessárias para uma gestão ambiental efetiva. Assim, ao verificar esse critério, deve-se ponderar se o fornecedor utiliza processos e embalagem sustentáveis (GHADIMI; DARGI; HEAVEY, 2017), ou mesmo se este possui capacidade para alterar processos e produtos de forma que se tornem ambientalmente sustentáveis (QIN; LIU; PEDRYCZ, 2016).

Além disso, é preciso apurar se o staff recebeu treinamento para desenvolver competências ambientais na empresa (ORJI e WEI, 2015), bem como avaliar se a empresa possui habilidade de implantar tecnologias limpas e de reduzir impactos da poluição (LUTHRA et al, 2016). Desse modo, avaliar uma organização a partir do critério Competências verdes corresponde a ponderar se o candidato a fornecedor possui know-how para realizar atividades com 0 intuito de reduzir os impactos ambientais da sua atuação.

Outro critério para seleção de fornecedores sustentáveis é a Imagem verde. Segundo Qin, Liu e Pedrycz (2016), esse critério pode ser definido como a proporção de consumidores verdes sobre o total de consumidores. Já Mousakhani, Nazari-Shirkouh e Bozorgi-Amiri (2017) definem-no como a habilidade do fornecedor de fabricar produtos verdes, conforme padrões ambientais. Dessa forma, ao analisar se um fornecedor atende a esse critério, considera-se a reputação deste no mercado, bem como a reputação de seus consumidores (GHADIMI; TOOSI; HEAVEY, 2017). Assim sendo, esse critério avalia se o fornecedor possui boa reputação quando se trata de questões ambientais nas suas operações, e se essa reputação atrai e retém empresas compradoras com reputação semelhante.

Diante disso, é possível notar certa similaridade entre os critérios descritos. Por exemplo, o Eco-design e a Produção e controle de poluição focam no uso de matérias-primas menos danosas ao meio ambiente, assim, a implementação de um está associada ao outro. O mesmo ocorre entre os critérios Competências ambientais e Sistemas de gestão ambiental, pois para implantar um sistema de gestão ambiental, as empresas necessitam desenvolver competências ambientais, tais como conhecimento, habilidades e estrutura para ações em prol do meio ambiente. Nesse sentido, quando uma empresa fornecedora decide atender a um critério, ela já está contribuindo para que os demais critérios sejam atendidos. Porém, falhar no atendimento a um dos critérios pode implicar no risco de não atendimento aos demais.

\section{CONSIDERAÇÕES FINAIS}

As seleções de fornecedores a partir de critérios ambientalmente sustentáveis foram descritas em diversas publicações na literatura recente. A partir da análise dessas publicações foi possível chegar aos critérios mais utilizados para avaliar fornecedores que seguem uma política verde, os quais são: Produção e controle de poluição, Sistemas de gestão ambiental, Eco-design, Consumo de recursos, Emissões atmosféricas, Tecnologia e Inovação verdes, Competências verdes e Imagem verde. 
Após sua descrição, percebeu-se que esses critérios são intrinsecamente relacionados uns aos outros e encontram certa sobreposição nos seus conceitos. Adicionalmente, notou-se que estes envolvem atividades de todos os setores de uma organização, bem como seu relacionamento com entes externos, como clientes, fornecedores, governos e comunidade. Além disso, exigem atenção ao aspecto ambiental do início até o fim do ciclo de vida do produto.

Dessa forma, a implementação de características verdes mostrou-se necessária em todos os âmbitos da organização, bem como em toda a cadeia de suprimentos. Caso isso não ocorra, poderá haver o insucesso do propósito da sustentabilidade ambiental. Portanto, os fornecedores que desejem fazer parte de uma cadeia de suprimentos verde devem estar atentos aos critérios citados e

\section{REFERÊNCIAS}

[1]. AWASTHI, A.; GOVINDAN, K.; GOLD, S.. Multi-tier sustainable global supplier selection using a fuzzy AHP-VIKOR based approach. International Journal of Production Economics, v. 195, p. 106117, jan. 2018. Disponível em: $<$ https://doi.org/10.1016/j.ijpe.2017.10.013>.

Acesso em 29 mar. 2018.

[2]. AYRES, A. de P. S.. Gestão de Logística e Operações. Curitiba: IESDE Brasil, 2009.

[3]. BANAEIAN, N.; MOBLI, H.; FAHIMNIA, B.; NIELSEN, I. E.; OMID, M. Green supplier selection using fuzzy group decision making methods: A case study from the agri-food industry. Computers and Operation Research, v. 89, p. 337-347, jan. 2018. Disponível em: < https://doi.org/10.1016/j.cor.2016.02.015>. Acesso em 30 mar. 2018

[4]. BOWERSOX, D. J.; CLOSS, D. J. Logística empresarial: o processo de integração da cadeia de suprimento. Tradução por Equipe do Centro de Estudos em Logística. 1 ed. São Paulo: Atlas, 2007.

[5]. BULLER, L. S.. Logística empresarial. Curitiba: IESDE Brasil, 2012.

[6]. CHERAGHALIPOUR, A.; FASARD, S. A biobjective sustainable supplier selection and order allocation considering quantity discounts under disruption risks: A case study in plastic industry. Computers \& Industrial Engineering, v. 118, p. 237250, 2018. Disponível em <https://doi.org/10.1016/j.cie.2018.02.041>. Acesso em 29 mar. 2018.

[7]. DOBOS, I.; VOROSMARTY, G.. Green supplier selection and evaluation using DEA-type desenvolver estrutura, habilidades e conhecimentos para a satisfação destes, e ainda buscar parceiros que também atendam ou demonstrem interesse em atendê-los.

Por fim, os resultados dessa pesquisa são úteis não só para empresas que buscam fornecedores verdes, mas também para fornecedores que desejem adotar práticas verdes. Entretanto, este estudo apresentou limitações quanto à quantidade de publicações analisadas, o que decorreu do cronograma da pesquisa e do uso de apenas uma plataforma de pesquisa para obtenção das publicações avaliadas. Portanto, para futuros trabalhos, sugere-se um estudo mais amplo - isto é, analisando-se um maior número de publicações -, da literatura relacionada à seleção de fornecedores verdes a fim de se obter uma compilação de critérios mais composite indicators. International Journal of Production Economics, v. 157, p. 273-278, nov. $2014 . \quad$ Disponível em <https://doi.org/10.1016/j.ijpe.2014.09.026>. Acesso em 30 mar. 2018.

[8]. ESFAHBODI, A.; ZHANG, Y.; WATSON, G.. Sustainable Supply Chain management in emerging economies: trade-offs between environmental and cost performance. International Journal of Production Economics, v. 181, p.350366, nov. 2016. Disponível em <https://doi.org/10.1016/j.ijpe.2016.02.013>. Acesso em 02 mar. 2018.

[9]. FALLAHPOUR, A.; OLUGU, E. U.; MUSA, S. N.; WONG,K. Y.; NOORI, S.. A decision support model for sustainable supplier selection in sustainable supply chain management. Computers \& Industrial Engineering, v. 105, p. 391-410, mar. $2017 . \quad$ Disponível em <https://doi.org/10.1016/j.cie.2017.01.005>.

Acesso em 30 mar. 2018.

[10]. GALANKASHI, M. R. et al. Prioritizing green supplier selection criteria using Fuzzy Analytical Network Process. Procedia CIRP, v.26, p. 689-694, 2015.Disponível em <https://doi.org/10.1016/j.procir.2014.07.044>. Acesso em 29 mar. 2018.

[11]. GHADIMI, P.; DARGI, A.; HEAVEY, C. Sustainable supplier performance scoring using audition check-list based fuzzy inference system: A case application in automotive spare part industry. Computers \& Industrial Engineering, v. 105, p. 1227. mar. 2017. Disponível em 
<https://doi.org/10.1016/j.cie.2017.01.002>. Acesso em 29 mar. 2018

[12]. GHADIMI, P.; HEAVEY, C. Sustainable supplier selection in Medical Device Industry: toward sustainable manufacturing. Procedia CIRP, v. 15, p. 165-170, 2014. Disponível em <https://doi.org/10.1016/j.procir.2014.06.096> Acesso em 29 mar. 2018

[13]. GHADIMI, P.; TOOSI, F. G.; HEAVEY, C. A multi-agent systems approach for sustainable supplier selection and order allocation in a partnership supply chain. European Journal of Operational Research, jul. 2017. Disponível em: $<$ https://doi.org/10.1016/j.ejor.2017.07.014>. Acesso em 29 mar. 2018

[14]. GHAYEBLOO, S. et al. Developing a biobjective model of the closed-loop supply chain network with green supplier selection and disassembly of products:. Journal of Manufacturing Systems, v. 36, p. 76-86, jul, 2015. Disponível em: <https://doi.org/10.1016/j.jmsy.2015.02.011>. Acesso em 31 mar. 2018

[15]. GHORABAEE, M. K. et al. Multi-criteria evaluation of green suppliers using an extended WASPAS method with interval type-2 fuzzy sets. Journal of Cleaner Production, v. 137, p. 213-229, 2016. Disponível em <https://doi.org/10.1016/j.jclepro.2016.07.031>. Acesso em 29 mar. 2018

[16]. GOREN, H. G.. A decision framework for sustainable supplier selection and order allocation with lost sales. Journal of Cleaner Production, v. 183, p. 1156-1169, 2018. Disponível em <https://doi.org/10.1016/j.jclepro.2018.02.211>. Acesso em 30 mar. 2018.

[17]. GOVINDAM, K.; KADZIŃSKI, M.; SIVAKUMAR, R.. Application of a novel PROMETHEE-based method for construction of a group compromise ranking for prioritization of green suppliers. Omega, v. 71, p. 129-145, 2017. Disponível <https://doi.org/10.1016/j.omega.2016.10.004> Acesso em 29 mar. 2018.

[18]. GUREL, O. et al. Determinants of the green supplier selection. Procedia - Social and Behavioral Sciences, v.181, p. 131-139. Disponível em:

<https://doi.org/10.1016/j.sbspro.2015.04.874>. Acesso em 29 mar. 2018.

[19]. HAMDAN, S.; CHEAITOU, A..Dynamic green supplier selection and order allocation with quantity discounts and varying supplier availability. Computers \& Industrial Engineering, v. 110, p. 573589, ago. 2017. Disponível em <https://doi.org/10.1016/j.cie.2017.03.028>.

Acesso em 30 mar. 2018

[20]. HAMDAN, S.; CHEAITOU, A.. Supplier selection and order allocation with green criteria: An MCDM and multi-objective optimization approach. Computers and Operations Research, v.81, p. 282-304, maio 2017. Disponível em: <https://doi.org/10.1016/j.cor.2016.11.005> Acesso em 31 mar. 2018.

[21]. HASHEMI, S. H.; KARIMI, A.; TAVANA, M. An integrated green supplier selection approach with analytic network process and improved Grey relational analysis. Int. J. Production Economics, v.159,p. 178-191, 2015. Disponível em: <https://doi.org/10.1016/j.ijpe.2014.09.027>. Acesso em 29 mar. 2018.

[22]. HONG, J.; ZHANG, Y.; DING, M.. Sustainable Supply Chain Management practices, supply dynamic capabilities, and enterprise performance. Journal of Cleaner Production, vol. 172, p. 3508-3519, jan. 2018. Disponível em: <https://doi.org/10.1016/j.jclepro.2017.06.093>. Acesso em 02 mar. 2018.

[23]. JAIN, V. et al. An integrated buyer initiated decision-making process for green supplier selection. Journal of Manufacturing Systems, v. 41, p. 256-265, out. 2016. Disponível em: $<$ https://doi.org/10.1016/j.jmsy.2016.09.004>. Acesso em 30 mar. 2018.

[24]. JAUHAR, S. K.; PANT, M..Integrating DEA with DE and MODE for sustainable supplier selection. Journal of Computational Science, v. 21, p. 299-306, 2017. Disponível em <https://doi.org/10.1016/j.jocs.2017.02.011>. Acesso em 30 mar. 2018.

[25]. KANNAN, D. Role of multiple stakeholders and the critical success factor theory for the sustainable supplier selection process. International Journal of Production Economics, v. 195, p 391-418, jan. 2018. Disponível em: <https://doi.org/10.1016/j.ijpe.2017.02.020> Acesso em 29 mar. 2018.

[26]. KANNAN, D.; GOVINDAN, K.; RAJENDRAN, S.. Fuzzy Axiomatic Design approach based green supplier selection: a case study from Singapore. Journal of Cleaner Production, v. 96, p. 194-208, 2015. Disponível em <https://doi.org/10.1016/j.jclepro.2013.12.076>. Acesso em 29 mar. 2018.

[27]. KANNAN, D.; JABOUR, A. B. L.; JABBOUR, C. J. C.. Selecting green suppliers based on GSCM practices: Using fuzzy TOPSIS applied to a Brazilian electronics company. European Journal of Operational Research, v. 233, n.2, p. 432-447, mar. 2014. Disponível em $<$ https://doi.org/10.1016/j.ejor.2013.07.023>. Acesso em 30 mar. 2018.

[28]. LUTHRA, S. et al. An integrated framework for sustainable supplier selection and evaluation in supply chains. Journal of Cleaner Production, v.140, p. 1686-1698, 2017. Disponível em: <https://doi.org/10.1016/j.jclepro.2016.09.078>. Acesso em 29 mar. 2018.

[29]. MIN, H.; KIM, I.. Green supply chain research: past, present, and future. Logistics Research, v. 4, n. 1-2, p. 39-47, mar. 2012. 
Disponível

em: $<$ https://link.springer.com/article/10.1007/s12159012-0071-3>. Acesso em 01 mar. 2018.

[30]. MOUSAKHANI, S.; NAZARI-SHIRKOUHI, S.; BOZORGI-AMIRI, A. A novel interval type-2 fuzzy evaluation model based group decision analysis for green supplier selection problems: A case study of battery industry. Journal of Cleaner Production, v. 168, p. 205-218, dez. 2017. Disponível <https://doi.org/10.1016/j.jclepro.2017.08.154>. Acesso em 29 mar. 2018.

[31]. ORJI, I. J; WEI, S.. An innovative integration of fuzzy-logic and systems dynamics in sustainable supplier selection: A case on manufacturing industry. Computers \& Industrial Engineering, v. 88, p. 1-12, out. 2015. Disponível em <https://doi.org/10.1016/..cie.2015.06.019>. Acesso em 29 mar. 2018.

[32]. QIN, J.; LIU, X.; PEDRYCZ, W..An extended TODIM multi-criteria group decision making method for green supplier selection in interval type-2 fuzzy environment. European Journal of Operational Research, v.258, p. 626-638, abr. 2017. Disponível em <https://doi.org/10.1016/j.ejor.2016.09.059>. Acesso em 29 mar. 2018.

[33]. SEHNEM, S. et al. Green Supply Chain Management: uma análise da produção científica recente (2001-2012). Production, v. 25, n. 3, p. 465481, 2015. Disponível em: $<$ http://dx.doi.org/10.1590/S0103-

65132014005000006>. Acesso em 01 mar. 2018.

[34]. SHANANPOUR, H.; YOUSEFI, S.; SAEN, R. F.. Future planning for benchmarking and ranking sustainable suppliers using goal programming and robust double frontiers DEA. Transportation Research Part D: Transport and Environment, v. 50, p. 129-143, jan. 2017. Disponível em < https://doi.org/10.1016/j.trd.2016.10.022>. Acesso em 31 mar. 2018.

[35]. SHANANPOUR, H.; YOUSEFI, S.; SAEN, R. F. Forecasting efficiency of green suppliers by dynamic data envelopment analysis and artificial neural networks. Journal of Cleaner Production, v. 142, p. 1098-1107, jan. 2017. Disponível em <https://doi.org/10.1016/j.jclepro.2016.08.147>. Acesso em 30 mar. 2018

[36]. SONG, W.; XU, Z.; LIU, H. Developing sustainable supplier selection criteria for solar airconditioner manufacturer: An integrated approach. Renewable and Sustainable Energy Reviews, v. 79, p. 1461-1471, nov. 2017. Disponível em <https://doi.org/10.1016/j.rser.2017.05.081 > Acesso em 30 mar. 2018.
[37]. SRIVASTAVA, S. K..Green supply-chain management: A state-of-the-art literature review. International Journal of Management Reviews, v. 9, n. 1 p. 53-80, 2007. Disponível em <https://doi.org/10.1111/j.1468-

2370.2007.00202.x>. Acesso em 01 mar. 2018.

[38]. VAHIDI, F.; TORABI, S. A.; RAMEZANKHANI, M. J.. Sustainable supplier selection and order allocation under operational and disruption risks. Journal of Cleaner Production, v. 174, p. 1351-1365, fev. 2018. Disponível em: <https://doi.org/10.1016/j.jclepro.2017.11.012>. Acesso em 29 mar. 2018.

[39]. WISNER, J. D.; TAN, K.; LEONG, G. K.. Principles of Supply Chain Management: a balanced approach. 3 ed. Ohio: South-Western Cengage Learning, 2012.

[40]. YAZDANI, M. et al..Integrated QFD-MCDM framework for green supplier selection. Journal of Cleaner Production, v. 142, p. 3728-3740, jan 2017. Disponível em <https://doi.org/10.1016/j.jclepro.2016.10.095>. Acesso em 30 mar. 2018.

[41]. YOUSEFI, S.; SHANANPOUR, H.; SAEN, R. $F$. Evaluating and ranking sustainable suppliers by robust dynamic data envelopment analysis. Measurement, v. 83, p. 72-85, abr. 2016. Disponível em

<https://doi.org/10.1016/j.measurement.2016.01.03 2>. Acesso em 30 mar. 2018.

[42]. YU, F.; YANG, Y.; CHANG, D. Carbon footprint based green supplier selection under dynamic environment. Journal of Cleaner Production, v. 170, p. 880-889, jan 2018. Disponível em <https://doi.org/10.1016/j.jclepro.2017.09.165>. Acesso em 30 mar. 2018.

[43]. ZHU, Q.; SARKIS, J.. Relationships between operational practices and performance among early adopters of green supply chain management practices in Chinese manufacturing enterprises. Journal of Operations Management, v. 22,n.3, p. 265-289, jun. 2004. Disponível em: <https://doi.org/10.1016/j.jom.2004.01.005>. Acesso em 01 mar. 2018.

[44]. ZHU, Q.; SARKIS, J.; LAI, K.. Institutionalbased antecedents and performance outcomes of internal and external green supply chain management practices. Journal of Purchasing and Supply Management, v. 19, n. 2, p. 106-117, jun. 2013. Disponível em: <https://doi.org/10.1016/j.pursup.2012.12.001>. Acesso em 02 mar. 2018. 


\section{Gapítulo 14}

\section{IMPACTOS AMBIENTAIS CAUSADOS PELO DESCARTE DO LODO DE ESTAÇÕES DE TRATAMENTO DE ÁGUA EM CORPOS HIDRICOS}

\section{Uedja Tatyane Guimarães Medeiros Lima}

Amanda Tenório da Costa

\section{Janaína Accordi Junkes}

Resumo: A forma de destinação final do resíduo sólido produzido nos sistemas de tratamento de água, comumente conhecido como lodo de ETA, pode causar impacto ambiental se não for descartado corretamente. A prática de despejo do lodo em corpos hídricos está em desacordo com a Política Nacional dos Resíduos Sólidos - PNRS, Política Nacional dos Recursos Hídricos - PNRH, lei de crimes ambientais, entre outras. Logo, pesquisas relacionadas aos possíveis impactos ambientais causados por essa prática e o incentivo ao tratamento e destinação ambientalmente correta deste resíduo apresenta grande relevância. Este trabalho levantou os possíveis impactos ambientais causados pelo descarte irregular do lodo de estações de tratamento de água em corpos hídricos, utilizando a ferramenta de matriz de correlação simplificada, fundamentada nos três grandes grupos de estudos ambientais: meio físico, biótico e antrópico e propôs formas de destinação final ambientalmente adequada.

Palavras-chave: resíduos sólidos; matriz simplificada; avaliação de impactos ambientais 


\section{INTRODUÇÃO}

A medida que ocorre o crescimento demográfico, cresce a necessidade do consumo da água que é um recurso natural indispensável a vida. A maior parte da água disponível, não pode ser diretamente utilizada, necessitando um processo de tratamento no qual serão eliminados agentes de contaminação que possam causar danos à saúde dos seres vivos.

O tratamento de água é um dos serviços oferecidos pelas companhias do saneamento, presente em todos os estados brasileiros, que proporciona a população, água potável com qualidade dentro dos padrões estabelecidos pela legislação. Este serviço se não planejado e gerenciado corretamente, ocasiona risco de impacto ao meio ambiente, pela geração de resíduo sólido com relevante concentração de produtos químicos, denominado lodo de Estação de Tratamento de Água (ETA).

Segundo a normas NBR 10.004 (ABNT, 2004), resíduos sólidos são resíduos nos estados sólido e semissólido, que resultam de atividades de origem industrial, doméstica, hospitalar, comercial, agrícola, de serviços e de varrição. Ficam incluídos nesta definição os lodos provenientes de sistemas de tratamento de água.

A grande maioria dos corpos hídricos utilizados para captação de água com a finalidade de abastecimento humano são águas doces superficiais de classe 2 e 3. A água doce é classificada em treze classes de qualidade, divididas em águas doces, salinas e salobras, as classes 2 e 3 referentes a água doce, atendem aos requisitos de abastecimento humano (CONAMA, 2005). Ambas necessitam de tratamento do tipo convencional ou avançado, em função do elevado índice de turbidez e cor da água bruta. Segundo Achon (2013) são cerca de 7.500 unidades de ETA em todo brasil, estas estações conferem ao processo de tratamento a seguinte sequência: coagulação, floculação, sedimentação, filtração, desinfecção, correção do pH e adição de flúor, como resultado desse processo, há geração de água de boa qualidade sanitária e geração de resíduo sólido (lodo), o qual é produzido nas etapas de decantação/sedimentação e filtração.

O lodo é classificado como resíduo sólido, classe II não perigoso, necessitando estudo de disposição final adequado e sendo proibida a prática de descarte sem tratamento prévio (ABNT, 2004). A preocupação com o descarte correto do lodo de ETA pôde ser observada a partir da década de 90, com o advento da Política Nacional dos Recursos Hídricos (PNRH) estabelecida pela Lei $n^{\circ}$ 9.433 (BRASIL, 1997) e com a Lei de Crimes Ambientais no 9.605 (BRASIL, 1998), em que é considerado crime ambiental o lançamento de lodo proveniente de ETA in natura (SILVEIRA, 2012). Grande parte das estações de tratamento de água brasileiras foram projetadas antes do surgimento destas leis, incluindo a Resolução CONAMA № 237/1997 a qual exige o licenciamento ambiental das atividades potencialmente poluidoras, não sendo incluído na fase de projeto pelas companhias a gestão do resíduo gerado, resultando em gerenciamento precário e de forma emergencial, acarretando em custos financeiros e ambientais.

Posteriormente a Lei 12.305/2010 (BRASIL, 2010) definiu os conceitos de resíduos e rejeitos, sendo o resíduo sólido material, substancia ou objeto passível de reutilização e/ou reciclagem e o rejeito sendo um resíduo que depois de esgotadas todas as possibilidades de tratamento e recuperação por meio de processos tecnológicos disponíveis e economicamente viáveis, não apresente mais valor, sendo necessária sua disposição final ambientalmente adequada. Dentro desta perspectiva, o lodo de ETA se enquadra como resíduo sólido, tornando assim imprescindível seu gerenciamento, objetivando $\mathrm{o}$ atendimento das premissas estabelecidas pela Política Nacional de Resíduos Sólidos - PNRS (Lei 12.305/2010).

A lei 12.305/2010 (BASIL, 2010) ainda institui uma ordem de prioridade no gerenciamento dos resíduos sólidos: não geração, redução, reutilização, reciclagem, tratamentos dos resíduos sólidos que não se aplicam a recuperação, disposição final ambientalmente adequada dos rejeitos.

De acordo com Soares (2004) a partir das características do lodo gerado e do processo de tratamento de água utilizado é possível prever o impacto ambiental ao seu lançamento em um corpo hídrico. A toxidade do resíduo final dependerá de suas características físico-químicas e da forma e situação em que é disposta, a quantidade varia de acordo com a qualidade da água bruta (sem tratamento), dos tipos de produtos químicos utilizados e das dosagens necessárias para sua coagulação. Segundo Sánches (2013) as ETA de ciclo completo, produzem lodo com concentrações de sólidos superiores a $2,5 \%$, que quando despejada em 
um corpo hídrico pode causar considerável degradação ambiental.

\section{OBJETIVO}

Realizar um levantamento dos possíveis impactos ambientais provenientes do descarte irregular do resíduo de ETA em águas superficiais, utilizando uma matriz de correlação simplificada que é uma a metodologia de avaliação de impactos ambiental e propor formas de destinação final ambientalmente adequada.

\section{FUNDAMENTAÇÃO TEÓRICA}

\subsection{FORMAÇÃO DO LODO DE ESTAÇÃO DE TRATAMENTTO DE ÁGUA}

As estações de tratamento de água de ciclo completo, executam os seguintes processos de tratamento: coagulação, floculação, sedimentação, filtração, desinfecção, correção do pH e adição de flúor, de acordo com a Figura 1.

Figura 1 - Fluxograma de uma ETA

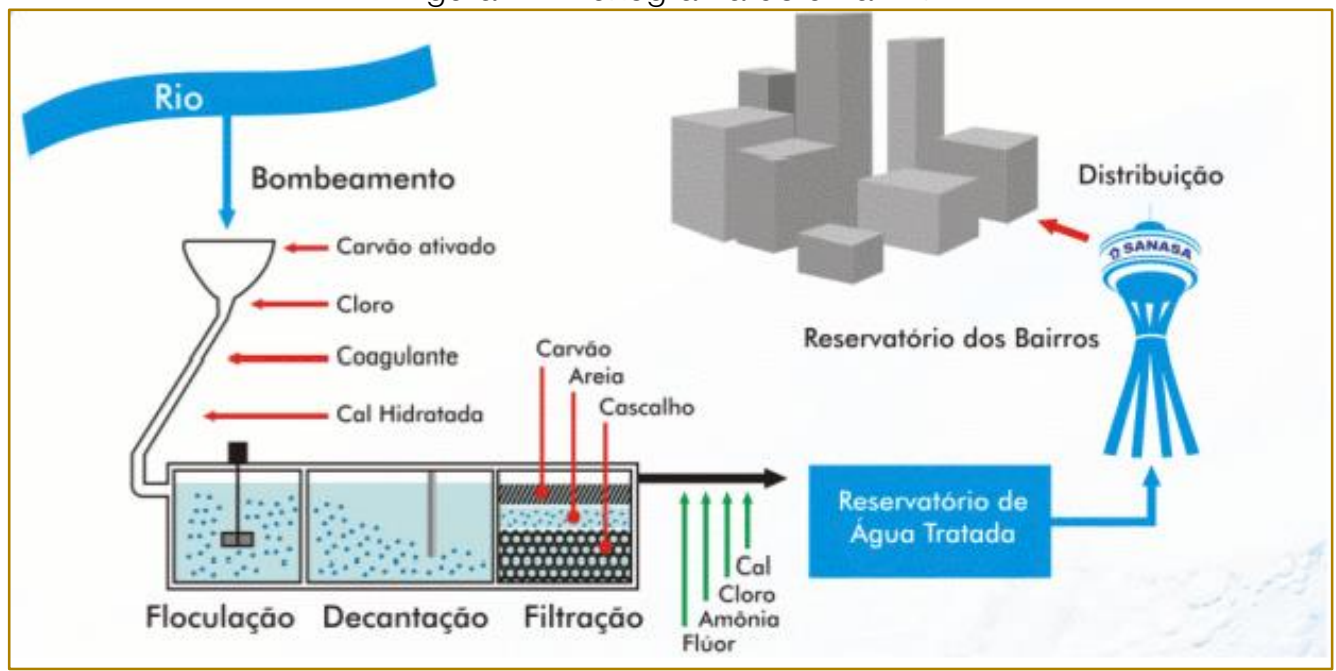

Fonte: SANASA, 2014

As primeiras etapas de coagulação e floculação são processos que promovem aglomeração de partículas presentes na água bruta. A coagulação ocorre pela adição de produtos químicos para que as partículas ali presentes desestabilizem eletricamente facilitando posterior agregação. Dois fenômenos agem no processo de coagulação: O químico pelas reações do composto com a água na formação de espécies hidrolisadas de carga positiva e o físico com o transporte das espécies hidrolisadas. Existem diversos tipos de coagulantes a base de ferro e alumínio utilizados nas ETAs de todo país, entre eles estão: o sulfato de alumínio (Al2(SO4)3.14H2O), o cloreto férrico (FeCl3.6H2O), o sulfato férrico (Fe2(SO4)3) e o sulfato ferroso (FeSO4.6H2O) (TARTARI, 2008).

A etapa de floculação possui a função de aglomerar partículas que foram anteriormente desestabilizadas resultando em partículas maiores, processo inteiramente físico aumentando o tamanho sub-microscópico em tamanho visível e de fácil decantação.
Na decantação ocorre a sedimentação dos flocos formados nas etapas anteriores, formando uma camada de lodo, a qual pode ser retirada através de raspadores ou manualmente. Posteriormente ocorre a filtração, etapa na qual são corrigidas falhas dos processos anteriores, removendo as impurezas e partículas em suspensão que não foram retiradas durante a decantação, gerando também acumulo de lodo (LIMA, 2016).

\subsection{IMPACTOS AMBIENTAIS CAUSADOS PELA DISPOSIÇÃO DE LODO EM CORPOS HÍ́RICOS}

Segundo a resolução CONAMA n.001 de 1986 (Resolução CONAMA № 001, Artigo 1o de 23 de janeiro de 1986), impacto ambiental é qualquer alteração das propriedades físicas, químicas e biológicas do meio ambiente, causada por qualquer forma de matéria ou energia resultante das atividades humanas que, direta ou indiretamente, afetam: "a saúde, a segurança e o bem-estar da população; as atividades sociais e 
econômicas; a biota; as condições estéticas e sanitárias do meio ambiente; a qualidade dos recursos ambientais" (CONAMA, 1986).

Wathern (1988) diz que impacto ambiental é a mudança em um parâmetro ambiental, num determinado período e numa determinada área, que resulta de uma dada atividade, comparada com a situação que ocorria se essa atividade não tivesse sido iniciada. Uma representação do conceito de impacto ambiental é apresentada na Figura 2.

Figura 2 - Representação do conceito de Impacto Ambiental.

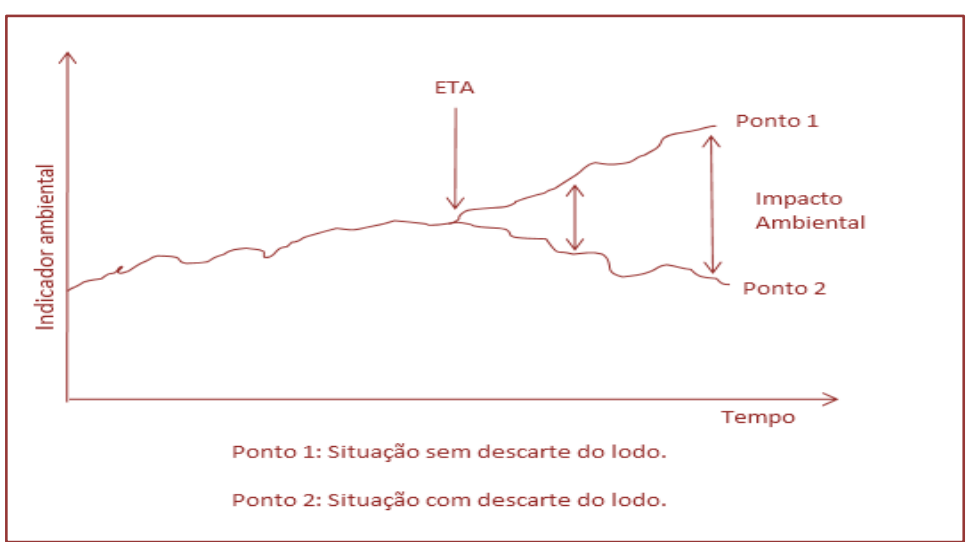

Fonte: adaptado de Sánchez, 2013

Não se deve confundir Aspecto ambiental com Impacto Ambiental, a emissão de lodo de ETA em um corpo hídrico não se caracteriza como impacto ambiental, e sim como aspecto ambiental, impactos são os resultados dessa emissão no meio, as alterações ambientais que irão acontecer. Um esquema explicativo está apresentado na Figura 3.

Figura 3 - Relação entre ação humana, aspecto e impacto ambiental.

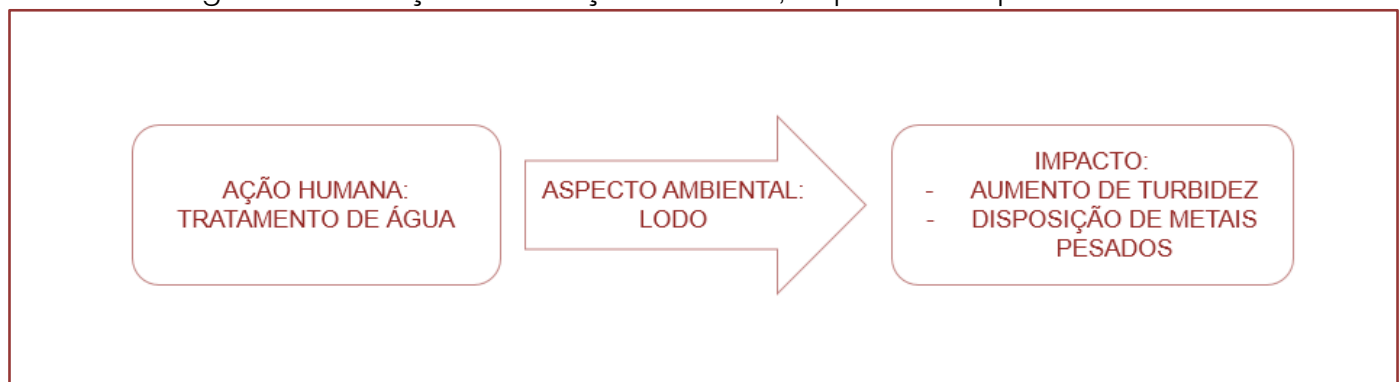

Fonte: Adaptado de Sánchez, 2013.

Segundo Soares (2004) com o conhecimento do processo utilizado para tratamento da água e com a determinação das características do lodo, é possível apontar os possíveis impactos ambientais que serão causados por seu lançamento. A toxidade do resíduo final dependerá de suas características físico-químicas e da forma e situação em que é disposta, a quantidade varia de acordo qualidade da água bruta (sem tratamento), dos tipos de produto químico utilizado e das dosagens necessárias para sua coagulação. Estações de ciclo completo, geralmente produzem lodo com concentrações de sólidos superiores a 2,5\%, podendo ocasionar degradação ambiental considerável em um corpo de água (REALI, et al, 1999 apud SÁNCHES, 2013).
Além da presença de sais diversos, metais, microrganismos, substâncias orgânicas e inorgânicas, outros contaminantes colaboram com o aumento de toxidade do lodo, deve-se levar em consideração: as reações sofridas dentro do processo, característica física, química e biológica, tempo de detenção e outros tipos de produtos químicos que por ventura sejam introduzidos ao tratamento da água.

A partir do levantamento dos impactos ambientais decorrentes do lançamento de lodo sem nenhum tipo de tratamento em corpos d'águas, foi elaborada uma matriz de correlação simplificada, os impactos observados são: aumento da turbidez que resulta na redução da camada eutrófica, sombreamento da macrofítas, soterramento 
dos bentos, hiperplasia das brânqueas dos peixes. Aumento da matéria orgânica no meio, diminuição de oxigênio dissolvido, havendo alteração na biota aquática. Presença de metais pesados a uma variação nas comunidades macrobentônicas, incidência de aumento de doenças cardiovasculares, doenças renais nos seres humanos, todos esses fatores resultam em degradação de qualidade ambiental, alterando as condições estéticas do corpo hídrico, diminuindo o potencial pesqueiro, recreativo e de irrigação da região e aumentando os custos para recuperação e potabilização da água (SOARES et al., 2004).

\section{METODOLOGIA}

Esta metodologia baseou-se em uma abordagem qualitativa, estruturada em duas fases. $\mathrm{Na}$ primeira fase foi realizado o levantamento de dados secundários, por meio de pesquisa bibliográfica, tendo como referência de bases dados de periódicos, artigos, livros, revistas, como também Leis Federais e Resoluções do Conselho Nacional do Meio Ambiente (CONAMA). As palavraschaves utilizadas foram: "Lodo de estação de tratamento de água"; "tratamento de lodo"; "destinação final de resíduo de ETA".

$\mathrm{Na}$ segunda fase ocorreu a triagem e compilação dos dados encontrados, instituindo indicadores com a finalidade de avaliar e qualificar os possíveis impactos ambientais provenientes do descarte do lodo de ETA. Para tanto, utilizou-se a matriz de correlação simplificada e com o resultado foi possível propor uma forma ambientalmente eficaz de destinação final para o lodo.

\section{RESULTADO E DISCUSSÃO}

A matriz de correlação simplificada, Tabela 1, foi elaborada de acordo com as publicações científicas estudadas na revisão bibliográfica. Traçou-se os indicadores: Turbidez, Matéria Orgânica, Metais Pesados e Degradação Ambiental. Foi avaliado fatores de sensibilidade em meio físico, biótico e antrópico, para cada um dos indicares e assim determinou-se a porcentagem dos indicadores. As características que determinaram cada indicador estão descritas na tabela.

O lançamento de lodo de ETA nos corpos hídricos eleva a concentração de sólidos suspensos, consequentemente aumenta a turbidez e diminui o teor de transparência da água. A presença desta turbidez em água bruta altera as condições de iluminação e alcance de radiação luminosa, influenciando negativamente na fotossíntese, no desenvolvimento de plantas aquáticas e de plânctons, ocasionando também redução da camada eutrófica, sombreamento da macrófita, soterramento de bentos e hiperplasia das brânquias dos peixes (VIEIRA, 2015).

As matérias orgânicas são substâncias compostas basicamente de carbono, hidrogênio e oxigênio, estas substâncias estão naturalmente presentes na água, porém seu excesso provoca alteração na biota aquática. Quando o lodo é disposto na água, há uma proliferação de bactérias aeróbicas, causada pela elevada disponibilidade de alimento (matéria orgânica) e de oxigênio, conforme as bactérias se multiplicam, a matéria orgânica é consumida pelo processo metabólico em distúrbios aquáticos (LIMA, 2016).

O potencial tóxico dos resíduos de estação de tratamento de água se deve principalmente a presença de metais pesados, em especial o alumínio, utilizado nos processos de coagulação da água, essa toxidade resulta em deficiência renal nos seres humanos, doenças cardiovasculares, destruição da camada betônica, apatia e desanimo nos peixes e inibição do movimento de pupas. Devido ao assoreamento do corpo hídrico, as condições estéticas são alteradas, há aumento no custo para recuperação e potabilização da água. Em decorrência da poluição há redução de potencial para usa da jusante como: pesca recreação, irrigação, resultando na degradação da qualidade ambiental (SOARES; et al. 2004).

Com a matriz, torna-se possível entender em quais níveis há o impacto ambiental ao descartar o lodo, sendo os mais elevados os indicadores de metais pesados e degradação ambiental.

Após a realização do estudo e visando seguir a prioridade de gerenciamento de resíduos sólidos estabelecida pela lei 12.305/2010 (BRASIL, 2010), pôde-se propor as seguintes formas de destinação final para o lodo de ETA, diminuindo o impacto: aplicação controlada no solo (GONÇALVES et al., 2016); compostagem (SANTOS et al., 2015); fabricação de material cerâmico (LIMA, 2016); (JUNKES et al., 2012) lançamento em sistemas de tratamento de esgoto (REIS, 2006); disposição em aterro sanitário (SILVEIRA, 2012). 
Das alternativas estudadas e com os descritores pesquisados na revisão bibliográfica foi possível obter em porcentagem, a quantidade de vezes que cada opção foi sugerida (Figura 4). A opção mais aclamada foi a fabricação de material cerâmico utilizando o lodo de ETA.

Tabela 1 - Matriz Correlacionada Simplificada.

\begin{tabular}{|c|c|c|c|c|c|c|c|}
\hline Indicadores & 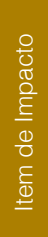 & $\begin{array}{l}\text { Fatores de } \\
\text { Impacto }\end{array}$ & $\begin{array}{l}\frac{0}{\frac{0}{0}} \\
\frac{0}{10} \\
\frac{0}{0} \\
\sum\end{array}$ & $\begin{array}{l}\frac{8}{0} \\
\frac{0}{0} \\
\frac{0}{0} \\
\frac{0}{0} \\
\frac{0}{2}\end{array}$ & 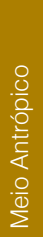 & 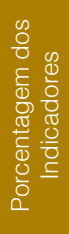 & Características dos indicadores \\
\hline \multirow{4}{*}{ Turbidez } & 1 & $\begin{array}{l}\text { Redução da } \\
\text { camada } \\
\text { eutrófica }\end{array}$ & & $x$ & & \multirow{4}{*}{20} & \multirow{4}{*}{$\begin{array}{l}\text { Parâmetro que determina a dificuldade } \\
\text { que o feixe de luz tem de atravessar o } \\
\text { fluido, conferindo aparência turva ao } \\
\text { mesmo. }\end{array}$} \\
\hline & 2 & $\begin{array}{l}\text { Soterramento de } \\
\text { bentos }\end{array}$ & & $x$ & & & \\
\hline & 3 & $\begin{array}{l}\text { Sombreamento } \\
\text { da macrófitas }\end{array}$ & & $x$ & & & \\
\hline & 4 & $\begin{array}{l}\text { Hiperplasia das } \\
\text { brânquias dos } \\
\text { peixes }\end{array}$ & & $x$ & & & \\
\hline \multirow{4}{*}{$\begin{array}{l}\text { Matéria } \\
\text { Orgânica }\end{array}$} & 5 & $\begin{array}{l}\text { Poluição } \\
\text { superficial }\end{array}$ & $x$ & & & \multirow{4}{*}{20} & \multirow{4}{*}{$\begin{array}{l}\text { Matéria de origem animal ou vegetal } \\
\text { encontrados sob a superfície do solo. }\end{array}$} \\
\hline & 6 & $\begin{array}{l}\text { Poluição } \\
\text { subterrânea }\end{array}$ & $x$ & & & & \\
\hline & 7 & $\begin{array}{l}\text { Diminuição de } \\
\text { O.D }\end{array}$ & $x$ & & & & \\
\hline & 8 & $\begin{array}{l}\text { Alteração na } \\
\text { biota aquática }\end{array}$ & & $x$ & & & \\
\hline \multirow{6}{*}{$\begin{array}{l}\text { Metais } \\
\text { Pesados }\end{array}$} & 9 & $\begin{array}{l}\text { Destruição da } \\
\text { camada } \\
\text { bentônica }\end{array}$ & & $x$ & & \multirow{6}{*}{40} & \multirow{6}{*}{$\begin{array}{l}\text { Metais que possuem nível de toxidade } \\
\text { alta para seres humanos, bioaculaveis. }\end{array}$} \\
\hline & 10 & Restrição de uso & $x$ & & $x$ & & \\
\hline & 11 & $\begin{array}{l}\text { Doenças } \\
\text { cardiovasculares }\end{array}$ & & $x$ & & & \\
\hline & 12 & $\begin{array}{l}\text { Desanimo e } \\
\text { apatia nos } \\
\text { peixes }\end{array}$ & & $x$ & & & \\
\hline & 13 & $\begin{array}{l}\text { Inibição no } \\
\text { movimento de } \\
\text { pumpas }\end{array}$ & & $x$ & & & \\
\hline & 14 & $\begin{array}{l}\text { Deficiencias } \\
\text { renais nos seres } \\
\text { humanos }\end{array}$ & & & $x$ & & \\
\hline \multirow{6}{*}{$\begin{array}{l}\text { Degradação } \\
\text { ambiental }\end{array}$} & 15 & $\begin{array}{l}\text { Condições } \\
\text { estéticas } \\
\text { afetadas }\end{array}$ & & & $x$ & \multirow{6}{*}{40} & \multirow{6}{*}{$\begin{array}{l}\text { Perda ou deterioração da qualidade } \\
\text { ambiental. }\end{array}$} \\
\hline & 16 & $\begin{array}{l}\text { Aumento de } \\
\text { custo para } \\
\text { recuperação }\end{array}$ & & & $x$ & & \\
\hline & 17 & $\begin{array}{l}\text { Aumento de } \\
\text { custo para } \\
\text { potabilização }\end{array}$ & & & $x$ & & \\
\hline & 18 & $\begin{array}{l}\text { Diminuição do } \\
\text { potencial para } \\
\text { irrigação }\end{array}$ & & & $x$ & & \\
\hline & 19 & $\begin{array}{l}\text { Diminuição do } \\
\text { potencial para } \\
\text { recreação }\end{array}$ & & & $x$ & & \\
\hline & 20 & $\begin{array}{l}\text { Diminuição do } \\
\text { potencial para } \\
\text { pesca }\end{array}$ & & & $x$ & & \\
\hline
\end{tabular}

Fonte: Autoras.

No total, foram abordados 20 itens de impacto ambiental, os quais estão distribuídos em 4 indicadores: turbidez, matéria orgânica, metais pesados e degradação ambiental, foi atribuído o percentual de $20 \%$ para os indicadores de turbidez e matéria orgânica e $40 \%$ para os indicadores de metais pesados e degradação ambiental, por conta da quantidade e relevância dos fatores de impactos referentes a eles, sendo estes fatores de impacto enquadrados nos fatores de sensibilidade do meio em que ocorre, físico, biótico ou antrópico. 
Figura 4 - Porcentagem das alternativas para a destinação do lodo de ETA.

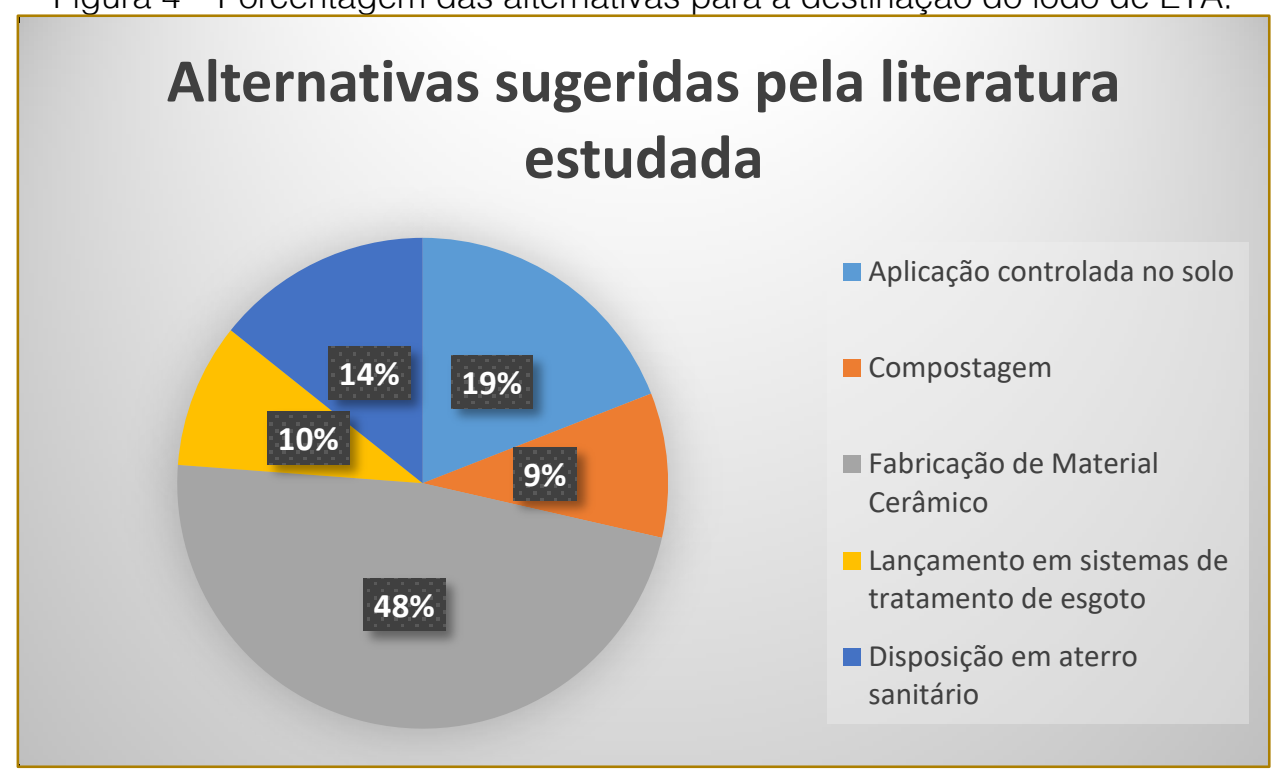

Fonte: Autoras.

A partir dos dados levantados é possível ver uma grande quantidade de pesquisas acerca do resíduo gerado pela ETA. O gráfico torna possível a compreensão de que a fabricação de material cerâmico pode ser um grande potencial de uso para o lodo e que além disso, há outras alternativas já estudadas e aplicadas em algumas ocasiões. As pesquisas relacionadas a essa problemática são de extrema importância para que a prática de despejo do lodo em corpos hídricos seja extinta e forneça às concessionárias de abastecimento de água soluções viáveis a serem implantadas.

\section{CONCLUSÃO}

Este trabalho demonstrou como o lodo pode impactar ambientalmente quando descartado em corpos hídricos. Com a matriz correlacionada pôde-se traçar os indicadores ambientais, fatores de impacto e sensibilidade do meio, atribuindo percentual de relevância de cada indicador, foi observada maior quantidade e relevância nos indicadores de metais pesados e degradação ambiental.

Com a literatura estudada também foi possível sugerir formas de dispor corretamente esse resíduo, sendo elas: aplicação controlada no solo; compostagem; fabricação de material cerâmico; lançamento em sistemas de tratamento de esgoto; disposição em aterro sanitário. Foi feito um estudo quantitativo das alternativas sugeridas, em que foi evidenciado que a fabricação de material cerâmico utilizando o lodo de ETA é uma opção amplamente discutida.

Logo, é possível concluir que o impacto ambiental causado pelo descarte do lodo de ETA em corpos hídricos é altamente prejudicial ambientalmente, e que há soluções e alternativas que estão sendo discutidas atualmente, com a finalidade de erradicar essa prática.

\section{REFERÊNCIAS}

[1]. ACHON, C.L.; BARROSO, M. M; CORDEIRO, J.S. (2013). Resíduos de estações de tratamento de água e a ISO 24512: desafio do saneamento brasileiro. Revista Engenharia Sanitária e Ambiental, ISSN 1413-4152, vol. 18, ํo.2, Rio de Janeiro, abril/junho 2013, pp. 115-122.

[2]. ASSOCIAÇÃO BRASILEIRA DE NORMAS TÉCNICAS - ABNT. NBR 10.004 - Resíduos sólidos: Classificação. Rio de Janeiro, 2004.

[3]. BRASIL. Política Nacional do Meio Ambiente: Lei n0 6.938, de 31 de agosto de 1981.
Dispõe sobre a Política Nacional do Meio Ambiente, seus fins e mecanismos de formulação e aplicação, e dá outras providências. Disponível em:

http://www.planalto.gov.br/ccivil_03/LEIS/L6938.ht $\mathrm{m}>$.

[4]. Política Nacional dos Recursos Hídricos: Lei no 9.433, 8 de janeiro de 1997. Disponível em: < http://www.planalto.gov.br/ccivil_03/leis/L9433.htm $>$. 
[5]. Crimes Ambientais: Lei n0 9.605, de 12 de fevereiro de 1998. Disponível em:< http://www.planalto.gov.br/ccivil_03/leis/L9605.htm $>$.

[6]. CONAMA. RESOLUÇÃO CONAMA № 001, de 23 de janeiro de 1986. Disponível em: < http://www.mma.gov.br/port/conama/res/res86/res0 186.html>.

[7]. CONAMA. Resolução CONAMA № 237, de 19 de dezembro de 1997. Procedimentos e critérios utilizados no licenciamento ambiental como instrumento de gestão ambiental. Ministério do Meio Ambiente, Brasil, 1997.

[8]. CONAMA. Resolução CONAMA № 357, de 17 de Março de 2005. Disponível em: < http://www2.mma.gov.br/port/conama/res/res05/res 35705.pdf>

[9]. GONÇALVES, F. et al. Incremento de lodo de ETA em barreiras impermeabilizantes de aterro sanitário. Revista DAE. v.65. n. 205. p.5-14. 2016.

[10]. JUNKES, J.A.; et al. Ceramic tile formulation from industrial waste. INTERCERAM 60. p.36-41, 2011.

[11]. LIMA, U. T. G. M. Utilização do Lodo de ETA como matéria prima alternativa para a indústria cerâmica. Trabalho de Conclusão de Curso - [Bacharel em Engenharia Ambiental]. Centro Universitário Tiradentes. 2016. 47f.

[12]. REIS, E. L. T. Abordagem sistêmica do sistema de tratamento de água de Registro, São Paulo, com ênfase na avaliação do impacto do descarte dos resíduos na bacia hidrográfica do Rio Ribeira de Iguape. São Paulo: IPEN/USP. 191 p, 2006.

[13]. SÁNCHES, L. E. Avaliação de impacto ambiental: conceitos e métodos. São Paulo: Oficina de Textos, $2^{\circ}$ ed. 2013.
[14]. SANTOS, L. et al. Compostagem nas escolas com uma ferramenta para implantação da educação ambiental no ensino fundamental. Resíduos sólidos: Tecnologias limpas e boas práticas. Recife, PE, 1. ed. EDUFRPE, p 268-280, 2015.

[15]. SANASA. $\|-$ PROCESSO DE PRODUÇÃO. Sanasa Campinas, 2014. Disponível em:

$<$ http://www.sanasa.com.br/noticias/not_con3.asp? par_nrod $=567 \&$ flag $=$ TA $>$.

[16]. SILVEIRA, C. Desaguamento de lodo de estações de tratamento de águas por leito de drenagem / secagem com manta geotêxtil. [Dissertação de Mestrado] - Universidade Estadual de Londrina, 2012. 136 p.

[17]. SOARES, L. V.; et al. Impactos ambientais causados pelo lançamento in natura de lodos provenientes de estação de tratamento de água. Congresso Brasileiro de ciência e Tecnologia em resíduo e desenvolvimento sustentável. Florianópolis, SC. ICTR 2004.

[18]. TARTARI, R. Incorporação de lodo gerado na estação de tratamento de água Tamanduá, como aditivo em massa para cerâmica vermelha. [Dissertação de Mestrado]. Programa de Pós Graduação em Engenharia Química. Universidade Estadual do Oeste do Paraná, Toledo, 2008

[19]. VIEIRA, M. Parâmetros de qualidade de água. Agência Nacional das águas - ANA, 2015. Disponível em: < http://capacitação .ana.gov.br/List/Cursos_Anexos/Attachments/32/Pa r\%C3\%A2metros.pdf $>$.

[20]. WATHERN, P. Environmental Impact Assessment: Theory and Practice. London: Unwin Hyman, 1988. 


\section{Bapítulo 15}

\section{A GESTÃO DE ATIVOS 4.0: CONTRIBUIÇÃO PARA A SUSTENTABILIDADE}

\section{Natali da Costa Emerick \\ Édison Renato Pereira da Silva}

Resumo: As organizações ativo-intensivas, ou seja, aquelas que dependem de bens físicos para entregar seus serviços e produtos e, consequentemente, gerar valor para o seu negócio, tomam decisões constantes buscando equilibrar custos, riscos e desempenho ao longo do ciclo de vida do ativo. Uma boa gestão de ativos oferece uma abordagem estruturada para a sustentabilidade e, em contrapartida, trazer metas ambientais, sociais e econômicas para a tomada de decisão fortalece a estratégia de gestão de ativos da organização. Além disso, o sucesso da gestão de ativos e do desenvolvimento sustentável está fortemente atrelado a uma boa tomada de decisão e, para tal, há a necessidade de ter informações corretas disponíveis em um curto espaço de tempo. Nesse caso, os pilares do avanço tecnológico como robótica, computação em nuvem, big data, internet das coisas, inteligência artificial permitem o monitoramento, a coleta e análise de dados, o diagnóstico e a tomada de decisão robusta e em tempo real. Esta pesquisa busca alavancar o debate sobre três temas atuais no cenário da gestão da produção organizacional que são a gestão de ativos físicos, a Indústria 4.0 e a sustentabilidade, analisando o papel da gestão de ativos para promover a manufatura sustentável, com foco particular na quarta Revolução Industrial e a contribuição de suas tecnologias.

Palavras-chave: Gestão de Ativos, Indústria 4.0, Sustentabilidade. 


\section{INTRODUÇÃO}

\subsection{CONTEXTUALIZAÇÃO}

O campo da gestão de ativos físicos vivencia um período de crescimento notável nos últimos anos e está sendo reconhecido como uma atividade fundamental para o sucesso das organizações (BASSON, 2016, p.2; SANCHEZ E ROMERO, 2014, p.606; REIS; COSTA; TEIXEIRA, 2009, p.259-260). Desde que as empresas perceberam que os programas tradicionais de manutenção não entregavam os resultados esperados foi necessária uma nova abordagem que conferisse valor para a empresa e que não fosse apenas "um mal necessário" (BASSON, 2016, p.2). O grande desafio tornou-se, então, aumentar a produção, reduzir o tempo de inatividade dos equipamentos, otimizar custos e operar com menos riscos à segurança e ao meio ambiente. Alcançar o equilíbrio entre custo, risco e desempenho na tomada de decisão ao longo do ciclo de vida do ativo é o objetivo da gestão de ativos (PORT; ASHUN; CALLAGHAN, 2011).

A gestão de ativos apoia o planejamento a longo prazo sobre os ativos físicos e oferece uma abordagem estruturada para uma manufatura mais sustentável (KORTELAINEN; REUNANEN; UUSITALO, 2015, p.341). O propósito é otimizar os processos de fabricação em termos de consumo de matérias-primas e recursos energéticos, redução de poluentes ambientais, geração e descarte adequados de resíduos, reutilização de equipamentos e de outros recursos técnicos, melhoria da eficiência e da utilização da capacidade produtiva, e, portanto, a implementação de uma política "sustentável" no gerenciamento do fluxo de materiais, seleção e operação de equipamentos. Todos os processos de manufatura têm papéis significativos na garantia do status "sustentável" durante todo o ciclo, desde a pré-fabricação até o pós-uso e a gestão de ativos, em particular, como um processo dedicado a garantir a robustez técnica e estratégica, deve dar uma grande contribuição a esse respeito (LIYANAGE E BADURDEEN, 2010, p.310).

Uma grande tendência na área de gestão de ativos é a introdução do conceito de Indústria 4.0. Especialistas apontam que a "quarta Revolução Industrial" provocada pela manufatura avançada terá forte impacto nesse setor. $\mathrm{Na}$ indústria baseada em conectividade, a gestão de ativos assume papel estratégico podendo gerar dados e informações importantes tanto para a operação quanto para a governança empresarial (CASSAPO, 2017, p.4-6). A Indústria 4.0 possibilitará coletar e analisar dados entre máquinas, permitindo processos mais rápidos, mais flexíveis e mais eficientes para produzir itens de maior qualidade a custos reduzidos e tomar decisões mais assertivas. Isso, por sua vez, aumentará a produtividade, mudará a economia, fomentará o crescimento industrial e modificará o perfil da força de trabalho, em última análise, mudando a competitividade das empresas (RUBMANN et. al., 2015, p.4).

\subsection{SITUAÇÃO-PROBLEMA}

Em nível global, numerosas questões associadas à mudança climática, crescimento populacional, danos aos ecossistemas e um futuro com restrição de carbono têm emergido (MARLOW; BEALE; BURN, 2010, p.57). Sabese que, práticas mal definidas com relação à gestão de ativos físicos levam a inúmeros problemas como emissões perigosas, desperdício de produção devido às falhas de sistemas, incidentes de saúde e segurança da força de trabalho, uso de energia ineficiente, mau consumo de recursos, desperdício de materiais armazenados, perdas financeiras devido à incapacidade ou tempo de inatividade produtiva (LIYANAGE E BADURDEEN, 2010, p.310-311). Nesse contexto, é importante discutir estratégias que possam ser usadas para integrar a gestão de ativos sob diferentes pontos de vista para promover uma abordagem mais sustentável, incluindo a modernização das plantas produtivas como um dos recursos (LIYANAGE E BADURDEEN, 2010, p.310-311).

A melhor tomada de decisão é crucial para alcançar as metas de uma gestão de ativos sustentável. Acredita-se que a chave para decisões mais assertivas é ter a informação certa, disponível no momento certo, para apoiar o processo decisório (BLOOMFIELD; DENT; MCDONALD, 2006, p.6304). Nessa circunstância, os mercados altamente intensivos em ativos físicos podem esperar da indústria 4.0 um ecossistema conectado. Essa nova revolução veio para fundir os dados operacionais e os sistemas físicos em um só e coincide com a demanda por informações cada vez mais rápidas e precisas (ENGEMAN, 2017). 


\subsection{OBJETIVOS}

O objetivo central é debater sobre três temas atuais no cenário da gestão da produção organizacional que são a gestão de ativos físicos, a sustentabilidade e a indústria 4.0, fundamentando a conexão entre eles. Os objetivos específicos do trabalho incluem a apresentação teórica sobre os temas e a construção da argumentação sobre como a gestão de ativos, abarcando os recursos da indústria 4.0, pode contribuir para promover um desempenho mais sustentável.

\section{MÉTODO}

As principais questões de pesquisa abordadas contemplam os questionamentos Como a gestão de ativos contribui para negócios mais sustentáveis? Quais as implicações que a demanda por sustentabilidade traz para a estratégia de gestão de ativos? De que forma os pilares e tecnologias da indústria 4.0 podem promover uma gestão de ativos mais sustentável? Para alcançar esta meta, o método de trabalho a ser conduzido é sintetizado na Figura 1.

Figura 1 - Método de pesquisa

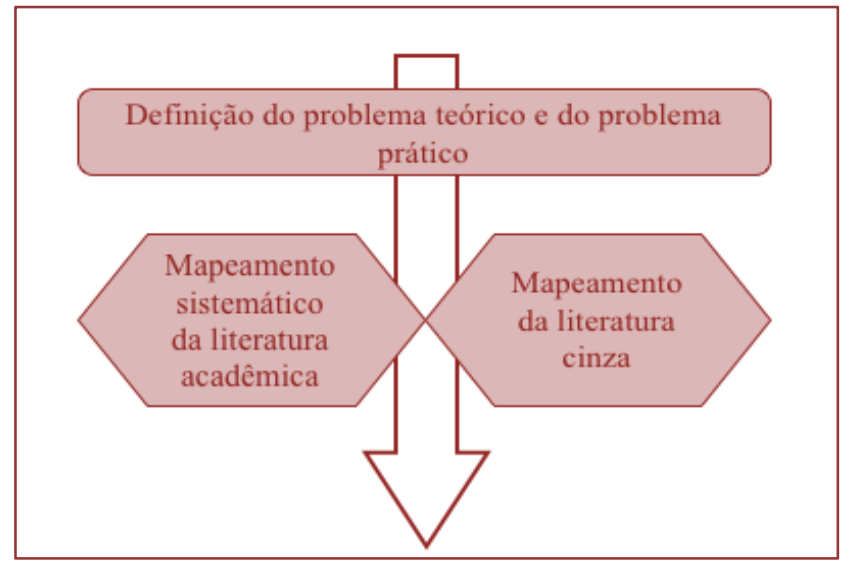

Fonte: os próprios autores

Inicialmente, foi elaborado o problema de pesquisa que motivou a investigação. Em seguida, realizou-se um mapeamento sistemático da literatura acadêmica utilizando como interfaces de busca a base Web of Science. Já a literatura cinza foi encontrada através de buscas por empresas de consultoria na área, sociedades profissionais mundiais, pesquisas abertas em mecanismo de busca da internet, utilizando softwares específicos para isso. Os termos de busca utilizados foram Asset Management, Industry 4.0 e Sustainability. As referências encontradas foram armazenadas em um software de gestão bibliográfica. Os trabalhos levantados foram analisados e o material relevante lido analiticamente.

A classificação metodológica desta pesquisa baseou-se nos critérios levantados por Lacerda et. al. (2007, p. 3-4). Assim, em termos de Natureza, trata-se de uma pesquisa aplicada buscando gerar novos conhecimentos úteis e exequíveis. Quanto ao Objetivo do Estudo, trata-se de uma análise Exploratória visando proporcionar maior familiaridade com o problema de gestão de ativos e o seu emprego nas organizações, adotando, para isso, uma Abordagem Qualitativa. O Método Científico empregado é o Dedutivo utilizando-se dos Procedimentos Técnicos de pesquisa bibliográfica e documental.

O campo de gestão de ativos, apesar de sua pertinência acadêmica, é, sobretudo, prático. Assim, entendeu-se que existe uma grande relevância nos materiais produzidos por consultorias, associações, empresas e profissionais atuantes no tema. Portanto, sabendo que o conteúdo cinza produzido é vasto, destaca-se que foi realizado um mapeamento tão sistemático quanto possível da literatura cinza em gestão de ativos. Entretanto, como tal acervo não se encontra organizado em uma base de dados específica, mas sim espalhado em diversos sites da internet, não se pode garantir a sistematicidade do processo de coleta de referências, de modo que alguma referência relevante pode não ter sido acessada. 


\section{A GESTÃO DE ATIVOS}

A velocidade dos avanços tecnológicos e a globalização têm provocado impactos significativos no funcionamento das organizações. As instituições passaram a viver em ambientes de incerteza, complexidade e de competição acirrada. Somado a isso, estão desafios como o desenvolvimento pessoal, inovação constante, comunicação intensiva (PAGLIUSO; CARDOSO; SPIEGEL, 2010, p.36). Nesse complexo cenário, o sucesso de uma organização intensiva em ativos está fortemente relacionado à adoção de práticas e sistemas de gestão de alta qualidade (MAHESHWARI, 2010, p.596; MA; ZHOU; SHENG, 2014, p.1668).

O debate sobre a abordagem holística de gerenciamento de ativos intensificou-se à medida que as organizações perceberam as oportunidades emergentes com a sua adoção (HODKIEWICZ, 2015, p.428). O aumento atual do ritmo e da volatilidade das operações exige a conformidade dos ativos físicos com as metas organizacionais definidas. O objetivo da gestão de ativos físicos resume-se a apoiar o plano estratégico organizacional, garantindo a entrega de produtos e serviços através do uso mais eficaz dos ativos e gerando valor para a empresa (BAUM E VLOK, 2013, p.48; KRIEGE E VLOK ,2015, p.435). Consequentemente, a gestão eficaz dos ativos tornou-se um componente crítico de lucratividade e sucesso dos negócios (MA, ZHOU, SHENG, 2014, p.1668).

Um ativo é um item, algo ou entidade que tem valor real ou potencial para uma organização. O valor pode variar entre diferentes organizações e suas partes interessadas e pode ser tangível ou intangível; financeiro ou não financeiro (ABNT NBR ISO 55000, 2014, p.3). Os ativos físicos são uma das cinco categorias de ativos. As outras compreendem os ativos humanos, financeiros, de informação e intangíveis (BSI PAS 55-1, 2008, p.7). Os ativos físicos são itens como instalações, maquinário, edifícios, estradas, veículos, ferrovias, aeronaves, tubulações, cabos, equipamentos de comunicação e outras infraestruturas que têm valor real ou potencial para uma organização (HASTINGS, 2014, p.7).

Para muitas instituições, os ativos físicos são a principal forma de gerar receita, como acontece nas indústrias pesadas que, em particular, dependem fortemente de uma infraestrutura física como o principal meio de operação e prestação de serviços (BAUM E VLOK, 2013, p.48). Os setores industriais nos quais os ativos físicos são de grande importância incluem eletricidade, gás e água, indústrias de transporte, extração e processamento de petróleo e gás, mineração, produtos químicos, fabricação, distribuição, aviação, defesa, entre outros (HASTINGS, 2014, p.7).

Existem várias definições para a gestão de ativos físicos (MAHESHWARI, 2006, p.596). As duas definições mais comumente utilizadas são a fornecida pela ISO 55000 que diz que a gestão de ativos é a "atividade coordenada de uma organização para obter valor a partir dos ativos" (ABNT NBR ISO 55000, 2014, p.16) e apresentada na BSI PAS 55-1 (2008, p.6) que a determina como "atividades práticas sistemáticas e coordenadas pelas quais uma organização gerencia, de forma ótima e sustentável, seus ativos e sistemas de ativos, os desempenhos associados deles, os riscos e despesas ao longo dos seus ciclos de vida para o propósito de cumprir seu planejamento estratégico organizacional".

O desenvolvimento do entendimento e do conhecimento em gestão de ativos tem resultado em padrões e modelos sendo produzidos em todo o mundo. Duas abordagens globais merecem destaque: PAS 55 e a família ISO 55000. A PAS 55 (BSI PAS $55-1,2008$ ) e a ISO 55000 (ABNT NBR ISO $55000,2014)$ fornecem definições claras e especificações de requisitos para sistemas de gestão de ativos otimizados e integrados e são um consenso global sobre o que é a gestão de ativos e o que pode ser feito para aumentar 0 valor gerado por todas as organizações. É importante lembrar que o objetivo principal das normas citadas é promover boas práticas. A recente publicação do conjunto de normas ISO 5500x reforçaram o interesse no tópico tanto pela indústria quanto pela academia (RODA E MACCHI, 2016, p.1; MALETIC et. al., 2017, p.4). No entanto, como disciplina, a gestão de ativos ainda está em seu estágio inicial dentro do debate científico e soluções que apoiem sua adoção em diferentes contextos industriais ainda se fazem necessárias (RODA E MACCHI, 2016, p.1). 


\section{SUSTENTABILIDADE}

A noção de sustentabilidade tem duas origens. A primeira, na biologia, por meio da ecologia, refere-se à capacidade de recuperação e reprodução dos ecossistemas em face de agressões antrópicas (uso abusivo dos recursos naturais, desflorestamento, fogo etc.) ou naturais (terremoto, tsunami, fogo etc.). A segunda, na economia, como adjetivo do desenvolvimento, em face da percepção crescente ao longo do século XX de que o padrão de produção e consumo em expansão no mundo, sobretudo no último quarto desse século, não tem possibilidade de perdurar. Ergue-se, assim, a noção de sustentabilidade sobre a percepção da finitude dos recursos naturais e sua gradativa e perigosa depleção (DO NASCIMENTO, 2012, p.51).

O termo desenvolvimento sustentável foi utilizado pela primeira vez no "Relatório Brundtland" da Organização das Nações Unidas (ONU) que estabeleceu que desenvolvimento sustentável é aquele que "satisfaz as necessidades do presente sem comprometer a capacidade das gerações futuras satisfazerem as suas próprias necessidades" (UNWECD, 1987). A força e a fraqueza dessa definição encontram-se justamente nessa estruturação ampla, pois deixam-se em aberto quais seriam as necessidades humanas atuais, e mais ainda as das gerações futuras. Contudo, um consenso se estabeleceu - o desenvolvimento sustentável compõe-se essencialmente de três dimensões: ambiental, econômica e social (DO NASCIMENTO, 2012, p.54-55).

A integração, particularmente dos fatores sociais, econômicos e ambientais, é a essência do conceito de sustentabilidade e deve ser uma consideração central na concepção e implementação de soluções, tanto ao nível estratégico, como ao nível operacional (GIBSON, 2006). Se o conteúdo central e as intenções subjacentes forem convertidos em uma definição, a atividade empresarial sustentável, de modo geral, implica em adaptar estratégias e atividades de negócios que atendam às necessidades de partes interessadas de uma empresa, por meio de processos e produtos que tenham uma economia de custos equilibrada, além de implicações sociais e ambientais positivas (LIYANAGE, 2007, p.306; TORRESI; PARDINI; FERREIRA, 2010, p.1).
A dimensão ambiental do desenvolvimento sustentável supõe que o modelo de produção e consumo seja compatível com a base que se assenta a economia, como subsistema do meio natural. Trata-se, portanto, de produzir e consumir de forma a garantir que os ecossistemas possam manter sua recomposição ou capacidade de resiliência. A segunda dimensão, a econômica, contempla o aumento da eficiência da produção e do consumo com economia crescente de recursos naturais. Trata-se de algo que alguns denominam como ecoeficiência, que supõe uma contínua inovação tecnológica que leve a sair do ciclo fóssil de energia e a ampliar a desmaterialização da economia. A terceira e última dimensão é a social. Uma sociedade sustentável supõe que todos os cidadãos tenham o mínimo necessário para uma vida digna e que ninguém absorva bens, recursos naturais e energéticos que sejam prejudiciais a outros. Isso significa erradicar a pobreza e definir o padrão de desigualdade aceitável, delimitando limites mínimos e máximos de acesso a bens materiais. Em resumo, implantar a velha e desejável justiça social (DO NASCIMENTO, 2012, p.54-55).

A sustentabilidade é um conceito complexo e multifacetado e os desafios do desenvolvimento sustentável são pelo menos tão heterogêneos e complexos quanto a diversidade das sociedades humanas e dos ecossistemas naturais em todo o mundo. Como um conceito, sua maleabilidade permite que este permaneça uma ideia aberta, dinâmica e em evolução, que pode ser adaptado para se adequar a situações e contextos muito diferentes no espaço e no tempo. Mas, sobretudo, o conceito de sustentabilidade precisa soar bastante positivo para as pessoas, imbuindo que a sustentabilidade é um valor e um recurso poderoso que vale a pena (KATES, 2018, p.20).

\section{INDÚSTRIA 4.0}

Desde o início da industrialização, os avanços tecnológicos levaram às mudanças de paradigmas que são conhecidas como "revoluções industriais". A primeira aconteceu no século XVIII com a introdução de equipamentos de fabricação mecânica que revolucionou a forma como os produtos eram fabricados; a segunda revolução industrial ocorreu na segunda metade do século XIX, com o surgimento da energia elétrica e 
aplicação do método de divisão do trabalho; a terceira com o emprego de tecnologia eletrônica e de informática para alcançar a automação dos processos de produção a partir dos anos de 1970 que perdura até hoje. Entretanto, uma nova mudança de paradigma de produção parece estar emergindo do processo contemporâneo de transformação digital e utilização das tecnologias e metodologias "inteligentes". Assim, a expressão "Indústria 4.0" vem despontando diante daquela que seria a quarta revolução industrial (LASI et. al., 2014, p.239).

O termo "Indústria 4.0" começou a ser amplamente utilizado na Europa, principalmente na Alemanha, para descrever um projeto do que seria a indústria do futuro com o seu cerne voltado para o modo de configuração dinâmico da produção (CHENG et. al., 2016, p.407). Essa reconfiguração de modelo produtivo leva em consideração, por um lado, as alterações das condições da estrutura operativa desencadeadas por mudanças sociais, econômicas e políticas e, por outro aspecto, o grande avanço tecnológico emergente que, muitas vezes, não é amplamente aproveitado e divulgado em contextos industriais como deveria (LASI et. al., 2014, p.240). A Indústria 4.0 pode ser descrita como fábricas inteligentes, resultantes da digitalização de toda cadeia de valor e a interconexão resultante de seres humanos, máquinas, sistemas e outros recursos por meio da troca de dados em tempo real (HENNING et al, 2013, p.19). O conceito de Indústria 4.0 pode, então, ser resumido como um processo de fabricação integrado, adaptado, otimizado, orientado a serviços que está correlacionado com algoritmos, dados importantes e altas tecnologias (LU, 2017, p.03).

O desenvolvimento e a implantação da indústria 4.0 fundamenta-se em seis princípios que definem os sistemas inteligentes, conforme exposto no Quadro 1 (HERMANN; PENTEK; OTTO, 2015, p.11-13). Esses princípios representam como as estruturas funcionais das fábricas 4.0 devem ser operacionalizadas.

\section{Quadro 1 - Princípios da indústria 4.0}

\begin{tabular}{|l|l|}
\hline \multicolumn{1}{|c|}{ Princípios } & $\begin{array}{l}\text { Capacidade dos sistemas cyber-físicos e humanos comunicarem-se uns com } \\
\text { Interoperalidade }\end{array}$ \\
\hline Virtualização & $\begin{array}{l}\text { Propõe a criação de uma cópia virtual do mundo físico permitindo a } \\
\text { rastreabilidade e o monitoramento remoto de todos os processos por meio de } \\
\text { sensores. }\end{array}$ \\
\hline Descentralização & $\begin{array}{l}\text { Capacidade dos sistemas cyber-físicos tomarem decisões por conta própria } \\
\text { e, além disso, das máquinas não apenas receberem comandos, mas } \\
\text { fornecerem informações sobre o seu ciclo de trabalho. }\end{array}$ \\
\hline $\begin{array}{l}\text { Capacidade de operação } \\
\text { em tempo real }\end{array}$ & $\begin{array}{l}\text { Consiste na aquisição e no tratamento de dados de forma instantânea } \\
\text { permitindo a tomada de decisão em tempo real. }\end{array}$ \\
\hline Orientação ao serviço & $\begin{array}{l}\text { Propõe que as aplicações usadas sejam disponibilizadas como uma espécie } \\
\text { de serviço. }\end{array}$ \\
\hline Modularidade & $\begin{array}{l}\text { Flexibilidade para alterar as tarefas das máquinas e produzir de acordo com } \\
\text { a demanda. }\end{array}$ \\
\hline
\end{tabular}

Fonte: adaptado de Hermann, Pentek e Otto (2015, p.11-13).

Tecnologias como a impressão 3D, sensores, inteligência artificial, robótica, drones, nanotecnologia são alguns dos exemplos de tecnologias em crescimento exponencial que estão mudando os processos industriais, acelerando-os e tornando-os mais flexíveis. Muitas dessas tecnologias não são novas e foram, de fato, "inventadas" há 20 ou 30 anos, no entanto, o recente aumento no poder de computação, miniaturização e a redução de custos, agora os tornam adequados para o uso industrial em um sistema totalmente integrado, automatizado e otimizado (DELOITTE, 2015, p. 05). O quadro 2 resume os principais pilares tecnológicos da Indústria 4.0. 
Quadro 2 - Pilares tecnológicos da Indústria 4.0

\begin{tabular}{|c|c|}
\hline $\begin{array}{c}\text { Pilares } \\
\text { Tecnológicos }\end{array}$ & Descrição \\
\hline $\begin{array}{l}\text { Big Data e } \\
\text { analytics }\end{array}$ & $\begin{array}{l}\text { A coleta e avaliação abrangente de dados de muitas fontes diferentes - equipamentos } \\
\text { e sistemas de produção, bem como sistemas de gerenciamento corporativo e de } \\
\text { clientes - tornar-se-á padrão para apoiar a tomada de decisões em tempo real. A } \\
\text { análise baseada em grandes conjuntos de dados otimiza a qualidade da produção, } \\
\text { economiza energia e melhora o serviço de equipamentos. }\end{array}$ \\
\hline Robôs autônomos & $\begin{array}{l}\text { Em muitos setores, os fabricantes já usam robôs para lidarem com atribuições } \\
\text { complexas. Entretanto, os robôs estão evoluindo para uma utilidade ainda maior. Eles } \\
\text { estão se tornando mais autônomos, flexíveis e cooperativos. Eventualmente, vão } \\
\text { interagir uns com os outros e trabalhar em segurança lado a lado com os humanos e } \\
\text { aprender com eles. Esses robôs custarão menos e terão uma gama maior de recursos } \\
\text { do que os usados atualmente. }\end{array}$ \\
\hline Simulação & $\begin{array}{l}\text { As simulações alavancarão dados em tempo real para espelhar o mundo físico em um } \\
\text { modelo virtual, que pode incluir máquinas, produtos e seres humanos. Isso permite } \\
\text { que os operadores testem e otimizem as configurações da máquina para o próximo } \\
\text { produto em linha no mundo virtual antes da troca física, reduzindo assim os tempos de } \\
\text { configuração da máquina e aumentando a qualidade. }\end{array}$ \\
\hline $\begin{array}{l}\text { Integração } \\
\text { horizontal e vertical } \\
\text { do sistema }\end{array}$ & $\begin{array}{l}\text { As empresas, departamentos, funções e capacidades tornar-se-ão muito mais coesas, } \\
\text { à medida que as redes universais de integração de dados entre empresas evoluírem e } \\
\text { permitirem cadeias de valor verdadeiramente automatizadas. }\end{array}$ \\
\hline Internet das coisas & $\begin{array}{l}\text { Até então, apenas alguns sensores e máquinas estão em rede e utilizam computação } \\
\text { incorporada. Com a internet das coisas, mais dispositivos serão enriquecidos com } \\
\text { computação embarcada e conectados usando tecnologias padrão. Isso permite que } \\
\text { os dispositivos de campo se comuniquem e interajam uns com os outros e com } \\
\text { controladores mais centralizados, conforme necessário. Também descentraliza a } \\
\text { análise e a tomada de decisões, permitindo respostas em tempo real. }\end{array}$ \\
\hline Cibersegurança & $\begin{array}{l}\text { Com o aumento da conectividade, a necessidade de proteger sistemas industriais } \\
\text { críticos e linhas de fabricação de ameaças de segurança cibernética aumenta } \\
\text { dramaticamente. Como resultado, comunicações seguras e confiáveis, bem como } \\
\text { gerenciamento sofisticado de identidade e acesso de máquinas e usuários são } \\
\text { essenciais. }\end{array}$ \\
\hline Nuvem & $\begin{array}{l}\text { As empresas já estão usando software baseado em nuvem para algumas aplicações } \\
\text { corporativas e analíticas, mas, com a Indústria 4.0, mais empreendimentos } \\
\text { relacionados à produção exigirão maior compartilhamento As de dados entre sites e } \\
\text { limites da empresa. Ao mesmo tempo, o desempenho das tecnologias de nuvem } \\
\text { melhorará, atingindo tempos de reação de apenas alguns milissegundos. Como } \\
\text { resultado, os dados e a funcionalidade das máquinas serão cada vez mais } \\
\text { implementados na nuvem, permitindo mais serviços orientados a dados para sistemas } \\
\text { de produção. }\end{array}$ \\
\hline Manufatura aditiva & $\begin{array}{l}\text { As organizações começaram a adotar a manufatura aditiva, como a impressão 3D, } \\
\text { que usam principalmente para prototipar e produzir componentes individuais. Com a } \\
\text { Indústria 4.0, esses métodos de fabricação serão amplamente utilizados para produzir } \\
\text { pequenos lotes de produtos personalizados que ofereçam vantagens de construção, } \\
\text { como desenhos complexos e leves. Sistemas de fabricação aditivos descentralizados } \\
\text { e de alto desempenho reduzem as distâncias de transporte e o estoque disponível. }\end{array}$ \\
\hline $\begin{array}{l}\text { Realidade } \\
\text { aumentada }\end{array}$ & $\begin{array}{l}\text { As empresas usarão muito mais a realidade aumentada para fornecer aos funcionários } \\
\text { informações em tempo real para melhorar a tomada de decisões e os procedimentos } \\
\text { de trabalho. }\end{array}$ \\
\hline
\end{tabular}

Fonte: Rubmann et al. (2015, p.5-7) 


\section{GESTÃO DE ATIVOS 4.0 E A CONTRIBUIÇÃO PARA A SUSTENTABILIDADE}

A gestão de ativos é particularmente importante para as organizações que dependem da função e do desempenho dos ativos físicos na entrega de serviços e produtos, estando o seu sucesso significativamente influenciado pela administração de seus ativos (BSI PAS 55-1, 2008, p.8). Isto é, os negócios intensivos em ativos onde custos significativos, recursos, dependência de desempenho e riscos estão associados com a criação, aquisição, utilização, manutenção, renovação e descarte dos ativos (BSI PAS 55-1, 2008, p.7).

Figura 2 - Representação do conceito de gestão de ativos físicos

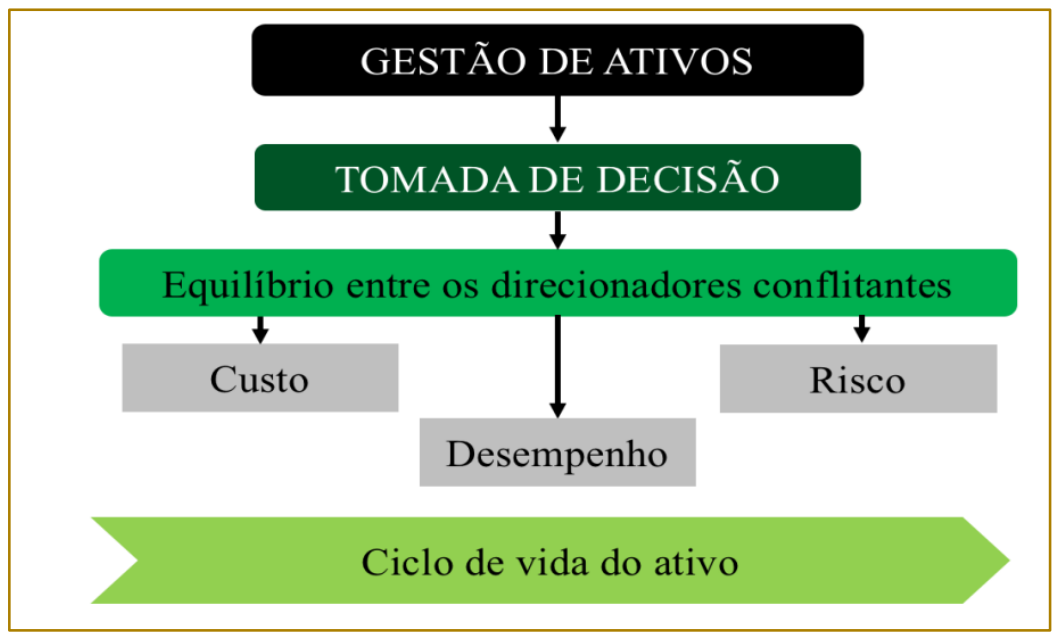

Fonte: Adaptado de BSI PAS 55-1 (2008) e ABNT NBR ISO 55000 (2014)

A gestão de ativos permite que uma organização obtenha valor a partir de seus ativos, enquanto equilibra os custos financeiros, ambientais e sociais, os riscos, qualidade de serviço e o desempenho associado aos ativos (ABNT NBR ISO 55000, 2014, p.2). A política de gestão de ativos deve declarar claramente os princípios a serem aplicados, tais como a abordagem da organização com relação à saúde e segurança ou ao desenvolvimento sustentável (BSI PAS 55-1, 2008, p.7). Essas definições se alinham ao tripé da sustentabilidade e podese inferir que as práticas de gestão de ativos desenvolvidas com base nelas contribuem para a entrega dos objetivos sociais, econômicos e ambientais. Assim, a sustentabilidade impacta a engenharia de gestão de ativos, ampliando o desafio de otimização ao incorporar, nas decisões ao longo do ciclo de vida dos ativos, a maximização do capital natural e social, enquanto minimiza simultaneamente os impactos econômicos (AMADI-ECHENDU, 2012, p.5)

O Fórum Global de Manutenção e Gestão de Ativos (GFMAN) descreveu em seu documento "Asset Management Landscape" as diferentes funções e disciplinas da gestão de ativos e, dentre os trinta e nove assuntos listados, está o desenvolvimento sustentável. O guia determina que todos os processos de gestão de ativos apoiem a estrutura de sustentabilidade da organização. Isso resulta na integração da estratégia, política e planos de gestão de ativos aos planos e atividades estratégicos da organização e às necessidades das partes interessadas. Os fatores a serem levados em conta nesses processos incluem: impacto ambiental, social e financeiro dos planos de gestão de ativos (GFMAN, 2014, p.47). 
Figura 3 - Representação do conceito de gestão de ativos físicos incluindo o conceito de desenvolvimento sustentável

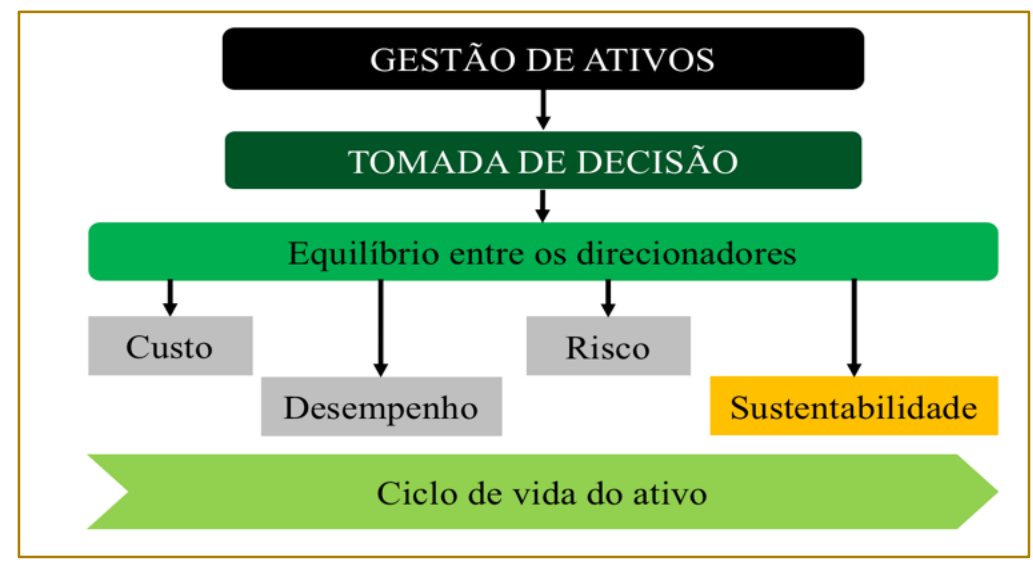

Fonte: Os próprios autores

A norma ABNT NBR ISO 55001 (2014, p.4) destaca que ao planejar um programa de gestão de ativos, a organização deve considerar os requisitos das partes interessadas relevantes e outros requisitos financeiros, técnicos, legais, regulatórios e organizacionais. Assim, os objetivos da gestão de ativos devem ser consistentes e alinhados com os objetivos organizacionais. Tal abordagem é coerente com a ideia geral de desenvolvimento sustentável, que requer a consideração dos requisitos e expectativas das partes interessadas (JASIULEWICZKACZMAREK, 2013, p.1149). A abordagem de "integração de sistemas de cima para baixo" visa assegurar que as políticas "sustentáveis" definidas e adotadas no nível estratégico da organização sejam sistematicamente implantadas e acompanhadas pelos sistemas técnicos até o nível crítico de desempenho do equipamento (LIYANAGE E BADURDEEN, 2010, p.310311). Os objetivos da gestão de ativos, incluídos no plano estratégico de gestão de ativos devem ser alinhados e consistentes com os objetivos organizacionais (ABNT NBR ISO 55001, 2014, p.1). Assim, se na definição da estratégia da empresa, princípios de sustentabilidade são considerados, a gestão de ativos refletirá esses requisitos. Portanto, é importante notar que a decisão de operar de maneira sustentável é externa ao escopo da gestão de ativos, residindo no domínio estratégico do negócio e nas decisões da alta liderança (MARLOW; BEALE; BURN, 2010, p.59). As organizações que seguem os objetivos econômicos, sociais e ambientais no nível estratégico, consequentemente, aplicarão práticas sustentáveis de gestão de ativos alinhadas com 0 tripé da sustentabilidade. Por outro lado, os objetivos de sustentabilidade na gestão de ativos não serão alcançados se não fizerem parte da estratégia corporativa (BADURDEEN; SHUAIB; LIYANAGE, 2012, p.63-64).

A ABNT NBR ISO 55001 (2014, p.4) realça que ao planejar o sistema de gestão de ativos, devem-se determinar os riscos e as oportunidades que necessitam ser tratados para dar garantia de que o sistema possa alcançar os resultados pretendidos. Além disso, ações devem ser planejadas para tratar os riscos e oportunidades considerando sua mudança com o tempo. De acordo com Liyanage e Badurdeen (2010, p.311-312), a gestão de ativos é integrada para permitir que os sistemas entreguem resultados em conformidade com as políticas de sustentabilidade específicas da empresa para o ativo em questão. $O$ processo de integração exigido deve ser baseado em uma análise de risco abrangente da função e desempenho do ativo considerando emissões perigosas, desperdício de produção devido ao mal funcionamento do sistema, incidentes de saúde e segurança, uso de energia ineficiente, consumo de recursos ineficientes, desperdício de materiais armazenados, perdas financeiras devido à perdas de capacidade ou tempo de inatividade, dentre outros (LIYANAGE E BADURDEEN, 2010, p.310-311).

A norma britânica BSI PAS 55 (2008, p.14) destaca que a organização deve estabelecer, implementar e manter processos para a realização do plano de gestão de ativo e para o controle das atividades durante todo o ciclo de vida do ativo. A integração da gestão de ativos e sustentabilidade é possível devido à 
sobreposição de conceitos fundamentais inerentes a ambos os frameworks. O elemento principal de ambas as abordagens é o foco no ciclo de vida. A ênfase no ciclo de vida serve como um ponto de intersecção a partir do qual a sustentabilidade e gestão de ativos podem ser integradas. As muitas decisões tomadas durante o processo de concepção, produção e operação de um objeto técnico influenciam diretamente o resultado em todas as dimensões da manufatura sustentável (JASIULEWICZ-KACZMAREK, 2013, p.1149; BLOOMFIELD et. al., 2018, p.3).

A ABNT NBR ISO 55000 (2014, p.15) define que o ciclo de vida são os estágios envolvidos na gestão de um ativo e que a designação desses estágios e as atividades de cada um variam em diferentes setores da indústria $e$ são determinados pela organização. A BSI PAS 55 (2008, p.36) define três estágios principais: o pré-operacional que inclui a criação ou aquisição dos ativos; o operacional que abrange a utilização e a manutenção e o pós-operacional com a desativação e/ou descarte dos ativos. No contexto da manufatura sustentável, na fase préoperacional, faz-se necessário verificar cuidadosamente os materiais de construção utilizados e sua influência no ambiente natural; a oportunidade de reutilizar os materiais, após o tempo de operação; a confiabilidade do equipamento em fase operacional; a facilidade de manutenção; a segurança e ergonomia para operadores; perfis de consumo de energia; emissões de CO2 e outros gases de efeito estufa; padrões de consumo de produtos químicos; requisitos de contingência (LIYANAGE E BADURDEEN, 2010, p.312-313; JASIULEWICZKACZMAREK, 2013, p.1149-1150).

A fase de operação e manutenção representam a mais longa, geralmente, a mais cara e mais crítica no ciclo de vida de um ativo. Portanto, decisões cuidadosas durante as fases de planejamento podem fornecer oportunidades de uma gestão sustentável eficaz durante a maior parte da vida dos ativos (BLOOMFIELD et. al., 2018, p.11-12). Os métodos de planejamento de manutenção, baseados na identificação de riscos emergentes de falha de uma máquina, permitem à definição de proporções corretas entre políticas de manutenção pré-definidas (incluindo reativas, preventivas, proativas $\mathrm{e}$ outras) com respeito não só às questões financeiras, mas também às questões ambientais e sociais (segurança das pessoas). O conjunto das técnicas mais usadas inclui: manutenção centrada em confiabilidade, inspeção baseada em risco, manutenção baseada em risco, análise de árvore de falhas, modo de falha e análise de efeito (LIYANAGE E BADURDEEN, 2010, p.312-313; JASIULEWICZ-KACZMAREK, 2013, p.1149).

Cada vez mais, há uma tendência para passar de programas de manutenção reativa para proativa com o suporte de sistema de gestão computadorizada. A manutenção preditiva, com o uso de tecnologias de monitoramento de desempenho e das condições, tais como vibração, calor, controle de fluxos, ajuda a detectar precocemente as ineficiências e falhas, entregando benefícios como reduções no uso de óleo e, consequentemente, custos mais baixos e menos impacto ao ambiente, uso mais eficiente da equipe de manutenção e maior confiabilidade, risco reduzido na prevenção de falhas catastróficas e da extensão da vida útil dos ativos. Nessa etapa, é importante o monitoramento com o uso de indicadores (KPIs) alinhados às metas estabelecidas de sustentabilidade (BLOOMFIELD et. al., 2018, p.11-13).

O descomissionamento e o descarte no final do ciclo de vida do ativo também marcam uma etapa importante, na qual a abordagem combinada de gestão de ativos e sustentabilidade produz fortes benefícios (BLOOMFIELD et. al., 2018, p.14-15). O ciclo continua até que o equipamento não tenha valor técnico compensatório. Após a exploração, cada máquina possui diversos materiais e componentes que podem ser usados para regeneração ou reparo de objetos técnicos semelhantes, podendo ser submetida a um processo de reciclagem de material. Além disso, os recursos podem ser recuperados e vendidos. Assim, a fase pósoperacional, objetiva o gerenciamento de peças e componentes dos equipamentos a serem descartados, com a carga mínima para o ambiente e para a sociedade e alguns efeitos econômicos positivos (LIYANAGE E BADUREEN, 2010, p.312-313; JASIULEWICZKACZMAREK, 2013, p.1150).

A alta direção de uma organização deve demonstrar liderança e comprometimento com respeito ao sistema de gestão de ativos garantindo o alinhamento com outras práticas organizacionais e sistemas de gestão (ABNT NBR ISO 55002, 2014, p.1). Assim, deve-se notar que a liderança organizacional é 
componente chave para sustentar uma gestão de ativos integrada à abordagem de sustentabilidade (BLOOMFIELD et. al, 2018, p.18). Os gerentes de manutenção devem permitir e estimular que os outros colaboradores da empresa participem de todas as fases do ciclo de vida da máquina e da implementação da manufatura sustentável. A equipe de gestão deve estar comprometida proativamente com todos os estágios do ciclo de vida do ativo (JASIULEWICZKACZMAREK, 2013, p.1149-1150).

A organização deve estabelecer, implementar e manter processos para monitorar e medir o desempenho do sistema de gestão de ativos e o desempenho e a condição dos ativos (BSI PAS 55, 2008, p.16). Em muitas organizações, a manutenção ainda está focada em indicadores-chave de desempenho convencionais como produtividade, confiabilidade, disponibilidade, mas não em indicadores de desempenho de sustentabilidade. Para mudar a visão convencional, é necessário integrar indicadores sustentáveis no processo de tomada de decisão da gestão de ativos. De acordo com esses desafios, novos processos e indicadores de sustentabilidade aplicado a gestão de ativos precisam ser definidos (IUNG E LEVRAT, 2014).

Inúmeros benefícios da gestão de ativos sustentáveis podem ser listados e alguns exemplos são apresentados no Quadro 3.

Quadro 3 - Exemplos de benefícios internos e externos da gestão de ativos sustentáveis

\begin{tabular}{|c|c|}
\hline \multirow{7}{*}{$\begin{array}{l}\text { Benefícios } \\
\text { internos }\end{array}$} & Econômico \\
\hline & $\begin{array}{l}\text { Limitação de encargos ambientais (por exemplo, graças à segregação de resíduos). } \\
\text { Limitação do estoque de materiais de operação (devido ao planejamento de manutenção). } \\
\text { Limitação do custo do produto por unidade (em razão do uso reduzido de energia no } \\
\text { estágio de fabricação). }\end{array}$ \\
\hline & Ambiental \\
\hline & $\begin{array}{l}\text { Limitação da quantidade de resíduos gerados (graças ao controle dos parâmetros de } \\
\text { trabalho de uma máquina). }\end{array}$ \\
\hline & Limitação do uso de lubrificação com óleo (em virtude a diagnósticos de óleo). \\
\hline & Social \\
\hline & $\begin{array}{l}\text { Maior segurança dos operadores e pessoal técnico. } \\
\text { Diminuição do número de acidentes e incidentes no trabalho. }\end{array}$ \\
\hline \multirow{10}{*}{$\begin{array}{l}\text { Benefícios } \\
\text { externos }\end{array}$} & Econômico \\
\hline & $\begin{array}{l}\text { Limitação do risco de falhas graves (graças a uma escolha de estratégia de manutenção } \\
\text { baseada na análise de risco). }\end{array}$ \\
\hline & $\begin{array}{l}\text { Limitação de multas emergentes de falhas (devido a cenários e procedimentos relativos à } \\
\text { limitação do desenvolvimento do intervalo de falhas). }\end{array}$ \\
\hline & $\begin{array}{l}\text { Maior competitividade de uma organização (por exemplo, graças ao risco legal limitado } \\
\text { por meio da conformidade com as regulamentações legais). }\end{array}$ \\
\hline & Ambiental \\
\hline & Eliminação ou redução de multas emergentes de práticas erradas. \\
\hline & $\begin{array}{l}\text { Diminuição de distúrbios e inconformidades para as sociedades locais (por exemplo, } \\
\text { ruído, emissões e poluição). }\end{array}$ \\
\hline & Redução do uso de recursos não renováveis - gás, petróleo. \\
\hline & Social \\
\hline & agem positiva de uma empresa no contexto de segurança e saúde. \\
\hline
\end{tabular}


Uma das principais barreiras para a implementação de políticas de gestão de ativos sustentáveis, do ponto de vista dos profissionais industriais e pesquisadores acadêmicos, é a falta de dados e informações que podem ser empregados para fornecer um melhor suporte na tomada de decisões relativas às fases do ciclo de vida (WU et al., 2010, p.32). A tendência emergente mostra que as tecnologias móveis têm um grande potencial para redefinir o cenário convencional da gestão de ativos e contribuir para a geração de informações para a tomada de decisão (EMMANOUILIDIS; LIYANAGE; JANTUNEN, 2009, p.92). A base para oferecer soluções avançadas, inteligentes, capazes de gerenciar remotamente ativos complexos, de alto risco e de capital intensivo, independentemente da localização geográfica, criando informações ágeis e redes de conhecimento, começa a ser redefinida (EMMANOUILIDIS; LIYANAGE; JANTUNEN, 2009, p.92).
A "Quarta Revolução Industrial" combina tecnologias de sistemas de produção embutidos com processos de produção inteligentes para abrir caminho para uma nova era tecnológica que transformará fundamentalmente indústria, cadeias de valor de produção e modelos de negócios (ZHONG et al., 2017, p.616). Uma das áreas que absorverá os impactos e desafios emergentes da indústria 4.0 é a de gestão de ativos (PHOGAT E GUPTA, 2017, p.236). Os mercados industriais, altamente intensivos em ativos, podem esperar da indústria 4.0 um ecossistema de ativos conectados (ENGEMAN, 2017). Além disso, as tecnologias da $4^{\text {a }}$ revolução industrial, frequentemente chamadas de "Indústria 4.0", podem contribuir para fornecer as informações necessárias para o sistema de gestão de ativos sustentável (FRANCIOSI, 2018, p.903).

Figura 4 - Indústria 4.0 apoiando a tomada de decisão na gestão de ativos sustentáveis

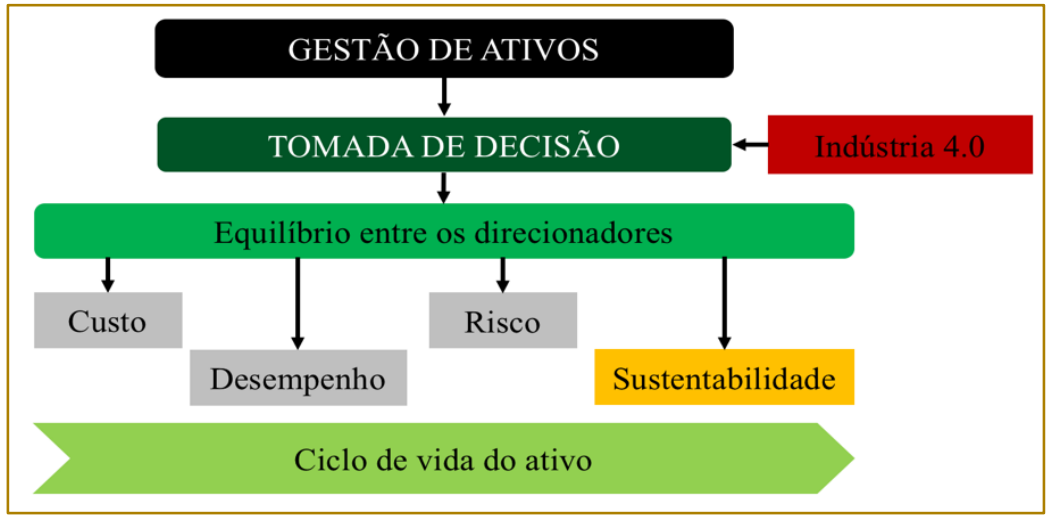

Fonte: os próprios autores

O paradigma da Indústria 4.0 será um passo para a criação de valor industrial mais sustentável. A alocação de recursos, ou seja, produtos, materiais, energia e água, pode ser realizada de forma mais eficiente com base em módulos inteligentes e interligados. Assim, a Indústria 4.0 possui uma grande oportunidade para realizar a criação de valor industrial sustentável em todas as três dimensões: econômica, social e ambiental (STOCK, 2016, p.539-540). Segundo pesquisas da McKinsey (2015, p.25), até 2025, a adoção de iniciativas da indústria 4.0, mundialmente, poderá reduzir custos de manutenção de equipamentos entre 10\% e $40 \%$, diminuir o consumo de energia cerca de
$10 \%$ e reduzir entre $30 \%$ a $50 \%$ o tempo de inatividade total da máquina, contribuindo assim para o incremento da produtividade entre $3 \%$ e $5 \%$.

A Indústria 4.0 não deve, portanto, ser abordada isoladamente, mas deve ser vista como uma das várias áreas em que é necessária ação e, consequentemente, deve ser implementada de forma interdisciplinar e em estreita cooperação com as outras áreas chaves (HENNING, et al, 2013, p.19). Segundo pesquisa realizada por WU et. al. (2010, p.31), é importante construir comunicações mais fortalecidas entre a indústria e o meio acadêmico através, por 
exemplo, de oficinas e estudos de caso, manuais, artigos e livros.

\section{CONSIDERAÇÕES FINAIS}

Os sistemas industriais têm um enorme impacto no consumo de energia e recursos, nas emissões ao meio ambiente e, portanto, na sociedade. Por estas razões, a manufatura sustentável é uma das questões mais importante a ser abordada para alcançar o desenvolvimento sustentável de nossa sociedade (FRANCIOSI et. al., 2018, p.903). As empresas passaram a reconhecer a importância de buscar políticas de negócios sustentáveis para garantir o sucesso corporativo. Portanto, é oportuno começar a incorporar o pensamento de sustentabilidade em todas as operações de negócios, incluindo a gestão de ativos, que é um contribuinte significativo, mas relativamente menos conhecido, para aumentar a sustentabilidade empresarial (LIYANAGE; BADURDEEN; RATNAYAKE, 2009, p.668).

A gestão de ativos sustentável concentra-se em prolongar a vida útil dos ativos e garantir maior produtividade dos sistemas dos quais eles fazem parte, por meio de métodos que atinjam objetivos econômicos, ecológicos e socialmente justos. Assim, dentro do quadro de sustentabilidade, a gestão de ativos sustentável surgiu como um ingrediente vital para alcançar 0 status de um empreendimento sustentável (LIYANAGE; BADURDEEN; RATNAYAKE, 2009, p.668).

A adoção de uma visão holística voltada para a sustentabilidade para a gestão de ativos é fundamental para as operações comerciais bem-sucedidas. A aplicação de abordagens inovadoras pode abrir oportunidades significativas para as empresas, particularmente em setores intensivos em capital. Isso também tem um grande potencial para melhorar o desempenho dos negócios em ambientes com maior risco de sustentabilidade devido ao controle regulatório mais rigoroso e ao aumento da conscientização social, exigindo práticas corporativas éticas e responsáveis (LIYANAGE; BADURDEEN; RATNAYAKE, 2009, p.686).

A gestão de ativos tem um potencial de negócios muito maior do que é conhecido pela maioria das organizações atuais na busca pela manufatura sustentável. Claramente, a inovação tecnológica é um dos principais contribuintes para um futuro sustentável, porém, a indústria pode enfrentar vários obstáculos e desafios ao recorrer apenas à tecnologia. O sucesso é alcançado através da combinação de tecnologia com foco na otimização de outros problemas organizacionais, permitindo assim, novas estratégias e medidas de melhoria dentro das instalações existentes (LIYANAGE E BADURDEEN, 2010, p.314).

O propósito principal deste capítulo é avançar no campo de pesquisa e elevar o grau de compreensão e alinhamento da disciplina de gestão de ativos por acadêmicos e gestores organizacionais. Como resultado, apresentouse uma discussão construída com base na revisão da literatura acadêmica e não acadêmica, sobre a importância de se incorporar a sustentabilidade na tomada de decisão ao longo do ciclo de vida dos ativos. Além disso, apresentou como um importante e recente instrumento para alinhar esses direcionadores - custo, risco, desempenho e sustentabilidade - à Indústria 4.0 e à capacidade de suas tecnologias de gerar informações precisas e em tempo real para o processo decisório.

Inicialmente, a pesquisa levantou de forma individual os aspectos principais das disciplinas de gestão de ativos, sustentabilidade e Indústria 4.0. Complementarmente, apresentaram-se vários tópicos relacionando os principais elementos do gerenciamento de ativos aos aspectos do desempenho sustentável. Entendeu-se que um dos principais desafios da integração da gestão de ativos e da sustentabilidade são as decisões a serem tomadas ao longo do ciclo de vida, decisões estas que podem ser otimizadas com a introdução dos conceitos de Indústria 4.0 nas operações. A partir de tal fato, percebe-se a oportunidade de realização de trajetórias de pesquisas sobre 0 desenvolvimento de metodologias, ferramentas e indicadores para a integração de dados do ciclo de vida, custos, riscos, consumo de recursos naturais e o cálculo do benefício econômico.

Por fim, é sabido que o caminho para a compreensão e aplicação da gestão de ativos é próprio de cada organização. Porém com o aumento da conscientização, as empresas estão prestando mais atenção a todos os elementos da sustentabilidade e as tendências nessa direção têm efeitos significativos para as práticas atuais de gestão de ativos. 


\section{REFERÊNCIAS}

[1]. AMADI-ECHENDU, J. E., et al. Asset condition, information systems and decision models. Springer Science \& Business Media, 2012.

[2]. ASSOCIAÇÃO BRASILEIRA DE NORMAS TÉCNICAS. NBR ISO 55000: Gestão de ativos visão geral, princípios e terminologia. Rio de Janeiro, 2014

[3]. ASSOCIAÇÃO BRASILEIRA DE NORMAS TÉCNICAS. NBR ISO 55001: Sistemas de Gestão Requisitos. Rio de Janeiro, 2014.

[4]. BASSON, W. Risk management solutions flow to implement quantitative methods as part of ISO 55000 for physical asset management. 2016. 198 f. Tese (Doutorado em Engenharia Industrial). University. Stellenbosch, África do Sul, 2016.

[5]. BAUM, J.; VLOK, P. J. Mapping primary constraints in physical asset management strategy execution, using social network analysis. South African Journal of Industrial Engineering, África do Sul, v. 24, n. 2, p. 47-58, 2013.

[6]. BADURDEEN, F.; SHUAIB, M.; LIYANAGE, J. P. Risk modeling and analysis for sustainable asset management. In: Engineering Asset Management and Infrastructure Sustainability. Springer, London, 2012. p. 61-75.

[7]. BSI PAS 55-1: Especificação para a gestão otimizada de ativos físicos. British Standard Institute. Tradução: Associação Brasileira de Manutenção. Rio de Janeiro, 2008.

[8]. BSI BS EN 13306: Maintenance: Maintenance terminology. European Committee for Standardization, Brussels, Bélgica. 2010.

[9]. BLOOMFIELD, P.; DENT, S.; MCDONALD, S. Incorporating sustainability into asset management through critical life cycle cost analyses. Proceedings of the Water Environment Federation, v. 2006, n. 6, p. 6304-6315, 2006.

[10]. CASSAPO F. Manufatura 4.0: Eficiência e Produtividade. Revista de Manutenção e Gestão de Ativos: Abraman, v.163. p.1-52. 2017.

[11]. CHENG, G. J.; LIU, L. T.; QIANG, X. J.; LIU, Y. Industry 4.0 Development and Application of Intelligent Manufacturing. In Information System and Artificial Intelligence, International Conference. p. 407-410. IEEE. 2016

[12]. DELOITTE. Industry 4.0: Challanges and solutions for the digital transformation and use of exponential technologies. The Creative Studio/Deloitte AG, 2015.

[13]. DO NASCIMENTO, E. P. Trajetória da sustentabilidade: do ambiental ao social, do social ao econômico. Estudos avançados, v. 26, n. 74, p. 51-64, 2012.

[14]. EMMANOUILIDIS, C.; LIYANAGE, J. P.; JANTUNEN, E. Mobile solutions for engineering asset and maintenance management. Journal of
Quality in Maintenance Engineering, v. 15, n.1, p. 92-105. 2009

[15]. ENGEMAN. Webinar: A indústria 4.0 na manutenção de ativos, o que esperar?. 2017. Disponível em: < https://www.youtube.com/watch?v=ZumbYdRgQ8Y >. Acesso em 29 de novembro de 2017.

[16]. FRANCIOSI, C. et al. Maintenance for Sustainability in the Industry 4.0 context: a Scoping Literature Review. IFAC-PapersOnLine, v. 51, n. 11, p. 903-908, 2018.

[17]. GIBSON, Robert B. Beyond the pillars: sustainability assessment as a framework for effective integration of social, economic and ecological considerations in significant decisionmaking. Journal of Environmental Assessment Policy and Management, v. 8, n. 03, p. 259-280, 2006.

[18]. GLOBAL FORUM ON MAINTENANCE AND ASSET MANAGEMENT. The Asset Management Landscape. 2014. Disponível em: < http://www.gfmam.org/files/isbn978_0_9871799_2_ 0_gfmamlandscape_secondedition_english.pdf>. Acesso em: 20 ago. 2018.

[19]. HASTINGS, N. A. Physical Asset Management: With an Introduction to Iso55000. Springer, 2014.

[20]. HENNING, K. Recommendations for implementing the strategic initiative Industrie 4.0. Working Group. Forschungsunion. 2013.

[21]. HERMANN, M.; PENTEK, T.; OTTO, B. Design Principles for Industrie 4.0 Scenarios: A Literature Review. 2015. Technische Universitat Dortmund. Disponível em: < http://www.snom.mb.tu-

dortmund.de/cms/de/forschung/Arbeitsberichte/De sign-Principles-for-Industrie-4_0-Scenarios.pdf > . Acesso em: 10 nov. 2018.

[22]. HODKIEWICZ, M. R. The development of ISO 55000 series standards. In: Engineering Asset Management-Systems, Professional Practices and Certification. Cham: Springer, 2015. p. 427-438.

[23]. IUNG, B.; LEVRAT, E. Advanced maintenance services for promoting sustainability. Procedia CIRP, v. 22, p. 15-22, 2014.

[24]. JASIULEWICZ-KACZMAREK, Małgorzata. The role and contribution of maintenance in sustainable manufacturing. IFAC Proceedings Volumes, v. 46, n. 9, p. 1146-1151, 2013.

[25]. KAGERMANN, H.; LUKAS, W.; WAHLSTER, W. Abschotten ist keine Alternative. In: VDI Nachrichten, v. 16, 2015.

[26]. KATES, R. W. What is sustainable development?. 2018.

[27]. KRIEGE, L.; VLOK, P. J. Human resources within ISO 55000-the hidden backbone to the 
asset management system. In 9th WCEAM Research Papers. Cham: Springer, 2015. p. 435446.

[28]. KORTELAINEN, H.; REUNANEN, M.; UUSITALO, T. Sustainability improvements through efficient asset management networks. In: Proceedings of the 7th World Congress on Engineering Asset Management (WCEAM 2012). Springer, Cham, 2015. p. 341-352.

[29]. LASI, H.; FETTKE, P.; KEMPER, H. G.; FELD, T.; HOFFMANN, M. Industry 4.0. Business \& Information Systems Engineering. v. 6, n. 4, p. 239242, 2014

[30]. LACERDA, D. P. et al. Algumas caracterizações dos métodos científicos em Engenharia de Produção: uma análise de periódicos nacionais e internacionais. XXVII Encontro Nacional de Engenharia de Produção, 2007

[31]. LIYANAGE, J. P.; BADURDEEN, F. Strategies for integrating maintenance for sustainable manufacturing. In: Engineering Asset Lifecycle Management. Springer, London. p. 308315. 2010

[32]. LIYANAGE, J. P. Operations and maintenance performance in production and manufacturing assets: The sustainability perspective. Journal of Manufacturing Technology Management, v. 18, n. 3, p. 304-314, 2007.

[33]. LIYANAGE; BADURDEEN; RATNAYAKE. Industrial asset maintenance and sustainability performance: Economical, environmental, and societal implications. Handbook on Maintenance Management and Engineering, p. 665-693. 2009.

[34]. LU, Y. Industry 4.0: A Survey on Technologies, Applications and Open Research Issues. Journal of Industrial Information Integration. p.1-40. 2017.

[35]. MARLOW, D.; BEALE, D.; BURN, S. Linking asset management with sustainability: Views from the Australian sector. Journal-American Water Works Association, v. 102, n. 1, p. 56-67, 2010.

[36]. MA, Z., ZHOU, L., SHENG, W. Analysis of the new asset management standard ISO 55000 and PAS 55. In: Electricity Distribution (CICED), China International Conference on IEEE, p. 16681674. 2014

[37]. MALETIČ, D., MALETIČ, M., AL-NAJJAR, B., GOTZAMANI, K., GIANNI, M., KALINOWSKI, T. B., \& GOMIŠČEK, B. Contingency Factors Influencing Implementation of Physical Asset Management Practices. Organizacija, Eslovênia, v. 50, n. 1, p. 3-16, 2017.

[38]. MAHESHWARI, A. Development of a Strategic Asset Management Framework. In: Engineering Asset Management. Londres: Springer. 2010. p. 596-605.
[39]. MCKINSEY. Industry 4.0 How to navigate digitization of the manufacturing sector. 2015. Disponível em: https://www.mckinsey.de/files/mck_industry_40_rep ort.pdf Acesso em 10 de maio de 2018.

[40]. MOYA, M. The control of the setting up of a predictive maintenance programme using a system of indicators. Omega, v. 32, n. 1, p. 57-75, 2004.

[41]. NG. Indústria 4.0: o que é e qual seu impacto na manutenção de ativos. 2017. Disponível em: < http://conteudo.ngi.com.br/ebook-industria4>. Acesso em 01 de dezembro de 2017

[42]. PAGLIUSO, A. T.; CARDOSO, R.; SPIEGEL, T. Gestão organizacional: o desafio da construção do modelo de gestão. Rio de Janeiro: Saraiva. 2010.

[43]. PHOGAT, S.; PHOGUPTA, A. K. Identification of problems in maintenance operations and comparison with manufacturing operations: A review. Journal of Quality in Maintenance Engineering, v.23, n.2, p. 226-238. 2017

[44]. PORT, T; ASHUN, J; CALLAGHAN, T. J. A framework for asset management. In: Asset management excellence: Optimizing equipment life-cycle decisions. Reino Unido: Taylor and Francis Group, p. 23-48, 2011.

[45]. REIS, C. B.; COSTA, A. P.; TEIXEIRA, A. Planning and competitiveness in maintenance management: An exploratory study in manufacturing companies. Journal of Quality in Maintenance Engineering, v. 15, n. 3, p. 259-270, 2009

[46]. RODA, I.; MACCHI, M. Studying the funding principles for integrating Asset Management in Operations: an empirical research in production companies. IFAC-PapersOnLine, $v$. 49, n. 28, p. 1-6, 2016.

[47]. RUBMANN, M.; LORENZ, M.; GERBERT, P.; WALDNER, M.; JUSTUS, J.; ENGEL, P.; HARNISCH, M. Industry 4.0: The Future of Productivity and Growth in Manufacturing Industries. The Boston Consulting Group (BCG), 2015.

[48]. SANCHEZ, A. M.; ROMERO, A. A. Consideraciones para la gestión de interruptores de alta tensión, en el marco de la ISO 55000. In: Biennial Congress of Argentina (ARGENCON). IEEE. p. 606-611. 2014

[49]. SILVEIRA, B. C. O Que é Indústria 4.0 e Como Ela Vai Impactar o Mundo. 2017. $<$ https://www.citisystems.com.br/industria-4-

0/\#disqus_thread> Acesso em 20 de maio de2018.

[50]. STOCK, T., SELIGER, G. Opportunities of sustainable manufacturing in industry 4.0. Procedia Cirp. v.40, p.536-541, 2016. 
[51]. STARR, A.; BEVIS, K. The role of education in industrial maintenance: the pathway to a sustainable future. In: Engineering Asset Lifecycle Management. Springer, London, 2010. p. 539-542.

[52]. TORRESI, S. I.; PARDINI, V. L.; FERREIRA, V. F. O que é sustentabilidade?. Química nova, v. 33, n. 1, p. 1-1, 2010.

[53]. UNITED NATIONS WORLD COMMISSION ON ENVIRONMENT AND DEVELOPMENT
(UNWECD). Our Common Future, Oxford University Press, Oxford. 1987

[54]. WU, S. et al. Research opportunities in maintenance of office building services systems. Journal of Quality in Maintenance Engineering, v. 16, n. 1, p. 23-33. 2010.

[55]. ZHONG, R. Y.; XUN X.; KLOTZ E.; NEWMAN S. T. Intelligent manufacturing in the context of industry 4.0: a review. Engineering, v. 3, n. 5, p. 616-630, 2017. 


\section{Capítulo 16}

\section{GESTÃO DE RESİDUOS SÓLIDOS: ESTUDO DE CASO EM UMA INDÚSTRIA MADEIREIRA NO AMAZONAS}

\section{Amanda Almeida de Souza \\ Beatriz Ferreira da Cruz \\ Emilly Felipe de Lima e Lima \\ Rute Holanda Lopes \\ Adilson Tavares Cruz \\ Nilce Lene Torres de Lima}

Resumo: As indústrias madeireiras são grandes consumidores dos recursos naturais que induz a necessidade de mudanças que reaproveite fontes energéticas, sendo a madeira um potencial renovável. As práticas das indústrias madeireiras da região Amazônica, assim como qualquer outra atividade econômica que possuem seus recursos procedentes das florestas, resultam em grandes impactos na sociedade e no meio ambiente. Especialmente, no caso das madeireiras, essas atividades envolve todos os possíveis riscos ambientais. Por isso, nota-se que essa atividade acaba influenciando na vida dos colaboradores da empresa e também da comunidade que cerca a organização. Essa é uma atividade muito atrativa por trazer desenvolvimento da economia tanto do local, em que a empresa reside, quanto no país. O objetivo desta pesquisa foi verificar e analisar o gerenciamento de resíduos sólidos no setor madeireiro. A indústria madeireira é um importante segmento que gera empregos, rendas e divisas nos países que fazem uso de tal recurso. A metodologia utilizada foi o estudo de caso, por meio da pesquisa de campo, bibliográfica e documental, com a aplicação de entrevistas, a observação em uma análise qualitativa.

Palavras-chave: Gestão ambiental, Madeireiras, Amazônia e Resíduos. 


\section{INTRODUÇÃO}

Desde a Revolução Industrial o cenário ambiental agravou-se, visto que a utilização da tecnologia favoreceu a vida da sociedade pré-moderna, colaborando para o engrandecimento populacional, o que concebeu a obrigação de se criar novas técnicas de produção em massa para ministrar a necessidade das pessoas, que consomem cada vez mais, dessa maneira produzindo maior quantidade de resíduos (DIAS, 2006).

O medo das consequências dos impactos ambientais, oriundos da atuação humana sobre a natureza, teve maior destaque na década devido a diminuição da qualidade de vida em determinadas regiões do planeta, a partir disso surgiu a preocupação com o meio ambiente, e então houve a criação de movimentos ambientalistas voltados para a proteção ambiental (RUPPENTHAL, 2014, p.19).

As indústrias madeireiras são grandes consumidores dos recursos naturais que induz a necessidade de mudanças que reaproveite fontes energéticas, sendo a madeira um potencial renovável.

As práticas das indústrias madeireiras da região Amazônica, assim como qualquer outra atividade econômica que possuem seus recursos procedentes da florestas, resultam em grandes impactos na sociedade e no meio ambiente. Especialmente, no caso das madeireiras, essa atividades envolve todos os possíveis riscos ambientais.

Por isso, nota-se que essa atividade acaba influenciando na vida dos colaboradores da empresa e também da comunidade que cerca a organização. Essa é uma atividade muito atrativa por trazer desenvolvimento da economia tanto do local, em que a empresa reside, quanto no país.

A falta de planejamento adequado, em alguns casos de atividades industriais tem como consequência diversos acidentes ambientais. $\mathrm{Na}$ maioria das vezes quando a organização do setor madeireiro trata os recursos somente como fonte de matéria-prima, sem os devidos "(...) cuidados com o meio ambiente e sua utilização indiscriminada" (REBOLLO, 2000) poderá ocorrer uma grande escassez dos recursos naturais para as próximas gerações, podendo também prejudicar $\mathrm{O}$ ambiente econômico do setor.
O sistema de gestão ambiental segundo a ISO14001: 2004 "possui como finalidade o equilíbrio a proteção ambiental e a prevenção da poluição com as necessidades econômicas das organizações." Desta forma, este estudo de caso buscou caracterizar e analisar os benefícios de um sistema de gerenciamento ambiental aplicado no dia-adia de uma indústria madeireira.

\section{REVISÃO TEÓRICA \\ 2.1 RESÍDUOS SÓLIDOS}

Entender a perspectiva de se ter conhecimento sobre os resíduos sólidos auxilia para o tratamento do mesmo, podendo ser útil e aproveitado pela sociedade.

Segundo a definição da Política Nacional de Resíduos Sólidos (BRASIL, 2010) os resíduos sólidos é todo:

Material, substância, objeto ou bem descartado resultante de atividades humanas em sociedade, a cuja destinação final se proceder, nos estados sólido ou semissólido, bem como gases contidos em recipientes e líquidos cujas particularidades tornem inviável o seu lançamento na rede pública de esgotos ou em corpos d'água, ou exijam para isso soluções técnicas ou economicamente inviáveis em face da melhor tecnologia disponível.

Por sua vez, pode -se determinar resíduos sólidos como materiais heterogêneos causados pelas inúmeras atividades humanas e da natureza, estimados inúteis, indesejáveis ou descartáveis formando problemas sanitário, econômico e principalmente estético. No entanto, podem ser parcialmente aproveitados, pois aquilo que não oferece mais serventia para quem o descarta, para outro pode se tornar matéria - prima para um novo produto ou processo (MONTEIRO et al, 2001),

\subsection{RESÍDUOS SÓLIDOS MADEIREIROS}

O setor madeireiro vem absorvendo tecnologias, e segundo Santa Rita (2003, p.6), ao avaliar as especialidades estruturais do complexo industrial, adverte que de forma análoga a outras indústrias, a moveleira tem passado por modificações em seus procedimentos de fabricação, refletidos em suas técnicas de organização industrial e equipamentos microeletrônicos. Empregando 
como matéria-prima principal em seus produtos a madeira maciça ou chapas de madeira reconstituída, as indústrias encontram-se em seus processos produtivos, com volumes acumulativos de resíduos que originam impactos ambientais.

Prevalece um modelo de produção, na indústria madeireira, baseado no princípio que o meio ambiente oferece recursos inacabáveis, considerando os impactos da indústria pequenos, por seus resíduos não serem perigosos. O receio com a quantia de produção, com a utilização de produtos longínquos, de onde vem a matéria-prima e a com a disposição final dos resíduos, torna-se insensato (NOLASCO,2014, p.15).

A origem dos resíduos tem seu efeito ligado a modificação da madeira maciça ou a reforma de painéis de madeira. Podemos qualificar os resíduos como cavacos de acordo com suas propriedades morfológicas (partículas com dimensões máximas de 50 × 20 mm, em geral provenientes do uso de picadores), maravalha (resíduo com mais de 2,5 mm), serragem (partículas de madeira provenientes do uso de serras, com dimensões entre 0,5 a 2,5 $\mathrm{mm}$ ), e por fim, o pó (resíduos menores que $0,5 \mathrm{~mm})$.

Mediante as três fases do método mecânico da madeira são produzidos subprodutos com diversas aproveitamentos comerciais que podem ser sucintas (IBQP, 2002.p.35). "Os resíduos de madeira podem ser utilizados tanto na confecção de material combustível, na agricultura, na geração de energia elétrica em termoelétricas, e principalmente na indústria de painéis reconstituídos" (IBQP, 2002. p.95).

Segundo Quirino (2004) existe duas formas de dar valor ao resíduo da madeira, sendo a valorização energética, quando o destino do resíduo é o aproveitamento da biomassa como fonte de energia, como, por exemplo: combustão direta e incineração, gaseificação, briquetagem, pirólise e a valorização da matéria quando a biomassa do resíduo é aplicada como matéria prima para a fabricação de outros materiais como: fertilizantes, compósito de madeira mais cimento, painéis reconstituídos e painéis e vigas colados.

Uma das utilizações mais antiga da madeira é a conversão da própria em energia térmica, essa queima de madeira direta causa calor, produtos químicos e gases, de forma que quando a combustão é completa também causa vapor d'água e gás carbônico (ASSUMPÇÃO, 1978).

Dessa maneira, em Fagundes (2003) ter uma destinação final adequada para os resíduos procedentes do processamento da madeira torna - se necessária, porque apesar de ser biodegradável, o acumulo deste material em um determinado local pode causar graves impactos ambientais.

\subsection{POLÍTICA NACIONAL DOS RESÍDUOS SÓLIDOS (PNRS)}

O projeto de Política Nacional de Resíduos Sólidos, após 19 anos de tramitação, foi consagrado no dia 10 de março de 2010 pela Câmara dos Deputados, entretanto no dia 2 de agosto de 2010 sob a lei 12.305 foi instituída a Política Nacional dos Resíduos Sólidos (PNRS), na qual nasceu com novas providências transformando a lei 9.605/98 (REVISTA MEIO AMBIENTE INDUSTRIAL, 2010: 76).

A discussão em volta desta política distinguiu o início de uma intensa articulação institucional envolvendo a União, estados e munícipios, o setor produtivo e a sociedade civil, na procura de recursos para as dificuldades ocasionadas pela gestão imprópria dos resíduos sólidos urbanos, que compromete a qualidade de vida da população (TEIXEIRA, 2013).

No Art.4ํ da lei 12.305/10 disserta que a Política Nacional de Resíduos tem um conjunto de princípios que visam a gestão integrada e ao gerenciamento ambientalmente adequada dos resíduos sólidos.

O artigo 9 da lei 12.305/10 diz respeito que na gestão de resíduos sólidos devem ter prioridade: a não geração, redução, reutilização, reciclagem, tratamento dos resíduos sólidos e a ter uma disposição final adequada ambientalmente.

Segundo a Política Nacional de Resíduos sólidos de 2010, em seu capítulo

\section{PROCEDIMENTOS METODOLÓGICOS}

O presente trabalho encontra-se alicerçado sobre as bases da pesquisa qualitativa (DENZIN; LINCOLN, 2000), cuja abordagem metodológica utilizada é o estudo de caso (YIN, 2010). 
Essa estratégia de pesquisa tem sido vastamente aproveitada como método de pesquisa (BERTERO, BINDER e VASCONCELOS, 2005; HOPPEN $P$ MEIRELLES, 2005; GIL et al., 2005). O estudo de caso é avaliado como uma opressão de um sistema restrito ou de um caso, abrangendo uma coleta de dados em profundidade e com múltiplas fontes de conhecimento, em determinado assunto. O caso pode ser um acontecimento, uma atividade ou até ainda indivíduos; de tal modo, a noção de sistema limitado está relacionada com o significado de tempo e espaço (CRESWELL, 1998).

A partir do período em que o método de estudo de caso passou a ser vastamente aproveitado pelos pesquisadores do campo de gestão, observa - se um empenho destes no sentido de desenvolver rígidos processos de pesquisa que deem a esta abordagem metodológica a força necessária para que ela tenha reconhecimento cientifico equivalente aos métodos estatísticos, predominantes no campo (ZANNI et al., 2011).

O estudo de caso precisa valer -se de múltiplas formas de demonstração (YIN, 2010). Para tanto, aceitou - se como ferramentas de coleta de dados a análise documental e a entrevista com roteiro semiestruturado com o engenheiro e analista responsável pelas questões ambientais da empresa focando, prioritariamente, o gerenciamento dos resíduos sólidos. Esse conjunto de abordagens proporcionou maior vigor e exatidão metodológica da presente pesquisa.

A pesquisa descritiva de maneira sucinta pode assumir diversas formas das quais trabalha sobre dados ou fatos embasados na realidade. Umas das características da pesquisa descrita é a coleta de dados para acontecer essa operação são empregados como instrumentos necessários a observação, a entrevista, o questionário e o formulário

\subsection{PERFIL DA EMPRESA EM ESTUDO}

O grupo Precious Woods começou suas atividades de manejo florestal em 1990 na Costa Rica, com um projeto de reflorestamento utilizando espécies nativas e exóticas em um sistema de manejo de plantações, na região noroeste de Guanacaste.

A captação de aquisições foi executada necessariamente na Suíça, por meio de convênios com investidores privados. Até hoje, a empresa refloresceu alguns milhares de hectares e instituiu um programa de treinamento para lecionar técnicas de manejo de plantações para profissionais e técnicos de campo da Costa Rica.

No Brasil as atividades tiveram abertura em 1993, com a efetivação do estudo de viabilidade de um projeto de manejo florestal sustentado na Amazônia. Este projeto foi aprovado pela direção da Precious Woods Amazon em 1994, quando então se adquiriu a Empresa Mil Madeireira Itacoatiara Ltda., localizada no município de Itacoatiara, Estado do Amazonas.

A Precious Woods Amazon sempre procura a adequação de suas atividades a sua política sustentável, para isso, é de suma importância à manutenção do manuseio apropriado dos resíduos originados pelo empreendimento, sempre de acordo com a legislação vigente.

A empresa é composta por diversos setores, estes por sua vez produzem diferentes tipos de resíduos. O quadro a seguir apresenta como acontece a geração de resíduos na organização.

Quadro 1- Geração de resíduos em cada setor da organização.

\begin{tabular}{|l|l|}
\multicolumn{2}{|c|}{ Setor } \\
\hline Setor de colheita e Manutenção florestal & Metal, Plástico, Papel, Orgânico, Óleo, Baterias \\
\hline Escritórios & Plástico, Papel, Metal, Cartuchos de tinta \\
\hline Refeitório & Papel, Orgânico, Plástico. \\
\hline Serraria & Metal, Óleo, Preservativo químico, Resíduos de serragem. \\
\hline
\end{tabular}

Elaborado pelo autores (2017) 


\subsection{INSTRUMENTOS DE COLETA DE DADOS}

Para elaboração dos instrumentos de coleta de dados, levaram-se em consideração os objetivos da pesquisa, o cenário e o universo da pesquisa. Baseou-se ainda em leituras, identificação e discussão sobre o bom gerenciamento de resíduos em uma organização. A pesquisa de campo foi desenvolvida com o objetivo de obter informações qualitativas que transpareçam a realidade do gerenciamento dos resíduos sólidos na empresa Mil Madeireira LTDA. Para os instrumentos utilizados na coleta dos dados foi utilizado um formulário, que continha perguntas fechadas e abertas. Foi abordado diversas questões visando à obtenção de informações quanto ao gerenciamento dos resíduos, a conscientização em relação à problemática ambiental, estimativa de quantidades de resíduos e sua devida destinação, entre outras questões, de acordo com o fluxograma a ser seguido. Slack (2009) afirma que o fluxograma auxilia o gestor de processos, pois essa técnica "dá uma compreensão detalhada das partes do processo em que algum tipo de fluxo ocorre".

Figura 1- Fluxo de metodologia aplicada para o presente trabalho.

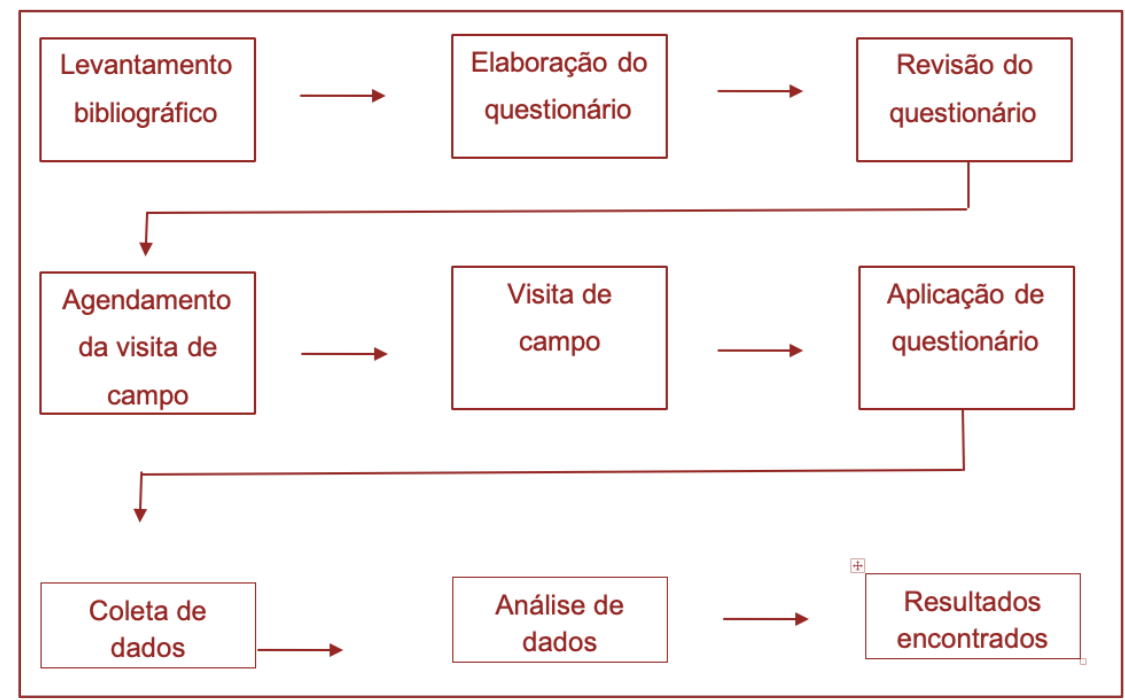

Elaborado pelos autores (2017)

A figura 1 apresenta o fluxo das etapas seguidas para elaboração deste trabalho. Inicialmente com o levantamento bibliográfico, em base de bibliotecas digitais, como a Scielo, Google Scholar, foram realizadas buscas em canais do ENEGEP (Encontro Nacional de Engenharia de Produção), este sendo um dos mais conceituados congressos da área de Engenharia da Produção. Com base na bibliografia encontrada foi feito um questionário, com perguntas direcionadas a questão da pesquisa que busca analisar o gerenciamento de resíduos em organizações do setor madeireiro.

$\mathrm{Na}$ segunda fase foi feito o contato com a organização para realizar um visita in loco, com a permissão para realizar o estudo, deuse início na visita ao local e à aplicação do questionário. $\mathrm{Na}$ sequência foram feita a análise dos dados e obteve-se sua interpretação que é apresentada dando seguimento da condução do trabalho na sessão 4 .

\section{RESULTADOS E DISCUSSÃO}

\subsection{ACONDICIONAMENTO DOS RESÍDUOS NA EMPRESA}

\subsubsection{RESÍDUOS NÃO PERIGOSOS}

Os resíduos classificados como Não Perigosos são recolhidos em recipientes nos locais de geração e em seguida os mesmos são depositados no contêiner do deposito reservado para o tipo de resíduo.

Os copos descartáveis não são utilizados pelos funcionários, pois a empresa tem a política de doar copos individuais para os seus colaboradores para que evite o desperdício e desta forma envolver os servidores com artifício sustentável. 
Para o reaproveitamento dos papéis a empresa utiliza para a impressão frente e verso, quando um lado é usado e outro não, estes são colocados em uma prateleira abaixo da impressora para que sejam utilizados outra vez. Como alternativa de sustentabilidade é feita a doação de toners já utilizados para uma gráfica do município.
Os resíduos de madeira provenientes dos processos realizados na empresa, em geral passam por um tratamento e armazenamento especial por conta do aproveitamento do mesmo para geração de energia.

Figura 2 - Silo usado para o acondicionamento do resíduo de madeira

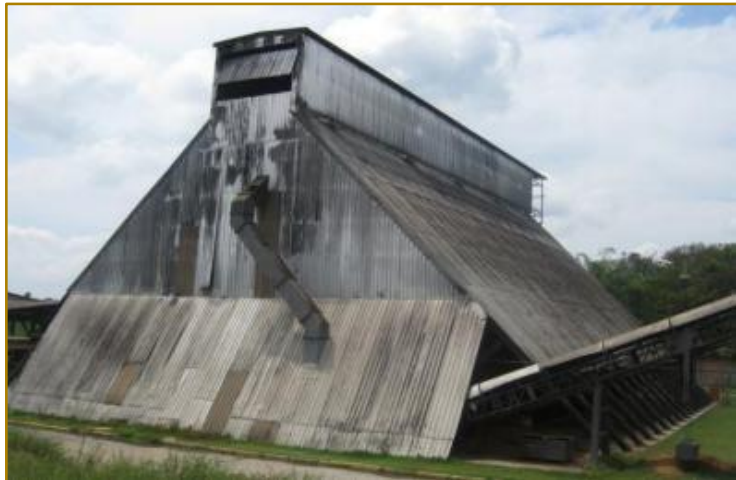

Pesquisa de campo, 2017
Esses resíduos são transportados por meio de esteiras por todo o trajeto, desde a indústria passando pelo armazenamento, até a caldeira.

A empresa utiliza-se de veículos que acabam por gerar mais resíduos, como os pneus que se encontram sem condições de uso, estes são depositados de maneira adequada no depósito de resíduos da empresa para que assim seja proporcionada a sua destinação final.

Figura 3- Depósito de Resíduos - Setor de Pneus usados

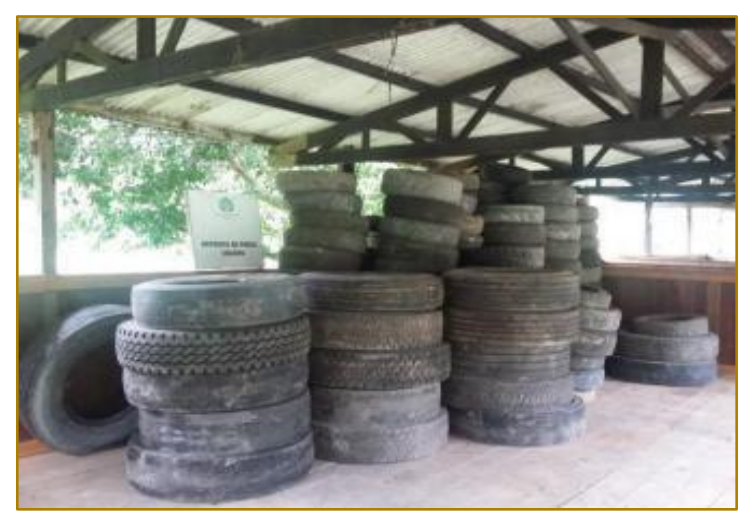

\subsubsection{RESÍDUOS PERIGOSOS}

"Os resíduos classificados como perigosos, à medida que forem gerados, são transportados para o depósito de resíduos perigosos da empresa, onde são armazenados separadamente por tipo de resíduo" conforme a NBR 10004.

\subsubsection{LÂMPADAS FLUORESCENTES}

As lâmpadas fluorescentes são acondicionadas separadamente, devidamente embaladas e mantidas intactas. Nos casos de quebra do material, os fragmentos são separados em sacos plásticos fechados, evitando o contato manual. 
Figura 4 - Depósito de Resíduos Perigosos - Setor de Lâmpadas Fluorescentes

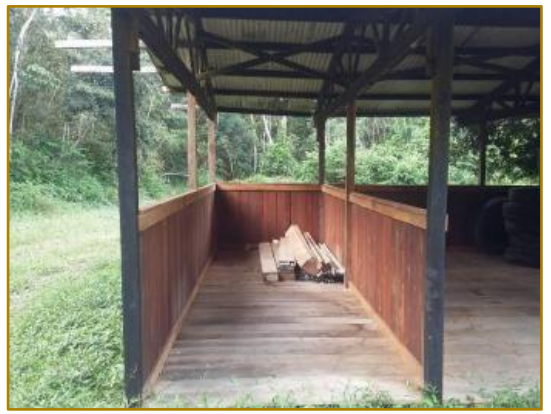

Pesquisa de campo, 2017

Os resíduos de óleo lubrificante e Preservativo químico são acondicionados em tambores de 200 litros, estes, são armazenados separadamente em baias identificadas. O piso é impermeabilizado com concreto, mantido seco e protegido de acesso de animais e pessoas não autorizadas.

Figura 5- Depósito de Resíduos Perigosos - Setor de Óleo Utilizado e Preservativos Químicos

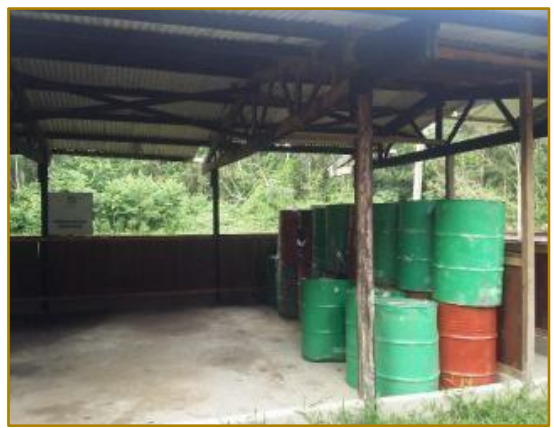

Pesquisa de campo, 2017

\subsubsection{COLETA E TRATAMENTO DE RESÍDUOS}

A incineração é realizada no Acampamento Florestal o qual processa resíduos Não Perigosos: - Plástico, papel.
Com relação a separação, toda a área de manutenção de máquinas e o posto de abastecimento, têm o piso de concreto com uma calha de saída de óleo. Este óleo é separado da água e recolhido em caixas de separação e levado ao depósito apropriado.

Figura 6 - Caixa de separação do óleo - Manutenção

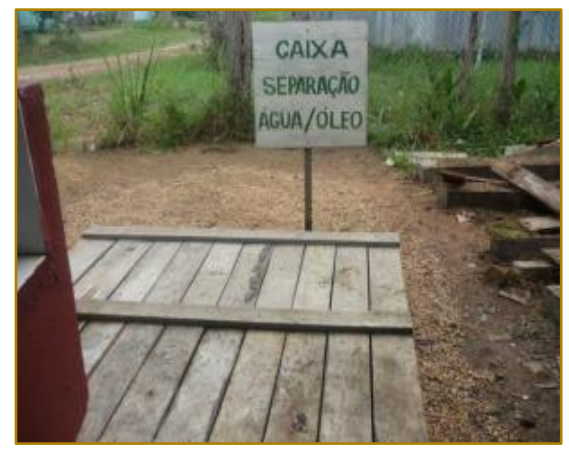

Pesquisa de campo, 2017 
Todo Resíduo oriundos dos escritórios e do refeitório da empresa como: papel, pilhas e resíduos orgânicos, são coletado separadamente, desta forma é realizada a destinação final adequada de cada um.

A empresa separa seus resíduos para diferentes fins: os resíduos orgânicos são aproveitados na fertilização dos canteiros de horta do refeitório, e doados para comunidades vizinhas que são criadores de animais.

\subsubsection{DESTINAÇÃO FINAL}

Todo o resíduo gerado na empresa, considerado não perigoso, é armazenado no contêiner do depósito de resíduos não perigosos. Esses resíduos são transportados a cada 15 dias, tendo como o destino final a lixeira municipal do município de Itacoatiara.

Para os resíduos considerados perigosos, a empresa busca 0 destino final mais apropriado. Os resíduos, como: Óleo lubrificante usado limpo e contaminado (como pó de serragem). Preservativos químicos e os seus respectivos vasilhames são destinados por meio de empresas devidamente credenciadas para o transporte e recebimento desses tipos de resíduos.

A empresa recebe, para cada coleta, um certificado de destinação final emitido pela empresa credenciada ao recebimento desse tipo de resíduo.
A caracterização qualitativa foi importante para avaliar a forma como a organização lidava com o gerenciamento dos resíduos sólidos.

Notou-se que, o gerenciamento de resíduos na organização é feita de forma adequada, colaborando para a saúde de seus funcionários e para a situação crítica do meio ambiente.

No setor de resíduos eletrônicos não há uma destinação final adequada, evidencia-se a falta de empresas para fazer parceria.

A valorização do resíduos, pela reutilização dos mesmos, é importante e é considerado um grande diferencial da organização.

Os resíduos madeireiros da organização são disponibilizados aos cidadãos que moram nas comunidades próximas, estes por sinal, utilizam os resíduos para a fabricação de artesanatos.

Na figura 7 é demonstrado o fluxograma do gerenciamento dos resíduos sólidos da organização onde os resíduos gerados são caracterizados e classificados designados também como perigosos ou não-perigosos, em seguida são armazenados temporariamente.

Os resíduos não perigosos que foram armazenados tem utilidade tanto para a reciclagem quando para a reutilização. Os perigosos podem ser tratados ou não até chegar a sua destinação final.

Figura 7 - Fluxograma do Gerenciamento de Resíduos da Empresa

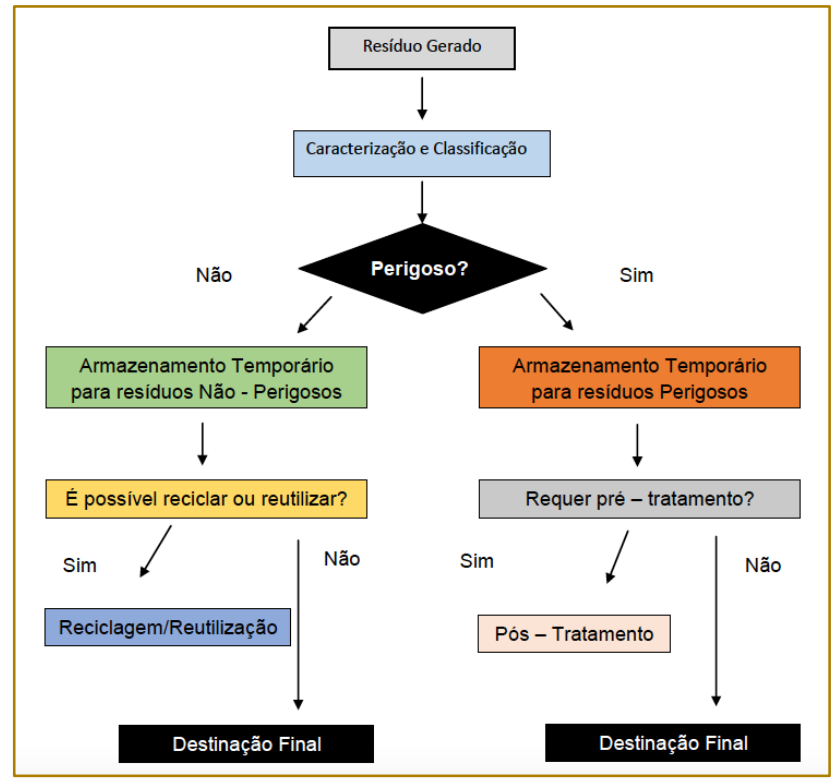

Fonte: PGR/01- PWA (2016) 
A madeira é uma matéria prima que gera muitos resíduos, cerca de $70 \%$ é resíduo e apenas $30 \%$ vira produto. Para o aproveitamento da grande quantidade de resíduos madeireiros em 2004, a empresa Mil Madeireira Preciosas fez uma parceria com a
BK, o qual a mesma abastece todo o complexo da Indústria e ainda resta para ser vendida à Itacoatiara, sendo que 30\% do município é abastecido pela BK, ou seja, além de gerar economia, também gera lucro.

Figura 7 - Utilização da madeira

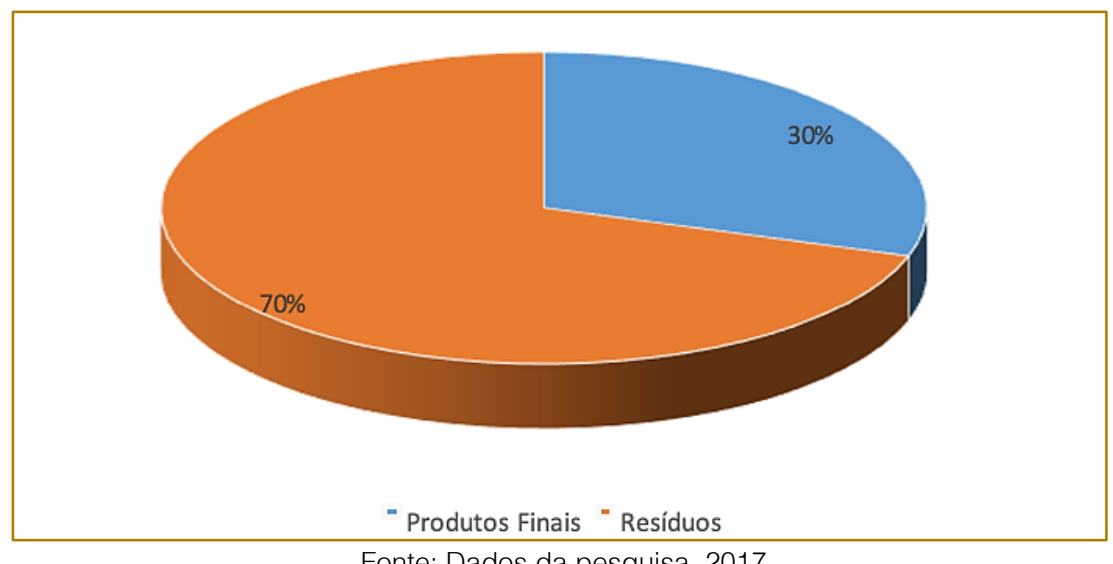

Fonte: Dados da pesquisa, 2017

De acordo com UNFCCC (s.d) a serragem e o Cavaco de madeira era um problema para a organização Mil Madeireira e para o município de Itacoatiara. Em 1997 o IPAM exigiu que a Mil Madeireiras LTDA deixasse de queimar os resíduos de madeira. Desde então a companhia começou a armazenar os resíduos de madeira em pilhas, isso gerou a acumulação de 110.000 toneladas de resíduos de madeira o que resulta em um problema ambiental e de segurança.

Para a solução destes problemas foi criada a BK Energia Itacoatiara LTDA para utilizar os resíduos certificados pela FSC - Forest Stewardship Council (uma organização não governamental internacional, fundada em 1993 para apoiar manejo ecologicamente, socialmente e economicamente sustentável da floresta) gerados pela Mil Madeireira, contribuindo para eliminar as grandes pilhas de resíduos deixados a deterioração, para a substituição da geração elétrica a diesel colaborando para a sustentabilidade ambiental e para o desenvolvimento econômico local, beneficiando a prefeitura com a redução de custos na importação de diesel e de eletricidade de outras regiões.

Figura 8 - Fluxo do processo de destinação dos resíduos

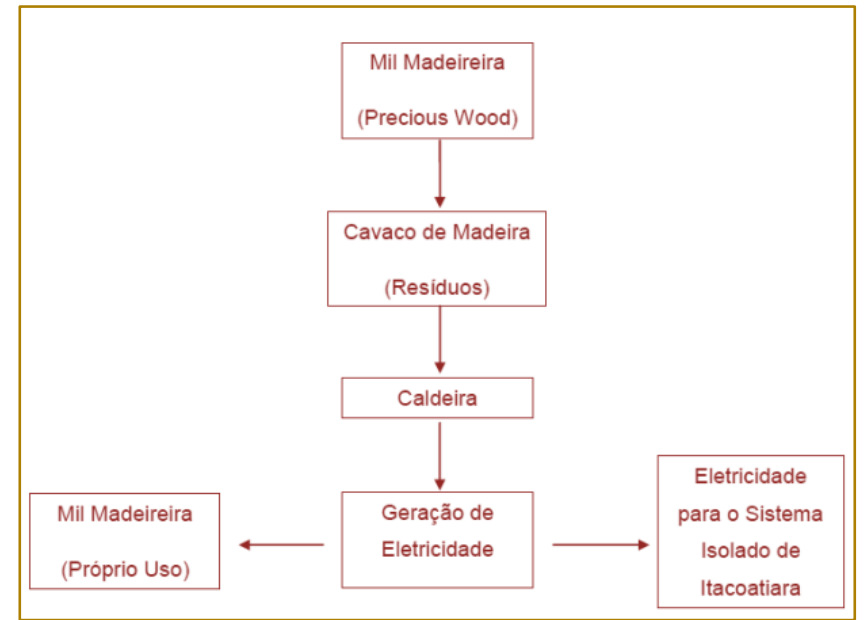

Elaborado pelos autores (2017) 
Os resultados encontrados no presente estudo sugerem que a organização Mil Madeiras Precious Woods apesar de ter um bom encaminhamento dos seus resíduos tem dificuldades de encontrar parcerias locais que podem trabalhar com o mesmo, consequentemente a organização terceirizada que tomam responsabilidade de adquirir os resíduos precisam vir de outra cidade (Manaus).

Com isso, observa-se que a empresa possui maiores despesas para o gerenciamento de resíduos, e que a criação de empresas voltadas para o sistema de gestão ambiental possibilita o melhor gerenciamento de resíduos.

Notou-se que os resíduos são acomodados de forma adequada mas poderia haver melhorias na estrutura do mesmo.

\section{CONCLUSÃO}

O objetivo desta pesquisa foi verificar e analisar o gerenciamento de resíduos sólidos no setor madeireiro. A indústria madeireira é um importante segmento que gera empregos, rendas e divisas nos países que fazem uso de tal recurso.

\section{REFERÊNCIAS}

[1]. ABNT. NBR10520: informação e documentação: citação em documentos. Rio de

[2]. ABNT. NBR6023: informação e documentação: elaboração: referências. Rio de

[3]. ASSUMPÇÃO, R, V. Floresta plantada como fonte de energia e matéria prima para a indústria química. Brasil Madeira, São Paulo, SP. 1978.

[4]. BRASIL, B. at al. Introdução a Engenharia ambiental. São Paulo: Prentice Hall, 2002)

[5]. BRASIL. Câmara dos Deputados. Comissão Especial - PL 203/91 - Política Nacional de Resíduos. Audiência Pública n. 0452/06. Debate sobre a política nacional de resíduos. 2006.

[6]. BRASIL. Lei no 12.2892, de 2 de agosto de 2010. Altera a Lei no 9 de 12 de fevereiro de 1998; e dá outras providencias; e legislação correlatada. 3 ed. Brasília: câmara dos deputados.2010.

[7]. DIAS, Jefferson Aparecido: Os Resíduos Sólidos e a Responsabilidade Ambiental. Cachoeira do caracol. Rio Grande do Sul, RS. 2006.

[8]. FOEKEL, Celso. Resíduos sólidos industriais da produção de celulose kraft de
Lança produtos que auxiliam em outras atividades, como na construção civil, e é uma atividade cuja matéria-prima é retirada de florestas, de modo que, quando não realizada de maneira consciente, é altamente predatória, gerando inúmeros problemas ambientais e sociais.

Porém com uso de políticas que ajudem a reduzir esses danos causados pela indústria da madeira no meio ambiente, tornando-se uma forma de amenizar o mínimo possível os danos causados por esse tipo de exploração. Um bom sistema de gerenciamento de resíduos, de acordo com o estudo de caso realizado neste trabalho mostra-se uma ferramenta essencial para o melhor aproveitamento do recurso, o controle e destinação de resíduos. O que gera maior valor agregado ao "produto" e a marca da organização fica é bem vista aos olhos do consumidor. Conclui - se que a organização tem uma adequada destinação dos resíduos sólidos se tornando referência para as empresas locais afim de se ter um desenvolvimento econômico sustentável do município.

eucalipto, Parte 01: Resíduos orgânicos fibrosos. 2007.

[9]. Fontes PJP. Autossuficiência Energética em Serraria de Pinus e Aproveitamento dos Resíduos [dissertação]. Curitiba: Universidade Federal do Paraná; 1994.

[10]. JACOBI, Pedro R. Desafios e reflexões sobre resíduos sólidos nas cidades brasileiras. In: SANTOS, M. C. L; DIAS, S.L.F. (orgs.) Resíduos sólidos urbanos e seus impactos socioambientais. São Paulo: IEE-USP, 2012. Janeiro, 2002. 24 p. Janeiro, 2002. $7 \mathrm{p}$

[11]. Manual de Gerenciamento Integrado de resíduos sólidos / José Henrique Penido Monteiro. [et al.]; coordenação técnica Victor Zular Zveibil. Rio de Janeiro: IBAM, 2001.

[12]. MONTEIRO, J.H.P, et al. Manual de Gerenciamento Integrado de Resíduos Sólidos. Rio de Janeiro. IBAM. 2001

[13]. NAIME, R.; SARTOR, I.; HULAKOWSKI, M.; GARCIA, A. C. Gestão dos resíduos sólidos na indústria madeireira, v. 13. 2013.

[14]. NETTO, J. Pó de serra substitui a lenha. Diário do Pará. Belém, 2002. Cidades. 
[15]. PAULINO JÚNIOR, José: Gestão de Resíduos Sólidos numa perspectiva educacional: estudo de caso no condomínio residencial. Universidade Federal do Amazonas, 2009.

[16]. PHILIPPI JR, Arlindo: Saneamento, saúde e ambiente: fundamentos para um desenvolvimento sustentável. Manole. Barueri, SP. 2005

[17]. REBOLLO, Mário Guilherme. Contabilidade como geradora de informações sobre o meio ambiente; Revista Pensar contábil, anoll, no 09, agosto/outubro de 2000.

[18]. REVISTA MEIO AMBIENTE INDUSTRIAL, março/abril de 2010.

[19]. RUPPENTHAL, Janis Elisa: Gestão Ambiental. Universidade Federal de Santa Maria. Rio Grande do Sul. 2014
[20]. SANTA RITA.L.P, Braga apud SPRAGIA, P. R. Aglomerados produtivos: acordos de cooperação e alianças estratégicas como condicionantes para 0 ingresso de pme's moveleiras em um processo de desenvolvimento sustentado. Faculdade de Economia, Administração e contabilidade da Universidade de São Paulo, 2003

[21]. SANTOS, Maria Cristina: Lixo: curiosidades e conceitos. Universidade Federal do Amazonas. Manaus, AM. 2002.

[22]. SÜFFERT, R. L; BAJAY, S. V; LIMA, C. R. Energia, sociedade e desenvolvimento florestas plantadas no Rio Grande do Sul. Energias renováveis. 2007. 


\section{Capítulo 17}

\section{REUTilizAÇÃo de RECIClados nO PROCESSO de INJEÇÃO}

\section{Fabiano Santos Ribeiro}

Deivid Henrique Borges

João Vicente Lucio Batista

\section{Acácio Ponciano Rodrigues}

Resumo: As últimas décadas testemunharam um aumento significativo na população mundial. Isso causou um aumento considerável na demanda por condições de vida de baixo custo, o que em parte leva a um aumento dramático no consumo de plásticos. Nos últimos anos, o foco da reciclagem de plásticos mudou. Mais cedo, o foco estava em educar e encorajar o público e a indústria a reciclar. A questão então se voltou para como coletar esse material e convertê-lo em uma matéria-prima comercializável. Portanto, é desejável encontrar usos para o material plástico reciclado que possa ser justificado por ter um custo similar à solução alternativa de um material virgem. Nesse estudo, como resultado da experimentação sistemática, usando experimentos de mistura, a qualidade dos produtos de plástico reciclado pode ser melhorada e se torna mais robusta às variações nas configurações operacionais ideais. Os resultados provaram que o fabricante pode usar essas configurações de POM reciclado e POM virgem para produzir produtos de qualidade com baixo custo (a qualidade depende da fonte, pois algumas qualidades de conteúdo reciclado podem ser muito altas) e a redução do impacto ambiental.

Palavras-chave: Recuperação de residuos, Reciclagem de Poliacetal, Injeção de polimeros, Reciclagem de polímeros 


\section{INTRODUÇÃO}

As últimas décadas testemunharam um aumento significativo na população mundial. Isso causou um aumento considerável na demanda por condições de vida de baixo custo, o que em parte leva a um aumento dramático no consumo de plásticos. Estatísticas anteriores mostram que a produção anual mundial de plásticos é superior a 100 milhões de toneladas por ano. Existem aproximadamente 3 milhões de toneladas de resíduos plásticos produzidos, dos quais as agências ambientais reportam cerca de $80 \%$, atingindo aterros sanitários. A solução prática é reciclar ou reutilizar o plástico que já foi produzido. De fato, a reciclagem de plástico tem muitas vantagens (HILLIG et al, 2016):

a) proporcionar emprego;

b) proteger os recursos naturais;

c) reduzir ou impedir a quantidade de resíduos depositados em aterros;

d) reduzir os custos envolvidos na eliminação de resíduos, o que, em última análise, leva à economia para a comunidade;

e) reduzir a poluição;

f) usa um recurso que seria desperdiçado.

Nos últimos anos, o foco da reciclagem de plásticos mudou. Mais cedo, o foco estava em educar e encorajar o público e a indústria a reciclar. À medida que a necessidade e os incentivos para reduzir o volume de materiais residuais que entram em nossos aterros afundaram nas mentes da população, as forças do mercado tornaram-se de tal forma que milhões de libras de resíduos plásticos destinados ao aterro agora tinham algum valor. A questão então se voltou para como coletar esse material e convertê-lo em uma matéria-prima comercializável.

As economias determinam que os materiais reciclados são as resinas de engenharia mais caras, como policarbonato, nylon e POM. Em alguns casos, o custo dos materiais recicláveis também excede 0 custo das matérias-primas devido aos custos de processamento e transporte. Nos Estados Unidos, a recuperação de plásticos pósconsumo para 2009 foi de aproximadamente 7\% (CLEMONS, 2014). Portanto, é desejável encontrar usos para o material plástico reciclado que possa ser justificado por ter um custo similar à solução alternativa de um material virgem.

\section{REFERENCIAL TEÓRICO}

\subsection{PLÁSTICOS}

Os plásticos que podem ser reciclados são chamados polímeros termoplásticos. Alguns exemplos típicos de polímeros termoplásticos são o tereftalato de poliacetal (POM), polipropileno, polietileno, policarbonato, etc. A seleção de materiais plásticos para muitos materiais (plásticos, metais, etc.) pode ser um processo altamente complexo se não utilizado adequadamente quando se usa plásticos reciclados. Sua metodologia varia de um alto grau de intuição subjetiva em algumas áreas até um alto grau de sofisticação em outras.

Ao selecionar um aditivo para uma mistura, é importante levar em conta também os potenciais efeitos colaterais que ele pode ter em outras propriedades. Em alguns casos, o custo do sistema será reduzido, mas em uma penalidade em outras direções, como propriedades mecânicas que podem influenciar o desempenho do produto fabricado. Qualquer tentativa de comparar plástico misturado com outros materiais convencionais (metal, madeira, vidro, etc.) em uma propriedade reta para propriedade ou uma base direta de custo por custo está condenada ao fracasso desde o início. Existem muitos tipos diferentes de notas e formulações agrupadas sob o título geral de plástico misto (CLEMONS, 2014).

\subsection{PLÁSTICOS POM}

As excelentes características técnicas dos poliacetais ou polioximetilenos (POM) e sua facilidade de transformação deram-lhes um campo bem diversificado de aplicações técnicas. Sua transformação experimentou nos últimos anos um dos crescimentos mais regulares de todos os polímeros técnicos.

Poliacetais ou polioximetilenos, mais conhecidos como POM, possuem características técnicas excelentes e são fáceis de transformar. Por este motivo, são apreciados pela indústria como polímeros técnicos. Um fator adicional favorável é a capacidade de POM para reciclagem química, por clivagem de monómeros, sem perda de propriedades físico-químicas, e que representa um atributo adicional para 
aplicações que têm de ter em conta a economia de reciclagem (HILLIG et al, 2016).

\subsection{HOMOPOLIIMEROS E COPOLIIMEROS}

Homopolímeros de acetal (por exemplo, Delrin) são formados durante a polimerização do formaldeído. Devido ao denso aglomerado de cadeias moleculares alternativas, construídas com grupos de oxigênio e metileno, elas são altamente cristalinas e estão entre os termoplásticos não reforçados mais rígidos e resistentes.

Os copolímeros de acetal (Hostaform, Duraform) são resistentes aos álcalis e ainda mais resistentes à água quente. Isto foi conseguido por um processo de polimerização modificado, em que o monómero principal o trímero cíclico de formaldeído (trioxano) e estrutura "acetal" é interrompida por ligações -CC- cadeia de carbono estável e termina com grupos terminais $\mathrm{HO}-\mathrm{CH} 2-\mathrm{CH} 2$. Há uma ligeira redução no grau de cristalização em relação ao homopolímero, que afeta a resistência mecânica e a dureza (CARASCHI et al, 2015).

\subsection{MOLDAGEM POR INJEÇÃO}

O termo Moldagem por Injeção é uma descrição super simplificada de um processo bastante complicado que é controlável dentro dos limites especificados. Material plástico derretido ou plastificado é injetado à força em uma cavidade do molde. O processo é um dos métodos mais econômicos para a produção em massa de produtos simples e complexos (HILLIG et al, 2016).

Existem três operações básicas. São as únicas operações nas quais as entradas mecânicas e térmicas do equipamento de injeção devem ser coordenadas com as propriedades fundamentais de comportamento do plástico que está sendo processado. Eles são o aquecimento do plástico para moldar a temperatura, injetá-lo e depois resfriar (ou solidificar) o produto no molde. A programação de diferentes velocidades e pressões de injeção durante o deslocamento para a frente do parafuso ou do êmbolo ajuda muito a preencher corretamente as cavidades (SILVA, 2015).

A tonelagem de fixação de uma máquina deve ter força de bloqueio suficiente para não causar a divisão das metades de retenção; ela resiste à força do plástico derretido se movendo em altas pressões para as metades do molde.

\subsection{SUSTENTABILIDADE DE PROCESSO}

Deixando de lado as preocupações ambientais, o sucesso ou fracasso econômico da reciclagem de plásticos depende de duas variáveis: o custo das matérias-primas usadas para fazer plástico virgem, petróleo e gás natural e o custo da reciclagem versus o custo do descarte, que flutua com base a proximidade de uma cidade a centros de reciclagem e o preço para despejar em aterros sanitários locais. No entanto, o custo de reciclar uma garrafa versus fazer uma nova simplesmente varia, dependendo de onde a garrafa está e qual o preço imprevisível do óleo (CANEVAROLO, 2014).

Descobriu-se que um fabricante de peças moldadas por injeção que usava sua própria mistura de resina reciclada foi realmente incrivelmente bem-sucedido, usando uma metodologia um pouco semelhante a este estudo. A AGS Technology, de Schaumburg, Illinois, reduz o custo das peças moldadas por injeção de plástico que fabrica usando plástico reciclado como matéria-prima. Eles são moldes de injeção certificados ISO/TS 16949 que usam seus plásticos reciclados patenteados para produzir componentes moldados de alta qualidade, principalmente para as indústrias automotiva e de bens duráveis (Ford, Chrysler e Chevrolet). Devido ao custo da matéria-prima reciclada ser substancialmente menor que os materiais virgens, a empresa é capaz de repassar aos seus clientes economias significativas de custo nos componentes moldados resultantes.

A AGS Technology formula sua própria matéria-prima, combinando suas propriedades com as resinas virgens correspondentes e com as especificações do cliente. Os tradicionais compostos plásticos convertem plástico reciclado em matériaprima para aplicações de moldagem por injeção, moendo o plástico reciclado e, em seguida, extrudindo-o em pellets, que é como o conteúdo reciclado pode às vezes exceder o custo do conteúdo virgem. Por outro lado, a AGS Technology molda seu material plástico diretamente e ignora a dispendiosa operação de extrusão / pelotização de uma fonte externa. Muitas vezes, os moldadores que poderiam ter economizado $10 \%$ em custos de matéria-prima usando plásticos reciclados veem essas economias de custo evaporarem- 
se devido aos problemas de fabricação que terão ao processá-las. Quando um moldador executa peças com material virgem, as execuções são consistentes. Mas com material reciclado, há mais variabilidade, portanto, a taxa de desperdício pode subir (CANEVAROLO, 2014).

Esses tipos de coisas teriam incorrido em custos e eliminado qualquer economia potencial. Portanto, é benéfico otimizar as misturas recicladas, reduzindo a variabilidade. A "Plastics News", uma revista especializada, lista o preço recente de pelotas de resina virgem POM entre 103 e 105 centavos por libra-peso, em comparação com apenas 66 a 74 centavos de dólar por libra esterlina para POM recicladas. Por um breve exemplo, podemos dizer que cerca de 250.000 libras de material é usado para um determinado trabalho por ano, e usa uma mistura arbitrária 50-50. O diferencial de custo entre o material reciclado e a resina virgem correspondente é de US \$ 0,34 por libra-peso (CLEMONS, 2014).

\section{METODOLOGIA}

Para o referido trabalho, a metodologia adotada foi a pesquisa-ação em engenharia de produção, com as fases de planejamento (revisão literária, relevância do projeto e delimitação da pergunta problema), seguidos da coleta e análise de dados, implementação da ação e emissão de relatórios. Bryman (1989) acrescenta que a pesquisa-ação é uma abordagem da pesquisa social aplicada na qual o pesquisador e o cliente colaboram no desenvolvimento de um diagnóstico e para a solução de um problema, por meio da qual as descobertas resultantes irão contribuir para a base de conhecimento em um domínio empírico particular.
Na pesquisa-ação, o termo pesquisa se refere a produção do conhecimento e o termo ação se refere a uma modificação intencional de dada realidade. A pesquisa-ação é a produção de conhecimento que guia a prática, com a modificação de uma dada realidade ocorrendo como parte do processo de pesquisa. Neste método de pesquisa, o conhecimento é produzido e a realidade é modificada simultaneamente, cada um ocorrendo devido ao outro (OQUIST, 1978).

No processo de fabricação de artefatos plásticos, transformação da matéria-prima em peças acabadas, produtos reprovados geram sucatas, provenientes de peças reprovadas por qualidade, devido a inúmeras variáveis de processo.

Nas indústrias de injeção de polímeros a realidade não é diferente. Os altos volumes de produção de uma injetora plástica, aliada a modernas técnicas de processamento dos polímeros, não impedem a geração de resíduos via contaminação da matéria-prima (óleos, graxas, pó, umidade ou, ainda, outro tipo de resina), ou por fatores dimensionais.

Outra fonte de desperdício são os canais de injeção, conhecidos popularmente como galho. Elemento fundamental nos moldes sem câmara quente, que é responsável pela distribuição da massa fluida do material do canhão da injetora até as cavidades dos moldes.

Esquema de galho de injeção com suas partes: A) Canal de injeção da bucha; B) Canal de distribuição primário; C) Canal de distribuição secundário; D) Entradas ou pontos de injeção; E) Produto a ser moldado; F) Poço frio. (Harada, 1991).

Figura 01 - Esquema do Canal de Injeção

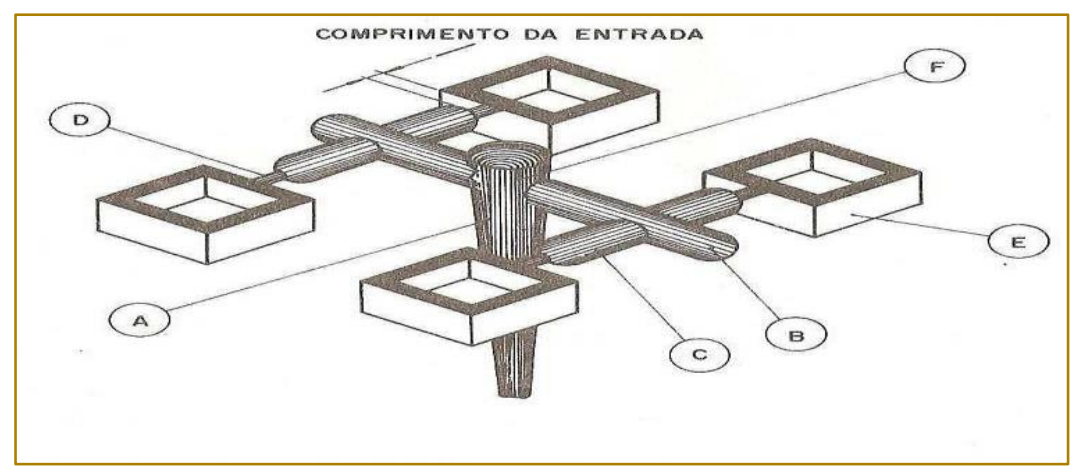

Fonte: Acervo Trauen 
Figura 02 - Exemplo de galho de injeção, onde podemos ver as 6 partes constituintes, conforme figura 01.

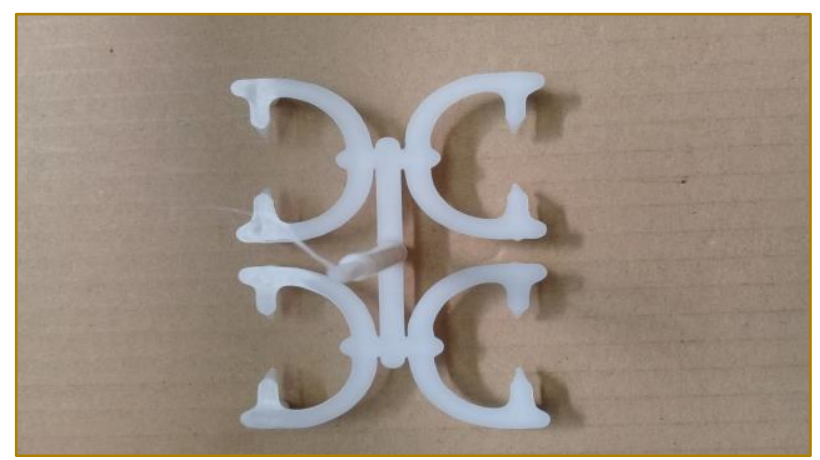

Fonte: Acervo do Autor

Por último, após o set-up de moldes, as primeiras peças injetadas podem apresentar falhas de injeção ou contaminação de qualquer origem. Pode-se ter situações que se injetarão peças fora dos padrões até que se estabilize o processo ou, ainda, que o material se homogeneíze no canhão de injeção.

\subsection{APRESENTAÇÃO DOS DADOS}

Os dados, aqui apresentados, foram obtidos de uma empresa de injeção de termoplástico, situada em Varginha MG, no primeiro trimestre de 2018.

A análise dos dados apresentados na Figura 04 e na Tabela 1, nos dá a ordem de grandeza da geração de material residual, em quilos $(\mathrm{kg})$, onde este número é composto pelo refugo de peças, canais de injeção, etc, de POM.

Figura 03 - Geração de Material Residual Semanal 1ำTrimestre 2018

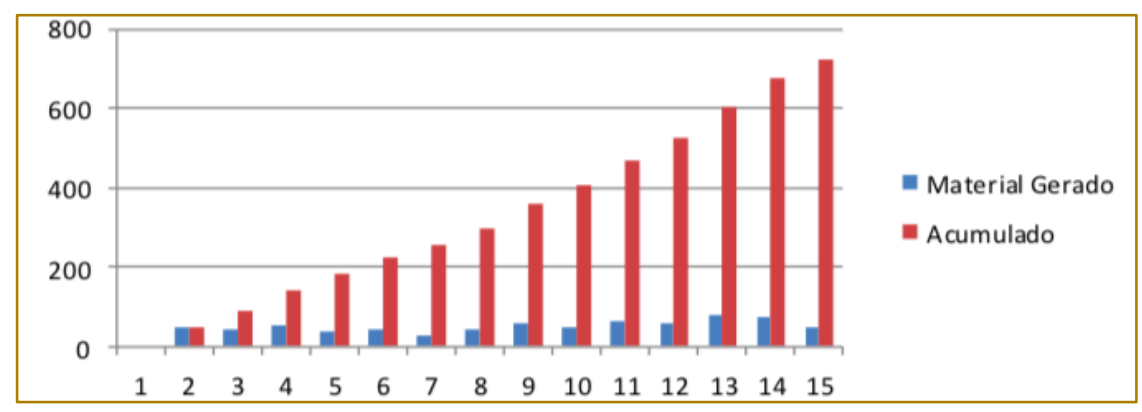

Fonte: Elaborado pelo autor

Tabela 1 - Geração de material residual e o montante acumulado em três meses (kg)

\begin{tabular}{|c|c|c|c|c|c|c|c|c|c|c|c|c|c|c|}
\hline \multicolumn{10}{|c|}{ Janeiro } & \multicolumn{10}{|c|}{ Mevereiro } \\
\hline Semana & 1 & 2 & 3 & 4 & 5 & 6 & 7 & 8 & 9 & 10 & 11 & 12 & 13 & 14 \\
\hline Material Residual Gerado & 50 & 41 & 52 & 39 & 44 & 29 & 44 & 58 & 47 & 62 & 58 & 77 & 75 & 47 \\
\hline Acumulado & 50 & 91 & 143 & 182 & 226 & 255 & 299 & 357 & 404 & 466 & 524 & 601 & 676 & 723 \\
\hline
\end{tabular}

O que se pôde notar da curva semanal da Figura 04 é que a geração de material residual segue de forma constante, tendo pequenos picos nas últimas semanas de cada mês. Essa constância é positiva pelo fato que podemos admitir um consumo constante na produção. 


\subsection{IMPLANTAÇÃO DA CENTRAL DE} RECUPERAÇÃO DE POLÍMEROS

O primeiro passo para a reintegração de resíduos plásticos ao processo produtivo foi ativar a área da moagem. Dessa forma iniciou-se a instalação de uma central de moagem dentro da planta, composta por moinhos de facas, que estavam desativados.

Figura 04 - Área de Moagem

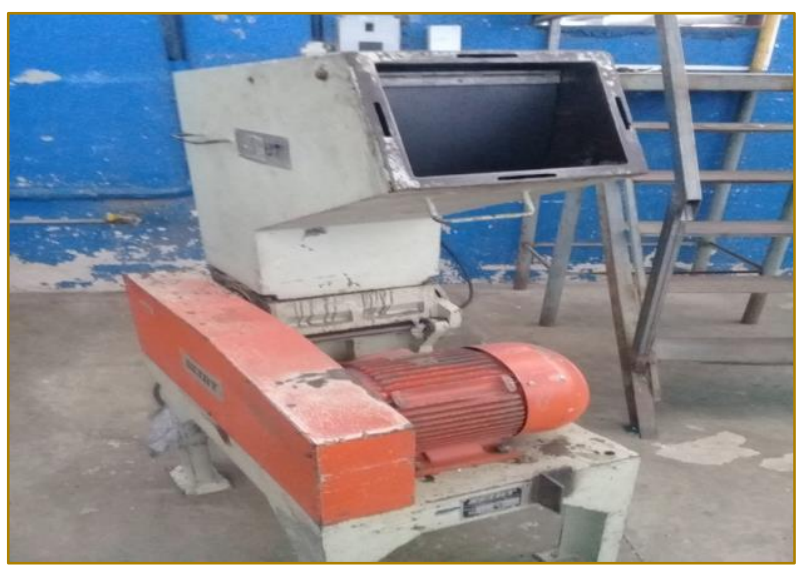

Fonte: Acervo do Autor

Etapa onde é preparada a matéria-prima para ser injetada. É realizada a mistura do material moído com o material virgem. Esta mistura é realizada de forma que os produtos a serem produzidos mantenham os padrões de qualidade exigidos. Os fornecedores da matéria- prima já especificam a quantidade máxima de material moído que deve ser misturado ao polímero virgem, que no caso do POM é de no máximo 30\%.

\subsection{SEPARAÇÃO DO MATERIAL RECICLADO}

Este processo foi implantado, pois quando o canal de injeção era vendido por completo, não se tinha a preocupação em separar os canais. Com o processo de reaproveitamento implantado é de fundamental importância que esta separação seja realizada, onde o custo adicional gerado por esta etapa é o da mão de obra do operador da injetora.

\subsection{QUALIDADE DO RECICLADO}

Este processo foi implantado de modo a verificar a qualidade do canal, onde o operador do moinho realiza uma verificação no canal separado pelo operador e destina o canal com boa qualidade para ser moído e a de má qualidade para ser vendida. O custo adicional gerado por este processo é somente o custo do operador do moinho.

\subsection{PROCESSO DE MOAGEM}

Este processo já era existente, porém estava desativado. Com o processo de reaproveitamento, adequações foram feitas, com posterior treinamento como os operadores. Sendo alocado como custo neste processo, a energia do moinho para trituração e mão-de-obra do operador.

\subsection{PREPARAÇÃO DO MATERIAL}

Este processo era utilizado somente para realizar a mistura de material virgem, onde sofreu adaptação para que fosse utilizado também a mistura entre material virgem e moído (reciclado), que passou a ter $20 \%$ de reciclado no material virgem. O custo gerado por este processo é somente do operador, pois a preparação é manual.

\section{RESULTADO E DISCUSSÕES}

a) Custo atual (utilizando matéria-prima reciclada comprada de terceiro)

- Custo da matéria-prima reciclada no mercado: $\mathrm{R} \$ 5,54 / \mathrm{kg}$;

- Custo logístico (frete): $\mathrm{R} \$ 0,50 / \mathrm{kg}$;

- Consumo médio de MP reciclada utilizado na peça estudada: $220 \mathrm{~kg} / \mathrm{mês}$, temos: 


$$
(220) \times(5,54+0,50)=R \$ 1.328,80 / \text { mês }=R \$ 15.954,60 / \text { ano }
$$

b) Ganho com a venda da sucata plástica

- Preço de venda da sucata plástica: $\mathrm{R} \$ 0,70 / \mathrm{kg}$;
- Geração média de sucata plástica: 250kg/mês:

$$
(250) \times(0,70)=\mathrm{R} \$ 175,00 / \text { mês }
$$

\subsection{VIABILIDADE ECONÔMICA}

\begin{tabular}{|c|c|c|c|c|c|}
\hline Processo & $\begin{array}{l}\text { Custo hora } \\
\text { Operador a }\end{array}$ & $\begin{array}{c}\text { Custo hora } \\
\text { KW b }\end{array}$ & $\begin{array}{c}\text { Consumo } \\
\text { energia Kw/h }\end{array}$ & Horas/Kg & Custo total $\mathrm{R} \Phi$ \\
\hline $\begin{array}{l}\text { Separação do } \\
\text { reciclado }\end{array}$ & $\mathrm{R} \$ 5,14$ & $\mathrm{R} \$ 0,3477$ & 0 & 0,00833 & 0,04282 \\
\hline Qualidade do reciclado & $\mathrm{R} \$ 5,14$ & $\mathrm{R} \$ 0,3477$ & 0 & 0,02 & 0,1028 \\
\hline Processo de moagem & $\mathrm{R} \$ 5,14$ & $\mathrm{R} \$ 0,3477$ & 12,7 & 0,00555 & 0,0536 \\
\hline Preparação do material & $\mathrm{R} \$ 5,14$ & $\mathrm{R} \$ 0,3477$ & 0 & 0,004 & 0,02056 \\
\hline 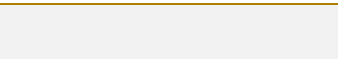 & & & & & 0,021923 \\
\hline \multicolumn{6}{|c|}{$\begin{array}{l}\text { a) Adota-se na Irauen IMG um unico custo hora operador para todos os processos } \\
\text { b) Média diária contando hora de ponta }\end{array}$} \\
\hline \multicolumn{5}{|c|}{$\begin{array}{l}\text { Separação do reciclado } \quad 120 \mathrm{Kg} / \mathrm{h} \\
\text { Qualidade do reciclado50Kg/h } \\
\begin{array}{l}\text { Processo de Moagem } \\
\text { Preparação do material } 250 \mathrm{Kg} / \mathrm{h}\end{array}\end{array}$} & \\
\hline
\end{tabular}

Tabela 2 - Custo do Processo de Reaproveitamento

Fonte: Elaborado pelo autor

Podemos verificar que o custo adicional gerado para realizar o reaproveitamento do canal de injeção fica em torno de $\mathrm{R} \$ 0,22$ por quilograma.

Comparando com o custo de aquisição da matéria-prima reciclado (POM)) que é de $R \$ 5,54$, fica evidenciado que é totalmente viável o processo de reutilização, tendo assim uma redução de custo de $\mathrm{R} \$ 5,32$ por quilograma reaproveitado, lembrando que, o estudo foi feito apenas de um item que utiliza esse material, na empresa existem vários produtos que utiliza a mesma matéria prima, o que futuramente poderá ser adaptado para as demais. 
Figura5 - Comparativa entre reprocessamento e compra de reciclado $1^{\circ}$ trimestre 2018

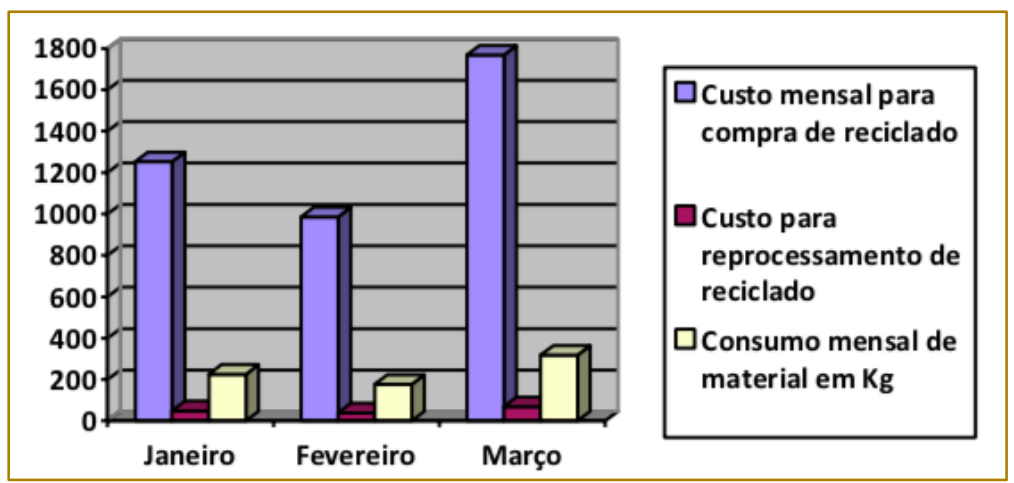

Fonte: Elaborado pelo autor

Tabela 3 - Custos com a compra e reprocessamento

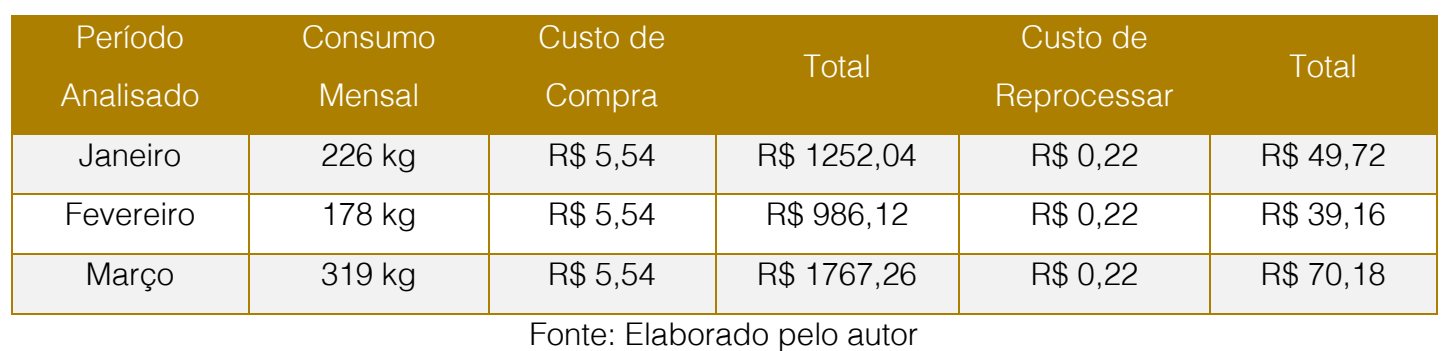

\section{CONCLUSÃO}

A reciclagem de plástico pode reduzir 0 consumo de energia, o uso de combustíveis fósseis não renováveis, bem como as emissões globais de dióxido de carbono. O efeito do POM reciclado e do POM virgem na resistência à tração e rigidez foi estudado. As quantidades ótimas de componentes de mistura para produzir produtos plásticos reciclados são determinadas. Como resultado da experimentação sistemática, usando experimentos de mistura, a qualidade dos produtos de plástico reciclado pode ser melhorada e se torna mais robusta às variações nas configurações operacionais ideais. Os resultados provaram que o fabricante pode usar essas configurações de POM reciclado e POM virgem para produzir

\section{REFERÊNCIAS}

[1] BRYMAN, A. Research methods and organization studies (contemporary social research). 1st ed. London: Routledge, 1989.

[2] CANEVAROLO Jr., S. V. Técnicas de Caracterização de Polímeros, Artliber, São Paulo, 2014. produtos de qualidade com baixo custo (a qualidade depende da fonte, pois algumas qualidades de conteúdo reciclado podem ser muito altas) e a redução do impacto ambiental.

O benefício final vem da descoberta de janelas operacionais que satisfazem todas as especificações do cliente de maneira mais econômica. A justificativa econômica é encabeçada por um designer que deseja otimizar seu material com reduzido impacto ambiental. Este estudo mostra que pode haver usos de resina reciclada fora de sua finalidade inicial, ganhando uma segunda vida como um novo material mecanicamente forte. Se isso for feito, você e sua empresa ganharão uma vantagem competitiva e gerarão grandes lucros.

[3] CARASCHI, J. C., LEÃO, A. L., Avaliação das propriedades mecânicas dos plásticos reciclados provenientes de resíduos sólidos urbanos. Acta Scientiarum Maringá, v. 24, n. 6, pp. 1599-1602, $2015 . \quad$ Disponível em: http://eduemojs.uem.br/ojs/ index.php/ActaSciTechnol/article/view/2462/1553. Acesso em: abril de 2018. 
[4] CLEMONS, C.M., Wood-Plastic Composites in the United States: The Interfacing of Two Industries, Forest Products Journal, pp. 10-18, June. 2014.

[5] CORREA, C. A. et al. Compósitos termoplásticos com madeira, Polímeros - Ciência e Tecnologia, v.13, n.3, pp.154-165, 2013.

[6] HILLIG, E. et. al. Caracterização de compósitos produzidos com polietileno de alta densidade e serragem da indústria moveleira, Revista Árvore, v.32, n.2, pp.299-310, 2016. Disponível em: http://www.scielo.br/pdf/rarv/v32n2/ a13v32n2.pdf. Acesso em abril de 2018.

[7] MONDARDO, F. H. Compósitos de polipropileno e farinha de madeira. Dissertação Instituto de Química, Universidade Federal do Rio
Grande do Sul, Porto Alegre, 2016. Disponível em: http://www.lume.ufrgs.br/handle/10183/27186. Acesso em abril de 2018.

[8] NEWELL, J. Essentials of Modern materials Science and Engineering, Hoboken: John Wiley and Sons Ltd, 2015. Disponível em: http://www.lume.ufrgs.br/bitstream/handle/10183/27 186/000763680.pdf? sequence=1>. Acesso em abril de 2018.

[9] OQUIST, P. The epistemology of action research. Acta Sociologica, v. 21, n. 2, p. 143-163, 1978.

[10] SILVA, C. L. \& MENDES, J. T. G. Reflexões sobre o desenvolvimento sustentável. Agentes e interações sob a ótica multidisciplinar. Editora Vozes. PETRÓPOLIS, 2015. 


\section{Gapítulo 18}

\section{AVALIAÇÃO DE RISCOS AMBIENTAIS NO PROCESSO PRODUTIVO DE UMA MINERADORA NO ESTADO DE SERGIPE}

\section{Celio Lemos Santos Junior}

Gláucia Regina de Oliveira Almeida

Nathalia Stephane Santos Nascimento

Ádria Maria de Castro Vasconcelos

\section{Aline Santos Passos}

Resumo: O presente trabalho realizou um estudo de caso em uma mineração de agregados de produção de britas, onde buscou-se conhecer e avaliar todo o processo produtivo desse material, que vai desde a extração das pedras através de operações de desmontes, até o seu produto final classificado de acordo com a sua granulometria. Foi adotada a metodologia de Análise Preliminar de Riscos (APR) para os reconhecimentos dos riscos e perigos ambientais. A ferramenta classifica o risco de acordo com a sua severidade versus a sua probabilidade de ocorrência, com isso obtêm-se o grau de risco para os eventos detectados. Foram realizadas duas planilhas de APR, uma para mina e a outra para área de britagem, e com os resultados coletados, foram feitas recomendações com o objetivo de reduzir ou eliminar os riscos e perigos encontrados.

Palavras-chave: Mineração, Pedreira, processo produtivo, Análise Preliminar de Riscos, Avaliação de ruído 


\section{INTRODUÇÃO}

O mercado de agregados fornece a matériaprima mineral de maior consumo no mundo sendo necessária para o desenvolvimento dos países, de modo que esses insumos serão utilizados na construção de moradias, manutenção e criação de estradas e infraestrutura urbana. No Brasil, a indústria de agregados apresenta grande expansão e com a melhora na economia espera-se que esse mercado receba grandes investimentos. A produção nacional concentra-se principalmente no beneficiamento das rochas, onde são encontradas as mineradoras a céu aberto, amplamente conhecidas como pedreiras.

No processo produtivo da pedra britada, observa-se que os trabalhadores estão expostos a uma série de riscos que podem comprometer a segurança e trazer sérios danos à saúde do trabalhador. Dentre os quais destacam-se os riscos físicos, químicos, biológicos conforme estabelece a Norma Regulamentadora NR 9 - Programa de Prevenção de Riscos Ambientais, além dos ergonômicos e os riscos de acidentes.

Não gerenciar os riscos pode acarretar em ficar suscetível a ocorrência destes, e as suas consequências podem trazer sérios prejuízos, sejam eles, a perda de produtividade, multas dos órgãos competentes, afastamentos, e até mesmo a morte de funcionários. Monitorar os riscos com base na legislação é a melhor forma de prevenir eventos indesejados.

O presente trabalho teve por finalidade a realização de uma avaliação de riscos ambientais no processo produtivo de uma pedreira, localizada no estado de Sergipe. Foi realizado reconhecimento dos riscos e condições perigosas encontradas no processo produtivo, realizou-se avaliações quantitativas e qualitativas dos resultados encontrados. Com o material coletado, comparou-se os dados obtidos com os valores especificados pelas normas regulamentadoras, com o intuito de propor melhorias para neutralização dos riscos e perigos associados aos trabalhadores no ambiente de trabalho na pedreira.

\section{FUNDAMENTAÇÃO TEÓRICA}

\subsection{RISCOS AMBIENTAIS}

De acordo com Sanders e McCormick (1993), risco é a possibilidade ou chance de levar a obtido ou causar lesão, já o perigo é uma causa ou conjunto delas, que tem a capacidade de ocasionar ou contribuir para levar a obtido ou causar lesão.

O risco estará presente em qualquer atividade exercida pelo ser humano, ao passo que qualquer ato realizado envolve um certo grau de incerteza. Segundo Ruppenthal (2013), o Gerenciamento de Riscos teve início nas indústrias após a segunda guerra mundial, oriundo ao rápido desenvolvimento das fábricas e consequentemente o aumento nos riscos associados. Sendo assim, ficou evidente a necessidade de garantir a proteção das empresas quanto aos riscos de acidentes.

Gerenciamento de Riscos "é a ciência, a arte e a função que visa à proteção dos recursos humanos, materiais, ambientais e financeiros de uma empresa, que através da eliminação ou redução de seus riscos" (DE CICCO e FANTAZZINI, 2003).

De acordo com Catai (2012), o processo de gerenciamento de risco define-se uma sequência de medidas e ações, estágios a serem executados como mostrado na figura 1

Figura 1 - Fluxograma de processos de gerenciamento de riscos

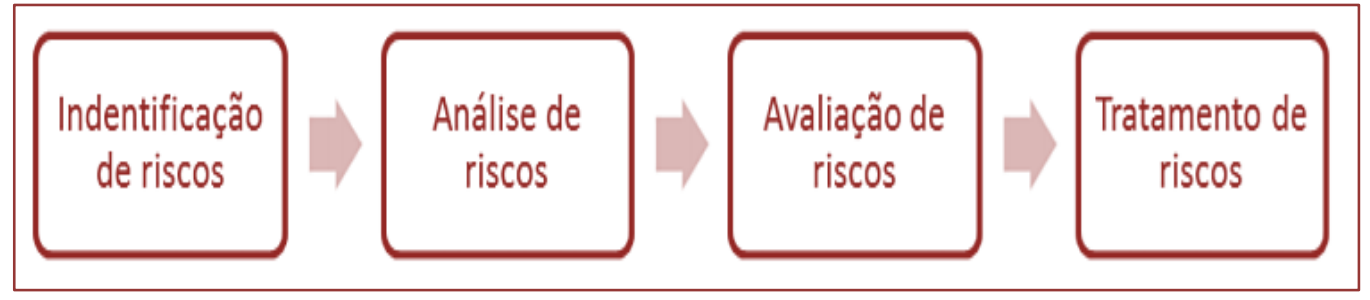

Fonte: CATAI (2012) 


\subsubsection{ANÁLISE PRELIMINAR DE RISCO}

Segundo Sella (2014), a análise preliminar de risco (APR) é uma metodologia empregada para identificação de riscos e eventos indesejados, as causas para a sua ocorrência, o modo como foi constatado, e as medidas de proteção para a neutralização.

A figura 2, mostra em ordem de execução as etapas que deverão ser seguidas para a elaboração e o desenvolvimento de uma análise preliminar de risco.

Figura 2 - Sequência de etapas para o desenvolvimento da APR

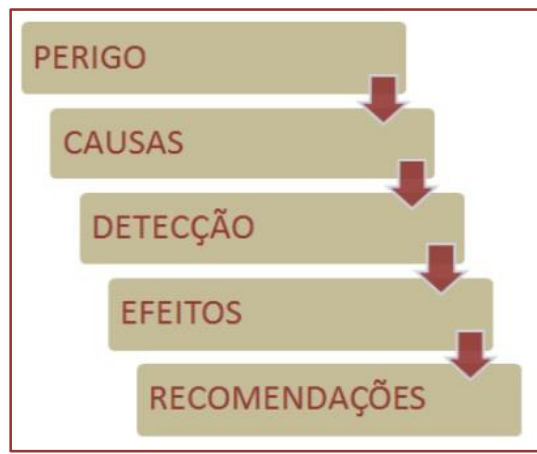

Fonte: SELLA (2014)

\subsection{RISCOS FÍSICOS}

A NR 9 define como agentes físicos as diversas formas de energia a que possam estar expostos os trabalhadores, tais como: ruído, vibrações, pressões anormais, temperaturas extremas, radiações ionizantes, radiações não ionizantes, bem como infrassom e ultrassom. Caracterizam-se por agir sobre pessoas que estão ou não estão em contato direto com fonte geradora, necessitam de um meio de transmissão para espalhar os efeitos nocivos, provocam em geral lesões crônicas (MATTOS e MÁSCULO, 2011).

O quadro 1 expõe a classificação dos riscos físicos e as suas consequências para os trabalhadores que se encontra expostos. Dentre os quais estão presentes em pedreiras ruído, calor, vibrações e radiações não ionizantes.

Quadro 1 - Riscos físicos e suas consequências

\begin{tabular}{|c|c|}
\hline Riscos Físicos & Consequências \\
\hline Ruído & $\begin{array}{l}\text { Cansaço, irritação, dores de cabeça, diminuição da audição, } \\
\text { aumento da pressão arterial, problemas do aparelho digestivo, } \\
\text { taquicardia e perigo de infarto. }\end{array}$ \\
\hline Vibrações & $\begin{array}{l}\text { Cansaço, irritação, dores nos membros, dores na coluna, } \\
\text { doença do movimento, artrite, problemas digestivos, lesões. }\end{array}$ \\
\hline Calor & $\begin{array}{l}\text { Taquicardia, aumento de pulsação, cansaço, irritação, prostração } \\
\text { térmica, choque térmico, fadiga térmica, perturbações das } \\
\text { funções digestivas, hipertensão, etc. }\end{array}$ \\
\hline Radiações ionizantes & $\begin{array}{l}\text { Alterações celulares, câncer, fadiga, problemas visuais, } \\
\text { acidentes de trabalho. }\end{array}$ \\
\hline Radiações não ionizantes & Queimaduras, lesões nos olhos, na pele e nos outros órgãos. \\
\hline Umidade & $\begin{array}{c}\text { Doenças do aparelho respiratório, quedas, doenças na pele, } \\
\text { doenças circulatórias. }\end{array}$ \\
\hline Frio & $\begin{array}{l}\text { Fenômenos vasculares periféricos, doenças respiratórias, } \\
\text { queimaduras pelo frio. }\end{array}$ \\
\hline Pressões anormais & $\begin{array}{l}\text { Hiperbarismo - Intoxicação por gases; } \\
\text { Hipobarismo - Mal das montanhas. }\end{array}$ \\
\hline
\end{tabular}

Fonte: FIOCRUZ (2014) 


\subsubsection{CALOR}

O Anexo III da NR 15, define os limites para exposição ao calor fazendo-se o uso do Índice de Bulbo Úmido Termômetro de Globo
- IBUTG, definidos pela equação 1 e equação 2 (BRASIL, 2017).

Para ambientes internos ou externos sem carga solar:

$$
I B U T G=0,7 T b n+0,3 T g \quad \text { (Equação 1) }
$$

Onde:

IBUTG = Índice Bulbo Úmido Termômetro de Globo.

Tbn = Temperatura de bulbo úmido natural, mede a temperatura por condução;

$\mathrm{Tg}=$ Temperatura de globo, mede a temperatura média de radiação.

Para ambientes externos com carga solar:

$$
I B U T G=0,7 T b n+0,1 T b s+0,2 T g \quad \text { (Equação 2) }
$$

Onde:

IBUTG = Índice Bulbo Úmido Termômetro de Globo;

Tbn = Temperatura de bulbo úmido natural, mede a temperatura por condução;

$\mathrm{Tg}$ = Temperatura de globo, mede a temperatura média de radiação;

Tbs = Temperatura de bulbo seco, mede a temperatura por convecção.

O quadro 2 expõe os limites de tolerância para a exposição ao calor, em regime de trabalho intermitente com períodos de descanso fora do local de trabalho (BRASIL, 2017).

Quadro 2: Limites de tolerância para a exposição ao calor

\begin{tabular}{|c|c|}
\hline M (Kcal/h) & MÁXIMO IBUTG \\
\hline 175 & 30,5 \\
200 & 30,0 \\
250 & 28,5 \\
300 & 27,5 \\
350 & 26,5 \\
400 & 26,0 \\
450 & 25,5 \\
500 & 25,0 \\
\hline
\end{tabular}

Fonte: NR 15 - Anexo 3 (BRASIL, 2017)

Onde $\mathrm{M}$ expressa a taxa de metabolismo média ponderada, para uma hora de realização da atividade, a equação 3 mostra como é efetuado os cálculos.

$$
M=\frac{(M t * T d+M d * T d)}{60}
$$


Onde:

$\mathrm{M}=$ Taxa de metabolismo média ponderada para uma hora;

Mt = Taxa de metabolismo no local de trabalho;

Md = Taxa de metabolismo no local de descanso;

$\mathrm{Td}=$ Soma dos tempos, em minutos, em que permanece, no local de descanso.

\subsection{RISCOS QUÍMICOS}

Os agentes químicos são substâncias, compostos ou produtos que possam penetrar no organismo pelas vias respiratórias na forma de poeira, fumos, névoas, neblinas, gases ou vapores ou que, pela natureza da atividade e exposição possam ter contato ou ser absorvidos pelo organismo através da pele ou por ingestão (SEBRAE/ES, 2012).

Em pedreiras a presença do agente químico acontece sobre a forma de poeira.

\subsection{RISCOS BIOLÓGICOS}

De acordo com Gomes e Oliveira (2012), os agentes biológicos são os fungos, as bactérias, parasitas, bacilos, vírus, protozoários, entre outros. As formas de contatos dos agentes biológicos podem ser através da ingestão de alimentos infectados, por vias respiratórias, quando o ambiente de trabalho apresenta contaminação no ar e por meio da pele, onde o contágio se dá através cortes e feridas.

\subsection{RISCOS ERGONÔMICOS}

Segundo Martins Neto (2012), postura imprópria, controle severo de produtividade, excesso de esforço físico, exigência de ritmos em demasia, jornadas estendidas de trabalho, trabalho noturno e em regime de turno, trabalhos repetitivos e monótonos, transporte de pesos manualmente e levantamento, dentre outras ocorrências onde se faz presente o stress psíquico e/ou físico, são apontados como os principais fatores ergonômicos.

\subsection{RISCOS MECÂNICOS}

Segundo Peixoto (2010), os agentes mecânicos caracterizam por gerar riscos através do contato físico direto com a vítima. São causadores de inúmeras lesões nos trabalhadores como arranhões, queimaduras, ferimentos, fraturas. Ausência de proteção em maquinários, probabilidade de incêndio, materiais mal empilhados, pisos sem aderência ou que apresentem defeitos são exemplos de agentes.

\section{METODOLOGIA}

O método de estudo abordado se deu através da realização de um estudo de caso em uma pedreira localizada no estado de Sergipe, que se encontra em pleno funcionamento. Foram realizadas visitas a mineradora para a observação e análise do processo produtivo e conversas informais com os trabalhadores para a coleta de dados. A partir das informações e dados coletados foi realizado uma APR - Análise Preliminar de Riscos, com o intuito de reconhecer os perigos e riscos encontrados na produção, classifica-los de acordo com a probabilidade e severidade, comparar com a legislação e fazer recomendações sempre que possíveis.

\subsection{ANÁLISE QUANTITATIVA DE RISCOS}

Os dados coletados na mineradora foram estruturados e organizados para a criação da planilha de análise preliminar de riscos.

Após a coleta dos dados, eles foram registrados na planilha de análise preliminar de riscos, de acordo com o quadro 3. 
Quadro 3 - Planilha de análise preliminar de riscos

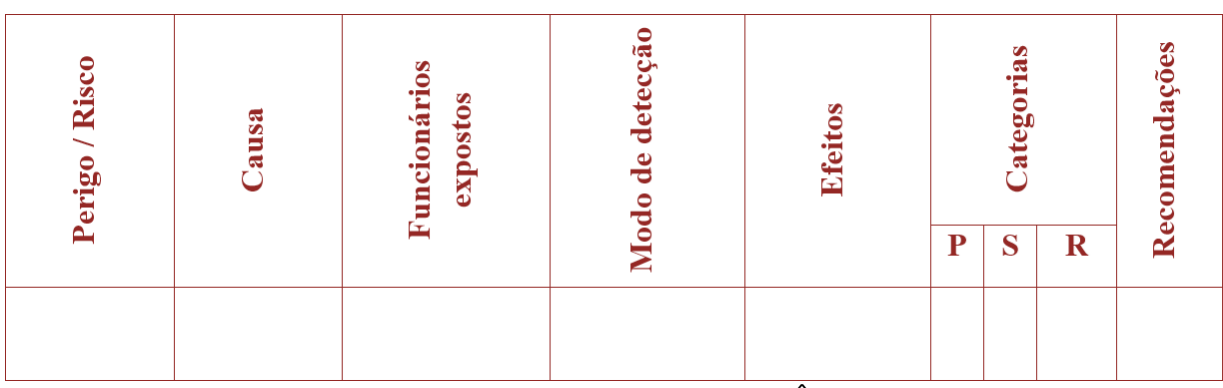

Fonte: Adaptado de VIANA, ALVES, JERÔNIMO (2014)

Foram realizadas duas planilhas para a análise preliminar de risco, uma para detecção dos riscos encontrados na mina da pedreira e outra para a área de britagem.

A elaboração da planilha consiste na identificação dos riscos/perigos, as causas para o problema encontrado, a identificação dos funcionários expostos, a probabilidade do evento ocorrer (quadro 4), a severidade das consequências do evento (quadro 5), o risco classificado de acordo com o seu grau (quadro 7) e as recomendações com o intuito de minimizar ou neutralizar os riscos encontrados nos processos.

A escala de probabilidade da ocorrência do dano é feita atribuindo-se um índice de probabilidade $P$ variando de $A$ a $D$, cujo significado encontra-se relacionado no quadro 4 (AMORIM, 2010).

Quadro 4: Probabilidade de ocorrência do evento.

\begin{tabular}{|c|c|l|}
\hline \multicolumn{3}{|c|}{ P = Probabilidade de ocorrência de evento } \\
\hline Categoria & Denominação & \multicolumn{1}{c|}{ Descrição } \\
\hline A & Frequente & $\begin{array}{l}\text { Esperado ocorrer com frequência durante a vida útil } \\
\text { da instalação. }\end{array}$ \\
\hline B & Provável & $\begin{array}{l}\text { Esperado ocorrer pelo menos uma vez durante a vida } \\
\text { útil da instalação. }\end{array}$ \\
\hline C & Remota & $\begin{array}{l}\text { Pouco provável de ocorrer durante a vida útil da } \\
\text { instalação. }\end{array}$ \\
\hline D & Extremamente Remota & $\begin{array}{l}\text { Conceitualmente possível, mas não é esperado } \\
\text { ocorrer. }\end{array}$ \\
\hline
\end{tabular}

Fonte: Adaptado de AMORIM (2010)

Para classificação da severidade da consequência do evento foi utilizado o quadro 5 (MORGADO, 2000). O quadro distribui em categorias e classifica as severidades de acordo com os riscos e perigos e as suas consequências para os trabalhadores ou para as instalações da empresa. 
Quadro 5: Classificação da severidade da consequência do evento.

\begin{tabular}{|c|c|c|}
\hline \multicolumn{2}{|c|}{ S = Severidade das consequências do evento } \\
\hline Gategoria & Nome & Característica \\
\hline I & Catastrófica & $\begin{array}{c}\text { Mortes ou lesões incapacitantes ao trabalhador. } \\
\text { - Perda total de instalações e equipamentos; }\end{array}$ \\
\hline II & Crítica & $\begin{array}{c}\text { Lesões severas ou incapacitante com possibilidade de } \\
\text { agravamento; }\end{array}$ \\
\hline III & Marginal & $\begin{array}{c}\bullet \text { Danos severos a instalações e equipamentos; } \\
\bullet \text { Danos moderados a instalações; }\end{array}$ \\
\hline IV & Desprezivel & $\begin{array}{c}\text { - Ausência de lesões, o máximo que pode ocorrer são } \\
\text { casos de primeiros socorros ou tratamento médico menor; } \\
\text { Sem danos ou danos não significativos a instalações e } \\
\text { equipamentos. }\end{array}$ \\
\hline
\end{tabular}

Fonte: MORGADO (2000)

Cruzando as informações das categorias de probabilidade de ocorrência com severidade de consequência, forma-se a matriz de classificação dos riscos (quadro 6) onde os resultados obtidos informam o grau de risco de acordo com uma escala de cor que varia para cada resultado encontrado, para cada cor existe uma classificação para o risco, que vai variar de desprezível até crítico.

Quadro 6: Matriz de classificação dos riscos

\begin{tabular}{|c|c|c|c|c|c|c|c|}
\hline & & & & & & \multicolumn{2}{|c|}{ Legenda } \\
\hline \multicolumn{6}{|c|}{$\mathrm{P}=$ Probabilidade } & \multicolumn{2}{|c|}{ Risco } \\
\hline \multirow{5}{*}{ 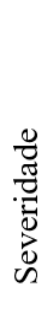 } & & A & $\mathrm{B}$ & $\mathrm{C}$ & $\mathrm{D}$ & 1 & Crítico \\
\hline & I & & & & & 2 & Sério \\
\hline & II & & & & & 3 & Moderado \\
\hline & III & & & & & 4 & Menor \\
\hline & IV & & & & & 5 & Desprezível \\
\hline
\end{tabular}

Fonte: Adaptado de CAMACHO (2005) e AMORIM (2010)

Já o quadro 7 apresenta a classificação por grau de risco e o seu significado, que será utilizado para o preenchimento da planilha de análise preliminar de risco (quadro 3), na coluna categoria, no item $\mathrm{R}$ que avalia o risco/perigo encontrado na pedreira. 
Quadro 7: Classificação por Grau de Risco

\begin{tabular}{|c|c|c|}
\hline $\begin{array}{l}\text { Grau } \\
\text { de } \\
\text { Risco }\end{array}$ & Categoria & Significado \\
\hline 1 & Muito Alto ou Crítico & $\begin{array}{l}\text { Fatores do ambiente ou elementos materiais que } \\
\text { constituem um risco para a saúde e integridade fisica do } \\
\text { trabalhador, com uma probabilidade de acidente ou } \\
\text { doença elevada. }\end{array}$ \\
\hline 2 & Alto ou Sério & $\begin{array}{l}\text { Fatores do ambiente ou elementos materiais que } \\
\text { constituem um risco para a saúde e integridade fisica do } \\
\text { trabalhador, cujo valores ou importâncias estão } \\
\text { notavelmente próximos dos limites regulamentares. }\end{array}$ \\
\hline 3 & Moderado & $\begin{array}{l}\text { Fatores do ambiente ou elementos materiais que } \\
\text { constituem um incomodo podendo ser de baixo risco para } \\
\text { a saúde ou integridade física. }\end{array}$ \\
\hline 4 & Baixo & $\begin{array}{l}\text { Fatores do ambiente ou elementos materiais que } \\
\text { constituem um incômodo sem ser uma fonte de risco para } \\
\text { a saúde ou integridade física. }\end{array}$ \\
\hline 5 & Insignificante & $\begin{array}{l}\text { Fatores do ambiente ou elementos materiais que não } \\
\text { constituem nenhum incômodo e nem risco para a saúde } \\
\text { ou integridade física. }\end{array}$ \\
\hline
\end{tabular}

Fonte: AMORIM (2010)

\subsection{ANÁLISE QUANTITATIVA DE RISCOS}

Para as análises quantitativas dos agentes físicos ruído e calor foram usados equipamentos devidamente calibrados.

Para a avaliação de ruído foi utilizado um dosímetro modelo DOS-500 da Instrutherm (dosímetro pessoal de ruído com RS-232 e Datalogger). $\mathrm{Na}$ avaliação de calor foi utilizado o medidor de stress térmico TGD-200 da Instrutherm. Utilizando-se do "Índice de Bulbo Úmido -Termômetro de Globo" (IBUTG), de acordo com a NR 15 Anexo III - Limites de Tolerância para a Exposição ao calor (BRASIL, 2017).

\section{ANÁLISE DOS RESULTADOS}

O processo de produção de britas na pedreira é descrito através de um fluxograma do sistema produtivo. A figura 3 mostra um esboço do fluxograma do processo produtivo da empresa, desde a fase inicial na mina, com a perfuração das rochas para a inserção dos explosivos, logo após o material ser desmontado tem início as operações de carregamento e transporte do material extraído para a área da britagem, segunda fase, com a alimentação do britador primário, após o primeiro britamento o material segue por uma correia para o britador secundário, e posteriormente para as peneiras de classificação que vai separar as britas de acordo com a sua granulometria, e por fim os materiais já separados seguem por esteiras para a área de estocagem. 
Figura 3: Fluxograma do processo produtivo da mineradora

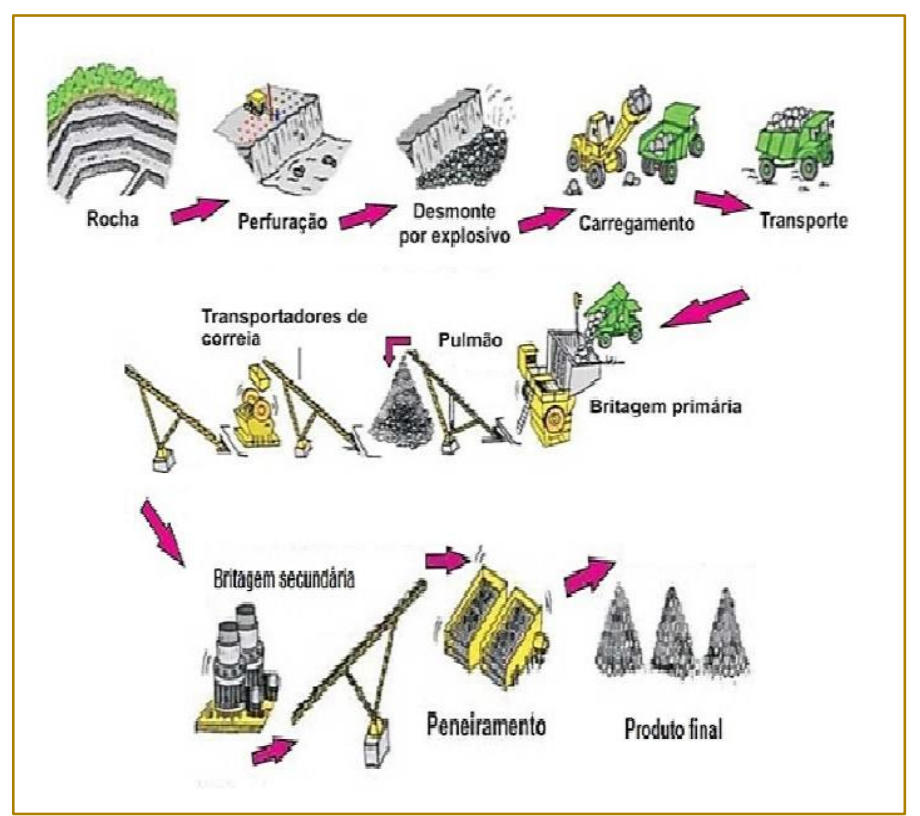

Fonte: Adaptado de LAPA (2006)

\subsection{ANÁLISE PRELIMINAR DE RISCO E PERIGO}

Nos quadros 8 e 9 estão apresentados os resultados da identificação dos riscos e perigos encontrados na mineradora através da técnica de Análise Preliminar de Risco (APR). No quadro 8 encontra-se os resultados encontrados na mina, já no quadro 9 os resultados obtidos para a área de britagem.

Quadro 8: APR para os riscos e perigos encontrados na mina

\begin{tabular}{|c|c|c|c|c|c|c|c|c|}
\hline \multirow{2}{*}{ 适 } & \multirow[t]{2}{*}{ 랭 } & \multirow{2}{*}{ 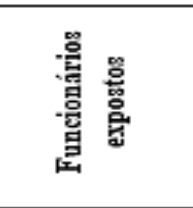 } & \multirow{2}{*}{ 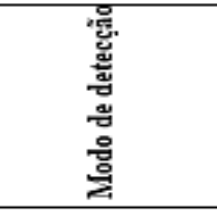 } & \multirow[t]{2}{*}{ 嵒 } & \multicolumn{3}{|c|}{ 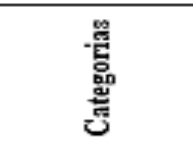 } & \multirow{2}{*}{ 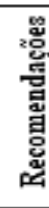 } \\
\hline & & & & & $\mathbf{P}$ & $\mathrm{S}$ & $\mathbf{R}$ & \\
\hline Calor & $\begin{array}{l}\text { Exposição } \\
\text { ao agente } \\
\text { durante a } \\
\text { atividade. }\end{array}$ & $\begin{array}{l}\text { Ajudante de } \\
\text { Minas e } \\
\text { Operador de } \\
\text { Perfuratriz. }\end{array}$ & $\begin{array}{c}\text { Avaliação de } \\
\text { calor no local. } \\
\text { Trabalho a céu } \\
\text { aberto. }\end{array}$ & $\begin{array}{l}\text { Sudorese, } \\
\text { desidratação, } \\
\text { entre outros. }\end{array}$ & A. & III & 2 & 5 \\
\hline Poeira & $\begin{array}{l}\text { Exposição a } \\
\text { poeiras } \\
\text { minerais e } \\
\text { silica. }\end{array}$ & $\begin{array}{l}\text { Ajudante de } \\
\text { Minas e } \\
\text { Operador de } \\
\text { Perfuratriz. }\end{array}$ & $\begin{array}{c}\text { Avaliação } \\
\text { qualitativa no } \\
\text { local. } \\
\text { Trabalho a céu } \\
\text { aberto. }\end{array}$ & $\begin{array}{l}\text { Problemas } \\
\text { respiratórios } \\
\text { e dermatoses. }\end{array}$ & A & II & 1 & 1 \\
\hline Vibração & $\begin{array}{l}\text { Exposição } \\
\text { do agente. }\end{array}$ & $\begin{array}{l}\text { Ajudante de } \\
\text { Minas e } \\
\text { Operador de } \\
\text { Perfuratriz. }\end{array}$ & $\begin{array}{l}\text { Vibração } \\
\text { gerada na } \\
\text { utilização da } \\
\text { máquina } \\
\text { perfuratriz. } \\
\text { Avsliş̧s̃o } \\
\text { local. }\end{array}$ & $\begin{array}{c}\text { Falta de } \\
\text { equilibrio } \\
\text { motor, visão } \\
\text { embagada, } \\
\text { alteraçöes no } \\
\text { sistema } \\
\text { digestörio, } \\
\text { etc. }\end{array}$ & A & III & 2 & 6 \\
\hline $\begin{array}{c}\text { Radiações } \\
\text { não } \\
\text { ionizantes }\end{array}$ & $\begin{array}{l}\text { Exposição } \\
\text { ao sol. }\end{array}$ & $\begin{array}{l}\text { Ajudante de } \\
\text { Minas e } \\
\text { Operador de } \\
\text { Perfuratriz. }\end{array}$ & $\begin{array}{c}\text { Trabalho a céu } \\
\text { aberto. }\end{array}$ & $\begin{array}{c}\text { Queimaduras } \\
\text { solares }\end{array}$ & A. & III & 2 & 4 \\
\hline Veiculos & $\begin{array}{c}\text { Ausência de } \\
\text { um } \\
\text { programa de } \\
\text { manutenção } \\
\text { para os } \\
\text { veículos }\end{array}$ & $\begin{array}{c}\text { Motorista } \\
\text { Caçambeiros }\end{array}$ & $\begin{array}{l}\text { Alto indice de } \\
\text { quebra dos } \\
\text { veículos. }\end{array}$ & $\begin{array}{c}\text { Traumas } \\
\text { múltiplos, } \\
\text { óbito. }\end{array}$ & A & I & 1 & 3 \\
\hline
\end{tabular}


Quadro 8: APR para os riscos e perigos encontrados na mina (continuação)

\begin{tabular}{|c|c|c|c|c|c|c|c|c|}
\hline \multirow{2}{*}{ 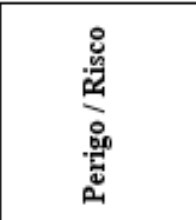 } & \multirow[t]{2}{*}{ 苞 } & \multirow{2}{*}{ 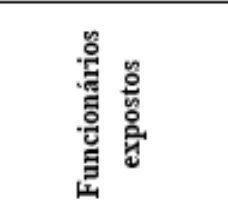 } & \multirow[t]{2}{*}{ 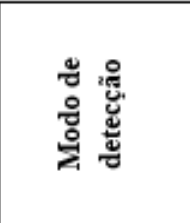 } & \multirow[t]{2}{*}{ 总 } & \multicolumn{3}{|c|}{ 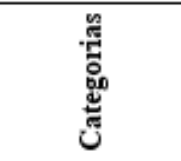 } & \multirow{2}{*}{ 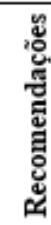 } \\
\hline & & & & & $\mathbf{P}$ & $\mathrm{S}$ & $\mathbf{R}$ & \\
\hline $\begin{array}{c}\text { Movimentação } \\
\text { de cargas }\end{array}$ & $\begin{array}{c}\text { Movimentação } \\
\text { de cargas em } \\
\text { locais } \\
\text { frequentados } \\
\text { por outros } \\
\text { trabalhadores }\end{array}$ & $\begin{array}{c}\text { Ajudante de } \\
\text { Minas, Operador } \\
\text { de Perfuratriz, } \\
\text { Motorista } \\
\text { Caçambeiro. }\end{array}$ & $\begin{array}{c}\text { Na realização } \\
\text { do } \\
\text { abastecimento } \\
\text { de caçambas } \\
\text { na mina. } \\
\text { Avaliação } \\
\text { local. }\end{array}$ & $\begin{array}{c}\text { Impacto de } \\
\text { pedras contra } \\
\text { os } \\
\text { trabalhadores } \\
\text { durante a } \\
\text { atividade. } \\
\text { Traumas } \\
\text { múltiplos e } \\
\text { óbito. }\end{array}$ & D & II & 4 & 10 \\
\hline $\begin{array}{c}\text { Transporte de } \\
\text { cargas }\end{array}$ & $\begin{array}{l}\text { Transporte de } \\
\text { cargas de } \\
\text { forma } \\
\text { indevida. }\end{array}$ & $\begin{array}{c}\text { Ajudante de } \\
\text { Minas, Operador } \\
\text { de Perfuratriz, } \\
\text { Motorista } \\
\text { Caçambeiro, } \\
\text { Operador de } \\
\text { Retroescavadeira. }\end{array}$ & \begin{tabular}{|c} 
Caçamba com \\
limite \\
excedido. \\
Avaliação \\
local.
\end{tabular} & $\begin{array}{c}\text { Atropelamentos } \\
\text { de } \\
\text { trabalhadores; } \\
\text { Perda de } \\
\text { controle e } \\
\text { queda do } \\
\text { veículo. } \\
\text { Traumas } \\
\text { múltiplos e } \\
\text { óbito. }\end{array}$ & C & II & 3 & 10 \\
\hline Atropelamento & $\begin{array}{l}\text { Alto limite de } \\
\text { velocidade } \\
\text { permitido, } \\
\text { circulação de } \\
\text { veículos. }\end{array}$ & $\begin{array}{c}\text { Ajudante de } \\
\text { Minas, Operador } \\
\text { de Perfuratriz, } \\
\text { Operador de } \\
\text { Retroescavadeira. }\end{array}$ & $\begin{array}{c}\text { Placas } \\
\text { instaladas na } \\
\text { mineradora. } \\
\text { Avaliação } \\
\text { local. }\end{array}$ & $\begin{array}{c}\text { Traumas } \\
\text { múltiplos e } \\
\text { óbito. }\end{array}$ & $\mathrm{C}$ & I & 3 & 9 \\
\hline
\end{tabular}

\begin{tabular}{|c|c|c|c|c|c|c|c|c|}
\hline \multirow{2}{*}{ 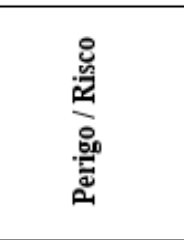 } & \multirow[t]{2}{*}{ 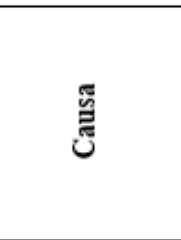 } & \multirow{2}{*}{ 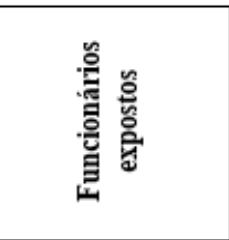 } & \multirow{2}{*}{ 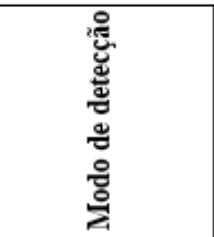 } & \multirow[t]{2}{*}{ 总 } & \multicolumn{3}{|c|}{ 产 } & \multirow{2}{*}{ 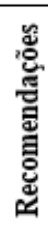 } \\
\hline & & & & & $\mathbf{P}$ & $\mathbf{S}$ & $\mathbf{R}$ & \\
\hline $\begin{array}{l}\text { Queda de } \\
\text { rochas ou } \\
\text { blocos }\end{array}$ & $\begin{array}{c}\text { Rochas soltas } \\
\text { após as } \\
\text { operações de } \\
\text { desmontes. }\end{array}$ & \begin{tabular}{|c|} 
Ajudante de \\
Minas, Operador \\
de Perfuratriz, \\
Motorista \\
Caçambeiro, \\
Operador de \\
Retroescavadeira.
\end{tabular} & Avaliação local & $\begin{array}{l}\text { Traumas } \\
\text { múltiplos, } \\
\text { óbito. }\end{array}$ & C & I & 1 & 13 \\
\hline $\begin{array}{c}\text { Equipamentos } \\
\text { com elevado } \\
\text { nivel de } \\
\text { desgaste }\end{array}$ & $\begin{array}{c}\text { Perfuratriz } \\
\text { apresentando } \\
\text { diversos } \\
\text { vazamentos } \\
\text { de óleo. }\end{array}$ & $\begin{array}{l}\text { Ajudante de } \\
\text { Minas e } \\
\text { Operador de } \\
\text { Perfuratriz. }\end{array}$ & $\begin{array}{l}\text { Avaliação do } \\
\text { equipamento } \\
\text { em } \\
\text { funcionamento. }\end{array}$ & $\begin{array}{l}\text { Explosões, } \\
\text { traumas } \\
\text { múltiplos, } \\
\text { óbito. }\end{array}$ & $\mathrm{A}$ & II & 1 & 1 \\
\hline $\begin{array}{l}\text { Vias de } \\
\text { circulação }\end{array}$ & $\begin{array}{l}\text { Caminhos } \\
\text { estreitos e } \\
\text { sinuosos. }\end{array}$ & $\begin{array}{c}\text { Motorista } \\
\text { Caçambeiro e } \\
\text { Operador de } \\
\text { Retroescavadeira }\end{array}$ & Avaliação local. & $\begin{array}{l}\text { Queda de } \\
\text { veículo. } \\
\text { Óbito. }\end{array}$ & $\mathrm{D}$ & $\mathrm{I}$ & 3 & 11 \\
\hline $\begin{array}{c}\text { Explosão do } \\
\text { compressor } \\
\text { da perfuratriz }\end{array}$ & $\begin{array}{c}\text { Ausência de } \\
\text { manutenção } \\
\text { em períodos } \\
\text { determinados. }\end{array}$ & $\begin{array}{l}\text { Ajudante de } \\
\text { Minas e } \\
\text { Operador de } \\
\text { Perfuratriz. }\end{array}$ & Avaliação & $\begin{array}{l}\text { Explosões, } \\
\text { traumas } \\
\text { múltiplos, } \\
\text { óbito. }\end{array}$ & $\mathrm{D}$ & II & 4 & 12 \\
\hline
\end{tabular}


Quadro 9: APR para os riscos e perigos encontrados na área de britagem

\begin{tabular}{|c|c|c|c|c|c|c|c|c|}
\hline \multirow{2}{*}{ 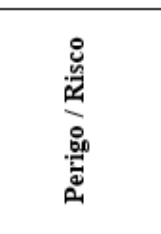 } & \multirow[t]{2}{*}{ 己ี } & \multirow{2}{*}{ 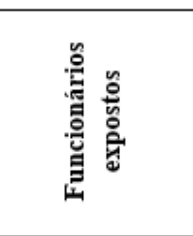 } & \multirow{2}{*}{ 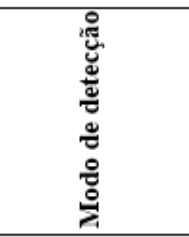 } & \multirow[t]{2}{*}{ 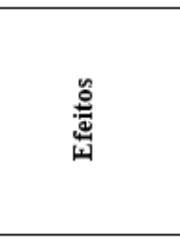 } & \multicolumn{3}{|c|}{ ن气 } & \multirow{2}{*}{ 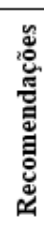 } \\
\hline & & & & & $\mathbf{P}$ & $\mathbf{S}$ & $\mathbf{R}$ & \\
\hline Calor & $\begin{array}{c}\text { Exposição ao } \\
\text { agente durante } \\
\text { a atividade. }\end{array}$ & Ajudante Geral & $\begin{array}{c}\text { Avaliação de } \\
\text { calor no local. } \\
\text { Trabalho a céu } \\
\text { aberto. }\end{array}$ & $\begin{array}{c}\text { Sudorese, } \\
\text { desidratação, } \\
\text { entre outros. }\end{array}$ & $\mathrm{A}$ & III & 2 & 7 \\
\hline Poeira & $\begin{array}{l}\text { Exposição a } \\
\text { poeiras } \\
\text { minerais e } \\
\text { sílica. }\end{array}$ & Ajudante Geral & $\begin{array}{c}\text { Avaliação no } \\
\text { local } \\
\text { qualitativa. } \\
\text { Trabalho a céu } \\
\text { aberto. }\end{array}$ & $\begin{array}{l}\text { Problemas } \\
\text { respiratórios e } \\
\text { dermatoses. }\end{array}$ & $\mathrm{A}$ & II & 1 & 1 \\
\hline $\begin{array}{l}\text { Radiações } \\
\text { não } \\
\text { ionizantes }\end{array}$ & $\begin{array}{c}\text { Exposição ao } \\
\text { sol. }\end{array}$ & Ajudante Geral & $\begin{array}{c}\text { Trabalho a céu } \\
\text { aberto. }\end{array}$ & $\begin{array}{l}\text { Queimaduras } \\
\text { solares }\end{array}$ & $\mathrm{A}$ & III & 2 & 8 \\
\hline Ergonômico & \begin{tabular}{|c|} 
Postura \\
inadequada. \\
Movimentação \\
de forma \\
repetitiva e \\
inadequada.
\end{tabular} & Ajudante Geral & $\begin{array}{l}\text { Levantamento } \\
\text { de peso. } \\
\text { Realização de } \\
\text { atividades com } \\
\text { movimentos } \\
\text { repetitivos. }\end{array}$ & $\begin{array}{c}\text { Dores } \\
\text { lombares. } \\
\text { Problemas de } \\
\text { circulação. }\end{array}$ & $\mathrm{A}$ & III & 2 & 9 \\
\hline
\end{tabular}

\begin{tabular}{|c|c|c|c|c|c|c|c|c|}
\hline \multirow{2}{*}{ 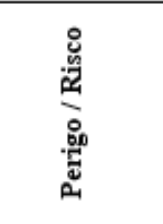 } & \multirow[t]{2}{*}{ 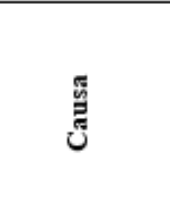 } & \multirow{2}{*}{ 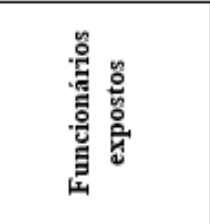 } & \multirow[t]{2}{*}{ 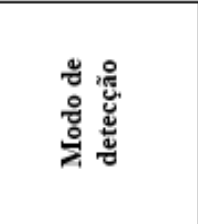 } & \multirow[t]{2}{*}{ 旁 } & \multicolumn{3}{|c|}{ 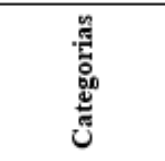 } & \multirow{2}{*}{ 惢 } \\
\hline & & & & & $\mathbf{P}$ & $\mathbf{S}$ & $\mathbf{R}$ & \\
\hline Ruido & $\begin{array}{l}\text { Exposição à } \\
\text { área ruidosa. }\end{array}$ & $\begin{array}{c}\text { Ajudante Geral e } \\
\text { Operador de } \\
\text { Britador } \\
\text { Primário }\end{array}$ & $\begin{array}{l}\text { Trabalho com } \\
\text { máquinas } \\
\text { barulhentas; } \\
\text { Dosimetria. }\end{array}$ & $\begin{array}{c}\text { Redução ou } \\
\text { perda auditiva. }\end{array}$ & A & II & 1 & 2 \\
\hline Eletricidade & $\begin{array}{l}\text { Utilização de } \\
\text { quadro de } \\
\text { comandos. }\end{array}$ & $\begin{array}{l}\text { Operador do } \\
\text { Britador } \\
\text { Primário e } \\
\text { Operador do } \\
\text { Britador } \\
\text { Secundário. }\end{array}$ & $\begin{array}{c}\text { Avaliação no } \\
\text { local. }\end{array}$ & $\begin{array}{l}\text { Choque } \\
\text { elétrico. }\end{array}$ & $\mathrm{C}$ & II & 3 & 11 \\
\hline $\begin{array}{c}\text { Trabalho em } \\
\text { altura }\end{array}$ & $\begin{array}{l}\text { Exposição a } \\
\text { altura nas } \\
\text { plataformas } \\
\text { de britagem } \\
\text { sem sinto de } \\
\text { segurança. }\end{array}$ & Ajudante Geral & $\begin{array}{l}\text { Substituição de } \\
\text { peneiras do } \\
\text { britador e } \\
\text { lubrificação dos } \\
\text { rolamentos. }\end{array}$ & $\begin{array}{c}\text { Queda de } \\
\text { altura e niveis } \\
\text { elevados. } \\
\text { Traumas } \\
\text { múltiplos, } \\
\text { óbito. }\end{array}$ & A & I & 2 & 3 \\
\hline $\begin{array}{c}\text { Guarda corpo } \\
\text { danificado }\end{array}$ & $\begin{array}{l}\text { Guarda corpo } \\
\text { quebrado } \\
\text { próximo a } \\
\text { área de } \\
\text { manutenção } \\
\text { do britador } \\
\text { primário. }\end{array}$ & Ajudante Geral & Avaliação local. & $\begin{array}{l}\text { Cair nas } \\
\text { correias do } \\
\text { motor do } \\
\text { britador } \\
\text { primário. }\end{array}$ & A & I & 1 & 4 \\
\hline
\end{tabular}


Quadro 9: APR para os riscos e perigos encontrados na área de britagem (continuação)

\begin{tabular}{|c|c|c|c|c|c|c|c|c|}
\hline \multirow{2}{*}{ 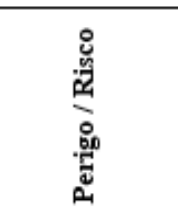 } & \multirow[t]{2}{*}{ 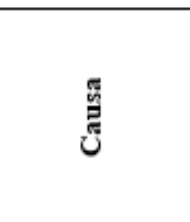 } & \multirow{2}{*}{ 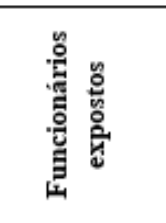 } & \multirow[t]{2}{*}{ 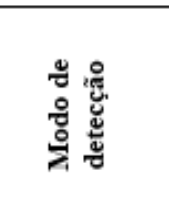 } & \multirow[t]{2}{*}{ 窇 } & \multicolumn{3}{|c|}{ שू } & \multirow{2}{*}{ 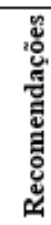 } \\
\hline & & & & & $\mathbf{P}$ & $\mathrm{s}$ & $\mathbf{R}$ & \\
\hline $\begin{array}{c}\text { Desobstrução } \\
\text { do britador } \\
\text { primário }\end{array}$ & $\begin{array}{c}\text { Acesso a } \\
\text { máquina em } \\
\text { funcionamento. } \\
\text { Acesso a zona e } \\
\text { locais perigosos } \\
\text { da máquina. } \\
\text { Nivel de ruido } \\
\text { ultrapassa } 140 \\
\mathrm{~dB} \text {. }\end{array}$ & $\begin{array}{l}\text { Operador de } \\
\text { Britador } \\
\text { Primário }\end{array}$ & $\begin{array}{c}\text { Procedimento } \\
\text { de } \\
\text { desobstrução } \\
\text { do britador } \\
\text { primário. } \\
\text { Dosimetria. }\end{array}$ & $\begin{array}{l}\text { Impacto de } \\
\text { pedra contra o } \\
\text { trabalhador, } \\
\text { cair dentro do } \\
\text { britador. } \\
\text { Esmagamento, } \\
\text { óbito. }\end{array}$ & $\mathrm{A}$ & I & 1 & 5 \\
\hline Atropelamento & $\begin{array}{l}\text { Alto limite de } \\
\text { velocidade } \\
\text { permitido. }\end{array}$ & $\begin{array}{c}\text { Ajudante } \\
\text { Geral, } \\
\text { Operador do } \\
\text { Britador } \\
\text { Primário e } \\
\text { Operador do } \\
\text { Britador } \\
\text { Secundário. }\end{array}$ & $\begin{array}{c}\text { Placas } \\
\text { instaladas na } \\
\text { mineradora. } \\
\text { Avaliaçäo } \\
\text { local. }\end{array}$ & $\begin{array}{l}\text { Traumas } \\
\text { múltiplos e } \\
\text { óbito. }\end{array}$ & $\mathrm{C}$ & I & 3 & 10 \\
\hline $\begin{array}{c}\text { Descarga de } \\
\text { materiais }\end{array}$ & $\begin{array}{l}\text { Projeção de } \\
\text { pedras }\end{array}$ & $\begin{array}{l}\text { Operador do } \\
\text { Britador } \\
\text { Primário }\end{array}$ & $\begin{array}{c}\text { Descarga no } \\
\text { britador } \\
\text { primário. } \\
\text { Avaliação } \\
\text { Local. }\end{array}$ & $\begin{array}{l}\text { Impacto de } \\
\text { pedras contra } \\
\text { cabine do } \\
\text { operador. } \\
\text { Traumas } \\
\text { múltiplos }\end{array}$ & $\mathrm{D}$ & II & 4 & 12 \\
\hline
\end{tabular}

\begin{tabular}{|c|c|c|c|c|c|c|c|c|}
\hline \multirow{2}{*}{ 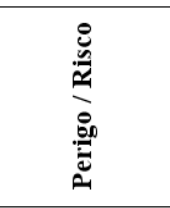 } & \multirow[t]{2}{*}{ Uू } & \multirow{2}{*}{ 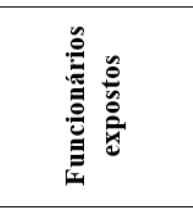 } & \multirow[t]{2}{*}{ 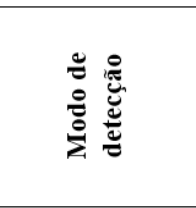 } & \multirow[t]{2}{*}{$\stackrel{气}{气}$} & \multicolumn{3}{|c|}{ Ũ } & \multirow{2}{*}{ 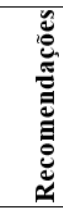 } \\
\hline & & & & & $\mathbf{P}$ & $\mathbf{S}$ & $\mathbf{R}$ & \\
\hline $\begin{array}{l}\text { Movimentação } \\
\text { de cargas }\end{array}$ & $\begin{array}{c}\text { Movimentação } \\
\text { de cargas em } \\
\text { locais } \\
\text { frequentados } \\
\text { por outros } \\
\text { trabalhadores }\end{array}$ & Ajudante Geral & $\begin{array}{l}\text { Na realização do } \\
\text { abastecimento de } \\
\text { caçambas na } \\
\text { área de } \\
\text { estocagem. }\end{array}$ & \begin{tabular}{|c|} 
Impacto de \\
pedras contra os \\
trabalhadores \\
ou \\
atropelamentos. \\
Traumas \\
múltiplos.
\end{tabular} & D & II & 4 & 12 \\
\hline $\begin{array}{c}\text { Limpeza da } \\
\text { plataforma de } \\
\text { acesso ao } \\
\text { britador }\end{array}$ & $\begin{array}{l}\text { Correias do } \\
\text { motor do } \\
\text { britador sem } \\
\text { proteção. }\end{array}$ & Ajudante Geral & Avaliação local & $\begin{array}{c}\text { Traumas } \\
\text { múltiplos, óbito. }\end{array}$ & A & I & 1 & 6 \\
\hline
\end{tabular}

\subsubsection{AVALIAÇÕES QUANTITATIVAS DE RUÍDO OCUPACIONAL}

No quadro 10 encontram-se os valores obtidos em decibéis para as avaliações de ruído, a principal fonte geradora para cargo.
As medições de ruído foram efetuadas com um representante de cada função durante um certo período de tempo. 
Quadro 10: Avaliações de ruído

\begin{tabular}{|c|c|c|}
\hline Cargo / Função & Principal Fon te Geradora & Nível de ruído \\
\hline Ajudante Geral & Britadores e esteiras & $102,34 \mathrm{~dB}$ \\
\hline Ajudante de Mina & Máquina Perfuratriz & $108,3 \mathrm{~dB}$ \\
\hline Operador de Perfuratriz & Máquina Perfuratriz & $108,3 \mathrm{~dB}$ \\
Operador de Britador Primário & Britador Primário & $<85 \mathrm{~dB}$ \\
\hline Operador de Britador Secundário & Britador Secundário & $<85 \mathrm{~dB}$ \\
\hline Operador de Pá Carregadeira & Máquina Pá Carregadeira & $<85 \mathrm{~dB}$ \\
\hline Operador de Retroescavadeira & Máquina Retroescavadeira & $<85 \mathrm{~dB}$ \\
\hline Motorista Caminhoneiro & Caminhão & $<85 \mathrm{~dB}$ \\
\hline
\end{tabular}

Nota-se que para as funções: ajudante geral, ajudante de mina e operador de perfuratriz, os níveis de ruído encontram-se acima do limite permitido pela legislação que é de $85 \mathrm{~dB}$. Esses funcionários realizam as suas atividades a céu aberto, bem próximo as fontes geradoras de ruído.

\subsubsection{AVALIAÇÕES QUANTITATIVAS DE CALOR}

Foram realizadas duas avaliações de calor, uma na mina e a outra na área de britagem. As avaliações foram feitas a ambientes a céu aberto, pois o sol é a fonte geradora de calor aos trabalhadores durante a execução das suas atividades.

As avaliações de calor na mina apresentaram os seguintes resultados:

$\mathrm{Tg}=38^{\circ}, \mathrm{Tbs}=32,8^{\circ}$ e Tbn $=25,3^{\circ}$

Taxa de metabolismo para trabalho pesado: $440 \mathrm{Kcal} / \mathrm{h}$ (quadro 4);

Ciclo de trabalho contínuo, ou seja, sem descanso (quadro 3);

Tempo de exposição: 60 minutos.

A partir desses dados calcula-se primeiramente o IBUTG para ambiente com carga solar:

$$
\begin{gathered}
\text { IBUTG }=0,7 \mathrm{Tbn}+0,1 \mathrm{Tbs}+0,2 \mathrm{Tg} \quad \text { (Equação 2) } \\
\text { IBUTG }=0,7 * 25,3+0,1 * 32,8+0,2 * 38 \\
I B U T G=28,6{ }^{\circ} \mathrm{C}
\end{gathered}
$$

Após achar o valor de do IBUTG, calcula-se a taxa de metabolismo média ponderada para uma hora:

$$
\begin{array}{cc}
M=\frac{M t * T t}{60} & \quad \text { (Equação 3) } \\
M & =\frac{440 * 60}{60} \\
M & =440 \mathrm{Kcal} / \mathrm{h}
\end{array}
$$

Assim, de acordo com a NR 15 Anexo 3, as atividades estão com o nível de IBUTG acima do permitido, o que torna o seu trabalho insalubre.
Para a área de britagem, os resultados encontrados: 
$\operatorname{Tg}=36,8^{\circ}, \mathrm{Tbs}=33,0^{\circ}$ e $\mathrm{Tbn}=24,6^{\circ}$

Taxa de metabolismo para trabalho pesado: $440 \mathrm{Kcal} / \mathrm{h}$;

Ciclo de trabalho contínuo, ou seja, sem descanso;

Tempo de exposição: 60 minutos
A partir desses dados calcula-se primeiramente o IBUTG:

$$
\begin{gathered}
\text { IBUTG }=0,7 \mathrm{Tbn}+0,1 \mathrm{Tbs}+0,2 \mathrm{Tg} \quad \text { (Equação 2) } \\
\text { IBUTG }=0,7 * 24,6+0,1 * 33,0+0,2 * 36,8 \\
\text { IBUTG }=27,9{ }^{\circ} \mathrm{C}
\end{gathered}
$$

Após achar o valor de do IBUTG, calcula-se a taxa de metabolismo média ponderada para uma hora:

$$
\begin{gathered}
M=\frac{M t * T t}{60} \quad \text { (Equação 3) } \\
M=\frac{440 * 60}{60} \\
M=440 \mathrm{Kcal} / \mathrm{h}
\end{gathered}
$$

De acordo com a NR 15 Anexo 3, o nível de IBUTG está acima do permitido, o que torna o seu trabalho insalubre.

\subsection{RECOMENDAÇÕES PARA OS RESULTADOS OBTIDOS NAS ANÁLISES PRELIMINARES DE RISCO}

\subsubsection{RECOMENDAÇÕES PARA A MINA DE ACORDO COM O QUADRO 8, SEGUEM AS MESMAS NUMERAÇÕES DESCRITAS NO QUADRO}

1. Poeira: Uso de máscaras semifaciais de acordo com a NR-6

2. Trabalho em altura: Sinalização do risco com uso de fitas zebradas

3. Veículos: Realizar um programa de manutenção preventiva para as caçambas

4. Radiações não ionizantes: Uso de protetor solar, óculos escuro e camisas de manga longa

5. Calor: Alterar o regime de trabalho de contínuo para intermitente

6. Vibração: Utilização de luvas anti-vibração

7. Trabalho com máquinas perfurantes e cortantes: Proteger as partes e zonas perigosas
8. Ergonômicos: Realização de alongamentos físicos antes de iniciar as atividades e durante a execução

9. Atropelamento: Recomendável a redução do limite de velocidade nas imediações da mineradora para $15 \mathrm{Km} / \mathrm{h}$

10. Movimentação de cargas: Estabelecer limite máximo de tolerância para cargas

11. Vias de circulação: Recomendável instalar placas de sinalização na mina

12. Explosão do compressor da perfuratriz: atender rigorosamente as datas estabelecidas para manutenção no compressor.

13. Queda de rochas e blocos: Indispensável a utilização de capacete de proteção e a sinalização do risco.

\subsubsection{RECOMENDAÇÕES PARA A ÁREA DE BRITAGEM DE ACORDO COM O QUADRO 9}

1. Poeira: Recomendável a criação de um sistema de abatimento de pó

2. Ruído: Recomenda-se um protetor auricular com grau de atenuação de no mínimo $18 \mathrm{~dB}$

3. Trabalho em altura: Uso de cinto do tipo paraquedista com talabartes para a fixação nas plataformas 
4. Guarda corpo danificado: Recomenda-se refazer toda a estrutura do guarda corpo dessa região

5. Desobstrução do britador primário: Instalação de uma pinça hidráulica

6. Limpeza da plataforma de acesso ao britador: Providenciar a proteção para as correias

7. Calor: Recomenda-se mudar o regime de trabalho de contínuo para intermitentes com períodos de descanso

8. Radiações não ionizantes: Uso de protetor solar, óculos escuro, camisas de manga longa

9. Ergonômicos: recomendável a realização de alongamentos físicos antes de iniciar as atividades e durante a sua execução

10. Atropelamento: Redução do limite de velocidade para $15 \mathrm{Km} / \mathrm{h}$

11. Eletricidade: Adoção de manutenção preventiva

\section{REFERÊNCIAS}

[1] AMORIM, E. L. C. de. Ferramentas de Análise de Risco. Apostila do curso de Engenharia Ambiental da Universidade Federal de Alagoas, CTEC, Alagoas: 2010. Disponível em: <https://pt.scribd.com/document/71505557/Apostil a-de-ferramentas-de-analise-de-risco>. Acessado em 30 set. 2017

[2] CATAl, Rodrigo Eduardo. Higiene do Trabalho - Gerência de Riscos. Notas de aula do curso de Especialização em engenharia de segurança do trabalho - UTFPR, 2012.

[3] COSTA, C. E. R. Análise dos fatores de riscos dos trabalhadores da indústria de beneficiamento da pesca: Natal/RN. Monografia (Especialista em Engenharia de Segurança do Trabalho) - Universidade Potiguar, Natal, 2010.

[4] DE CICCO, Francesco M. G. A. F.; FANTAZZINI, Mario Luiz. Tecnologias consagradas de gestão de riscos. 2. ed. [São Paulo]: Risk Tecnologia, 2003. 194 p. (Risk management).

[5] ELETRONUCLEAR. Estudo de Impacto Ambiental - EIA da Unidade 3 da Central Nuclear Almirante Álvaro Alberto. Volume 6 - Análise e Gerenciamento de Risco e de Emergência, cap. 12.2.7.2, 2014. Disponível em: <http://www.eletronuclear.gov.br/hotsites/eia/v06_1 2_analise.html\#12272> Acessado em 30 de set. de 2017.

[6] FIOCRUZ. Fundação Oswaldo Cruz. Disponível em: <http://www.fiocruz.br/biosseguranca/Bis/virtual\%2
12. Descarga de materiais e movimentação de cargas: Recomendável criar procedimentos operacionais padrões para condução de veículos

\section{CONCLUSÃO}

O estudo procurou fazer uma avaliação ambiental para a detecção de riscos encontrados no processo produtivo de uma mineradora de britas. As investigações realizadas com o uso da metodologia de análise preliminar de risco (APR) procurou classificar os riscos de acordo com a sua probabilidade de ocorrência versus a severidade, encontrando assim o grau de risco. A APR foi realizada para a mina e para a área de britagem. Foram sugeridas medidas de segurança para cada situação encontrada, podendo contribuir para a atenuação ou mesmo a eliminação dos riscos.

Otour/hipertextos/up1/riscos_fisicos.html>

Acessado em 15 set. de 2017.

[7] GOMES, P. C. dos R.; OLIVEIRA, P. R. A. de.. Introdução à Engenharia de Segurança do Trabalho. Brasília: WEducacional e Cursos LTDA, 2012. $63 \mathrm{p}$.

[8] GONÇALVES, Fernando dos Santos. Revisão de programa de prevenção de riscos ambientais. 2013. 47 f. Monografia (Especialização) - Escola de Engenharia da Universidade Federal do Rio Grande do Sul, Rio Grande do Sul, 2013.

[9] GRANDJEAN, Etienne. Manual de Ergonomia: adaptando o trabalho ao homem. 4 ed. Porto Alegre: Bookman, 1998.

[10] IIDA, Itiro. Ergonomia: projeto e produção. 9a reimpressão. São Paulo: Edgard Blucher LTDA, 2003.

[11] IIDA, Itiro. Ergonomia Projeto e Produção, 2 a Ed., Ed. Edgard Blucher, São Paulo, 2005.

[12] LAPA, R. P. Metodologia de identificação de perigos e avaliação de riscos ocupacionais. São Paulo: Escola Politécnica da Universidade de São Paulo, 2006. 104p. (Dissertação de Mestrado).

[13] LOEWE, Katharina e KARIUKI S.G. Integrating human factors into process hazard analysis. Reliability Engineering and System Safety, Technische Universität Berlin, Institute of Process and Plant Technology. Berlin, Germany, n. 92, p. 1764-1773, 2007. 
[14] MARTINS NETO, E. Apostila de Ergonomia. 2012. Disponível em: <http://www.ergonomianotrabalho.com.br/artigos/A postila_de_Ergonomia_2.pdf $>$. Acessado em 18 set. 2017.

[15] MATTOS, Ubirajara A. O. de., MÁSCULO, Francisco S. Higiene e Segurança do Trabalho. Elsevir Ed., Rio de Janeiro, 2011.

[16] MORGADO, C.R.V. Gerência de riscos. Rio de Janeiro: SEGRAC - Núcleo de Pesquisa em Engenharia de Segurança, Gerenciamento de Riscos e Acessibilidade na UFRJ, 2000.

[17] POSSEBON, José. AGENTES QUÍMICOS: Reconhecimento, Avaliação e Controle. 2009. 48 f. Apostila (Pós - Graduação) - Curso de Pós Graduação em Engenharia de Segurança do Trabalho, Faculdade de Engenharia Industrial FEI, São Bernardo do Campo, 2009.

[18] PROMOPETRO. Apostila de segurança no trabalho. Disponivel em: $<$ http://www.laco.ufpe.br/wpcontent/uploads/2013/08/apostila_seguranca.pdf > . Acessado em 19 set. de 2017.

[19] RUPPENTHAL, J.E. Gerenciamento de riscos. Universidade Federal de Santa Maria/Colégio Técnico Industrial de Santa Maria. 120 p. Santa Maria: Rede e-Tec Brasil, 2013.

[20] SALIBA, T. M. Curso Básico de Segurança e Higiene Ocupacional. São Paulo: LTr, 2013.

[21] SALIBA, T. M. Manual Prático de Avaliação e Controle do Ruído - PPRA. São Paulo: LTr, 2001.
[22] SANDERS, M. S.; MCCORMICK, E. J. Human factors in engineering and design. New York: McGraw-Hill, 1993. 790 p

[23] SEBRAE/ES. Serviço de Apoio às Micro e Pequenas Empresas do Espírito Santo. Cartilha de Segurança e Saúde do Trabalho na Construção Civil/ES NR-18. Vitória: SEBRAE, 2012.

[24] SELLA, B. C. Comparativo entre as Técnicas de Análise de Risco APR e HAZOP. Monografia (Curso de Especialização em Engenharia de Segurança do Trabalho) Departamento de Construção Civil, Universidade Tecnológica Federal do Paraná. Curitiba, 2014.

[25] VENDRAME, A. C. Agentes químicos: reconhecimento, avaliação e controle na higiene ocupacional. São Paulo: Ed. do Autor, 2007. 197 p. : ISBN 9788590704508

[26] VIANA, M. G. P.; ALVES, C. S.; JERÔNIMO, C. E. de M. Análise preliminar de risco na atividade de acabamento e revestimento externo de um edifício. Revista Monografias Ambientais - REMOA. UFSM, Santa Maria. v. 14, n. 3, maio-ago. 2014, 3289-3298 p.

[27] VIDAL, Mario César. Guia para análise ergonômica do trabalho (AET) na empresa. Rio de Janeiro: Virtual Científica, 2003

[28] VIEIRA, I. L. Audiologia clínica - Ruído e perda auditiva. Monografia (Especialização em fonoaudiologia clínica) - Centro de especialização em fonoaudiologia clínica. Recife, 1999. 36 p.

[29] ZOCCHIO, Álvaro. Prática da prevenção de acidentes: abc da segurança do trabalho. 6 . ed., rev. ampl. São Paulo: Atlas, 1996. 222 p. ISBN 85-224-1370-3 


\section{Capítulo 19}

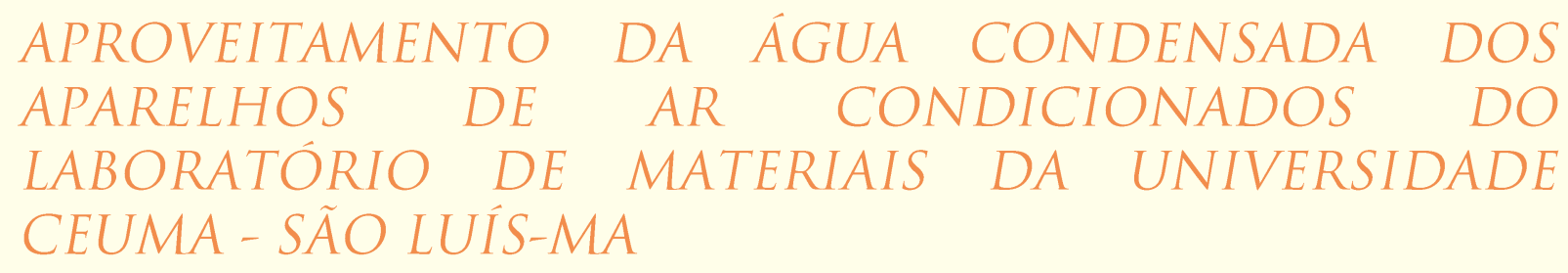

Fernanda Gomes Dias

Alicia Silva Carvalho

Danielle Alves Costa Silva

Ruan Rodrigues da Silva

Ailton Celio Alves de Araújo Júnior

Osman José de Aguiar Gerude Neto

Resumo: A água é um recurso natural fundamental para a manutenção da vida no planeta, pois possui profunda importância no desenvolvimento de diversas atividades biológicas, econômicas e sociais. No entanto, os altos níveis de poluição, o seu desperdício, a má distribuição ou até mesmo o grande aumento populacional tedem a afetar diretamente os recursos hídricos, ressaltando que se deve levar em conta a pouca quantidade de água potável no mundo. Devido a esta problemática torna-se necessário desenvolver alternativas sustentáveis, que sejam economicamente viáveis para preservar esse bem. Os aparelhos de ar condicionado são utilizados em larga escala em todo mundo e geram um grande volume de água, proveniente do processo de condensação. Sendo assim, foi realizado um estudo no Laboratório de Materiais da Universidade CEUMA, com o objetivo de quantificar o volume de água diário, semanal e mensal, provenientes dos condicionadores de ar instalados no local; e estabelecer um comparativo no que diz respeito às diferentes posições das palhetas (para cima, para baixo e oscilando. Com o auxílio de provetas e de um cronômetro, foram feitas medições para que fosse possível calcular a volume médio da vazão da água de cada aparelho. Deste modo, através dos cálculos resultantes das medições, foi perceptível que os aparelhos com a palheta oscilando obtém, significativamente, o maior volume de água, totalizando uma vazão mensal de 5.705,39L/mês em comparação as outras duas posições. Além disso foram realizadas análises qualitativas no que diz respeito aos diferentes parâmetros da qualidade da água, levando em consideração que este recurso pode ser utilizado de várias formas para fins não potáveis

Palavras-chave: Ar- condicionado, Desperdício, Equilíbrio ecológico, aproveitamento 


\section{INTRODUÇÃO}

A água é um recurso natural essencial para o equilíbrio ecológico do planeta, tendo em vista que praticamente todas as formas de vida conhecidas dependem deste recurso. Por isso, o modo de uso racional e sustentável da água, deve ser pautado em práticas de reaproveitamento deste recurso, que é fundamental para a humanidade.

A escassez de corpos hídricos no mundo vem sendo constantemente agravada, seja pelo crescimento populacional aliado a alta procura deste recurso ou pela poluição, desperdício ou sua má distribuição, levando em consideração que nosso planeta possui uma pequena quantidade de água potável. De acordo com dados da ONU sobre a água, em 2012, um bilhão de pessoas, no mundo, não tinham água potável para consumo e a tendência é esta estatística crescer, podendo chegar a 3 bilhões, em 2025.

O uso racional e sustentável da água, assim como a preservação de sua qualidade e práticas de reaproveitamento são fundamentais para humanidade. As empresas e pessoas físicas estão cada vez mais preocupadas com as questões ambientais, procurando formas de preservar os recursos naturais.

Os aparelhos de ar condicionado são utilizados em larga escala em todo mundo e geram um grande volume de água através do gotejamento contínuo, onde esta água, proveniente da condensação destes aparelhos, podem ser reaproveitadas para os mais diversos usos. Diante desta perspectiva é necessário desenvolver alternativas sustentáveis, que sejam economicamente viáveis para preservar este bem.
Dentro deste contexto, se encaixa a Universidade CEUMA, empresa com 4 campi na cidade de São Luís - MA, com uma média de 200 aparelhos por campus, caracterizando um grande potencial de reaproveitamento de água condensada para os mais devidos fins. Sendo assim o objetivo deste trabalho é mensurar o potencial de água gerada por 6 aparelhos de ar condicionados instalados no Laboratório de Materiais da Universidade CEUMA, que servirá de projeto piloto para os demais setores da instituição, serão verificadas a média de volume produzido e a qualidade da água, para posterior destinação e reaproveitamento deste recurso dentro da instituição.

\section{REFERENCIAL TEÓRICO}

\subsection{RECURSOS HÍDRICOS}

Desde os primórdios da vida no planeta Terra e da história da espécie humana, a água sempre foi essencial. Qualquer forma de vida depende da água para sua sobrevivência e para seu desenvolvimento. A água é o que nutre colheitas e florestas, mantém a biodiversidade e os ciclos do planeta e produz paisagens de grande e variada beleza. (TUNDISI; TUNDISI, 2014, p. 23)

A terra é constituída por uma grande extensão de água, por isso é conhecida como planeta água. Calcula-se que a quantidade de água no planeta seja de 1,386 milhões de $\mathrm{km}^{3}$, sendo que $97,5 \%$ do volume total forma os oceanos e os mares, dos quais apenas 2,5\% são de água doce (REBOUÇAS; BRAGA; TUNDISI, 1999)

Segundo Faria (2013, pg. 26) a distribuição da água no planeta ocorre conforme ilustrado na figura 1 abaixo:

Figura 1 - Distribuição da água no planeta

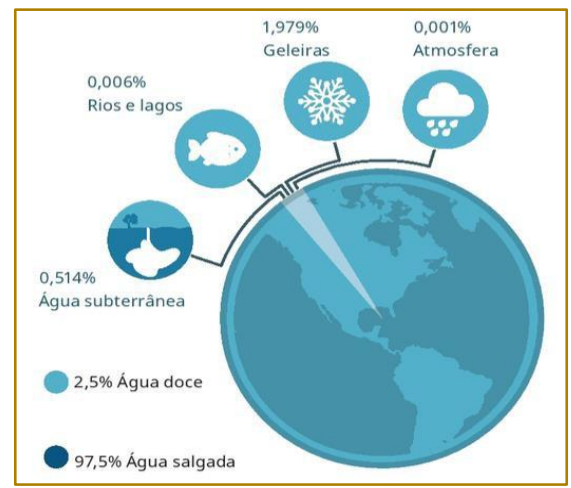

Fonte: adaptado de Faria (2013) 
Segundo Soares (2015, p. 118) o Brasil possui a maior reserva hidrológica do planeta, mas existem muitas dificuldades em relação ao uso dessa água, pois uma parte considerável dela está poluída. O ritmo acelerado do crescimento populacional, as formas de ocupação humana, a devastação ambiental e a poluição produzem graves desequilíbrios no ambiente, provocam a morte de muitos animais e da vegetação e comprometem seriamente $\mathrm{o}$ abastecimento de água ás populações. Devido a essa problemática a autora ainda ressalta o quando é imprescindível que se note a importância de cuidar e utilizar de forma consciente $e$ sustentável os recursos hídricos.

De acordo com Reis; Fadigas; Carvalho (2012, pg. 110) é necessário que a água esteja disponível não apenas em quantidade, mas em qualidade para consumo humano e das plantas. Os condicionantes específicos de qualidade da água são definidos pelos padrões de potabilidade que, no Brasil, são estabelecidos pelo Ministério da Saúde. Grandes centros urbanos, em todo mundo, já sofrem não apenas com a escassez quantitativa como também com a qualitativa da água para consumo.

\subsection{QUALIDADE DA ÁGUA}

Entende-se por poluição da água a alteração de suas características por quaisquer ações ou interferências, sejam elas naturais ou provocadas pelo homem. O conceito de poluição da água tem-se tornado cada vez mais amplo em função de maiores exigências com relação à conservação e ao uso racional dos recursos hídricos. (BRAGA; BENETIDO p. 16, 2013).

Segundo o Ministério da Saúde (2006), as características físicas, químicas e biológicas da água estão associadas a uma série de processos que ocorrem no corpo hídrico e em sua bacia de drenagem. Ao se abordar a questão da qualidade da água, é fundamental ter em mente que o meio líquido apresenta duas características marcantes, que condicionam de maneira absoluta a conformação desta qualidade: capacidade de dissolução e a capacidade de transporte.

Para que uma água apresente boa qualidade, é necessário observar e se atentar para suas características, com isso, dependendo de seu propósito de uso ela poderá ser considerada como própria ou impropria para tal finalidade desejada (Hardenbergh, 1964). O principal objetivo de um tratamento de água é fazer a remoção de contaminantes existentes, sendo que este pode ser realizado para atender diversos aspectos, um dos mais citados são análises microbiológicas que visam a redução ou eliminação de organismos patogênicos (bactérias, protozoários, vírus); as análises físico-químicos em que há a correção da cor, sabor e odor, sendo físico (decantação e filtração) e químico (desinfecção e coagulação), e os econômicos que estão relacionados redução de corrosividade (que danifica as tubulação), turbidez, ferro e manganês.

A Portaria do Ministério Da Saúde 518 (2004) apresenta o padrão de potabilidade para o consumo humano:

Quadro 01 - Padrão microbiológico de potabilidade da água para consumo humano.

\begin{tabular}{|c|c|c|}
\hline FINALIDADE & PARÂMETRO & VMP (valor máximo permitido) \\
\hline Água para consumo humano & Escherichia coli (CTT) & Ausência em 100ml \\
\hline Água na saída do tratamento & Coliformes totais & Ausência em 100ml \\
\hline & Escherichia coli & Ausência em 100ml \\
\hline $\begin{array}{l}\text { Água tratada no sistema de } \\
\text { distribuição (reservatórios e rede) }\end{array}$ & Coliformes totais & $\begin{array}{l}\text { Sistemas que analisam } 40 \text { ou mais } \\
\text { amostras por mês: Ausência em } \\
\text { 100ml em 95\% das amostras } \\
\text { examinadas no mês; } \\
\text { Sistemas que analisam menos de } \\
40 \text { amostras por mês: Apenas uma } \\
\text { amostra poderá apresentar } \\
\text { mensalmente resultado positivo em } \\
\text { 100ml }\end{array}$ \\
\hline
\end{tabular}

Fonte: adaptado de Portaria Ministério da Saúde 518 (2004) 
No entanto é perceptível que a qualidade da água está intrinsecamente ligada a utilidade que será dada à mesma e aos requisitos que, de forma generalizada e conceitual, interligam a desejada qualidade com os padrões de qualidade embasados em suporte legal (VENDRAME, 2006). É importante ressaltar que é de suma importância profissionais com conhecimentos específicos para solucionar os problemas pertinentes a essas questões e que compreendam a problemática com um todo (Philippi JR et al., 2004).

\subsection{REUTILIZAÇÃO DA ÁGUA}

Em razão da limitação dos recursos hídricos o homem primitivo não fixava morada e mudava-se constantemente numa permanente busca de locais com suposta abundância de água. Essas mobilizações tornaram-se cada vez mais difíceis em razão do crescimento das populações surgindo a necessidade de as comunidades disciplinarem e racionalizarem o uso da água. (FILHO; MANCUSO,2003)

Existem relatos de sua prática na Grécia Antiga, com a disposição de esgotos e sua utilização na irrigação. No entanto, a demanda crescente por água tem feito do reuso planejado da água um tema atual e de grande importância (CETESB, 2010 apud CUNHA, 2011).De acordo com Cunha (2011, p. 1234) fazer reuso de água trata-se da implantação de uma pequena estação de tratamento de água de uso 'nobre' (banho e pias) para reutilização em fins 'menos nobres', como descargas, lavagens de piso e outros.

De acordo com a Organização Mundial Da saúde (1973) existem três classificações dos reuso da água: reuso indireto, reuso direto e reciclagem interna. O reuso indireto ocorre quando a água já usada, uma ou mais vezes para uso doméstico ou industrial, é descarregada nas águas superficiais ou subterrâneas e utilizada novamente a jusante, de forma diluída. Já o reuso direto é o uso planejado e deliberado de esgotos tratados para certas finalidades como irrigação, uso industrial, recarga de aquífero e água potável. E por fim a reciclagem é o reuso da água internamente a instalações industriais, recarga de aquífero e água potável.

\section{METODOLOGIA}

Para o estudo de caráter exploratório, bem como de análise quantitativa e qualitativa, foi feito um levantamento do número de aparelhos de ar condicionado instalados Laboratório de Materiais da Universidade Ceuma, assim como suas respectivas marcas e potências. Desta forma, o presente estudo é classificado como exploratório, onde serão calculados o volume de água diário, semanal e mensal provenientes dos aparelhos de ar condicionado, e também foram realizadas analises no que diz respeito a qualidade de água para o direcionamento de seus diversos fins, pois a partir das análises qualitativas é possível classificar o grau de potabilidade da água.

\subsection{ANÁLISE QUANTITATIVA}

Para o cálculo da vazão média total de água proveniente do gotejamento contínuo dos condicionadores de ar, as aferições e foram realizadas em três turnos (manhã, tarde e noite), e em seis horários distintos (8:30am; 11:00am; 14:00pm; 17:00pm; 19:00pm e 21:00pm), onde foram feitas medições dos volumes de 6 (seis) aparelhos, através do dreno, enquanto funcionavam a $17 \stackrel{\circ}{\circ} \mathrm{C}$. O quadro 02 a seguir mostra as marcas dos aparelhos do laboratório, suas respectivas quantidades e potências de refrigeração.

Quadro 02 - Relação das marcas, potências e quantidade dos aparelhos de ar condicionado

\begin{tabular}{|c|c|c|}
\hline Aparelho & Marca (tipos) & Potência (BTUS) \\
\hline Ar1 & Springer CARRIER & 48.000 \\
\hline Ar2 & Springer CARRIER & 48.000 \\
\hline Ar3 & Springer CARRIER & 48.000 \\
\hline Ar4 & Springer CARRIER & 48.000 \\
\hline Ar5 & Springer CARRIER & 22.000 \\
\hline Ar6 & MIDEA & 9.000 \\
\hline
\end{tabular}

Fonte: Autores (2018) 
Para a coleta da água condensada foram utilizadas 3 provetas de $250 \mathrm{ml}$ (imagem 02) sendo o tempo de coleta cronometrado de um minuto para cada medição. Foram realizadas 3 coletas seguidas por aparelho (imagem 01), de acordo com as diferentes posições da palheta (para cima, baixo e oscilando), e assim tirou-se a média aritmética de geração para cada horário coletado, que consistiu na soma da média das posições de palhetas dividido pelo número de medições.

Imagem - 1: Coleta da água.

Imagem - 2: Provetas de 250ml

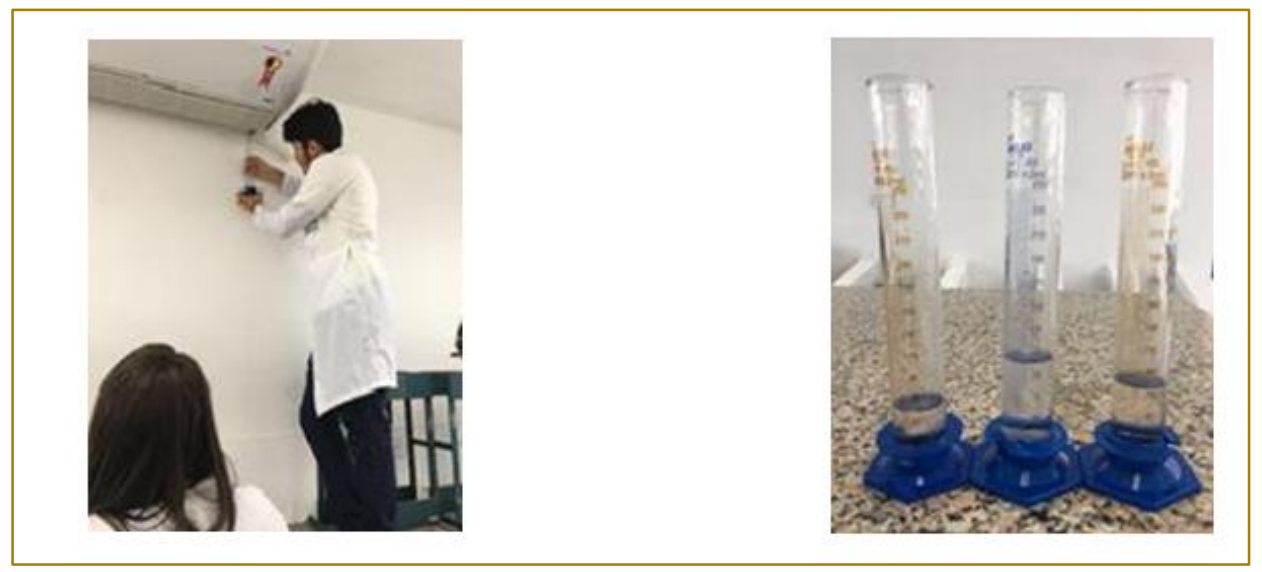

Fonte: Autores (2018)

O período de funcionamento de laboratório de materiais da UniCEUMA, é de 14h por dia e cinco dias por semana. Desta forma, o cálculo para a média das vazões diária; semanal e mensal, foi estimado da seguinte forma:

- Vazão diária: Soma das vazões totais dos seis horários $\times$ nํ de horas/dia

- Vazão semanal: Soma das vazões totais dos seis horários $x$ nํำ de dias/semana

- Vazão mensal: Soma das vazões totais dos seis horários $x$ nº de dias/mês

\subsection{ANÁLISE QUALITATIVA}

No primeiro momento foram coletadas amostras da água, com ajuda de frascos para reagente com tampa rosqueada de $100 \mathrm{ml}$, esterilizadas e sem contato direto com os drenos, para que não houvesse contaminação. Em seguida foram colocadas em recipientes devidamente fechados, disponibilizados pelo Laboratório de Ciências do Ambiente - LACAM da Universidade CEUMA e mantida em uma incubadora a 35ㄷ por 48h, rotulados com identificação dos pontos e datas da coleta. Em seguida foram realizados testes que indicassem a presença ou ausência de CF (coliformes fecais) e CT (coliformes totais), pelo método substrato definido, utilizando reagente COLItest, onde a amostra apresentava uma coloração amarelada forte ou marrom na presença de coliformes e azul na ausência de coliformes, exibidas nas imagens 3 e 4 abaixo:

Imagem 3: Frascos com reagente COLItest.

Imagem 4: Resultado das análises de coliformes.

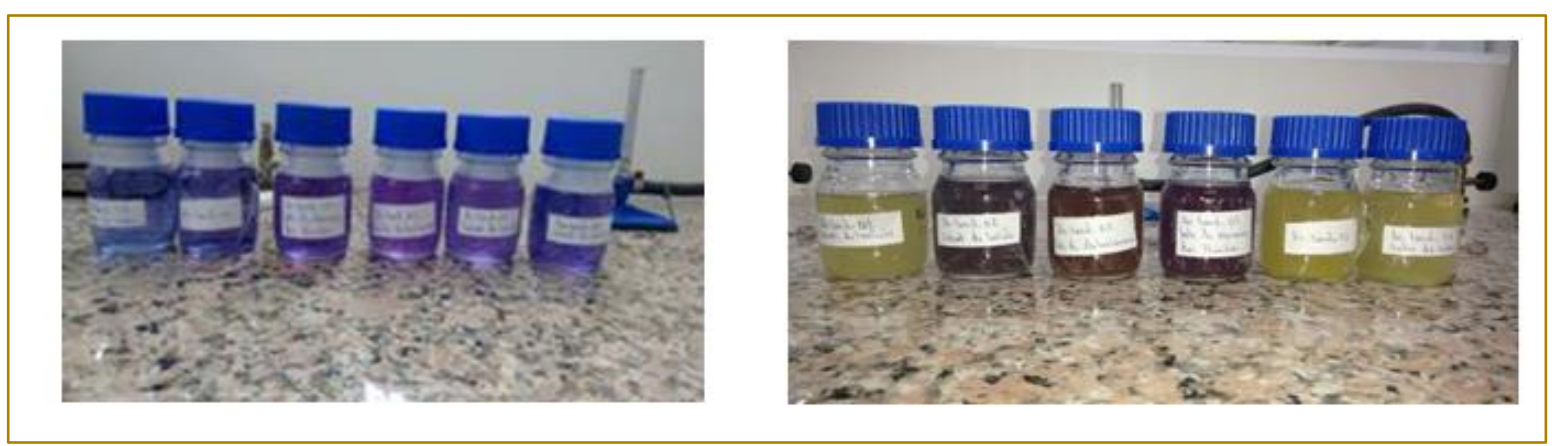


No segundo momento, foram coletadas amostras, desta vez com o auxílio de garrafas secas de água mineral de $500 \mathrm{ml}$, totalmente cheias, devidamente fechadas, mantidas em temperatura ambiente e enviadas para a análise. Em 216emina, com o auxílio de béqueres de $50 \mathrm{ml}$, foram feitas as 216 eminal216 para encontrar valores dos principais parâmetros da água: Potencial de Hidrogeniônico $(\mathrm{pH})$ das amostras para encontrar os valores da concentração de íons $\mathrm{H}+$ presente; condutividade elétrica (CE), para representar em valores, a facilidade ou dificuldade da 216eminal de eletricidade na água; salinidade (S) para medir a quantidade de sais dissolvidos; sólidos totais dissolvidos (TDS) e turbidez (T) que consiste na presença de partículas em suspensão na água em comparação à intensidade da luz espalhada.

Quadro 3 - Relação do aparelho de auxílio para encontrar valores dos parâmetros analisados.

\begin{tabular}{|c|c|}
\hline Parâmetros analisados & \\
\cline { 1 - 2 } PH (potencial hidrogeniônico) & \multirow{3}{*}{ Multiparâmetho Utilizado digital Horiba U-10 } \\
\cline { 1 - 2 } Condutividade elétrica (CE) & \\
\hline Salinidade (S) & \\
\hline TDS (sólidos totais dissolvidos) & \\
\hline Turbidez (T) Fonte: Elaborada pelos autores (2018)
\end{tabular}

As variáveis como temperatura, $\mathrm{pH}$, turbidez, salinidade, sólidos totais dissolvidos e condutividade elétrica. Foram analisadas seguindo a metodologia descrita no APHA, 2005, com o auxílio de um multiparâmetro digital Horiba U-10.

\section{RESULTADOS E DISCUSSÕES}

De acordo com a análise 216eminal216tive dos dados dos aparelhos de acondicionado instalados no Laboratório de Materiais, obteve-se a vazão de água diária em litros de 255, 27 L/dia com palheta para cima; 283, 28L/dia com palheta para baixo e 285, 27L/dia com a palheta oscilando, tendo em vista que os aparelhos instalados no laboratório funcionam 14 horas por dia.

Referente ao volume de água produzido semanalmente, considerando que os condicionadores de ar funcionam 5 dias durante a semana, foi obtido a vazão 216eminal da água em litros de 1.276, 33 L/semana com a palheta para cima, 1.416, 42L/semana com palheta para baixo e 1.426, 35L/semana com a palheta oscilando.

Como o laboratório funciona 20 dias no mês, a vazão de água mensal em litros apresentou os valores de 5.105, 32 L/mês com palheta para cima, com palheta para baixo $5.665,69 \mathrm{~L} / \mathrm{mês}$ com palheta para baixo e 5.705, 39L/mês com a palheta oscilando

Os gráficos 1, 2 e 3 a seguir ilustram as medias diária, semanal e mensal por litros de água nas diferentes posições das palhetas (cima, baixo e oscilando) dos aparelhos. 
Gráfico 1 - Vazão Diária de água condensada dos seis aparelhos de Ar condicionados do laboratório de matérias da UniCEUMA.

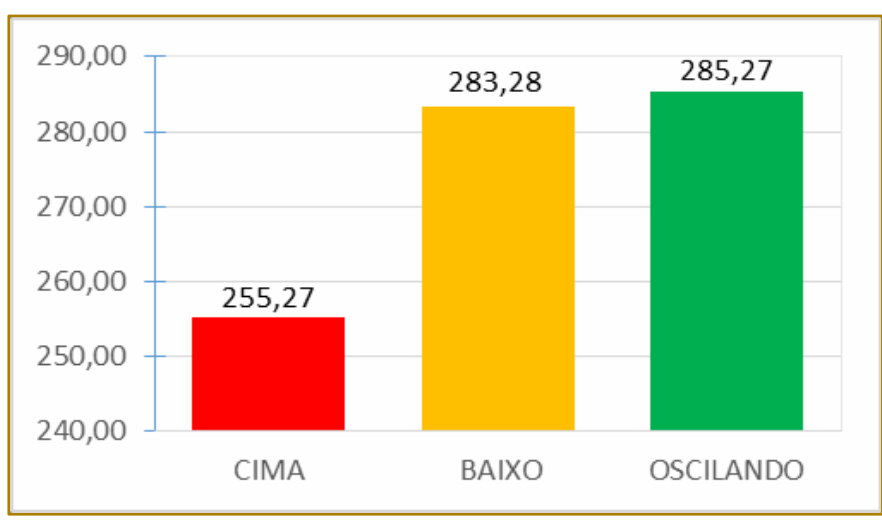

Fonte: Autores (2018)

Gráfico 2 - Vazão semanal de água condensada dos seis aparelhos de Ar condicionados do laboratório de matérias da UniCEUMA

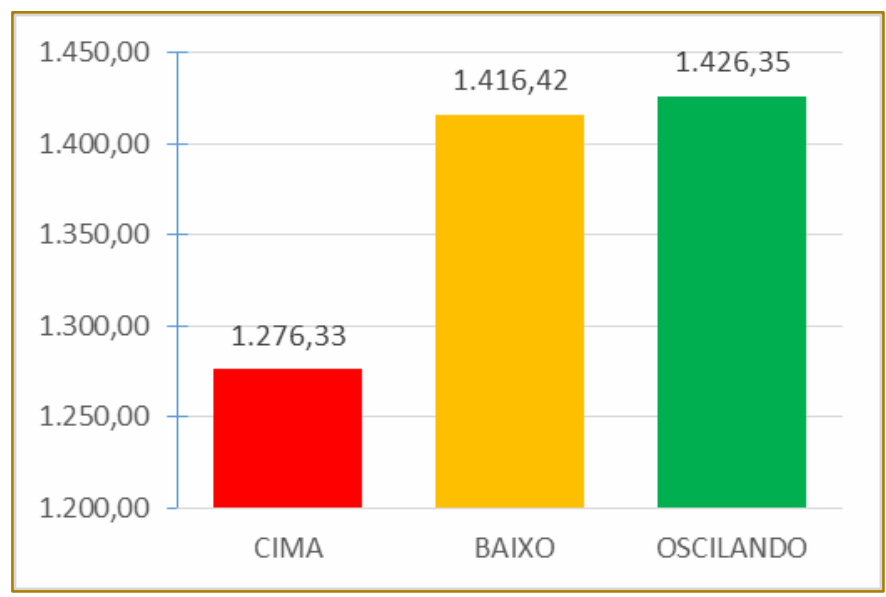

Fonte: Autores (2018)

Gráfico 3 - Vazão mensal de água condensada dos seis aparelhos de Ar condicionados do laboratório de matérias da UniCEUMA

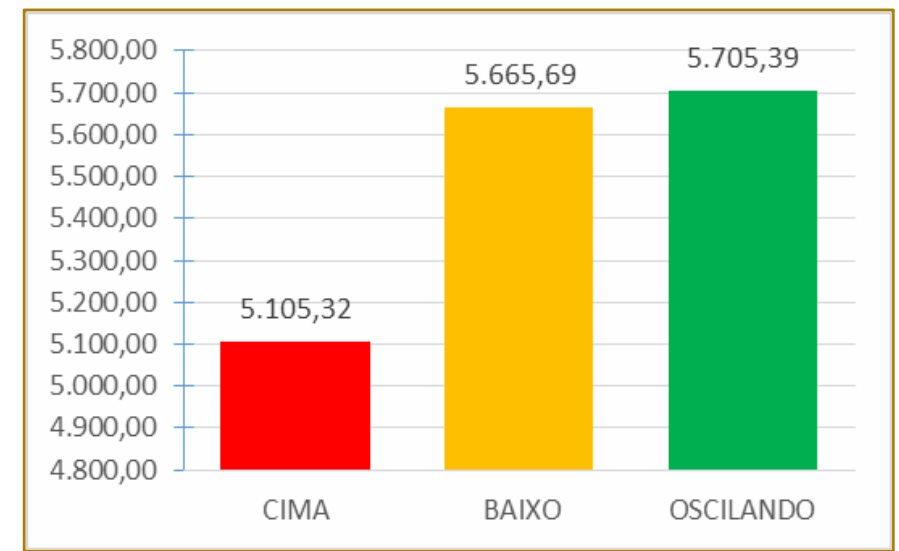

Fonte: Autores (2018) 
Para as análises qualitativas, foi possível fazer a medição do Potencial de Hidrogeniônico $(\mathrm{pH})$ das amostras de água dos 6 aparelhos de ar condicionado, obtendo-se assim os valores da concentração de íons de hidrogênio. As 6 amostras apresentaram os seguintes percentuais hidrogeniônico: 6,8; $7.6 ; 7,3 ; 7,4 ; 7,1$; e 7,1 respectivamente. Os valores de 6 a 9 são os ideais para a saúde humana. Portanto, os aparelhos que apresentam esse valor são os condicionadores de ar 02; 03; 04; 05 e 06. O valor de 6,8 do ar condicionado 01 está abaixo da média, representando assim uma água não alcalinizada e sem poder de hidratação.

Para a condutividade elétrica (CE), que é representada pela unidade miliSiemens por $\mathrm{cm}^{2}$ ou micro Siemens por $\mathrm{cm}^{2}\left(\mathrm{uS} / \mathrm{cm}^{2}\right)$. Os 6 aparelhos de ar condicionado não representam uma água sem condutividade, pois seus valores equivalem a 50,$5 ; 25,1$; 35,3; 35,8; 56,7 e 89,1 de modo respectivo, sendo que a água ideal para o consumo deve possuir uma condutividade elétrica de 50 Us/cm.

Em seguida foi feita a análise para a verificação dos Sólidos Totais Dissolvidos (TDS) das amostras de água. A partir do ensaio foi possível detectar quaisquer compostos neutros (sem carga). Como por exemplo açúcar, álcool, produtos orgânicos e diversas formas de sílica, amônia e dióxido de carbono. Vale ressaltar que feita essa pesquisa não se detectam "ferrugem", bactérias ou vírus, pois esses componentes não são partículas que se movem em um campo elétrico. Portanto os resultados obtidos são, respectivamente, 25,2 PPM; 12,6PPM; 17,7PPM; 17,9PPM; 28,4; E 45,1PPM, levando em consideração que $\mathrm{O}$ valor ideal para 0 consumo da água é de 10 a 20PPM.

A salinidade (S) é medida para a obtenção dos valores de sais dissolvidos na água. A medição das amostras foi feita através do aparelho de condutividade de mesa, onde os resultados colhidos foram de 0,03PPT; 0,01PPT; 0,02PPT; 0,02PPT; 0,03PPT; $0,05 \mathrm{PPT}$, respectivamente. A unidade utilizada é o PPT (partes por trilhão). As águas das amostras representam uma água com o teor de salinidade baixo, sendo classificada como água doce por possui salinidade inferior ou igual a 0,05PPT.
A turbidez (T) também foi umas das análises realizadas para que fosse possível medir como um feixe de luz atravessa uma certa quantidade de água, e assim conferir se a aparência será turva ou não. A medição foi feita com o turbidômetro, nele é comparado o espalhamento de um feixe de luz ao passar pela amostra e com o de um de igual intensidade quando passa por uma suspensão padrão, assim quanto maior o espalhamento, maior será a turbidez. Os resultados das respectivas amostras foram de 52UNT; 2,16UNT; 1,86UNT; 0,09UNT; 0,46 UNT e 0,46UNT. Esses valores são expressos normalmente pela Unidade Nefelométrica de Turbidez - UNT, assim o valor ideal para o consumo é de até 5UNT.

As últimas análises realizadas foram para detectar a presença de coliformes fecais (CF) e totais (CT). O ensaio destina-se a indicar se há contaminação fecal ou outros agentes patogênicos que podem estar presentes na água. Essa contaminação pode afetar de forma negativa a saúde humana. Para a obtenção dos resultados, o experimento foi feito a partir da mistura de um reagente chamando de colitest com a água das amostras, observando como seria o comportamento da mesma de acordo com a variação da cor, exibindo uma borda

Resultados da análise da água dos condicionadores de ar vermelha na superfície, sendo esse um dos indicadores que permitiram afirmar se existia contaminação. As amostras dos aparelhos 01, 02, 03,04 e 06 apresentaram ausência de coliformes fecais e somente a amostra do aparelho 05 apresentou presença de contaminação fecal. Já a presença de coliformes totais foram detectadas nas amostras dos aparelhos 01 , 02, 03, 05 e 06 e somente a amostra do aparelho 04 não estava contaminado.

A análise da temperatura é um indicador importante de qualidade e para destinação da água, pois dependendo da temperatura que se encontra as espécies que a utilizarão se proliferará ou se extinguirá. As amostras dos aparelhos condicionadores de ar apresentaram valores entre 15 a $20^{\circ} \mathrm{C}$ sendo considerada uma temperatura média, onde plantas, besouros d'água e algumas doenças sobrevivem

A quadro 04 a seguir ilustra os dados obtidos através da análise dos parâmetros da água. 
Quadro 4- Parâmetros analisados na água

\begin{tabular}{|c|c|c|c|c|c|c|}
\hline Parâmetros & Aparelho 1 & Aparelho 2 & Aparelho 3 & Aparelho 4 & Aparelho 5 & $\begin{array}{c}\text { Aparelho } \\
6\end{array}$ \\
\hline $\mathrm{PH}$ & 6,8 & 7,6 & 7,3 & 7,4 & 7,1 & 7,1 \\
\hline CE & 50,5 & 25,1 & 35,3 & 35,8 & 56,7 & 89,1 \\
\hline TDS & 25,2 & 12,6 & 17,7 & 17,5 & 28,4 & 45,1 \\
\hline$S$ & 0,03 & 0,01 & 0,02 & 0,02 & 0,03 & 0,05 \\
\hline T & 52 & 2,16 & 1,86 & 0,09 & 0,46 & 1,23 \\
\hline CF & Ausência & Ausência & Ausência & Ausência & Presença & Presença \\
\hline CT & Presença & Presença & Presença & Ausência & Presença & Presença \\
\hline
\end{tabular}

Fonte: Elaborado pelos autores (2018)

A Resolução CONAMA(Conselho Nacional do Meio Ambiente) №020/1996 dispõe sobre a classificação dos parâmetros ideais que as águas doces precisam possuir, conforme ilustra no quadro 5.

Quadro 4 - Parâmetros CONAMA

\begin{tabular}{|c|c|}
\hline \multicolumn{1}{|c|}{ PARAMETROS } & CONAMA No020/1996 \\
\hline PH & 6,0 a 9,0 \\
\hline CE & 50 Us/cm \\
\hline TDS & $500 \mathrm{mg} / \mathrm{L}$ \\
\hline S & Menor que 0,05PPT \\
\hline T & Até 5 UNT \\
\hline CF & $4000 / 100 \mathrm{~mm}$ \\
\hline CT & $4000 / 100 \mathrm{~mm}$ \\
\hline
\end{tabular}

Fonte: Elaborado pelos autores

\section{CONCLUSÃO}

Os aparelhos de ar condicionado do Laboratório de Materiais da Universidade CEUMA, de acordo com as análises quantitativas e qualitativas, geram um volume significativo de água e apresenta valores baixos de contaminação, podendo a água gerada por eles, ser reaproveitada de várias formas e para fins não potáveis como: descargas de banheiros, regas de jardins, limpeza de dependências da universidade e etc. 


\section{REFERENCIAS}

[1] APHA. Standard Methods for the examinaton of water and wastewaters 25 ed. New York, McGraw-HILL, 1995. 720p

[2] CETESB. Reúso da água. São Paulo. SP. Disponível em: $<$ http://www.cetesb.sp.gov.br/Agua/rios/gesta_reus o.asp>

[3] CUNHA, Ananda Helena Nunes. O reúso de água no brasil: a importância da reutilização de água no país. Goiânia: Enciclopédia biosfera, Centro Científico, 2011.

[4] FARIA, A. M. J. B. Gerenciamento de recursos hídricos. Curitiba: Instituto Federal do Paraná; Rede e-Tec Brasil, 2013.

[5] FILHO, Darcy Braga; MANCUSO, P. C. S. Reúso da água. 2. Ed. São Paulo, 2012.

[6] HARDENBERGH, 1964; LEME, 1984. Disponível em: <https://pt.scribd.com/document/18951878/Purifica cao-de-agua-para-o-consumo-humano $>$. Acesso em: 11 maio de 2018.

[7] MANCUSO, P. C. S.; SANTOS, H. F. Reuso da água. Barueri, SP: Manole, 2003

[8] ORGANIZAÇÃO MUNDIAL DA SAÚDEReuso da água. 2. Ed. São Paulo, 1973.
[9] MINISTÉRIO DA SAÚDE - MS. Portaria №. 518, de 25 de março de 2004. Diário Oficial, Brasília, 26 de março de 2004. Seção 1, p. 266.

[10] PHILIPPI JR., A.; ROMÉRO, M. de A.; BRUNA, G. C. Curso de Gestão Ambiental. Barueri, São Paulo: Nisam-USP Manole, 2004 (Coleção Ambiental 1).

[11] REBOUÇAS, A.C.; BRAGA, B.; TUNDISI, J.G. Águas doces no Brasil: capital ecológico, uso e conservação. São Paulo: Acad. Bras. Cien./IEAUSP, 1999.

[12] REIS, Lineu Belico; FADIGAS, Eliane A. F. Amaral; CARVALHO, Cláudio Elias. Energia, Recursos Naturais e a Prática do Desenvolvimento Sustentável. 2. ed. Barueri, SP: Manole, 2012.

[13] SOARES, Stela Almeida. Gestão de Recursos Hídricos. Curitiba: InterSaberes, 2015.

[14] TUNDISI, José Galizia; TUNDISI, Takako Matsumura. Recursos Hídricos no século no século XXI. São Paulo: Oficina de Textos, 2011.

[15] VENDRAME, A. C. Perícia Ambiental Uma abordagem Multidisciplinar. São Paulo: IOB Thonson, 2006. 


$$
\text { Alutary }
$$




\section{ACÁCIO PONCIANO RODRIGUES}

Doutorando em Ciências da Linguagem, pela Universidade do Vale do Sapucaí - UNIVÁS; Mestre em Desenvolvimento Sustentável e Qualidade de Vida, pelo Centro Universitário das Faculdades Associadas de Ensino - UNIFAE (2013); Licenciatura Plena em Química, pela Universidade Vale do Rio Doce - UNINCOR (2011); Especialização em Química, pela Universidade Federal de Lavras - UFLA (2008); Graduação em Engenharia Química, com ênfase em Engenharia de Alimentos, pelo Centro Universitário do Sul de Minas - UNIS (2002); Técnico em Química, pelo Centro Técnico do Ensino Médio - CETEM (1982). Experiência de 30 anos em Indústria de transformação de plástico, atuando como Operador de Processo, Analista, Pesquisador e Encarregado de Laboratório Químico, Supervisor de Laboratório e de Controle de Qualidade e Assistente Técnico. Assessor Técnico para Gestão e Controle da Qualidade. Professor de Química no Ensino Médio. Professor em Curso Tecnólogo de Gestão Ambiental, disciplina de Gestão de Efluentes Atmosféricos. Professor Universitário de disciplinas da Área de Engenharia Química, sendo: Processos Químicos Industriais, Eletroquímica, Trocadores de Calor, Estrutura dos Materiais e Práticas Interdisciplinares. Disciplinas da área de Engenharia de Produção, sendo: Sistemas de Produção, Introdução a Engenharia de Produção, Gestão da Qualidade, Introdução a Ciência e Tecnologia dos Materiais, Fenômenos de Transporte, Estatística e Química Geral. Disciplina da área de Administração, Gestão Ambiental e Responsabilidade Social e Gestão da Qualidade. Coordenador do Curso de Engenharia de Produção da Faculdade CNEC Varginha, desde 2013, responsável pelos processos de gerenciamento do curso, rotinas administrativas, previsão, definição e realização de atividades acadêmicas, recebimento de comissões avaliadores do Ministério da Educação para autorização, reconhecimento e renovação de reconhecimento de cursos de graduação. Vice-presidente da Agenda 21 Local para a cidade de Varginha, MG. Conselheiro Suplente (Agenda 21) do Conselho Municipal de Conservação e Defesa do Meio Ambiente - CODEMA de Varginha.

\section{ADILSON TAVARES CRUZ}

Possui graduação em Engenharia de Software pela Universidade Federal do Amazonas (2017)

\section{ÁDRIA VASCONCELOS}

Graduanda em Engenharia de Produção pela Universidade Tiradentes (UNIT).

\section{AILTON CELIO}

Graduando em Engenharia de Produção pela Universidade CEUMA, Integrante do Projeto Movimento Sustentável focado na reutilização de água condensada dos aparelhos de ar condicionado.

\section{ALDERY SILVEIRA JÚNIOR}

Doutor em Engenharia de Transportes, Mestre em Administração, Especialista em Administração Financeira, Bacharel em Administração Pública e de Empresas, Professor do Quadro Permanente de Docentes da Universidade de Brasília (UnB), lotado no Departamento de Administração. Tem experiência em Administração Estratégica, Planejamento Estratégico, Reestruturação Organizacional, Modelagem de Processos de Trabalho, Matemática Financeira, Logística, Transporte de carga por cabotagem e na utilização da metodologia Multicritério de Apoio à Decisão (MCDA). Larga experiência em Consultoria para Instituições públicas e privadas e para o Banco Mundial. Participa como pesquisador dos seguintes grupos de pesquisa: Grupo de Pesquisa sobre Planejamento e Inovação em Transportes (GPIT), Grupo de Pesquisa em Métodos e Modelos de Apoio à Decisão (GMAD) e Grupo de Pesquisa em Operações, Logística e Métodos de Análise (GOMETA). 


\section{ALESSANDRO LUCAS DA SILVA}

Possui graduação em Engenharia de Produção Mecânica pela Universidade de São Paulo (2001) e mestrado em Engenharia de Produção pela Universidade de São Paulo (2004). Doutor em Engenharia de Produção pela Universidade de São Paulo. Atuou como engenheiro de desenvolvimento de processos na Embraer. Foi professor assistente doutor na Universidade Estadual Paulista - UNESP no período de 2010 a 2012. Atualmente é professor assistente doutor na Universidade de Campinas - UNICAMP no curso de Engenharia de Produção.

\section{ALICIA SILVA CARVALHO}

Graduanda em Engenharia de Produção pela Universidade CEUMA, Integrante do Projeto Movimento Sustentável focado na reutilização de água condensada dos aparelhos de ar condicionado.

\section{ALINE SANTOS PASSOS}

Graduanda em Engenharia de Produção pela Universidade Tiradentes (UNIT). Técnica em Edificações pelo Instituto Federal de Sergipe (IFS). Atualmente atua como projetista de ambientes na Florense, unidade de Aracaju/SE. Possui ainda experiência com as ferramentas computacionais AUTOCAD e PROMOB.

\section{AMANDA ALMEIDA DE SOUZA}

Acadêmica do curso de Bacharelado em Engenharia de Produção 5ำ período. Voluntária no Núcleo de Economia, Tecnologia, Gestão e Inovação, envolvida também em projetos de iniciação científica da Universidade Federal do Amazonas.

\section{AMANDA DUARTE FEITOSA}

Graduando em Engenharia de Produção Mecânica pela Universidade Regional do Cariri. Foi bolsista/pesquisadora de iniciação científica (2014-2015). Na parte profissional foi estagiária na empresa Singer do Brasil (2015-2016). Fez graduação sanduíche (2016-2017) na França pela ENSGSI (École nationale supérieure en génie des systèmes et de l'innovation), em que foi bolsista pelo programa BRAFITEC fornecido pela CAPES. Atualmente pesquisadora e bolsista de iniciação cientifica da Universidade Regional do Cariri.

\section{AMANDA TENÓRIO DA COSTA}

Graduada em Engenharia Civil pelo Centro Universitário Tiradentes - UNIT (2018), técnica em Edificações pelo Instituto Federal de Alagoas - IFAL (2011). Atua como integrante do grupo de pesquisa: Observatório de Impactos Ambientais e de Saúde (OIAS/CNPq). Participou de projeto de iniciação científica PROBIC/FAPEAL (2017-2018). Estagiou na Companhia de Saneamento de Alagoas (2017-2018) e na Gerdau (2010-2011). Realizou intercâmbio cultural em Montreal no Canadá (2014-2015) com curso intensivo na língua francesa. É fluente em inglês, possui nível intermediário em francês e espanhol. Tem interesse nas áreas de Saneamento, Gestão de Resíduos Sólidos, Geotecnia Ambiental e Tecnologias aplicadas ao meio ambiente.

\section{ANA CAROLINA ALVES}

Bacharela em Administração pela Universidade de Brasília. 


\section{ANA CAROLINA MOUZINHO}

Engenheira de Produção. Estagiária na Eletrobras Eletronorte (jun à dez/12) São Luís/MA, Estagiária de Engenharia na GASMAR (abr/16 à jan/18) O\&M Gás Natural S.A.L./MA. Estagiária de Engenharia na VALE S.A. (fev à dez/18) CCO e Combustível em São Luís/MA. Projeto de Extensão Escritório Escola UNDB 2018.2

\section{ANTONIO CARLOS PACAGNELLA JUNIOR}

Possui graduação em Engenharia Mecânica pela Universidade Estadual de Campinas (2002), mestrado em Administração de Organizações pela Faculdade de Economia Administração e Contabilidade da Universidade de São (2006) e doutorado em Engenharia de Produção pela Universidade Federal de São Carlos (2011). Atualmente atua como professor na Faculdade de Ciências Aplicadas - FCA da Universidade Estadual de Campinas - UNICAMP. Suas principais áreas de docência e pesquisa são o Gerenciamento de Projetos e a Gestão de Operações.

\section{ANTONIO LUIS ARAUJO SILVA}

Formação Master MIDI pela ENSGSI, universidade francesa. Através do projeto de intercâmbio CAPES-BRAFITEC (2016-2017). Atualmente graduando em Engenharia de Produção Mecânica pela Universidade Regional do Cariri. Bolsista de iniciação científica do projeto intitulado "Aprendizagem baseada em problemas como estratégia pedagógica para o ensino em cursos de Engenharia de Produção" (2018).

\section{BEATRIZ FERREIRA DA CRUZ}

Acadêmica do curso de Bacharelado em Engenharia de Produção 5 período. Voluntária no Núcleo de Economia, Tecnologia, Gestão e Inovação, envolvida também em projetos de iniciação científica da Universidade Federal do Amazonas.

\section{CAMILLA CAMPOS MARTINS DA SILVA}

Mestra em Engenharia de Produção e Sistemas Computacionais pela UFF (Tese de mestrado: O uso do Benchmarking Interno aliado ao conceito de "Yokoten" para a propagação de boas práticas em uma empresa multinacional do setor de óleo e gás). Possui Graduação em Engenharia de Produção pela Universidade Federal Fluminense (2014) e Técnico em Mecânica pelo CEFET (2009). Atualmente atua como Engenheira de Processos na empresa Vallourec Transportes e Serviços (VTS), sendo responsável pelos projetos de qualificação e melhoria dos processos. Exerce função de focal point de Benchmarking da filial, sendo a representante global da VTS por todos os assuntos que envolvem os processos de acabamento dentro do grupo Vallourec. Realizou um programa de 6 meses para aprimoramento da língua inglesa: Intercâmbio - Dublin, Irlanda (2012/2013). Atua como engenheira responsável pela segurança no setor da Produção. Durante sua graduação foi bolsista da UFF no projeto "Implementação de Estratégias de Melhoria da Gestão". Por dois anos consecutivos, 2017 e 2018, foi premiada pela melhor implementação do plano de ação de benchmarking anual e melhor contribuição para a comunidade global de boas práticas do grupo Vallourec. Em 2014 recebeu o prêmio de "Láurea Acadêmica" concedido pela UFF em reconhecimento ao mérito da discente. No mesmo ano, foi premiada pelo 1ㅇ lugar Nacional na Categoria Produtividade dos Grupos de Melhoria Contínua da Vallourec Brasil.

\section{CELIO LEMOS SANTOS JUNIOR}

Engenheiro de Produção. Técnico em Petróleo e Gás. Estagiou em mineradora e fábrica de móveis. Trabalhou na construção civil como assistente de engenharia. 


\section{CRISTIANE APARECIDA BOLINO}

Graduanda do curso de Engenharia de Produção, na Universidade Positivo ( Previsão de término em dezembro de 2019). Técnica em logística pelo Senai (2014) e atualmente aprendiz na empresa AGP do Brasil.

\section{DAIANE FERREIRA FRANÇA}

Graduada em Engenharia de Produção pela Universidade Estadual do Maranhão. Certificada em Lean Sigma por Milwaukee School of Engineering. Especialista em Logística Empresarial pela Faculdade Laboro. Cursando MBA em Gestão de Projetos pela Universidade de São Paulo.

\section{DALILA RAYANNE DO NASCIMENTO ANDRADE}

Graduanda em Engenharia de Produção Mecânica pela Universidade Regional do Cariri, bolsista de extensão do projeto intitulado por "Ações Sistemáticas para iniciar a prática de logística reversa de resíduos eletroeletrônicos na Região Metropolitana do Cariri" (2018).Na parte profissional foi estagiária na empresa Vinick Fardamentos(2018).

\section{DANIEL GUIMARÃES TEDESCO}

Possui graduação em Física pela Universidade do Estado do Rio de Janeiro (2008), mestrado em Física pela Universidade do Estado do Rio de Janeiro (2010) e doutorado em Física pela Universidade do Estado do Rio de Janeiro (2014). Atualmente é professor do curso de Engenharia de Produção da Universidade Positivo. Tem experiência na área de Física, com ênfase em Física das Partículas Elementares e Campos, atuando nos seguintes temas: Confinamento de glúons, Simetria BRST, espaço-tempo não comutativo. Tem experiência em modelagem matemática em Engenharias e em Ensino de Física e Matemática.

\section{DANIELLE ALVES COSTA SILVA}

Graduanda em Engenharia de Produção pela Universidade CEUMA, Integrante do Projeto Movimento Sustentável focado na reutilização de água condensada dos aparelhos de ar condicionado.

\section{DEIVID HENRIQUE BORGES}

Engenheiro de Produção, trainne de produção na empresa Fertipar Sudeste, com atuação no chão de fábrica na produção de fertilizantes. Vivência no ambiente de escritório adquirida na função de Analista de Crédito ao longo de 6 anos, desempenhando as funções de análise e aprovação de pedidos. Conhecimento no Pacote Office e Sistema ERP Protheus, perfil de profissional empenhado, comprometido e com facilidade para trabalhar em equipe.

\section{ÉDISON RENATO PEREIRA DA SILVA}

Doutor e Mestre em Engenharia de Produção pelo Instituto Alberto Luiz Coimbra de Pesquisa (COPPE/UFRJ). Professor do Departamento de Engenharia Industrial da Escola Politécnica da Universidade Federal do Rio de Janeiro (UFRJ) e Professor da área de Gestão e Inovação do Programa de Engenharia de Produção (COPPE/UFRJ).

\section{EDUARDO DE OLIVEIRA SOUZA NETO}

Possui graduação em Engenharia de Produção pela Universidade Federal do Piauí (2017). Atualmente é coordenador de processos da qualidade - CLINICENTER. Tem experiência na área de Engenharia de Produção, com ênfase em Gestão da Qualidade. 


\section{ELPIDIO OSCAR BENITEZ NARA}

Pós Doutorado em Universidade federal de Santa Maria (2014), Doutorado em Gestão da Qualidade e Produtividade pela Universidade Federal de Santa Catarina (2005). Mestrado em Engenharia de Produção pela Universidade Federal de Santa Maria (1997). Possui Graduação em Engenharia Mecânica pela Universidade Federal de Santa Maria (1986). Atualmente é Professor Titular da Universidade de Santa Cruz do Sul (UNISC) atuando nos cursos de graduação em Engenharia de Produção, Mecânica e como Coordenador do Programa de Mestrado em Sistemas e Processos Industriais. Tem experiência na área de gestão e Engenharia com ênfase em Administração da Produção e Engenharia de Produção atuando principalmente nos seguintes temas: Planejamento estratégico, Qualidade total, Analises multicritérios, Planejamento Industrial, Gestão por processos e Gestão Ambiental.

\section{EMILLY FELIPE DE LIMA E LIMA}

Acadêmica do curso de Bacharelado em Engenharia de Produção, cursando o $7^{\circ}$ período e desenvolvendo projetos de logísticas e estatística, e ainda envolvida com projetos de iniciação científica da Universidade Federal do Amazonas.

\section{FABIANO SANTOS RIBEIRO}

Engenheiro de Produção, formado pela Faculdade Cenecista de Varginha - MG, possuo mais de 14 anos de experiência na área de Injeção de termoplásticos, exercendo a liderança de operação industrial, processo de produção da fábrica, formação e gerenciamento de equipes multidisciplinares.

\section{FERNANDA GOMES DIAS}

Graduanda em Engenharia de Produção pela Universidade CEUMA, Integrante do Projeto Movimento Sustentável focado na reutilização de água condensada dos aparelhos de ar condicionado.

\section{FRANCISCA JEANNE SIDRIM DE FIGUEIREDO}

Possui graduação em Desenho Industrial (UFCG - 1990), mestrado em Engenharia de Produção (UFPB -1998) e doutorado em CIÊNCIAS (UNESP - 2017). Atualmente é avaliadora voluntária da AEDB, Editora Abril e Associação Brasileira de Engenharia de Produção, professora Adjunta da Universidade Regional do Cariri, Coordenadora de desenvolvimento Territorial Sustentável do Geopark Araripe. Tem experiência na área de Administração, com ênfase em Gestão da Qualidade, atuando principalmente nos seguintes temas: processo, qualidade, métodos, seis sigma, desenvolvimento sustentável e produção segura.

\section{FREDJOGER BARBOSA MENDES}

Possui graduação em Engenharia de Produção pela Faculdade Cenecista de Rio das Ostras (2012), graduação em Normalização e Qualidade Industrial pelo Centro Federal de Educação Tecnológica de Minas Gerais(2001), especialização em Administração Financeira pelo Fundação Getúlio Vargas(2015), especialização em Gestão e Tecnologia da Qualidade pelo Centro Federal de Educação Tecnológica de Minas Gerais(2003), curso-técnicoprofissionalizante em Técnico em Mecânica Industrial pelo Centro Federal de Educação Tecnológica de Minas Gerais(1994), curso-técnico-profissionalizante em Técnico em Informática Industrial pela SENAI - Departamento Regional de Minas Gerais(1997), ensinomédio-segundo-grau pelo Centro Federal de Educação Tecnológica de Minas Gerais(1994) e aperfeiçoamento em Automação Industrial pela SENAI - Departamento Regional de Minas Gerais(1998). Atualmente é Gerente de Produção da Vallourec S.A. Tem experiência na área de Engenharia de Produção 


\section{GLÁUCIA REGINA DE OLIVEIRA ALMEIDA}

Graduada em Engenharia de Produção pela Faculdade de Administração e Negócios de Sergipe - Fanese. Mestre em Engenharia de Processos pela Universidade Tiradentes. Doutorado em Engenharia de Processos. Consultora em Ergonomia. Possui experiência na área de química e engenharia com ênfase em eletroquímica e no desenvolvimento de novos materiais atuando principalmente nos seguintes temas: eletro-oxidação de metanol e etanol, desenvolvimento de nanomateriais, células a combustível. Prêmio Professor Giulio Massarani como destaque de melhor trabalho na área de Engenharia de Materiais e Nanotecnologia no XX Congresso Brasileiro de Engenharia Química - COBEQ -2014, Associação Brasileira de Engenharia Química. Desenvolvimento de projetos integradores na área de Engenharia de Produção voltados para o desenvolvimento social. Membro de Colegiado do curso de Engenharia de Produção. Atualmente faz parte do Núcleo Docente Estruturante do curso de Engenharia de Produção da Universidade Tiradentes. Professora Adjunta dos cursos de Engenharia de Produção, Engenharia Civil, Engenharia Elétrica, Engenharia Mecatrônica e Engenharia de Petróleo. Possui certificação nível 1 nas ferramentas da G Suite for Education ( Google Certified Educator Level 1).

\section{GUSTAVO CHOAIRE}

Graduando em Engenharia Mecânica na Universidade de Santa Cruz do Sul. Atualmente é estagiário na empresa Geguton Presentes e Decoração Ltda. Atuou como bolsista PROBIC/FAPERGS (2018/2018) no projeto: Tomada de decisão gerencial com enfoque multicritérios: fundamentos teóricos e utilização da prática corporativa. Atuou como bolsista PUIC (2017/2018) no projeto: O uso da gestão por processos baseada em uma abordagem sistêmica no gerenciamento das organizações - Fase 3. Atuou como bolsista PUIC (2016/2017) no projeto: O uso da gestão por processos baseada em uma abordagem sistêmica no gerenciamento das organizações - Fase 3. Tem experiência na área de Engenharia Mecânica.

\section{ISMAEL CRISTOFER BAIERLE}

Doutorando em Engenharia de Produção e Sistemas pela Unisinos, Mestre em Sistemas e Processos Industriais pela UNISC e graduado em Engenharia de Produção também pela UNISC. Atualmente atua como consultor empresarial na empresa Incrementum Consultoria e Assessoria e prestador de serviços de docência e consultoria e assessoria empresarial para o SENAI-RS. Tem experiência na área de Engenharia de Produção, com ênfase em Panejamento e Gerenciamento de Produção, atuando principalmente nos seguintes temas: Gestão de processos, gestão da inovação, inteligência artificial, redes neurais e análise muticriterial.

\section{JACKSON MILANO}

Mestre em Desenvolvimento de Tecnologia pelos Institutos Lactec. Possui MBA Empresarial com concentração em Gestão das Organizações Educacionais pela Universidade Positivo, graduação e licenciatura em Física pela Universidade Federal do Paraná (1992). Atualmente é professor da Universidade Positivo ministrando aulas na Engenharia de Produção, Engenharia de Energia, Engenharia Elétrica. Tem experiência na área de Física, com ênfase em Física Clássica.

\section{JANAÍNA ACCORDI JUNKES}

Doutora em Ciência e Engenharia de Materiais - UFSC (2011), com período Sanduíche na Universidade de Aveiro-Portugal no instituto de materiais - CICECO. Pesquisadora Associada ao Instituto de Tecnologia e Pesquisa (ITP). Professora do Programa de Pós-Graduação em Sociedade, Tecnologias e Políticas Públicas do Centro Universitário Tiradentes (Unit/Alagoas). Tem experiência na área de Engenharia de Materiais com ênfase na área de materiais cerâmicos, gestão de resíduos e sustentabilidade e saúde ambiental. Pós-doutora 
pela Universidade Friedrich-Alexander de Erlangen-Nuremberg - Alemanha (2012) onde trabalhou no Zentralinstitut für Neue Materialien und Prozesstechnik- ZMP sob orientação do Prof. Dr. Nahum Travitzky e Pós-doutora pela Universidade Federal de Santa Catarina - UFSC (2013 e 2014). Faz parte do Grupo de Pesquisas CERMAT - Núcleo de Materiais Cerâmicos e Compósitos, da Universidade Federal de Santa Catarina, Campus Florianópolis e é Co-Líder do Grupo de Pesquisa Observatório de Impactos Ambientais e de Saúde da UNIT/AI. Licença maternidade em 2013 e 2017.

\section{JARBAS DELLAZERI PIXIOLINI}

Engenheiro de Produção pela UFF, destaca-se em gestão organizacional, direcionado para análise financeira e de processos. Em consultoria já realizou projetos estratégicos, táticos e operacionais nos seguintes segmentos: mineração e siderurgia, logística, indústria de alimentos, bens, saúde e serviços. Atualmente é Diretor de Operações de uma startup na área da saúde. Também já foi consultor financeiro capitando novos investidores, reestruturando áreas financeiras de empresas, renegociando dívidas com credores e fornecedores, recuperando a saúde financeira dos negócios.

\section{JOÃO MARCELO CARNEIRO}

Possui graduação em Engenharia de Produção Mecânica - Universidade Federal do CearáUFC (2006), especialização em Regulação de Transportes Terrestres - Universidade Federal do Rio de Janeiro-UFRJ (2008) e mestrado em Transportes - Universidade de Brasília-UnB (2011). Atualmente exerce os cargos de Especialista em Regulação na Agência Nacional de Transportes Terrestres-ANTT, Professor na Universidade de Fortaleza-UNIFOR e Coordenador do curso de Engenharia de Produção na Faculdade de Fortaleza-FAFOR.

\section{JOÃO VICENTE LUCIO BATISTA}

Engenheiro de Produção, formado pela faculdade Cenecista de Varginha - MG, atualmente atuo como consultor em segurança do trabalho prestando consultoria nas empresas .

\section{JONATAS COSTA}

Engenheiro Civil Sênior. Especialista em Engenharia Ferroviária. Mestre em Engenharia de Estruturas. Aperfeiçoamento em Gestão de Projetos.

\section{JONES LUÍS SCHAEFER}

Mestrando do Programa de Pós-Graduação Sistemas e Processos Industriais da UNISC. Integrante dos projetos de pesquisa: 1- Tomada de decisão gerencial com enfoque multicritérios: fundamentos teóricos e utilização de prática corporativa. 2- Tomada de decisão gerencial com enfoque em teoria dos conjuntos nebulosos (fuzzy sets) e lógica nebulosa (fuzzy logic); integração fuzzy. Dissertação em andamento sob o título: Mensuração da Competitividade em Micro e Pequenas Empresas. Engenheiro de Produção formado pela Universidade de Santa Cruz do Sul (2006).

\section{JORGE ALFREDO CERQUEIRA SREIT}

Doutorando em Administração pela Universidade de Brasília (UnB); Mestre em Sustentabilidade na Gestão Ambiental pela Universidade Federal de São Carlos - campus Sorocaba (UFSCar); Bacharel em Administração pela Universidade de Brasília (UnB); Professor de Administração e Logística no Centro Universitário Projeção (Brasília-DF); Membro do Grupo de Pesquisa em Operações, Logística e Métodos de Análise (GOMETA UnB); Membro do Grupo de Estudos e Pesquisas Avançadas em Logística e Supply Chain Management (GEALOGS - UnB). 


\section{JOSÉ LUCAS VIANA MORAIS}

Formado em Técnico em Eletromecânica pelo Instituto Federal do Maranhão - Campus Santa Inês (2015), atualmente cursando Engenharia de produção pela Universidade Federal do Piauí (UFPI), membro do colegiado do curso.

\section{KARINA BATAGLIA}

Graduação em andamento em Engenharia de Produção. Universidade Estadual de Campinas, UNICAMP, Brasil.

\section{KAYQUE BEZERRA DE OLIVEIRA}

Possui Graduação em Engenharia de Produção Mecânica (URCA - 2017) e cursando PósGraduação em Gestão Financeira e Consultoria Empresarial (URCA). Atualmente trabalha como Gerente de Produção na Fábrica Indústria de Massas (PANAZZO) em Fortaleza - Ce. Experiência em Palestras e Minicursos na área de consultoria de vendas e atendimento ao cliente.

\section{LARISSA HAVENNA MATOS SANTOS}

Possui graduação em Arquitetura e Urbanismo pelo Instituto de Ciências Jurídicas e Sociais Professor Camillo Filho (2017). Atualmente é consultor - Multiplac Comunicação Visual. Tem experiência na área de Arquitetura e Urbanismo, com ênfase em Arquitetura e Urbanismo

\section{LORRANE ALVES RIBEIRO}

Acadêmica do curso de Administração da Universidade de Brasília.

\section{MARCOS ANTÔNIO OLIVEIRA FERREIRA}

Graduado em Engenharia de Produção pela Universidade federal do Piauí - UFPI. Atualmente desempenhando a função de Analista de Rota (Distribuição) com ênfase na gestão e desempenho das equipes de entrega, análise de KPIs da distribuição, como: Produtividade, Jornada, Devolução, Utilização e ocupação da frota, dentre outros. Conhecimento e habilidades em análise de custos de transporte (combustível, manutenção, pneus, etc.), acompanhamento e controle de processos logísticos. Aplicação de ferramentas e desenvolvimento de indicadores. Bom relacionamento e coordenação de equipes. Interesse nas áreas de Logística, Planejamento e Controle da Produção, Gestão e Controle da Qualidade, Engenharia Econômica.

\section{MARIANE LEITE DE SOUZA}

Graduanda em Engenharia de Produção Mecânica pela Universidade Regional do Cariri, bolsista de iniciação científica do projeto intitulado por "Estudo da Pegada Hídrica associada a práticas da sustentabilidade na Região Metropolitana do Cariri" (2015-2017) e bolsista voluntária de iniciação científica do projeto intitulado "Aprendizagem baseada em problemas como estratégia pedagógica para o ensino em cursos de Engenharia de Produção" (2018).

\section{NATALI DA COSTA EMERICK}

Mestranda em Engenharia de Produção, com ênfase de Gestão e Inovação, pelo Instituto Alberto Luiz Coimbra de Pesquisa (COPPE), na Universidade Federal do Rio de Janeiro (UFRJ). É especialista (MBA) em Qualidade e Gestão por Processos pela Universidade Católica de Petrópolis (UCP) e graduada em Engenharia de Produção pela Universidade Federal Fluminense (UFF). 


\section{NATAN MELO NASCIMENTO}

Possui graduação em Gestão Ambiental pelo Instituto Federal do Piauí(2015) e ensino-médiosegundo-grau pelo Instituto Federal do Piauí(2012). Tem experiência na área de Ciências Ambientais.

\section{NATHALIA STEPHANE SANTOS NASCIMENTO}

Graduanda em Engenharia de Produção pela Universidade Tiradentes - Unit. Estagiou na Secretaria de Estado da Educação de Sergipe (SEED) em 2017 desenvolvendo principalmente as atividades: Controle de material (entrada e saída); atualização de planilhas e de instruções de trabalho. Interesse pelas áreas de Gestão da Qualidade e Gestão da Produção.

\section{NILCE LENE TORRES DE LIMA}

Acadêmica do curso de licenciatura em Letras desenvolvedora de projetos de iniciação científica da Universidade Estadual do Amazonas e envolvida com pesquisas de extensão e ensino.

\section{OSMAN JOSÉ DE AGUIAR GERUDE NETO}

Graduação em ZOOTECNIA pela Universidade Estadual do Maranhão (2012) e Mestrado em Ciência Animal pela Universidade Federal do Maranhão (2015). Atualmente é professor ,pesquisador da Universidade CEUMA. Atua na produção e criação de animais, preservação da fauna, gerenciamento, planejamento e administração de empreendimentos do agronegócio. Atua em todos os setores da produção animal desde a nutrição, melhoramento genético, reprodução, sanidade até administração rural, respeitando o bem-estar animal, considerando a sustentabilidade econômica e ambiental como prioridade. Desenvolve atividades que visam à preservação do meio ambiente por meio da defesa da fauna e orientação da criação das espécies de animais silvestres.

\section{PAULO SERGIO DE ARRUDA IGNACIO}

Doutor em Engenharia Civil pelo LALT/DGT/ FEC/UNICAMP (2010), na área de Engenharia de Transportes. Possui graduação em Engenharia de Produção Mecânica pela Universidade Metodista de Piracicaba (1985) e Mestrado em Gestão da Qualidade pelo IMECC (2001). Atualmente é Professor Doutor e Coordenador Associado do Curso de Engenharia de Produção da Faculdade de Ciências Aplicadas (FCA), da Universidade Estadual de Campinas (UNICAMP). E referee adhoc em periódicos. Possui artigos publicados em revistas e congressos. Tem experiência em consultoria em pequenas e grandes empresas nacionais e internacionais.. Interesses e atuação em grupos de pesquisa com foco na engenharia de produção, contemplando: gestão da cadeia de suprimentos; gestão de operações e serviços, com ênfase em gestão de operações, lean thinking, logística, produtividade, armazenagem, sustentabilidade, qualidade e medição do desempenho, com modelagem de sistemas.

\section{RAFAEL DUARTE ARAÚJO}

Graduação em andamento em Engenharia de Produção. Universidade de Fortaleza, UNIFOR, Brasil

\section{RAÍSSA COSTA MARTINS}

Possui graduação em Engenharia de Produção pela Universidade de Fortaleza (2016) e MBA em Gestão de Portfolio de Projetos e Processos também pela Universidade de Fortaleza (2018). Atualmente exerce cargo de Analista em empresa do ramo de Educação e Ensino (Grupo Arco Educação) no estado do Ceará. 


\section{RAISSA RIBEIRO}

Engenheira Civil. Voluntário Habitat for Humanit Canada/ Estagiária Camosun College. Estagiária Construtora BERG Engenharia. Estagiária de Engenharia na VALE S.A. (fev/17 à dez/18) CCO e Combustível em São Luís/MA.

\section{RENER ANTÔNIO MELO NASCIMENTO}

Graduado em Engenharia de Produção Pela Universidade Federal do Piauí. Pós-Graduado em Engenharia de Segurança do Trabalho. Atua como Agente Local de Inovação no Programa Agentes Locais de Inovação, promovido pelo CNPq em parceria com o SEBRAE. Foi monitor das disciplinas de Processos Químicos e de Logística e Cadeias de Suprimentos.

\section{RODOLFO CARDOSO}

Tem Doutorado em Engenharia de Produção com ênfase em Gestão e Inovação pela Universidade Federal do Rio de Janeiro e Mestrado em Engenharia de Sistemas Organizacionais pelo Instituto Militar de Engenharia (IME), sendo graduado em Engenharia Mecânica pela Universidade Federal Fluminense e em Engenharia de Armamento pelo IME. Nas suas áreas de atuação Rodolfo possui mais de 18 anos em aplicações nas organizações públicas e privadas, dezenas de artigos publicados em revistas e congressos nacionais e internacionais, capítulos e livros. Entre os projetos de consultoria que participou, diversos clientes possuem notoriedade e referência em seus setores de atuação: Área de Negócios do Abastecimento da Petrobras: (Premiada PNQ 2007), CEMIG Distribuição (Finalista PNQ 2011), Coelce (Premiada PNQ 2011), Hemorio (Prêmio Qualidade Rio/Ouro 2004 e 2003, Join Comission da ONU, Américan Associate of Blood Banks), IME (PQRio/Ouro 2003 e

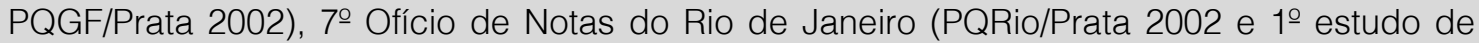
Caso Real utilizado pela FNQ) e Delegação de Mulheres Centro RJ (PQRio/Prata 2002). Ao longo de sua trajetória atuou também em projetos de Planejamento Estratégico, Operacionalização estratégica segundo o Balance ScoreCard, Diagnóstico Organizacional e Gestão por Processos. Entre as organizações que atuou destacam-se: Inmetro, Petrobras, Natura, Anvisa, Nitriflex, Bicicletas Caloi, Vice-presidência de tecnologia do Banco do Brasil, Operador Nacional do Sistema Elétrico (ONS), Cenpes/Petrobras, PESA/Petrobras/Argentina, Biomanguinhos/Fiocruz, BR Distribuidora. Junto a Fundação Nacional da Qualidade (FNQ) Rodolfo atua como Orientador do Prêmio Nacional da Qualidade (PNQ) desde 2006 e Instrutor desde 2001, tendo anteriormente atuado como Examinador Sênior entre 2002 a 2005. Foi premiado por 3 vezes pela FNQ: Examinador Sênior Destaque Nacional 2003, Orientador Destaque Nacional 2007 e Destaque 10 anos em 2009.

\section{RODRIGO LUSTOSA SOARES}

Graduação em andamento em Engenharia de Produção. Universidade Federal do Piauí, UFPI, Brasil

\section{RUAN RODRIGUES DA SILVA}

Graduando em Engenharia de Produção pela Universidade CEUMA, Integrante do Projeto Movimento Sustentável focado na reutilização de água condensada dos aparelhos de ar condicionado.

\section{RUTE HOLANDA LOPES}

Professora Adjunto da Universidade Federal do Amazonas - UFAM/ ICET (Economia Rural, Introdução à Economia e Gestão Ambiental). Coordenadora do Curso de Engenharia de Produção, Vice coordenadora do COMEXI - Comitê de Extensão do ICET e Coordenadora do Núcleo de Economia, Tecnologia, Gestão e Inovação; Coordenadora Administrativa da Incubadora do ICET - ICETech. Doutora em Ciências do Ambiente e Sustentabilidade da 
Amazônia pela UFAM (2015). Mestra em Desenvolvimento Regional pela UFAM (2008). Graduada em Ciências Econômicas pelo CIESA (2001), MBA em Empresas e Negócios pelo CIESA (2003)

\section{Silvia Maria Santana Mapa}

Possui graduação em Engenharia de Produção pela Universidade Federal de Ouro Preto (2005), mestrado em Engenharia de Produção pela Universidade Federal de Itajubá (2007) e doutorado em Ciência da Computação pela Universidade Federal de Minas Gerais (2014). Atualmente é professora efetiva do Instituto Federal de Minas Gerais. Tem experiência na área de Engenharia de Produção, com ênfase em Logística e Pesquisa Operacional, atuando principalmente nos seguintes temas: algoritmos em grafos, subgrafo acíclico máximo, restrições disjuntivas, análise combinatória, sistemas de informações geográficas, problemas de localização e alocação de instalações, simulated annealing, programação de tripulações, método de pesquisa em vizinhança variável, metaheurísticas.

\section{TAIS BARROS DA SILVA SOARES}

Mestranda em Gestão e Avaliação de Sistemas de Produção pela Universidade Federal Fluminense, graduada em Engenharia de Produção com ênfase em Petróleo e Gás, pela Faculdade Cenecista de Rio das Ostras (2014) e Técnica em Mecânica Industrial pelo Instituto Péricles Velloso de Assis (2014). Possui dez anos de experiência em empresas da indústria de Óleo e Gás, sendo os últimos cinco anos na área de engenharia de serviços. Participa ativamente de grupos de análises e melhorias de processos. Em 2013, atuou como facilitadora do Grupo de Melhoria Contínua de Redução de Não Conformidades do Grupo Vallourec, onde foi premiada com a Certificação Ouro. Em 2018 foi premiada através do programa Ideia de Melhorias da Vallourec como fornecedora da melhor ideia da categoria Produção. Participou da publicação de artigos em anais de eventos e congressos nacionais nos quais pode apresentar trabalhos que contribuem para a aproximação da ciência com projetos práticos e reais de empresas multinacionais.

\section{THAYZA DE SOUZA DE ALMEIDA}

Graduanda do curso de Engenharia de Produção na Universidade Positivo - UP, com graduação prevista para dezembro de 2019. Formada em técnico administrativo pela Guarda Mirim - SJP - 2015. Atualmente é estagiária na empresa Mão Colorida no setor comercial.

\section{THIAGO FERREIRA SILVA}

Engenheiro Eletricista Sênior. Professor e Coordenador de Pós Graduação. Palestrante e Master Player da Play to Play.

\section{THIAGO HENRIQUE FREITAS POLICARPO}

Graduado em Engenharia de Produção pelo IFMG, MBA em Gestão, Empreendedorismo e Marketing pela PUCRS. Empreendedor, trabalha com desenvolvimento de processos e negócios.

\section{THUANNY CUNHA DOS REIS}

Possui graduação em Engenharia de Produção - Universidade de Fortaleza - UNIFOR (2017), pós-graduanda no MBA em Excelência Operacional - Universidade de Fortaleza - UNIFOR (2020). Atualmente exerce o cargo de Analista Pleno com atuação em Consultoria SAP MM/SRM na empresa Accenture. Atuou durante 3 anos nas áreas de Qualidade, Gestão da Produção e Engenharia de Processos no setor alimentício e de confecção. 


\section{UEDJA TATYANE GUIMARÃES MEDEIROS LIMA}

Engenheira Sanitarista e Ambiental formada pelo Centro Universitário Tiradentes- UNIT 2016.2, atuou como aluna bolsista de iniciação científica na área de resíduos sólidos industriais por 2 anos, possui experiência em laboratório e em campo. Estagiou na empresa Prisco Ambiental na área de tratamento de efluente, apresentou trabalhos na linha de resíduos sólidos em Congressos Brasileiros e internacional, atualmente cursa Mestrado em Gestão Ambiental pelo Instituto Federal de Pernambuco- IFPE e MBA em Engenharia de saneamento básico e ambiental pelo INBEC. 
Agência Brasileira do ISBN ISBN 978-85-7042-036-7

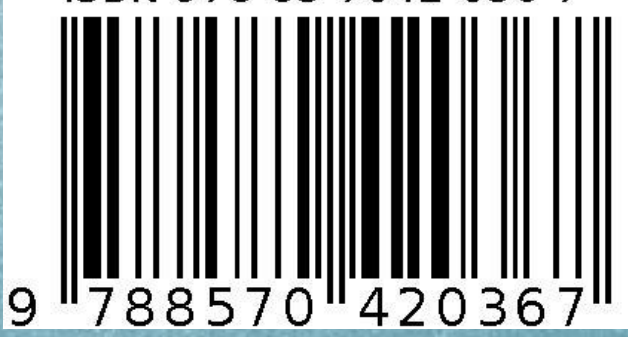

